\title{
The Probability of Containment Failure by Direct Containment Heating in Zion
}

Prepared by

M. M. Pilch, H. Yan, T. G. Theofanous

Sandia National Laboratories

Operated by

Sandia Corporation

Prepared for

U.S. Nuclear Regulatory Commission 


\section{AVAILABILITY NOTICE}

Availability of Reference Materials Cited in NRC Publications

Most documents cited in NRC publications will be avallable from one of the following sources:

1. The NRC Public Document Room, 2120 L Street, NW., Lower Level, Washington, DC 20555-0001

2. The Superintendent of Documents, U.S. Government Printing Office, P. O. Box 37082, Washington, DC 20402-9328

3. The National Technical Information Service, Springfleld, VA 22161-0002

Although the listing that follows represents the majority of documents cited in NRC publications, it is not intended to be exhaustive.

Referenced documents available for inspection and copying for a fee from the NRC Public Document Room include NRC correspondence and internal NRC memoranda; NRC bulletins, circulars, information notices, inspection and investigation notices; licensee event reports; vendor reports and correspondence: Commission papers; and applicant and licensee documents and correspondence.

The following documents in the NUREG series are avallable for purchase from the Government Printing Office: formal NRC staff and contractor reports, NRC-sponsored conference proceedings, international agreement reports, grantee reports, and NRC booklets and brochures. Also available are regulatory guldes, NRC regulations in the Code of Federal Regulations, and Nuclear Regulatory Commission Issuances.

Documents available from the National Technical Information Service include NUREG-series reports and technical reports prepared by other Federal agencies and reports prepared by the Atomic Energy Commission, forerunner agency to the Nuclear Regulatory Commission.

Documents available from public and special technical libraries include all open literature items, such as books. journal articles, and transactions. Federal Register notices, Federal and State legislation, and congressional reports can usually be obtained from these libraries.

Documents such as theses, dissertations, foreign reports and translations, and non-NRC conference proceedings are available for purchase from the organization sponsoring the publication cited.

Single coples of NRC draft reports are avallable free, to the extent of supply, upon written request to the Office of Administration, Distribution and Mall Services Section, U.S. Nuclear Regulatory Commission, Washington, DC 20555-0001.

Copies of industry codes and standards used in a substantive manner in the NRC regulatory process are maintained at the NRC Library. Two White Flint North, 11545 Rockville Pike, Rockville, MD 20852-2738, for use by the public. Codes and standards are usually copyrighted and may be purchased from the originating organization or, If they are American National Standards, from the American National Standards Institute, 1430 Broadway, New York, NY 10018-3308.

\section{DISCLAIMER NOTICE}

This report was prepared as an account of work sponsored by an agency of the United States Government. Neither the United States Government nor any agency thereof, nor any of their employees, makes any warranty, expressed or implied, or assumes any legal liability or responsibility for any third party's use, or the results of such use, of any information, apparatus, product, or process disclosed in this report, or represents that its use by such third party would not infringe privately owned rights. 


\section{DISCLAIMER}

Portions of this document may be illegible in electronic image products. Images are produced from the best available original document. 


\section{The Probability of Containment Failure by Direct Containment Heating in Zion}

Manuscript Completed: July 1994

Date Published: December 1994

Prepared by

M. M. Pilch, H. Yan ${ }^{1}$, T. G. Theofanous ${ }^{2}$

Sandia National Laboratories

Albuquerque, NM 87185

\section{Prepared for}

Division of Systems Research

Office of Nuclear Regulatory Research

U.S. Nuclear Regulatory Commission

Washington, DC 20555-0001

NRC Job Code J6027

${ }_{1}^{1}$ Formerly of Center for Risk Studies, University of California, Santa Barbara, CA

${ }^{2}$ Center for Risk Studies, University of California, Santa Barbara, CA 



\section{ABSTRACT}

This report is the first step in the resolution of the Direct Containment Heating (DCH) issue for the Zion Nuclear Power Plant using the Risk Oriented Accident Analysis Methodology (ROAAM). This report includes the definition of a probabilistic framework that decomposes the DCH problem into three probability density functions that reflect the most uncertain initial conditions ( $\mathrm{UO}_{2}$ mass, zirconium oxidation fraction, and steel mass). Uncertainties in the initial conditions are significant, but our quantification approach is based on establishing reasonable bounds that are not unnecessarily conservative. To this end, we also make use of the ROAAM ideas of enveloping scenarios and "splintering." Two causal relations (CRs) are used in this framework: CR1 is a model that calculates the peak pressure in the containment as a function of the initial conditions, and CR2 is a model that returns the frequency of containment failure as a function of pressure within the containment. Uncertainty in CR1 is accounted for by the use of two independently developed phenomenological models, the Convection Limited Containment Heating (CLCH) model and the Two-Cell Equilibrium (TCE) model, and by probabilistically distributing the key parameter in both, which is the ratio of the melt entrainment time to the system blowdown time constant. The two phenomenological models have been compared with an extensive data base including recent integral simulations at two different physical scales $\left(1 / 10^{\text {th }}\right.$ scale in the Surtsey facility at Sandia National Laboratories and $1 / 40^{\text {th }}$ scale in the COREXIT facility at Argonne National Laboratory). The loads predicted by these models were significantly lower than those from previous parametric calculations. The containment load distributions do not intersect the containment strength (fragility) curve in any significant way, resulting in containment failure probabilities less than $10^{-3}$ for all scenarios considered. Sensitivity analyses did not show any areas of large sensitivity. The feasibility of extrapolating containment loads distributions to most other Pressurized Water Reactors (PWRs) is explored. 


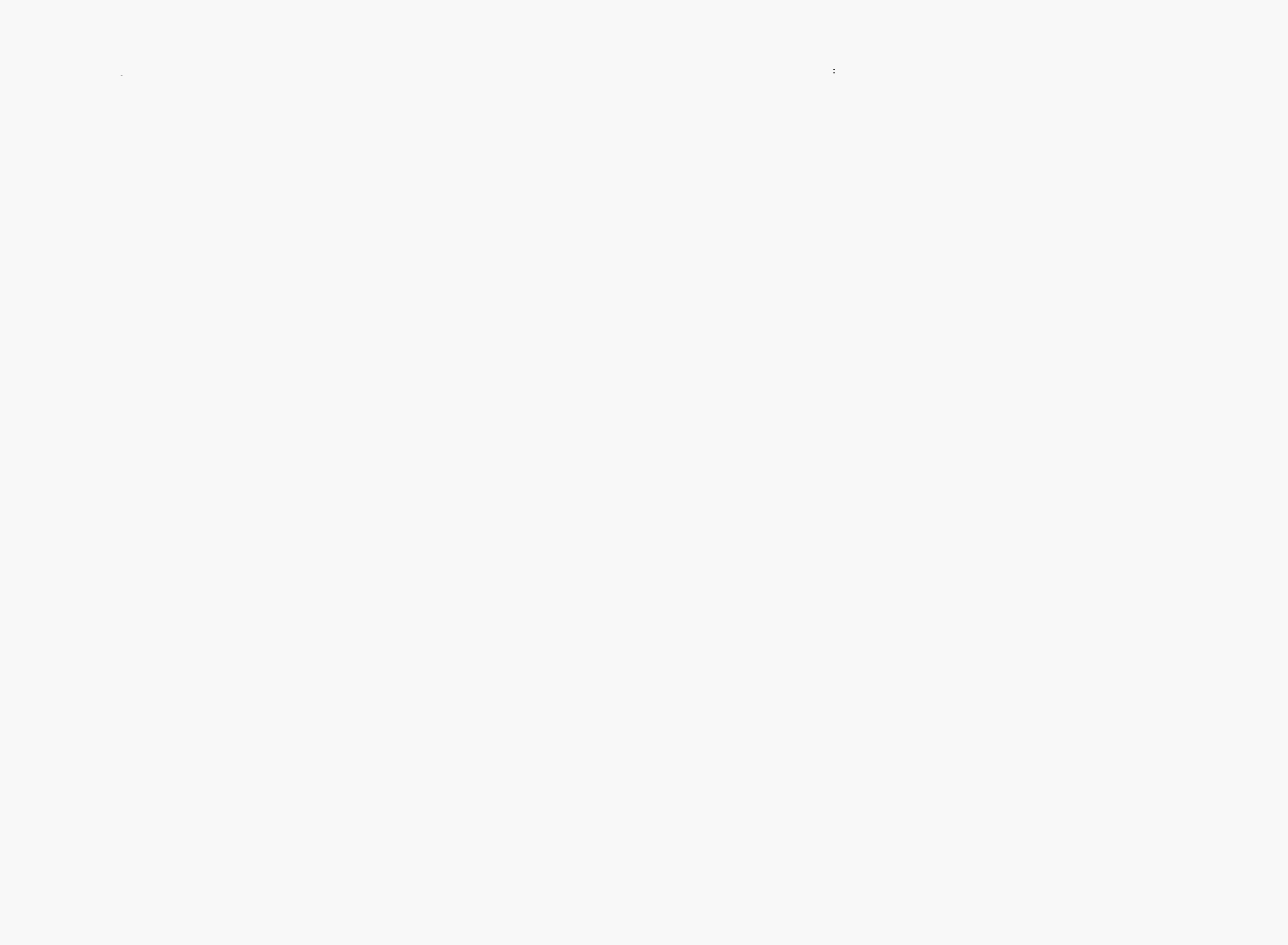


Section $\quad \underline{\text { Page }}$

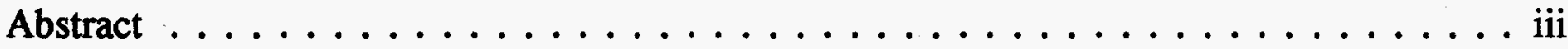

Figures $\ldots \ldots \ldots \ldots \ldots \ldots \ldots \ldots \ldots \ldots \ldots \ldots \ldots \ldots \ldots \ldots \ldots \ldots$

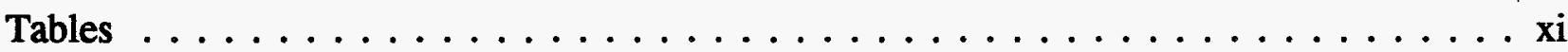

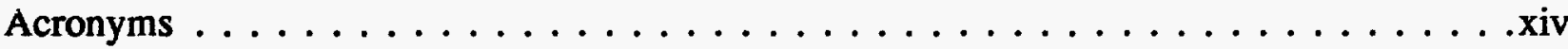

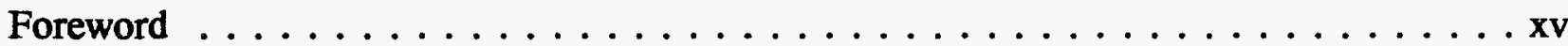

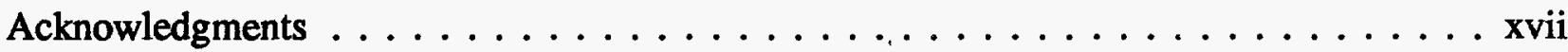

Executive Summary . . . . . . . . . . . . . . . . . . . xix

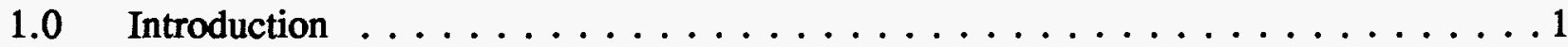

2.0 Probabilistic Framework $\ldots \ldots \ldots \ldots \ldots \ldots$

3.0 Quantification of Initial Conditions $\ldots \ldots \ldots \ldots \ldots$

4.0 Quantification of the DCH Phenomenon .................. 46

5.0 Quantification of Containment Fragility .................. 51

6.0 Results and Sensitivities . . . . . . . . . . . . . . . . 56

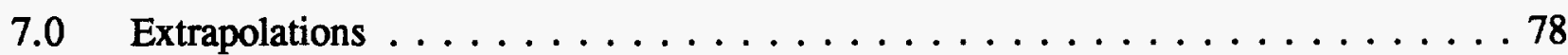

8.0 Conclusions and Recommendations ................... 86

Appendix A. The Risk Oriented Accident Analysis Methodology (ROAAM) . . . . . A A-1

Appendix B. The Gradual Relocation Versus Crucible Phenomenologies . . . . . . . B-1

Appendix C. The Main Lower Head Failure Bifurcation . . . . . . . . . . . . . . C-1

Appendix D. The Prediction of Direct Containment Heating . . . . . . . . . . . . D-1

Appendix E. A Two-Cell Equilibrium Model for Predicting DCH . . . . . . . . . . . E-1

Appendix F. Autoignition Temperature in DCH events . . . . . . . . . . . . . F-1

Appendix G. The Sandia Integral Effects Test Series . . . . . . . . . . . G-1

Appendix H. Results of Direct Containment Heating Integral Experiments at

1/40 Scale at Argonne National Laboratory . . . . . . . . . . . . H-1

Appendix I. The Role of the Annular Gap Around the RPV . . . . . . . . . . . . I-1

Appendix J. Continued Enlargement of the Initial Failure Site in the Reactor

Pressure Vessel .........................

Appendix K. Comparison of Melt Mass and Composition Quantifications with

Prior Work .......................... 


\section{LIST OF FIGURES}

Figure Page

2.1. The probabilistic framework for containment failure under Direct Containment Heating

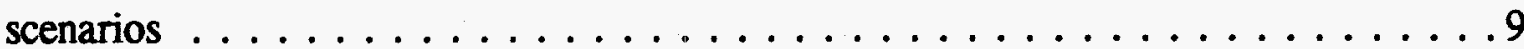

2.2. Illustration of the probabilistic framework in terms of schematic depiction of its

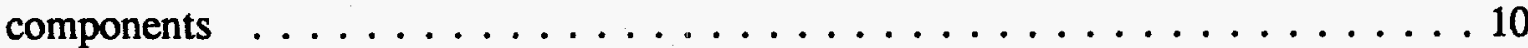

3.1. Splinter DCH scenarios ....................... 36

3.2. Zion Nuclear Power Plant . . . . . . . . . . . . . . . 37

3.3. Scenario I - Distribution of $\mathrm{UO}_{2}$ mass $\ldots \ldots \ldots \ldots$

3.4. Scenarios I, II - Distribution for fraction of $\mathrm{Zr}$ oxidized (core wide) . . . . . . 39

3.5. Scenario II - Distribution of $\mathrm{UO}_{2}$ mass . . . . . . . . . . . . . . . . 40

3.6. Scenario III - Distribution for fraction of $\mathrm{Zr}$ oxidized (core wide) $\ldots \ldots \ldots$

3.7. Scenario III - Distribution of steel mass . . . . . . . . . . . . . 42

3.8. Scenario IV - Distribution of $\mathrm{UO}_{2}$ mass $\ldots \ldots \ldots \ldots$

3.9. Scenario IV - Distribution for fraction of $\mathrm{Zr}$ oxidized (core wide) . . . . . . . 44

5.1. Fragility of the Zion containment ... . . . . . . . . . . . . 54

6.1. Scenario I - Calculated distribution for hole size $\ldots \ldots \ldots \ldots 1$

6.2. Scenario I - Calculated distribution for coherence ratio . . . . . . . . . . 62

6.3. Scenario I - Calculated distribution for containment temperature . . . . . . 63

6.4. Scenario I - Calculated distribution for containment pressure . . . . . . . . . 64

6.5. Scenario II - Calculated distribution for hole size . . . . . . . . . . . 65

6.6. Scenario II - Calculated distribution for coherence ratio . . . . . . . . . . 66

6.7. Scenario II - Calculated distribution for containment temperature . . . . . . . 67

6.8. Scenario II - Calculated distribution for containment pressure . . . . . . . . . 68

6.9. Scenario III - Calculated distribution for hole size . . . . . . . . . . . . 69

6.10. Scenario III - Calculated distribution for coherence ratio . . . . . . . . . . 70

6.11. Scenario III - Calculated distribution for containment temperature . . . . . . . 71

6.12. Scenario III - Calculated distribution for containment pressure . . . . . . . . 72

6.13. Scenario IV - Calculated distribution for hole size . . . . . . . . . . . 73

6.14. Scenario IV - Calculated distribution for coherence ratio . . . . . . . . . . 74

6.15: Scenario IV - Calculated distribution for containment temperature . . . . . . . 75 


\section{LIST OF FIGURES (cont.)}

Figure

6.16. Scenario IV - Calculated distribution for containment pressure . . . . . . . . 76

C.1 The function of $\mathrm{F}(\beta)$ for Equation $\mathrm{C} .2 \ldots \ldots \ldots \ldots \ldots \ldots$

C.2 Lower head temperatures predicted by the numerical model (with and without melt relocation) and by the analytical model of Theofanous et al. (1991) . . . . . . C-10

C.3 Range of vessel failure times versus RCS pressure . . . . . . . . . . C-10

C.4 Ceramic and metal liquid fractions plotted as functions of time . . . . . . . . C-11

C.5 Peak temperatures in the debris bed .................... . . . .

D.1 The containment geometry considered and an illustration of the recirculation in the

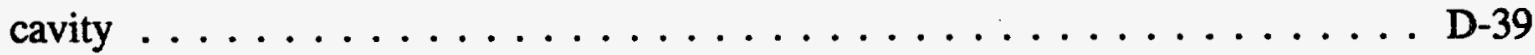

D.2a Prediction of containment pressurization due to $\mathrm{DCH}$ using the CLCH model . . . . . . . . . . . . . . . . . . D-40

D.2b Prediction of containment pressurization due to $\mathrm{DCH}$ using the CLCH model $\ldots \ldots \ldots \ldots \ldots \ldots \ldots \ldots \ldots \ldots \ldots \ldots$. . . . . . . . . . . . . . . . . . .

D.2c Prediction of containment pressurization due to $\mathrm{DCH}$ using the

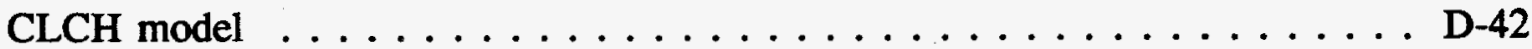

D.2d Prediction of containment pressurization due to DCH using the CLCH model . . . . . . . . . . . . . . . . . . D-43

D.3a Prediction of containment pressurization due to $\mathrm{DCH}$ using the

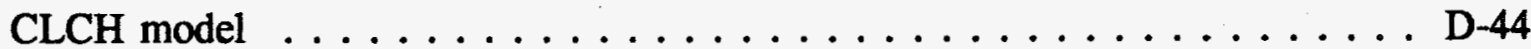

D.3b Prediction of containment pressurization due to DCH using the CLCH model $\ldots \ldots \ldots \ldots \ldots \ldots \ldots \ldots \ldots \ldots \ldots \ldots \ldots$

D.3c Prediction of containment pressurization due to $\mathrm{DCH}$ using the CLCH model $\ldots \ldots \ldots \ldots \ldots \ldots \ldots \ldots \ldots \ldots \ldots$

D.4a Illustration of sensitivity of onset and results of autoignition to the initial steam pressure, with the stainless steel content in the melt as the parameter . . . . . . . . D-47

D. $4 \mathrm{~b}$ Illustration of sensitivity of onset and results of autoignition to the initial steam pressure, with the hydrogen content in the blowdown gases as the parameter . . . . D D-48

D.5a Illustration of autoignition boundaries in the $\omega_{s s}-\omega_{\mathrm{Zr}}$ plane, at a pressure ratio of 80 , with the melt quantity as the parameter . . . . . . . . . . . . . . . D-49 


\section{LIST OF FIGURES (cont.)}

Figure

Page

D.5b Illustration of autoignition boundaries in the $\omega_{3 s}-\omega_{\mathrm{Zr}}$ plane, as a melt mass of 80 tons, with the pressure ratio as the parameter $\ldots \ldots \ldots \ldots \ldots \ldots \ldots$ D-50

D.6 Surtsey vessel, high-pressure melt ejection system, and subcompartment structures used in the SNL/IET experiments $\ldots \ldots \ldots \ldots \ldots \ldots \ldots \ldots \ldots \ldots$ D-51

D.7 Isometric view of the subcompartment structures inside the Surtsey vessel . . D-52

D.8a Comparison of containment pressurization predicted (lower limit of "L"-predictions) with the $\mathrm{CLCH}$ model and measurements in the SNL/IET series of tests $\ldots \ldots \ldots$ D-53

D.8b Comparison of containment pressurization predicted (upper limit of " $U$ "-predictions) with the $\mathrm{CLCH}$ model and measurements in the SNL/IET series of tests $\ldots \ldots \ldots$ D-54

D.9 Comparison of containment pressurization predicted (upper limit of " $U$ "-predictions) with the $\mathrm{CLCH}$ model and measurements in the ANL/IET series of tests . . . . . D-55

D.10 Illustration of determination of the experimental value of $\tau_{\mathrm{m}}$ from the pressure transients in the cavity and upper compartment $\ldots \ldots \ldots \ldots \ldots \ldots \ldots \ldots \ldots$

D.11 Comparison of predicted with measured debris dispersal (sweepout) times . . D D-57

D.12 Comparison of predicted with measured "DCH-scales" for all available tests that satisfy conditions described in the text $\ldots \ldots \ldots \ldots \ldots \ldots \ldots \ldots \ldots$ D-58

E.1 Comparison of the single-cell equilibrium model with the existing

DCH database . . . . . . . . . . . . . . . . . . . . . . . . . . . . . E-69

E.2 Validation of the two-cell equilibrium model with the experiments where the atmosphere was inert . . . . . . . . . . . . . . . . . . . . . E-70

E.3 Validation of hydrogen production predictions (no cavity/containment water and nonreactive atmospheres) $\ldots \ldots \ldots \ldots \ldots \ldots \ldots \ldots \ldots$. . . . . . E-71

E.4 Comparison of hydrogen production predictions with experiment data (water in cavity and/or containment and/or reactive atmospheres $\ldots \ldots \ldots \ldots \ldots \ldots$ E-72

E.5 Validation of the two-cell equilibrium model with experiments where hydrogen could burn in a reactive atmosphere $\ldots \ldots \ldots \ldots \ldots \ldots \ldots \ldots \ldots$. $\ldots \ldots$

E.6 Validation of the two-cell equilibrium model against all experiments with compartmentalized geometry . . . . . . . . . . . . . . . . E-74

E.7 Typical cavity pressurization record $\ldots \ldots \ldots \ldots \ldots \ldots \ldots$ E-75 


\section{LIST OF FIGURES (cont.)}

Figure

Page

E.8 Typical accumulated $(\mathrm{RCS})$ blowdown record $\ldots \ldots \ldots \ldots \ldots$. . . . . . E-75

E.9 Validation of the coherence ratio for Zion-like cavity designs . . . . . . . . E-76

E.10 Validation of the coherence ratio for Surry-like cavity designs $\ldots \ldots \ldots \ldots$. . E-77

E.11 Validation of the coherence ratio against the combined Zion and

Surry database . . . . . . . . . . . . . . . . . . E-78

F.1 Reported autoignition temperatures in small scale experiments . . . . . . F-15

F.2 Case I; SENKIN calculations for volumetric hydrogen combustion . . . . . . . F-16

F.3 Case II; SENKIN calculations for volumetric hydrogen combustion . . . . . . . F-17

F.4 Threshold for volumetric hydrogen combustion in a temperature decaying

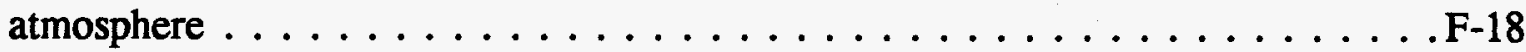

F.5 Temperature history of the upper dome during the IET-10 experiment $\ldots \ldots$ F-19

G.1 Surtsey vessel, high-pressure melt ejection system, and subcompartment structures used in the IET experiments $\ldots \ldots \ldots \ldots \ldots \ldots \ldots \ldots \ldots \ldots \ldots$. $\ldots \ldots \ldots$

G.2 Schematic of the $1: 10$ linear scale model of the Zion reactor cavity . . . . . . G-23

G.3 Isometric view of subcompartment structures inside the Surtsey vessel . . . . G-24

G.4 Upward propagation flammability limit for hydrogen/oxygen/nitrogen

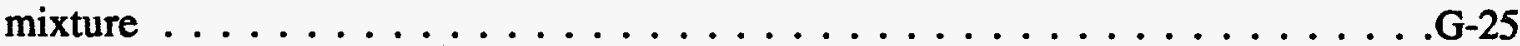

G.5 Surtsey vessel pressure comparisons versus time for the IET experiments . . . . G-26

G.6 Comparison of the cavity pressures versus time for the IET experiments . . . . G-27

G.7 Temperature history in the triangular vent spaces above RCP 1A in the IET experiments $\ldots \ldots \ldots \ldots \ldots \ldots \ldots \ldots \ldots \ldots \ldots \ldots \ldots$. . . . . . . . . .

G.8 Temperature history of the vessel thermocouple array in the IET experiments . . . . . . . . . . . . . . . . . . . . . . . .G-29

G.9 Comparison of the oxygen levels versus time in the IET experiments . . . . . G-30

G.10 Comparison of the hydrogen levels versus time in the IET experiments . . . . . G-31

G.11 Comparison of the hydrogen combustion versus time in the IET experiments . . G-32

G.12 Comparison of the hydrogen production versus time in the IET experiments . . . G-33

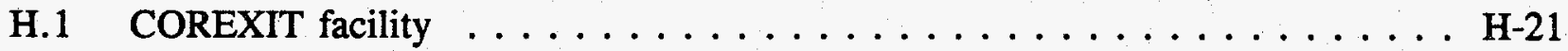

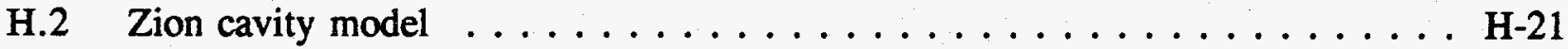




\section{LIST OF FIGURES (concluded)}

Figure

H.3 Schematic of melt generator and injector (MGI) $\ldots \ldots \ldots \ldots \ldots \ldots$ H-22

H.4 Schematic of the subcompartment model . . . . . . . . . . . . H-22

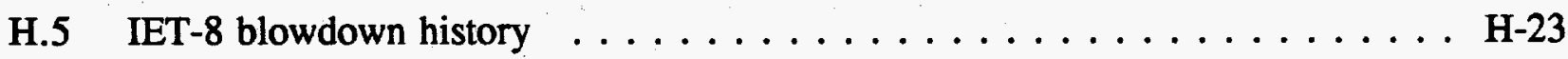

H.6 IET-8 RCS blowdown rate $\ldots \ldots \ldots \ldots \ldots \ldots \ldots \ldots \ldots \ldots$ H-23

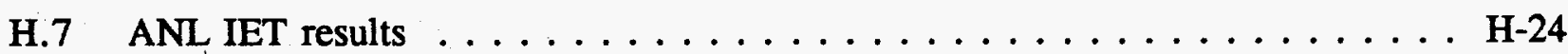

H.8 IET-8 cavity pressure and photocell output $\ldots \ldots \ldots \ldots \ldots \ldots \ldots \ldots$ H-24

H.9 Cavity gas temperature obtained in the IET-3 test $\ldots \ldots \ldots \ldots \ldots \ldots$ H-25

H.10 Number of oxygen and hydrogen moles in IET- $6 \ldots \ldots \ldots \ldots$. . . . . . . . .

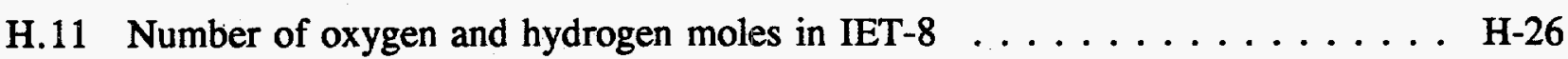

J.1 Thermal conditions in the orifice walls before and after the initiation

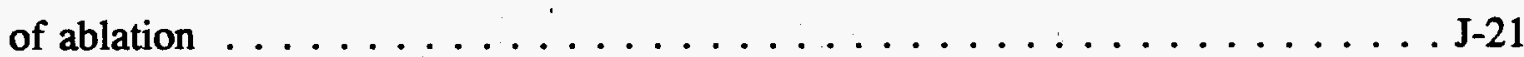

J.2 Validation of the hole ablation model against experiment data $\ldots \ldots \ldots \ldots \mathrm{J}-22$ 


\section{LIST OF TABLES}

Table $\quad$ Page

3.1. Summary of initial condition quantification $\ldots \ldots \ldots \ldots$

3.2. Characterization of the Zion Plant . . . . . . . . . . . . . . 34

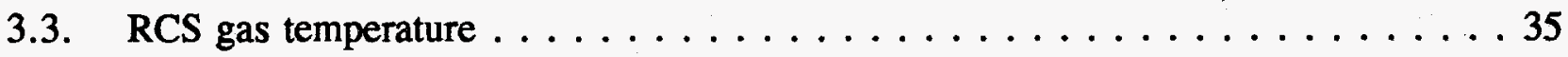

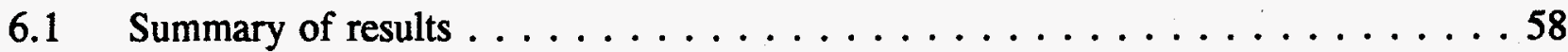

6.2 Scenario I - sensitivity studies $\ldots \ldots \ldots \ldots \ldots \ldots$

6.3 Scenario II - sensitivity studies . . . . . . . . . . . . . . . . . 59

6.4 Scenario III - sensitivity studies $\ldots \ldots \ldots \ldots$

6.5 Scenario IV - sensitivity studies $\ldots \ldots \ldots \ldots$

7.1 Basis for extrapolation to other PWRs ................ 81

7.2 Plant specific sensitivities using the TCE model, containment loads (MPa) at a cumulative probability of 95 percent . . . . . . . . . . . . . . 84

A.1 Definition of probability levels . . . . . . . . . . . . . . . . A-10

D.1 Numerical representation of the function in Eq. (D.12) in the relevant ranges of its

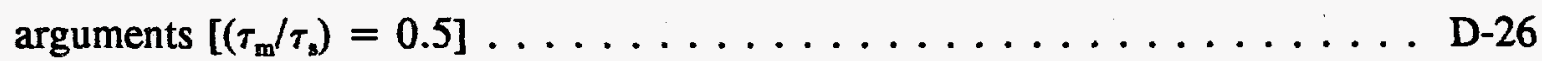

D.2 Numerical representation of the function in Eq. (D.12) in the relevant ranges of its

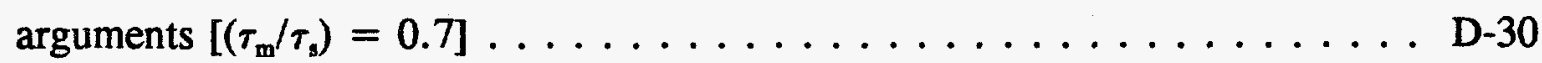

D.3 Summary of initial conditions in the SNL/IET series of tests . . . . . . . . D-34

D.4 Summary of initial conditions in the ANL/IET series of tests . . . . . . . D D-34

D.5 Summary of posttest material distributions, in $\mathrm{kg}$, for the SNL/IET series

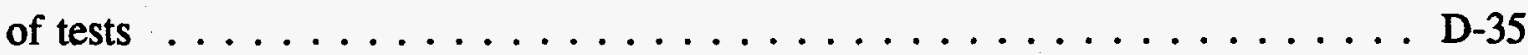

D.6 Summary of posttest material distributions, in $\mathrm{kg}$, for the ANL/IET series

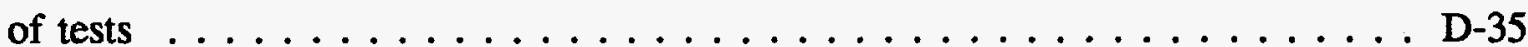

D.7 Comparison of predicted with the "measured" quantities (moles) of hydrogen produced in the SNL/IET series of tests . . . . . . . . . . . . . . D-36

D.8 Comparison of predicted with the "measured" quantities of hydrogen produced in the ANL/IET series of tests . . . . . . . . . . . . . . . D D $\ldots$

D.9 Relevant conditions in the LFP test series . . . . . . . . . . . . D-37 


\section{LIST OF TABLES (cont.)}

Table

D.10 Comparison of CLCH model predictions with the LFP test series in the Surtsey Facility . . . . . . . . . . . . . . . . D-38

E.1 Survey of DCH relevant experiments $\ldots \ldots \ldots \ldots \ldots \ldots \ldots \ldots$ E-56

E.2 Specific molar properties of debris $\ldots \ldots \ldots \ldots \ldots \ldots \ldots \ldots$ E-59

E.3 Specific molar heat capacity of containment atmosphere $\ldots \ldots \ldots \ldots \ldots$ E-59

E.4 Representative composition of corium and thermite . . . . . . . . . . E-60

E.5 Representative composition of a containment atmosphere . . . . . . . . . E-60

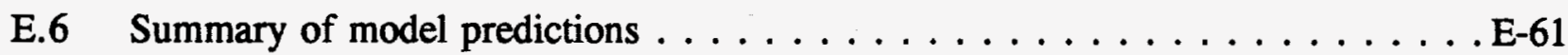

E.7 Inerting criteria for jet combustion $\ldots \ldots \ldots \ldots \ldots \ldots \ldots \ldots$ E-64

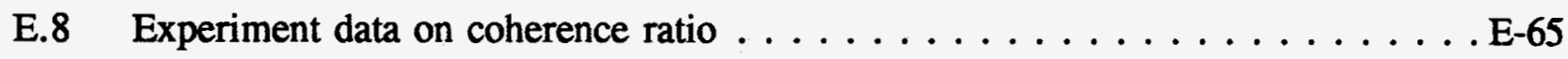

E.9 Applicability of the database to reactor applications $\ldots \ldots \ldots \ldots \ldots \ldots$ E-68

F.1 Kinetics of hydrogen combustion $\ldots \ldots \ldots \ldots \ldots \ldots \ldots \ldots \ldots$ F-13

F.2. Kinetics of hydrogen combustion $\ldots \ldots \ldots \ldots \ldots \ldots \ldots \ldots \ldots$ F-13

F.3 Scale effect on autoignition temperature $\ldots \ldots \ldots \ldots \ldots \ldots \ldots \ldots$ F-13

F.4 Validation of scale dependence . . . . . . . . . . . . . . . F-13

F.5 Combustion of preexisting hydrogen in DCH tests . . . . . . . . . F-14

G.1 Initial conditions for the IET experiments $\ldots \ldots \ldots \ldots \ldots \ldots \ldots \ldots$ G-20

G.2 Summary of the results of the IET experiments $\ldots \ldots \ldots \ldots \ldots \ldots \ldots$ G-21

H.1 Summary of specified reference initial and boundary conditions . . . . . . H-13

H.2 Instrumentation $\ldots \ldots \ldots \ldots \ldots \ldots \ldots \ldots \ldots \ldots \ldots \ldots \ldots$ H-14

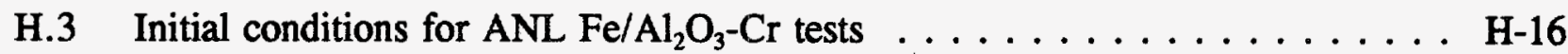

H.4 Summary of results from ANL $1 / 40$ scale tests $\ldots \ldots \ldots \ldots \ldots \ldots \ldots$ H-17

H.5 Summary of gas sample measurements for ANL IET-1, 1R, 1RR, 3 and $6 \ldots$ H-18

H.6 Summary of debris disposition . . . . . . . . . . . . . . . . H-19

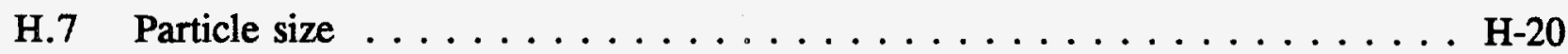

H.8 DCH pressurization results $\ldots \ldots \ldots \ldots \ldots \ldots \ldots \ldots \ldots \ldots \ldots \ldots$

I.1 Validation of debris dispersal through the annular gap $\ldots \ldots \ldots \ldots \ldots$ I-5

J.1 Initial conditions for validation of hole ablation model $\ldots \ldots \ldots \ldots \ldots$ J-16 


\section{LIST OF TABLES (concluded)}

Table

J.2 Validation of the hole ablation model $\ldots \ldots \ldots \ldots \ldots \ldots \ldots$ J-17

J.3 Base case for sensitivity studies $\ldots \ldots \ldots \ldots \ldots \ldots \ldots \ldots \ldots \ldots \ldots \ldots$ J-18

J.4 Sensitivity to initial melt mass $\ldots \ldots \ldots \ldots \ldots \ldots \ldots \ldots \ldots \ldots \ldots$ J-18

J.5 Sensitivity to variations in melt composition $\ldots \ldots \ldots \ldots \ldots \ldots \ldots$ J-19

J.6 Sensitivity to variations in RCS pressure . . . . . . . . . . . . . J J-19

J.7 Sensitivity to melt temperature $\ldots \ldots \ldots \ldots \ldots \ldots \ldots \ldots \ldots \ldots$ J-19

J.8 Sensitivity to lower head temperature $\ldots \ldots \ldots \ldots \ldots \ldots \ldots \ldots \ldots$ J-19

J.9 Sensitivity to lower head thickness $\ldots \ldots \ldots \ldots \ldots \ldots \ldots \ldots \ldots \ldots$ J-20

J.10 Sensitivity to initial hole size $\ldots \ldots \ldots \ldots \ldots \ldots \ldots \ldots \ldots \ldots \ldots \ldots$ J-20

J.11 Sensitivity to the number of simultaneous penetration failures . . . . . . J J-20

K.1 Comparison of prior work with Scenario I $\ldots \ldots \ldots \ldots \ldots \ldots \ldots \ldots$

K.2 Comparison of prior work with Scenario II $\ldots \ldots \ldots \ldots \ldots \ldots \ldots$ K-5

K.3 Comparison of prior work with șcenario IV $\ldots \ldots \ldots \ldots \ldots \ldots \ldots$ K-6 


\section{ACRONYMS/INITIALISMS}

ANL Argonne National Laboratory

CE Combustion Engineering

CFP Containment Failure Probability

$\mathrm{CLCH}$ Convection Limited Containment Heating

CR Causal Relation

DCH Direct Containment Heating

DPD Discrete Probability Distribution

GPM Gallons Per Minute

HPI High Pressure Injection

INEL Idaho National Engineering Laboratory

IPE Individual Plant Examination

NPP Nuclear Power Plant

NRC Nuclear Regulatory Commission

OTSG Once-Through Steam Generation

PORV Pilot-Operated Relief Valve

PRA Probabilistic Risk Assessment

PWR Pressurized Water Reactor

RCP Reactor Coolant Pump

RCS Reactor Coolant System

ROAAM Risk Oriented Accident Analysis Methodology

ROAAQ Risk Oriented Accident Analysis Quantification

RPV Reactor Pressure Vessel

SASM Severe Accident Scaling Methodology

SBLOCA Small Break Loss-of-Coolant Accident

SCE Singe Cell Equilibrium

SNL Sandia National Laboratories

TCE Two-Cell Equilibrium

TPG Technical Program Group 


\section{FOREWORD}

NUREG/CR-6075 describes a probabilistic framework to assess the Direct Containment Heating (DCH) issue for the Zion Nuclear Power Plant. This document consists of the main body and Appendices A* through K. It was prepared in January 1993 for internal NRC review, and it was in final draft form by June 1993. Draft NUREG/CR-6075 was reviewed by a panel of 15 experts representing national laboratories, universities, and industry. Comments from the reviewers were received by the NRC and forwarded, along with a summary from Energy Research Inc., to the authors in October 1993. A point-by-point response to reviewer comments was prepared and submitted to the NRC in March 1994 for distribution to the reviewers. Rebuttals from the reviewers were received in April 1994. Typographical errors were corrected and minor points of clarification were incorporated into NUREG/CR-6075 to reflect the peer reviewers' comments and suggestions. Major issues that were identified as part of the peer review process will be addressed in a separate document referred to as NUREG/CR-6075, Supplement 1.

Following the comment, response, and rebuttal process, two meetings of select members of the original peer review group were held in May 1994 to resolve the two key residual concerns: initial conditions and model validity. Additional analyses identified by the working groups to strengthen the original conclusions are addressed in NUREG/CR-6075, Supplement 1. This supplement report also contains the following information: the NRC letter of request to the peer reviewers, peer reviewer comments, responses to the peer reviewers, rebuttals from the peer reviewers, and minutes from the two working group meetings. As suggested by the peer reviewers, NUREG/CR-6075, Supplement 1, focuses on DCH issue resolution for the Zion Nuclear Power Plant. Extrapolation to other power plants is being addressed in another NUREG/CR report to be released soon.

Just prior to the publication of this report, it was discovered that the temperature ratio in the coherence ratio used in the two-cell equilibrium (TCE) model (Appendix E) was inverted from the correct expression. The derivation has been corrected; and the experiment data have been refit with the correct expression. The text has been modified to reflect the corrections. 
Computed results for the distribution of containment pressure (using the TCE model) have not been corrected. For Scenarios I and II, the corrected containment pressures are $\leq 0.7$ percent higher; therefore, the differences are negligible. The increase in containment pressure (due to the correction) for Scenarios III and IV is more pronounced ( $\sim 9$ percent and $\sim 15$ percent, respectively); hówever, containment load distributions still do not intersect the containment strength (fragility) distribution. Furthermore, subsequent activities (documented in NUREG/CR6075, Supplement 1) have demonstrated that the high metallic content of Scenarios III and IV is inconsistent with the RCS being at high pressure. These corrections to the calculated loads do not affect the conclusion that the likelihood of containment failure by direct containment heating at Zion is negligibly low. The corrected expression for the coherence ratio was used in all the NUREG/CR-6075, Supplement 1 analyses.

* Appendix A was not authored by Sandia and contains views not necessarily consistent with the views of Sandia, however, any differences in views do not impact the conclusions in this report. 


\section{ACKNOWLEDGMENTS}

This work was supported by the U.S. Nuclear Regulatory Commission Office of Nuclear Regulatory Research. This work was made possible by the existence of well scaled experiments conducted at Sandia National Laboratories and Argonne National Laboratory. Guidance for the development of the test matrix was provided by the Accident Evaluation Branch of the Nuclear Regulatory Commission with technical support from a Direct Containment Heating Peer Review Committee. This report has benefitted from review by the staff of the Nuclear Regulatory Commission, Sandia National Laboratories, and Idaho National Engineering Laboratory, and an NRC panel of peer reviewers. 


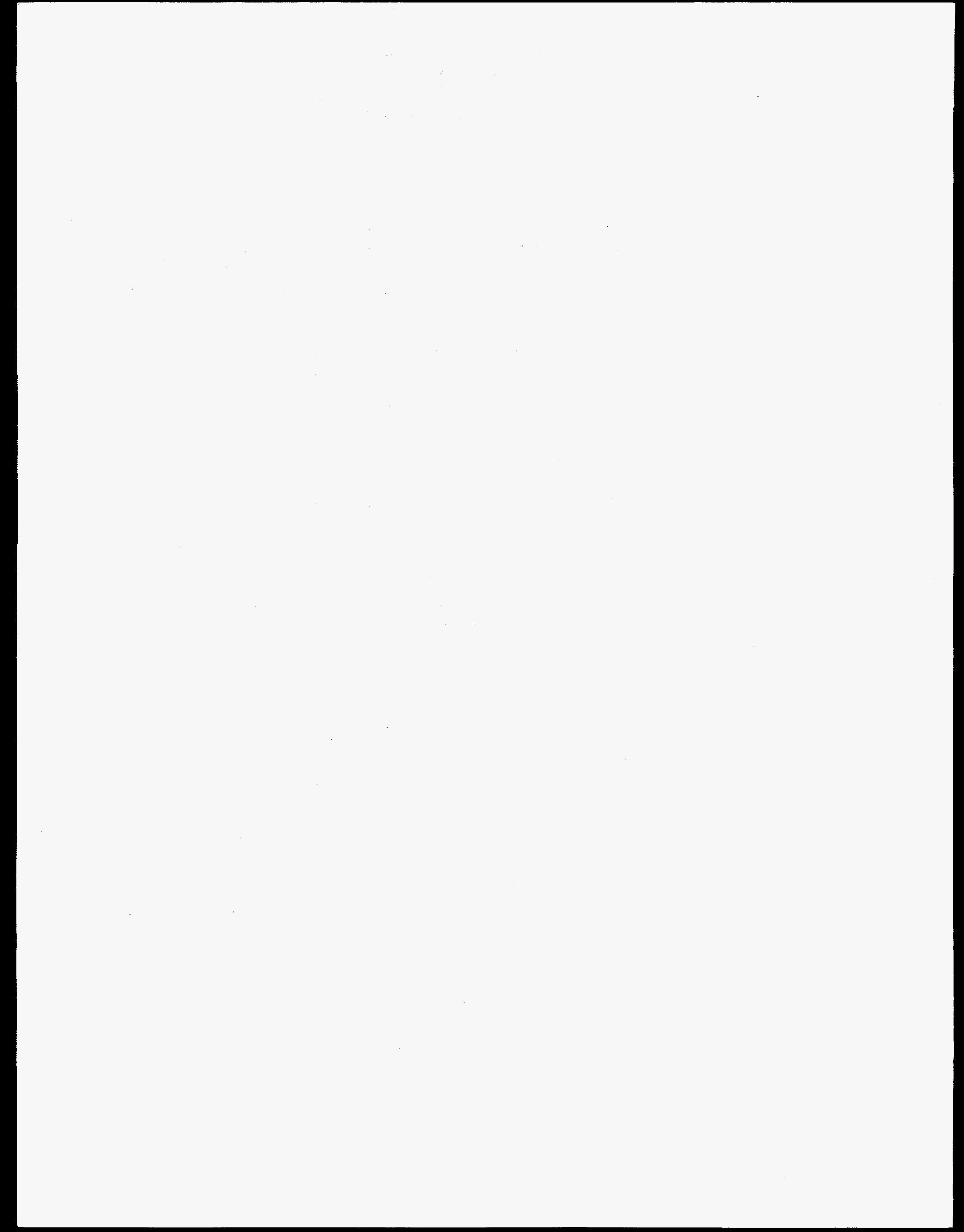




\section{EXECUTIVE SUMMARY}

Direct Containment Heating (DCH) has been a prominent severe accident issue because of its potential for early containment failure. Nuclear Regulatory Commission (NRC)-sponsored research has culminated in two elements to DCH issue resolution. The first element to DCH resolution focuses on possible overpressurization of the containment from $\mathrm{DCH}$ processes. This report addresses DCH for Zion from this perspective. The second element to DCH resolution focuses on both intentional and unintentional depressurization of the primary system prior to bottom head failure. The NRC has sponsored an integrated effort that will address both elements to $\mathrm{DCH}$ resolution.

The Risk Oriented Accident Analysis Methodology (ROAAM) is applied to quantify the likelihood of containment failure resulting from DCH in the Zion Nuclear Power Plant (NPP). We conclude that the containment failure probability (CFP) at Zion is so low as to be considered physically unreasonable (CFP $<10^{-3}$ ). Sensitivity studies did not find any areas of large sensitivity. The key criteria for applicability of these analyses are: 1) there is an intermediate compartment that is large compared to the reactor cavity but small compared to the main containment volume, and 2) there is no significant line-of-sight pathway for debris transport from the cavity to the main containment volume. The key technical features of this evaluation follow.

Core-melt progression, melt relocation to the lower plenum, and lower head failure define the initial conditions for DCH. Uncertainties in these processes are treated by considering splinter scenarios that envelope the expected phenomenologies. Four such scenarios are identified based on two accident classes (small break loss-of-coolant accident-like [SBLOCA-like] and TMLB'-like) and two failure modes (penetration failures and ruptures). The two accident classes are characterized by crucible formation and failure (SBLOCA-like) and gradual relocation (TMLB'-like). Within this enveloping approach, distributions for melt mass, zirconium content, zirconium oxidation, and steel content are estimated for each of the four splinter scenarios. The initial failure size for penetration and rupture type failures are characterized with a new model 
that places a physical limit to the maximum rupture size. The final hole size in the lower head is based on the failure mode and melt mass coupled with a model for hole ablation.

Two independently developed and fundamentally based models that calculate the containment loads, the Two-Cell Equilibrium (TCE) model and the Convection Limited Containment Heating (CLCH) model, are shown to quantitatively capture the essence of the multiple interactions involved in DCH. Each model is compared against the extensive database of experiments conducted with both the prototypic and simulant materials, at different physical scales, and in prototypic plant geometries. The key model parameter for both the TCE and CLCH models is the coherence ratio, which is defined as the ratio of melt dispersal time to the system depressurization time. Scaling laws for the coherence ratio are proposed and verified by comparison to a broad and prototypic database, including two cavity geometries (Zion and Surry), two scales (1/10 and 1/40), system pressures in the 2.6 to $7.1 \mathrm{MPa}$ range, and breach diameters in the 0.35 to $0.66 \mathrm{~m}$ (scaled to reactor size) range. Insights found in recent largescale prototypic experiments indicate that large-scale volumetric combustion of preexisting hydrogen (autoignition) cannot occur on the time scale of peak DCH loads. The two containment loads models, coupled with distributions for the key initial conditions and a distribution for the coherence ratio, are used to compute a distribution of containment pressures for each scenario.

The pressure capacity (fragility) of the Zion containment is specified in probabilistic terms. A fragility curve from the Zion individual plant examination (IPE) is used in the current quantifications. NRC-sponsored research to integrate current understanding of containment failure mechanisms within their own probabilistic framework is expected to become available.

The load distribution curve is intersected with the containment fragility curve, yielding a containment failure probability for each of the scenarios. There is essentially no overlap between load and strength distributions, so we conclude that the likelihood of containment failure for Zion is so low as to be considered physically unreasonable. The results of this report are the culmination of many new and recent perspectives on DCH-related phenomena. Residual uncertainties in some of these areas may require some confirmatory activity. Sensitivities studies 
have been performed on the autoignition temperature, debris transport to the dome, lower head failure size, and reactor coolant system pressure. In each case, the parameter of interest is shifted outside the expected range of behavior in such a way as to increase DCH loads. Multiple combinations of sensitivity parameters were also examined. No areas of large sensitivity were discovered.

We generalize Zion's containment load predictions to most Pressurized Water Reactors (PWRs) excluding Ice Condenser and Combustion Engineering (CE) plants using scaling considerations. Several items requiring further attention, of a confirmatory nature, are as follows:

(a) Deeply Flooded Cavities: This plant-specific item is needed to identify any cases where geometry allows the buildup of water depths significantly higher than the condensate levels examined so far. Need for any additional evaluations will depend on the extent of such situations and on the particulars of each case.

(b) System Pressure Level: Even though we show that melt expulsion with maximum primary system pressures do not lead to any significant concerns for Zion, we cannot categorically exclude system pressures above $8 \mathrm{MPa}$ at this time for all plants. It may be worthwhile to determine if system pressures above $8 \mathrm{MPa}$ can be excluded. This issue is explicitly addressed in integrated DCH issue resolution tasks.

(c) Containment Strength: It remains to be determined whether there are any significant deviations from the Zion fragility for containments of a similar class. Containment capability is affected by design details and must be examined on a plant-specific basis, possibly through the IPE or ongoing research sponsored by the NRC.

The last item above, in conjunction with the similarity of the containment loads, could allow the the application of this methodology to calculate containment failure probabilities for most other PWRs. 


\subsection{INTRODUCTION}

Direct Containment Heating (DCH) is a prominent severe accident issue because of its potential for early containment failure. The Nuclear Regulatory Commission (NRC) has identified DCH as a major issue for resolution in the Revised Severe Accident Research Plan (NRC, 1992) and has sponsored an integrated approach for DCH issue resolution. The integrated approach involves two key elements: evaluating possible overpressurization failure of the containment from DCH processes, and evaluating both intentional and unintentional depressurization of the primary system prior to bottom head failure. The results of the approach of the first element are presented in this report. Intentional and unintentional depressurization for the Zion plant has been addressed by the Idaho National Engineering Laboratory (INEL). The NRC has also sponsored a research program that will integrate both of these elements for DCH issue resolution. This effort will include plant-specific calculations for Surry, will summarize other relevant research, and will develop a methodology to resolve the DCH issue for all existing pressurized water reactors. This fully integrated approach, involving containment loads and reactor coolant system (RCS) depressurization, may be needed to achieve DCH resolution for some plants.

In this report, the Risk Oriented Accident Analysis Methodology (ROAAM) was applied to resolve the DCH issue for the Zion Nuclear Power Plant (NPP). ROAAM was developed specifically for the purpose of addressing severe accident issues. The philosophical basis for ROAAM is described in Appendix A. ROAAM has been applied to the Mark I Liner Attack issue (Theofanous et al., 1991; Theofanous et al., 1993). It involves a multistep process, and this report is the first step in the process.

In order to apply the ROAAM methodology, one must understand the physics of an NPP accident well enough to identify a small set of the key physical processes that control the outcome. The key processes that occur in an extremely complex accident sequence must be quantified in a simple manner that will reasonably bound the outcome. The NRC-sponsored experimental program has played a major role in developing an understanding of the key physical processes in DCH. The technical basis for these scaled experiments was developed by the Severe Accident Scaling Methodology Technical Program Group (SASM-TPG) 
(Zuber et al., 1992) and by Pilch et al. (1992). The extensive database from the Sandia National Laboratories/Argonne National Laboratory (SNL/ANL) counterpart experiments has allowed the development and validation of two analytical models for predicting the containment load: the Convection Limited Containment Heating (CLCH) model and the Two-Cell Equilibrium (TCE) model. Both models focus on the same phenomenological insights, that is, the noncoherence of debris entrainment and RCS blowdown provides only a limited resource for debris/gas interactions in compartmentalized containment geometries. The development of these models, although initially independent, has found mutual benefit from collaboration during the course of this work. These models are described in Appendices D and E, which also describe the nature of the DCH issue and the basic physics involved.

The first task of the ROAAM application is to decompose the issue into specific technical topics amenable to quantification. The structure of this decomposition is called a probabilistic framework, which is described in Section 2. Quantification (the Risk Oriented Accident Analysis Quantification, or ROAAQ) consists of developing the rationale for assigning numerical values to each component of this structure. It is followed by the probabilistic synthesis of these individually quantified components in the manner specified by the probabilistic framework. The major components in the present framework are melt initial conditions, the DCH phenomena, and the containment fragility curve; their quantifications are given in Sections 3, 4, and 5, respectively. Further details on DCH phenomena are given in Appendices D and E. The synthesis is carried out using the method of Discrete Probability Distribution (DPD) and the ALPHA code, which was developed for this purpose, as discussed in Sections 2 and 6. Section 6 also contains the results of the calculations where we also pursue the quantification using sensitivity studies; that is, we investigate the impact of systematically varying the base quantifications by specifying arbitrary variations in key parameters. Based on these results and with the guidance of the scaling analyses found in Appendices D and E, a method for extrapolation of the quantification to most other Pressurized Water Reactors (PWRs) with large dry containments (excluding Combustion Engineering Plants and ice condensers) is explored in Section 7. Finally, the key results and implications are summarized in Section 8. 


\subsection{References}

NRC (December 1992). Severe Accident Research Program Plan Update, NUREG-1365, Rev. 1, U.S. Nuclear Regulatory Commission, Washington, DC.

Pilch, M.M., M.D. Allen, and J.L. Binder (1992). "Counterpart and Replicate DCH Experiments Conducted at Two Different Physical Scales: The SNL/IET-1, 1R and the ANL/IET-1R, 1RR Experiments, " Letter Report to the NRC, Sandia National Laboratories, Albuquerque, NM.

Theofanous, T.G., W.H. Amarasooriya, H. Yan, and U. Ratnam (August 1991). The Probability of Liner Failure in a Mark-I Containment, NUREG/CR-5423.

Theofanous, T.G. et al. (November 1993). The Probability of Mark-I Containment Failure by Melt Attack on the Liner, NUREG/CR-6025.

Zuber, N. et al. (1992). An Integrated Structure and Scaling Methodology for Severe Accident Technical Issue Resolution, Draft for Comment, NUREG/CR-5809, EGG-2659, EG\&G Idaho, Inc., Idaho Falls, ID. 


\subsection{PROBABILISTIC FRAMEWORK}

The basic understanding upon which this DCH issue resolution approach is based is that the intermediate (or steam generator) compartment traps the debris dispersed from the reactor cavity and that the thermal/chemical interactions during this dispersal process are limited by the incoherence in the steam blowdown and melt entrainment processes. To put this simply, for blowdowns that are sufficient to cause entrainment and significant thermal/chemical interactions, the entrainment time is short compared to the blowdown time so that the molten debris is only exposed to a small fraction of the steam from the primary system. Because this steam is the medium for carrying the melt energy and the hydrogen produced by steam/metal interactions to the main containment volume, this incoherence is a crucial mitigating factor. With this understanding, it is possible to reduce most of the complexity of the DCH phenomenon to a single parameter: the ratio of melt entrainment time constant to the system blowdown time constant $\left(\mathrm{R}_{\tau}=\tau_{\mathrm{m}} / \tau_{\mathrm{s}}\right.$ in the CLCH model and $\mathrm{R}_{\tau}=\tau_{\mathrm{e}} / \tau_{\mathrm{b}}$ in the TCE model $\left.{ }^{1}\right)$. For simplicity, $R_{\tau}$ is referred to as a coherence ratio.

Besides these modeling factors, the DCH loads depend on parameters that characterize the system initial conditions; that is, primary system pressure, temperature and composition (i.e., hydrogen mole fraction), melt quantity and composition (zirconium and stainless steel mass fractions), initial containment pressure and composition (hydrogen mole fraction), and geometry (containment volume and the size of breach). The key component of the framework, therefore, is the causal relation (CR1) between these parameters and the resulting containment pressure (and temperature) under the influence of the uncertainty in the coherence ratio, $R_{r}$. Of these parameters, some are fixed, some vary only over a narrow range, and some are so uncertain that they can be approached only in a very bounding sense. The following features are considered in coming up with the final choice of a framework:

(a) Geometry. The specific geometry is fixed for a given plant; however, the basic features are that there is an intermediate compartment between the cavity and the main

${ }^{1}$ The definitions for the ratio $R_{r}$ differ only by a constant factor in the two applications. 
containment volume and that the lower head fails in a local (rather than global) manner. In addition, the geometry is characterized by the free volume of the containment and the primary system volume.

(b) Containment Conditions. Typically, high-pressure scenarios evolve with significant primary system venting prior to vessel breach (Section 3); this venting increases the containment pressure to $-0.25 \mathrm{MPa}$ with temperatures near saturation. This pressure will be lower if any of the active containment heat removal systems are operational (i.e., sprays), but such cases are not considered here. The containment atmosphere will also contain hydrogen at a concentration of a few mole percent. It is uncertain how hydrogen produced in vessel will be partitioned between the primary system and containment volume at the time of vessel breach. Moreover, such preexisting hydrogen is bounded by the quantity of zirconium available to react in the core, and thus there is a constrained relationship between preexisting hydrogen in the containment and the hydrogen produced by steam/zirconium reactions in the $\mathrm{DCH}$ event.

(c) Primary System Conditions. Model predictions indicate that DCH loadings are insensitive to the temperature of the primary system (Appendix D), and accident analyses indicate that the primary system pressure can be enveloped rather than predicted (Section 3). This leaves only the expelled melt parameters in need of quantification: melt quantity, composition, and temperature. These are the variables that drive the $\mathrm{DCH}$ process; 'however, they are highly uncertain. They depend on the complex interactions and the many scenario bifurcations in the core meltdown, relocation, and lower head failure processes and are hence in need of very careful quantification. This is done in Section 3.

On the basis of the above, the probabilistic framework can be structured in the manner illustrated in Figures 2.1 and 2.2. As shown in these figures, the initial melt parameters are to be quantified as independent probability density functions, representing modelling uncertainty in the parameters (variations from stochastic processes are assessed to be insignificant relative to modelling uncertainty). These functions are formed into a joint probability density function 
and then combined with CR1, under the parameter distribution function that represents model uncertainty for the $\mathrm{DCH}$ processes, $\mathrm{R}_{r}$, to obtain a probability density function for the peak containment pressure. This distribution function is combined with the set of containment fragility curves (probabilistically distributed themselves ${ }^{2}$ ) to obtain a probability distribution of the containment failure frequency. ${ }^{3}$ The arithmetic operations involved are as follows.

In DPD format ${ }^{4}$ probability density functions (pdf's) 1,2 , and 3 can be discretized and then expressed as sets of 2 arrays each by

$$
\left\{P_{i}\left(M_{U O 2, i}\right), M_{U 02, i}\right\} ;\left\{P_{j}\left(x_{Z r, j}\right), x_{z r, j}\right\} ;\left\{P_{k}\left(M_{s s, k}\right), M_{s s, k}\right\}
$$

The joint operation produces a joint probability density function that assigns a probability to every point in the range of interest in the $\left(\mathrm{M}_{\mathrm{UO} 2}, \mathrm{x}_{\mathrm{Zr}}, \mathrm{M}_{\mathrm{ss}}\right)$ space that can be expressed as

$$
\left\{P_{i j k}\left(M_{U O 2, i}, \dot{x}_{\mathrm{zr}, j}, M_{s s, k}\right) ; M_{U O 2, i}, x_{z r, j}, M_{s s, k}\right\}
$$

and can be obtained from

$$
P_{i j k}\left(M_{v o 2, i}, x_{z r, j}, M_{s s, k}\right)=P_{i}\left(M_{v o 2, i}\right) P_{j}\left(x_{z r, j}\right) P_{k}\left(M_{s s, k}\right)
$$

This joint pdf is the pdf5 shown in Figure 2.2. In the calculation, the next joint operation with pdf4 is actually done simultaneously; here it is shown separately to emphasize that pdf4 is used

\footnotetext{
${ }^{2}$ In the current assessments, only a single fragility curve is available, but the discussion here has been generalized to accommodate desired improvements in information.

${ }^{3}$ Note here the terminology that each fragility curve is expressed in terms of failure frequency, and this frequency expresses the statistically meaningful variations (based on actual experience) in containment strength due to variations in material and workmanship; that is, the fraction failed from a nominally similar population of structures subjected to the same load. On the other hand, the probability assigned to each fragility curve expresses a subjective degree of belief as to the appropriateness of it in meeting the intended task.
}

4 Since the DPDs are the discrete analogs of the respective pdf's, the two names will be used interchangeably throughout this report. 
to express model uncertainty in CR1. Thus, the four-dimensional joint probability distribution is obtained by

$$
P_{i j k l}\left(M_{v o 2, i}, x_{z r j}, M_{s s, k}, R_{\tau, l}\right)=P_{i j k}\left(M_{v o 2, i}, x_{z r j}, M_{s s, k}\right) P_{l}\left(R_{\tau, l}\right)
$$

We note here that $R_{r}$ is conditional on the melt mass, hole size, and RCS conditions. The function operation shown next maps the probability of any quadruplet $\left(\mathrm{M}_{\mathrm{m}, \mathrm{i}}, X_{\mathrm{Zr,j}, \mathrm{j}}, \mathbf{M}_{s \mathrm{~s}, \mathrm{k}}, \mathbf{R}_{\tau, \mathrm{V}}\right)$ from the above to a final containment pressure using CR1. By considering all possible combinations of the discrete intervals for the quadruplet variables, the total probability for each discrete containment pressure result can be computed. This result is the probability density function for final containment pressure $P_{f}$, or pdf6

$$
\left\{P_{n}\left(P_{f, n}\right), P_{f, n}\right\}
$$

and can be computed using the "function" operation as

$$
P_{n}\left(P_{f, n}\right)=\sum_{i=1}^{l} \sum_{j=1}^{J} \sum_{k=1}^{K} \sum_{l=1}^{L} P_{i j k l}\left(M_{v o z, i}, x_{z r, j}, M_{s s, k}, R_{\tau, l}\right) H\left[F-P_{f, n-1}\right] H\left[P_{f, n}-F\right],
$$

where $\mathrm{F}$ is the function expressed by CR1,

$$
P_{f}=F\left(M_{v o 2, i}, x_{z r, j}, M_{s s, k}, R_{\tau, l}\right)
$$

$\mathrm{H}[\mathrm{]}$ is the Heaviside function (i.e., zero for negative values of its argument and unity otherwise. Finally, this probability density is intersected by the fragility curves of CR2 using the "function" operation to produce the pdf7 for the containment failure frequency, i.e.,

$$
\left\{P_{r}\left(F_{F, r}\right), F_{F, r}\right\}
$$

and

$$
P_{r}\left(F_{F, r}\right)=\sum_{n=1}^{N} P_{n}\left(P_{f, n}\right) \cdot P_{n}\left(F_{F, n}, P_{f, n}\right)
$$


This distribution function becomes the final result when interpreted with the help of the probability scale (Table A. 1 in Appendix A). Furthermore, the mean and standard deviation can be computed to obtain somewhat more integral measures of the expected value and the breadth of the distribution, i.e.,

$$
E\left\{F_{F}\right\}=\sum_{r=1}^{R} F_{F, r} \cdot P_{r}\left(F_{F, r}\right)
$$

and

$$
\sigma^{2}=\sum_{r=1}^{R}\left[F_{F, r}-E\left\{F_{F}\right\}\right]^{2} P_{r}\left(F_{F, r}\right)
$$

The interpretations for actual results are given in Section 6.

\subsection{Nomenclature}

$$
\begin{aligned}
& \mathbf{F}_{\mathbf{F}}=\quad \text { Failure frequency } \\
& \mathbf{H}=\text { Heaviside function } \\
& \mathbf{M}_{\mathrm{UO2}}=\mathrm{UO}_{2} \text { mass released from vessel } \\
& \mathbf{M}_{\mathrm{Ss}}=\text { stainless steel mass released from vessel } \\
& \mathbf{P}_{\mathrm{f}}=\text { DCH pressure load on containment } \\
& \mathbf{P}_{\mathrm{i}} \cdots=\text { probability } \\
& \mathbf{R}_{\boldsymbol{\tau}}=\text { coherence ratio }\left(\tau_{\mathrm{m}} / \tau_{\mathrm{s}} \text { or } \tau_{\mathrm{d}} / \tau_{\mathrm{b}}\right) \\
& \mathbf{x}_{\mathrm{Zr}}=\text { fraction of zirconium oxidized }
\end{aligned}
$$

\section{Greek}

$\tau_{\mathrm{m}}=$ melt dispersal time

$\tau_{s}=$ system depressurization time constant

\section{Subscripts}

$\mathrm{M} \quad=$ melt

ss $=$ stainless steel

$\mathrm{Zr}=$ zirconium

$\mathrm{UO}_{2}=$ uranium dioxide 


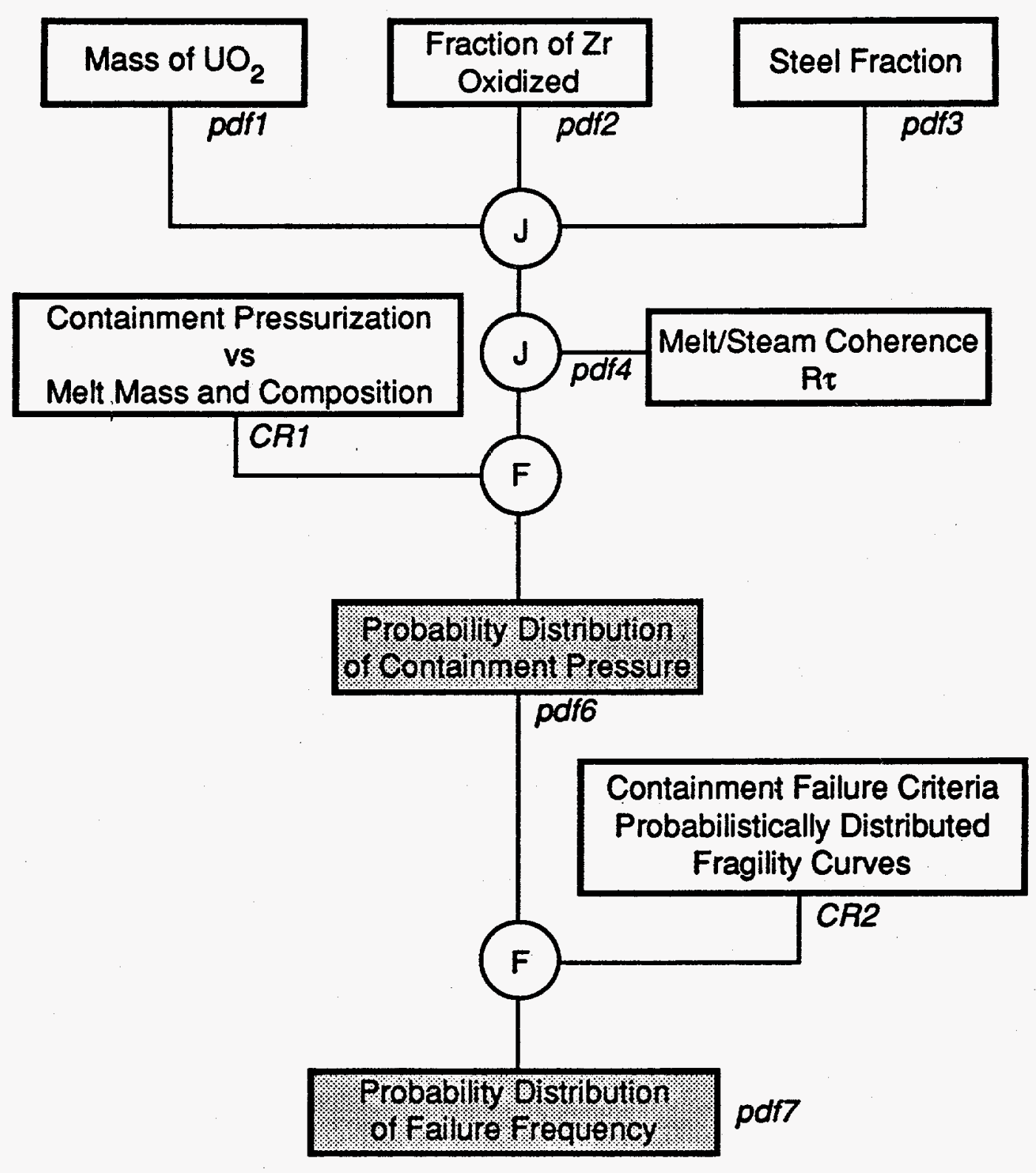

Figure 2.1. The probabilistic framework for containment failure under Direct Containment Heating scenarios. The $(J)$ and $(F)$ are the "joint" and "function" operations, respectively, as described in the text. 

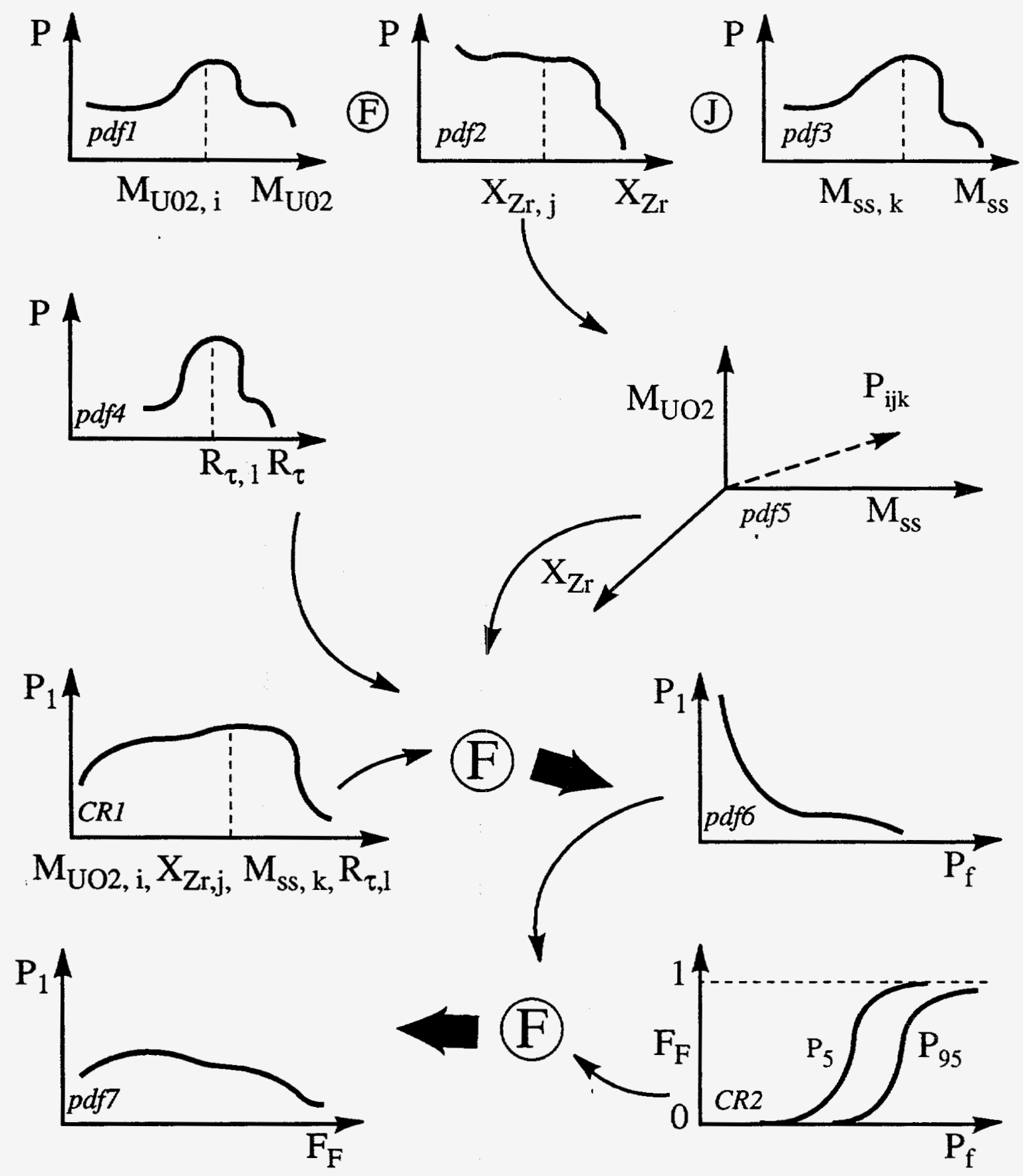

Figure 2.2. Illustration of the probabilistic framework in terms of schematic depiction of its components. 


\subsection{QUANTIFICATION OF INITIAL CONDITIONS}

\subsection{Introduction}

DCH has traditionally been examined in a rather narrow range of severe accident phenomenology: unmitigated station blackout at full system pressure, formation of a ceramic crust in the core that is able to contain a large fraction of core in a molten state, sudden failure of this crust resulting in a massive relocation of the melt into the lower plenum, failure of a penetration passing through the lower head of the reactor pressure vessel (RPV), rapid ablation of the resulting hole in the RPV from 5 to about $40 \mathrm{~cm}$ (Pilch and Tarbell, 1985), and high pressire melt ejection from the single hole followed by high pressure steam blowdown. In attempts to address the $\mathrm{DCH}$ issue from either a systems point of view or an accident management point of view, primary system depressurization (both intentional and spontaneous) has been examined (Hanson et al., 1990). Experiments have shown that the pressure must be very low (less than $1 \mathrm{MPa}$ ) to preclude the onset of dispersal from the cavity and to prevent the possibility of $\mathrm{DCH}$ (Tutu et al., 1988). Bounding calculations, suggesting that only 20 percent of the core (participating in DCH) could pose a threat for the containment (Pilch and Tarbell, 1986), have been performed. With this traditional understanding, containment threatening loads from DCH can only be precluded if the RCS is almost fully depressurized. Based on the understanding developed in the current work, substantial reduction of DCH is achieved without having to invoke nearly complete depressurization of the RCS.

In the current work, quantification of melt release conditions must envelope the physically possible behavior in a comprehensive and systematic manner. This means that we need to examine all reasonably conceivable severe accident scenarios, identify key aspects of their phenomenology and respective ranges of behavior, and establish the few scenarios that envelope the DCH challenge to the containment. At the outset, we note that our DCH models predict reductions in containment loads for reductions in initial primary system pressures (say from $\sim 16$ to $-8 \mathrm{MPa}$ ). This provides a major element in our approach; eschewing unreasonable conservatism in RCS pressure makes it more feasible to envelope the much greater 
phenomenological complexity leading to melt quantity, temperature, and composition in the lower head at the time of vessel breach.

Specifically, the phenomenological complexity of severe accidents leads to the possibility of two major scenario bifurcations: one concerned with the quantity of melt that accumulates in the core region prior to its release and relocation into the lower plenum, and the other concerned with the mode and timing of the lower head failure. Both topics are the subject of ongoing analytical and experimental programs including the examination and analysis of TMI-II data.

We have reviewed prior efforts (SASM and NUREG-1150) as well as recent SCDAP/RELAP5 calculations (Knudson and Dobbe, 1993; Knudson, 1993) in our efforts to quantify the initial conditions at vessel breach. The SCDAP/RELAP5 calculations are viewed to provide insights for estimating the pressure at vessel breach. However, due to the parametric nature of the lower plenum modeling and the lack of complete modeling of lower head failure mechanisms, the calculations cannot be used directly to estimate the melt mass at vessel breach. (Our findings are consistent with conclusions of the recent SCDAP/RELAP5 Peer Review Report [Corradini et al., 1993].) Furthermore, the number of plant calculations is quite limited, and the available calculations do not address all the phenomenological bifurcations, accident sequences, or sensitivity studies of interest. Therefore, we turn to a basic principles approach that aims to establish a conservative envelope for melt mass and composition. As part of the ROAAM process, however, we expect that additional analyses will be used to assess our quantifications, thus providing additional perspectives on our recommendations.

The dependence of the melt conditions at vessel breach on the core-to-lower plenum relocation behavior arises from the observation that melt progression may proceed under two distinct scenarios. The first state evolving from SBLOCA-like scenarios, involves the formation and failure of core blockages (as in TMI-II), allowing a relatively rapid relocation of melt to the lower plenum. The second state, evolving from TMLB'-like scenarios, involves the gradual relocation of melt to the lower plenum. We recognize that some TMLB' scenarios leading to dry core conditions may likely form core blockages like TMI-II, but we chose to lump such 
behavior under the SBLOCA-like scenarios defined above. Gradual relocation is only possible in dry core scenarios, which are most likely to evolve from TMLB' sequences. A second bifurcation involves the mode and timing of lower head failure, with penetration failures and creep rupture representing the extremes.

Figure 3.1 illustrates the four bounding scenarios used to quantify initial conditions for DCH analyses. Table 3.1 provides a concise summary of initial conditions necessary to carry out containment loads analyses using the CLCH and TCE models.

\subsection{Characterization of the Zion Plant}

Quantification of initial conditions for containment loads analyses is based on the plant characteristics shown in Table 3.2. It is worth noting that approximately 30 percent of the core is within one fuel assembly distance to the edge of the core. This material, owing to its low decay power and high heat transfer to the core barrel, is difficult to melt, and it is an unlikely contributor to the core melt (in the lower plenum) at vessel breach. Although the core contains little steel, the upper and lower plena contain large quantities of steel that might be added to the core melt, depending on the scenario. Here, we have restricted ourselves to relatively thin steel that has no substantial inertia to thermal loads that might be imposed on the structure.

Figure 3.2 depicts the Zion NPP. Debris ejected from the reactor pressure vessel first enters the reactor cavity where high pressure blowdown gases can disperse the debris into the containment by one of two possible paths. The first is an annular gap around the RPV, which would allow debris to disperse directly to the upper dome. This annular gap is partially filled with reflective insulation and is largely blocked by the eight nozzles near the top of the RPV. The SNL/IET-11 (Blanchat et al., 1994) experiment showed that if gas can carry debris into the gap, then the insulation will melt and be swept clear of the gap. Such a situation cannot be precluded at Zion; consequently, this potential flow path is explicitly bounded in the containment loads evaluations. 
As shown in Figure 3.2, the likely dispersal path is through a tunnel leading from under the RPV, which exists so that incore instrument guide tubes can have access to the lower head. Debris dispersed from the cavity through this path will enter the lower compartmentalized regions of the containment. In particular, a significant amount of debris will enter the containment basement. The basement comprises only $\sim 6$ percent of the containment volume. The TCE model (Appendix E) treats this subcompartment room as part of its basic formulation, but it is found that $\mathrm{DCH}$ interactions are dominated by the interaction with the blowdown gas rather than any gas initially in the subcompartment. Consequently, this room plays no real role in DCH except to confine debris to an insignificant portion of the containment atmosphere. However, hydrogen produced in the cavity and basement during the $\mathrm{DCH}$ event will be pushed to the upper dome through numerous vent paths by blowdown steam.

The seal table room sits over the cavity exit. Experiments have shown that some dispersed debris can reach the upper dome through the seal table room and through vents located above the reactor coolant pumps.

\subsection{Quantification of Primary System Pressure and Temperature}

Since the very early days of the DCH problem, it has been argued (Nourbaksh et al., 1986) that at full system pressure (safety valve setpoint, i.e., $\sim 16 \mathrm{MPa}$ ), naturally circulating steam can redistribute the core thermal load throughout the primary system leading to failure of the pressure boundary and a spontaneous depressurization. The most vulnerable points for such failure were identified as the hot leg nozzles and the steam generator tubes (if the water seals at the bottom of the downcomer and at the cold leg loop seals happened to clear). The importance of natural circulation to core melt progression was recognized earlier by Denny and Sehgal (1983), who developed the CORMLT code with natural circulation as a key process. Core melt progression under the influence of natural circulation was modeled in the MELPROG code (Kelly et al., 1987; Heames and Smith, 1991) and in the SCDAP/RELAP5 code (Bayless, 1988; Knudson and Dobbe, 1993; Knudson, 1993). In addition, the MELCOR code (Martinez et al., 1992) has been used to provide an independent assessment of the SCDAP/RELAP5 results and to analyze full loop natural circulation scenarios not analyzed by SCDAP/RELAP5. 
Experimental simulations (Schatz et al., 1991) also confirmed the predicted behavior and were examined even in more detail with the COMMIX code.

Besides natural convection, the periodic actuation of the safety valves creates forced convection through the pressurizer surge line, which is predicted to fail even earlier than the hot leg. Moreover, these periodic actuations create the possibility of a stuck-open valve, yet another mechanism for depressurization. At this time, it can safely be concluded that a severe accident cannot evolve to significant core melting at full pressure (as in a station blackout accident) without spontaneous failure of the pressure boundary and nearly complete depressurization of the RCS prior to failure of the lower head. This was also recognized by the NUREG-1150 expert panel during the work done to revise the draft document. Therefore, full pressure scenarios are not explicitly treated in the base case analyses. However, sensitivity studies for full pressure scenarios were performed as part of this work, but the basic conclusions are not altered (i.e., no significant containment failure probabilities).

These scenarios lead to intermediate primary system pressures incapable of producing depressurization by a spontaneous failure of the RCS and yet might still be able to pose a DCH challenge to the containment. For such "just-right" conditions, one must look for breaks (or leaks) large enough to bring the pressures down to the $-8 \mathrm{MPa}$ range, where energy redistribution by natural convection begins to degrade sufficiently that maintaining pressure boundary integrity is not quite physically unreasonable and yet small enough that the leak does not produce complete system depressurization. A primary candidate for such a leak is a pump seal failure, which is quite likely in Westinghouse plants such as Zion (Rhodes et al., 1987) in the absence of seal cooling during a station blackout. Consideration of such conditions must also include SBLOCAs, with size attributes similar to those just mentioned. However, for such accidents to progress to severe core damage, one must further assume failure of the safety-grade high pressure injection (HPI) system or highly peculiar operator intervention, as in the TMI-II accident. Also, for such cases to produce a DCH containment challenge, it would require the independent failure of the containment safeguard systems (sprays); unavailability of such systems in station blackout scenarios is due to common-cause failure. System pressures for TMLB'-like and SBLOCA-like scenarios are examined separately below. 
In examining TMLB'-like scenarios, we limit our consideration to scenarios in which there is pump seal leakage due to loss of cooling. Pump seal leaks, occurring during a TMLB' scenario, of 250 (highest probability in NUREG-1150) and 480 gallons per minute (gpm) per pump were examined for the Surry and Zion reactors under a variety of modeling assumptions using the SCDAP/RELAP5/Mod3 code (Knudson and Dobbe, 1993; Knudson, 1993). All cases produced pressures below $3.5 \mathrm{MPa}$ at the time of core relocation onto the lower head. These calculations were continued beyond core relocation with various assumptions of melt-to-water heat transfer during the relocation. At the time of predicted lower head failure, the calculated pressures ranged from 2 to $4.5 \mathrm{MPa}$ in all but one case. We note that failure of the lower head sometimes occurred following cyclic repressurization of the RCS resulting from accumulator discharge. Uncertainties in timing of bottom head failure mean that the RCS pressure could have been higher.

In the one SCDAP/RELAP calculation, a pressure of $9 \mathrm{MPa}$ was calculated. This pressure was obtained by maximizing melt to water heat transfer; however, in this case, the rapid vaporization quenched all of the melt and, hence, this case is not important for DCH considerations. We note that repressurization events as predicted by SCDAP/RELAP are based on parametric heat transfer modeling. We expect that in massive core relocations, heat transfer to coolant is inadequate to produce significant repressurization. We note that TMI-II is indicative of likely relocation scenarios under reflooded conditions. At TMI-II, the vessel repressurized $\sim 2 \mathrm{MPa}$, but at the expense of quenching some of the melt so that it had a lavalike character. In gradual relocation scenarios the steam production may be significant, but the resulting debris is unable to produce failure until much later, after having gone through a reheat and remelt cycle, during which there is adequate opportunity to depressurize again.

In summary, we can conclude the following. First, TMLB'-like scenarios cannot evolve to significant core melting at full pressure without spontaneous failure of the pressure boundary and nearly complete depressurization prior to failure of the lower head. Second, energy redistribution by natural convection degrades significantly for RCS pressures below $\sim 8 \mathrm{MPa}$ so that maintaining pressure boundary integrity is not quite physically unreasonable at these 
reduced pressures. These are the cases of most interest for DCH. Finally, code calculations for pump seal leaks consistently evolve to relatively low pressures and repressurization on melt relocation (treated from a bounding perspective) only increases the RCS pressure to $\sim 8 \mathrm{MPa}$ (Knudson and Dobbe, 1993; Knudson, 1993). On this basis, we conclude that an adequate enveloping initial primary system pressure for relevant TMLB'-like scenarios at the time of vessel breach is $-8 \mathrm{MPa}$.

SBLOCA-like scenarios have also been considered in the quantification of the system pressure. Because the pump seal leaks discussed above are representative of the smallest break sizes normally considered as potential SBLOCAs, the enveloping nature of an $\sim 8 \mathrm{MPa}$ pressure is quite evident here too, except for any potential complications due to "partial" HPI operation or peculiar operator actions. For example, though the TMI-II system depressurized down to $\sim 5$ MPa because of the stuck-open pilot-operated relief valve (PORV), operator intervention isolating the leak after core damage caused the major relocation event to occur at $10 \mathrm{MPa}$. With our current understanding of severe accidents, we view such peculiar operator actions as extremely unlikely; therefore, we conclude that the $\sim 8 \mathrm{MPa}$ pressure envelopes the SBLOCA scenarios as well as the TMLB' scenarios.

Level 1 Probabilistic Risk Analyses (PRAs) consider thermal-hydraulic scenarios, including operator actions and management procedures, which have a direct bearing on the primary system pressure. Our quantifications are not a substitute for Level 1 PRAs, but rather a complement of a bounding nature. We fully recognize that such a probabilistic evaluation can add substantially to the robustness of the current results. In particular, we believe that the conservative bounds on the primary system pressure presented here will be strengthened by detailed examination of TMLB'-like and SBLOCA-like transients in the PRA context, which should be carried out using the screening-out sequence criteria in the sense discussed in Appendix A. Indeed, the NUREG-1150 Level 1 results provide a strong indication that this is the case, except (in our opinion) a much more focused consideration on this issue is needed to establish a definitive result specific to this topic. 
The temperature of RCS gas at the time of vessel breach clearly must be superheated. In conjunction with the pressure and volume, the moles of gas in the RCS can be computed with the RCS temperature. The RCS temperature can be estimated with the aid of Table 3.3 where the entire RCS is broken down into representative regions with the approximate fraction of RCS free-volume noted for each region. For TMLB'-like sequences, gradual relocation of core material produces steaming which feeds zirconium reactions in the core. The temperature within the core region is taken as $-2800 \mathrm{~K}$. Upper plenum structures are expected to melt, so the gas temperature in the upper plenum must exceed $\sim 1700 \mathrm{~K}$. SCDAP/RELAP5 calculations (Knudson and Dobbe, 1993) indicate that the minimum structure temperature of $\sim 1200 \mathrm{~K}$ is required before surge line or hot leg failure is initiated, and the hot leg gas temperatures most assuredly are 100-200 K hotter. The remainder of the RCS is assumed to be near saturation temperature. Given this assessment, a lower bound of $\sim 900 \mathrm{~K}$ is assigned to TMLB'-like sequences.

For SBLOCA-like scenarios, we expect lower steam superheats compared to dry core sequences. In addition, relocation of melt into the lower plenum will cause some steaming, which has the tendency to flush the system with saturated steam. The upper plenum and the hot leg are now assumed to be $\sim 1000 \mathrm{~K}$. Only the core region, protected by the crust, is shielded from this quenching action. Referring again to Table 3.3, it is seen that an RCS gas temperature of $\sim 800 \mathrm{~K}$ can be assigned to SBLOCA-like scenarios.

\subsection{Quantification of Melt Mass, Composition, and Temperature}

We take a principle-based approach in quantifying melt initial conditions that accounts for key bifurcations in scenario development. In Section 3.3, we concluded that TMLB'-like and SBLOCA-like sequences typify and envelope all potentially interesting DCH scenarios from a systems thermal-hydraulics point of view (i.e., pressure and temperature in the RCS). It turns out that these two classes of accidents typify and encompass all physically reasonable possibilities from a melt quantity and composition point of view when the above-mentioned bifurcations are factored into the analyses. Because the emphasis is on physical consistency with an enveloping attitude, we proceed to examine each of the four scenarios separately. Basically, 
the intent of this list of four scenarios is to include everything that cannot be excluded with a high degree of confidence. While for some of these scenarios, we may have some idea of what might be more likely, we stop short of proposing relative likelihoods because this cannot be done in a rigorous manner. This is the idea of "splinters" (Appendix A), and it is essential in the quantification of DCH initial conditions.

We consider the following in developing the melt mass and composition quantification: Mass of $\mathrm{UO}_{2}$ in the melt, mass of unoxidized $\mathrm{Zr}$ in the melt, mass of $\mathrm{ZrO}_{2}$ in the melt, mass of steel in the melt, and mass of control rod material in the melt. We also use the amount of $\mathrm{Zr}$ oxidation to calculate the amount of preexisting hydrogen in the containment. The key dependencies are preserved in the quantifications, and any distributions treated as independent are appropriately justified. Comparisons with prior work (Appendix $\mathrm{K}$ ) generally support our current recommendations, although improved understanding of core melt progression generally leads to conditions that produce less severe DCH loads.

\subsubsection{Scenario I - SBLOCA-Like Scenarios with Early Penetration Failure}

In our characterization, SBLOCA-like scenarios are characterized by crust formation within the core followed by a massive release of melt when the crust fails. It should be noted that the currently existing system level computer codes do not contain sufficient modeling to adequately represent the geometrical details and phenomenological behavior necessary to predict the meltdown behavior beyond the formation of blockages; most use parametric models for this phase. The codes may predict global trends, but detailed predictions are beyond the current scope. Therefore, we cannot rely solely on these calculations.

Recent studies by Schmidt and Humphries (1993) indicate that $\sim 50$ percent of the core could be involved in the degradation process, prior to crust failure and melt release into the lower plenum. The amount of melt release is a function of where the crust fails. Two potential locations for failure have been identified: downward or sideward. The MP-2 experiment confirms that downward failure of an oxidic crust or blockage is unlikely even in the absence of active cooling. Schmidt and Humphries' analysis is consistent with the MP-2 experimental 
result. Consequently, the wet-core scenario is extremely likely to develop in a way that is quite similar to the TMI-II accident (i.e., formation of crucible followed by side failure). We use this picture to develop our melt mass quantification for Scenario I.

Scenario I is expected to look like TMI-II at the time of melt relocation. In the TMI-II accident, a nearly hemispherical blockage formed in the core when relocating clad material was arrested by water, which still covered part of the core. An oxidic crust is then formed over the blockage and a pool of molten core material accumulates over the crust. Consideration of natural convection in such volumetrically heated pools (Theofanous, 1988; Epstein and Fauske, 1989) indicates that the melt superheat cannot exceed $\sim 200 \mathrm{~K}$ and that the main thermal loading is in the upper crust (if one exists) and upper portions of the crust. As discussed above, more recent calculations by Schmidt and Humphries (1993) indicate that bottom failure of the crust is quite unlikely, even in the absence of convective flow. In TMI-II, pool discharge from a side failure and overflow of the crust caused by falling debris appear to have played a role in the main relocation event. The total quantity of relocated material in TMI-II is estimated at about $20 \mathrm{mt}$, and it was mainly oxidic. We use this picture as our best-estimate and proceed to develop mass distributions for Zion, which is about 6 percent larger than TMI-II. We take the best-estimate melt mass to be $\sim 21 \mathrm{mt}$ of which $\sim 19 \mathrm{mt}(90 \%$ of $21 \mathrm{mt})$ is $\mathrm{UO}_{2}$.

To develop bounds on melt, we consider that a hemispherical crust that excludes only the outer assemblies can hold approximately $70 \mathrm{mt}$ of molten core material. For our edge of spectrum estimate (process likelihood 0.1 ), we expect that the initial relocation involves about half the melt contained in the crust $(\sim 35 \mathrm{mt})$. This agrees well with the TMI-II observations concerning the fraction of melt pour. Thus, the edge of spectrum estimate for the amount of $\mathrm{UO}_{2}$ in the melt is given by $0.90 \times 0.5 \times 70 \mathrm{mt} \approx 30 \mathrm{mt}$. As an upper bound (process likelihood 0.01 ), we consider the possibility that the melt crust could fail near the bottom allowing 75 percent of its contents to drain out. Thus, the upper bound $\mathrm{UO}_{2}$ amount is given by $0.90 \times 0.75 \times 70 \approx 45 \mathrm{mt}$. However, near bottom failures are considered very unlikely and are assigned a low probability accordingly (i.e., $P \sim 0.01$ ). With these considerations, the distribution for $\mathrm{UO}_{2}$ melt mass can be constructed as shown in Figure 3.3. 
$\mathrm{Zr}$ oxidation occurs predominantly before significant core degradation occurs, as demonstrated in 2-D MELPROG calculations performed by Kelly et al. (1987). In these calculations, 80 percent of the $\mathrm{Zr}$ oxidation occurred prior to core degradation. Furthermore, most $\mathrm{Zr}$ will be permanently retained in core blockages with any $\mathrm{Zr}$ remaining in the melt appearing as a eutectic with the other (mainly oxidic) constituents. Little of this zirconium is expected to oxidize during massive relocations. To first order, then, $\mathrm{Zr}$ oxidation is independent of the core melt progression that follows the main oxidation event; and because oxidation occurs before core degradation, existing system level computer codes are technically adequate to assess the range of possible oxidation.

Referring then to SCDAP/RELAP5 calculations (Knudson and Dobbe, 1993; Knudson, 1993), MELPROG/PWR-MOD1 calculations (Kelly et al., 1987), and CORMLT calculations (Denny and Sehgal, 1983), we find that the fraction of $\mathrm{Zr}$ oxidized ranges from 20-60 percent with a mean around 40 percent. Consistent with prior assessments, these extremes are assigned a low probability. The distribution is shown in Figure 3.4. The calculations cited were chosen because of their explicit treatment of recirculating flow patterns in the core.

There are about $4 \mathrm{mt}$ of control rod material in the core. This material is released with about $700 \mathrm{~K}$ of superheat when its steel clad melts. Owing to its high superheat, and consistent with TMI-II observations, we conservatively assume that this material drains into the lower plenum where it freezes on the lower, head. This control rod material remains frozen at the time of an early penetration failure because there is no time to remelt this material.

The relocation of $\mathrm{Zr}$ metal within the core plays a key role in the ultimate formation of a crucible. Upon melting, $\mathrm{Zr}$ metal relocates downwards until it freezes in cooler portions of the core forming partial or complete blockages, depending on the amount of relocating material. The subsequent melting of $\mathrm{UO}_{2} / \mathrm{ZrO}_{2}$ eutectics allows molten oxides (at least initially) to settle and refreeze on top of the metallic blockages. In this way, the accumulating melt selfcrucibilizes itself on top of the metallic blockage. This separation of molten oxides from the metallic blockage ensures that metal does not enter the melt, except possibly when the crust 
fails. However, as in TMI-II, the crust is expected to fail locally (due to inhomogeneities in the crust), carrying only insignificant quaritities of metal from the blockage into the lower plenum.

Given the core-wide fraction of $\mathrm{Zr}$ oxidized, we are in a position to estimate the amount of $\mathrm{ZrO}_{2}$ that is actually contained in the relocated melt, which can be calculated from

$$
M_{\mathrm{Zro2}}=\frac{M_{U O 2}(\text { melt })}{M_{U O 2}(\text { core })} M_{\mathrm{Zr}}^{0} \text { (core) } f_{\mathrm{zr}} \frac{123}{91} \text {. }
$$

This expression assumes that $\mathrm{ZrO}_{2}$ is contained in the melt in the same fraction to which the core is degraded, $\mathrm{M}_{\mathrm{Uo2}}$ (degraded) $/ \mathrm{M}_{\mathrm{UO2}}$ (core), and that $\mathrm{ZrO}_{2}$ relocates to the lower plenum in the same fraction as the $\mathrm{UO}_{2}$, that is, $\mathrm{M}_{\mathrm{UO} 2}$ (melt)/ $\mathrm{M}_{\mathrm{UO} 2}$ (degraded).

The core-wide oxidation of $\mathrm{Zr}$ also controls the amount of preexisting hydrogen that can exist in the containment building at the time of vessel breach. The RCS retains very little of this hydrogen because it is produced early in the accident and most is vented to the containment. This is supported by SCDAP/RELAP5 calculations (Knudson, 1993). The moles of preexisting hydrogen in the containment are given by:

$$
N_{H z}(g-\text { mole })=\frac{2}{0.091} f_{\mathrm{Zr}} M_{\mathrm{Zr}}^{o} \text { (core) }
$$

or alternatively, a concentration can be specified

$$
X_{H 2}=\frac{N_{H 2}}{N_{A T M}^{o}} .
$$

There are three possible sources for steel in the melt: steel initially in the core, upper plenum steel, and lower plenum steel. Core steel $(\sim 3 \mathrm{mt})$, however, is expected to be an early contributor to blockages within the core, and as such, is not part of the melt. At reduced system pressures, we do not expect natural circulation to be effective at melting upper plenum structures. Lower plenum structures can only be melted by direct contact with the melt but for early penetration failures, there is no time to meit lower plenum steel. Hence, we do not expect any steel in the melt for Scenario I. 
Consideration of natural convection in volumetrically heated pools (Theofanous, 1988; Epstein and Fauske, 1989) indicates that the melt superheat cannot exceed $\sim 200 \mathrm{~K}$. The $\mathrm{UO}_{2} / \mathrm{ZrO}_{2}$ eutectic melts at about $2800 \mathrm{~K}$, so the maximum temperature on relocation is about $3000 \mathrm{~K}(\sim 2900 \mathrm{~K}$ has been estimated for TMI-II), but some cooling on relocation is expected. Thus, we believe that a conservative bounding value of $\sim 2800 \mathrm{~K}$ is appropriate for Scenario I.

\subsubsection{Scenario II - SBLOCA-Like Scenarios with Early Rupture of the Lower Head}

Scenario II is a continuation of Scenario I. In evaluating an early rupture of the lower head, we consider two factors. First, heating of the lower head to a temperature where rupture is likely causes additional oxide to solidify. Second, the melt in the lower plenum may quench due to presence of water and other heat sinks (steel in particular). As a minimum, the creation of molten steel in the lower plenum will tend to cause solidification of the molten oxides, while decay heating will slow the process.

As a conservative upper bound (process likelihood 0.01), we can envision that the entire core, excluding only the outer assemblies, is in a degraded state. We then assume that up to 75 percent of this material will relocate into the lower plenum. The maximum amount of $\mathrm{UO}_{2}$ accumulated on the lower head is $0.7 \times 0.75 \times 100 \approx 55 \mathrm{mt}$. Comparing the upper bound of $\mathrm{UO}_{2}$ mass $(55 \mathrm{mt})$ to the upper bound for Scenario I $(45 \mathrm{mt})$, we see that an additional $10 \mathrm{mt}$ of $\mathrm{UO}_{2}$ has relocated to the lower plenum. We apply this same $10 \mathrm{mt}$ shift to the entire $\mathrm{UO}_{2}$ distribution, including the best estimate, which is now centered on $30 \mathrm{mt}$ instead of $20 \mathrm{mt}$.

Due to the delay in head failure, not all of the relocated material will be available for ejection. The analyses of Boucheron (referenced in Zuber et al., 1991) shows that $\sim 15 \mathrm{mt}$ of oxide must solidify to heat the lower head to a point where it loses its strength and ruptures. This value is insensitive to the melt mass in the lower plenum while being somewhat sensitive to the debris/vessel contact resistance. With this in mind, and recognizing that $\mathrm{UO}_{2}$ comprises about 90 percent of the oxide mass, the upper bound for molten $\mathrm{UO}_{2}$ is $\sim 40 \mathrm{mt}$, and the best estimate is centered near $15 \mathrm{mt}$. The full distribution is depicted in Figure 3.5. Note that there 
is somewhat less molten $\mathrm{UO}_{2}$ (compared to Scenario I) even though more material has accumulated on the lower head.

Metal blockages are not readily oxidized and crucible formation blocks steam flow to the core so that little additional oxidation of $\mathrm{Zr}$ is expected during the period prior to rupture. Consequently, the distribution for $\mathrm{Zr}$ oxidation fraction is the same as Scenario $\mathrm{I}$, and the procedure (Equation 3.3) for calculating preexisting hydrogen in the containment is also the same.

In analogy with the discussion on molten $\mathrm{UO}_{2}$, the mass of molten $\mathrm{ZrO}_{2}$ can be computed from Equation 3.1. Zirconium metal is largely retained as permanent blockages within the core. The continued meltdown process, however, could conservatively bring down additional $\mathrm{Zr}$ metal that is not part of the original blockages. The quantity of any such $\mathrm{Zr}$ metal is given by

$$
M_{z r}=0.1 M_{z r}^{o}\left(1-f_{z r}\right)
$$

where the factor (0.1) represents the additional core fraction liquified $\left(10 \mathrm{mt} \mathrm{UO} / 100 \mathrm{mt} \mathrm{UO}_{2}\right.$ in core) following the original relocation event.

Control rod material is assumed to have fully drained into the lower plenum prior to significant core damage. In contrast to Scenario I, we now assume that there has been sufficient time to fully remelt the control rod material $(\sim 4 \mathrm{mt})$.

As in Scenario I, we melt no upper plenum steel, and core steel is permanently retained in core blockages. The possibility of melting lower plenum steel now exists because of the delay incurred in waiting for the lower head to heat to the rupture point. Only lower plenum steel that is submerged in the accumulating core material is assumed to melt. The quantity of submerged steel depends on the amount of core material in the lower plenum and can be computed from

$$
M_{S}=M_{S, L P} \frac{M_{U O 2}+M_{Z r O 2}+15 \times 10^{3}+M_{Z r}+M_{C R M}}{\rho_{d} \alpha_{d} V_{L P}},
$$


where $\alpha_{d}(\sim 0.82$ at TMI-II) accounts for the fact that puddled core material is not fully dense. Thus, the mass of lower plenum steel subject to melting is weighted by the volume of core material on the lower head divided by the volume of the lower plenum $\left(30 \mathrm{~m}^{3}\right)$. A representative debris density (theoretical) of $10400 \mathrm{~kg} / \mathrm{m}^{3}$ is used in the calculation.

The numerator in Equation 3.5 represents the total mass of all core debris on the lower head. The quenched $15 \mathrm{mt}$ (required to heat the lower head) must be taken into account and added to the mass of molten oxides $\left(\mathrm{M}_{\mathrm{UO2}}+\mathrm{M}_{\mathrm{Zro2} 2}\right)$. We see from Equation 3.5 that $\sim 4.7 \mathrm{mt}$ of steel can be melted in the extremes of the oxide distributions.

Additional cooling of the melt occurs if an early penetration failure does not occur. Consistent with SASM recommendations (Zuber et al., 1991), we place the melt temperature at $2500 \mathrm{~K}$ for Scenario II. We note that the estimated melt temperature at TMI-II was $\sim 2600 \mathrm{~K}$ on the lower head. At these low temperatures; the material had a lava-like character that might preclude the kind of melt ejection and fragmentation necessary to generate significant DCH. Predictions using the CLCH and TCE models are quite conservative in this situation.

\subsubsection{Scenario III - TMLB' Scenarios with Delayed Penetration Failure}

In our characterization, TMLB'$^{\prime}$-like scenarios lead to a gradual relocation of core material to the lower plenum without significant core blockages. Core material gradually relocates into the lower plenum where there is sufficient water to quench all the relocating material. An early penetration failure, if it could occur, would be of no interest to $\mathrm{DCH}$ since there would be little or no molten material available for heating of the atmosphere. Furthermore, no oxidic material is expected to be molten during this early reheat phase of the core debris.

Steaming during relocation will accelerate $\mathrm{Zr}$ oxidation in the core shifting the Scenario I distribution to the right by 10 percentage points. The new distribution is shown in Figure 3.6. This distribution is important in assessing the amount of preexisting hydrogen in the containment 
as described by Equation 3.3; however, no $\mathrm{Zr}$ or $\mathrm{ZrO}_{2}$ is molten during this phase of debris heatup.

Acceleration of $\mathrm{Zr}$ oxidation makes it possible that elements of upper plenum steel will be melted. The accumulation of steel in the lower plenum could therefore have contributions from the upper plenum, steel initially in the core, and steel initially located in the lower plenum. As the debris bed reheats, some of this steel will melt, possibly initiating a delayed penetration failure (the penetrations themselves being steel) of the lower head.

We first seek an upper bound to the total steel available on the lower head. As a conservative bound, all the upper plenum steel $(-20 \mathrm{mt})$ can be added to all the steel initially in the core $(\sim 3 \mathrm{mt})$. Lower plenum steel is available to melt only to the extent that it is submerged in the debris bed,

$$
M_{S, L P}=M_{S, L P}^{o} \frac{0.7 M_{\text {core }}+M_{S, U P}+M_{S, L P}^{o}}{\rho_{d} \alpha_{d} V_{L P}} \approx 10
$$

Here we assume that the entire core, excluding only the outer assemblies, plus the relocated upper plenum steel, exists as a debris bed $\left(\alpha_{d} \sim 0.6\right)$ on the lower head.

The total steel available to melt is $33 \mathrm{mt}$, but not all of this steel will be molten at the time of vessel failure. Dosanjh and Pilch (1991) predict that as steel becomes molten it will relocate to the bottom of the debris bed and refreeze on the lower head. They predict that no more than $\sim 73$ percent of the steel will be molten for times up to when rupture is assured. Thus, the upper bound on molten steel mass is $0.73 \times 33 \approx 25 \mathrm{mt}$. Dosanjh and Pilch further show that there is a main (steel) relocation event and that only $\sim 50$ percent of the steel is molten at this time. Possible ejection of an incore instrument guide tube from the lower head is most likely precipitated by this main relocation event; consequently, $0.5 \times 33 \approx 15 \mathrm{mt}$ is taken as the best estimate. With these considerations, the distribution of molten steel can be constructed as shown in Figure 3.7. The $4 \mathrm{mt}$ of control rod material would also be molten at the time of vessel failure. 
For Scenario III type conditions, Dosanjh and Pilch (1991) show that the peak temperatures, which occur near the top of the debris bed, do not exceed $\sim 2200 \mathrm{~K}$ for times preceding potential rupture. Molten steel, however, relocates to the lower head, where a significant portion solidifies. Large temperature gradients cannot be sustained in that portion of the debris bed because steel, which has filled the interstices, has such a high thermal conductivity. We assume that the liquid portion is $-200 \mathrm{~K}$ above its melting point or $\sim 1900 \mathrm{~K}$.

\subsubsection{Scenario IV - TMLB'-Like Scenarios with Delayed Rupture of the Lower Head}

The whole core, excluding only the outer assemblies, is assumed to be on the lower head as a debris bed. The competition between melting of oxidic components of the debris bed and lower head failure was originally examined by Theofanous et al. (1991). They concluded that creep rupture would be expected before the oxide phases began to melt. Dosanjh and Pilch (1991) accounted for steel relocation with the debris bed. They predict that $0-30$ percent of the oxide can be molten when the lower head fails by creep rupture ( $4000-5000 \mathrm{~s})$. Thus, the upper bound (process likelihood 0.01 ) on the $\mathrm{UO}_{2}$ mass is given by $0.30 \times 0.70 \times 100 \mathrm{mt} \approx$ $20 \mathrm{mt}$.

Still, these results cannot be interpreted as best estimate because local hot spots and possible natural convection of molten metals within the oxide matrix will accelerate rupture. The longest rupture time predicted by Dosanjh and Pilch (1991) is $5000 \mathrm{~s}$. Witt (1994) has shown that hot spots can accelerate rupture by $\sim 15$ percent (depending on the conditions) in his TMI-II analyses; thus, the longest rupture time of $5000 \mathrm{~s}$ could be accelerated to $\sim 4250 \mathrm{~s}$ by hot spots. For this time, Dosanjh and Pilch (1991) predict that the oxide is fully solid, consistent with Theofanous et al. (1991). This is taken as the best estimate. With these considerations, the distribution of molten $\mathrm{UO}_{2}$ mass is given in Figure 3.8.

Steaming, resulting from gradual relocation of the core into the lower plenum, can result in substantial oxidation of $\mathrm{Zr}$ in the core. The distribution shown in Figure 3.9 is skewed to the 
right to reflect this added propensity for oxidation. In particular, the distribution indicates that the whole core, excluding only the outer assemblies, is likely to be fully oxidized.

Any $\mathrm{Zr}$ metal in the lower plenum will be in solution with the oxides. Thus, the mass of molten $\mathrm{Zr}$ metal will be in the same proportion as the molten oxides,

$$
M_{\mathrm{zr}}=\frac{M_{U O 2}(\text { molten })}{M_{\text {UO2 }}^{o}(\text { core })} \quad\left(1-f_{\mathrm{zr}}\right) M_{\mathrm{zr}}^{o}(\text { core })
$$

This is conservative because any unoxidized $\mathrm{Zr}$ is likely to be in the outer assemblies and not part of debris on the lower head. Not all the $\mathrm{ZrO}_{2}$ is molten, and consistent with the reasoning for $\mathrm{UO}_{2}$, the molten mass of $\mathrm{ZrO}_{2}$ can be computed by Equation 3.1. The amount of preexisting hydrogen in the containment can still be computed from Equation 3.3.

Consistent with arguments set forth for Scenario III, $25 \mathrm{mt}$ is the upper bound for the amount of molten steel on the lower head. The calculations of Dosanjh and Pilch (1991), however, show that this upper bound is only realized when rupture has been delayed long enough to generate molten oxides. Should rupture occur before molten oxides are present, then the Scenario III distribution for molten steel is more appropriate. Thus

$$
M_{s}=\left\{\begin{array}{c}
25 m t \text { if } M_{U O 2}>0 \\
\text { Fig. } 3.7 \text { if } M_{V O 2}=0
\end{array} .\right.
$$

Control rod material is taken as fully molten for this case.

Should a delayed penetration failure (as in Scenario III) not occur, then the upper portions of the debris bed will continue to heat, possibly to the point where some oxides begin to melt $(\sim 2800 \mathrm{~K})$. For Scenario IV, approximately equal portions of molten steel and molten oxide will be present (in the extreme). A mixture temperature of $2350 \mathrm{~K}$ is assigned to Scenario IV for performing DCH calculations. 


\subsection{Containment Quantification}

CONTAIN calculations for the Surry Plant indicate that the containment pressure at vessel breach is $\sim 0.17 \mathrm{MPa}$, but Surry is a subatmospheric plant while Zion is not. Correcting for this difference gives $\sim 0.20 \mathrm{MPa}$ for Zion. This was the basis for the SNL/ANL counterpart tests.

MAAP calculations for the Zion plant indicate that the containment pressure at vessel breach is about $\sim 0.25 \mathrm{MPa}$ and the conditions are saturated $(\sim 380 \mathrm{~K})$. CONTAIN calculations (Tutu et al., 1990) for the Zion plant produced 0.3 MPa at vessel breach. Recent SCDAP/RELAP (Knudson, 1993) calculations produce containment pressures ranging from 0.38 to $0.45 \mathrm{MPa}$; however, these calculations were neither designed nor intended to accurately predict containment response. As a result, $-0.25 \mathrm{MPa}$ is representative for our purposes. Appendix D concludes that DCH loads are insensitive to reasonable choices of initial containment pressure. The Zion containment is initially at atmospheric pressure, so approximately $0.1 \mathrm{MPa}(383 \mathrm{~K} / 314 \mathrm{~K}) \approx 0.12 \mathrm{MPa}$ of the pressure at vessel breach is air. Consequently, the steam concentration is -50 percent.

\subsection{References}

Bayless, P.D. (October 1988). Analyses of Natural Circulation During a Surry Station Blackout Using SCDAP/RELAPS, NUREG/CR-5214, EGG-2547, EG\&G Idaho, Inc., Idaho Falls, ID.

Blanchat, T.K. et al. (April 1994). Experiments to Investigate Direct Containment Heating Pehnomena With Scaled Models of the Surry Nuclear Power Plant, NUREG/CR-6152, SAND93-2519, Sandia National Laboratories, Albuquerque, NM.

Corradini, M.L. et al. (January 1993). SCDAP/RELAP5 Independent Peer Review, LA-1248, Los Alamos National Laboratory, Los Alamos, NM.

Denny, V.E. and B.R. Sehgal (1983). "Analytical Prediction of Core Heatup/Liquefaction/ Slumping," Proceedings International Meeting on Light Water Reactor Severe Accident Evaluation, Aug. 28-Sept. 1, Cambridge, MA.

Dosanjh, S.S. and M. Pilch (1991). "Lower Head Creep Rupture Sensitivity Studies," Nuclear Science and Engineering, Vol. 108, 172-183. 
Epstein M. and H.K. Fauske (1989). "The Three Mile Island Unit 2 Core Relocation -- Heat Transfer Mechanisms," Nuclear Technology, Vol 87, 1021.

FAI (1991). Zion IPE Position Paper on Direct Containment Heating, FAI/91-18, submitted to Commonwealth Edison Co.

Ginsberg, T. and N. K. Tutu (1988). Progress in Understanding Direct Containment Heating Phenomena in Pressurized Light Water Reactors, BNL-NUREG-41751, Brookhaven National Laboratory, Upton, NY.

Hanson, D.J. et al. (October 1990). Depressurization as an Accident Management Strategy to Minimize the Consequence of DCH, NUREG/CR-5447, US Nuclear Regulatory Commission, Washington, DC.

Heames, T.J. and R.C. Smith (1991). "Integrated MELPROG/TRAC Analyses of a PWR Station Blackout," Nuclear Engineering and Design, Vol. 125, 175-188.

Kelly, J.E., R.J. Henninger, and J.F. Dearing (January 1987). MELPROG-PWT/MOD1 Analysis of a TMLB' Accident Sequence, NUREG/CR-4742, SAND86-2175, Sandia National Laboratories, Albuquerque, NM.

Knudson, D.L. (April 1993). Transmittal of SCDA/RELAP5/MOD3 Results for the Zion Power Station, Letter Report to NRC.

Knudson, D.L. and C.A. Dobbe (November 1993). Assessment of the Potential for High Pressure Melt Ejection Resulting from a Surry Station Blackout Transient, NUREG/CR-5949, EGG-2689, EG\&G Idaho, Inc., Idaho Falls, ID.

Martinez, G.M., R.J. Gross, M.J. Martinez, and G.S. Rightly (August 1992). Independent Review of SCDAP/RELAP5 Natural Circulation Calculations, SAND91-2089, Sandia National Laboratories, Albuquerque, NM.

Nourbaksh, H.D., C.H. Lee, and T.E. Theofanous (March 1986). "Natural Circulation Phenomena and Primary System Failure in Station Blackout Accidents," Proceedings of the Sixth Information Exchange Meeting on Debris Coolability, EPRI-NP-4455.

Pilch, M. and W.W. Tarbell (September 1985). High Pressure Ejection of Melt from a Reactor Pressure Vessel: The Discharge Phase, NUREG/CR-4383, SAND85-0012, Sandia National Laboratories, Albuquerque, NM.

Pilch, M. and W.W. Tarbell (July 1986). Preliminary Calculations on Direct Heating of a Containment Atmosphere by Airborne Core Debris, NUREG/CR-4455, SAND85-2439, Sandia National Laboratories, Albuquerque, NM. 
Rhodes, D.B., R.C. Hill, and R.G. Wensel (May 1987). Reactor Coolant Pump Shaft Seal Stability During Station Blackout, NUREG/CR-4821, EG\&G-2492, AECL-9342, EG\&G Idaho, Inc., Idaho Falls, ID.

Schmidt, R.L. and L.L. Humphries (1993). Late Phase Melt Progression Scoping and Sensitivity Studies, Draft, SAND92-2831, Sandia National Laboratories, Albuquerque, NM.

Theofanous, T.G. (1988). "Some Considerations of Severe Accidents at Loviisa," Report Prepared for Imatron Voima 04, Helsinki, Finland.

Theofanous, T.G., W.H. Amarasooriya, H. Yan, and U. Ratnam (August 1991). The Probability of Liner Failure in Mark-I Containment, NUREG/CR-5423, U.S. Nuclear Regulatory Commission, Washington, D.C.

Tutu, N.K., T. Ginsberg, and L. Fintrok (1988). "Low Pressure Cutoff for Melt Dispersal from Reactor Cavities," Fourth Proceedings of Nuclear Thermal Hydraulics, 29-37.

Tutu, N.K., C.K. Park, C.A. Grimshaw, and T. Ginsberg, (January 1990). Estimation of Containment Pressure Loading Due to Direct Containment Heating for the Zion Plant, NUREG/CR-5282, BNL-NUREG-52181, Brookhaven National Laboratory, Upton, NY.

Witt, R.J. (1994). "Local Creep Rupture Failure Modes on a Curium-Loaded Lower Head," in Press, Nuclear Engineering and Design.

Zuber, N. et al. (1991). An Integrated Structure and Scaling Methodology for Severe Accident Technical Issue Resolution, NUREG/CR-5809, EGG-2659, EG\&G Idaho, Inc., Idaho Falls, ID.

\subsection{Nomenclature}

$\begin{array}{ll}\mathbf{f}_{\mathrm{Zr}}= & \text { Core-wide Fraction of } \mathrm{Zr} \text { Oxidized } \\ \mathbf{M}_{\mathrm{CORE}} & =\text { Core Mass } \\ \mathbf{M}_{\mathrm{CRM}} & =\text { Mass of Control Rod Material } \\ \mathbf{M}_{\mathbf{S}}= & \text { Mass of Molten Steel in Lower Plenum } \\ \mathbf{M}_{\mathbf{s}, \mathrm{LP}}= & \text { Mass of Steel Initially in Lower Plenum } \\ \mathbf{M}_{\mathrm{s}, \mathrm{UP}}= & \text { Mass of Steel Initially in Upper Plenum } \\ \mathbf{M}_{\mathrm{UO2}}= & \text { Mass of Molten UO } \mathrm{U}_{2} \text { in Lower Plenum } \\ \mathbf{M}_{\mathrm{Zr}}= & \text { Mass of Molten } \mathrm{Zr} \text { in Lower Plenum }\end{array}$


$\mathbf{M}_{\mathbf{Z}_{\mathbf{r}}}^{\mathrm{O}}=\quad$ Mass of $\mathrm{Zr}$ Initially in Core

$\mathbf{M}_{\mathbf{Z r o 2}}=$ Mass of Molten $\mathrm{ZrO}_{2}$ in Lower Plenum

$\mathbf{N}_{\text {ATM }}^{\mathbf{o}}=$ Moles of Gas Initially in the Containment Atmosphere

$\mathrm{N}_{\mathrm{Hz}}=$ Moles of Hydrogen in the Containment

$V_{L P}=$ Volume of Lower Plenum

$\mathrm{X}_{\mathrm{H} 2}=$ Molar Concentration of Hydrogen in the Containment

Greeks

$\rho_{\mathrm{d}}=$ Theoretical Density of Core Material

$\alpha_{d}=$ Debris Volume Fraction on Lower Head 
Table 3.1. Summary of initial condition quantification

\begin{tabular}{|c|c|c|c|c|}
\hline \multirow[b]{2}{*}{ Parameter } & \multicolumn{2}{|c|}{$\begin{array}{c}\text { SBLOCA-Like } \\
\text { Crusts }\end{array}$} & \multicolumn{2}{|c|}{$\begin{array}{c}\text { TMLB'-Like } \\
\text { Gradual Relocation }\end{array}$} \\
\hline & $\stackrel{\text { I }}{\text { Penetration Failure }}$ & $\begin{array}{c}\text { II } \\
\text { Rupture }\end{array}$ & III & $\begin{array}{c}\text { IV } \\
\text { Rupture }\end{array}$ \\
\hline RCS Pressure (MPa) & 8 & 8 & 8 & 8 \\
\hline RCS Temperature (K) & 800 & 800 & 900 & 900 \\
\hline RPV Temperature (K) & 600 & 1000 & 800 & 1000 \\
\hline Initial Hole Dia. (m) & 0.0254 & 0.4 & 0.0254 & 0.4 \\
\hline Final Hole Dja. (m) & Eq. $J .6$ & Eq. J.6 & Eq. J.6 & Eq. J.6 \\
\hline Melt Temp. (K) & 2800 & 2500 & 1900 & 2350 \\
\hline $\mathrm{UO}_{2}$ Mass (mt) & Fig. 3.3 & Fig. 3.5 & 0 & Fig. 3.8 \\
\hline Fraction $\mathrm{Zr}$ Oxidized & Fig. 3.4 & Fig. 3.4 & Fig. 3.6 & Fig. 3.9 \\
\hline $\mathrm{Zr}$ Mass (mt) & 0 & Eq. 3.4 & $\mathbf{0}$ & Eq. 3.7 \\
\hline $\mathrm{ZrO}_{2}$ Mass (mt) & Eq. 3.1 & Eq. 3.1 & 0 & Eq. 3.1 \\
\hline Steel Mass (mt) & 0 & Eq. 3.5 & Fig. 3.7 & Eq. 3.8 \\
\hline CRM Mass (mt) & 0 & 4 & 4 & 4 \\
\hline Preexisting $\mathrm{H}_{2}$ & Eq. 3.3 & Eq. 3.3 & Eq. 3.3 & Eq. 3.3 \\
\hline $\begin{array}{l}\text { Autoignition } \\
\text { Temperature (K) } \\
\end{array}$ & 1100 & 1100 & 1100 & 1100 \\
\hline $\begin{array}{l}\text { Melt Fraction Ejected } \\
\text { into Cavity }\end{array}$ & 1.0 & 1.0 & 0.90 & 0.90 \\
\hline $\begin{array}{l}\text { Ejected Fraction } \\
\text { Dispersed from } \\
\text { Cavity }\end{array}$ & 0.85 & 0.85 & 0.85 & 0.85 \\
\hline $\begin{array}{l}\text { Dispersed Fraction } \\
\text { through Gap }\end{array}$ & 0.09 & 0.09 & 0.09 & 0.09 \\
\hline $\begin{array}{l}\text { Dispersed Fraction } \\
\text { through Seal Table } \\
\text { Room and SG Vents }\end{array}$ & 0.05 & 0.05 & 0.05 & 0.05 \\
\hline Coherence Ratio & $\begin{array}{l}\text { Eq. } 4.1 \mathrm{CLCH} \\
\text { Eq. 4.3 TCE }\end{array}$ & $\begin{array}{c}\text { Eq. } 4.1 \mathrm{CLCH} \\
\text { Eq. } 4.3 \mathrm{TCE}\end{array}$ & $\begin{array}{l}\text { Eq. } 4.1 \mathrm{CLCH} \\
\text { Eq. } 4.3 \mathrm{TCE}\end{array}$ & $\begin{array}{l}\text { Eq. } 4.1 \mathrm{CLCH} \\
\text { Eq. } 4.3 \mathrm{TCE}\end{array}$ \\
\hline $\begin{array}{l}\text { Containment } \\
\text { Pressure (MPa) }\end{array}$ & 0.25 & 0.25 & 0.25 & 0.25 \\
\hline $\begin{array}{l}\text { Containment } \\
\text { Temperature (K) }\end{array}$ & 383 & 383 & 383 & 383 \\
\hline
\end{tabular}


Table 3.2. Characterization of the Zion Plant

\begin{tabular}{|l|c|}
\hline \multicolumn{1}{|c|}{ Parameter } & Value \\
\hline Thermal power $(\mathrm{MWt})$ & 3238 \\
\hline Core Height $(\mathrm{m})$ & 3.66 \\
\hline Core diameter $(\mathrm{m})$ & 3.39 \\
\hline Number of fuel assemblies & 193 \\
\hline Number of fuel assemblies at edge of core & 64 \\
\hline Fuel assembly dimensions $(\mathrm{m})$ & 0.214 \\
\hline Number of In-Core Instruments & 58 \\
\hline RCS volume $\left(\mathrm{m}^{3}\right)$ & 353 \\
\hline Lower head ID $(\mathrm{m})$ & 4.2 \\
\hline Lower head thickness $(\mathrm{m})$ & 0.14 \\
\hline Core inventory $(\mathrm{mt})$ & \\
\hline UO & \\
Zr & 98.2 \\
Steel & 20.0 \\
CRM & 3.2 \\
\hline Thin upper plénum steel & 3.6 \\
\hline Thin lower plenum steel & 20 \\
\hline Lower plenum volume $\left(\mathrm{m}^{3}\right)$ & 15 \\
\hline Containment volume $\left(\mathrm{m}^{3}\right)$ & 30 \\
\hline Subcompartment volume $\left(\mathrm{m}^{3}\right)$ & 316 \\
\hline Cavity volume $\left(\mathrm{m}^{3}\right)$ & $26.9 \times 10^{3}$ \\
\hline Pressure $(\mathrm{MPa})$ & $4.83 \times 10^{3}$ \\
\hline Temperature $(\mathrm{K})$ & 190 \\
\hline
\end{tabular}


Table 3.3. RCS gas temperature

\begin{tabular}{|c|c|c|c|}
\hline \multirow[t]{2}{*}{ RCS Region } & \multirow[t]{2}{*}{ Volume Fraction } & \multicolumn{2}{|c|}{ Temperature (K) } \\
\hline & & TMLB'-Like & SBLOCA-Like \\
\hline $\begin{array}{l}\text { Core } \\
\text { Upper plenum } \\
\text { Hot leg } \\
\text { Cold leg } \\
\text { Lower plenum and } \\
\text { downcomer }\end{array}$ & $\begin{array}{l}0.10 \\
0.20 \\
0.28 \\
0.28 \\
0.14\end{array}$ & $\begin{array}{c}2800 \\
1700 \\
1200 \\
600 \\
600\end{array}$ & $\begin{array}{c}2800 \\
1000 \\
1000 \\
600 \\
600\end{array}$ \\
\hline RCS Avg. Temp. (K & $=\left[\sum \frac{f_{v, i}}{T_{i}}\right]^{-1}$ & 920 & 822 \\
\hline
\end{tabular}




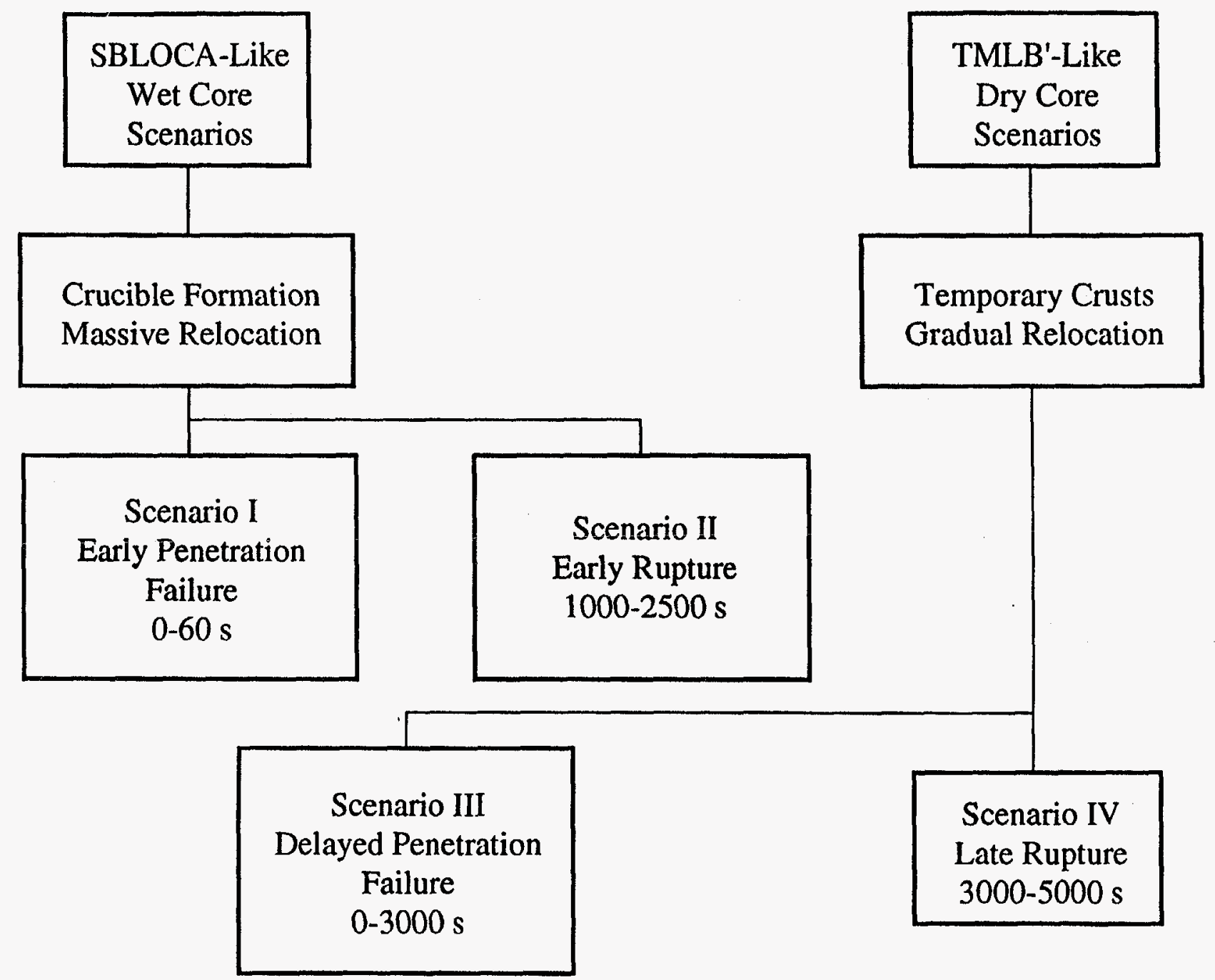

Figure 3.1. Splinter DCH scenarios. 


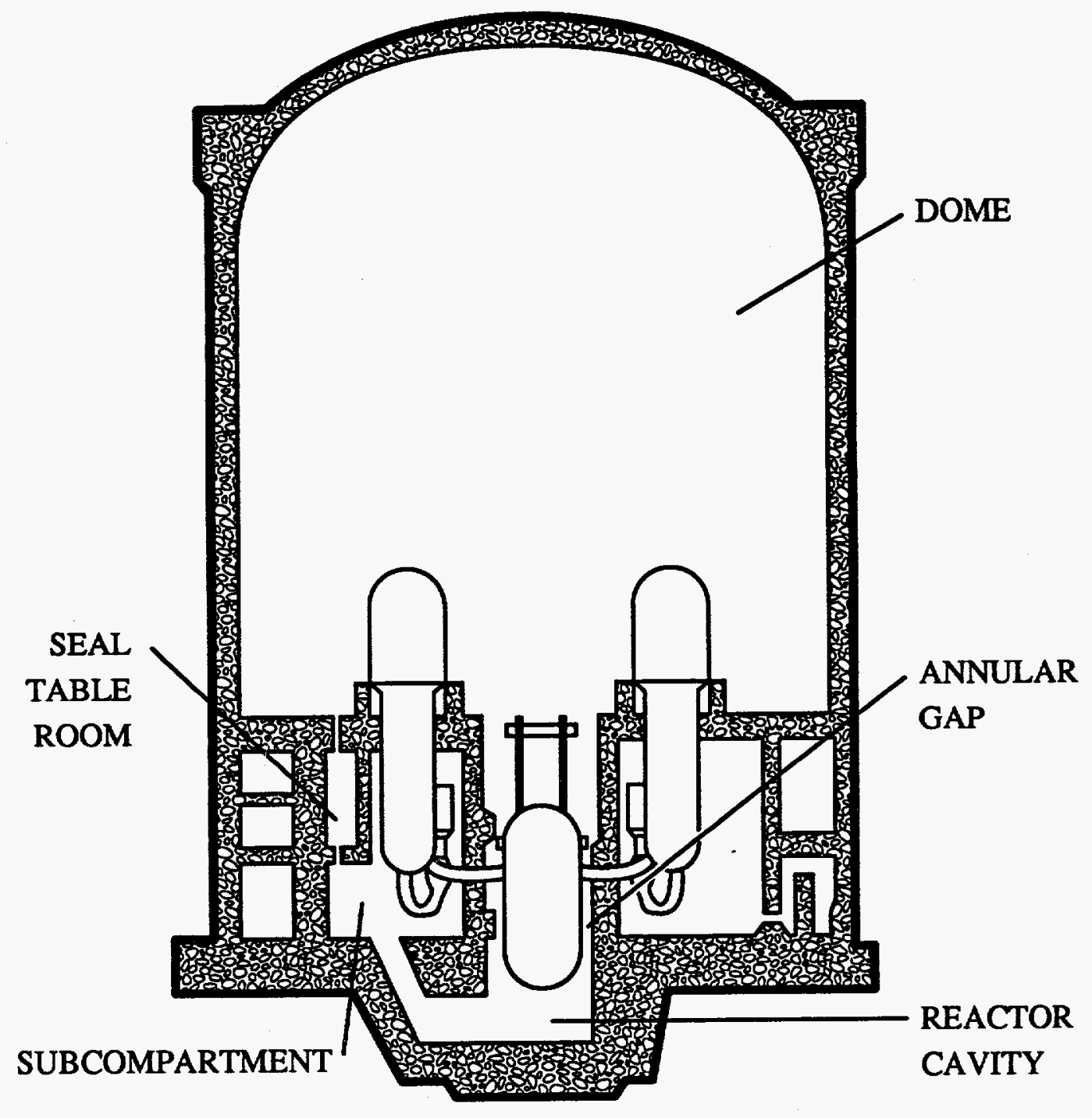

Figure 3.2. Zion Nuclear Power Plant. 


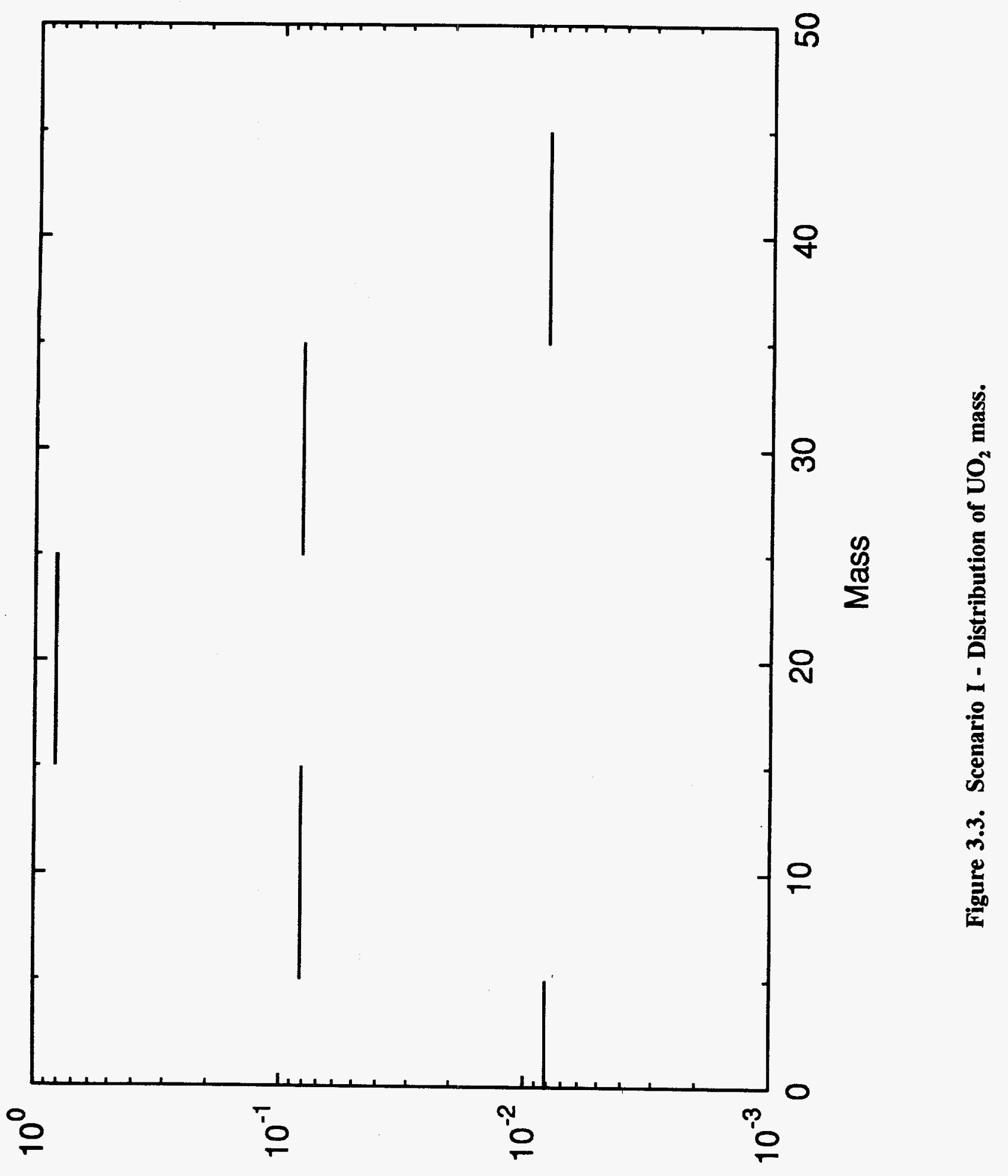

ㅅ‼!qeqodd 


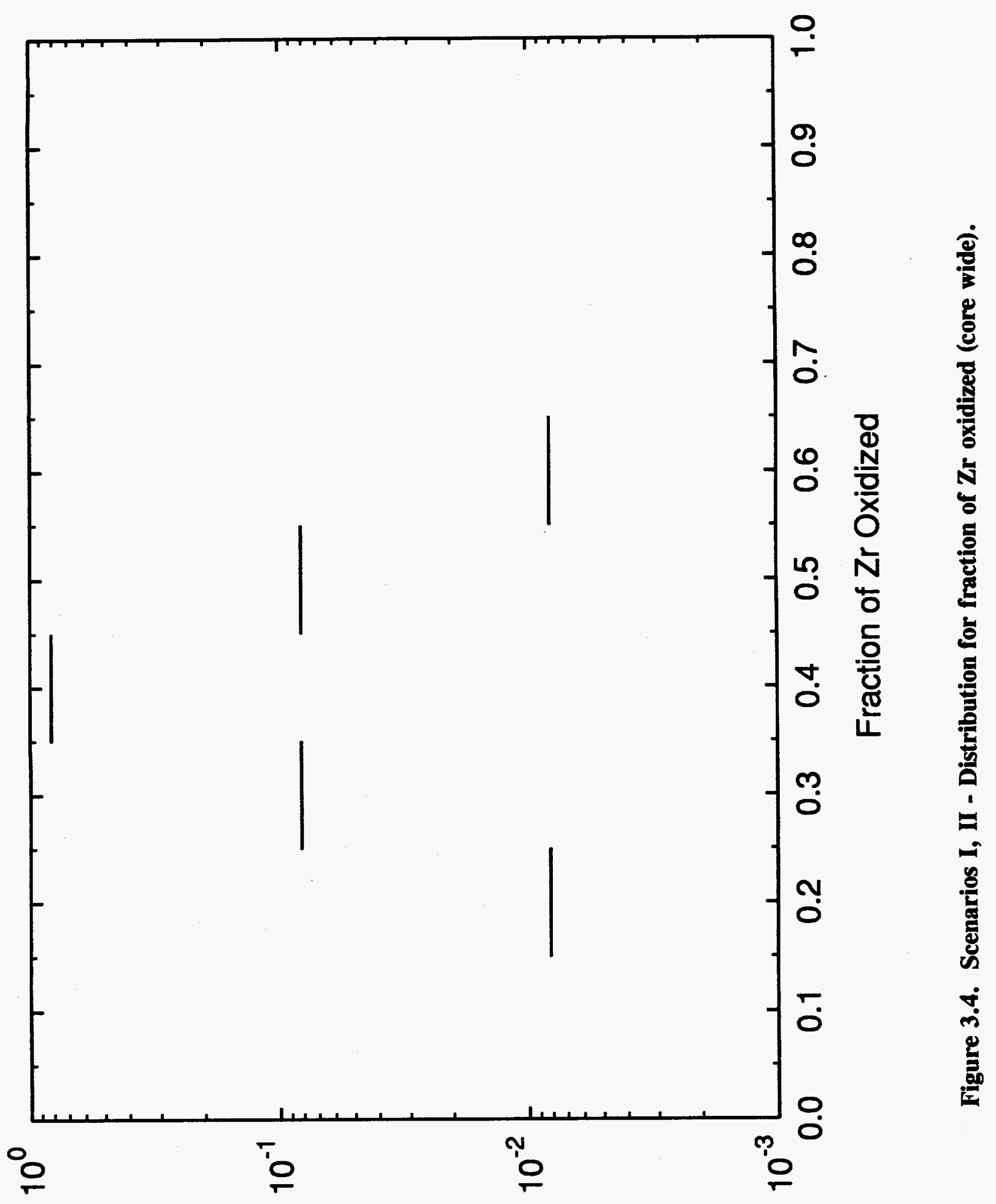

ㅅ‼!qeqodd 


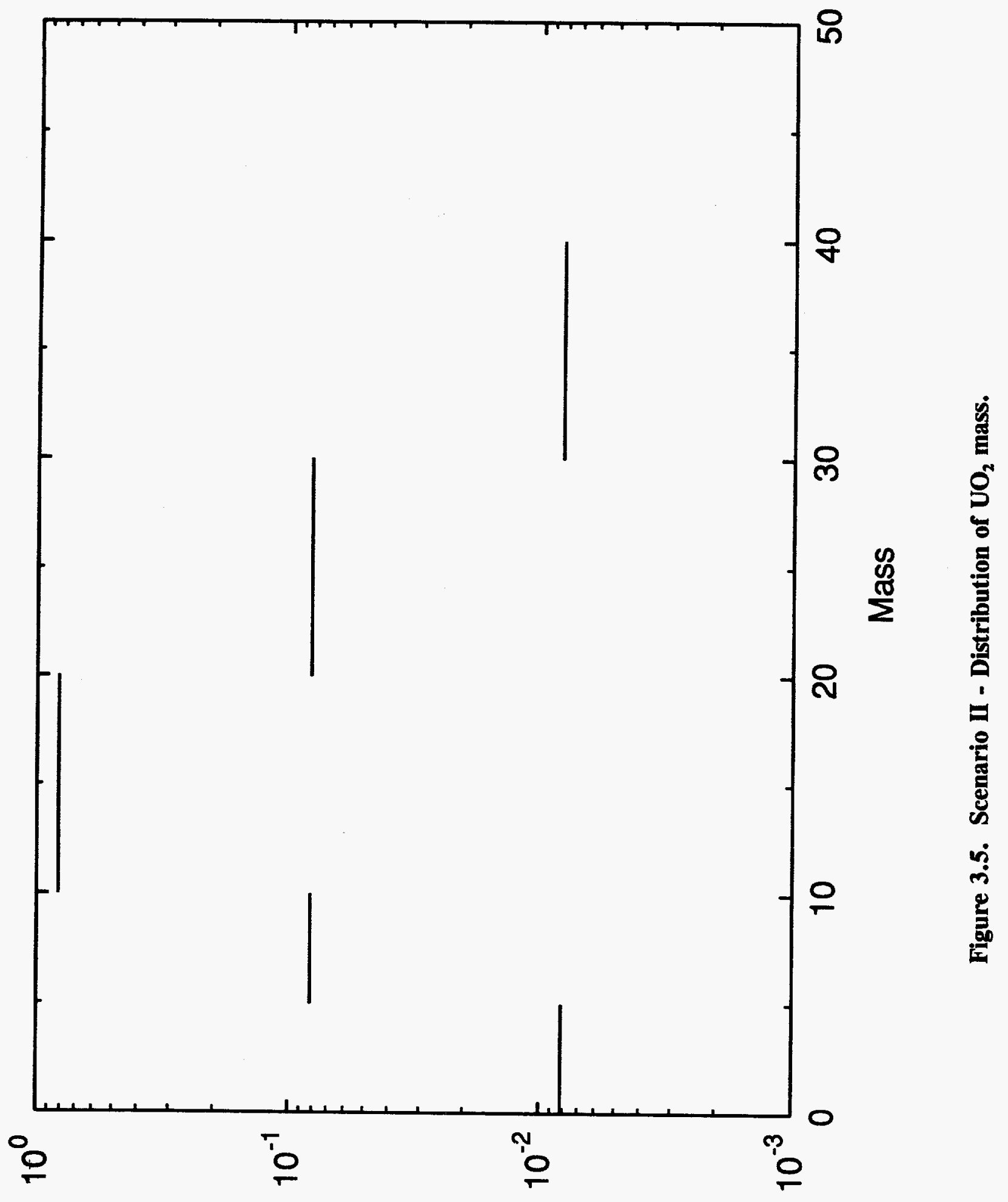

ᄉl!!!qeqodd 


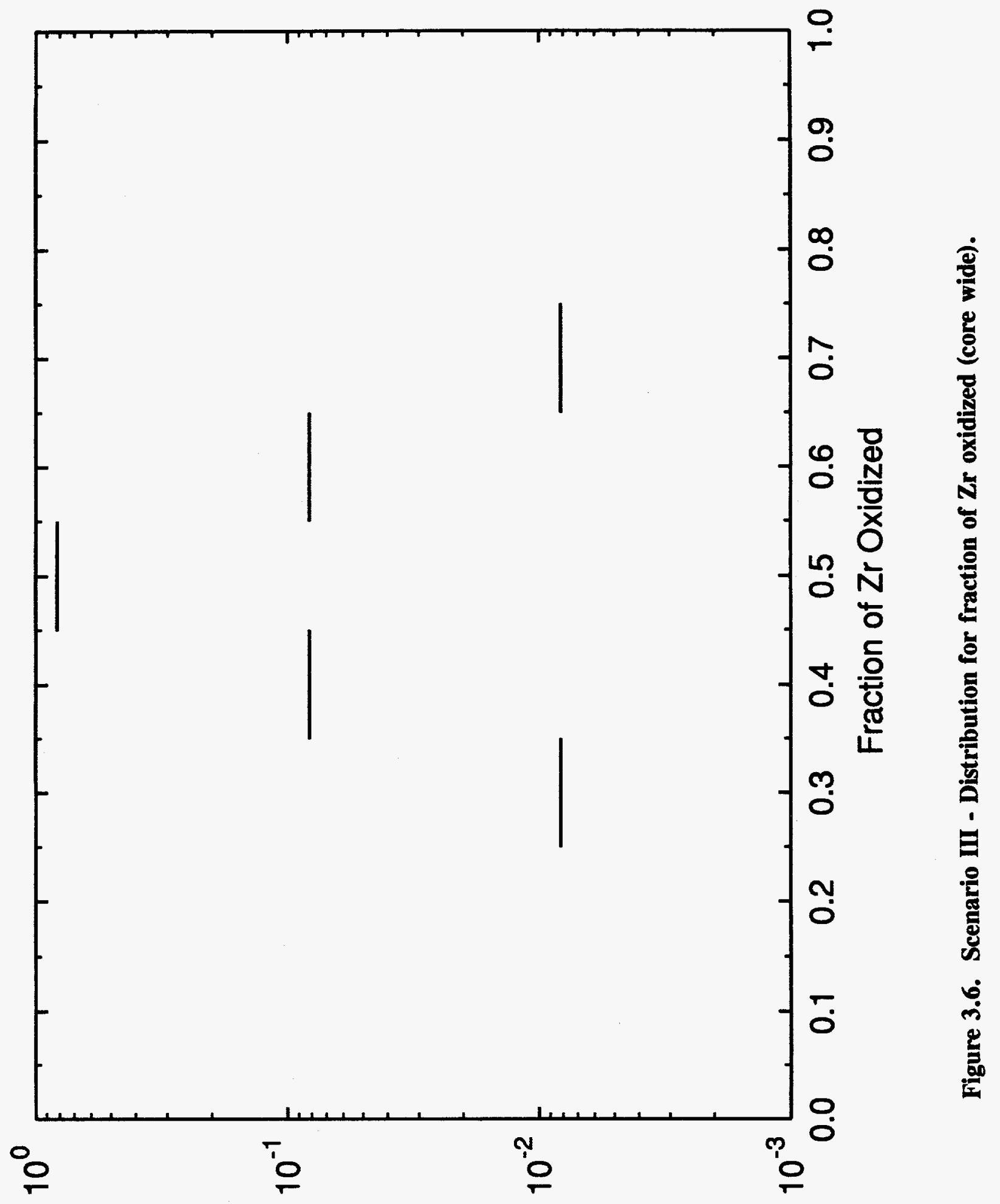

K4!!!qeqodd 


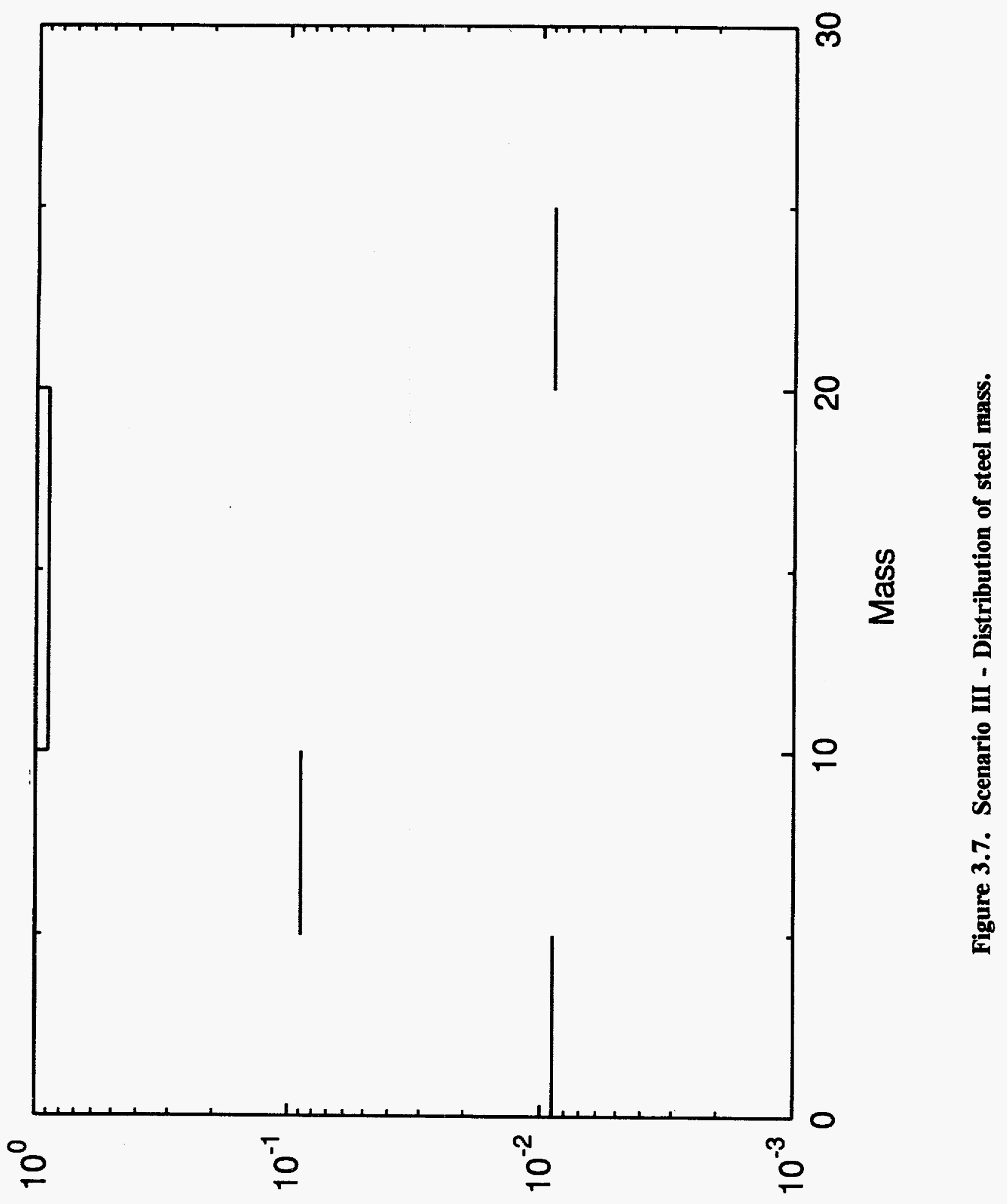

N4!!!qeqodd 


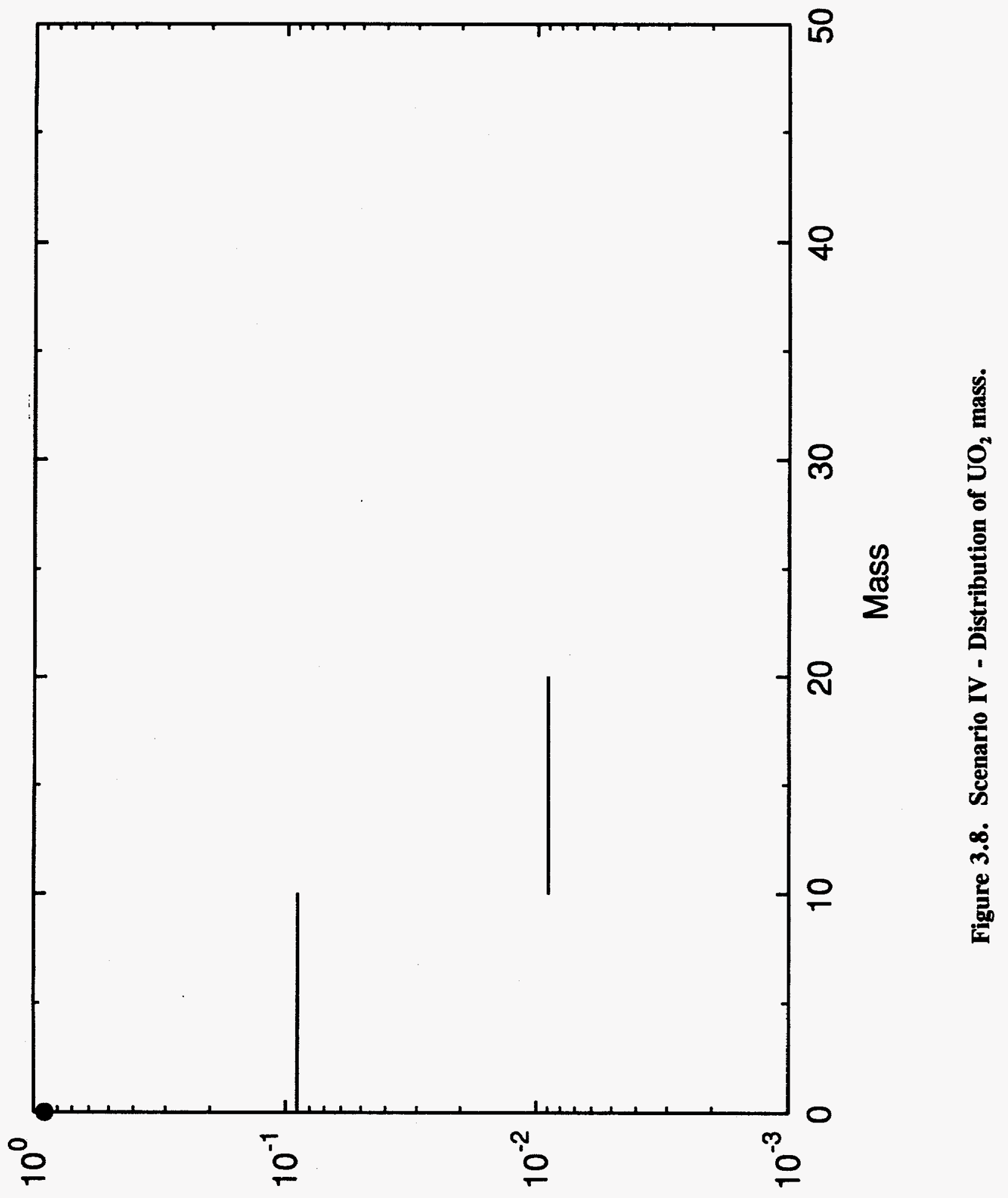

ㅅ‼!qeqodd 


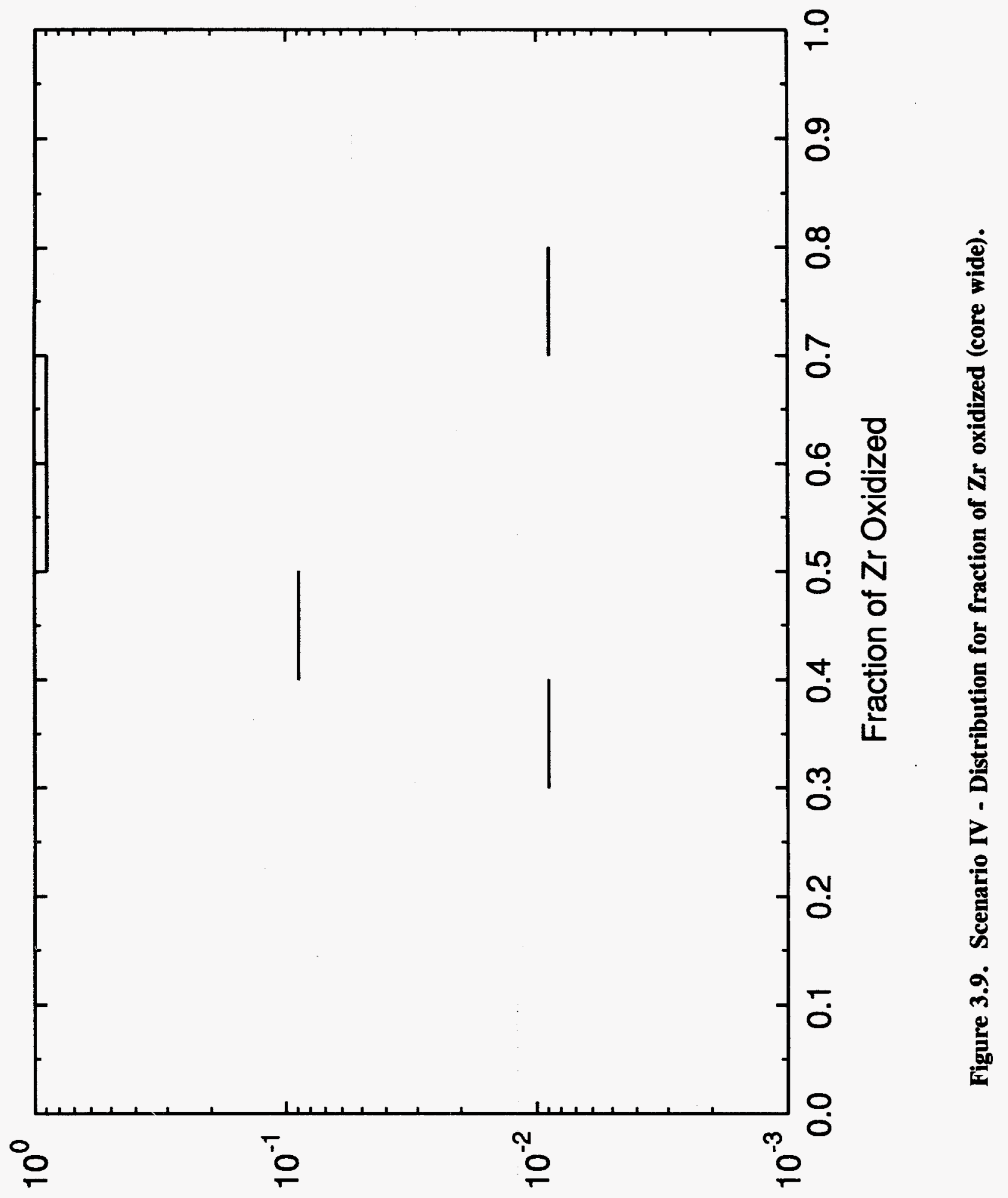

ㅅ‼!qeqodd 


\subsection{QUANTIFICATION OF THE DCH PHENOMENON}

The quantification of the DCH phenomenon is carried out by means of CR1, represented by two independently developed models: the CLCH and the TCE models presented in Appendices D and E, respectively. Most input parameters in both models are related to initial conditions and material properties. The key modeling parameter in both models is the melt-to-steam coherence ratio. Because the entrainment time is short compared to the blowdown time, molten debris is exposed to a small fraction of the primary system steam during the dispersal process. Since this steam is the medium for carrying the melt energy and the hydrogen produced by steam/metal interactions to the main containment volume, this incoherence is a crucial mitigating factor. With this understanding, it is possible to reduce most of the complexity of cavity phenomena to the coherence ratio (i.e., $\mathrm{R}_{\tau}=\tau_{\mathrm{m}} / \tau_{\mathrm{s}}$ in the CLCH model and $\mathrm{R}_{\tau}=\tau_{\mathrm{e}} / \tau_{\mathrm{b}}$ in the TCE model). The definition of coherence ratio differs only by a constant factor in the two models. We now focus on the coherence ratio and its quantitative representation in the calculations (i.e., pdf4).

The database for the coherence ratio largely overlaps the range of individual parameters that are of interest to reactor applications. However, the database does not include all possible combinations of parameters for each of the potential applications; consequently, a correlation for the coherence ratio is required to fill gaps in the database. It is significant that this process is one of interpolation rather than extrapolation.

We note that the coherence ratio performs a similar role in the CLCH and TCE models. In application, however, the coherence ratio is implemented in a way uniquely suited to the individual model. Numerical values of the coherence ratio have been determined for each of the experiments, and this information has been used to develop a correlation for the coherence ratio. This process has been carried out independently using a procedure best suited to the individual model. For most experiments, the measured coherence ratio is consistent using the independent procedures, but this is not always so. These differences have proved problematic in selecting from candidate correlations. In particular, Appendix D develops a correlation that is best suited for application in the CLCH model, and Appendix E develops a correlation that 
is best suited for application in the TCE model. This uncertainty is accounted for here by pairing the correlation for coherence ratio with the model to which it is best suited.

In Appendix D, it is shown that pressure, temperature, and breach-size variation effects on $R_{\tau}$ can be reasonably accounted for by combining Eqs. (D.4) and (D.16), i.e.,

$$
R_{\tau}=\frac{0.2 V_{c}^{1 / 3} \frac{\sqrt{T_{s 0, v}}}{P_{s 0, v}}}{\tau_{s}}
$$

with

where

$$
\tau_{s}=\frac{V_{v}}{\eta A_{b} \sqrt{\gamma R_{s} T_{s 0, v}}}
$$

$$
\begin{array}{lll}
\gamma & = & \text { ratio of specific heats, } \\
R_{\mathrm{s}} & = & \text { gas constant of steam, } \mathrm{J} / \mathrm{Kg} / \mathrm{K}, \\
\mathrm{V}_{\mathrm{c}} & = & \text { volume of cavity, } \mathrm{m}^{3}, \\
\eta & = & \text { discharge coefficient, } \\
\mathrm{A}_{\mathrm{b}} & = & \text { breach area in the } \mathrm{RPV}, \mathrm{m}^{2}, \\
\mathrm{~V}_{\mathrm{v}} & = & \text { volume of the RPS, } \mathrm{m}^{3}, \\
\mathrm{~T}_{\mathrm{s} 0, \mathrm{v}} & = & \text { RCS gas temperature, } \mathrm{K}, \\
\mathrm{P}_{\mathrm{s} 0, \mathrm{v}}= & \mathrm{RCS} \text { gas pressure, } \mathrm{MPa} .
\end{array}
$$

Eq. 4.1 has been tested with experiment data as shown in Fig. (D.12), which includes data of breach diameters (scaled to the reactor system) of 0.4 to $0.67 \mathrm{~m}$, primary system pressure in the 3.6 to $13.5 \mathrm{MPa}$ range, and the steam temperature in $\sim 600$ to $\sim 800 \mathrm{~K}$ range. It is also worth noting that the experimental data cover a good range of scales: $1 / 40$-scale (ANL), $1 / 10$-scale (SNL), and 1/6-scale (SNL).

The CLCH calculations were run using Eq. (4.1) with the parameters in it appropriate

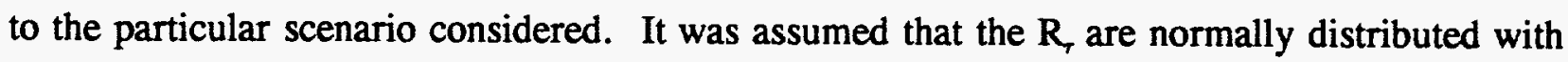
a mean given by Eq. (4.1) and a standard deviation of $t /-12.5$ percent (see Fig. (D.12) in Appendix D). 
Appendix E develops a correlation for the coherence ratio based on experiment values obtained by a procedure best suited to the TCE model. For this application, the Zion data are best correlated by

$$
R_{\tau}=9.661 f_{d}\left(\frac{T_{r c s}^{o}}{T_{d}^{o}}\right)^{\frac{1}{4}}\left[C_{d} \frac{M_{d}^{o}}{M_{g}^{o}} \frac{A_{h} V_{c a v}^{\frac{1}{3}}}{V_{r c s}}\right]^{\frac{1}{2}}
$$

where

$$
\begin{array}{lll}
\mathbf{f}_{d} & =\text { fraction dispersed, } \\
\mathrm{T}_{\mathrm{d}}^{0} & =\text { debris temperature, } \\
\mathrm{T}_{\mathrm{rcs}}^{0} & = & \text { RCS gas temperature, } \\
\mathrm{C}_{\mathrm{d}} & = & \text { discharge coefficient }(0.6) \\
\mathbf{M}_{\mathrm{d}}^{0} & = & \text { initial melt mass, } \\
\mathbf{M}_{\mathrm{g}}^{0}= & \text { initial RCS gas mass, } \\
\mathrm{A}_{\mathrm{h}}= & \text { breach area in RPV } \\
\mathrm{V}_{\mathrm{cav}}= & \text { cavity volume, and } \\
\mathrm{V}_{\mathrm{rcs}}= & \text { RCS volume. }
\end{array}
$$

It is assumed that $R_{r}$ values are distributed normally about the mean given by Eq. (4.3) with a relative standard deviation of 29 percent as indictated by the database.

The amount of material participating in DCH is typically less than the melt mass on the lower head at the time of bottom head failure. The SNL/ANL counterpart experiments (Appendices G, H) exhibited melt retention in both the crucible (scaled to the bottom head of the RPV) and the reactor cavity below the RPV. On average, $93(+/-4.4)$ percent of the melt was ejected into the cavity in these experiments. A conservative upper bound of 100 percent will be used for Scenarios I and II. For Scenarios III and IV, the melt largely resides in the interstices of a debris bed, a situation not modeled in any experiments. This solid debris will largely remain in the vessel except for a cone-shaped region over the hole (some preliminary insights into this process are presented by Griffith as cited in Zuber et al., 1991). Some residual melt will be retained in the debris bed, particularly in regions far from the hole where pressure 
gradients are negligible. For Scenarios III and IV we conservatively assume that 90 percent of the melt is ejected into the cavity.

The SNL/ANL counterpart experiments have also shown that only $76(+/-7.2)$ percent of the melt in the cavity is dispersed into the containment. Appendix $\mathrm{E}$ summarizes investigations showing that dispersal is insensitive to physical scale. We assign a dispersal fraction of 85 percent to all scenarios.

The SNL/ANL counterpart experiments have shown that 8.5 percent of the debris dispersed from the cavity through the instrument tunnel (not the annular gap) will enter the upper dome, some through the seal table room (located directly over the cavity exit) and some through vents above the Reactor Coolant Pumps (RCPs). Ishii (1993) reports 3 percent transport to the dome in experiments using water. Of this, 2 percent is carried to the dome through the vents above the RCPs surrounding the steam generators located on either side of the cavity exit. The remaining 1 percent, which is carried to the dome through the seal table room, is nonprototypic because of low film velocities at the cavity exit. Minimal transport to the dome is supported by additional scoping experiments using water (FAI, 1991). This transport to the dome is accounted for in both the CLCH and TCE evaluations of containment loads. For our evaluations, we assume 5 percent transport through the seal table room and RCP vents to the upper dome. Such treatment, however, is deemed conservative because the experiments did not model the seal table that blocks access into the seal table room, because the experiments did not model the "penthouse" over the cavity exit (a steel enclosure with blowout panels intended to prevent unwanted personnel access into the cavity), and because the experiments did not model the vast array of incore instrument guide tubes that will be dispersed from the cavity with the debris.

A second possible flow path to the upper dome is the annular gap around the RPV. The SNL/IET-11 experiment showed the melt laden gas will melt the insulation and sweep it from the gap. The SNL/HIPS-8C experiment also simulated the gap without insulation. Analysis of these two experiments indicates that the fraction of dispersed debris that goes through the gap is equivalent to the minimum flow area through the gap divided by the sum of the minimum gap 
and tunnel flow areas (see Appendix $\mathrm{K}$ ). For Zion, the minimum tunnel flow area is $-5.6 \mathrm{~m}^{2}$ and the minimum gap flow area (at the level of the nozzles) is $\sim 0.54 \mathrm{~m}^{2}$. Consequently, $\sim 9$ percent of all dispersed debris will be transported through the gap to the dome. This can be added to the $\sim 5$ percent transport through the seal table room and RCP vents, so that 14 percent of all dispersed debris will enter the dome.

A second phenomenological uncertainty concerns the temperature at which sudden volumetric combustion (autoignition) of all preexisting hydrogen occurs. This phenomenon is discussed in Appendix F. Autoignition did not occur in large-scale experiments conducted under fully prototypic conditions. Stratification of the containment atmosphere is proposed as the mitigating mechanism. In particular, hot gases venting from the subcompartment rise to the dome displacing the cooler preexisting atmosphere downwards with minimal heating. With this as the controlling physics, it may be difficult for autoignition to occur on DCH time scales; however, we place the autoignition temperature for NPP analyses at $1100 \mathrm{~K}$. Such an assignment is consistent with some small-scale measurements of autoignition under lean conditions. The SNL/IET-11 experiment achieved volume averaged temperatures of $\sim 1100 \mathrm{~K}$ with significant combustion of preexisting hydrogen. Even here, however, the burning was mixing limited and did not contribute to peak containment pressure.

\subsection{References}

FAI (1991) Zion IPE Position Paper on Direct Containment Heating, FAI/91-18, Submitted to Commonwealth Edison Co.

Ginsberg, T. and N.K. Tutu (1988). Progress in Understanding Direct Containment Heating Phenomena in Pressurized Light Water Reactors, BNL-NUREG-41751, Brookhaven National Laboratory, Upton, NY.

Ishii, M., S.T. Revankar, G. Zhang, Q. Wu, and P. O'Brien (March 1993). Separate Effects Experiments on Phenomena of Direct Containment Heating - Air-Water Simulation Experiments in Zion Geometry, PU NE-93/1, Purdue University, West Lafayette, IN.

Zuber, et al. (1991). An Integrated Structure and Scaling Methodology for Severe Accident Technical Issue Resolution, draft for comment, NUREG/CR-5809, EGG-2659. 


\subsection{QUANTIFICATION OF CONTAINMENT FRAGILITY}

This section characterizes the strength of the Zion containment in probabilistic terms. The pressure capacity of the Zion containment is treated as a random variable because of the variability in material properties, because of unknown differences between the as-built and design conditions, and because of modeling uncertainties. The probability that the containment failure pressure is less than a specified pressure is known as the containment overpressure fragility curve.

Fragility curves represent a probabilistic estimate of the capacity of the containment, and as such are not directly derivable from existing data or full-scale experiments. In general, they are derived from a combination of material property data, tolerances in dimensions from drawings, and on judgment of the analyst. Analyst judgment is used in determining what level of analysis is required and what failure mechanisms are considered to govern the containment capacity. In addition, analyst judgment is utilized in translating the results of material property tests into a probabilistic estimate of the variability of the various material properties involved. Finally, analyst judgment is exercised in assigning "modelling" uncertainty to the models to characterize the analyst's confidence in the selected models to represent the actual failure mechanisms involved. Modeling uncertainty is that which could, in principle, be reduced with further analysis or testing. Funding constraints, however, usually require the analyst to exercise his judgment to reflect the uncertainty involved.

In addition, it should be noted that a containment fragility curve is, in fact, a plantspecific entity. It is to be anticipated that the fragility curves derived for a specific containment are sensitive to local design details, tolerances, and the design philosophy used for that particular containment. While it is likely that various sub-models representing different local containment failure modes may be applicable to a variety of containments of a given type, it is also true that the combination of failure mechanisms existing in a given containment is unique. Thus, the reader is cautioned against reading any generic applicability into the fragility curves developed for any specific containment. 


\subsection{Fragility Curve Selected For DCH Evaluation}

The Zion containment is a prestressed, post-tensioned concrete cylinder with a shallowdomed roof. The foundation is a reinforced concrete slab. The containment is lined with welded $6.35 \mathrm{~mm}(0.25 \mathrm{inch})$ steel plate. The post-tensioning system is composed of 63 dome tendons, 216 vertical tendons, and 555 hoop tendons. The design pressure and temperature are $0.42 \mathrm{MPa}$-abs and $375 \mathrm{~K}$ (47 psig and $217^{\circ} \mathrm{F}$ ). The free volume is about $76.9 \times 10^{3} \mathrm{~m}^{3}$ (2.7 million cubic feet).

The containment fragility curve used for this study (Figure 5.1) is taken from the Zion IPE (1992). This curve reflects the most recent judgment of the licensee of the plant. As described by the licensee, the Zion IPE fragility was derived as follows.

Analyses of the ultimate pressure capacity of the Zion containment were performed independently by Sargent \& Lundy (S\&L) for the IDCOR program, Brookhaven National Laboratory (BNL) for the NRC, and Los Alamos National Laboratory for the NRC. Two limiting failure locations were identified, i.e., the basemat/shell junction and the shell wall (hoop direction). The three studies show large discrepancies in the prediction of the failure pressure at the basemat/shell junction. However, only the S\&L results were consistent with the Sandia 1:6 scale test. Therefore, the S\&L prediction of $152 \mathrm{psig}$ is adopted as the mean failure pressure for the basemat/shell junction in the containment fragility curve calculation. With regard to the failure pressure for the shell wall (hoop direction), the S\&L result (134.4 psig) was in good agreement with the Los Alamos result (136 psig). The smaller failure pressure of $134.4 \mathrm{psig}$ is adopted in the containment fragility curve calculation.

Uncertainties in the estimated failure pressures, in terms of a coefficient of variation, are $5 \%$ and $15 \%$ for the hoop shell wall and the basemat/shell junction, respectively. The containment fragility curve, constructed based upon the two limiting failure locations and their associated uncertainties, is shown in Figure 5.1. The total failure probability is the 
sum of the individual failure probabilities. As shown in Figure 5.1, the mean failure pressure, where the total probability of failure becomes $50 \%$, is $132 \mathrm{psig}$. Containment failure at pressures above 128 psig would most likely occur at the hoop shell wall, while failure below 128 psig would likely occur at the basemat/shell junction. In addition, the S\&L study concluded that the containment failure pressure and location would not be sensitive to the pressurization rates or temperature effects caused by any postulated failure mechanisms.

Figure 5.1 presents the total containment overpressure fragility curve from the Zion IPE report as well as the contributions from the two failure modes identified. The total curve predicts a median pressure at failure in the range 1.0 to $1.03 \mathrm{MPa}$-abs (130 to $135 \mathrm{psig}$ ) and has zero probability of failure below $0.68 \mathrm{MPa}-\mathrm{abs}$ ( $85 \mathrm{psig}$ ).

\subsection{Sensitivity Considerations}

A detailed, mechanism-specific analysis of the Zion containment overpressure fragility is reported in Bohn et al. (1993). This work draws on the recent insights obtained from the joint NRC/Containment Model Test Program performed at SNL and is part of ongoing methodology development aimed at improving tools for the screening of vulnerabilities of containments. Based on a review of potential Zion containment failure modes, three failure mechanisms were felt to be potentially governing for the Zion containment system: gross structural failure due to failure of the tendons, leakage due to local liner tearing near reinforced piping penetrations, and leakage due to strain-induced ovalization of the equipment hatch. To analyze these failure modes, deterministic models for computing the free-field membrane strains, local liner strains and strain-induced ovalization of the equipment hatch were developed. These models include the non-linear behavior of all constituents of the composite wall (the rebar, the liner, the liner plate, and the tendons) and material properties determined from tests on the actual materials used in constructing the Zion containment.

These deterministic models were embedded in a Monte Carlo calculational procedure along with a description of the random and systematic uncertainties in the parameters involved 
in the models. A Monte Carlo analysis was performed that computed the membrane containment hoop strains and the local penetration hoop strains as a function of pressure, and compared them to the appropriate Zion-specific failure criteria, resulting in probabilistic fragility curves for each of the three failure mechanisms.

This work is under NRC review and will be subjected to external peer review. Any new results will be utilized in the overall closure process. However, preliminary comparisons show that use of these curves would not substantially change the perspectives obtained using the Zion IPE containment fragility curve shown in Figure 5.1 and the DCH pressure distributions presented in this report.

\subsection{References}

Bohn, M.P. et al. (June 1993). A Mechanistic-Specific Analysis of the Zion Containment Overpressure Fragility, Draft Report, SAND93-1346, Sandia National Laboratories, Albuquerque, NM.

Zion IPE (April 1992). Commonwealth-Edison Zion Station: Individual Plant Evaluation, NRC Doc. No 9204290315. 


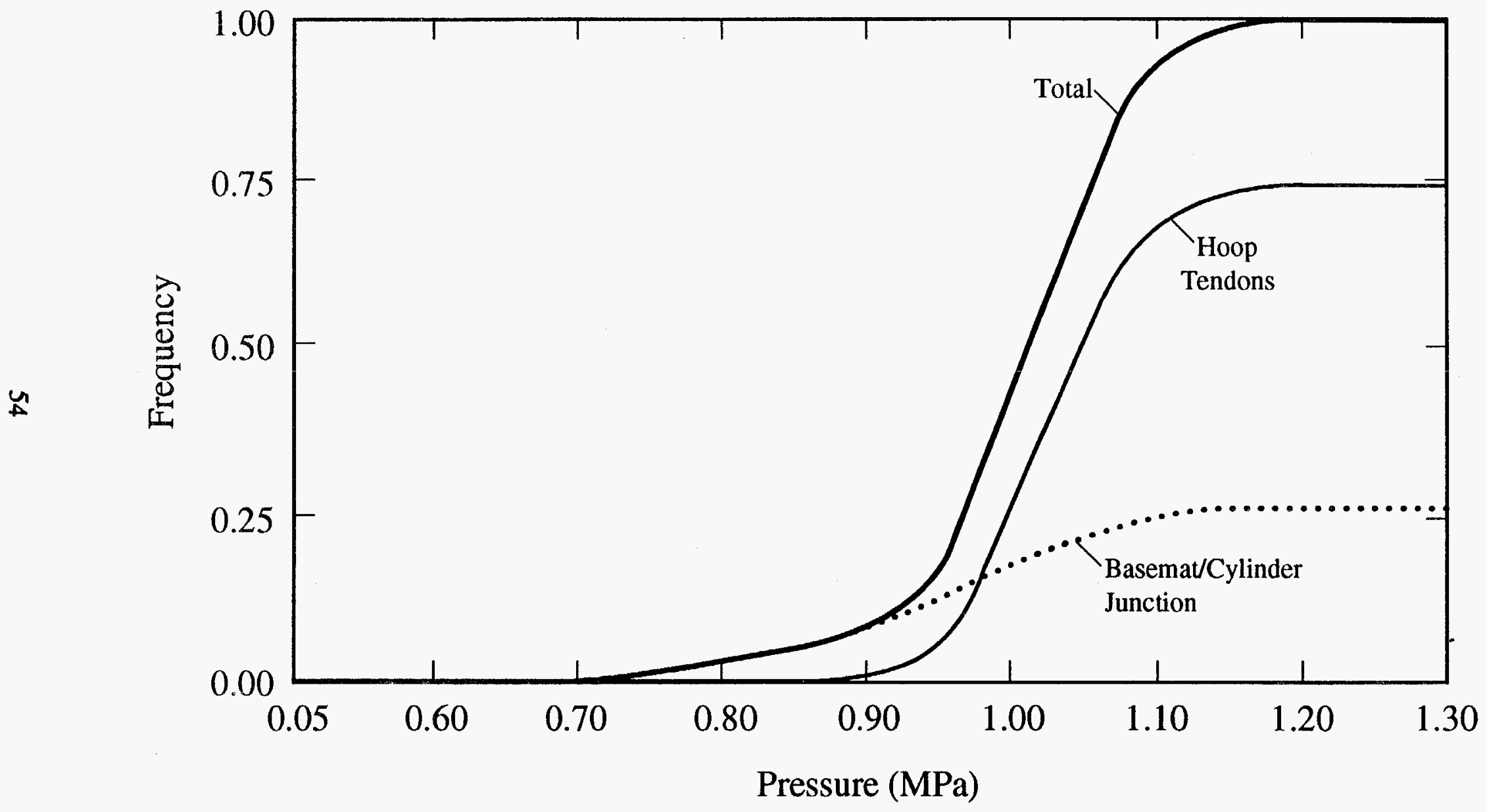

Figure 5.1. Fragility of the Zion containment. 


\subsection{RESULTS AND SENSITIVITIES}

Each scenario identified in Section 3, supplemented with the respective coherence ratio distribution as discussed in Section 4 and the fragility curve of Section 5, was run through the arithmetic defined by the probabilistic framework of Section 2 to produce probability distributions for the final hole size, coherence ratio, containment temperature, and containment pressure. Finally, the containment failure probability was computed. The calculations were carried out using the computer code ALPHA. With a goal of quality control, independent calculations have been carried out at SNL using a Monte Carlo technique to verify the results obtained with the ALPHA code. In all cases, the results were in agreement.

Table 6.1 provides a concise summary of where to find each of the calculated distributions. The distributions for hole size, coherence ratio, and containment temperature are provided so the reader can see firsthand the range over which these key intermediate parameters vary. Table 6.1 shows that the expected value for the conditional failure probability is much less than $10^{-3}$ for all scenarios (containment loads never intersect the fragility curve), and we can thus conclude that containment failure by DCH in the Zion plant is physically unreasonable.

Examination of the results led to the following observations:

1. The results from the two DCH models are in good agreement in most cases.

2. Scenario I is very benign, Scenarios II and III produce similar and slightly higher loads, and Scenario IV is the most severe.

3. Calculated temperatures do not exceed $950 \mathrm{~K}$ except in Scenario IV where the total probability of exceedance is less than $\sigma\left(10^{-3}\right)$; thus, DCH events are far from autoignition.

4. The calculated final breach diameters are well within the scaled range used in the experiments. 
Systematic sensitivity studies were also performed by arbitrarily varying the key inputs characterized in the base quantification with fixed values to other values chosen so as to produce higher loads. The sensitivities analyzed include the autoignition temperature, amount of debris dispersed to the dome, initial hole size, and primary system pressure. These sensitivity studies include all single and pairwise combinations among these four parameters, one in which all four parameters were varied simultaneously, and several triplet combinations in the manner specified in Tables 6.2 to 6.5 .

We emphasize the arbitrary nature of these variations towards more severe conditions because our base results (Table 6.1) are already quite conservative, both in terms of individual inputs as well as by virtue of using bounding models (CLCH and TCE) for computing the containment loads. This means that the base quantifications must be viewed, evaluated, and/or used on their merits alone. It may be appropriate to list the possible uses of the sensitivity studies presented here: a) provide answers to most "what if" questions by the reader, b) better illustrate the workings of the probabilistic modeling and the role of various inputs, and c) provide a more complete perspective on what is important.

The sensitivity tables are organized according to four significant phenomenological areas that have been identified in this report:

1. The autoignition temperature is assigned a value of $950 \mathrm{~K}$ for a sensitivity study.

2. Total debris transport to the dome (annular gap, seal table room, and steam generator vents) is assigned a value of 20 percent for a sensitivity study.

3. The initial hole size for rupture scenarios (II, IV) is assigned a value of $0.7 \mathrm{~m}$ for a sensitivity study.

4. Full system pressure is chosen for a sensitivity study. 
With regard to the full system pressure studies, it is important to use initial conditions consistent with being at full pressure. No significant pressure dependence of the initial conditions is expected for Scenarios I, II, or III. For Scenario IV, however, the quantity, composition, and temperature of the melt is quite sensitive to the timing of bottom head rupture. Dosanjh and Pilch (1991) show that rupture will occur in less than $4000 \mathrm{~s}$, and more recent insights on hot-spot-induced ruptures suggest that the failure could be even quicker. For such failure times, Dosanjh and Pilch show that no oxide can be molten; consequently, only molten steel (distribution similar to Scenario III, T $\sim 1900 \mathrm{~K}$ ) will be present. For these high driving pressures, melt dispersal from the cavity is assumed to be complete. Lastly, 20 percent of all hydrogen produced during core degradation will be retained in the RCS with the remaining 80 percent preexisting in the containment atmosphere prior to vessel failure.

The sensitivity tables are organized as a matrix where repetitious elements are shaded. Furthermore, an initial hole size of $0.7 \mathrm{~m}$ only has meaning for rupture scenarios, so such entries are also shaded for Scenarios I and III, which represent penetration-type failures.

Single variations from the base qualifications lie along the diagonals of the sensitivity matrix. Examination of the sensitivity tables shows that single variations never produce containment failure probabilities in excess of $10^{-3}$ for any of the scenarios. The search for large sensitivities can be pushed further by considering simultaneous combinations of two sensitivity parameters. Such combinations are found in the off diagonal elements of the sensitivity tables. Simultaneous combination of two sensitivity parameters never produces containment failure probabilities in excess of $10^{3}$ except in scenario IV, where a large hole in conjunction with low autoignition results in CFP $\sim 4 \times 10^{-3}$.

We now seek the sensitivity to additional combinations of parameters. We do this as a two-step process: the first step involves varying all parameters except pressure simultaneously, the second step involves varying all parameters simultaneously at full pressure (with modified initial conditions, as discussed above, for consistency). Simultaneous variations of all parameters always result in CFP $<10^{-3}$ except for scenario IV where simultaneous variations of all parameters results in CFP $\sim 2 \times 10^{-2}$. 
In summary, the containment failure probability by DCH for Zion is less than $10^{-3}$. Single variations of sensitivity parameters, simultaneous variations of two sensitivity parameters, and simultaneous variations of all sensitivity parameters do little to alter this basic conclusion. Therefore, we are drawn to the conclusion that no single process or parameter is of controlling influence to the results. The results of these sensitivity studies further support the conclusion of the base quantification, i.e., containment failure by DCH for Zion is physically unreasonable.

\subsection{References}

Dosanjh, S.S. and M. Pilch (1991). "Lower Head Creep-Rupture Sensitivity Studies," Nuclear Science and Engineering, 108, 172-183.

Table 6.1. Summary of results

\begin{tabular}{||l|c|c|c|c||}
\hline \multirow{2}{*}{\multicolumn{1}{|c|}{ Distribution/Result }} & \multicolumn{4}{|c|}{ Scenario } \\
\cline { 2 - 5 } & I & II & III & IV \\
\hline Hole Size & Fig. 6.1 & Fig. 6.5 & Fig. 6.9 & Fig. 6.13 \\
Coherence Ratio & Fig. 6.2 & Fig. 6.6 & Fig. 6.10 & Fig. 6.14 \\
Containment Temperature & Fig. 6.3 & Fig. 6.7 & Fig. 6.11 & Fig. 6.15 \\
$\begin{array}{l}\text { Containment Pressure } \\
\text { Containment Failure } \\
\text { Probability }\end{array}$ & Fig. 6.4 & Fig. 6.8 & Fig. 6.12 & Fig. 6.16 \\
\hline
\end{tabular}


Table 6.2. Scenario I - sensitivity studies

\begin{tabular}{|c|c|c|c|c|}
\hline & \multicolumn{4}{|c|}{ Containment Failure Probability (CFP) } \\
\hline & $\begin{array}{l}\text { Autoignition } \\
950 \mathrm{~K}\end{array}$ & $\begin{array}{c}\text { Dome Transport } \\
20 \%\end{array}$ & $\begin{array}{l}\text { Initial Hole } \\
\text { Size, } 0.7 \mathrm{~m}\end{array}$ & $\begin{array}{c}\text { Full Pressure } \\
16 \mathrm{MPa}\end{array}$ \\
\hline $\begin{array}{l}\text { Autoignition } \\
950 \mathrm{~K}\end{array}$ & 0 & & & \\
\hline $\begin{array}{c}\text { Dome Transport } \\
20 \%\end{array}$ & 0 & 0 & & \\
\hline $\begin{array}{l}\text { Initial Hole } \\
\text { Size, } 0.7 \mathrm{~m}\end{array}$ & & & & \\
\hline $\begin{array}{c}\text { Full Pressure } \\
16 \mathrm{MPa}\end{array}$ & 0 & 0 & & 0 \\
\hline
\end{tabular}

Simultaneous combination of three sensitivities at $16 \mathrm{MPa}, \mathrm{CFP}=0$.

Table 6.3. Scenario II - sensitivity studies

\begin{tabular}{|c|c|c|c|c|}
\hline & \multicolumn{4}{|c|}{ Containment Failure Probability (CFP) } \\
\hline & $\begin{array}{l}\text { Autoignition } \\
\quad 950 \mathrm{~K}\end{array}$ & $\begin{array}{c}\text { Dome Transport } \\
20 \%\end{array}$ & $\begin{array}{l}\text { Initial Hole } \\
\text { Size, } 0.7 \mathrm{~m}\end{array}$ & $\begin{array}{c}\text { Full Pressure } \\
16 \mathrm{MPa}\end{array}$ \\
\hline $\begin{array}{l}\text { Autoignition } \\
950 \mathrm{~K}\end{array}$ & 0 & & & \\
\hline $\begin{array}{c}\text { Dome Transport } \\
20 \% \\
\end{array}$ & 0 & 0 & & \\
\hline $\begin{array}{l}\text { Initial Hole } \\
\text { Size, } 0.7 \mathrm{~m}\end{array}$ & 0 & 0 & 0 & \\
\hline $\begin{array}{c}\text { Full Pressure } \\
16 \mathrm{MPa}\end{array}$ & 0 & 0 & 0 & 0 \\
\hline
\end{tabular}

Simultaneous combination of first three sensitivities at $8 \mathrm{MPa}, \mathrm{CFP}=0$.

Simultaneous combination of four sensitivities at $16 \mathrm{MPa}, \mathrm{CFP}=0$. 
Table 6.4. Scenario III - sensitivity studies

\begin{tabular}{|c|c|c|c|c|}
\hline & \multicolumn{4}{|c|}{ Containment Failure Probability (CFP) } \\
\hline & $\begin{array}{c}\text { Autoignition } \\
950 \mathrm{~K} \\
\end{array}$ & $\begin{array}{c}\text { Dome Transport } \\
20 \%\end{array}$ & $\begin{array}{l}\text { Initial Hole } \\
\text { Size, } 0.7 \mathrm{~m}\end{array}$ & $\begin{array}{c}\text { Full Pressure } \\
16 \mathrm{MPa}\end{array}$ \\
\hline $\begin{array}{c}\text { Autoignition } \\
950 \mathrm{~K}\end{array}$ & 0 & & & \\
\hline $\begin{array}{c}\text { Dome Transport } \\
20 \%\end{array}$ & 0 & 0 & & \\
\hline $\begin{array}{l}\text { Initial Hole } \\
\text { Size, } 0.7 \mathrm{~m} \\
\end{array}$ & & & & \\
\hline $\begin{array}{c}\text { Full Pressure } \\
16 \mathrm{MPa}\end{array}$ & 0 & 0 & & 0 \\
\hline
\end{tabular}

Simultaneous combination of three sensitivities at $16 \mathrm{MPa}, \mathrm{CFP}=0$.

Table 6.5. Scenario IV - sensitivity studies

\begin{tabular}{|c|c|c|c|c|}
\hline & \multicolumn{4}{|c|}{ Containment Failure Probability (CFP) } \\
\hline & $\begin{array}{c}\text { Autoignition } \\
950 \mathrm{~K} \\
\end{array}$ & $\begin{array}{c}\text { Dome Transport } \\
20 \%\end{array}$ & $\begin{array}{l}\text { Initial Hole } \\
\text { Size, } 0.7 \mathrm{~m}\end{array}$ & $\begin{array}{l}\text { Full Pressure } \\
16 \mathrm{MPa}\end{array}$ \\
\hline $\begin{array}{c}\text { Autoignition } \\
950 \mathrm{~K} \\
\end{array}$ & $\begin{array}{c}0 \mathrm{TCE} \\
0 \mathrm{CLCH}\end{array}$ & & & \\
\hline $\begin{array}{l}\text { Dome- } \\
\text { Transport } \\
20 \%\end{array}$ & $\begin{array}{l}<<10^{-3} \mathrm{TCE} \\
\sim 10^{-3} \mathrm{CLCH}\end{array}$ & $\begin{array}{c}\text { O TCE } \\
<<10^{-3} \mathrm{CLCH}\end{array}$ & & \\
\hline $\begin{array}{l}\text { Initial Hole } \\
\text { Size, } 0.7 \mathrm{~m}\end{array}$ & $\begin{array}{l}<<10^{-3} \mathrm{TCE} \\
\sim 4 \times 10^{-3} \mathrm{CLCH}\end{array}$ & $\begin{array}{l}<<10^{-3} \mathrm{TCE} \\
<<10^{-3} \mathrm{CLCH}\end{array}$ & $\begin{array}{l}0 \mathrm{TCE} \\
0 \mathrm{CLCH}\end{array}$ & \\
\hline $\begin{array}{c}\text { Full Pressure } \\
16 \mathrm{MPa}\end{array}$ & $\begin{array}{c}0 \text { TCE } \\
<<10^{-3} \mathrm{CLCH}\end{array}$ & $\begin{array}{l}<<10^{-3} \mathrm{TCE} \\
<<10^{-3} \mathrm{CLCH}\end{array}$ & $\begin{array}{l}<<10^{-3} \text { TCE } \\
<<10^{-3} \mathrm{CLCH}\end{array}$ & $\begin{array}{c}0 \mathrm{TCE} \\
<<10^{-3} \mathrm{CLCH}\end{array}$ \\
\hline
\end{tabular}

Simultaneous combination of first three sensitivities at $8 \mathrm{MPa}$; CFP $<<10^{-3} \mathrm{TCE}$; CFP $-5 \times 10^{-3}$ CLCH.

Simultaneous combination of four sensitivities at $16 \mathrm{MPa}$; CFP $<<10^{-3} \mathrm{TCE}$; CFP $\sim 2 \times 10^{-2}$ CLCH. 


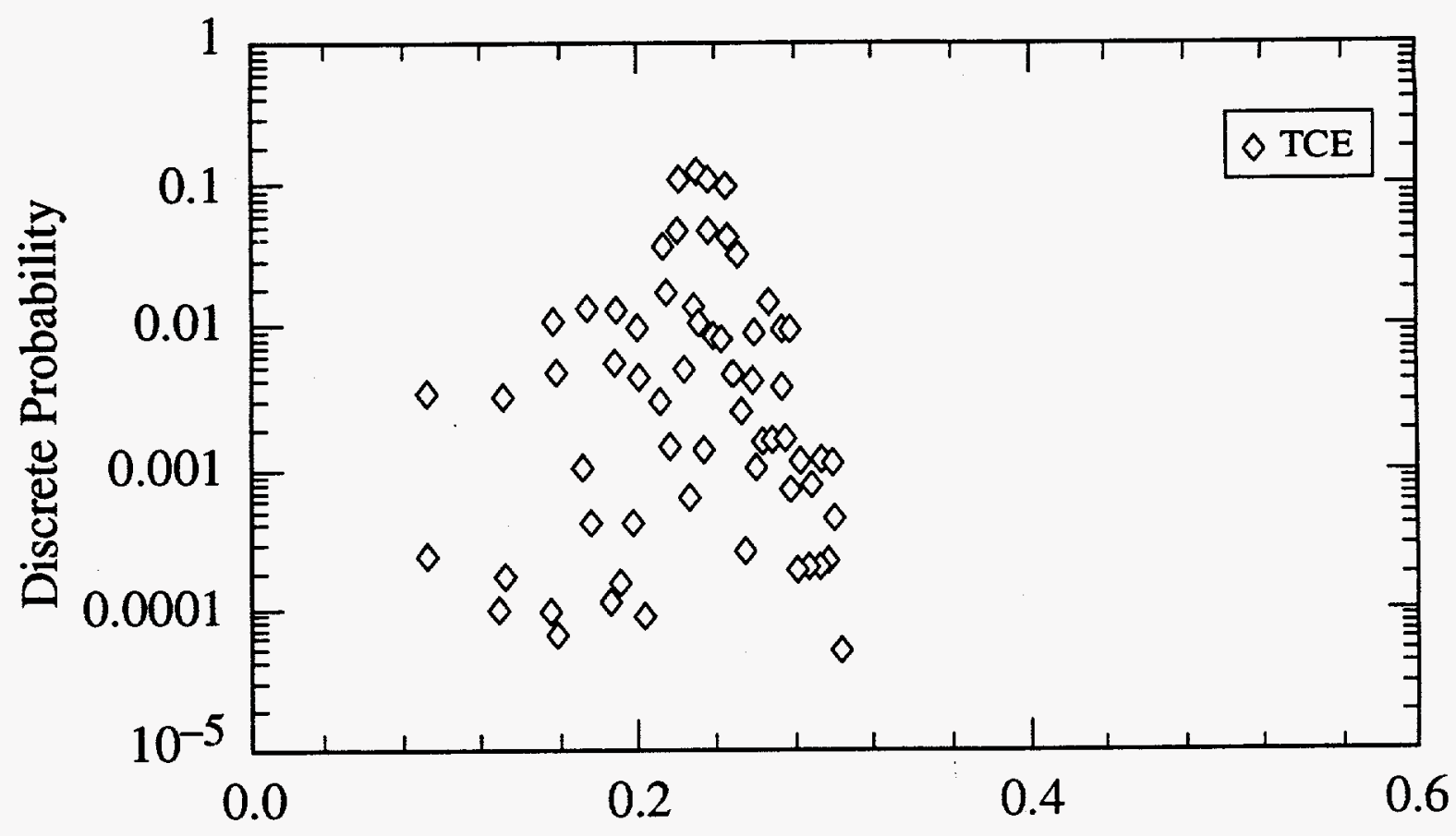

Diameter of Ablated Hole (m)

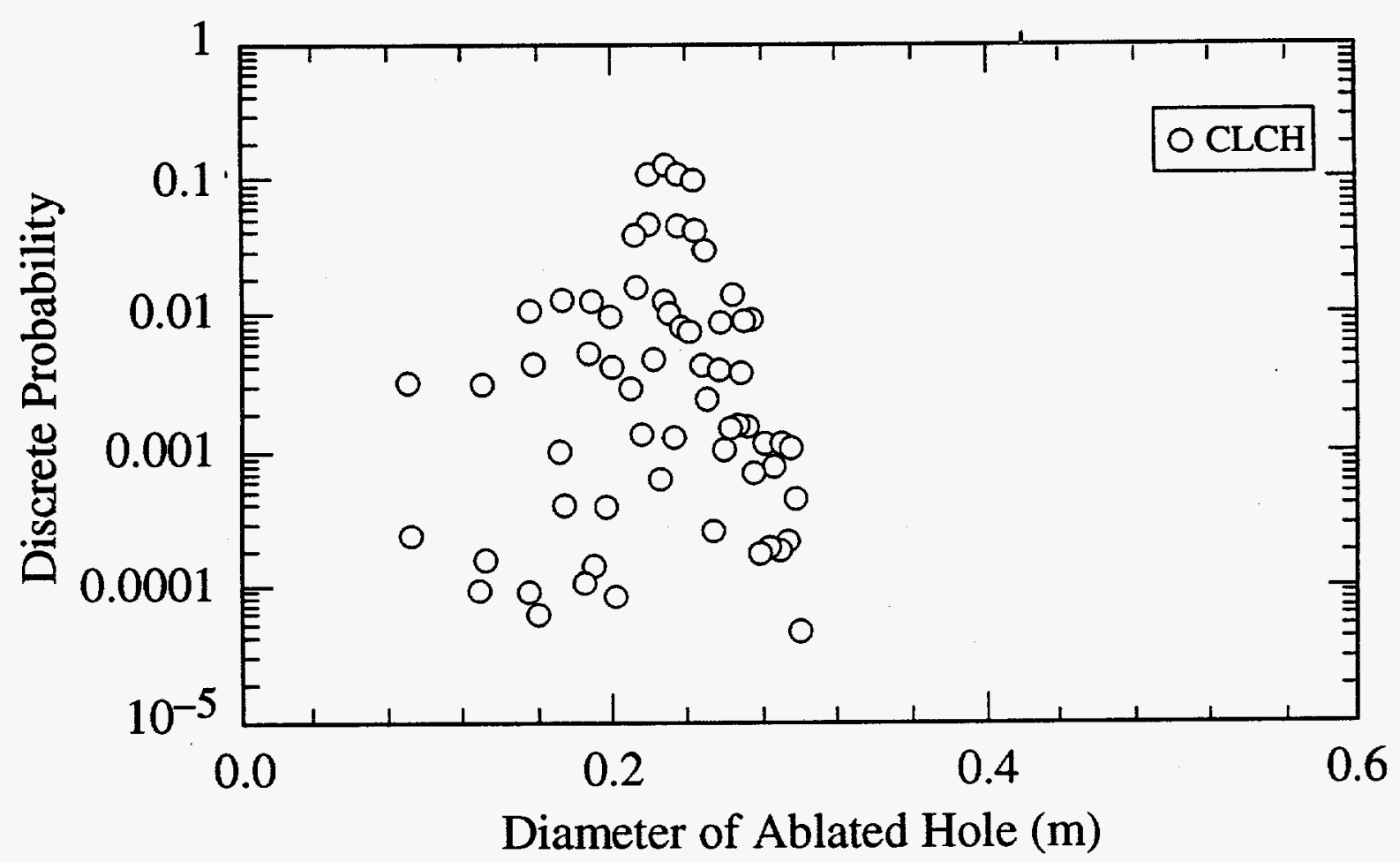

Figure 6.1. Scenario I - Calculated distribution for hole size. 

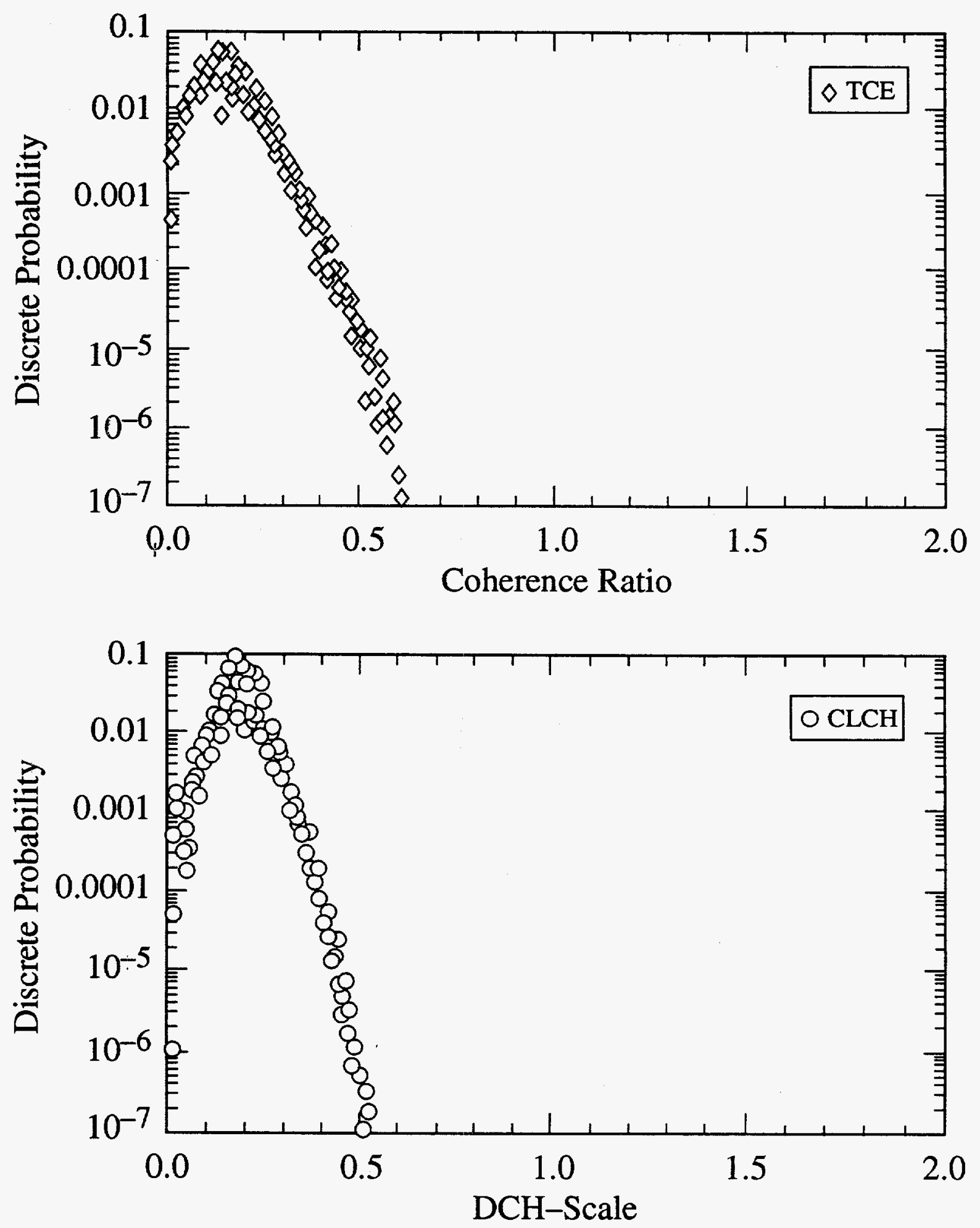

Figure 6.2. Scenario I - Calculated distribution for coherence ratio. 

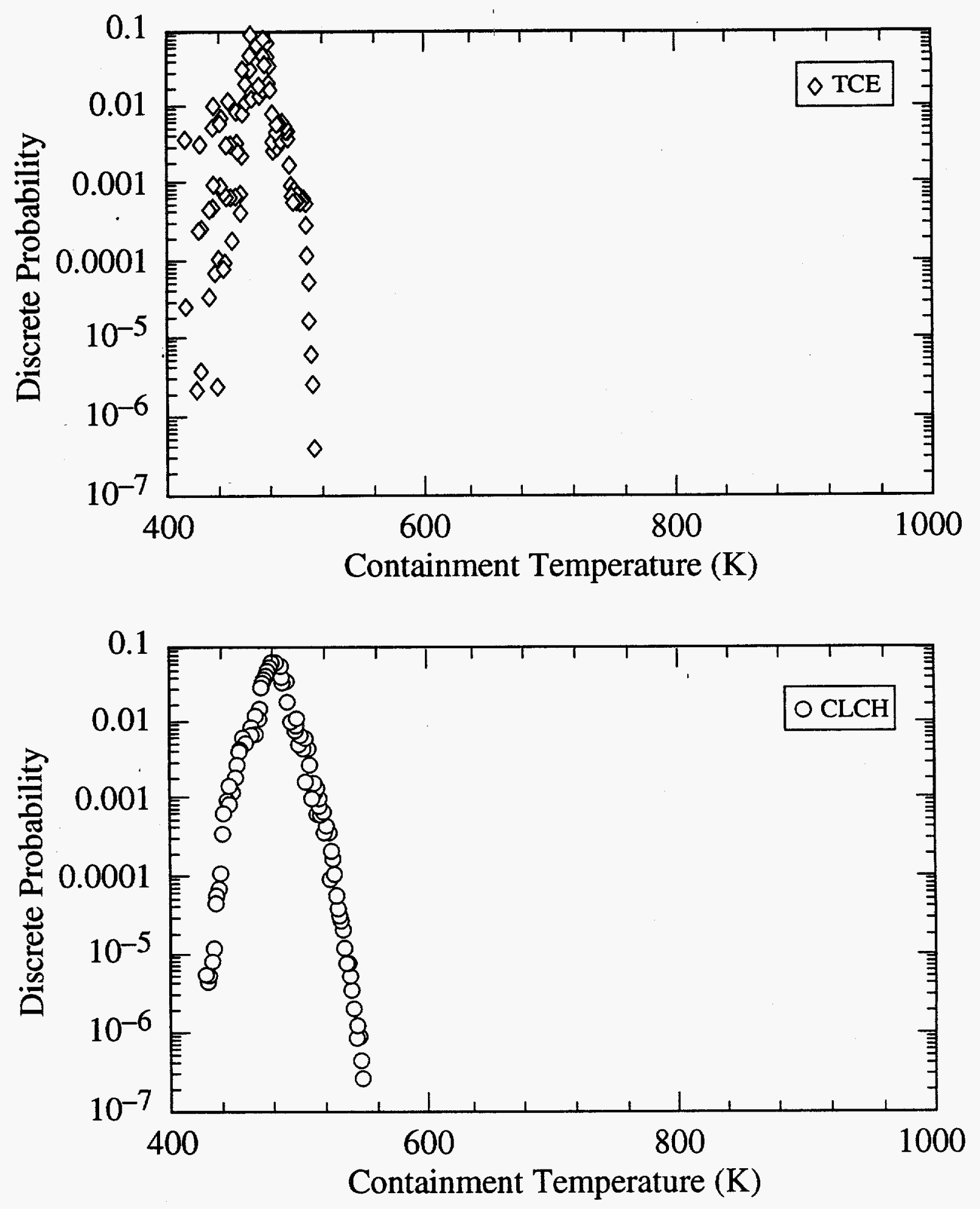

Figure 6.3. Scenario I - Calculated distribution for containment temperature. 

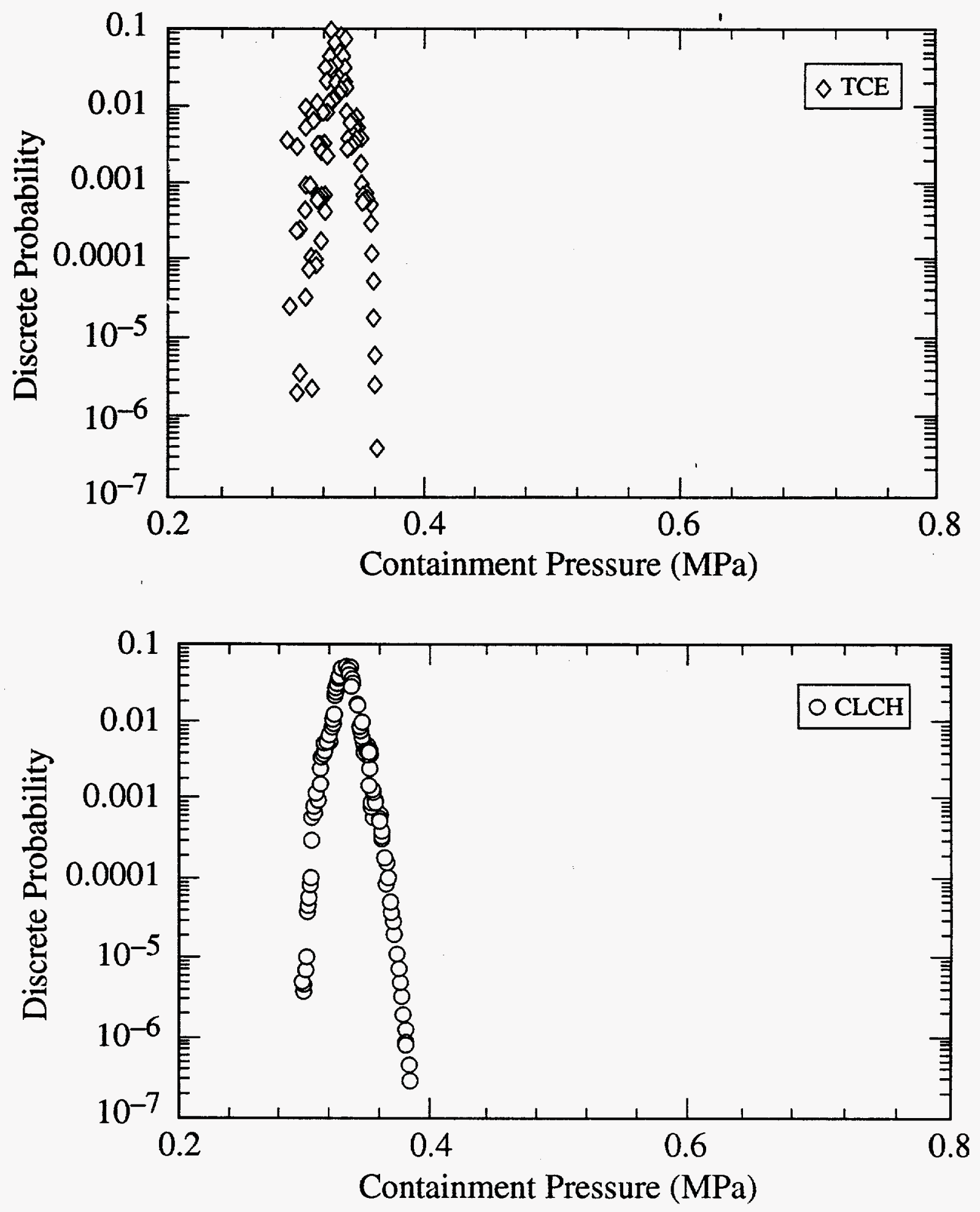

Figure 6.4. Scenario I - Calculated distribution for containment pressure. 

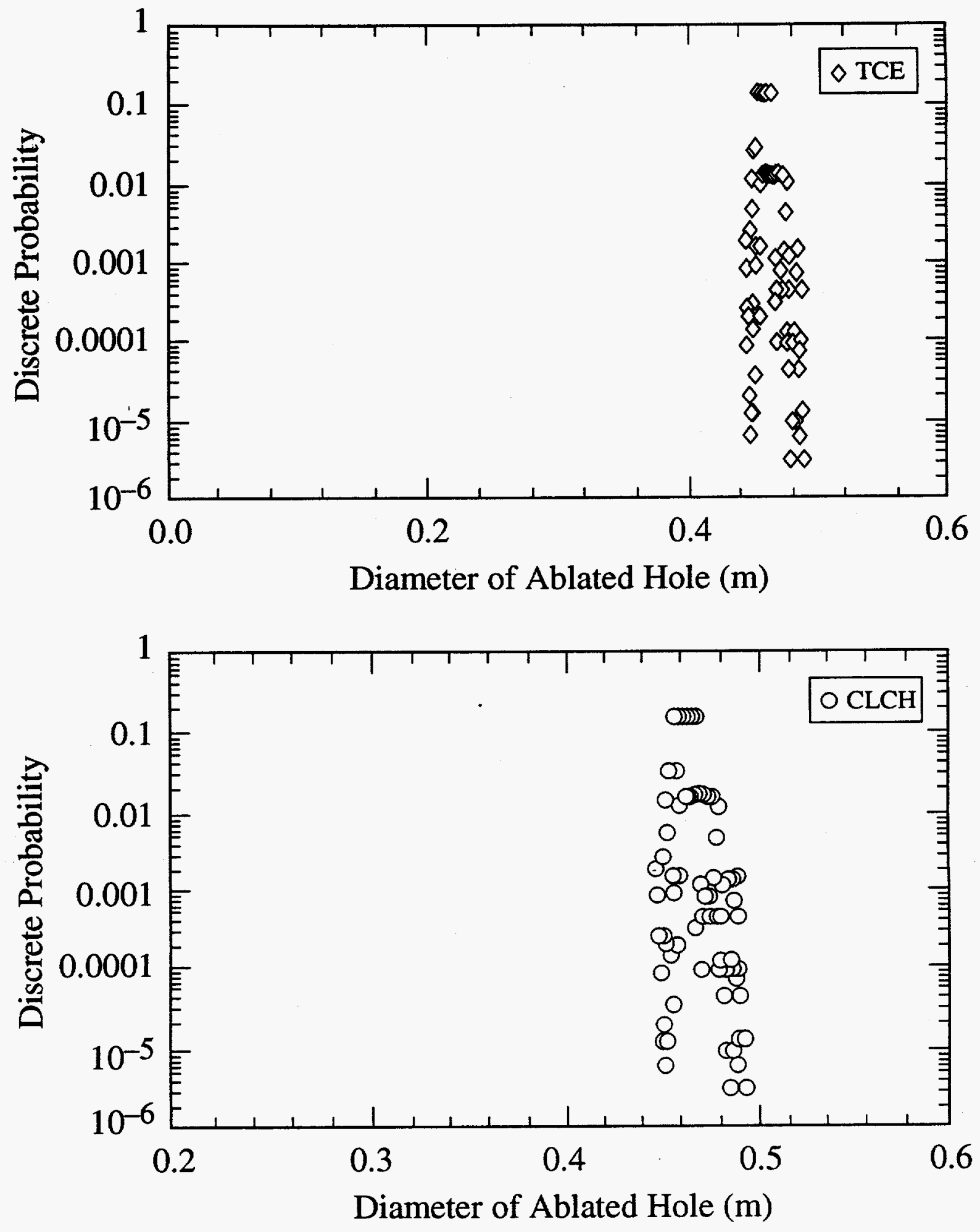

Figure 6.5. Scenario II - Calculated distribution for hole size. 

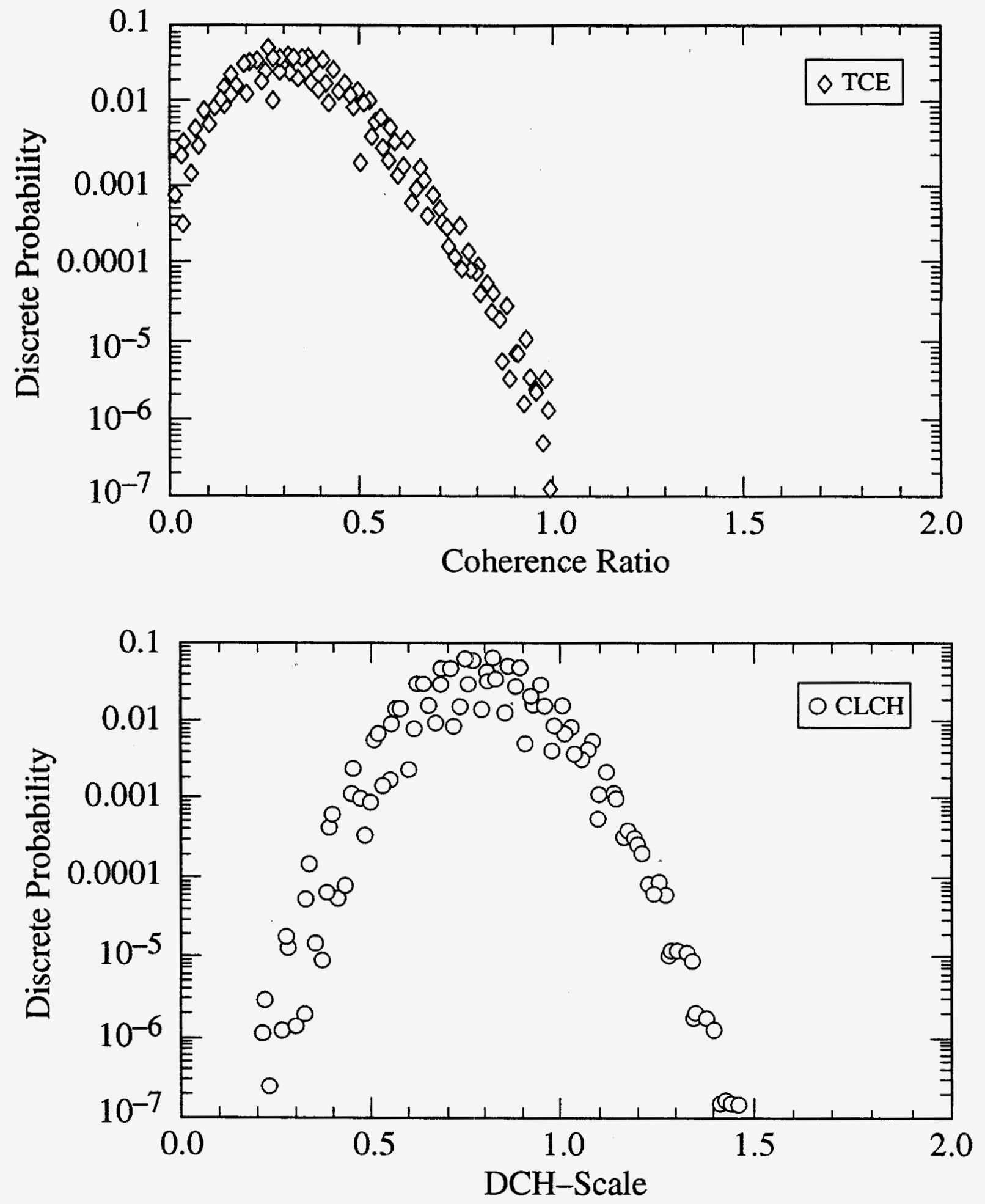

Figure 6.6. Scenario II - Calcullated distribution for coherence ratio. 

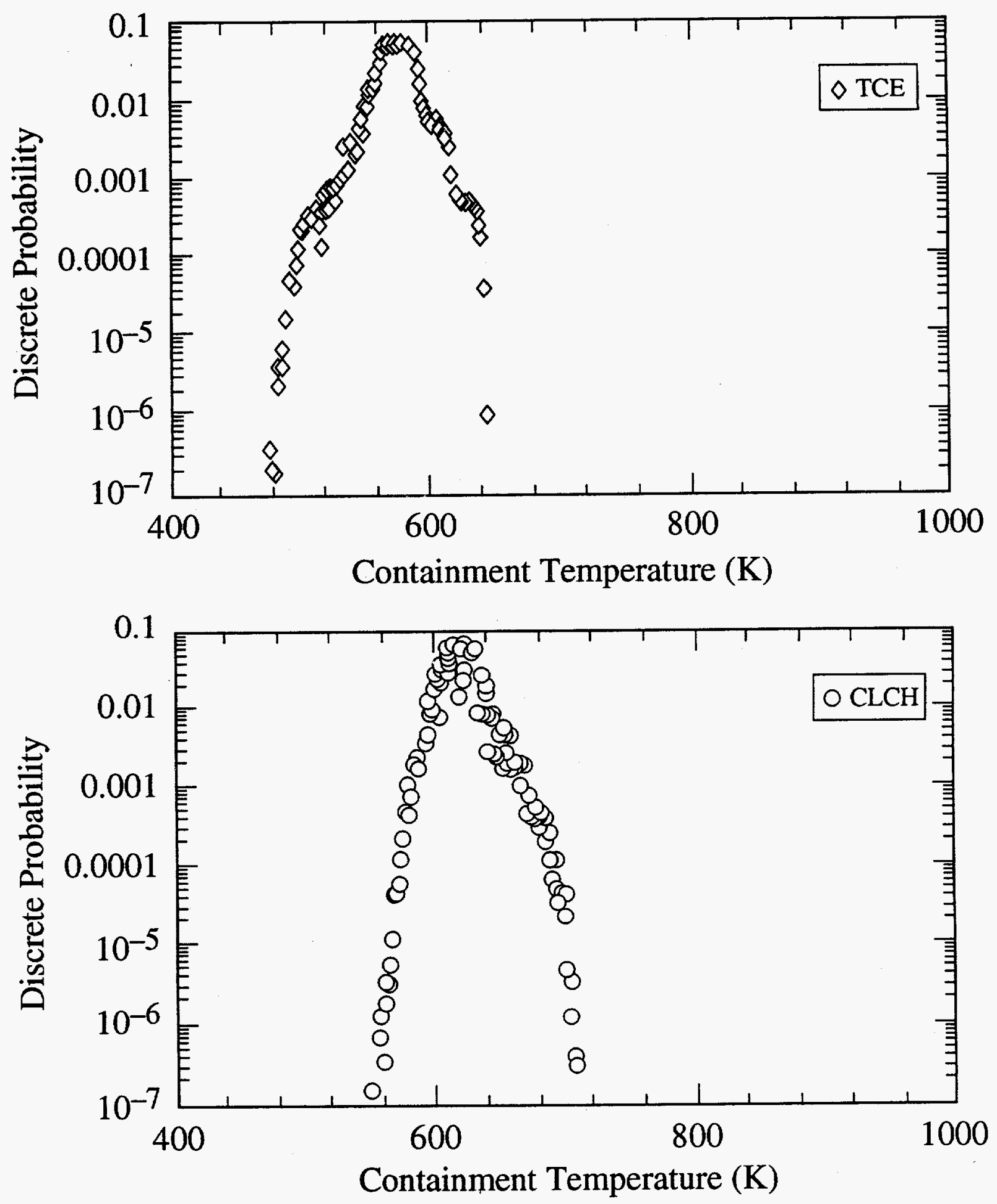

Figure 6.7. Scenario II - Calculated distribution for containment temperature. 

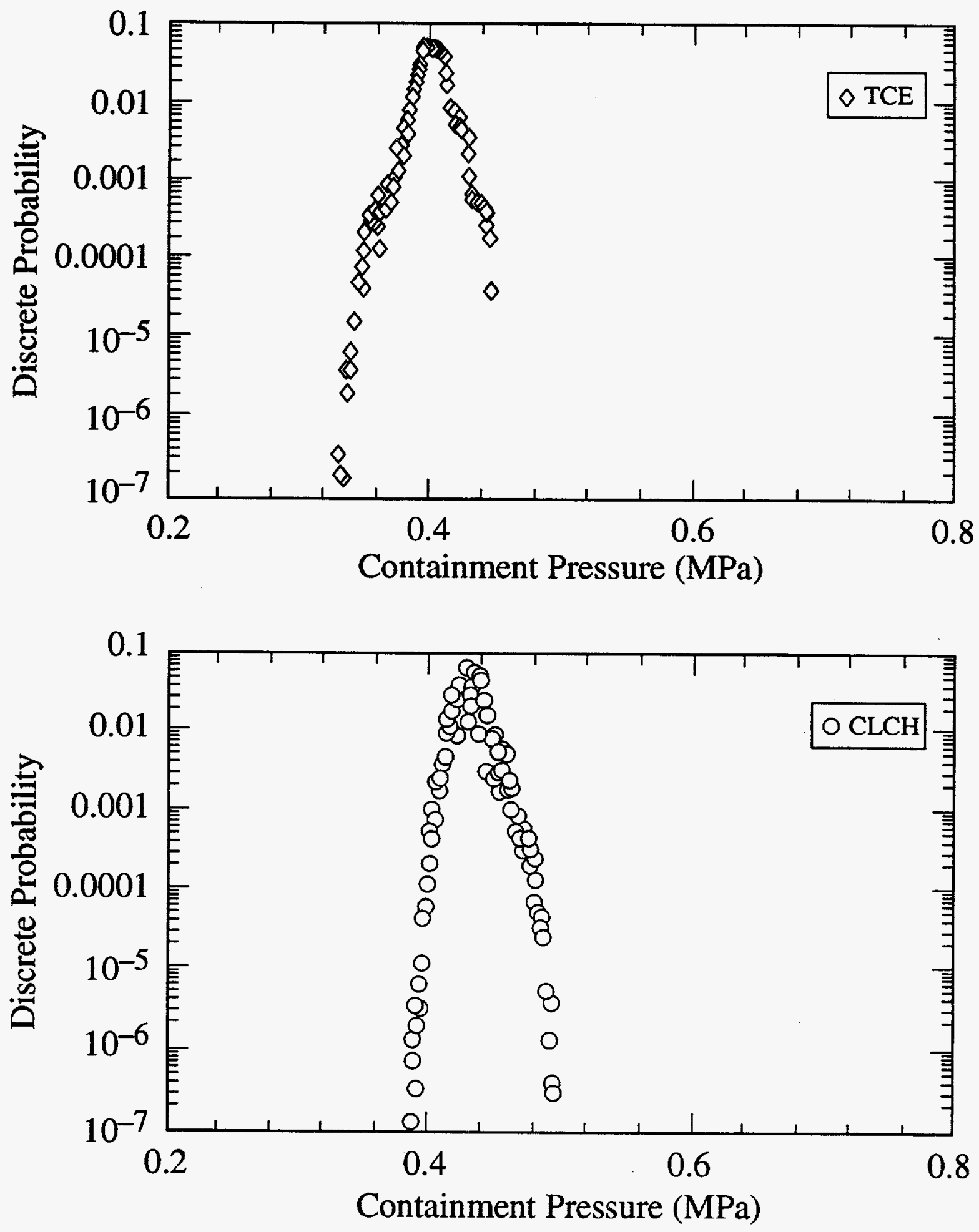

Figure 6.8. Scenario II - Calculated distribution for containment pressure. 

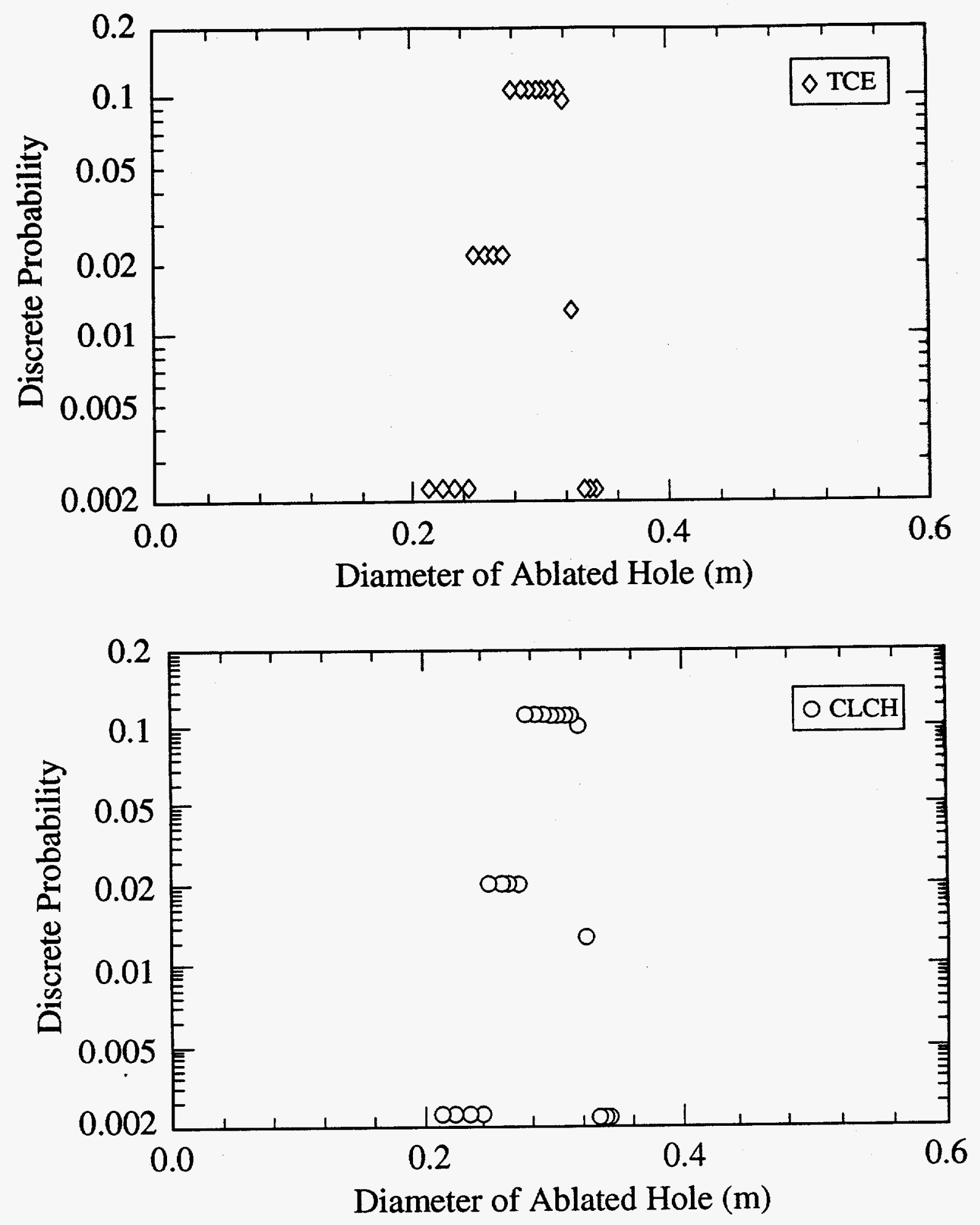

Figure 6.9. Scenario III - Calculated distribution for hole size. 

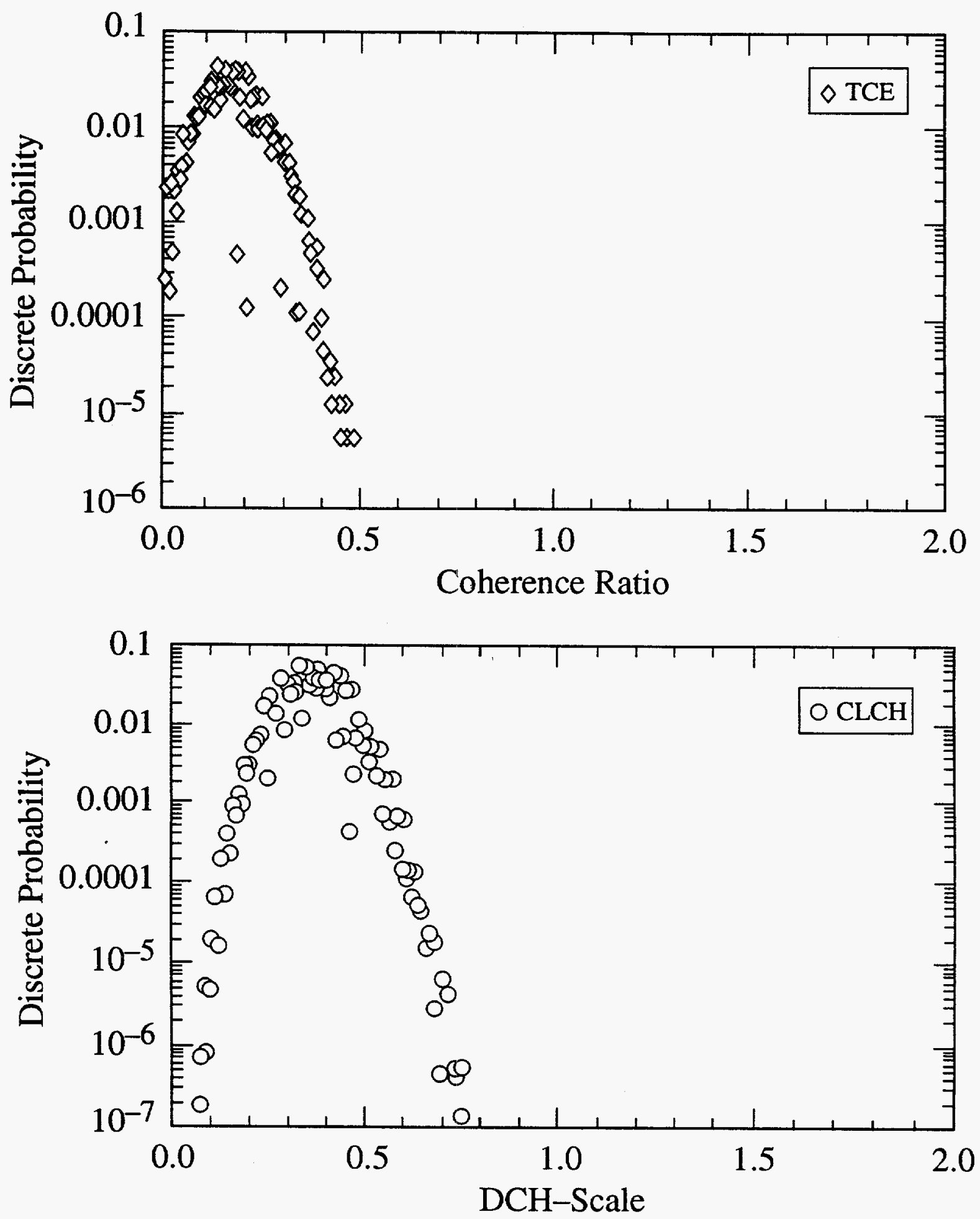

Figure 6.10. Scenario III - Calculated distribution for coherence ratio. 

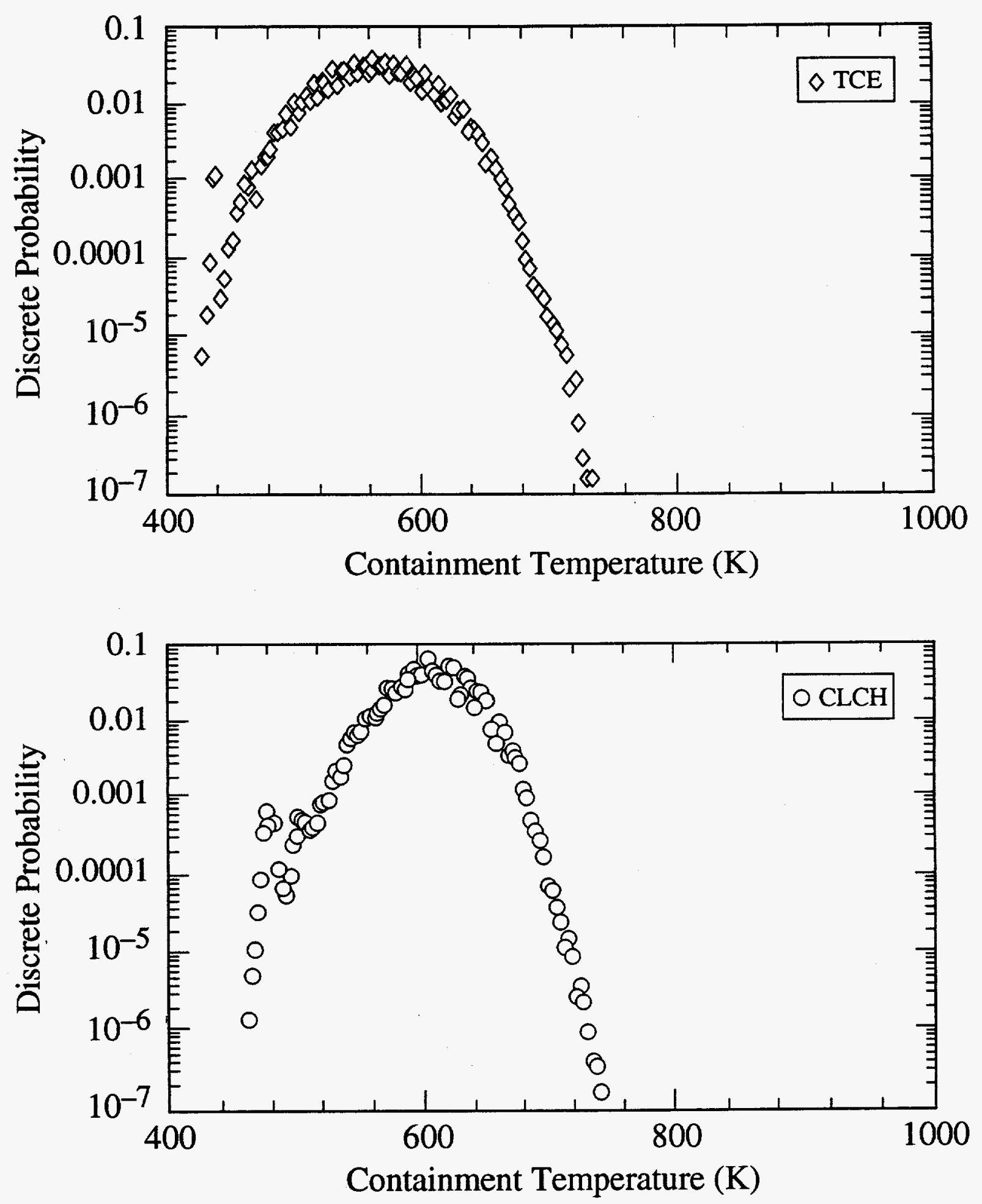

Figure 6.11. Scenario III - Calculated distribution for containment temperature. 

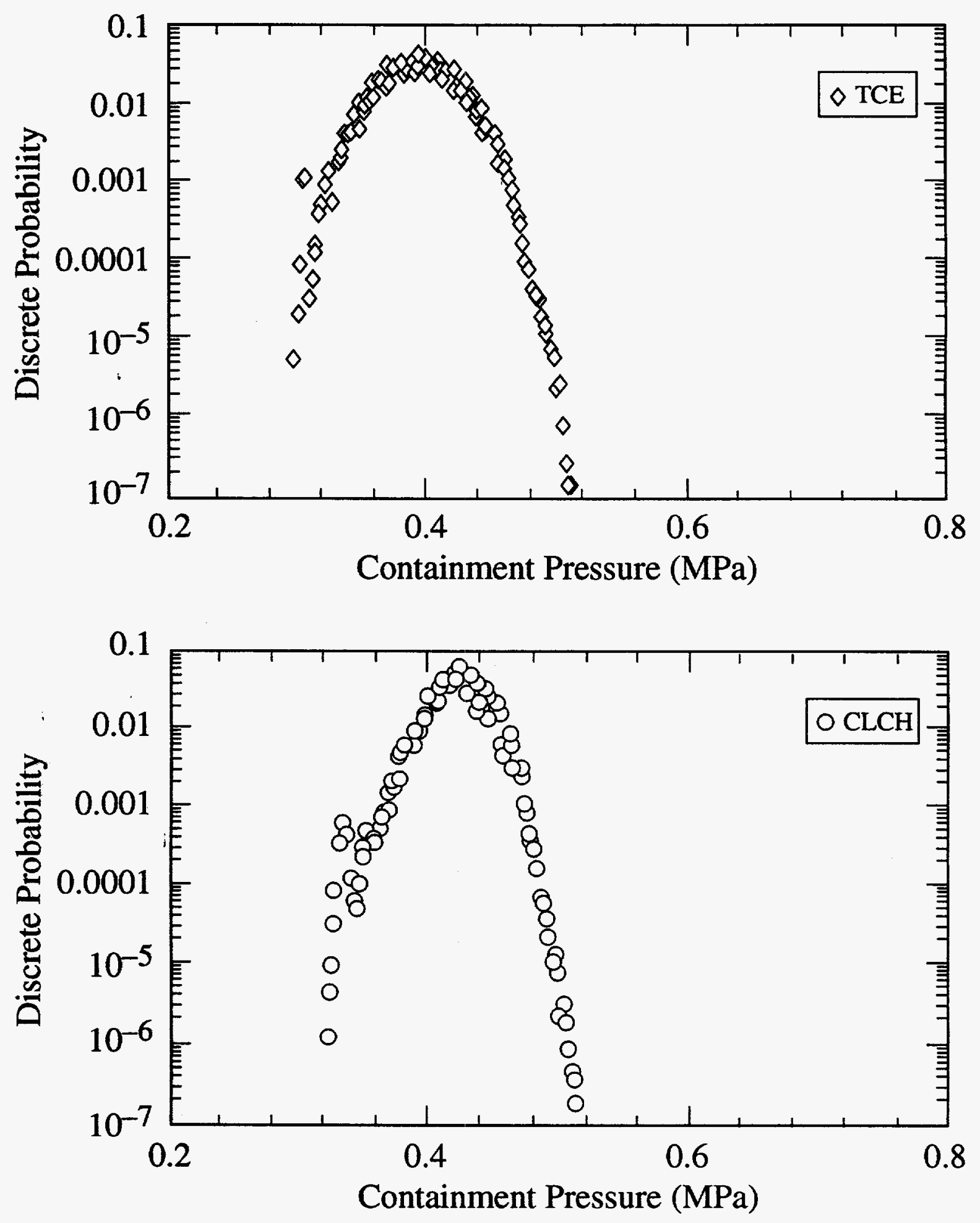

Figure 6.12. Scenario III - Calculated distribution for containment pressure. 

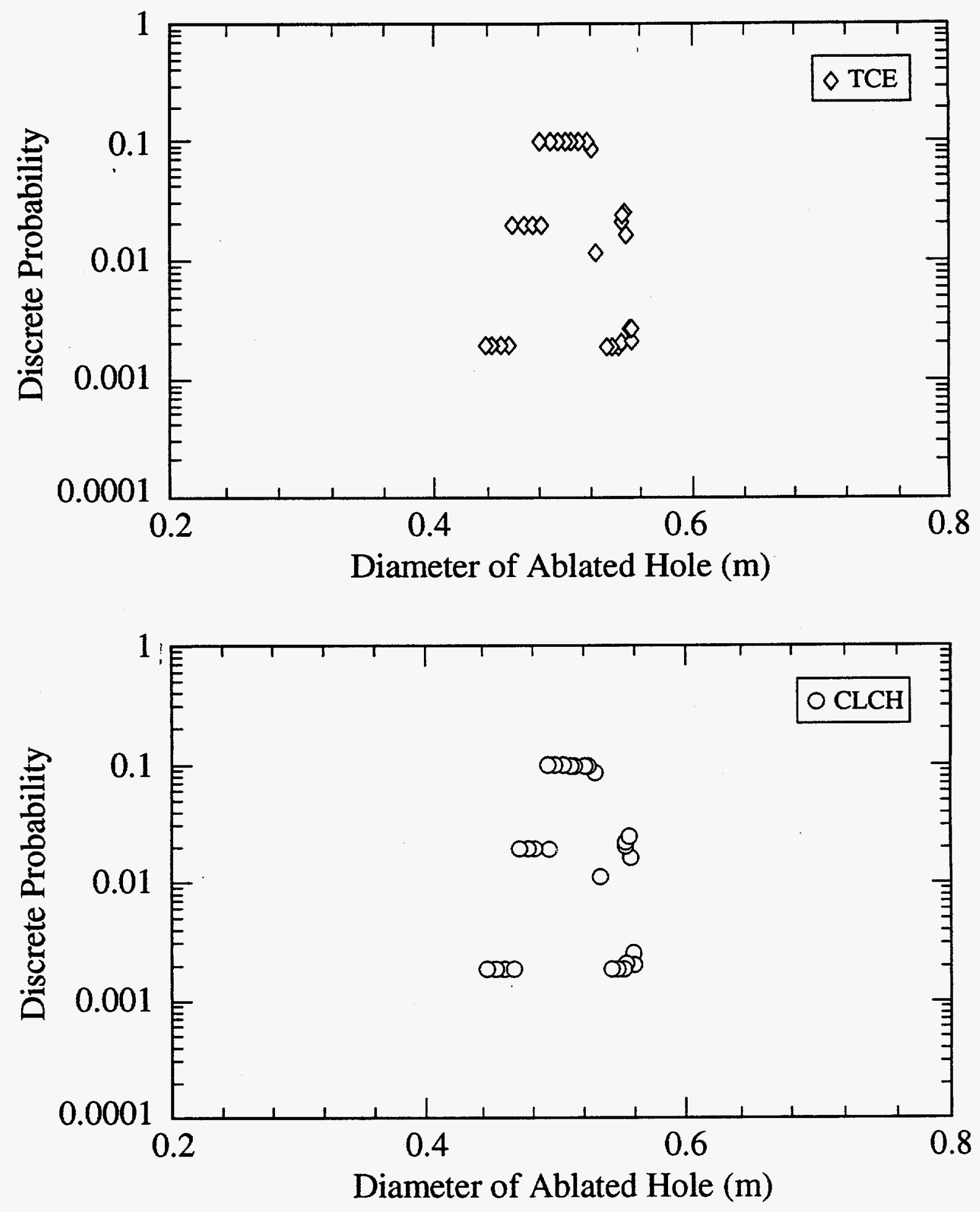

Figure 6.13. Scenario IV - Calculated distribution for hole size. 

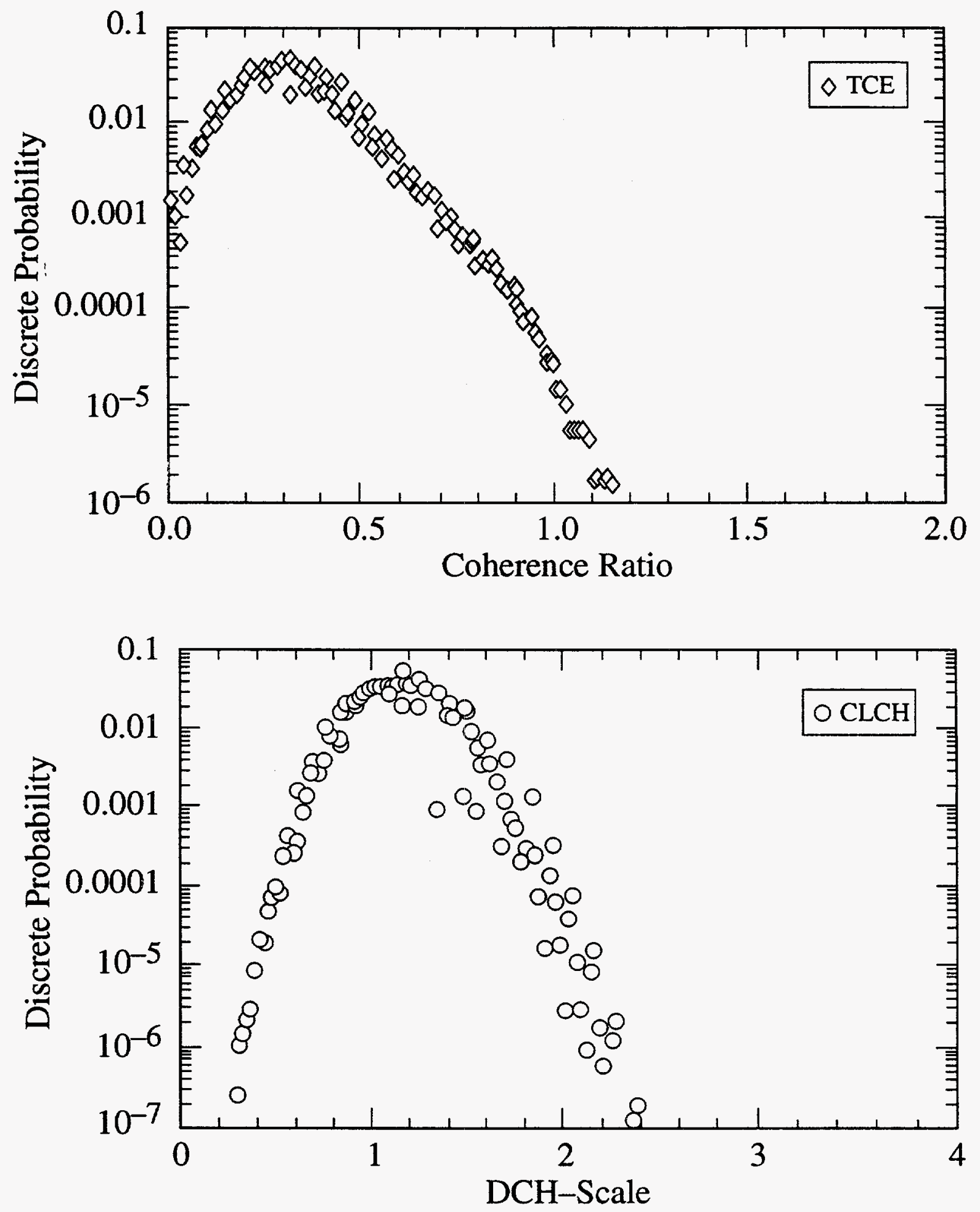

Figure 6.14. Scenario IV - Calculated distribution for coherence ratio. 

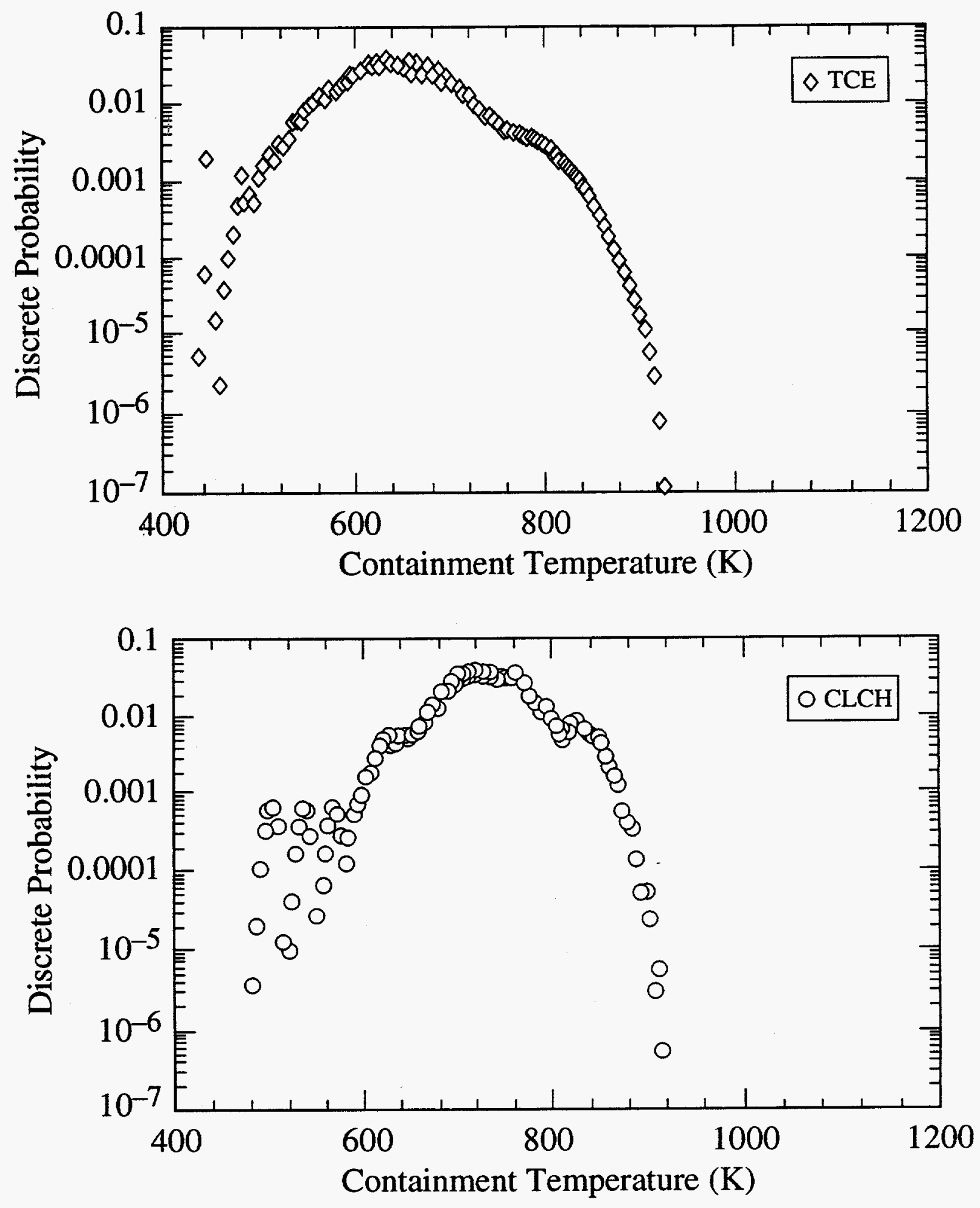

Figure 6.15. Scenario IV - Calculated distribution for containment temperature. 

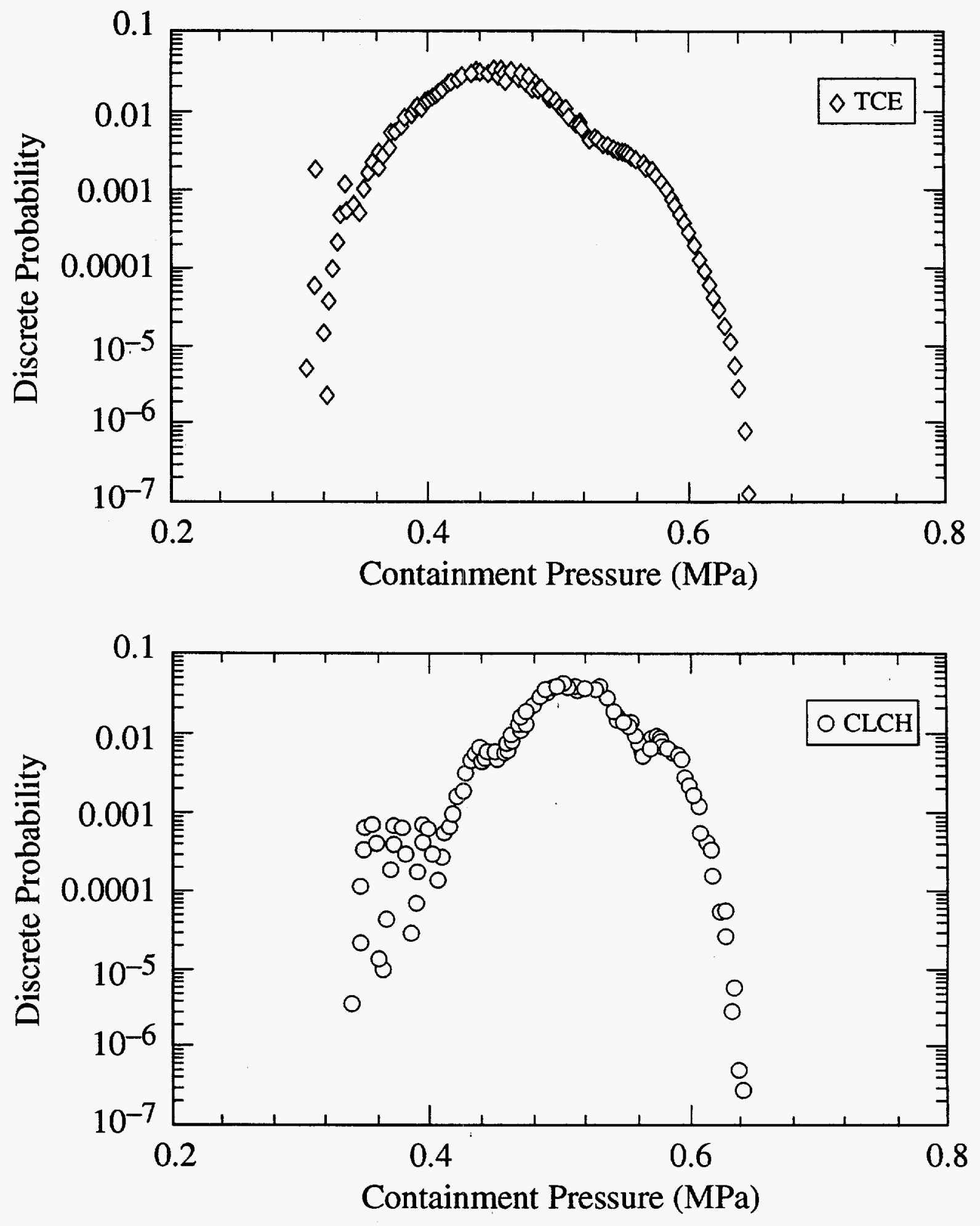

Figure 6.16. Scenario IV - Calculated distribution for containment pressure. 


\subsection{EXTRAPOLATIONS}

The containment loads predicted here are far from containment failure for Zion. We did not expect to find such significant margins when this work began. Encouraged by this result, we investigated the feasibility of extrapolating the Zion load results to other PWRs in the U.S. If the following assumptions are satisfied, we believe the Zion DCH loads can be applied directly to other plants. The assumptions in this extrapolation also constitute the areas in which some confirmatory activity would be desirable. The assumptions are listed as follows:

1. There is an intermediate compartment between the reactor cavity and the upper dome that is large compared with the cavity but small compared with the main containment volume, and there is no direct pathway for debris transport from the cavity exit to the main containment volume. Both of the analytical tools used in the Zion analysis are based on this geometry, as is most of the experimental database employed in the current assessment. CE plants (15 in number) are explicitly excluded from the extrapolation discussion because their cavities favor dispersal directly to the upper dome. Quantitatively, the primary difference in model predictions that can arise is for cavity designs that are more retentive (because they are larger) than those in the Zion and Surry plants, but we have already demonstrated (Appendices D and E) that in such cases the models will overpredict the loads.

2. The cavity is not expected to collect a significant amount of water such that energetic fuel-coolant interactions do not dominant the DCH phenomenon. The case of a waterflooded cavity was not included in the scope of this work because the various plant designs have not yet been examined in detail to find the extent to which this situation is relevant. Some preliminary experiments (Allen et al., 1993; Allen et al., 1994) indicate that for flooded cavities, containment loads are less than those with wet cavities. In fact, the observed loads appear to be dominated more by a steam spike than heating of the atmosphere. Still, it would be premature at this point to rearh definitive conclusions in this case; the issue is therefore flagged here for further attention in future work. 
3. The containment is essentially adiabatic on the time scale of the DCH event $(\sim 15 \mathrm{~s})$. Therefore, plants with pressure suppression containments (i.e., 11 ice condenser plants) are also explicitly excluded from the extrapolation.

4. Melt quantities, containment volume, and RCS volume for different sized reactors are proportional to the reactor power. This is important because the interplay between these parameters is the key to $\mathrm{DCH}$ containment loads.

Items 1 through 3 above pertain to the application of the models themselves. Item 4, however, forms the basis for extrapolating known containment loads from Zion to other reactors. In particular, we expect containment loads to be independent of physical scale or reactor power.

With item 4 above, the scaling discussion for the CLCH model (Eq. D.15) and the TCE model (Eq. E. 86) show that physical scale effects are largely reflected in $R_{\tau}$ because of potential distortions in the breach area. The ablation model (Appendix J), however, shows only a weak dependence on scale $\left(D_{b, f} \sim L^{.13}\right)$; consequently, the scale dependence of $R$, is less than the uncertainty in correlating $\mathrm{R}_{\boldsymbol{r}}$. Lastly, scale effects on hydrogen combustion (diffusion flame or autoignition) are negligible or nonexistent at reactor scale. If all the scaling groups are independent of physical size, then the containment loads are independent of reactor power. Thus, all PWRs will exhibit DCH loads similar to those predicted for Zion, subject only to the exclusions and assumptions cited in items 1 through 4 above.

The bases of item 4 are put to the test in Table 7.1 (Combustion Engineering [CE] and ice condenser plants are not listed) where it is seen that the scaling ratios (power/containment volume and power/RCS volume) are indeed similar to Zion for many plants, but there are exceptions. In particular, the ratio of reactor power to containment volume can exceed Zion's ratio by a maximum of 39 percent, with 80 percent of the entries exceeding Zion's value by less than 20 percent. The ratio of reactor power to RCS volume can exceed Zion's by a maximum of 16 percent, with 80 percent of the entries exceeding Zion's value by less than 9 percent. Perhaps significantly, we note that some reactors have proportionately more clad than Zion. The 
ratio of clad mass to reactor power exceeds Zion's ratio by a maximum of 41 percent, with 80 percent of the entries exceeding Zion's value by less than 17 percent.

Table 7.2 investigates what impact these variations might have on containment loads relative to Zion. We note that when a plant has a large variation in one ratio, it may also have a large variation in one of the other ratios. These two-way variations are not considered in Table 7.2; nonetheless, we can conclude that a large number of reactors will have containment loads similar to Zion.

The true metric of interest, of course, is the containment failure probability which represents the intersection of containment loads with containment fragility. NRC-sponsored research, however, has shown that plant specific features can dominate containment fragility for some plants. The extrapolation of containment failure probabilities then introduces a fifth item requiring confirmatory activity:

5. It remains to be determined whether there are any significant deviations from the Zion fragility for containments of a similar class. Containment capability is affected by design details and should be examined on a plant-specific basis, possibly through the IPE or ongoing research sponsored by the NRC.

Even though we show that melt expulsion with maximum primary system pressures do not lead to any significant concerns for Zion, we must recognize that plants with once-through steam generators (OTSGs) may not have the same magnitude of natural circulation. However, recent experimental work suggests that hot leg or surge line failures in plants with OTSGs occur on a time scale comparable to plants with U-tube steam generators. M. di Marzo's experiments (1993) suggest that hot leg failure occurs in $\sim 4500-5500 \mathrm{~s}$ and that surge line failure occurs in $4000-5000 \mathrm{~s}$. These times can be compared to SCDAP/RELAP calculations for Zion (Knudson 1993) and Surry (Knudson and Dobbe 1993) under similar core heatup rates and RCS pressures. The SCDAP/RELAP calculations give $-6000-6500 \mathrm{~s}$ for hot leg failure and $\sim 4600-5300 \mathrm{~s}$ for surge line failure. Comparing failure times, we conclude that there is no 
significant difference in natural circulation phenomena for OTSGs and U-tube steam generators. However, this is an area that system codes are just now exploring; consequently,

6. It remains to be verified that RCS pressures above $-8 \mathrm{MPa}$ can be excluded.

\subsection{References}

Allen, M.D., T.K. Blanchat, M. Pilch, and R.T. Nichols (1993). Experiments to Investigate the Effects of Fuel/Coolant Interactions on Direct Containment Heating - The IET-8A and IET-8B Experiments, SAND92-2849, Sandia National Laboratories, Albuquerque, NM.

Allen, M.D. et al. (May 1994). Experiments to Investigate Direct Containment Heating Phenomena With Scaled Models of the Zion Nuclear Power Plant in the Surtsey Test Facility, NUREG/CR-6044, SAND93-1049, Sandia National Laboratories, Albuquerque, NM.

Brownson, D.A. (October 1991). Extension of Surry Late Depressurization Strategy Results to Commercially Operating Pressurized Water Reactors, EG\&G-EAST-9717, EG\&G Idaho, Inc., Idaho Falls, ID.

Knudson, D.L. (April 1993). Transmittal of SCDAP/RELAP5/MOD3 Results for the Zion Power Station, Letter Report to NRC.

Knudson, D.L. and C.A. Dobbe (November 1993). Assessment of the Potential for High Pressure Melt Ejection Resulting from a Surry Station Blackout Transient, NUREG/CR-5949, EGG-2689, EG\&G Idaho, Inc., Idaho Falls, ID. 


\begin{tabular}{|c|c|c|c|c|c|c|c|c|c|c|c|}
\hline \multirow[b]{2}{*}{ Plant } & \multirow[b]{2}{*}{$\begin{array}{l}\text { Power } \\
\text { (MWt) }\end{array}$} & \multirow[b]{2}{*}{$\begin{array}{l}\text { Free vol } \\
\left(1000 \mathrm{~m}^{3}\right.\end{array}$} & \multirow[b]{2}{*}{$\begin{array}{l}\text { Design } \\
\text { Pressure } \\
\text { (MPa) }\end{array}$} & \multirow[b]{2}{*}{$\begin{array}{l}\text { RCS } \\
\text { Volume } \\
\left(100 \mathrm{~m}^{3}\right)\end{array}$} & \multirow[b]{2}{*}{$\begin{array}{l}\text { Clad } \\
\text { Mass } \\
\text { (mt) }\end{array}$} & \multirow[b]{2}{*}{$\begin{array}{c}\text { Power } \\
\text { /Cont } \\
\text { Volume }\end{array}$} & \multirow[b]{2}{*}{$\begin{array}{c}\text { Power } \\
\text { /RCS } \\
\text { Volume }\end{array}$} & \multirow[b]{2}{*}{$\begin{array}{c}\mathrm{clad} / \mathrm{Pwr} \\
(\mathrm{kg} / \mathrm{MW})\end{array}$} & \multicolumn{3}{|c|}{ Ratios Relative to Zion } \\
\hline & & & & & & & & & $\begin{array}{c}\text { Power/ } \\
\text { Cont } \\
\text { Volume }\end{array}$ & $\begin{array}{l}\text { Power/ } \\
\text { RCS Vol }\end{array}$ & $\begin{array}{r}\text { clad } \\
\text { /Power }\end{array}$ \\
\hline \multicolumn{12}{|c|}{ PWR atmospheric containment: deformed bar, reinforced concrete cylinder, hemispherical dome, flat base, steel liner } \\
\hline Haddam Neck & 1825 & 48.4 & 0.377 & 2.49 & 13.8 & 38 & 734 & 7.54 & 0.94 & 0.81 & 1.35 \\
\hline Indian Point 2 & 2758 & 73.9 & 0.425 & 3.42 & 18.1 & 37 & 807 & 6.57 & 0.93 & 0.89 & 1.18 \\
\hline Indian Point 3 & 3025 & 73.9 & 0.425 & 3.42 & 18.1 & 41 & 885 & 5.99 & 1.02 & 0.98 & 1.07 \\
\hline Salem 1 & 3411 & 74.2 & 0.425 & 3.57 & 19.2 & 46 & 955 & 5.62 & 1.15 & 1.06 & 1.01 \\
\hline Salem 2 & 3411 & 74.2 & 0.425 & 3.57 & 19.2 & 46 & 955 & 5.62 & 1.15 & 1.06 & 1.01 \\
\hline Comanche Peak 1\&2 & 3411 & 84.4 & 0.446 & 3.54 & 19.2 & 40 & 964 & 5.62 & 1.01 & 1.07 & 1.01 \\
\hline Diablo Canyon 1 & 3338 & 74.5 & 0.425 & 3.62 & 19.2 & 45 & 921 & 5.75 & 1.12 & 1.02 & 1.03 \\
\hline Diablo Canyon 2 & 3411 & 74.5 & 0.425 & 3.65 & 19.2 & 46 & 934 & 5.62 & 1.14 & 1.03 & 1.01 \\
\hline Shearon Harris & 2775 & 64.3 & 0.412 & 2.65 & 15.6 & 43 & 1045 & 5.63 & 1.08 & 1.16 & 1.01 \\
\hline Seabrook & 3411 & 76.5 & .460 & 3.47 & 19.2 & 45 & 982 & 5.62 & 1.11 & 1.09 & 1.01 \\
\hline \multicolumn{12}{|c|}{ PWR atmospheric containment st } \\
\hline Davis-Besse & 2772 & 80.1 & 0.350 & 3.37 & 16.8 & 35 & 821 & 6.06 & 0.86 & 0.91 & 1.09 \\
\hline Kewaunee & 1650 & 37.4 & 0.418 & 1.75 & 10.0 & 44 & 941 & 6.04 & 1.10 & 1.04 & 1.08 \\
\hline Prairie Island $1 \& 2$ & 1650 & 37.4 & 0.418 & 1.75 & 10.0 & 44 & 941 & 6.04 & 1.10 & 1.04 & 1.08 \\
\hline \multicolumn{12}{|c|}{$\begin{array}{l}\text { PWR atmospheric containment: concrete vertical cylinder with prestressed vertical reinforcements and deformed bar hoop reinforcement. Deformed } \\
\text { bar, reinforced concrete hemispherical dome and flat base. Complete steel lined structure. }\end{array}$} \\
\hline Ginna & 1520 & 27.5 & 0.515 & 1.72 & 10.0 & 55 & 885 & 6.55 & 1.38 & 0.98 & 1.18 \\
\hline
\end{tabular}




\begin{tabular}{|c|c|c|c|c|c|c|c|c|c|c|c|}
\hline \multirow[b]{2}{*}{ Plant } & \multirow[b]{2}{*}{$\begin{array}{l}\text { Power } \\
\text { (MWt) }\end{array}$} & \multirow[b]{2}{*}{$\begin{array}{l}\text { Free vol } \\
\left(1000 \mathrm{~m}^{3}\right.\end{array}$} & \multirow[b]{2}{*}{$\begin{array}{l}\text { Design } \\
\text { Pressure } \\
(\mathrm{MPa})\end{array}$} & \multirow[b]{2}{*}{$\begin{array}{l}\text { RCS } \\
\text { Volume } \\
\left(100 \mathrm{~m}^{3}\right)\end{array}$} & \multirow[b]{2}{*}{$\begin{array}{l}\text { Clad } \\
\text { Mass } \\
\text { (mt) }\end{array}$} & \multirow{2}{*}{$\begin{array}{c}\text { Power } \\
\text { /Cont } \\
\text { Volume }\end{array}$} & \multirow[b]{2}{*}{$\begin{array}{c}\text { Power } \\
\text { /RCS } \\
\text { Volume }\end{array}$} & \multirow[b]{2}{*}{$\begin{array}{l}\mathrm{clad} / \mathrm{PWr} \\
(\mathrm{kg} / \mathrm{MW})\end{array}$} & \multicolumn{3}{|c|}{ Ratios Relative to Zion } \\
\hline & & & & & & & & & $\begin{array}{l}\text { Power/ } \\
\text { Cont } \\
\text { Volume }\end{array}$ & $\begin{array}{c}\text { Power/ } \\
\text { RCS Vol }\end{array}$ & $\begin{array}{r}\text { clad } \\
\text { /Power }\end{array}$ \\
\hline Robinson 2 & 2300 & 59.5 & 0.391 & 2.65 & 18.0 & 39 & 869 & 7.84 & 0.96 & 0.96 & 1.41 \\
\hline \multicolumn{12}{|c|}{ PWR atmospheric containment:prestressed } \\
\hline Callaway & 3411 & 70.8 & 0.515 & 3.44 & 19.2 & 48 & 993 & 5.62 & 1.20 & 1.10 & 1.01 \\
\hline South Texas 1,2 & 3800 & 100.8 & 0.491 & 3.98 & 22.4 & 38 & 956 & 5.90 & 0.94 & 1.06 & 1.06 \\
\hline Summer & 2775 & 52.1 & 0.494 & 2.66 & 15.6 & 53 & 1041 & 5.63 & 1.33 & 1.15 & 1.01 \\
\hline Vogtle 1,2 & 3411 & 77.9 & 0.460 & 3.53 & 19.2 & 44 & 967 & 5.62 & 1.09 & 1.07 & 1.01 \\
\hline Wolf Creek & 3411 & 70.8 & 0.515 & 3.44 & 19.2 & 48 & 993 & 5.62 & 1.20 & 1.10 & 1.01 \\
\hline ANO 1 & 2568 & 59.2 & 0.515 & 3.26 & 16.8 & 43 & 789 & 6.54 & 1.08 & 0.87 & 1.17 \\
\hline Farley 1,2 & 2652 & 56.6 & 0.474 & 2.75 & 15.6 & 47 & 963 & 5.90 & 1.17 & 1.07 & 1.06 \\
\hline Braidwood 1,2 & 3411 & 77.9 & 0.446 & 3.47 & 19.2 & 44 & 983 & 5.62 & 1.09 & 1.09 & 1.01 \\
\hline Byron 1,2 & 3411 & 77.9 & 0.446 & 3.47 & 19.2 & 44 & 983 & 5.62 & 1.09 & 1.09 & 1.01 \\
\hline Crystal River 3 & 2544 & 56.6 & 0.481 & 2.85 & 16.8 & 45 & 893 & 6.60 & 1.12 & 0.99 & 1.18 \\
\hline Oconee 1 & 2568 & 54.1 & 0.508 & 3.38 & 16.8 & 47 & 760 & 6.54 & 1.18 & 0.84 & 1.17 \\
\hline Oconee 2,3 & 2568 & 54.1 & 0.508 & 3.42 & 16.8 & 47 & 750 & 6.54 & 1.18 & 0.83 & 1.17 \\
\hline Point Beach 1,2 & 1519 & 28.3 & 0.515 & 1.71 & 10.0 & 54 & 888 & 6.56 & 1.34 & 0.98 & 1.18 \\
\hline TMI 1 & 2535 & 56.6 & 0.481 & 3.39 & 16.8 & 45 & 748 & 6.62 & 1.12 & 0.83 & 1.19 \\
\hline Turkey Point 3,4 & 2200 & 43.9 & 0.508 & 2.65 & 14.7 & 50 & 832 & 6.70 & 1.25 & 0.92 & 1.20 \\
\hline Zion 1,2 & 3250 & 81.0 & 0.425 & 3.60 & 18.1 & 40 & 903 & 5.57 & 1.00 & 1.00 & 1.00 \\
\hline
\end{tabular}




\begin{tabular}{|c|c|c|c|c|c|c|c|c|c|c|c|}
\hline \multirow[b]{2}{*}{ Plant } & \multirow[b]{2}{*}{$\begin{array}{l}\text { Power } \\
\text { (MWt) }\end{array}$} & \multirow[b]{2}{*}{$\begin{array}{l}\text { Free vol } \\
\left(1000 \mathrm{~m}^{3}\right.\end{array}$} & \multirow[b]{2}{*}{$\begin{array}{l}\text { Design } \\
\text { Pressure } \\
\text { (MPa) }\end{array}$} & \multirow[b]{2}{*}{$\begin{array}{l}\text { RCS } \\
\text { Volume } \\
\left(100 \mathrm{~m}^{3}\right)\end{array}$} & \multirow[b]{2}{*}{$\begin{array}{l}\text { Clad } \\
\text { Mass } \\
\text { (mt) }\end{array}$} & \multirow[b]{2}{*}{$\begin{array}{c}\text { Power } \\
\text { /Cont } \\
\text { Volume }\end{array}$} & \multirow[b]{2}{*}{$\begin{array}{c}\text { Power } \\
\text { /RCS } \\
\text { Volume }\end{array}$} & \multirow{2}{*}{$\begin{array}{l}\text { clad/Pwr } \\
(\mathrm{kg} / \mathrm{MW})\end{array}$} & \multicolumn{3}{|c|}{ Ratios Relative to Zion } \\
\hline & & & & & & & & & $\begin{array}{r}\text { Powerl } \\
\text { Cont } \\
\text { Volume }\end{array}$ & $\begin{array}{c}\text { Powerl } \\
\text { RCS Vol }\end{array}$ & $\begin{array}{r}\text { clad } \\
/ \text { Power }\end{array}$ \\
\hline Beaver Valley 1 & 2652 & 51.0 & 0.412 & 2.75 & 15.6 & 52 & 964 & 5.88 & 1.30 & 1.07 & 1.06 \\
\hline Beaver Valley 2 & 2652 & 51.0 & 0.412 & 2.65 & 15.6 & 52 & 999 & 5.88 & 1.30 & 1.11 & 1.06 \\
\hline Millstone 3 & 3411 & 65.1 & 0.412 & 3.47 & 19.2 & 52 & 984 & 5.62 & 1.31 & 1.09 & 1.01 \\
\hline North Anna 1,2 & 2893 & 51.8 & 0.412 & 2.82 & 15.6 & 56 & 1026 & 5.40 & 1.39 & 1.14 & 0.97 \\
\hline Surry 1,2 & 2441 & 51.0 & 0.412 & 2.68 & 14.7 & 48 & 911 & 6.03 & 1.19 & 1.01 & 1.08 \\
\hline
\end{tabular}


Table 7.2. Plant specific sensitivities using the TCE model, containment loads (MPa) at a cumulative probability of 95 percent

\begin{tabular}{|c|c|c|c|c||}
\hline & \multicolumn{4}{|c||}{ Scenario } \\
\cline { 2 - 5 } & I & II & III & IV \\
\hline \hline Base Quantification & $0.34 \mathrm{TCE}$ & $0.42 \mathrm{TCE}$ & $0.44 \mathrm{TCE}$ & $0.53 \mathrm{TCE}$ \\
& $0.35 \mathrm{CLCH}$ & $0.45 \mathrm{CLCH}$ & $0.45 \mathrm{CLCH}$ & $0.57 \mathrm{CLCH}$ \\
\hline$\frac{\text { Power }}{\text { Cont. Vol. }}=1.38$ & $0.36 \mathrm{TCE}$ & $0.47 \mathrm{TCE}$ & $0.51 \mathrm{TCE}$ & $0.64 \mathrm{TCE}$ \\
& $0.38 \mathrm{CLCH}$ & $0.52 \mathrm{CLCH}$ & $0.53 \mathrm{CLCH}$ & $0.69 \mathrm{CLCH}$ \\
\hline$\frac{\text { Power }}{\text { RCS Vol. }}=0.81$ & $0.35 \mathrm{TCE}$ & $0.43 \mathrm{TCE}$ & $0.45 \mathrm{TCE}$ & $0.54 \mathrm{TCE}$ \\
& $0.35 \mathrm{CLCH}$ & $0.46 \mathrm{CLCH}$ & $0.46 \mathrm{CLCH}$ & $0.59 \mathrm{CLCH}$ \\
\hline Clad & & & & \\
\hline Power & & & & \\
& & & & \\
& $0.34 \mathrm{TCE}$ & $0.44 \mathrm{TCE}$ & $0.45 \mathrm{TCE}$ & $0.55 \mathrm{TCE}$ \\
\hline
\end{tabular}




\subsection{CONCLUSIONS AND RECOMMENDATIONS}

DCH has been a prominent severe accident issue because of its potential for early containment failure. NRC-sponsored research has culminated in two elements to DCH issue resolution. The first element to $\mathrm{DCH}$ resolution focuses on possible overpressurization of the containment from DCH processes. This report addresses DCH for Zion from this perspective. The second element to $\mathrm{DCH}$ resolution focuses on both intentional and unintentional depressurization of the primary system prior to bottom head failure. The NRC has sponsored an integrated effort that will address both elements to DCH resolution.

ROAAM is applied to quantify the likelihood of containment failure resulting from DCH in the Zion NPP. We conclude that the CFP at Zion is so low as to be considered physically unreasonable (i.e., CFP $<10^{-3}$ ). Sensitivity studies did not find any areas of large sensitivity. The key criteria for applicability of these analyses are: 1) there is an intermediate compartment that is large compared to the reactor cavity but small compared to the main containment volume, and 2) there is no significant line-of-sight pathway for debris transport from the cavity to the main containment volume. The key technical features of this evaluation follow.

Core-melt progression, melt relocation to the lower plenum, and lower head failure define the initial conditions for DCH. Uncertainties in these processes are treated by considering splinter scenarios that envelope the expected phenomenologies. Four such scenarios are identified based on two accident classes (SBLOCA-like and TMLB'-like) and two failure modes (penetration failures and ruptures). The two accident classes are characterized by crucible formation and failure (SBLOCA-like) and gradual relocation (TMLB'-like). Within this enveloping approach, distributions for melt mass, zirconium content, zirconium oxidation, and steel content are estimated for each of the four splinter scenarios. The initial failure size for penetration and rupture type failures are characterized with a new model that places a physical limit to the maximum rupture size. The final hole size in the lower head is based on the failure mode and melt mass coupled with a model for hole ablation. 
Two independently developed and fundamentally based models that calculate the containment loads, the TCE model and the CLCH model, are shown to quantitatively capture the essence of the multiple interactions involved in DCH. Each model is compared against the extensive database of experiments conducted with both the prototypic and simulant materials, at different physical scales, and in prototypic plant geometries. The key model parameter for both the TCE and CLCH models is the coherence ratio, which is defined as the ratio of melt dispersal time to the system depressurization time. Scaling laws for the coherence ratio are proposed and verified by comparison to a broad and prototypic database, including two cavity geometries (Zion and Surry), two scales (1/10 and 1/40), system pressures in the 2.6 to 7.1 MPa range, and breach diameters in the 0.35 to $0.66 \mathrm{~m}$ (scaled to reactor size) range. Insights found in recent large-scale prototypic experiments indicate that large-scale volumetric combustion of preexisting hydrogen (autoignition) cannot occur on the time scale of peak DCH loads. The two containment loads models, coupled with distributions for the key initial conditions and a distribution for the coherence ratio, are used to compute a distribution of containment pressures for each scenario.

The pressure capacity (fragility) of the Zion containment is specified in probabilistic terms. A fragility curve from the Zion IPE is used in the current quantifications. NRCsponsored research to integrate current understanding of containment failure mechanisms within their own probabilistic framework is expected to become available.

The load distribution curve is intersected with the containment fragility curve, yielding a containment failure probability for each of the scenarios. There is essentially no overlap between load and strength distributions, so we conclude that the likelihood of containment failure for Zion is so low as to be considered physically unreasonable. The results of this report are the culmination of many new and recent perspectives on DCH-related phenomena. Residual uncertainties in some of these areas may require some confirmatory activity. Sensitivities studies have been performed on the autoignition temperature, debris transport to the dome, lower head failure size, and reactor coolant system pressure. In each case, the parameter of interest is shifted outside the expected range of behavior in such a way as to increase DCH loads. Multiple 
combinations of sensitivity parameters were also examined. No areas of large sensitivity were discovered.

We generalize Zion's containment load predictions to most PWRs excluding Ice Condenser and CE plants using scaling considerations. Several items requiring further attention, of a confirmatory nature, are as follows:

(a) Deeply Flooded Cavities: This plant-specific item is needed to identify any cases where geometry allows the build-up of water depths significantly higher than the condensate levels examined so far. Need for any additional evaluations will depend on the extent of such situations and on the particulars of each case.

(b) System Pressure Level: Even though we show that melt expulsion with maximum primary system pressures do not lead to any significant concerns for Zion, we cannot categorically exclude system pressures above $8 \mathrm{MPa}$ at this time for all plants. It may be worthwhile to determine if system pressures above $8 \mathrm{MPa}$ can be excluded. This issue is explicitly addressed in integrated DCH issue resolution task.

(c) Containment Strength: It remains to be determined whether there are any significant deviations from the Zion fragility for containments of a similar class. Containment capability is affected by design details and must be examined on a plant specific basis, possibly through the IPE or ongoing research sponsored by the NRC.

The last item above, in conjunction with the similarity of the containment loads, could allow the application of this methodology to calculate containment failure probabilities for most other PWRs. 


\title{
APPENDIX A \\ THE RISK-ORIENTED ACCIDENT ANALYSIS METHODOLOGY (ROAAM) ${ }^{5}$
}

\author{
T. G. Theofanous and H. Yan \\ University of California
}

\section{A.1 INTRODUCTION}

Since WASH-1400 and the germinal papers of Kaplan (1981) and Kaplan and Garrick (1981), the use of probabilities has made major inroads, from the classical reliability type applications (fault trees) to the quantification of sequences of physical events (event trees). Such use has made possible a systematic approach to understanding, and even quantifying, the risk from severe accidents in complex technological systems (nuclear primarily); however, the use has been loose, thus leading to substantial controversies as well. The nature, and intensity, of these problematic aspects can be well surmised by an open debate on "The Interpretation of Probability in Probabilistic Safety Assessments" (Apostolakis, 1988) and a recent editorial exchange between Evans (1989) ("Bayes is for the Birds") and Kaplan (1990) ("Bayes is for the birds all right; it's for eagles').

To a large extent, these problems are due to misplaced, in our view, efforts to bridge the gap between "judgmental degree of belief" and "statistical expectation (inference)" of the likelihood of a physical event. Indeed, some of the key staples of Bayesian thought envision that "probabilities only exist in the mind of the expert," while on the other hand, "a well-founded probabilistic estimate would coincide with the relative frequency in a large number of trials, were they ever to become available." This conceptual bridge leaves begging the legitimacy of such use and opens the door to misuse (by the practitioner) as well as to misinterpretation (by the critic/user of the results).

These problems become critical in addressing the so-called "issues." Such "issues" arise in a PRA because there is disagreement, among the experts, in the quantification of

5 According to Webster's 7th Collegiate Dictionary, "roam" is defined as: "to travel purposefully, unhindered, through a wide area." 
respective branches of an event tree. Typically, these issues have a dominant influence on the outcome (i.e., failure vs. non-failure), and one is interested in quantifying uncertainty as well. From the field of nuclear technology well known issues are the " $\alpha$-mode (steam-explosion-induced containment) failure," the "Mark I liner attack," and the "Direct Containment Heating." The state of the art in dealing with issues in a global PRA context is reflected in NUREG-1150, which was instrumental in bringing to the forefront their existence.

As a complement to these PRA efforts, the ROAAM approach described here is focused on the resolution of such issues. Its key characteristics are an intimate tying of the probabilistic to the phenomenological aspects, quality controls on quantification, and a gradual, consensusbuilding approach to resolution.

\section{A.2 OVERALL STRUCTURAL ASPECTS}

The method is based on the recognition that as a first step toward resolution, the experts must be given an opportunity to compare results on the same basis. Given that the issue exists because bottom-line results are quite different (i.e., failure vs. non-failure), the above requirement means that such comparisons must be made on smaller parts of the problem. Thus we arrive at the ideas of "decomposition" and "convergence." An assembly of the complete problem in terms of its component parts is called a "framework." "Convergence" means that on each part there is broad agreement on the quantification among the experts. Clearly, such by-parts convergence guarantees agreement on the conclusions provided the decomposition (framework) and synthesis are both soundly based. The key point is that the framework must be constructed as to adequately represent the controlling physics while at the same time be amenable to comparisons and convergence in each of its parts. In particular, it must allow comparisons of widely different models or scaled experiments. In this fashion, the method tackles "model uncertainty" as well. In severe accident analysis, modelling uncertainty is the dominant factor; in general, it can not be represented by parameter uncertainties in a specific model. 
The particular level of decomposition is critical in this regard. At one extreme, a suite of models/codes can be used for a totally mechanistically coupled analysis of a sequence. In this case the decomposition is at the parameter level, i.e., discussions focus on individual parameters and uncertainties are represented by appropriate probabilistic quantification of such parameters and their propagation through the models. A good example of this approach (besides numerous ones in NUREG-1150) is a recent study carried out in connection with the QUASAR program (Khatib-Rabbar et al., 1989). They utilized the Source Term Code Package (STCP) and dealt with hundreds of parameters. At the other extreme, decomposition can take the form of a mini-event tree (i.e., the WASH-1400 treatment of $\alpha$-mode failure) where each key event in the complex sequence leading to failure is assigned a probability. Decomposition at the parameter level is appropriate where the physics of the process is adequately understood and reflected in the modelling approach adopted. However, for "issues" this is never the case, and as a consequence there are more than one, if not a proliferation of mocels. Parametric variations within any one of such models can explore only a subregion of the uncertainty space--the question of model uncertainty remains open. Decomposition at the sub-event level, on the other hand, can only represent an ad hoc selected subset of events and does not appear conducive (as past experience demonstrated) to focusing the technical debate on clearly delineated sub-areas of the phenomenology.

In ROAAM, the emphasis is placed on model uncertainty and a level of decomposition that allows a physically based appreciation of the sequence of events; that is, the probabilistic model is structurally composed (the framework) of a sequence of cause-effect relationships (called "causal relations" or CRs).

\section{A.3 PROBABILISTIC QUANTIFICATION}

Our approach here recognizes that, in the absence of experiments that are fully representative (scaled) of the sequence in question, it makes no sense to speak of "statistical expectation" or "relative frequency." Nor can there be any claim that our judgment of the likelihood can be cast in actual frequensic terms. Moreover, variability (i.e., statistical variations for nominally similar conditions) would normally be dwarfed by uncertainties in the 
phenomena themselves. Thus we use probability as a tool to propagate judgmental degrees of belief through the probabilistic model, i.e., the numbers by themselves have no intrinsic meaning. That is, we use a physically-based probability scale (see Table A.1 for an example) for the quantification of inputs, and using the same scale we convert bottom-line results to a physical interpretation.

As this is a Risk Oriented approach, the quantification is probabilistic, aiming to account for phenomenological uncertainty, while at the same time broadly enveloping the range of behavior. In particular, when uncertainties are large, again a manifestation of an "issue," it is rather impossible to identify "appropriate" probability distributions. Nor is it hopeful that one can get the experts to agree to any such distribution. Attempts to bypass this problem included averaging, or weighted averaging of individual expert quantifications, and the use of a maximum entropy (uncertainty) "principle." On "issues" the quantifications are often highly diverse and averaging may become highly problematic (i.e., see NUREG-1150). Weighted averaging has been expounded from self-grading of experts, to rather elaborate self-calibrating schemes (Cooke, 1988), however, difficulties with application to severe accident phenomenological issues are again obvious. The idea to maximize uncertainty (the so-called entropy "principle'), results in uniform, or log-uniform, distributions of the quantified parameter, over a range of it deemed "probable" (Unwin et al., 1989; Bari and Park, 1989). Again, for "issues" this procedure would yield ranges that span the whole behavior, i.e., from failure to non-failure; thus the utility is often limited to emphasizing the range of uncertainty, rather than to helping resolve the issue. Moreover, even though for truly random events this may be appropriate, phenomenology is anything but random and hence such treatment is actually highly misleading. Other criticisms, put in a more general (than phenomenology) context also have been expressed (Cooke, 1989; Kaplan, 1989; von Winterfeldt, 1989). In ROAAM these difficulties are avoided by means of two schemes. When the range of behavior is deemed too wide and the conservative trend (in it) is unclear we resort to an appropriate number of "splinters"; that is, a number of qualitatively different scenarios that together envelop the physically possible behavior. Rather than attempting to assign probabilities, each such splinter is pursued to quantification independently. This approach produces multiple results, which are to be interpreted independently of each other. If, on the other hand, the conservative trend is 
clear, we seek an adequately conservative distribution with the aim that it can envelop what any expert might expect. During the ROAAM process some adjustments may become necessary; however, clearly such an approach is much more amenable to convergence than using a distribution that is intended to reflect $a$ high degree of ignorance.

\section{A.4 THE CONTEXT OF ROAAM APPLICATION}

The ROAAM has been developed and is specifically aimed at key containment integrity (or even vessel integrity) issues. As such it has to be used in the context of the whole realm of severe accident scenarios, including in their definition respective plant damage states. Thus it interfaces with Level 1 PRAs in the same way a Level 2 PRA would. A crucial aspect of ROAAM is that the "physical consistency" that permeates the quantification be carried over to a similar consistency with what is "physically possible" in this scenario (and plant damage state) definitions. This "consistency" is found by applying a screening-out level of frequency on major contributing classes of plant damage states and by ensuring that the Level 1 PRA quantifications examined, for such screening, are in themselves sufficiently robust. This then

provides the initial context of selecting the enveloping scenarios in the ROAAM itself. In practical terms this consistent approach addresses core melt frequency goals in the "frequency" domain, and containment integrity goals (but only for severe accident sequences above the screening level) in the "qualitative probabilistic" domain as specified (i.e., Table A.1). Since the emphasis is on high-confidence assessments, i.e., in removing the intangible factors, accident management becomes a natural integral part of ROAAM (Tuomisto and Theofanous, 1991).

\section{A.5 PROCEDURAL ASPECTS}

Another major operative element in ROAAM is "time." Again, the mere existence of the issue typically means that it has survived extensive prior work, perhaps even leading to hardened polarized positions. Above, we explained how the experts can be forced to compare notes on small parts of the problem---by the way, this allows also the use of a larger cadre of experts since narrow specialties now may be possible to contribute independently, to individual parts. Moreover, this comparison is on strictly technical grounds and it is in no way affected 
by the integral result which is not known until the "integration" through the framework is carried out. Clearly the "time" element is essential for such comparisons, and gradual adjustment of individual expert's opinions, so that it is more appropriate to think of ROAAM as a "process" rather than a single shot affair. At any time one has a clear depiction of the status, with a clear appreciation of specific areas of uncertainty, and their respective influence on the results. One is thus able to make judgments (i.e., use of such results) as one must make, one can order priorities and, most importantly, the path continues to provide a synergistic effect among the workers with beneficial impact on "enriching" the technical basis of the component parts and thus refining the respective quantification. In this fashion, the method can lead to ever improved convergence and thus continuing reduction of the "intangible uncertainty (Theofanous, 1988). Of course, it is the job of the decision makers to determine when adequate convergence has been achieved, although when this is the case it is quite self-evident.

In implementation, there is a substantive and a formal aspect. The substantive refers to minimum standards of acceptable quantification. In particular, the models must be explicit, physically based, and testable. The experiments must be clearly applicable. In both experiments and analyses there must be explicit rationale for applicability documented. The formal aspect refers to the manner of integrating the experts into the study. The ROAAM "process" begins with a first complete documentation/quantification put together by one expert or a collaborative research group. Expert comments are invited on it, preferably with a prior presentation to the whole panel given only for the purpose of clarification on the written material. The panel must not be selective, but rather to include all experts on the problem to the extent possible while ensuring that it is of sufficient breadth of expertise needed to evaluate all aspects of the quantification. These comments, under respective expert's signature, are then made part of the study, together with the responses provided by the authors. The "process" can then continue by a general workshop, where comments and responses are openly discussed, specialized working group meetings for further in-depth discussions, and additional research. Any remaining questions can crystalize, and continuation of the "process" can be pursued by any appropriate combination of the above. 


\section{A.6 SUMMARY OF PAST EXPERIENCE WITH ROAAM}

The very preliminary formative stages of ROAAM can be found in a licensing assessment of core disruptive accident energetics of the Clinch River Breeder Reactor Plant (Theofanous and Bell, 1983; 1986). An initial, and partial, demonstration of the ROAAM followed a few years later by addressing the $\alpha$-mode (steam-explosion-induced) containment failure (Theofanous et al., 1987; 1989). We say "partial" because it included only the initial step of "peer-review-and-authors-rebuttal." The experimental data needed (as identified by this first step) are only now becoming available.

For the next ROAAM application it became possible to achieve a complete and timely resolution. This application was for the "Mark-I liner attack" issue and constitutes the first complete definition and full demonstration of the ROAAM. The "process" began with the issuance of draft NUREG/CR-5423 for peer review in January 1990. A two-day workshop with the peer review panel (19 experts involved) followed in July 1990. As a result of this workshop four small working groups were formed to pursue in a more focused way certain issues that needed further clarification. In August 1991, the NUREG/CR-5423 was issued, including the status reports of these four working groups and their specific recommendations for follow-on activities. In the meanwhile, these recommendations led to four research projects, one each at ANL (on spreading analyses using the MELTSPREAD code), SNL (on corium-concrete interaction analyses using the CORCON.Mod3 code), RPI (on core melt progression analyses using the APRIL code), and ANATECH (on liner failure criteria using the ABAQUS code and new high temperature creep data from INEL). These projects have been completed recently and demonstrate good "convergence" (Theofanous and Yan, 1992). The final report is now undergoing the final peer review (Theofanous et al., 1993). Even though the original quantification was specific to Peach Bottom, the results at this stage were generalized to all Mark I plants (by collecting all relevant geometric details and showing that the initial quantification is applicable or conservative). A final report, including all these results, and a final quantification is scheduled for December 15, 1992, followed by peer review and completion of the work during January 1993. Thus in this case the complete ROAAM process has taken $\sim 2$ years. 
For the Direct Containment Heating issue (the subject of this report), we expect that the completion of the ROAAM process will take even less time. This is because DCH is phenomenologically a much narrower issue, and because with the IET-series tests we can rely on a very solid data base, and finally because, as shown in this report, the quantification shows that we are quite far from any areas of large sensitivity in the results.

\section{A.7 REFERENCES}

Apostolakis, G.E. (1988). "The Interpretation of Probability in Probabilistic Safety Assessments," Reliability Engineering and Systems Safety, 23, 247--252.

Bari, R.A. and C.K. Park (1989). "Uncertainty Characterization of Data for Probabilistic Risk Assessment," Reliability Engineering and Systems Safety, 26, 163--172.

Cooke, R.M. (1988). "Uncertainty in Risk Assessment; A Probabilist's Manifesto," Reliability Engineering and Systems Safety, 23, 277--283.

Cooke, R.M. (1989). "Comment: Entropy and Experts," Reliability Engineering and Systems Safety, 23, 173--177.

Evans, R.A. (1989). "Bayes is for the Birds," IEEE Transactions on Reliability, 38, (4).

Kaplan, S. (1981). "On the Method of Discrete Probability Distributions in Risk and Reliability Calculations---Application to Seismic Risk Assessment," Risk Analysis, 1 (3), 189--196.

Kaplan, S. (1989). "Comments and Questions on Bari and Park's Paper 'Uncertainty Characterization of Data for Probabilistic Risk Assessment,'" Reliability Engineering and Systems Safety, 26, 177--180.

Kaplan, S. (1990). "Bayes is for Eagles," Letter to the Editor IEEE Transactions on Reliability.

Kaplan, S. and B.J. Garrick (1981). "On the Quantitative Definition of Risk," Risk Analysis, 1, (1), 11--27.

Khatib-Rabbar, M., E. Cazzoli, M. Lee, H. Nourbakhsh, R. Davis, and E. Schmidt (1989). "A Probabilistic Approach to Quantifying Uncertainties in the Progression of Severe Accidents," Nucl. Sci. and Engr., 102, 219--259.

Theofanous, T.G. (1988). "Dealing with Phenomenological Uncertainties in Severe Accident Assessments and Probabilistic Risk Analyses," Proceedings of the Third International Topical Meeting on Nuclear Power Plant Thermal Hydraulics and Operations, Seoul, Korea, Nov. 14-17 . 
Theofanous, T.G., W.H. Amarasooriya, B. Najafi, M.A. Abolfadl, G.E. Lucas and E. Rumble (1987). "An Assessment of Steam-Explosion-Induced Containment Failure." Parts I--IV, Nuclear Science and Engineering, 97, 259-326.

Theofanous, T.G., W.H. Amarasooriya, B. Najafi, M.A. Abolfadl, G.E. Lucas and E. Rumble (February 1989). "An Assessment of Steam-Explosion-Induced Containment Failure," NUREG/CR-5030.

Theofanous, T.G. and C.R. Bell (1983). "An Assessment of CRBR Core Disruptive Accident Energetics," LA-9716-MS, March 1983 and NUREG/CR-3224, March 1983.

Theofanous, T.G. and C.R. Bell (1986). "An Assessment of Clinch River Breeder Reactor Core Disruptive Accident Energetics," Nuclear Science and Engineering, 93, 215-228.

Theofanous, T.G. and H. Yan (Feb. 4-7, 1991). "ROAAM: A Risk-Oriented Accident Analysis Methodology" Proc. Int. Conf. on Probabilistic Safety Assessment and Management (PSAM), Beverly Hills, CA.

Theofanous, T.G. and H. Yan (1992). "The Probability of Mark-I Liner Attack, " Presentation at the 20th Water Reactor Safety Information Meeting, Bethesda, MD, October 21-23.

Theofanous, T.G. et al. (November 1993). "The Probability of Mark-I Containment Failure by Melt Attack on the Liner," NUREG/CR-6025.

Tuomisto, H. and T.G. Theofanous (1991). "A Consistent Approach to Severe Accident Management," Proceedings, Specialist Meeting on Severe Accident Management Programme Development ENEA/DISP, Rome, Italy, September 23-25, 1991, pp. 133--151.

Unwin, S.D., E.G. Cazzoli, R.E. David, M. Khatib-Rabbar, M. Lee, H. Nourbakhsh, C.K. Park, and E. Schmidt (1989). "An Information--Theoretic Basis for Uncertainty Analysis: Application to the QUASAR Severe Accident Study," Reliability Engineering and Systems Safety, 26, 143--162.

von Winterfelt, D. (1989). "Comment: Whose Opinion are We Eliciting: the Expert's or the Analyst's?" Reliability Engineering and Systems Safety, 26, 180--184. 
Table A.1. Definition of Probability Levels

\begin{tabular}{|c|l|}
\hline Process Likelihood & \multicolumn{1}{c|}{ Process Characteristics } \\
\hline $1 / 10$ & $\begin{array}{l}\text { Behavior is within known trends but obtainable only at the } \\
\text { edge-of-spectrum parameters. } \\
\text { Behavior cannot be positively excluded, but it is outside the } \\
\text { spectrum of reason. } \\
\text { Behavior is physically unreasonable and violates well- } \\
\text { known reality. Its occurrence can be argued against } \\
\text { positively. }\end{array}$ \\
\hline
\end{tabular}




\title{
APPENDIX B \\ THE GRADUAL RELOCATION VERSUS CRUCIBLE PHENOMENOLOGIES
}

\author{
T.G. Theofanous \\ University of California, Santa Barbara
}

\section{B.1 INTRODUCTION}

This major bifurcation has been recognized in principle, yet it has been approached in the past, more as an issue of reactor type, rather than an issue within a given design. For PWRs, for example, we find no significant examples of departures from the crucible phenomenology found in TMI, while for BWRs, the gradual relocation scenario seems to be the norm (Hodge and Ott 1990; Kim et al., 1988). One notable exception is the MELPROG calculation by Heames and Smith (1989), in which molten cladding, and later fuel, was assumed to flow freely through the relatively large holes of the lower core plate. The particular calculation was for a station blackout with a pump seal LOCA. The loop seals were found to clear, and the resulting strong natural circulation flows around the steam generators produced a slow and very nearly homogeneous heatup transient. Thus, the core became "setup" for rapid escalation of heatup/oxidation "autocatalized" in a way, by the relocation and associated steaming processes in the lower plenum.

Regarding possible utility of these results, we first need to clarify that loop seal clearance is associated with relatively large pump seal leaks. These lead to depressurization, as did this particular MELPROG calculation, and can have no DCH consequences. As noted in Section 3 of the main report, such large pump seal LOCAs cannot be guaranteed, and smaller breaks cannot produce loop seal clearance. Second, we need to examine the assumption in this MELPROG calculation, that the molten cladding will flow through the holes of the lower core plate unimpeded. Clearly, the content of this discussion is limited to the TMLB'-like class of accidents; the crucible phenomenology cannot be doubted for SBLOCAs.

The key characteristics of such accidents are a water level below the lower core plate, a relatively flat axial temperature distribution, and a two-region radial shape corresponding to 
the down- and up-flow of steam in the natural circulation flow pattern limited mostly in-vessel (the flows that reach out to the steam generators are limited by counter-current flows in the hot leg). Two other key characteristics are that the molten cladding that reaches the lower core plate first is highly superheated, and that the stearning generated by the molten cladding (and in fact, earlier by control materials) reaching and being quenched in the lower plenum provides a strong coherence-inducing factor in the subsequent evolution of the core heatup and material meltdown/relocation processes.

These last two items need some explanation. The superheat derives from the interference of spacer grids with the downward flow of cladding. This interference produces temporary blockages that " hold up" relocating cladding--eventually, these blockages fail, releasing streams of superheated cladding that are more massive (more coherent) than at the time of their generation. Also note that since there are several rows of spacer grids, and since relocation begins in the central core regions, the above may actually be a multistep process (the "steps" getting bigger each time). The steaming feedback, on the other hand, derives from the fact that the large holes in the lower core plate allow a clear-shot fall-through from about $30 \%$ of the fuel rods. Thus, independent of the tendency of the cladding that is intercepted by the core plate to freeze on it, we have a $30 \%$ chance that it is sure to by-pass the plate and fall straight into the water of the lower plenum. Clearly, this steaming will accelerate the oxidation and meltdown process rapidly increasing the thermal load on the lower core plate by means of the intercepted cladding; the thermal processes associated with these interactions together with the feedback effect of steam will eventually determine the "fate" of the core plate.

Calculations of this type are outside the scope of this work, but with the above perspective and recognizing that (a) the core plate is only $5 \mathrm{~cm}$ thick, (b) that the zirconium melts about $500 \mathrm{~K}$ higher than steel and that it has $50 \%$ larger heat capacity and thermal conductivity than steel, and (c) core heatup can be easily "autocatalyzed" by steam due to the highly exothermic clad-oxidation reaction, we find that within the enveloping approach pursued here, we must allow for scenarios in which the lower core plate eventually melts under most of the central core area. Such melting would allow the relocation of mostly solid fuel debris into the lower plenum and the TMLB'-like lower head failure scenario discussed in Appendix C. 
Clearly, a quantitative modelling approach should be pursued as part of the ROAAM process if this scenario is to remain as a part of the finally-accepted splinter scenarios relevant to $\mathrm{DCH}$.

The key characteristic of SBLOCA-like conditions (including conditions where the lower core is sufficiently cold due to the close proximity of water) is the formation of a corewide blockage within the core region that prevents core material from flowing into the lower plenum. The blockage forms because the downward relocating metallic melt freezes in the core region, and is expected to cover the lowermost portions of the core. Accumulation of frozen ceramic material on the metallic blockage produces a crust that can support large quantities of core material until it remelts or fails. The strength derives from the cementing together of the lower portions of fuel stubs, which are well supported from below by the lower core grid plate and support columns. The relative permanence of the crust derives from four factors (1) the local decay heating is low, (2) the crust material is mostly ceramic with a relatively high melting point, (3) the bottom of the crust is cooled by radiation or boiling and (4) downward heat fluxes to the crust in a naturally-convecting system are low. The formation of such blockages has been observed in out-of-pile experiments in the CORA (Hering et al., 1991), PBF (Petti et al., 1989), and ACRR (Gasser et al., 1990) facilities and, of course, in TMI-II, which also demonstrated the retentive property of such a crust for significant quantities of melt. The crust eventually is expected to fail allowing a relocation of core material into the lower plenum.

\section{B.2 REFERENCES}

Gasser, R.D. et al. (Jan. 1990). Damaged Fuel Experiment DF-1: Results and Analyses, NUREG/CR-4668, SAND86-1030, Sandia National Laboratories, Albuquerque, NM.

Heames, T.J., and R.C. Smith (1989). "Integrated MELPROG/TRAC Analyses of a PWR Station Blackout," Proceedings 1989 National Heat Transfer Conference, Philadelphia, PA, Aug., 6-9, Vol. 4, 205.

Hering, W., K. Muller and A. Schatz (1991). "Verification of the KESS Code System Using CORA-Experiments," AICHE Symposium Series, Heat Transfer--Minneapolis, 159-176. 
Hodge, S.A. and L. Ott (1990). "BWRSAR Calculations of Reactor Vessel Debris Pours for Peach Bottom Short-Term Station Blackout," Nuclear Engineering and Design, 121, No. $3,327-339$.

Kim et al. (1988). The Development of APRIL.MOD2 - A Computer Code for Core Meltdown Accident Analysis of Boiling Water Nuclear Reactors," NUREG/CR-5157, US Nuclear Regulatory Agency, Washington, DC.

Petti, D.A. et al. (April 1989). Power Burst Facility (PBF) Severe Fuel Damage Test 1-4 Test Results Report, NUREG/CR-5163, EGG-2541, EG\&G Idaho, Inc., Idaho Falls, ID. 


\section{APPENDIX C \\ THE MAIN LOWER HEAD FAILURE BIFURCATION}

T.G. Theofanous

University of California, Santa Barbara

\section{C.1 INTRODUCTION}

The second bifurcation concerns the mode and timing of bottom head failure. Under SBLOCA-like conditions, the main relocation event might induce failure of the lower head by jet impingement, ejection of an instrument guide tube, or rupture of an incore instrument guide tube after melt has flowed into the tube and beyond the confines of the lower head (Rempe, et al., 1993). Such penetration type failures are expected to occur during or shortly after the main relocation event. This defines Scenario I in Figure 3.1. It is quite possible to have a delayed penetration failure that could occur at any time prior to a possible rupture. Such cases are not explicitly analyzed here since the quantifications for guide tube rupture and early penetration failures do not differ sufficiently to warrant an intermediate assessment.

Under TMLB'-like conditions, any possible penetration failure will be delayed until the debris bed dries out and begins to reheat. A delayed penetration failure likely will occur when steel in the debris becomes molten, possibly attacking - the weld of a penetration after the molten steel drains to the bottom of the debris bed or possibly causing a penetration to rupture outside the vessel after flow of molten steel into a penetration. A delayed penetration failure can occur any time prior to a possible rupture of the lower head. This defines Scenario III in Figure 3.1. Here, the time is referenced to debris bed dryout.

The second extreme in failure mode and timing occurs when portions of the lower head have been heated sufficiently that the lower head steel no longer has the strength necessary to carry the stresses induced by high RCS pressures. This leads to rupture of the lower head. For SBLOCA-like cases, assuming partial quench of the debris to $2500 \mathrm{~K}$ following crust failure, Pilch and Dosanjh (1991) predict that the lower head will rupture in 
1500-2500 $\mathrm{s}$ after the initial relocation. Similar times have been predicted by Boucheron (Referenced in Zuber et al., 1992) for interface conductivity ratios characteristic of a debris bed or a consolidated mass (such as a molten pool) in perfect contact with the lower head. The recent SCDAP/RELAP5 calculations (Knudson, 1993) predict lower head rupture at $1700 \mathrm{~s}$ if quenching occurs and $\sim 400 \mathrm{~s}$ if it does not; however, the SCDAP/RELAP calculations were intentionally biased to accelerate lower head failure. Recirculating convection patterns in the molten pool may accelerate rupture. In addition, hot spots must assuredly form on the lower head leading to accelerated rupture. Such hot spots can form at the impingement region of the relocating material and can also form as a result of partially quenched material accumulating in a nonuniform manner on the lower head. Witt (1994) has shown that hot spots on the lower head could accelerate rupture, by $\sim 15$ percent in the TMI-II application that was analyzed. Such considerations define a lower bound of about $1000 \mathrm{~s}$ to the expected rupture time. This defines Scenario II in Figure 3.1.

Under TMLB'-like conditions, possible rupture of the lower head will be delayed because the core debris must first go through a reheat phase. Dosanjh and Pilch (1991) predict lower head rupture in 4000 - $5000 \mathrm{~s}$ (after dryout) under such conditions. Again, formation of hot spots might accelerate the time to rupture by 25 percent. This defines Scenario IV in Figure 3.1.

The bifurcation in behavior (mode of failure) arises because of the possibility that failed instrument tube penetrations plug and remain in this state for the length of time necessary for the lower head to fail otherwise, i.e., by creep rupture. Such failures and plugging have been found to have occurred in TMI-II, and in fact, recognizing that the tubes are within the primary system pressure boundary and full of water, plugging is not at all surprising. By comparison, an instrument tube ejection is conclusive--under the tremendous pressure gradient, the melt is forcibly ejected, and not only can it not plug, in fact, it ablates an even bigger passage. For an ejection to occur, the weldment that holds the tube to the lower head must fail by melt attack, and this most likely will occur only early during the 
melt relocation process due to convective heat transfer effects. These convective effects need to be strong in order to overcome the large heat sink associated with the thickness of the lower head and to cause a local ablation sufficient to lead to loss of support. Recognizing uncertainties in the path, quantities, and rates of this relocation, and in its interactions with the lower internal structures and the water in the lower head, it is not at all clear it can ever provide a reliable failure mechanism, thus focusing the scenario into one single path. Again, despite the rather massive relocation and rather strong localized heating found of the lower head in TMI-II, such failures did not occur. Once the main convective effects are over (end of relocation), the wall heat sink becomes even more prominent (the corium-wall interface temperature drops as heat diffuses into the relatively high thermal conductivity of the bare metal, while the debris develops a thermal diffusion boundary layer) and tube ejection is even less likely. In a high pressure scenario, creep rupture of the lower head wall is more limiting than integrity of the tube weldment--note that they are at essentially the same temperature. At this time, we have not been able to find any conclusive evidence that this bifurcation (rupture) does not exist. Further insights can be gained by exploring the behavior of each branch in slightly more detail.

Strong convective effects leading to tube ejection can be obtained in the middle portion of the lower head only during the very early stages of relocation, and prior to significant melt accumulation in it, or off to the side (as would occur by a core baffle failure, as in TMI) at any time during relocation. Now, in the former case, depressurization resulting from tube ejection will begin with only a small amount of melt available, and depressurization will continue simultaneously with the melt relocation process. This would mitigate DCH loads compared to the ejection scenarios considered for quantification in this report by enhancing the incoherence (decreasing the $\tau_{\mathrm{m}} \mid \tau_{\mathrm{s}}$ ) between the melt ejection and steam blowdown processes. Furthermore, the hole ablation is also delayed, which is reflected by a smaller $m$ in Eq. 4.1 of the main report, which rather mitigates the DCH loads. In the second case (off to the side failure), on the other hand, the melt may have accumulated already, but with the failure above the melt surface only small fractions of melt can be ejected. (Note that 50 tons of melt occupy roughly $6 \mathrm{~m}^{3}$, which in a hemispherical 
lower heat with a radius of 2 meters would occupy a depth of $\sim 1.5$ meters.) Again, we can see significantly mitigated DCH loads from those considered in this report.

\section{C.2 FAILURE SIZE}

The second bifurcation concerns the mode and timing of bottom head failure. The two extremes in failure mode (penetration failure or vessel rupture) require independent assessments of the final hole size in the RPV. The main relocation event might induce failure of the lower head by jet impingement, ejection of the an incore instrument guide, or rupture of an incore instrument guide tube after melt has flowed into the tube and beyond the confines of the lower head (Rempe, et al., 1993). Such penetration type failures are expected to occur during or shortly after completion of the main relocation. Penetration failures are initially quite small $(\sim .025-.050 \mathrm{~m})$, but ablation (see Appendix J) during melt discharge can cause the hole to grow to $\sim 0.4 \mathrm{~m}$ depending on the melt mass and composition, although the sensitivity is not extreme. For consistency, the final hole size is computed with the ablation model (Eq. J.5) for each combination of mass and composition. Such calculations also require the temperature of the lower head as input. For Scenario I, this is taken as saturation $(\sim 600 \mathrm{~K})$ since the penetration failure occurs at relocation. For Scenario III (a delayed penetration failure), a value of $800 \mathrm{~K}$ is used because it lies midway between saturation and a temperature where rupture is likely.

In SBLOCA-like scenarios, it is quite possible to have a delayed penetration failure that could occur at any time prior to rupture. Such cases are not analyzed here since the quantifications for rupture and early penetration failures do not differ sufficiently to warrant an intermediat ${ }^{-}$assessment.

With respect to the vessel rupture mode, it is evident from the TMI-II investigations that hot spots must assuredly form on the lower head, leading to accelerated rupture. Such hot spots can form at the impingement region of the relocating material and can also form as a result of material accumulating in a nonuniform manner on the lower head. These hot spots will likely overlay one of the locations where an incore instrument guide tube passes 
through the lower head. As a result, the hot spot not only accelerates rupture, but the rupture is likely to occur around such penetrations because of local stress concentrations that are double the free field stress in the hot spot and because an instrument tube penetrating the vessel will be twisted or cocked as the tube attempts to resist vessel deformation through tube supports outside the vessel. Such a rupture is relatively small, but ablation will increase its size to $\sim 0.4 \mathrm{~m}$.

If the hot spot does not overlay a penetration, then the size of the rupture will likely scale with the size of the hot spot. Witt's (1994) TMI-II calculations stop short of defining the rupture size because such predictions are beyond the current state of the art for numerical simulations. The spacing between lower head penetrations at Zion is $-0.5 \mathrm{~m}$; and insisting that the hot spot not interact with the stress concentration fields about the penetrations, the maximum rupture size is $\sim 0.4 \mathrm{~m}$. Appendix $\mathrm{J}$ concludes that RCS depressurization will preclude continued enlargement of the hole by mechanical processes. Ablation, however, can result in some continued expansion of the initial rupture; and using $0.4 \mathrm{~m}$ as the initial size, the final size after ablation is again computed with the ablation model (Eq. J.5) for each combination of mass and composition. For such ablation calculations following a rupture, the initial RPV temperature is taken as $1000 \mathrm{~K}$.

\section{C.3 DEBRIS STATE}

The creep rupture branch is of more fundamental interest. The situation here is quite different depending on whether the relocation into the lower head is massive or gradual. In a massive relocation, as we expect in the SBLOCA-like class of scenarios, we have a molten pool situation; that is volumetrically heated and naturally-convecting energy to the lower head hemisphere below and to any water above. In a gradual relocation, as we expect in the TMLB'-like class of scenarios, we have a largely solid debris bed in the process of heating up, melting some its constituents (the metallic components and eutectics) and thermally loading primarily the lower head. 
This problem was originally examined by Theofanous et al. (1991). The key idea in this analysis was that with its $15-\mathrm{cm}$ thickness, the lower head represents a significant thermal inertia, which has a significant impact on the race between debris heating toward melting and the head's own heatup toward weakening and creep failure. The poor thermal transport properties of the oxidic (heat generating) component of the debris would tend to favor a greater lag between these two heatup processes; on the other hand, the great difference between the melting temperatures of the two materials (over $1000 \mathrm{~K}$ ) would tend to minimize the effects of such lag. An analytical solution was obtained, to scope out the conduction-only process, as:

$$
\begin{gathered}
T-T_{0}=\frac{q^{\prime \prime \prime}}{k \delta^{\prime 2}} \beta^{2} \\
T_{s}-T_{0}=\frac{q^{\prime \prime \prime}}{k \delta^{\prime 2}}\left[\beta^{2}-\left[\frac{2}{\sqrt{\pi}} \beta+e^{\beta^{2}} \operatorname{erfc}(\beta)-1\right]\right]=\frac{q^{\prime \prime \prime}}{k \delta^{\prime 2}} F(\beta)
\end{gathered}
$$

where

$$
\delta^{\prime}=\delta \rho_{s} c_{p s} \quad \beta=\delta^{\prime} \sqrt{\alpha t}
$$

with the function $\mathrm{F}(\beta)$ given in graphical form in Figure C.1. Sample calculations using this solution led to the conclusion that creep rupture would be expected before the oxide had time to reach melting, and it was emphasized that this would be especially so if one were to account for the effects of steel relocation upon melting, within the bed porosity downward, and of the metallic's natural convection currents within the solid oxidic matrix (these two mechanisms were not included in the analytical solution above).

These predictions were subsequently checked by Dosanjh and Pilch (1991). Their aim was primarily the high pressure scenario in PWRs, they coupled a transient debris head heat up model with a creep rupture calculation using the Larson-Miller parameter. They confirmed the importance of steel relocation in accelerating further the lower head thermal loading (Figure C.2) and thus the conciusions of Theofanous et al. that creep rupture would 
be expected prior to significant melting of the oxidic component, especially high-pressure scenarios. In fact, a creep rupture would be even further accelerated (limiting the steel superheat at failure) because of the natural convection currents not accounted for in the calculations by Dosanjh and Pilch.

Now, recognizing the large non-uniformities in porosity and other bed characteristics, the real significance of these convection currents is in producing large variations of heat fluxes along the area of contact with the lower head, thus inducing a local "blister" rather than a global creep failure. This is the Scenario IV considered in Section 3 of the main report.

The calculations of Dosanjh and Pilch (1991) show the time to rupture is a function of RCS pressure, as shown in Figure C.3. This has implications in the amount of molten material that is present on the lower head at the time for failure. This can be seen in Figure C.4. Specifically, no oxides are predicted to be molten at the time of rupture when the RCS pressure is high. Although significant oxides could be molten by $6000 \mathrm{~s}$, the RCS pressure would have to be so low that DCH would be of no concern.

The distinguishing feature of the Dosanjh and Pilch (1991) calculations is the relocation of molten steel to the bottom of the debris bed. This can be seen clearly in Figure C.4 where the fraction of molten steel first rises rapidly (steel melting) and then drops suddenly (relocation). The consequence of this is twofold. First, steel relocation accelerates heating of the lower head, as mentioned previously. Secondly, relocation allows molten steel to refreeze on the lower head. The consequence of resolidification is to limit the amount of steel in the debris bed that can be molten. The plateau occurs when all the steel has drained to the lower head. The permanence of the solidified steel fraction stems from the fact that the inside of the lower head is still well below the melting point of steel and that the steel saturated debris bed has excellent downward thermal conductivity. Any steel that remains molten cannot sustain any significant superheat. Lastly, the predictions of Dosanjh and Pilch (1991) provide insight into the peak temperatures (Figure C.5) in the debris bed which occur in the oxide regions near the top of the debris bed. 


\section{C.4 REFERENCES}

Dosanjh, S.S. and M. Pilch, 1991 "Lower Head Creep-Rupture Sensitivity Studies," Nuclear Science and Engineering, 108, 172-183.

Knudson, D.L., April 19, 1993, Transmittal of SCDAP/RELAP5/MOD3: Results for the Zion Power Station, Letter Report to NRC.

Pilch, M. and Dosanjh, S.S., 1990, "Debris State at the Time of Bottom Head Failure by Creep Rupture," in Partners Review Meeting, Brookhaven National Laboratory, April 30 May 3.

Rempe, J.L. et al., April 1993, Light Water Reactor Lower Head Failure Analysis, NUREG/CR-5642, EGG-2018, EG\&G Idaho, Idaho Falls, ID.

Theofanous, T.G., W.H. Amarasooriya, H. Yan and U. Ratnam, 1991, The Probability of Liner Failure in a Mark-I Containment, NUREG/CR-5423, U.S. Nuclear Regulatory Commission, Washington, DC.

Witt, R.J., 1993, "Local Creep Rupture Failure Modes on a Corium-Loaded Lower Head," Accepted for Publication, Nuc. Engineering Design.

Zuber, N. et al., 1992, An Integrated Structure and Scaling Methodology for Severe Accident Technical Issue Resolution, Draft Report for Comment, NUREG/CR-5809, EGG-2659. 


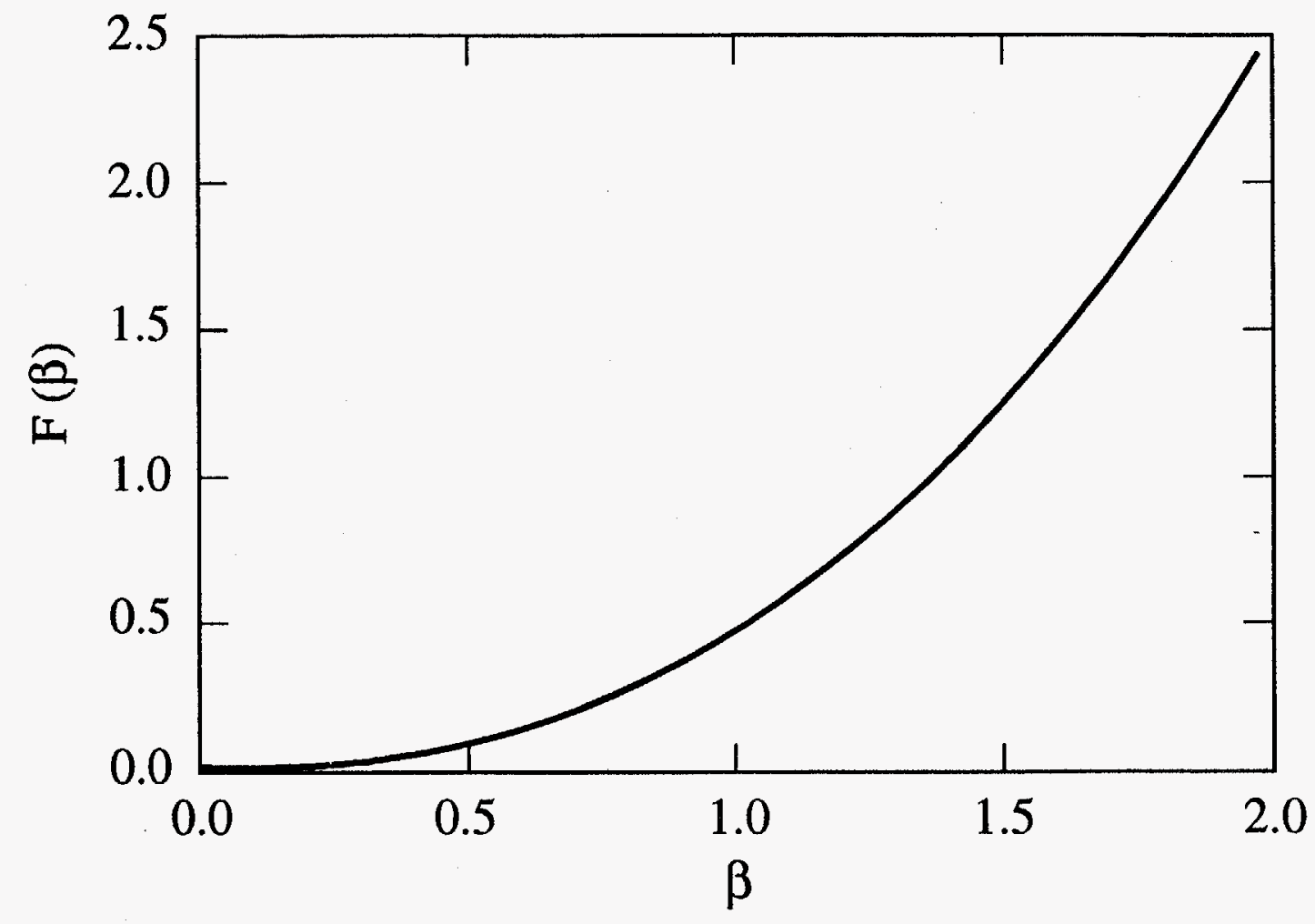

Figure C.1. The function $F(\beta)$ for Equation C.2. 


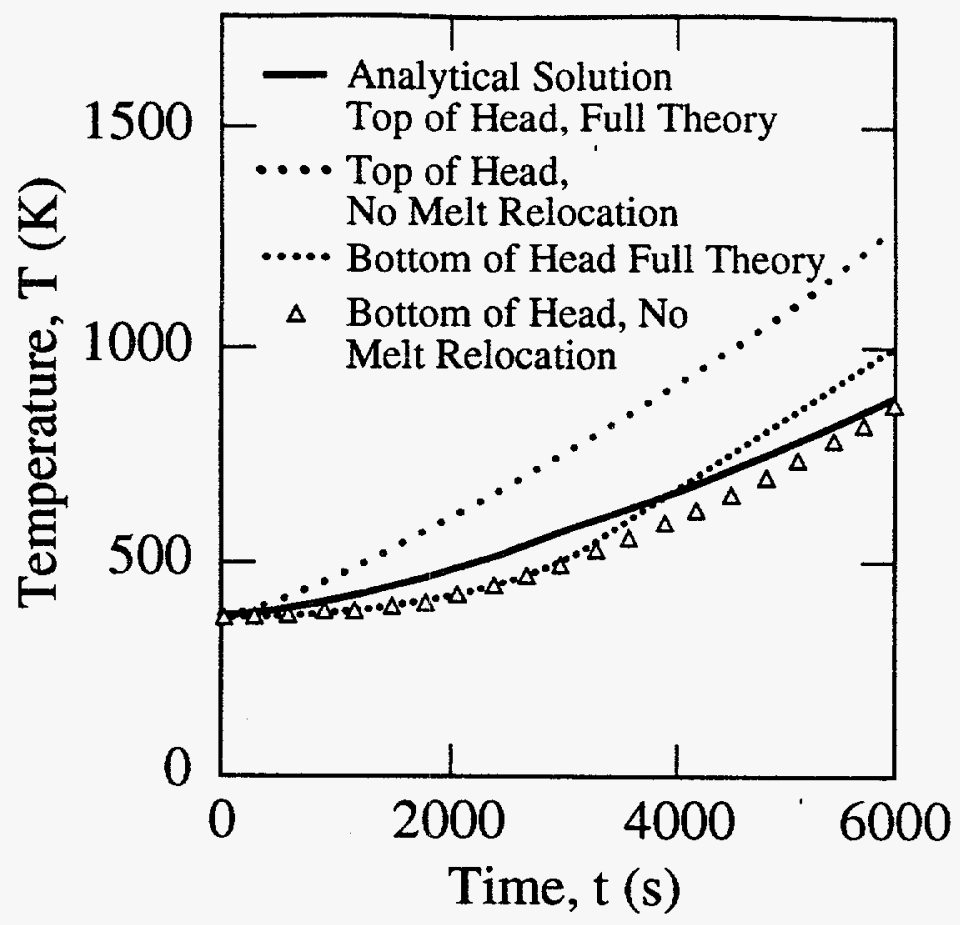

Figure C.2. Lower head temperatures predicted by the numerical model (with and without melt relocation) and by the analytical model of Theofanous et al. 1991.

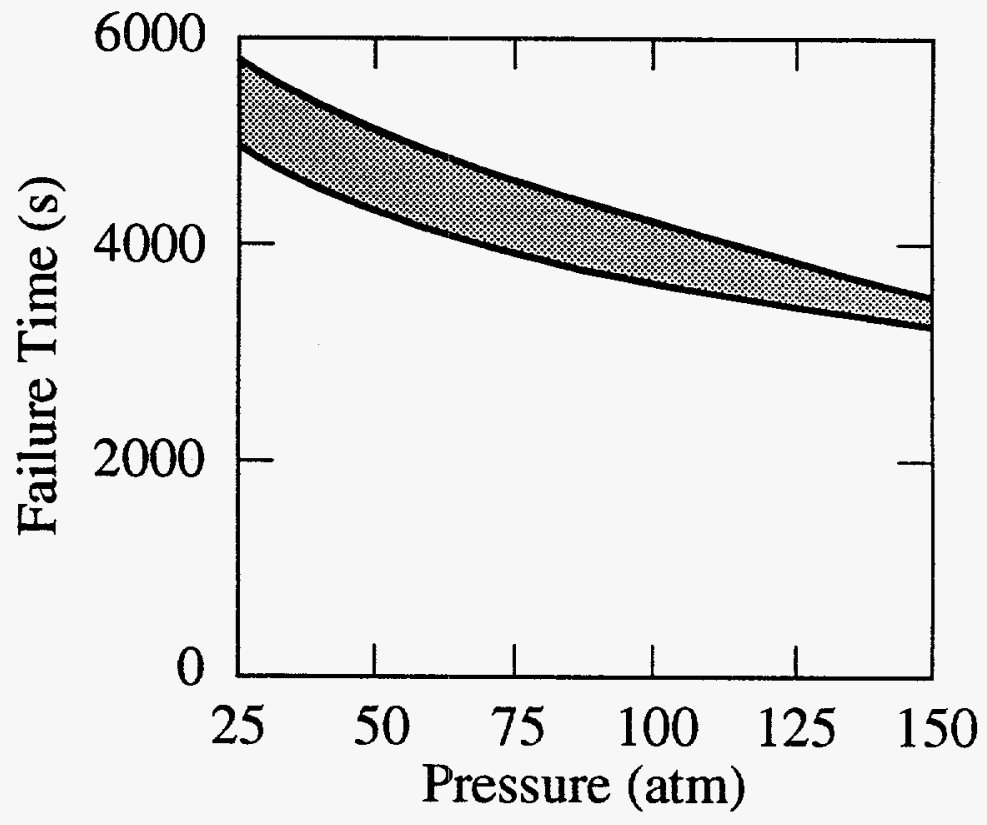

Figure C.3. Range of vessel failure times versus RCS pressure. 


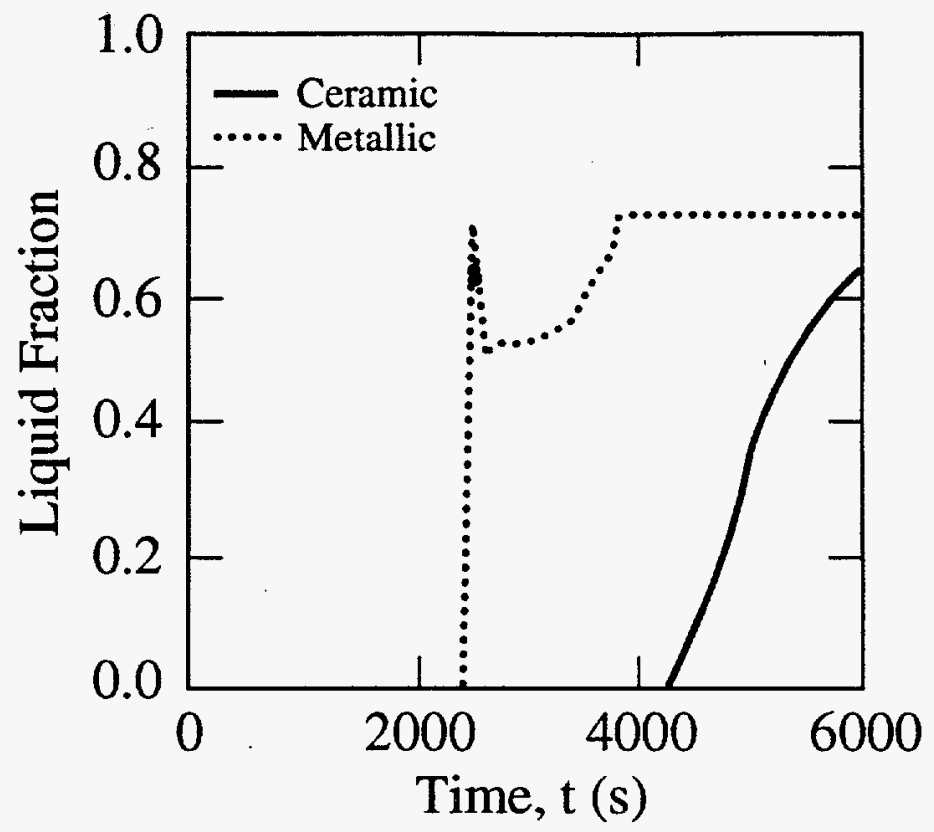

Figure C.4. Ceramic and metal liquid fractions plotted as functions of time.

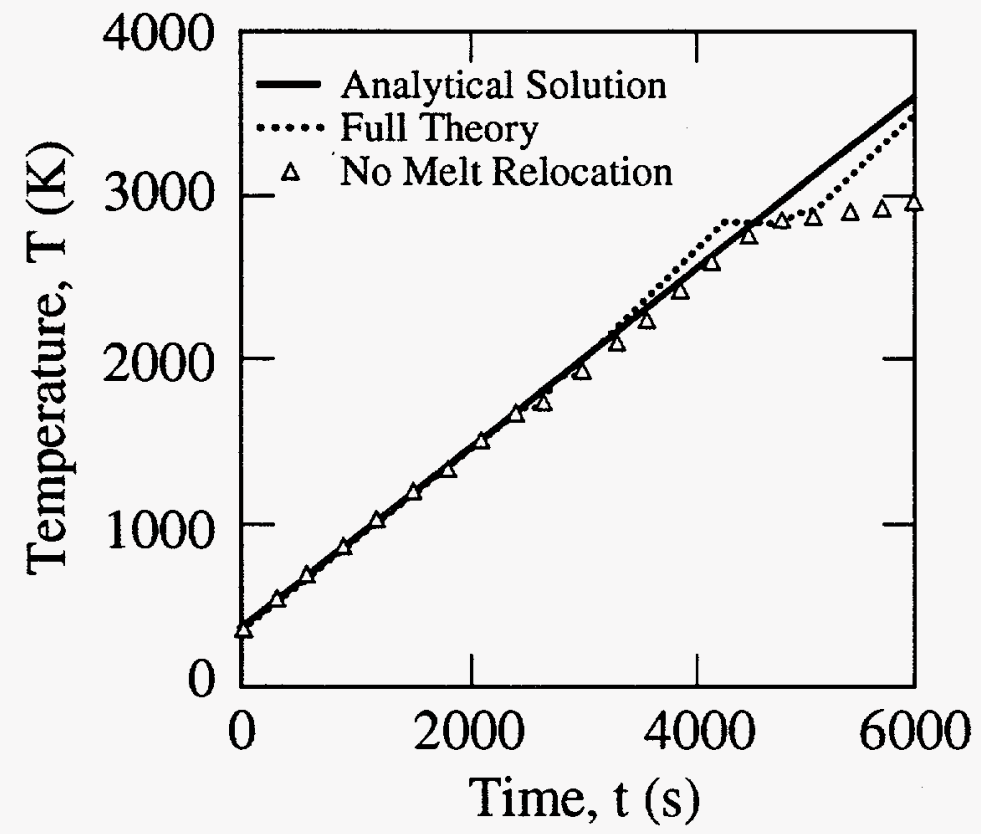

Figure C.5. Peak temperatures in the debris bed. 


\title{
APPENDIX D \\ THE PREDICTION OF DIRECT CONTAINMENT HEATING
}

\author{
H. Yan and T. G. Theofanous \\ University of California, Santa Barbara
}

\section{D.1 INTRODUCTION}

Direct Containment Heating $(\mathrm{DCH})$ is a collective name used to express a rather complicated set of phenomena originating from a postulated release of a core melt from a reactor vessel found at high pressure, and resulting in the pressurization and heatup of the containment atmosphere. The primary mechanism is melt dispersal from the reactor cavity, driven by the high velocity steam flow that follows melt ejection from the reactor vessel. This sort of dispersal process was first recognized in the Zion/Indian Point probabilistic risk assessment where it was taken to imply coolability of the resulting highly dispersed debris configuration, and thus termination of the accident. Follow-up work during the NRC's review of this study, and also within the more generalized context of the NRC's Containment Loads Working Group, led to significant concerns that such intense interactions could produce containment-threatening levels of pressurization. Indeed, a limiting, upper bound analysis, based on the assumption that all ejected melt and the driving steam come to thermodynamic equilibrium with the containment atmosphere, indicated failure of the Zion containment with only 20 percent of the reactor core participating in this ejection-dispersal process (Bergeron and Williams, 1985). As a consequence, the problem has been studied extensively; however, its resolution has remained elusive.

Besides the direct contact of the dispersed melt with the containment atmosphere, the DCH-pressurization process includes oxidation of any metallic components in the melt by the steam that drives the dispersal and burning of the produced hydrogen with oxygen in the containment atmosphere. This burning may also involve some of the hydrogen released from the primary system during early phases of the severe accident (hence called "preexisting"). Normally, this process will be limited to quantities that can be entrained in the high temperature DCH plume (typically 10-20 percent), but it potentially could be generalized to include all 
preexisting hydrogen, if temperatures of this hydrogen-air-steam premixture could reach the autoignition threshold.

Much of the work has been focused on defining conditions under which the melt may not be prone to being dispersed out of the reactor cavity. To begin with, the IDCOR project attempted to categorize existing reactor cavity geometries into a few classes and to attribute a "dispersive" or "retentive" quality to each (IDCOR, 1985), while attempting also to address how much of the debris removed from the cavity could be finely dispersed. Along these lines, simulant experiment work at Brookhaven National Laboratory and at Winfrith, UK, provided data on fractions of "melt" dispersed as a function of the driving gas pressure (in the primary system). The specific geometries examined were those of Zion, Watts Bar, and Sizewell reactors, while the fluids and vessel breach area were varied to address dimensional (scale-up) considerations (Tutu et al., 1988a; Tutu et al., 1988b; Tutu and Ginsberg, 1990; Macbeth and Trenberth, 1987; Rose, 1987; Macbeth et al., 1988). Besides the investigators' own interpretations (i.e., dominant scaling groups, degree of dispersal correlations), an independent interpretation of these data has been made also by Levy (1991). In addition, Henry (1989) considered this problem analytically and concluded that even if conditions were such as to promote complete removal of the melt from the cavity, because of competition between entrainment and purely displacement (of the melt) processes, much of the melt would reach the steam generator compartment not in a highly fragmented state--as such, it would be trapped there contributing minimally to the DCH phenomena.

Near prototypic material "simulations" using thermitic materials were carried out in a long list of various experimental series, and respective facilities, at Argonne National Laboratory (ANL) and Sandia National Laboratories (SNL). This work was primarily computer-code oriented, that is, aiming to provide data for development/validation of the computer code CONTAIN at SNL and the HARDCORE/PARCEC codes at ANL (Sienicki and Spencer, 1986; 1987). The Argonne work, the CWTI tests, and related code calculations were summarized by Spencer et al. (1988) who underlined the importance of plant structural features in impeding corium dispersal and thus mitigating the DCH loads ("DCH may be no worse and possibly far less severe than the previously examined steam spike"). The early SNL tests included the 
Technology Development Series (TDS) and important Limited Flight Path (LFP) tests (Allen et al., 1991), aimed to represent the basic behavior of a compartmentalized geometry. All these experiments have been reexamined recently as a part of a systematic approach to the DCH problems in an effort known as the Severe Accident Scaling Methodology (SASM).

This effort (Zuber, et al. 1991) laid out the basic scaling requirements, both from the integral (called "top-down" approach) and the phenomena-based (called "bottom-up" approach) perspectives, and led to a significant redirection of the experimental program. Besides the systematic scaling approach, these tests (called the Integral Effects Tests, or IET series) also emphasize the preservation (linearly scaled) of the key geometric features, and especially with respect to the cavity and the so-called intermediate compartment, and they are conducted in counterparts at two scales: at 1/10-scale in the Surtsey facility at SNL and at 1/40-scale in the COREXIT facility at ANL. Currently, these tests are near completion, and they are supplemented by a limited number of runs at $1 / 6$-scale in the Containment Technology Test (CTT) facility at SNL.

The IET series demonstrated the importance of the intermediate compartment to "capture" the debris dispersed from the cavity and have provided a wealth of relevant experimental data in two different reactor geometries; namely, those of the Zion and the Surry nuclear power plants. We will show here that these data take us quite far, further than might have been anticipated, in our quest to predict DCH loads in reactor geometries.

The key idea is that once the melt is trapped (in the subcompartment) it cannot produce any significant additional heating, leaving only the blowdown steam as the medium of contact between the hot debris and the containment atmosphere. The maximum heat "extraction" can be estimated by bringing the dispersing debris and the driving steam to chemical and thermal equilibrium in a flow process, and clearly it is a function of the degree of contact (or coherence between the debris dispersal and steam blowdown process) achieved. Let us suppose that the debris is swept out of the cavity over a time scale $\tau_{\mathrm{m}}$; this contact then can be expressed by scaling this $\tau_{\mathrm{m}}$ by the natural time scale of the steam blowdown $\tau_{\mathrm{s}}$ (the vessel depressurization time constant). The whole $\mathrm{DCH}$ phenomenon would then scale with this single parameter, the 
$\tau_{\mathrm{m}} / \tau_{\mathrm{s}}$, which we therefore call "DCH scale." The primary purpose of this paper is to show how this DCH scale naturally arises from the non-dimensionalization of the equations for the physical process just described and to demonstrate, by comparison to the available data, its value in characterizing quantitatively the DCH phenomenon. In particular, since both the $\tau_{\mathrm{m}} / \tau_{\mathrm{a}}$ and containment pressurization are available from the experiments (the IET series), we have a clear test of the basic premise of this modeling approach. On this basis, reactor predictions can be made quite simply, provided the DCH scale for the particular conditions of interest is known. This issue is also addressed by means of a scaling approach that seems to be consistent with the available experimental data. Another interesting aspect of this model (called the Convection Limited Containment Heating, or $\mathrm{CLCH}$, model) is that it demonstrates a certain bounding feature of resulting pressurization with the $\mathrm{DCH}$ scale, which may be very convenient when such a bounding quality in predictions is desirable.

In a concurrent effort, Pilch (Appendix E) is also developing a predictive scheme for DCH. This approach, which is a takeoff from the bounding Bergeron and Williams (1985) approach described earlier (usually referred to as the single-cell equilibrium model), recognizes the importance of trapping in the intermediate compartment and reflects it in a two-cell equilibrium (TCE) model whereby the melt is brought to equilibrium with all the steam and air in the intermediate compartment and, in a second step, the resulting hot gases are brought to equilibrium with the rest of the containment atmosphere. This basic concept has also been augmented by a number of kinetic considerations, and resulting "efficiencies" backed out from the data as a way to bring them together with predictions (Pilch, 1992a; Appendix E). A two-cell equilibrium model also has been developed for and used in the MAAP3B code (Henry and Plys, 1990). Besides the above, this model includes a calculation to equilibrate the water dispersed from the reactor coolant system with the debris.

Currently, the CLCH model is used in conjunction with the TCE model in a comprehensive assessment of the likelihood of containment failure by DCH in the Zion reactor. This study includes a consideration and quantification of initial conditions (melt quantities, compositions, superheats, system pressure, containment pressure and composition, see Section 3.0 of this report) and of the strength of the containment (Section 5.0 of this report). 


\section{D.2 SOME BASIC CONSIDERATIONS}

The problem can be described in quite general terms using the illustration of Figure D.1. The primary system is characterized by the initial pressure, $P_{\mathrm{so}, \mathrm{v}}$, and temperature, $T_{\mathrm{so}, \mathrm{v}}$, by its steam contents and the size of the breach in the lower head, $d_{b}$. The containment is characterized by the presence of the reactor cavity, the chute, the intermediate compartment in which one of the steam generators and associated piping normally reside, and the open, main volume of the containment. The particular geometrical details and dimensions in these structures may differ from plant to plant, but it is essential (for the model to apply) that this sequence of structures be present. It is also essential that the subcompartment characteristic dimension is quite large (normally much larger than that of the cavity and chute) such that (a) mean velocities through it are quite small in comparison to those required to entrain millimeter-sized corium particles and (b) any jetting and associated recirculation flows can readily dissipate. In particular, it is important that the chute exit does not have a "clear path" through the subcompartment exit to the containment. Depending on the specific design, this flow path can vary from rather simple to a quite complicated one, around a lot of internal structures (this is the case, for example, in the Surry containment); however, the effect of such additional complications is always to reduce the resulting DCH loads. Within the frame of the CLCH model, it is not necessary to go into this kind of detail. The containment, therefore, can be simply characterized by its total free volume, $\mathrm{V}_{\mathrm{a}}{ }^{\mathrm{f}}{ }$ The initial atmospheric conditions in it are also needed; that is, its pressure, $\mathrm{P}_{\mathrm{aO}}$, temperature, $\mathrm{T}_{\mathrm{aO}}$, and composition (mole fractions) in

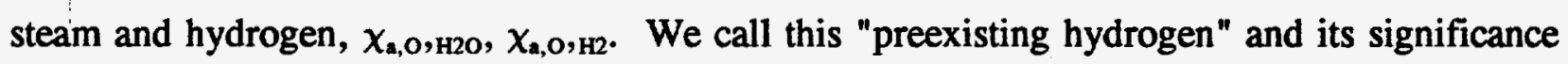
is that it may be induced into burning during the DCH phenomena, thus adding additional (combustion) energy to the resulting loads. The steam concentration is also significant in affecting the heat capacity of the atmosphere and in affecting flammability of preexisting hydrogen. Finally, the melt is characterized by its mass, $m_{m}$ (or its volume, $v_{m}$ ), its energy or

fNot shown clearly in Figure D. 1 is an annular space between the reactor vessel and the surrounding concrete structure. Depending on the detailed design, this annulus could represent a flow path (bypassing the intermediate compartment) to containment volume. The melt quantity "directly" dispersed through the flow bypass path would be expected to be normally small $(\sim 10 \%)$, and its effect can be considered in the analysis in the manner similar to the small quantities expected to disperse through the intermediate compartment, as described below. 
temperature, $\mathrm{T}_{\mathrm{m}}$, and composition, especially in the mass fractions of the metallic contents such as $\mathrm{Zr}, \mathrm{Cr}$, and $\mathrm{Fe}$, that is, $\omega_{\mathrm{Zr}}, \omega_{\mathrm{Cr}}$, and $\omega_{\mathrm{Fe}}$, respectively. The reactions of $\mathrm{Zr}$ and $\mathrm{Cr}$ with steam are very fast and highly exothermic. They are significant in both producing hydrogen and in heating up (i.e., speeding up) the resulting steam/hydrogen mixtures. The resulting hot hydrogen can further react (combust) upon entering a reactive atmosphere in the main containment volume. Thus we have the cumulative result of the heats of metal-steam and hydrogen-oxygen reactions to the energetics of the DCH phenomenon. For the iron, the reactions are only slightly exothermic, so the main role is one of hydrogen production. Also, the chemical affinities are such that $\mathrm{Zr}$ and $\mathrm{Cr}$ react fast and completely (as long as there is steam, of course), while the Fe participates in a chemical equilibrium described by $\mathrm{Fe}+\mathrm{H}_{2} \mathrm{O}$ $\Leftrightarrow \mathrm{FeO}+\mathrm{H}_{2}$ with an equilibrium constant of 2.1 .

The detailed interactions of the melt-steam interactions within the cavity/chute regions have not been examined in any direct way so far; however, some general trends of behavior can be visualized.

(a) Within the cavity (or pedestal region), we expect a recirculating flow pattern as illustrated in Figure D.1. [This flow pattern has been envisioned also in the HARDCORE model (Sienicki and Spencer, 1986).] The recirculation is induced by the strong jetting effect of the incoming steam and its effect is to provide for an intimate contact between melt and steam. We can visualize the melt gradually fragmenting and entraining in the steam flow as it exits into the chute region. We believe that this is the main process that controls the time scale over which melt is swept out of the cavity. As we have mentioned already, this time scale is rather important because it defines the degree of incoherence between steam blowdown and melt dispersal and hence it defines the degree of interaction possible between the two fluids. Within this region, important feedback effects are the heating up of steam and the gradual depletion of it as it reacts to produce hydrogen. The heat of reaction adds to this heating which is important in maintaining the high velocities responsible for the mixing and entrainment in the first place. 
(b) The main contact is between the gases and the fine debris particles that can follow the exiting gas streamlines into the keyway and chute region. Once in this region there may be strong deposition and reentrainment phenomena; however, we expect them to be of secondary significance in comparison to those within the pedestal region as discussed just above.

(c) Once into the intermediate compartment the two-phase, particle-laden gaseous jet will expand and impinge, thus providing a very effective mechanism for particle deposition (deentrainment) and permanent "trapping." Note that velocities in this compartment are too low for reentrainment, so only the very small fraction of extremely small particles that avoid such impact deposition can follow the gas as it streams into the open volume of the containment. Again, the thermal interactions in the subcompartment are considered of secondary significance to those that have already taken place within the pedestal area of the reactor cavity.

The physical concept (or perhaps hypothesis) that emerges from the above is that as a limiting condition the melt comes to chemical and thermal equilibrium in a flow process as it becomes entrained and swept out by the flowing steam. This basically occurs for the most part within the pedestal, which serves as a "metering device" for the flow entrainment process--that is, it provides the rate-limiting step in the entrainment and dispersal processes. Once in equilibrium the subsequent flow and interaction details in the chute and subcompartment regions do not really matter, but only to the extent that there is an efficient separation mechanism to trap the melt before it can exit into the main volume of the containment. Clearly, this concept is amenable to a straightforward bounding sort of analysis, which is not sensitive to the details of the geometry: simply maximize the loads with the entrainment rate (or time for complete sweepout) being the parameter. In fact, we expect that the resulting containment loading will increase monotonically as the sweepout time increases, while an upper bound to this can be easily defined in terms of the time that it takes to depressurize the vessel. 


\section{D.3 THE CONVECTION LIMITED CONTAINMENT HEATING (CLCH) MODEL}

The mathematical formulation of the conceptual model described above can be put into nine simple equations. The primary system pressure transient as a result of the blowdown-induced expansion (adiabatic) and the blowdown rate can be obtained from Eqs. (D.1) and (D.2), respectively (Shapiro, 1953).

$$
\begin{gathered}
\frac{P_{s, v}}{P_{s o, v}}=\left(1+\frac{\gamma-1}{2} \Gamma \frac{t}{\tau_{s}}\right)^{2 \gamma /(1-\gamma)} \\
\dot{m}_{s, b}=\eta A_{b} \rho_{s o, v} a_{s o} \Gamma\left(1+\frac{\gamma-1}{2} \Gamma \frac{t}{\tau_{s}}\right)^{(\gamma+1) /(1-\gamma)}
\end{gathered}
$$

In these equations the steam temperature transient is obtained from Eq. (D.3) and the speed of sound, $\mathrm{a}_{\mathrm{so}}$ and depressurization time constant $\tau_{\mathrm{s}}$ are defined in Eq. (D.4).

$$
T_{s, v}=T_{s o, v}\left[\frac{P_{s, v}}{P_{s o, v}}\right]^{(\gamma-1) / \gamma}
$$

where

$$
a_{s o}=\sqrt{\gamma R T_{s o, v}}, \Gamma=\left(\frac{2}{\gamma+1}\right)^{(\gamma+1) / 2(\gamma-1)} \text {, and } \tau_{s}=\frac{V_{y}}{\eta A_{b} a_{s o}}
$$

Now, assuming a sweepout, or entrainment/dispersal time of $\tau_{m}$, the entrainment rate can be defined, on a uniform basis, as in Eq. (D.5).

$$
\dot{m}_{m}= \begin{cases}\frac{m_{m o}}{\tau_{m}} & t \leq \tau_{m} \\ 0 & t>\tau_{m}\end{cases}
$$

From the chemical equilibration process we obtain complete reaction of the reactive metals $(\mathrm{Zr}$, Cr)--both represented here by an equivalent amount of zirconium, for convenience--with steam 
to the maximum extent allowed by the reactants. The heat of reaction added to the thermal equilibration flow process is depicted by a simple energy balance as in Eq. (D.6).

$$
T_{s, c}=\frac{\dot{m}_{m} C_{p, m} T_{m}+\dot{m}_{s, b} C_{p, s} T_{s, v}+\Delta H_{p} \dot{m}_{m}\left(\omega_{z r}\right)}{\dot{m}_{m} C_{p, m}+\dot{m}_{s, b} C_{p, s}} \quad t \leq \tau_{m}
$$

Finally, the containment atmosphere heatup resulting from the addition of the so-derived hot gases and the hydrogen combustion event associated with the burning of this hot hydrogen is obtained from Eqs. (D.7) and (D.8), appropriate to the entrainment and post-entrainment time periods, respectively (see item $c$ in the previous section).

$$
\begin{gathered}
\left(m_{s, a} C_{v, s}+m_{a} C_{v, a}\right) \frac{d T_{c}}{d t}=\dot{m}_{s} C_{p, s} T_{s, c}-\dot{m}_{s} C_{v, s} T_{a} t \leq \tau_{m} \\
T_{a, f}=\frac{m_{s, v}\left(\tau_{m}\right) C_{v, s} T_{s, v}\left(\tau_{m}\right)+m_{s, a}\left(\tau_{m}\right) C_{v, s} T_{a}\left(\tau_{m}\right)+m_{a} C_{v, a} T_{a}\left(\tau_{m}\right)+\Delta H_{H 2} m_{H 2}}{m_{s o} C_{v, s}+m_{a} C_{v, a}} \quad t>\tau_{m} \\
(\mathbf{D . 8})
\end{gathered}
$$

The last term in the unsteady energy balance [Eq. (D.7)] is due to the mass change of the containment atmosphere due to the steam flow. The steady-state energy balance [Eq. (D.8)] simply adds the remaining energy (and mass) of the reactor vessel (at the end of the entrainment period) to the containment atmosphere. This equation also contains all combustion energy, including the combustion that occurred during the entrainment period (this is simply a matter of convenience). Finally, the pressure corresponding to this final containment temperature is obtained from the ideal gas law as in Eq. (D.9).

$$
P_{a, f}=\left[\frac{m_{s o, v}}{V_{v}+V_{a}} R_{s}+\frac{m_{a}}{V_{v}+V_{a}} R_{a}\right] T_{a, f}
$$

By putting this system of equations into dimensionless form, it can be readily shown that the solution can be written (for a given set of thermal physical properties) as a function of five 
independent dimensionless groups involving the initial conditions, geometry, and the DCH-scale, as follows:

$$
\frac{\Delta P}{P_{a O}} \equiv \frac{P_{a, f}-P_{a O}}{P_{a O}}=f\left(\frac{P_{s o, v}}{P_{a O}}, \frac{V_{m}}{V_{a}}, \frac{T_{s o, v}}{T_{a O}}, \frac{\tau_{m}}{\tau_{s}}, \omega_{\mathrm{Zr}}\right)
$$

This means that the whole family of solutions can be mapped out once and for all by performing a series of calculations that cover the range of interest of the independent variables involved. This was done, and the results are summarized in Figure D.2--note that combustion of preexisting hydrogen has not been taken into account in these solutions; this issue is addressed momentarily. The following observations on these solutions can be made.

(a) All results attain an asymptotic behavior already at $\tau_{\mathrm{m}} / \tau_{\mathrm{s}} \sim 1$. Note that $\tau_{\mathrm{m}}$ (still at this point an unknown parameter) cannot be significantly greater than $\tau_{\mathrm{s}}$, in any case, because by such time the most significant fraction of driving force for dispersal has already been lost. On the other hand, significant gains in mitigating containment loading can be found if $\tau_{\mathrm{m}}$ were to obtain values well below $\tau_{\mathrm{s}}$. The asymptotic limits give us the absolute upper bounding estimates of such loads, while the case for the more realistic lower loads will be discussed in conjunction with experiments in the next section.

(b) Among the four other parameters (note that these are known as part of the specification of a particular situation of interest), the most important ones are the quantity of melt and the zirconium mass fractions in it. The initial primary system pressure has a moderate effect, and the initial primary system temperature effect is rather small. The overall trends are quite as expected; that is, loads increase with melt mass, amount of zirconium, driving pressure and with decreasing steam temperature. This last trend is because for a given steam pressure (and volume) decreasing temperature implies a larger mass of steam.

(c) Some additional subtle trends may also be noted. The pressurization trend "saturates" (reaches the asymptotic limit) at higher and higher values of $\tau_{\mathrm{m}} / \tau_{\mathrm{g}}$ as the quantity of melt increases (Figure D.2a). This is because at small values of 
$\tau_{\mathrm{m}} / \tau_{\mathrm{s}}$ the limiting ingredient in this convection-limited heating and metal oxidation is the steam, and for larger quantities of melt this limit is met sooner as $\tau_{\mathrm{m}} / \tau_{\mathrm{s}}$ is reduced to below a value of 1 . Basically, the same trend can be found in Figure D.2b, depicting the variation with zirconium content---the explanation is also the same. Finally, in Figures D.2c and D.2d we see a sort of "opposite" effect; it is related in both cases to the quantity of steam available which again becomes evident (as the limiting ingredient) at smaller and smaller values of $\tau_{\mathrm{m}} / \tau_{\mathrm{s}}$ as the quantity of steam increases. Evidently in all four figures we have a clear depiction of the drastic effect of incoherence between the steam blowdowns and melt entrainment phenomena, to reduce the loads even further from the asymptotic (just convection limited) loads.

Within the context of the $\mathrm{CLCH}$, the scaling rationale is quite simple, as depicted in Eq. (D.10). What is implicit there, and it is important to make it explicit here, is that to relate an experiment (or a calculation) correctly to a given reactor condition, we need to establish the basis for scaling the DCH-scale. On the other hand, we must also point out that such scaling is actually not needed (it can be bypassed) if one is willing to live with the somewhat higher than realistic values of loads at the asymptotic limits of the $\mathrm{CLCH}$ model solution. Conversely, to take credit for realistically lower loads one must address this challenging question of understanding and scaling the $\tau_{\mathrm{m}} / \tau_{\mathrm{s}}$ group. This point is taken up again in the next section, following the comparison with the experimental data. At this juncture, however, it is important to observe that the asymptotic loads produced here are rather modest and possible to live with, even though they may be somewhat conservative.

Finally, turning to hydrogen we must consider in more detail the role of iron as a source (this is important in experiments where the iron is a major component of the melt and, in particular, reactor scenarios for which the same is true, e.g., see Section 3 of the main report), and its combined effect with the preexisting hydrogen as a further energy contributor to containment pressurization. This source is reflected in an augmented CLCH model in terms of three components. The first accounts for reactions in the flow process between any remaining steam (after reacting with $\mathrm{Zr}$ and $\mathrm{Cr}$ ) and iron, with the hydrogen produced participating in the 
equilibrium mentioned in Section 2. Supposing that $\dot{r}$ moles of steam and $\dot{r}$ moles of iron participate in this reaction per unit time, this chemical equilibrium can be expressed by

$$
K=\frac{\dot{r}\left(\dot{M}_{H 2}+r\right)}{\left(\dot{M}_{m} \chi_{F e}-r\right)\left(\dot{M}_{s}-r\right)}
$$

where $\dot{M}$ is the molar rate of flow of component i. This is solved for $r$, and the solution is restricted to $\dot{r} \leq \dot{M}_{m} \chi_{F e}$ and $\dot{r} \leq \dot{M}_{s}$. Note that there may be hydrogen in the blowdown gas already, and in this case $\dot{M}_{H 2}$ must include this rate of release plus that produced from the highly reactive metals $\mathrm{Zr} / \mathrm{Cr}$. Exiting into a reactive atmosphere all this high temperature hydrogen, i.e. $\dot{M}_{H 2}+\dot{r}$, now is taken to burn. Thus the last terms in Eqs. (D.6) and (D.8) are modified to include these additional Fe-reaction and $\mathrm{H}_{2}$-combustion energies, respectively. As noted already, the effect of the Fe reaction energy itself is negligible, and usually the chromium component of the stainless steel together with any zirconium in reactor calculations are sufficient to nearly deplete the steam in the time interval $\tau_{\mathrm{m}}$; thus neither the predicted containment pressurization nor the hydrogen production is significantly affected by this component. The second and third components account for "additional" reactions occurring outside the entrainment/flow-equilibrium process between steam and the iron that remained "captured" in the cavity, and that "completely dispersed" outside the subcompartment into the open containment volume, respectively. These two components of the hydrogen "source," therefore, do not participate in the combustion processes; however, their consideration provides an important contribution in the interpretation of measured hydrogen in experiments, and they become important if the containment atmosphere reaches autoignition temperatures, in which case "everything" burns. [In the following discussions the hydrogen from these two mechanisms will be called "additional" hydrogen and more specifically, it will be referred to as the "captured" and "dispersed" iron sources, respectively.] For calculation purposes the "captured" iron is taken to react with the remainder of the blowdown (following $\tau_{\mathrm{m}}$ ), until either of the reactants is depleted, while the "dispersed" iron is taken to react with the steam in the open containment volume outside the DCH plume. Using only the "captured" iron source we define a lower, or "L"-prediction, and using both the "captured" and "dispersed" we define an upper or " $U$ "-prediction of hydrogen produced according to $\mathrm{CLCH}$. Because the primary purpose of considering this "additional" hydrogen is to understand the experiments, we use the experimental 
values for "captured" and "dispersed" iron. [Note, however, that the "L" characterization is appropriate for relatively small corrections due to relatively small amounts of melt "captured," as in the IET tests; when applied to cases where the fraction captured is as large, this equilibrium reaction approach to a non-entraining system may significantly overestimate this hydrogen source.] On the other hand, if the rest of the DCH process is severe enough to produce conditions favorable for autoignition the resulting loadings must account for the contribution of this additional hydrogen.

The autoignition process in steam-diluted hydrogen-air mixtures is not well understood today. Even without steam, quoted values vary from $850 \mathrm{~K}$ (DeSoete, 1975) to $1070 \mathrm{~K}$ (Hustad and Sonju, 1988). With these values as a general guide and some further insights from the IET tests (some of which produced quite high containment atmosphere temperatures), we expect that in the lean (under $\sim 5 \%$ ) hydrogen mixtures relevant to $\mathrm{DCH}$, that the upper limit quoted above may be applicable. As such, the autoignition is not expected to play a significant role in $\mathrm{DCH}$ loads, still in the following, and only for the purpose of illustrating the interesting structure of the solutions with autoignition, its occurrence was taken to occur at the temperature of $780 \mathrm{~K}$.

With the above, Eq. (D.10) must be modified to include the mass fraction of stainless steel in the melt, $\omega_{s s}$, the molar fraction of hydrogen in the RCS, $\chi_{v o, H 2}$, and the molar fraction of the preexisting hydrogen in the containment $\chi_{a O, H 2} .[10 \%$ of this preexisting hydrogen is taken to burn by entrainment in the hot plume exiting the subcompartment.] That is:

$$
\frac{\Delta P}{P_{a O}}=g\left[\frac{P_{s O, v}}{P_{a O}}, \frac{V_{m}}{V_{a}}, \frac{T_{s o, v}}{T_{a O}}, \frac{\tau_{m}}{\tau_{s}}, \omega_{z r}, \omega_{s s}, \chi_{v O, H 2}, \chi_{a O, H 2}\right]
$$

We illustrate (in these calculations $10 \%$ of the melt is assumed to be dispersed in the main containment volume--see next section) the behavior/structure of this function in two different ways. One, along the lines of representing the function of Eq. (D.10), is obtained by fixing the parameters already covered in Figure D.2 to some representative, nominal values, and showing the effect of independent variations in $\omega_{s s}, \chi_{v O, H 2}$ and $\chi_{a O, H 2}$. The other way is aimed at actually representing the function itself and is given in tabular form for two fixed values of $\tau_{\mathrm{m}} / \tau_{\mathrm{s}}$, 0.5 and 0.7 (see next section) and includes all permutations of the parameters in this function 
over reasonable intervals of variation for reactor conditions (see Section 3.0 of the body of the report). These two sorts of results are given in Figure D.3 and Table D.1 and D.2, respectively. From these results we see that the structure (i.e., shape, trends and asymptotic form) of function $\mathrm{g}$ in Eq. (D.12) is very similar to function $\mathrm{f}$ in Eq. (D.10), except for the sudden "jumps" in pressurization due to autoignition (as noted already, this is taken to occur at a containment temperature of $780 \mathrm{~K}$; this was not reflected in the solutions given for $\mathrm{f}$ ). Now, regarding this important new feature, we see that it does not set in except for large values of $\tau_{\mathrm{m}} / \tau_{\mathrm{s}}$ (in the next section we find that for the reactor values greater than 0.7 are extremely unlikely), but even if it does, the resulting dimensionless pressure ratios are below $\sim 3.0$. For an initial containment pressure of $0.2 \mathrm{MPa}$, this implies a final pressure of under $0.8 \mathrm{MPa}$, which happens to be near the point where the Zion fragility curve (see Section 5 of the main report) begins to exist! Also, it is interesting to see in these results that the onset of autoignition (in terms of $\tau_{m} / \tau_{s}$ ), rather than the final pressure, is affected by broad variations in steel melt fraction and the hydrogen content of the blowdown gases. On the other hand, as expected, the "preexisting" hydrogen does have a significant effect on the final pressure (its effect on $\tau_{\mathrm{m}} / \tau_{\mathrm{s}}$, for autoignition, is from burning $10 \%$ of it in the calculation as already stated), but note that to produce a "preexisting" $3.5 \%$ fraction in the containment would require oxidizing about half of the zirconium in the core.

To further test the onset of autoignition bounds we have carried out the same kinds of calculations with an initial (steam) pressure ratio of 50. The results are shown in Figure D.4, and again the $\tau_{\mathrm{m}} / \tau_{\mathrm{s}}$ values (needed for autoignition) are outside the realm of being physically meaningful. In fact, they would be expected to be even lower than 0.7 for initial pressures greater than $8 \mathrm{MPa}$ (see next section)--a pressure ratio of 50 means an initial steam pressure of $10 \mathrm{MPa}$. Based on all this, we conclude that using realistic initial conditions, autoignition cannot be obtained with physically meaningful treatment of $\mathrm{DCH}$ phenomenon (embodied in the $\tau_{\mathrm{m}} / \tau_{\mathrm{s}}$ ratio). From a complementary perspective, using a realistic treatment of $\tau_{\mathrm{m}} / \tau_{\mathrm{s}}$ (say a value of 0.5 ), we find that the needed initial conditions are grossly in violation of what is possible. This is illustrated by the autoignition boundary maps in Figure D.5. For 80 tons of melt participating in the ejection process, and pressure ratio lower than 70 , we see that the autoignition boundary vanishes off the map. This pressure ratio translates to an initial steam 
pressure of $14 \mathrm{MPa}$ which, as discussed in section 3 of the main report, is not possible to exist at the time of lower head failure in a reactor system. To conclude this discussion, it is recalled that the $780 \mathrm{~K}$ autoignition threshold was selected for sensitivity purposes. The margins to autoignition are even greater for the more realistic value of $1070 \mathrm{~K}$.

\section{D.4 COMPARISONS WITH THE INTEGRAL EXPERIMENT TESTS}

As mentioned already, based on SASM's advice the NRC redirected the DCH experimental program with emphasis on representing the intermediate compartment. The counterpart series of tests was conducted, accordingly, in the Surtsey (1/10 scale) and COREXIT (1/42 scale) facilities at SNL and ANL, respectively. The Surtsey facility is depicted in Figures D.6 and D.7, and the design of the COREXIT facility is very similar. The melt is simulated in these tests by iron-alumina thermite, spiked with chromium metal at quantities intended to represent (chemically) the zirconium content in the corium melt. Experiments were carried out with inerted containment atmospheres (to exclude combustion of the hydrogen produced), with non-inerted (reactive) atmospheres, and also with preexisting hydrogen in them ( $2 \%$ by volume which represents typical conditions for reactor accidents and $4 \%$ to test the limits of flammability of this hydrogen). All tests were driven with near-saturated steam at pressures around 6 to 7 MPa. Other conditions such as breach size, quantity of melt, etc., were chosen according to certain scaling attempts made as a part of the SASM efforts (Pilch, 1992b). Initial containment pressure in all but one test was fixed at 2 bar; in one test (at ANL) a pressure of 1 bar was selected for the purpose of checking the scaling suggested by the CLCH model. Further details on these facilities and experimental results can be found in Appendices $\mathrm{G}$ and $\mathrm{H}$. At this time, after a total of 7 experiments in Surtsey and 4 experiments in COREXIT the experimental program is complete for the Zion Geometry. The Surtsey facility is now being modified to represent the Surry reactor geometry, which also will be modeled in a new facility, the Containment Technology Test (CTT) facility at $1 / 6$ scale.

The conditions that define each test in the SNL and ANL facilities are given in Tables D.3 and D.4, respectively. The results obtained using the CLCH model are shown in comparison to the measured pressure rises in Figures D.8 and D.9. In these figures, the 
experimental results were located over a $\tau_{\mathrm{m}} / \tau_{\mathrm{g}}$ range, to include uncertainties, in the as deduction of this quantity from the experimental data in each case. For this purpose, the $\tau_{\mathbf{z}}$ was calculated from Eq. (D.14) with a discharge coefficient obtained by matching the pressure decay measured in each experiment (typically, this gave values in the 0.5 to 0.7 range), and the $\tau_{\mathrm{m}}$ was found from the upper compartment and cavity pressure transients in the manner illustrated in Figure D.10. This procedure was also confirmed by the pyrometer signals ("seeing" the beginning and the end of the entrainment period) placed at the cavity exit in Surtsey. As seen in Figures D.8a and D.8b, the Surtsey data are closely within the narrow bounds defined by the " $L$ " and " $U$ " limits, reflecting the treatment of iron chemistry, as discussed in the previous section. [Moreover, it should be noted that these predictions are only slightly affected by the iron chemistry--i.e., very similar results are obtained by ignoring it altogether.] In Figure D.9, we see that the comparison with COREXIT data is also good, but slightly over-predicted for tests IET-3 and IET-7. This could be because of heat losses, not accounted for, and becoming more pronounced (than in Surtsey), at the small scale of COREXIT. Test IET-7 was run at half the initial containment pressure to check for $\mathrm{CLCH}$ scaling--it predicts doubling of $\triangle \mathrm{P} / \mathrm{P}_{\mathrm{\alpha}}$, and the data bear this out. These figures also show the importance of combustion--the prediction lines and data with a $\Delta \mathrm{P} / \mathrm{P}_{\mathrm{aO}}-0.5$ are for inerted containment atmospheres.

Finally, we note that in all these tests, the experimental $\tau_{\mathrm{m}} / \tau_{\mathrm{s}}$ values are in the range 0.4 to 0.9 , while the CLCH predictions are very consistent with the lower end of this range. This shows a lack of scale dependence, and in earlier considerations, we thought this might be a characteristic ratio appropriate to be used directly in predicting pressure rises in reactor applications of the CLCH model as well. It turned out that this is not quite so; a simple scaling argument revealed strong dependencies on pressure, temperature, and breach area "changes" from the IET-series of tests (in which all these parameters were nominally the same). This led to an examination of the previous test series in Surtsey [the Limited Flight Path, or LFP series (Allen et al., 1991)] in which these parameters happened to have been varied over significantly wide ranges and revealed a remarkable agreement with the predictions. This is discussed in the next section. The discussion of hydrogen production is postponed until the following section. 


\section{D.5 THE PREDICTION OF THE "DCH-SCALE"}

As already discussed, the melt sweepout time, $\tau_{\mathrm{m}}$, is related to the in-pedestal recirculation time scale which by consideration of the system size (length scale) and the driving steam velocity [see Eq. D.2], can be seen to scale as

$$
\tau_{m} \sim L \frac{\sqrt{T_{s o, v}}}{P_{s o, v}}
$$

where $\mathrm{L}$ is a characteristic cavity length scale. On the other hand, from Eq. D.4 we see that $\tau_{\mathrm{s}}$ scales as

$$
\tau_{s} \sim \frac{L}{m(\eta) \sqrt{T_{s o, v}}}
$$

where $m(\eta)$ is the breach area scale factor, including the effect of the discharge coefficient, to account for variations in break area in otherwise geometrically similar systems (that is, $\mathrm{m}=$ $A_{b} / A_{b, r}$, where $A_{b, r}$ is some arbitrary breach area taken as a reference value). From the above, we find that the "DCH-scale" scales as

$$
\frac{\tau_{m}}{\tau_{s}} \sim m(\eta) \frac{T_{s o, v}}{P_{s o, v}}
$$

and that, in particular, it is independent of the physical system scale (size).

Comparisons of these relations with experimental data is done for $\tau_{\mathrm{m}}$ separately, as well as for the $\tau_{\mathrm{m}} / \tau_{\mathrm{s}}$ combination, which is the quantity of primary interest. In each experiment, the discharge coefficient is determined by matching the measured vessel (accumulator) pressure to the calculated one, thus there is no need to show comparisons of the $\tau_{3}$ 's. We ignore tests in which the determination of $\tau_{\mathrm{m}}$ and/or $\tau_{\mathrm{s}}$ from the available data was ambiguous. To maintain attention to the highly dispersive regime of interest here, we consider only data for which the observed dispersal (out of the cavity) was high (over 70\%). Also, we ignore tests in which the discharge coefficient was found to be too low (say, less than 0.6 ) as indicative of some internal restriction in the blowdown system or of some other unforeseen malfunction (in a few of the old tests, $\eta$ values as low as 0.3 were found). This leaves only the following tests: 
1/40-Scale (ANL): IET-7, IET-8

1/10-Scale (SNL): IET-1, IET-6

1/6-Scale (SNL): IET-9, IET-10, IET-11

and the comparison with Eq. D.13 is shown in Figure D.11. In this application, the system length scale was taken as the cube-root of the cavity volume, in a view that the different cavity geometries may be seen as "distortions" of system scale. The result is

$$
\tau_{m}(s)=0.2 V_{c}^{1 / 3}\left(m^{3}\right) \frac{\sqrt{T_{s o, v}(K)}}{P_{s o, v}(M P a)}
$$

Note that there is no independent effect of breach area, and this is also born out from Figure D.11, which includes data of breach diameters (scaled to reactor systems) of 0.40 to $0.56 \mathrm{~m}$. These data cover primary system pressure conditions in the 6 to $13.5 \mathrm{MPa}$ range, and temperatures in the 571 to $787 \mathrm{~K}$ range.

A further, but more tentative test of Eq. D.16, is made by including three additional runs made with steam pressures in the 3.6 to $4.6 \mathrm{MPa}$ range and relaxing the discharge coefficient acceptance criteria to include values down to the 0.4 to 0.6 range. These three tests are the WC-1 (Allen et al., 1991a), LFP-1A and LFP-2B, all run at 1/10-scale. With these tests, the reactor-scaled breach range considered is extended to $0.67 \mathrm{~m}$. As seen in Figure D.11 (these data are referred to as extended data range), the comparison remains very good.

The $\tau_{\mathrm{m}} / \tau_{\mathrm{s}}$ can be predicted by combining Eqs. D.4 and D.16. The results of these predictions are compared to the experimental data, for all 10 runs considered here, in Figure D.12. Note that the low pressures and large breach areas in tests LFP-1A and LFP-2B drive the "DCH-scale" to quite large values $(\sim 2)$, in agreement with Eq. D.15, while the low pressure in WC-1 is well compensated by the small breach size to maintain a "DCH-scale" value to less than 1, again in agreement with Eq. D.15. On the other hand, we should also note that for the high driving pressures of interest in reactor predictions $\left(\mathrm{P}_{\mathrm{sO}, \mathrm{v}}>6 \mathrm{MPa}\right)$ and for the expected breach sizes (as in IET-9 or IET-11) we expect the "DCH-scale" for the reactor to be less than 1. 


\section{D.6 DISCUSSION OF IRON CHEMISTRY IN DCH}

From the comparisons shown in section D.4, it is clear that the energetics of hydrogen production and combustion are fully well represented in the CLCH model. Also, the energetics of the iron chemistry during the dispersal period are well represented, but because the process in the DCH-scale range of interest is steam-limited (by the reaction of the highly reactive metals), this does not provide a really good test for it. More importantly, we need to consider in more detail the "additional" hydrogen discussed in section D.3, because although it does not enter the comparisons made so far (on $\Delta \mathrm{P} / \mathrm{P}_{\mathrm{a}}$ ), it would, if a case were to produce autoignition. In particular, we need to be sure that the CLCH model conservatively estimates this "additional" hydrogen. The main emphasis in this discussion will be on the IET-series, but the LFP experiments and two tests reported by Henry and Hammersley (1991) from FAI/DCH test series can provide some very useful perspectives, and they are included in the discussion.

Hydrogen measurements were made from the so-called "grab samples" taken at several times, beginning at 2 minutes after the blowdown, and at several locations within the containment volume. From the measured hydrogen-to-nitrogen ratio, the total "remaining" quantity of hydrogen could be deduced, and from the oxygen-to-nitrogen ratio, the total quantity of oxygen depletion and hence of hydrogen "burned" could be obtained. From these results, and after accounting for any "preexisting" hydrogen, the total quantity of hydrogen "produced" could be estimated. Now, recognizing that oxygen may be consumed even after the DCH event, it is clear that the data (on hydrogen production) of really high confidence are those obtained in tests with inerted atmospheres. This issue became clear when in the last ANL-IET experiment an earlier grab sample, at 30 seconds, gave a hydrogen production estimate of 3.45 moles, as compared to a value of 5.19 moles deduced from the samples taken later. However, following this up with a similar check in the last SNL-IET experiment did not indicate any discrepancy, and on this basis, it would not appear appropriate at this time to discard the SNL-IET hydrogen data.

The implementation of the CLCH model was made with the posttest measured material dispositions shown in Tables D.5 and D.6 for the SNL and ANL tests, respectively. The "L" 
and "U" predictions of hydrogen produced are compared to the experimentally deduced values in Tables D.7 and D.8. From a first impression of these comparisons, the "predictions" are rather good; in fact, upon a closer examination, they are even better.

Let us view the comparisons in Table D.7 in terms of two sub-groups; namely, tests \#1, $1 R$, and 5 , involving non-reactive atmospheres, and tests $\sharp 3,4,6$ and 7 , involving reactive atmospheres. The hydrogen data in the first group are not subject to the "difficulties" mentioned above, and for these demonstrably high quality tests we see that the " $L$ " and " $U$ " limits narrowly bound the measured values. For the second group a test-by-test discussion is necessary. Test \#3 is the only one where even the " $L "$ limit overpredicts the data--such a low measurement is not seen in any of the other tests and it must therefore be considered suspect. For test \#4, the " $\mathrm{L}$ " limit is a little too low, but the "U" limit agrees very well with the data. In this test, the maximum dispersal was observed and the interpretation here is that it needs to be accounted for in estimating "additional" hydrogen production. For test \#6, which as far as material disposition looks very much like test \#1, there is a significant underprediction in both limits--this is in contrast to test \#1 where the prediction is excellent. Note in Table D.7 that the two sets of predictions are almost identical, while the data differ by $\sim 30 \%$. A likely explanation is that this additional $30 \%$ derived from the relatively strong fuel-coolant interaction observed in this test and associated steam production. Finally, for test \#7, the predictions narrowly bound the data, which are consistent with data from other tests.

Similarly, for the ANL tests, in Table D.8, we see that for the inert atmosphere test (ANL/IET-1RR) the prediction is excellent. The comparisons for the reactive atmosphere tests are shown for completeness; as noted already, these "measurements" may be significantly in error. However, also note that for the "better" (30-second grab sample) data in test ANL/IET-7, the prediction is quite good.

The LFP tests are very interesting with regard to hydrogen production because all of them were run with an inert atmosphere. Also, they are interesting because, as discussed in section D.5, they introduce significant parameter variations (steam pressure, breach size, cavity geometry) in relation to the IET series. These tests were run in Surtsey without a detailed 
subcompartment, but with a horizontal plate positioned at various distances away from the cavity exit. This separation is deemed an adequate approximation of the main subcompartment feature (i.e., to capture the debris dispersed out of the cavity); thus, the CLCH model is applicable, except perhaps for the last test where the plate was put at $8 \mathrm{~m}$, i.e., near the roof of the Surtsey containment vessel. The relevant parameters are summarized in Table D.9. The predictions, including that of pressure rise, are compared to the data in Table D.10.

All of these predictions were made at the " $U$ " limit; however, with the exception of test LFP-1B, the fraction of melt dispersed above the plate was less than $1 \%$, so that the " $U$ " and " $L$ " limits essentially coincide. For test LFP-2C, the dispersal was $8 \%$, but even for this case the two limits are very close, in relation to the total, because of the large fraction of melt retained in the cavity. We see the hydrogen prediction to be very good in the one test $(1 \mathrm{~A})$ that gave reasonably larger dispersal, and to be considerably off in all other tests that produced significant melt retention in the cavity (see Table D.9). As noted in Section D.3, this is to be expected, as the model uses equilibrium reaction kinetics for this largely stratified geometry involving significant quantities of melt. This could be easily rectified by reducing, for example, the reaction rates after the primary system pressure decayed below some level, but in light of the intended CLCH application, introducing this complication did not appear to be worthwhile. The pressurization results are excellent except for the two tests (1B and 2A) with the lowest dispersal. For these tests, the final pressure is significantly overpredicted, as expected. It is also interesting to see that the model begins to break down when the "subcompartment" geometry is lost by moving the plate to the roof of the main containment space. As expected, when this occurs, the model begins to lose its bounding quality; test LFP-8A, where this occurs, is the only one underpredicted by the CLCH model!

Finally, the FAI tests are interesting because the melt did not include highly reactive metals, but only iron $(20 \mathrm{~kg})$ and revealed significant hydrogen production. The geometry was similar to Zion (as in the IET-series) at a linear scale of $1 / 20$ th. In tests FAI/DCH-1 and FAI/DCH-4 the model cavity was supplied with $0.7 \mathrm{~kg}$ of water to a depth of $1.6 \mathrm{~cm}$, and this water provided sufficient contact with the melt to produce -17.3 moles of hydrogen (equivalent to a $2.4 \%$ molar concentration in the containment atmosphere), as demonstrated by the 
nitrogen-driven test DCH-1. Test DCH-4, on the other hand, was steam-driven, and it produced $\sim 37$ moles of hydrogen ( $\sim 5.4 \%$ molar concentration) or about double the amount. If we assume that the difference, -20 moles, is due to iron melt reactions with the steam driving the ejection, it would compare favorably with the 21 moles predicted by CLCH model applied to the particular conditions of these tests.

\section{D.7 CONCLUSIONS}

A simple analytical model is proposed and shown to capture the essence of the DCH phenomenon. The model is based on assuming thermal/chemical equilibrium in the melt dispersal (flow) process, and separation of the melt out of this "equilibrium steam" in the intermediate compartment. The model reveals a natural scale (hence, named the "DCH-scale") for the DCH phenomenon, and the results are in very good agreement with the IET series. On this basis, reactor predictions can be made quite simply, provided the "DCH-scale" for the particular condition of interest is known. This prediction of "DCH-scale" is also addressed by a scaling approach that is shown to be consistent with the experimental data. Finally, reactor predictions of $\mathrm{DCH}$ loads are convenient for use under a wide variety of conditions.

\section{D.8 REFERENCES}

Allen, M.D., M. Pilch, R.T. Nichols and R.O. Griffith (1991). Experiments to Investigate the Effect of Flight Path on Direct Containment Hearing (DCH) in the Surtsey Test Facility, SAND91-1105, Sandia National Laboratories, Albuquerque, NM.

Allen, M.D., M. Pilch, R.T. Nichols, and R.O. Griffith (1991a). Experiments to Investigate the Effects of Hole Diameter Resulting From Bottom Head Failure on Direct Containment Heating (DCH) in the Surtsey Test Facility: The WC-1 and WC-3 Tests, SAND91-2153, Sandia National Laboratories, Albuquerque, NM.

Bergeron, K.D. and D.C. Williams (1985). "CONTAIN Calculations of Containment Loading of Dry PWRs," Nucl. Eng. Des., 90, 153-159.

DeSoete, G.G. (1975). "The Flammability of Hydrogen-Oxygen-Nitrogen Mixtures at High Temperatures," Riv. Combust, XXIX, 5. 
Henry, R.E. (1989). "Evaluation of Fission Product Release Rates During Debris Dispersal," PSA '89, Proceedings of the ANS/ENS International Topical Meeting: Probability, Reliability and Safety Assessment, pp. 375-383.

Henry, R.E. and R.J. Hammersley (1991). "Direct Containment Heating Experiments in a Zion-Like Geometry," Proceedings National Heat Transfer Conference, Minneapolis, AIChE Symposium Series No. 283, Vol. 87.

Henry, R.E. and M.G. Plys. (1990). MAAP-3.OB -- Modular Accident Analysis Program for LWR Power Plants: User Guidance, Electric Power Research Institute Report EPRI NP-7071-CCML, Volumes 1, 2 and 3.

Hustad, J.E. and O.K. Sonju (1988). "Experimental Studies of Lower Flammability Limits of Gases and Mixtures of Gasses at Elevated Temperatures," Combust. Flame, 71, 283.

IDCOR (July 1985). Technical Support for Issue Resolution, IDCOR Technical Report 85.2.

Levy, S. (1991). "Debris Dispersal From Reactor Cavity During Low Temperature Simulant Tests of Direct Containment Heating. Part I: Tests with Constant Gas Flow Rates; Part II: Tests with Blowdown Gas Conditions," Proceedings National Heat Transfer Conference, Minneapolis, MN.

Macbeth, R.V., P.W. Rose and D.J. Mogford (1988). "Experimental Modelling of Core Debris Dispersion from the Vault Under a PWR Pressure Vessel --- Part 3. Results of Varying the Size Scaling Factor of the Model Used," AEEW-R2426, December 1988.

Macbeth, R.V. and R. Trenberth (1987). "Experimental Modelling of Core Debris Dispersion from the Vault Under a PWR Pressure Vessel -- Paft 1. Preliminary Experimental Results," AEEW-R1888, December 1987.

Pilch, M. (1992a). "Kinetic Limitations to Adiabatic Equilibrium Models of DCH," AIChE Proceedings National Heat Transfer Conference, San Diego.

Pilch, M. (1992b). "Scaling Rationale for Counterpart Tests Conducted at Two Different Physical Scales," Report submitted to NRC's DCH Peer Review Group.

Rose, P.W. (1987). "Experimental Modelling of Core Debris Dispersion from the Vault Under a PWR Pressure Vessel -- Part 2. Results of Including the Instrument Tubes Support Structure in the Experiment," AEEW-R2143, December 1987.

Shapiro, A.H. (1953). The Dynamics and Thermodynamics of Compressible Fluid Flow, 2 vols., Ronald, New York.

Sienicki, J.J. and B.W. Spencer (1986). "A Multifluid, Multiphase Flow and Heat Transfer Model for the Prediction of Sweepout from a Reactor Cavity," Proceedings of 4th Miami International Symposium on Multi-phase Transport and Particulate Phenomena, Miami Beach, FL, December 15-17, 1986. 
Sienicki, J.J. and B.W. Spencer (1987). "The PARSEC Computer Code for Analysis of Direct Containment Heating by Dispersed Debris, Heat Transfer--Pittsburg 1987, ed. R. W. Lyczkowski, AIChE Symposium Series No. 257, Vol. 83, p. 355, American Institute of Chemical Engineers, New York.

Spencer, B.W., J.J. Sienicki, B.R. Sehgal and M. Merilo (1988). "Results of EPRI/ANL DCH Investigations and Model Development," Water Reactor Safety Information Meeting, Avignon, 314-1.

Tutu, N.K., et al. (1988a). Debris Dispersal from Reactor Cavities During High Pressure Melt Ejection Accident Scenarios, NUREG/CR-5146, BNL-NUREG-52147, July 1988.

Tutu, N.K., T. Ginsberg and C. Finfrock (1988b). "Low Pressure Cutoff for Melt Dispersal from Reactor Cavities," Fourth Proceedings of Nuclear Thermal Hydraulics, 29-37.

Tutu, N.K. and T. Ginsberg (1990). Melt Dispersal Experiments with the 1/42 Scale Watts Bar Cavity Model, Brookhaven National Laboratory, Technical Report No. A-3024, April 1990.

Zuber, N., B. Boyack, A. Dukler, P. Griffith, J. Healzer, R. Heniry, M. Ishii, J. Lehner, S. Levy, F. Moody, M. Pilch, B. Sehgal, B. Spencer, T. Theofanous, J. Valente, G. Wilson and W. Wulff (November 1991). An Integrated Structure and Scaling Methodology for Severe Accident Technical Issue Resolution, NUREG/CR-5809, EGG-2659, Idaho National Engineering Laboratory, EG\&G Idaho, Inc.

\section{D.9 NOMENCLATURE}

$\begin{array}{ll}A & \text { area } \\ \mathrm{a}_{\mathrm{s}} & =\left(\tau \mathrm{R}_{\mathrm{s}} \mathrm{T}_{\mathrm{so}}\right)_{0.5} \text { initial sound speed of steam } \\ \mathrm{C}_{\mathrm{p}} & \text { specific heat for constant pressure } \\ \mathrm{C}_{\mathrm{v}} & \text { specific heat for constant volume } \\ \mathrm{d} & \text { diameter } \\ \mathrm{m} & \text { mass; scale factor } \\ \dot{m} & \text { mass flow rate } \\ \mathrm{P} & \text { pressure } \\ \mathrm{R} & \text { gas constant } \\ \mathrm{T} & \text { temperature } \\ \mathrm{t} & \text { timer } \\ \mathrm{V} & \text { volume }\end{array}$

Greek

$\Delta \mathrm{H}_{\mathrm{r}} \quad$ heat of metal-steam reaction (per unit mass of metal)

$\Delta \mathrm{H}_{\mathrm{H} 2}$ heat of hydrogen combustion (per unit mass) 
$\eta \quad$ discharge coefficient

$\tau_{\mathrm{m}} \quad$ time for the process of melt removal from cavity

$\tau_{\mathrm{s}} \quad=\mathrm{V}_{\mathrm{v}} / \mathrm{A}_{\mathrm{b}} \mathrm{a}_{\mathrm{so}}$ primary system time constant, Eq. (D.4)

$\gamma=\mathcal{C}_{p} / \mathcal{C}_{v}$ ratio of specific heats

$\rho$ density

$\chi \quad$ mole fraction

$\omega$ mass fraction

\section{Subscripts}

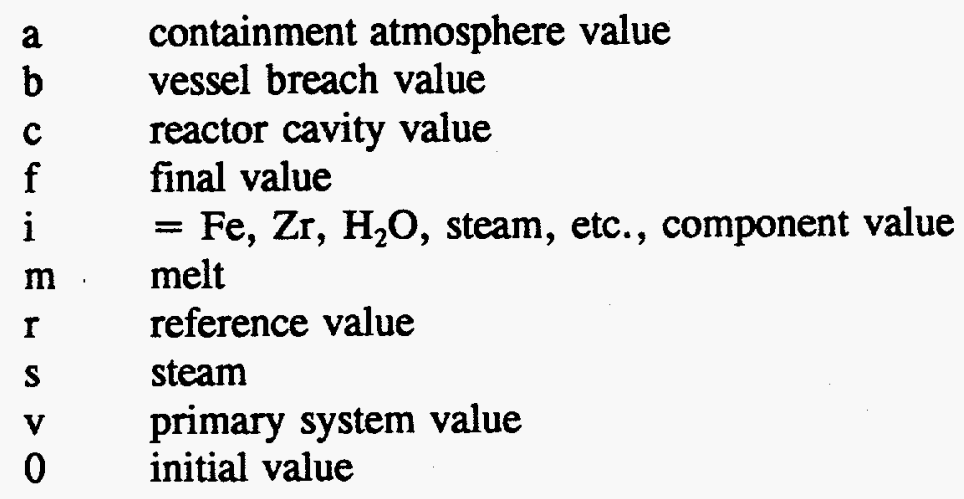




\begin{tabular}{|c|c|c|c|c|c|}
\hline \multicolumn{6}{|c|}{$\begin{array}{l}\text { Table D.1 } \\
\begin{array}{l}\text { Numerical representation of the function in Eq. } \\
\text { in the relevant ranges of its arguments } \\
\left(\tau_{m} / \tau_{p}\right)=0.5\end{array}\end{array}$} \\
\hline$P_{s o, v} / P_{a o}$ & $V_{m} / V_{a}$ & $\boldsymbol{\omega}_{z_{r}}$ & $\boldsymbol{\omega}_{s s}$ & $\chi_{a 0, H 2}$ & $\Delta P / P_{a o}$ \\
\hline 30. & $0.64 \mathrm{E}-04$ & 0.10 & 0.10 & 0.028 & 0.848 \\
\hline 30. & $0.64 \mathrm{E}-04$ & 0.10 & 0.25 & 0.028 & 0.857 \\
\hline 30. & $0.64 \mathrm{E}-04$ & 0.10 & 0.40 & 0.028 & 0.867 \\
\hline 30. & $0.64 \mathrm{E}-04$ & 0.25 & 0.10 & 0.018 & 0.811 \\
\hline 30. & $0.64 \mathrm{E}-04$ & 0.25 & 0.25 & 0.018 & 0.821 \\
\hline 30. & $0.64 \mathrm{E}-04$ & 0.25 & 0.40 & 0.018 & 0.831 \\
\hline 30. & $0.64 \mathrm{E}-04$ & 0.40 & 0.10 & 0.007 & 0.775 \\
\hline 30. & $0.64 \mathrm{E}-04$ & 0.40 & 0.25 & 0.007 & 0.785 \\
\hline 30. & $0.64 \mathrm{E}-04$ & 0.40 & 0.40 & 0.007 & 0.794 \\
\hline 30. & $0.95 \mathrm{E}-04$ & 0.07 & 0.07 & 0.028 & 0.894 \\
\hline 30. & $0.95 \mathrm{E}-04$ & 0.07 & 0.17 & 0.028 & 0.905 \\
\hline 30. & $0.95 \mathrm{E}-04$ & 0.07 & 0.27 & 0.028 & 0.916 \\
\hline 30. & $0.95 \mathrm{E}-04$ & 0.17 & 0.07 & 0.018 & 0.858 \\
\hline 30. & $0.95 \mathrm{E}-04$ & 0.17 & 0.17 & 0.018 & 0.868 \\
\hline 30. & $0.95 \mathrm{E}-04$ & 0.17 & 0.27 & 0.018 & 0.879 \\
\hline 30. & $0.95 \mathrm{E}-04$ & 0.27 & 0.07 & 0.007 & 0.822 \\
\hline 30. & $0.95 \mathrm{E}-04$ & 0.27 & 0.17 & 0.007 & 0.832 \\
\hline 30. & $0.95 \mathrm{E}-04$ & 0.27 & 0.27 & 0.007 & 0.843 \\
\hline 30. & $0.13 E-03$ & 0.05 & 0.05 & 0.028 & 0.945 \\
\hline 30. & $0.13 \mathrm{E}-03$ & 0.05 & 0.12 & 0.028 & 0.956 \\
\hline 30. & $0.13 \mathrm{E}-03$ & 0.05 & 0.20 & 0.028 & 0.967 \\
\hline 30. & $0.13 E-03$ & 0.12 & 0.05 & 0.018 & 0.908 \\
\hline 30. & $0.13 \mathrm{E}-03$ & 0.12 & 0.12 & 0.018 & 0.919 \\
\hline 30. & $0.13 \mathrm{E}-03$ & 0.12 & 0.20 & 0.018 & 0.931 \\
\hline 30. & $0.13 \mathrm{E}-03$ & 0.20 & 0.05 & 0.007 & 0.872 \\
\hline
\end{tabular}




\begin{tabular}{|c|c|c|c|c|c|}
\hline \multicolumn{6}{|c|}{ 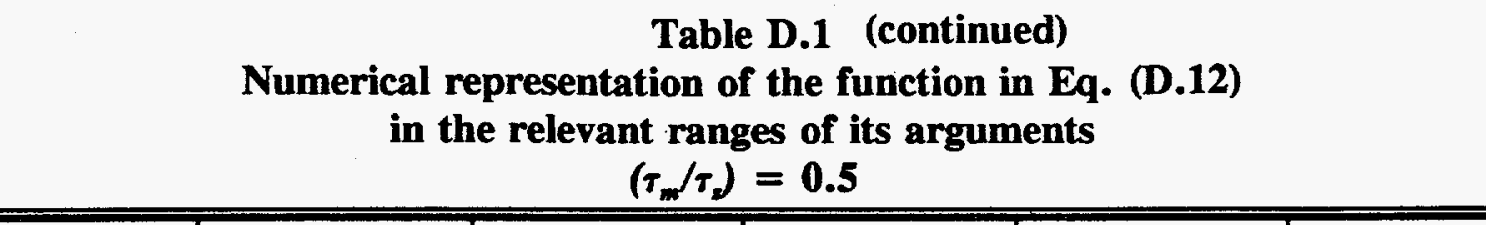 } \\
\hline$P_{s o, v} / P_{a b}$ & $V_{m} / V_{a}$ & $\boldsymbol{\omega}_{\mathrm{zr}}$ & $\boldsymbol{\omega}_{s s}$ & $\chi_{a 0, H 2}$ & $\Delta P / P_{a o}$ \\
\hline 30. & $0.13 \mathrm{E}-03$ & 0.20 & 0.12 & 0.007 & 0.883 \\
\hline 30. & $0.13 \mathrm{E}-03$ & 0.20 & 0.20 & 0.007 & 0.894 \\
\hline 40. & $0.64 \mathrm{E}-04$ & 0.10 & 0.10 & 0.028 & 1.068 \\
\hline 40. & $0.64 \mathrm{E}-04$ & 0.10 & 0.25 & 0.028 & 1.076 \\
\hline 40. & $0.64 \mathrm{E}-04$ & 0.10 & 0.40 & 0.028 & 1.085 \\
\hline 40. & $0.64 \mathrm{E}-04$ & 0.25 & 0.10 & 0.018 & 1.034 \\
\hline 40. & $0.64 \mathrm{E}-04$ & 0.25 & 0.25 & 0.018 & 1.042 \\
\hline 40. & $0.64 \mathrm{E}-04$ & 0.25 & 0.40 & 0.018 & 1.050 \\
\hline 40. & $0.64 \mathrm{E}-04$ & 0.40 & 0.10 & 0.007 & 0.998 \\
\hline 40. & $0.64 \mathrm{E}-04$ & 0.40 & 0.25 & 0.007 & 1.005 \\
\hline 40. & $0.64 \mathrm{E}-04$ & 0.40 & 0.40 & 0.007 & 1.014 \\
\hline 40. & $0.95 \mathrm{E}-04$ & 0.07 & 0.07 & 0.028 & 1.109 \\
\hline 40. & $0.95 \mathrm{E}-04$ & 0.07 & 0.17 & 0.028 & 1.119 \\
\hline 40. & $0.95 \mathrm{E}-04$ & 0.07 & 0.27 & 0.028 & 1.129 \\
\hline 40. & $0.95 \mathrm{E}-04$ & 0.17 & 0.07 & 0.018 & 1.074 \\
\hline 40. & $0.95 \mathrm{E}-04$ & 0.17 & 0.17 & 0.018 & 1.084 \\
\hline 40. & $0.95 \mathrm{E}-04$ & 0.17 & 0.27 & 0.018 & 1.094 \\
\hline 40. & $0.95 \mathrm{E}-04$ & 0.27 & 0.07 & 0.007 & 1.038 \\
\hline 40. & $0.95 \mathrm{E}-04$ & 0.27 & 0.17 & 0.007 & 1.047 \\
\hline 40. & $0.95 \mathrm{E}-04$ & 0.27 & 0.27 & 0.007 & 1.057 \\
\hline 40. & $0.13 \mathrm{E}-03$ & 0.05 & 0.05 & 0.028 & 1.156 \\
\hline 40. & $0.13 \mathrm{E}-03$ & 0.05 & 0.12 & 0.028 & 1.167 \\
\hline 40. & $0.13 \mathrm{E}-03$ & 0.05 & 0.20 & 0.028 & 1.178 \\
\hline 40. & $0.13 \mathrm{E}-03$ & 0.12 & 0.05 & 0.018 & 1.121 \\
\hline 40. & $0.13 \mathrm{E}-03$ & 0.12 & 0.12 & 0.018 & 1.132 \\
\hline
\end{tabular}




\begin{tabular}{|c|c|c|c|c|c|}
\hline \multicolumn{6}{|c|}{$\begin{array}{l}\text { Table D.1 (continued) } \\
\text { Numerical representation of the function in Eq. (D.12) } \\
\text { in the relevant ranges of its arguments } \\
\left(\tau_{m} / \tau_{\nu}\right)=0.5\end{array}$} \\
\hline$P_{s o, v} / P_{a o}$ & $V_{m} / V_{a}$ & $\boldsymbol{\omega}_{\mathrm{zr}}$ & $\boldsymbol{\omega}_{s s}$ & $\chi_{a o, H z}$ & $\Delta P / P_{a o}$ \\
\hline 40. & $0.13 \mathrm{E}-03$ & 0.12 & 0.20 & 0.018 & 1.142 \\
\hline 40. & $0.13 \mathrm{E}-03$ & 0.20 & 0.05 & 0.007 & 1.084 \\
\hline 40. & $0.13 \mathrm{E}-03$ & 0.20 & 0.12 & 0.007 & 1.095 \\
\hline 40. & $0.13 \mathrm{E}-03$ & 0.20 & 0.20 & 0.007 & 1.106 \\
\hline 50. & $0.64 \mathrm{E}-04$ & 0.10 & 0.10 & 0.028 & 1.266 \\
\hline 50. & $0.64 \mathrm{E}-04$ & 0.10 & 0.25 & 0.028 & 1.287 \\
\hline 50. & $0.64 \mathrm{E}-04$ & 0.10 & 0.40 & 0.028 & 1.294 \\
\hline 50. & $0.64 \mathrm{E}-04$ & 0.25 & 0.10 & 0.018 & 1.260 \\
\hline 50. & $0.64 \mathrm{E}-04$ & 0.25 & 0.25 & 0.018 & 1.266 \\
\hline 50. & $0.64 \mathrm{E}-04$ & 0.25 & 0.40 & 0.018 & 1.273 \\
\hline 50. & $0.64 \mathrm{E}-04$ & 0.40 & 0.10 & 0.007 & 1.224 \\
\hline 50. & $0.64 \mathrm{E}-04$ & 0.40 & 0.25 & 0.007 & 1.229 \\
\hline 50. & $0.64 \mathrm{E}-04$ & 0.40 & 0.40 & 0.007 & 1.236 \\
\hline 50. & $0.95 \mathrm{E}-04$ & 0.07 & 0.07 & 0.028 & 1.303 \\
\hline 50. & $0.95 \mathrm{E}-04$ & 0.07 & 0.17 & 0.028 & 1.325 \\
\hline 50. & $0.95 \mathrm{E}-04$ & 0.07 & 0.27 & 0.028 & 1.335 \\
\hline 50. & $0.95 \mathrm{E}-04$ & 0.17 & 0.07 & 0.018 & 1.293 \\
\hline 50. & $0.95 \mathrm{E}-04$ & 0.17 & 0.17 & 0.018 & 1.302 \\
\hline 50. & $0.95 \mathrm{E}-04$ & 0.17 & 0.27 & 0.018 & 1.311 \\
\hline 50. & $0.95 \mathrm{E}-04$ & 0.27 & 0.07 & 0.007 & 1.256 \\
\hline 50. & $0.95 \mathrm{E}-04$ & 0.27 & 0.17 & 0.007 & 1.265 \\
\hline 50. & $0.95 \mathrm{E}-04$ & 0.27 & 0.27 & 0.007 & 1.274 \\
\hline 50. & $0.13 \mathrm{E}-03$ & 0.05 & 0.05 & 0.028 & 1.347 \\
\hline 50. & $0.13 \mathrm{E}-03$ & 0.05 & 0.12 & 0.028 & 1.371 \\
\hline 50. & $0.13 \mathrm{E}-03$ & 0.05 & 0.20 & 0.028 & 1.381 \\
\hline
\end{tabular}


Table D.1 (concluded)

Numerical representation of the function in Eq. (D.12)

in the relevant ranges of its arguments

$$
\left(\tau_{m} / \tau_{2}\right)=0.5
$$

\begin{tabular}{|c|c|c|c|c|c|}
\hline \hline$P_{s o,} / P_{a o}$ & $V_{m} / V_{a}$ & $\sigma_{\mathrm{zr}}$ & $\boldsymbol{\sigma}_{s s}$ & $\chi_{a o, H 2}$ & $\Delta P / P_{a o}$ \\
\hline 50. & $0.13 \mathrm{E}-03$ & 0.12 & 0.05 & 0.018 & 1.336 \\
\hline 50. & $0.13 \mathrm{E}-03$ & 0.12 & 0.12 & 0.018 & 1.346 \\
\hline 50. & $0.13 \mathrm{E}-03$ & 0.12 & 0.20 & 0.018 & 1.356 \\
\hline 50. & $0.13 \mathrm{E}-03$ & 0.20 & 0.05 & 0.007 & 1.299 \\
\hline 50. & $0.13 \mathrm{E}-03$ & 0.20 & 0.12 & 0.007 & 1.309 \\
\hline 50. & $0.13 \mathrm{E}-03$ & 0.20 & 0.20 & 0.007 & 1.319 \\
\hline
\end{tabular}




\begin{tabular}{|c|c|c|c|c|c|}
\hline \multicolumn{6}{|c|}{$\begin{array}{l}\text { Table D.2 } \\
\text { Numerical representation of the function in Eq. (D.12) } \\
\text { in the relevant ranges of its arguments } \\
\qquad\left(\tau_{n} / \tau_{g}\right)=0.7\end{array}$} \\
\hline$P_{s o, v} / P_{a o}$ & $V_{m} / V_{a}$ & $\boldsymbol{\omega}_{\mathrm{zr}}$ & $\boldsymbol{\omega}_{s s}$ & $\chi_{a o, H 2}$ & $\Delta P / P_{a o}$ \\
\hline 30. & $0.64 \mathrm{E}-04$ & 0.10 & 0.10 & 0.028 & 1.009 \\
\hline 30. & $0.64 \mathrm{E}-04$ & 0.10 & 0.25 & 0.028 & 1.017 \\
\hline 30. & $0.64 \mathrm{E}-04$ & 0.10 & 0.40 & 0.028 & 1.025 \\
\hline 30. & $0.64 \mathrm{E}-04$ & 0.25 & 0.10 & 0.018 & 0.975 \\
\hline 30. & $0.64 \mathrm{E}-04$ & 0.25 & 0.25 & 0.018 & 0.983 \\
\hline 30. & $0.64 \mathrm{E}-04$ & 0.25 & 0.40 & 0.018 & 0.991 \\
\hline 30. & $0.64 \mathrm{E}-04$ & 0.40 & 0.10 & 0.007 & 0.939 \\
\hline 30. & $0.64 \mathrm{E}-04$ & 0.40 & 0.25 & 0.007 & 0.947 \\
\hline 30. & $0.64 \mathrm{E}-04$ & 0.40 & 0.40 & 0.007 & 0.955 \\
\hline 30. & $0.95 \mathrm{E}-04$ & 0.07 & 0.07 & 0.028 & 1.050 \\
\hline 30. & $0.95 \mathrm{E}-04$ & 0.07 & 0.17 & 0.028 & 1.060 \\
\hline 30. & $0.95 \mathrm{E}-04$ & 0.07 & 0.27 & 0.028 & 1.070 \\
\hline 30. & $0.95 \mathrm{E}-04$ & 0.17 & 0.07 & 0.018 & 1.016 \\
\hline 30. & $0.95 \mathrm{E}-04$ & 0.17 & 0.17 & 0.018 & 1.026 \\
\hline 30. & $0.95 \mathrm{E}-04$ & 0.17 & 0.27 & 0.018 & 1.036 \\
\hline 30. & $0.95 \mathrm{E}-04$ & 0.27 & 0.07 & 0.007 & 0.979 \\
\hline 30. & $0.95 \mathrm{E}-04$ & 0.27 & 0.17 & 0.007 & 0.989 \\
\hline 30. & $0.95 \mathrm{E}-04$ & 0.27 & 0.27 & 0.007 & 0.999 \\
\hline 30. & $0.13 \mathrm{E}-03$ & 0.05 & 0.05 & 0.028 & 1.098 \\
\hline 30. & $0.13 \mathrm{E}-03$ & 0.05 & 0.12 & 0.028 & 1.108 \\
\hline 30. & $0.13 \mathrm{E}-03$ & 0.05 & 0.20 & 0.028 & 1.119 \\
\hline 30. & $0.13 \mathrm{E}-03$ & 0.12 & 0.05 & 0.018 & 1.063 \\
\hline 30. & $0.13 \mathrm{E}-03$ & 0.12 & 0.12 & 0.018 & 1.073 \\
\hline 30. & $0.13 \mathrm{E}-03$ & 0.12 & 0.20 & 0.018 & 1.084 \\
\hline 30. & $0.13 \mathrm{E}-03$ & 0.20 & 0.05 & 0.007 & 1.026 \\
\hline
\end{tabular}




\begin{tabular}{|c|c|c|c|c|c|}
\hline \multicolumn{6}{|c|}{$\begin{array}{l}\text { Table D.2 (continued) } \\
\text { Numerical representation of the function in Eq. (D.12) } \\
\text { in the relevant ranges of its arguments } \\
\left(\tau_{m} / \tau_{2}\right)=0.7\end{array}$} \\
\hline$P_{s o, v} / P_{a o}$ & $V_{m} / V_{a}$ & $\boldsymbol{\omega}_{z r}$ & $\boldsymbol{\sigma}_{s s}$ & $\chi_{a 0, H 2}$ & $\Delta P / P_{a o}$ \\
\hline 30. & $0.13 \mathrm{E}-03$ & 0.20 & 0.12 & 0.007 & 1.037 \\
\hline 30. & $0.13 \mathrm{E}-03$ & 0.20 & 0.20 & 0.007 & 1.047 \\
\hline 40. & $0.64 \mathrm{E}-04$ & 0.10 & 0.10 & 0.028 & 1.240 \\
\hline 40. & $0.64 \mathrm{E}-04$ & 0.10 & 0.25 & 0.028 & 1.280 \\
\hline 40. & $0.64 \mathrm{E}-04$ & 0.10 & 0.40 & 0.028 & 1.287 \\
\hline 40. & $0.64 \mathrm{E}-04$ & 0.25 & 0.10 & 0.018 & 1.259 \\
\hline 40. & $0.64 \mathrm{E}-04$ & 0.25 & 0.25 & 0.018 & 1.264 \\
\hline 40. & $0.64 \mathrm{E}-04$ & 0.25 & 0.40 & 0.018 & 1.270 \\
\hline 40. & $0.64 \mathrm{E}-04$ & 0.40 & 0.10 & 0.007 & 1.222 \\
\hline 40. & $0.64 \mathrm{E}-04$ & 0.40 & 0.25 & 0.007 & 1.227 \\
\hline 40. & $0.64 \mathrm{E}-04$ & 0.40 & 0.40 & 0.007 & 1.233 \\
\hline 40. & $0.95 \mathrm{E}-04$ & 0.07 & 0.07 & 0.028 & 1.276 \\
\hline 40. & $0.95 \mathrm{E}-04$ & 0.07 & 0.17 & 0.028 & 1.317 \\
\hline 40. & $0.95 \mathrm{E}-04$ & 0.07 & 0.27 & 0.028 & 1.326 \\
\hline 40. & $0.95 \mathrm{E}-04$ & 0.17 & 0.07 & 0.018 & 1.290 \\
\hline 40. & $0.95 \mathrm{E}-04$ & 0.17 & 0.17 & 0.018 & 1.298 \\
\hline 40. & $0.95 \mathrm{E}-04$ & 0.17 & 0.27 & 0.018 & 1.307 \\
\hline 40. & $0.95 \mathrm{E}-04$ & 0.27 & 0.07 & 0.007 & 1.253 \\
\hline 40. & $0.95 \mathrm{E}-04$ & 0.27 & 0.17 & 0.007 & 1.261 \\
\hline 40. & $0.95 \mathrm{E}-04$ & 0.27 & 0.27 & 0.007 & 1.270 \\
\hline 40. & $0.13 \mathrm{E}-03$ & 0.05 & 0.05 & 0.028 & 1.320 \\
\hline 40. & $0.13 \mathrm{E}-03$ & 0.05 & 0.12 & 0.028 & 1.362 \\
\hline 40. & $0.13 \mathrm{E}-03$ & 0.05 & 0.20 & 0.028 & 1.372 \\
\hline 40. & $0.13 \mathrm{E}-03$ & 0.12 & 0.05 & 0.018 & 1.331 \\
\hline 40. & $0.13 \mathrm{E}-03$ & 0.12 & 0.12 & 0.018 & 1.341 \\
\hline
\end{tabular}




\begin{tabular}{|c|c|c|c|c|c|}
\hline \multicolumn{6}{|c|}{$\begin{array}{l}\text { Table D.2 (continued) } \\
\text { Numerical representation of the function in Eq. (D.12) } \\
\text { in the relevant ranges of its arguments } \\
\left(\tau_{m} / \tau_{s}\right)=0.7\end{array}$} \\
\hline$P_{s o, v} / P_{a o}$ & $V_{m} / V_{a}$ & $\boldsymbol{\omega}_{\mathrm{Zr}}$ & $\boldsymbol{\omega}_{s s}$ & $\chi_{a 0, H 2}$ & $\Delta P / P_{a o}$ \\
\hline 40. & $0.13 \mathrm{E}-03$ & 0.12 & 0.20 & 0.018 & 1.351 \\
\hline 40. & $0.13 \mathrm{E}-03$ & 0.20 & 0.05 & 0.007 & 1.294 \\
\hline 40. & $0.13 \mathrm{E}-03$ & 0.20 & 0.12 & 0.007 & 1.304 \\
\hline 40. & $0.13 \mathrm{E}-03$ & 0.20 & 0.20 & 0.007 & 1.314 \\
\hline 50. & $0.64 \mathrm{E}-04$ & 0.10 & 0.10 & 0.028 & 1.398 \\
\hline 50. & $0.64 \mathrm{E}-04$ & 0.10 & 0.25 & 0.028 & 1.512 \\
\hline 50. & $0.64 \mathrm{E}-04$ & 0.10 & 0.40 & 0.028 & 1.544 \\
\hline 50. & $0.64 \mathrm{E}-04$ & 0.25 & 0.10 & 0.018 & 1.549 \\
\hline 50. & $0.64 \mathrm{E}-04$ & 0.25 & 0.25 & 0.018 & 1.551 \\
\hline 50. & $0.64 \mathrm{E}-04$ & 0.25 & 0.40 & 0.018 & 1.555 \\
\hline 50. & $0.64 \mathrm{E}-04$ & 0.40 & 0.10 & 0.007 & 1.512 \\
\hline 50. & $0.64 \mathrm{E}-04$ & 0.40 & 0.25 & 0.007 & 1.514 \\
\hline 50. & $0.64 \mathrm{E}-04$ & 0.40 & 0.40 & 0.007 & 1.517 \\
\hline 50. & $0.95 \mathrm{E}-04$ & 0.07 & 0.07 & 0.028 & 1.432 \\
\hline 50. & $0.95 \mathrm{E}-04$ & 0.07 & 0.17 & 0.028 & 1.546 \\
\hline 50. & $0.95 \mathrm{E}-04$ & 0.07 & 0.27 & 0.028 & 1.579 \\
\hline 50. & $0.95 \mathrm{E}-04$ & 0.17 & 0.07 & 0.018 & 1.569 \\
\hline 50. & $0.95 \mathrm{E}-04$ & 0.17 & 0.17 & 0.018 & 1.575 \\
\hline 50. & $0.95 \mathrm{E}-04$ & 0.17 & 0.27 & 0.018 & 1.583 \\
\hline 50. & $0.95 \mathrm{E}-04$ & 0.27 & 0.07 & 0.007 & 1.531 \\
\hline 50. & $0.95 \mathrm{E}-04$ & 0.27 & 0.17 & 0.007 & 1.538 \\
\hline 50. & $0.95 \mathrm{E}-04$ & 0.27 & 0.27 & 0.007 & 1.545 \\
\hline 50. & $0.13 \mathrm{E}-03$ & 0.05 & 0.05 & 0.028 & 1.475 \\
\hline 50. & $0.13 \mathrm{E}-03$ & 0.05 & 0.12 & 0.028 & 1.588 \\
\hline 50. & $0.13 \mathrm{E}-03$ & 0.05 & 0.20 & 0.028 & 1.622 \\
\hline
\end{tabular}




\begin{tabular}{|c|c|c|c|c|c|}
\hline \multicolumn{6}{|c|}{$\begin{array}{l}\text { Table D.2 (concluded) } \\
\text { Numerical representation of the function in Eq. (D.12) } \\
\text { in the relevant ranges of its arguments } \\
\left(\tau_{m} / \tau_{2}\right)=0.7\end{array}$} \\
\hline$P_{s o, v} / P_{a o}$ & $V_{m} / V_{a}$ & $\boldsymbol{\omega}_{z r}$ & $\boldsymbol{\sigma}_{s s}$ & $\chi_{a 0, H 2}$ & $\Delta P / P_{\infty o}$ \\
\hline 50. & $0.13 \mathrm{E}-03$ & 0.12 & 0.05 & 0.018 & 1.603 \\
\hline 50. & $0.13 \mathrm{E}-03$ & 0.12 & 0.12 & 0.018 & 1.612 \\
\hline 50. & $0.13 \mathrm{E}-03$ & 0.12 & 0.20 & 0.018 & 1.621 \\
\hline 50. & $0.13 \mathrm{E}-03$ & 0.20 & 0.05 & 0.007 & 1.566 \\
\hline 50. & $0.13 \mathrm{E}-03$ & 0.20 & 0.12 & 0.007 & 1.574 \\
\hline 50. & $0.13 \mathrm{E}-03$ & 0.20 & 0.20 & 0.007 & 1.583 \\
\hline
\end{tabular}


Table D.3

Summary of initial conditions in the SNL/IET series of tests

\begin{tabular}{|c|c|c|c|c|c|c|c|}
\hline & 1 & $1 \mathbf{R}$ & 3 & 4 & 5 & 6 & 7 \\
\hline$P_{s o, v}, \mathrm{MPa}$ & 7.1 & 6.3 & 6.1 & 6.7 & 6.0 & 6.3 & 5.9 \\
\hline$T_{s o, v}, K$ & 600 & 585 & 585 & 555 & 584 & 571 & 599 \\
\hline$d_{b}, c m$ & 4.04 & 4.02 & 4.53 & 4.22 & 4.31 & 3.91 & 4.08 \\
\hline$\chi_{\infty \mathrm{O}, \mathrm{H} 2}, \%$ & 0 & 0 & 0 & 0 & 2.76 & 2.59 & 3.97 \\
\hline$\chi_{\mathrm{a}, 0,02}, \%$ & $\sim 0$ & $\sim 0$ & 9 & 9 & $4.3^{*}$ & 9.8 & 9.57 \\
\hline $\mathrm{M}_{\mathrm{m}}, \mathrm{kg}$ & 43 & 43 & 43 & 43 & 43 & 43 & 43 \\
\hline $\mathrm{P}_{\mathrm{AO}}, \mathrm{MPa}$ & 0.2 & 0.2 & 0.19 & 0.2 & 0.2 & 0.2 & 0.2 \\
\hline
\end{tabular}

Table D.4

Summary of initial conditions in the ANL/IET series of tests

\begin{tabular}{||c|c|c|c|c|}
\hline & IRR & 3 & 6 & 7 \\
\hline $\mathrm{P}_{\mathrm{so}, \mathrm{v}}, \mathrm{MPa}$ & 6.7 & 5.7 & 6.6 & 6.1 \\
\hline $\mathrm{T}_{\mathrm{s} \mathrm{O}, \mathrm{v}}, \mathrm{K}$ & 600 & 600 & 600 & 600 \\
\hline $\mathrm{d}_{\mathrm{b}}, \mathrm{cm}$ & 1.3 & 1.1 & 1.1 & 1.1 \\
\hline$\chi_{\mathrm{aO}, \mathrm{H} 2}, \%$ & 0 & 0 & 2 & 0 \\
\hline$\chi_{\mathrm{aO}, 02}(\mathrm{O}), \%$ & 0.12 & 10 & 9.9 & 10.8 \\
\hline $\mathrm{M}_{\mathrm{m}}, \mathrm{kg}$ & 0.82 & 0.82 & 0.713 & 0.715 \\
\hline $\mathrm{P}_{\mathrm{aO}}, \mathrm{MPa}$ & 0.2 & 0.2 & 0.2 & 0.1 \\
\hline
\end{tabular}


Table D.5

Summary of posttest material distributions, in $\mathbf{k g}$, for the SNL/IET series of tests

\begin{tabular}{|l|c|c|c|c|c|c|c|}
\hline & $\mathbf{1}$ & $\mathbf{1 R}$ & $\mathbf{3}$ & $\mathbf{4}$ & $\mathbf{5}$ & 6 & $\mathbf{7}$ \\
\hline Melt generator & 4.5 & 4.6 & 4.5 & 4.8 & 2.6 & 2.3 & 6.7 \\
\hline Cavity and chute & 7.1 & 13.2 & 16.8 & 9.5 & 20.1 & 8.5 & 13.3 \\
\hline Subcompartment & 38 & 32.4 & 31.3 & 32.7 & 31.2 & 36 & 34 \\
\hline Dispersed $^{\mathrm{a}}$ & 5 & 3.8 & 3 & $8^{\mathrm{b}}$ & 1.9 & 5.9 & 2.7 \\
\hline $\begin{array}{l}\text { 'Outside the subcompartment. } \\
\text { 'Hole blown in the crane wall in the seal table room. }\end{array}$ \\
\hline
\end{tabular}

Table D.6

Summary of posttest material distributions, in $\mathbf{k g}$, for the ANL/IET series of tests

\begin{tabular}{||l|c|c|c|c|}
\hline & IRR & 3 & 6 & 7 \\
\hline Melt generator & 0.03 & 0.07 & 0.03 & 0.00 \\
\hline Cavity and chute & 0.26 & 0.23 & 0.21 & 0.15 \\
\hline Subcompartment & 0.51 & 0.59 & 0.44 & 0.54 \\
\hline Dispersed $^{\mathrm{a}}$ & $0.10^{\mathrm{b}}$ & 0.03 & 0.04 & 0.02 \\
\hline
\end{tabular}

"Outside the subcompartment.

'Hole blown in the crane wall in the seal table room. 
Table D.7

Comparison of predicted with the "measured" quantities (moles) of hydrogen produced in the SNL/IET series of tests. The " $L$ " and " $U$ " designations refer to lower and upper values obtained in the manner described in the text. The "O" designations refer to the CLCH model option that ignored the iron chemistry.

\begin{tabular}{|c|c|c|c|c|c|c|c|c|}
\hline Test & Measured & $\begin{array}{c}\text { Predicted } \\
\text { "O" }\end{array}$ & \% Deviation & $\begin{array}{c}\text { Predicted } \\
\text { "L" }\end{array}$ & $\begin{array}{c}\% \\
\text { Deviation }\end{array}$ & $\begin{array}{c}\text { Predicted } \\
\text { "U" }\end{array}$ & $\begin{array}{c}\% \\
\text { Deviation }\end{array}$ & Comments \\
\hline SNL/IET-1 & 223 & 118 & -47 & 210 & -5.8 & 242 & +8 & No $\mathrm{O}_{2}$, no burn \\
\hline SNL/IET-3 & 223 & 110 & -51 & 280 & +25 & $305^{\circ}$ & +37 & \\
\hline SNL/IET-4 & 297 & 112 & -62 & 227 & -23 & 290 & -2 & \\
\hline SNL/IET-6 & 308 & 106 & -66 & 198 & $-35^{a}$ & 245 & $-20^{\circ}$ & \\
\hline SNL/IET-7 & 271 & 102 & -62 & 261 & -3.7 & 281 & +3.6 & Minimal dispersal \\
\hline
\end{tabular}


Table D.8

Comparison of predicted with the "measured" quantities of hydrogen produced in the ANL/IET series of tests. The " $L$ " designation refers to the lower value obtained in the manner described in the text.

\begin{tabular}{|c|c|c|c|c||}
\hline Test & Measured & Predicted-"L" & $\%$ Deviation & Comments \\
\hline ANL/IET-1RR & 4 & 4.44 & +11 & No $\mathrm{O}_{2}$, no burn \\
\hline ANL/IET-3 & $4.65^{*}$ & 2.98 & -35 & \\
\hline ANL/IET-6 & $4.89^{*}$ & 4.37 & -10 & \\
\hline \multicolumn{7}{|l|}{ ANL/IET-7 } & $3.45^{*}$ & 4.03 & +16 & \\
\hline "Taken 2 minutes after blowdown, value in doubt. \\
"Taken 30 seconds after blowdown, better value.
\end{tabular}

Table D.9

Relevant conditions in the LFP test series

\begin{tabular}{||l|c|c|c|c|c|c||}
\hline Test: LFP & 1A & 1B & 2A & 2B & 2C & 8A \\
\hline Plate position $^{\mathbf{a}}$ & 0.91 & 0.91 & 1.85 & 1.85 & 1.85 & 7.70 \\
\hline Steam pressure (MPa) & 3.7 & 2.6 & 3.0 & 3.6 & 3.3 & 2.9 \\
\hline Hole diameter (cm) & 6.41 & 3.5 & 3.5 & 5.97 & 8.57 & 3.5 \\
\hline Temperature (K) & 585 & 583 & 563 & 606 & 572 & 631 \\
\hline Melt Mass (kg) & 80 & 50 & 50 & 50 & 50 & 50 \\
\hline Fraction dispersed & 0.725 & 0.209 & 0.484 & 0.616 & 0.62 & 0.392 \\
\hline Fraction above the plate & 0.019 & 0.007 & 0.033 & 0.017 & 0.081 & 0.010 \\
\hline $\begin{array}{l}\text { 'Distance from chute exit. } \\
\text { 'Dispersed outside the reactor cavity. }\end{array}$
\end{tabular}


Table D.10

Comparison of CLCH model predictions with the LFP test series in the Surtsey Facility

\begin{tabular}{||c|c|c|c|c|c|c||}
\hline \multicolumn{3}{|c|}{ Hydrogen (moles) } & \multicolumn{4}{c||}{ Final Pressure (MPa) } \\
\hline Text & Measured & Predicted & \% Deviation & Measured & Predicted & \% Deviation \\
\hline LFP-1A & 235 & 252 & 7.2 & 0.28 & 0.30 & 7.1 \\
\hline LFP-1B & 128 & 180 & 40.6 & 0.22 & 0.31 & 38.4 \\
\hline$L F P-2 A$ & 151 & 215 & 42.4 & 0.26 & 0.31 & 19.2 \\
\hline LFP-2B & 154 & 230 & 49.4 & 0.27 & 0.27 & 1.8 \\
\hline LFP-2C & 194 & 232 & 26.1 & 0.29 & 0.31 & 6.9 \\
\hline$L F P-8 A$ & 139 & 187 & 34.5 & 0.33 & 0.30 & -9.1 \\
\hline
\end{tabular}




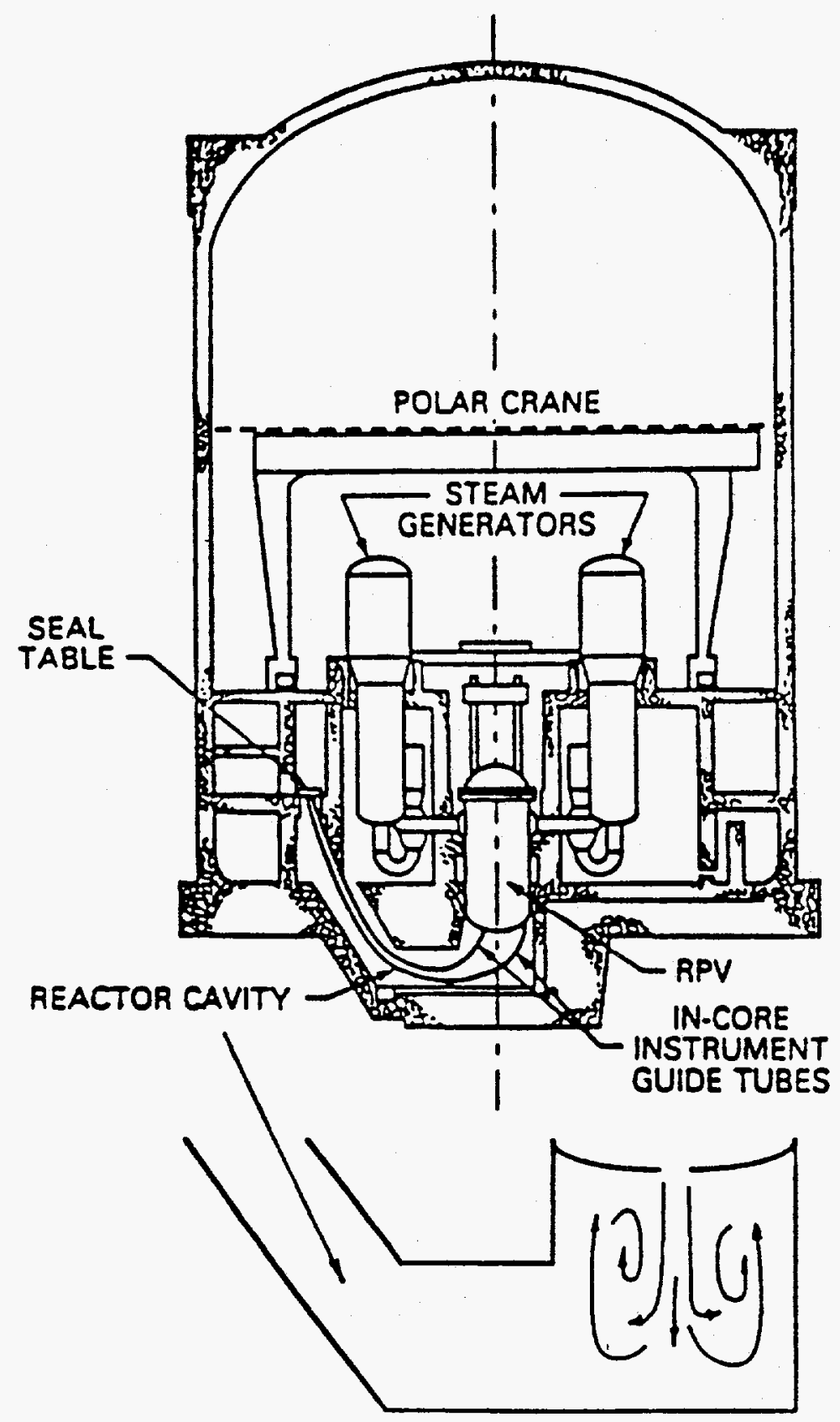

Figure D.1. The containment geometry considered and an illustration of the recirculation in the cavity. 


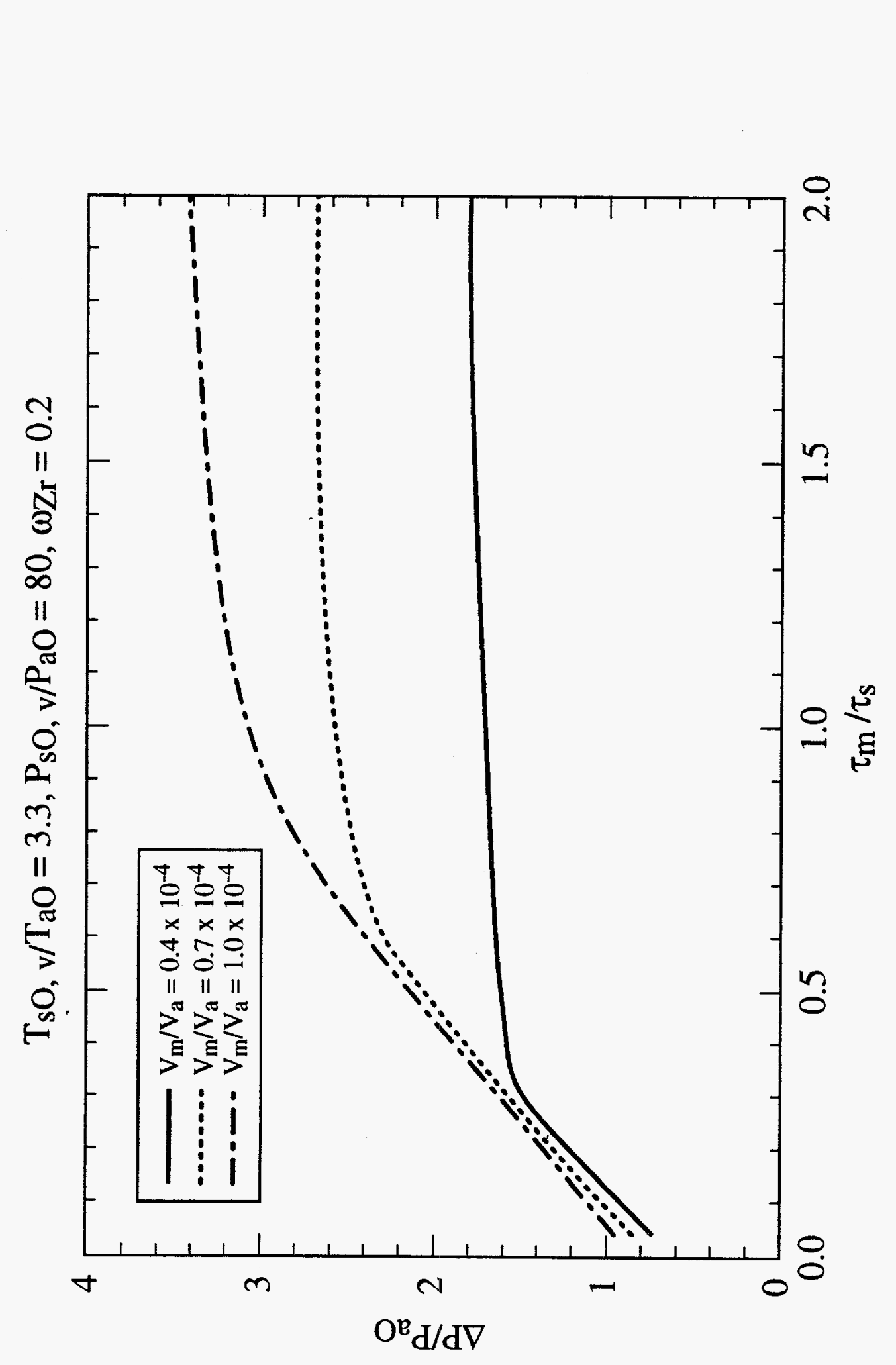

Е

5 


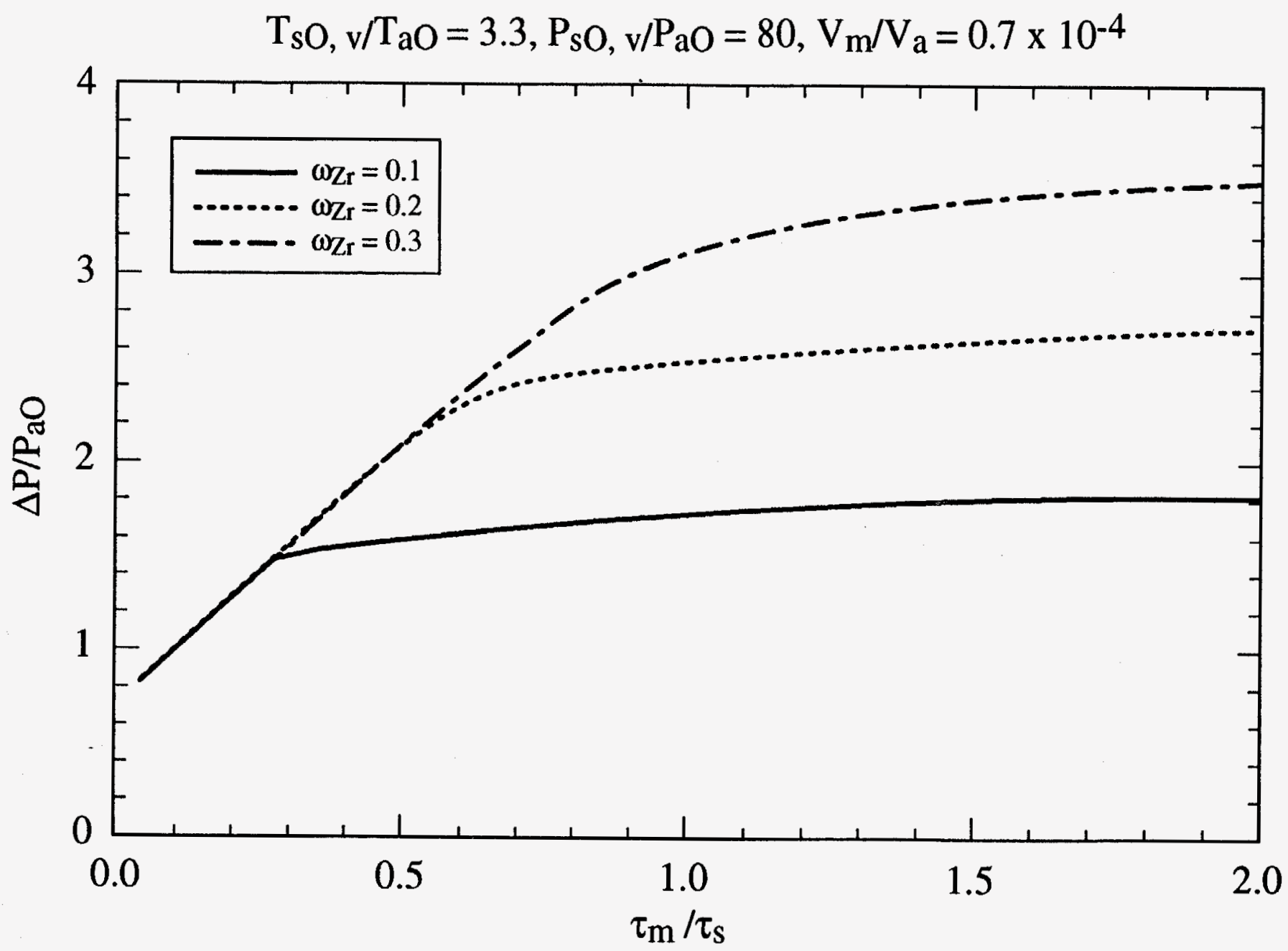

Figure D.2b. Prediction of containment pressurization due to DCH using the CLCH model. The zirconium mass fraction in the melt is the parameter. 

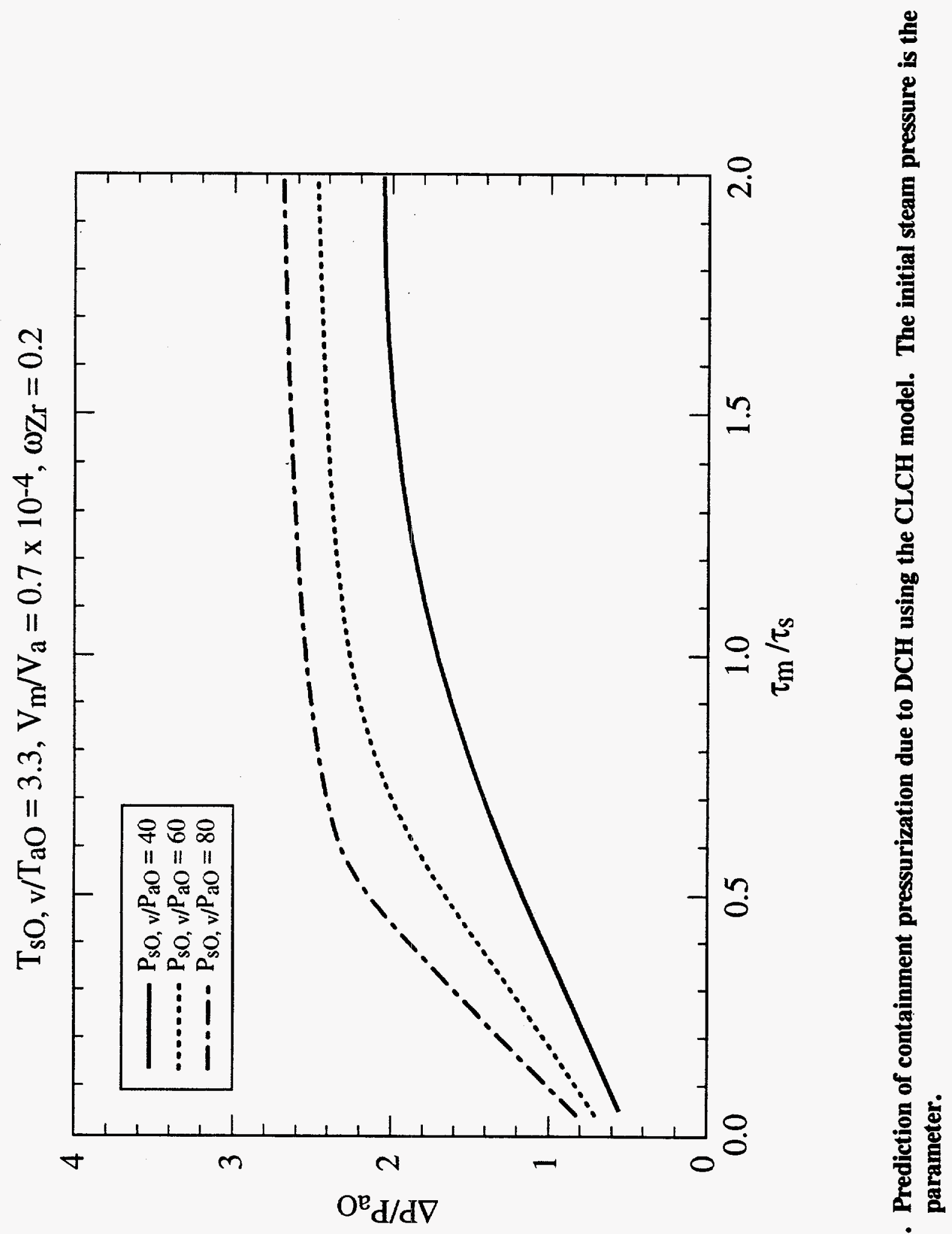

芦 
Et-ם

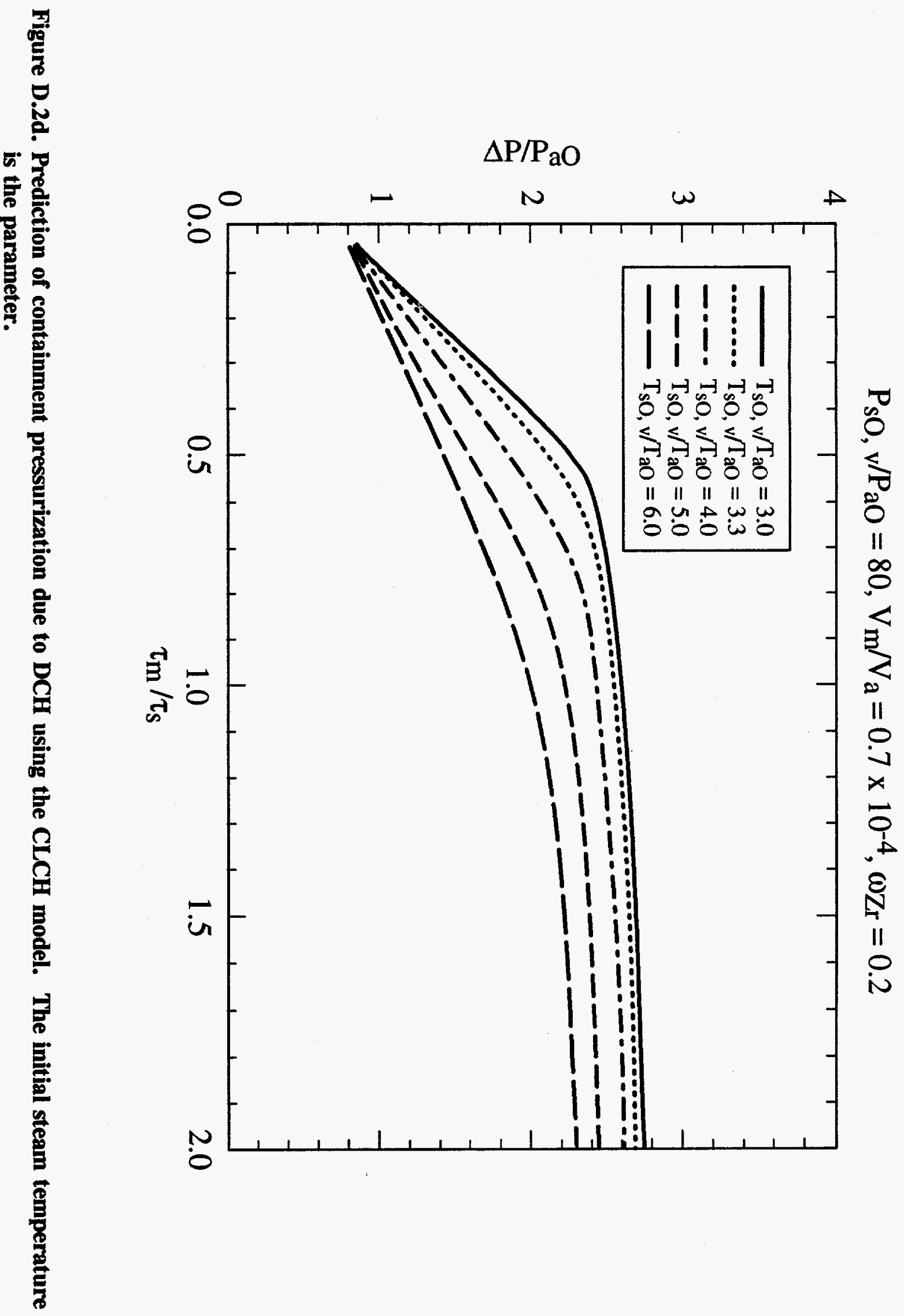




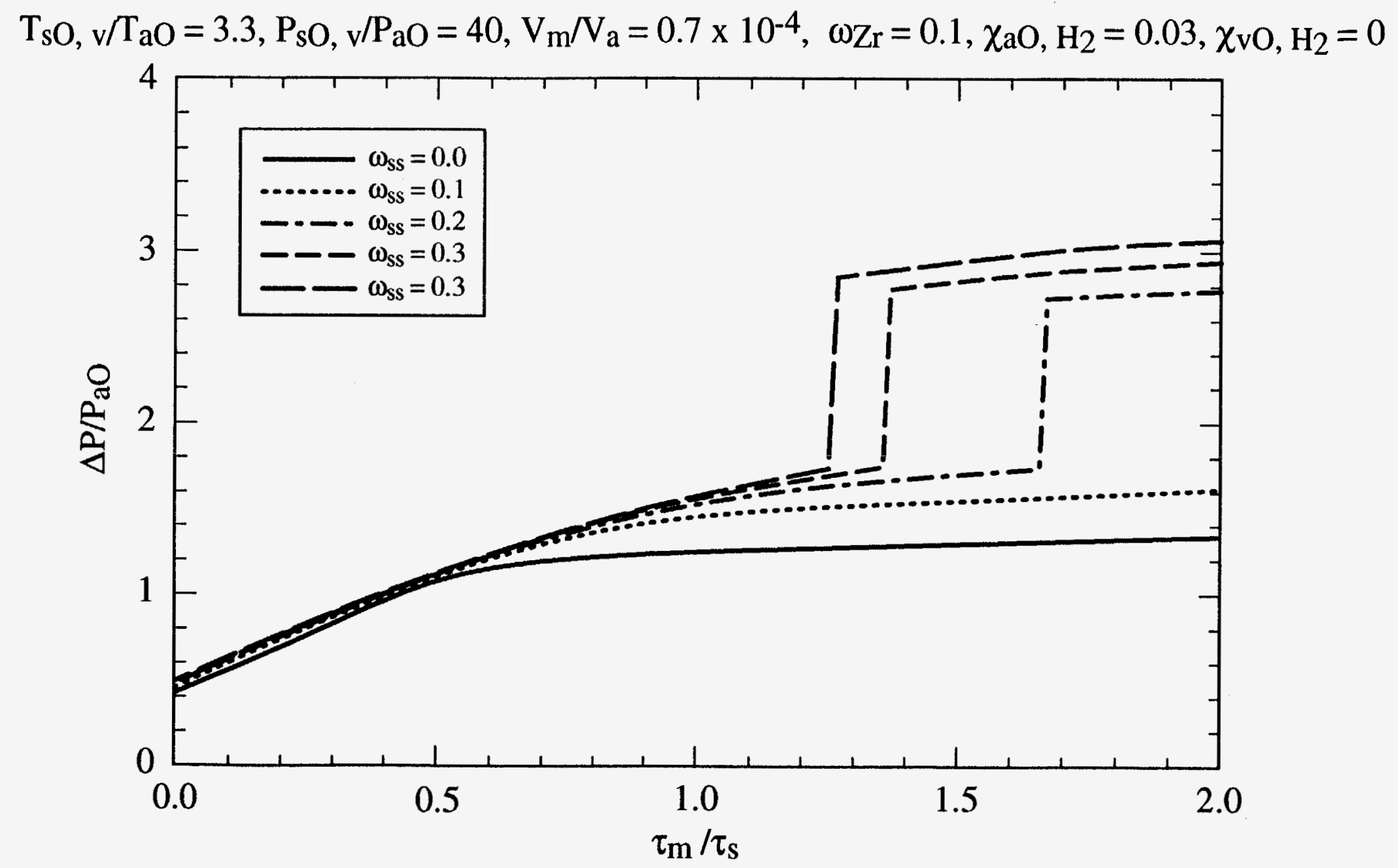

Figure D.3a. Prediction of containment pressurization due to DCH using the CLCH model. The mass fraction of stainless steel in the melt is the parameter. 


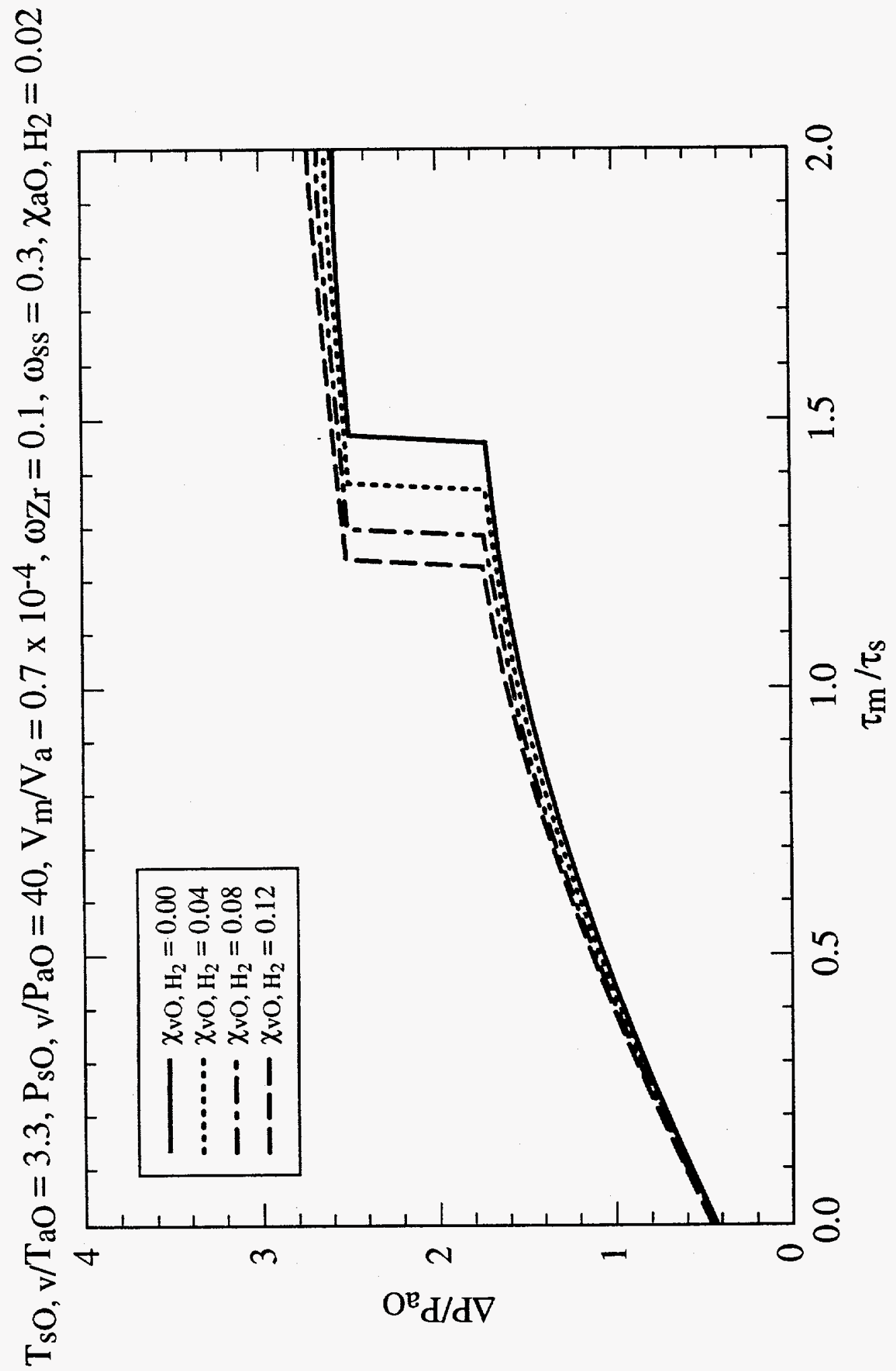



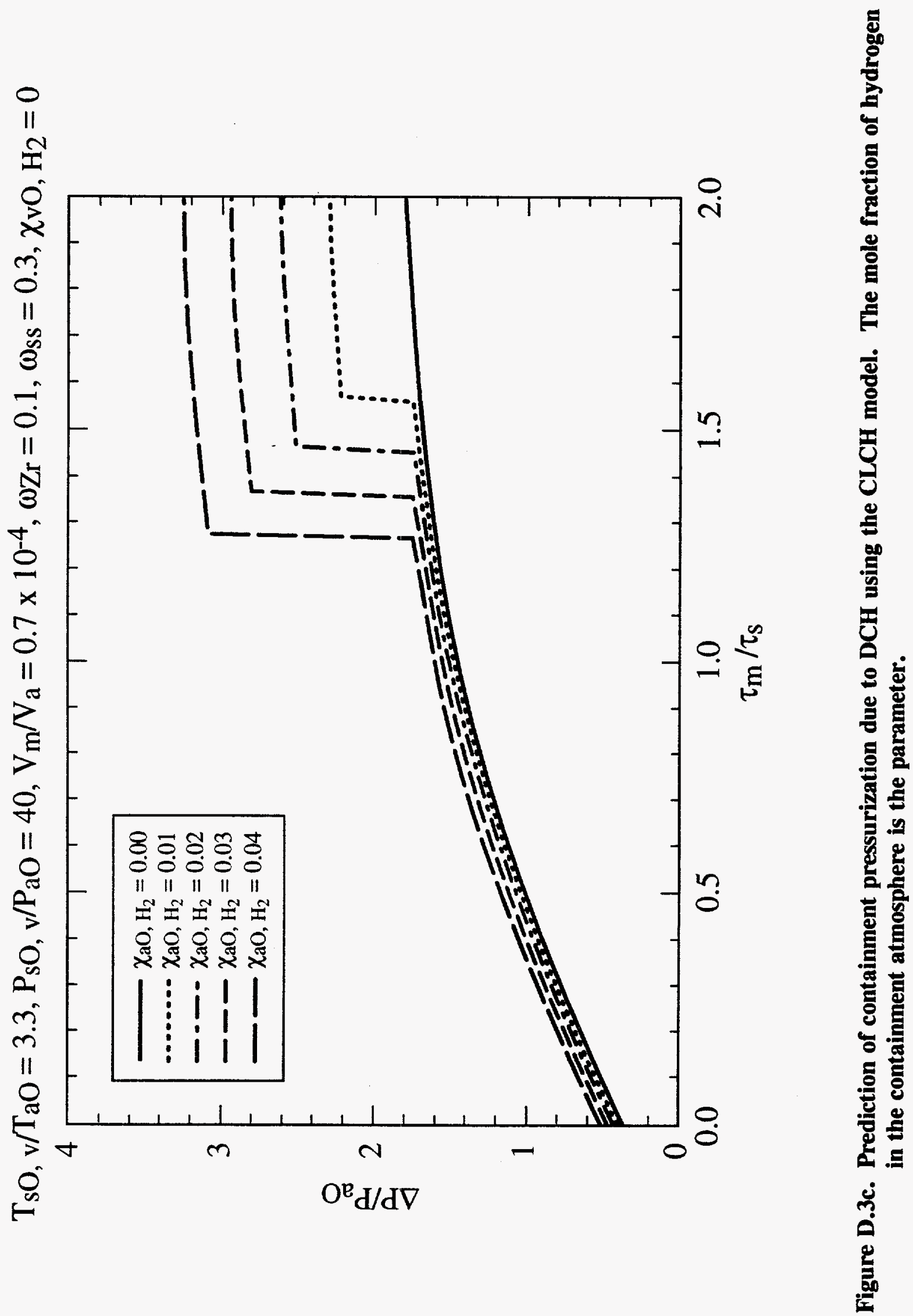


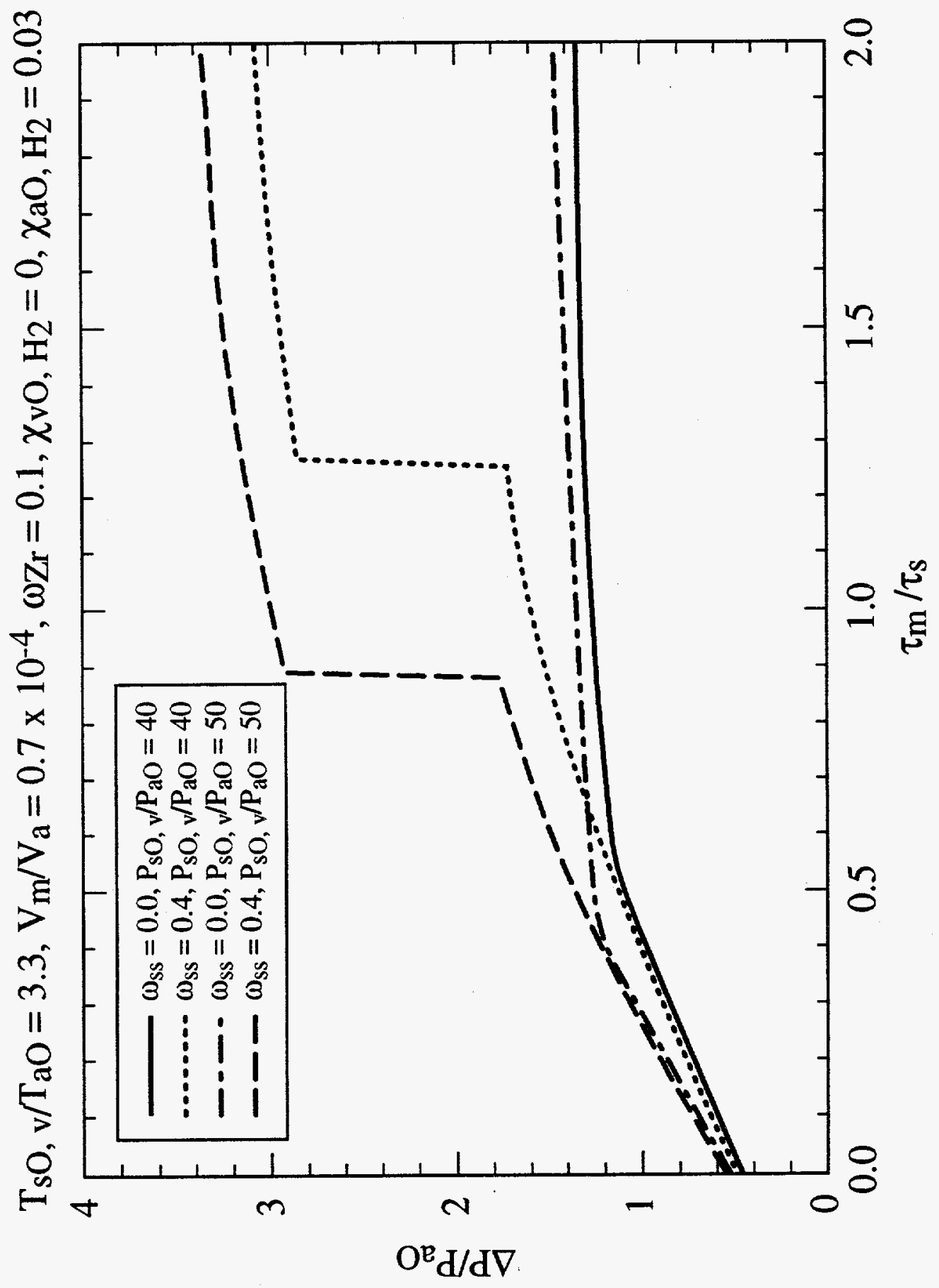

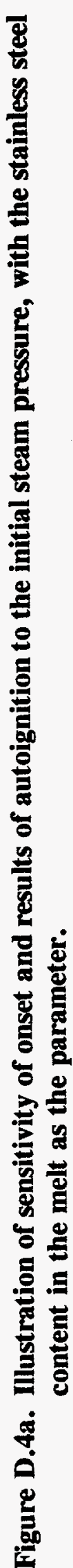




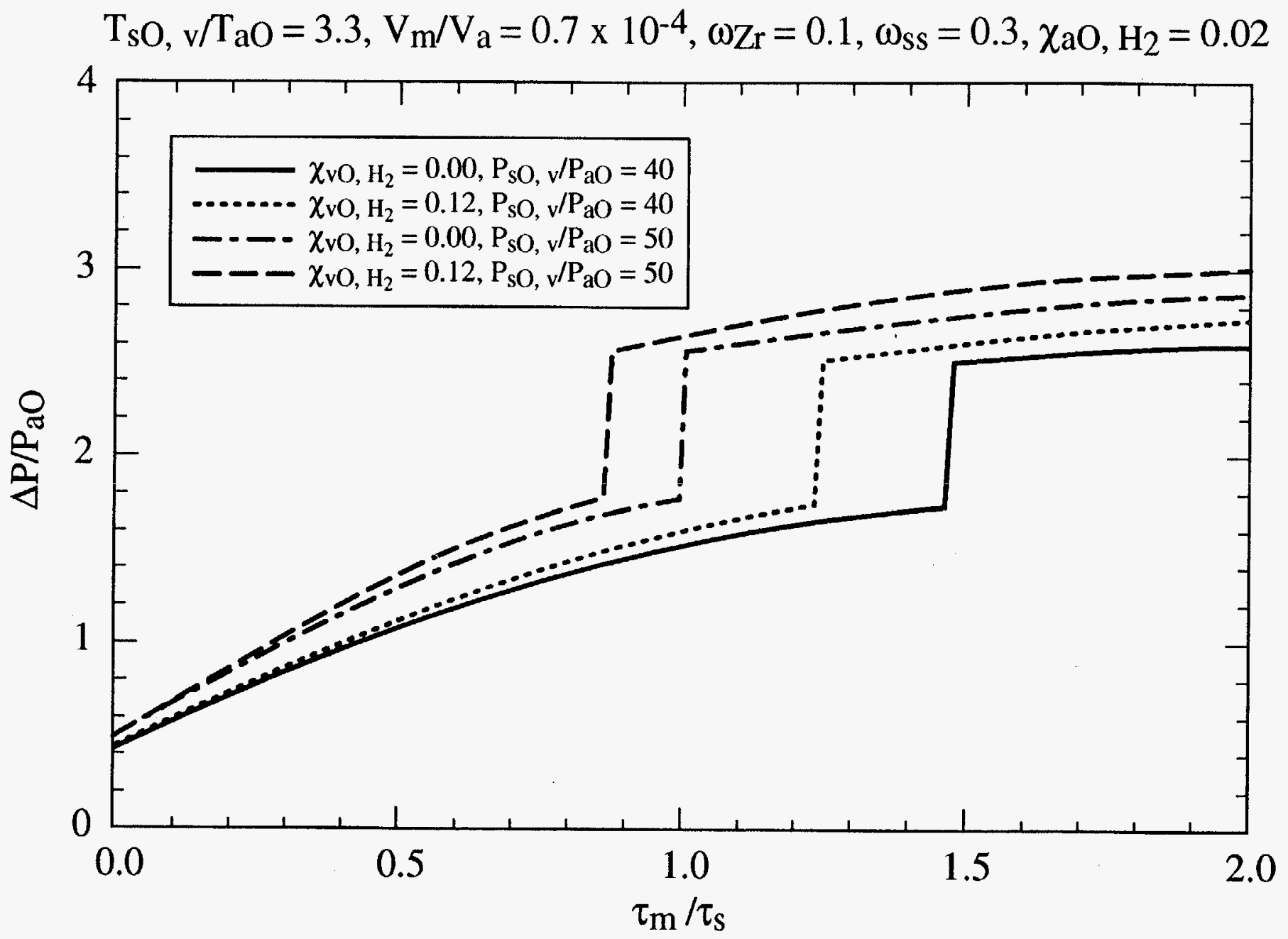

Figure D.4b. Illustration of sensitivity of onset and results of autoignition to the initial steam pressure, with the hydrogen content in the blowdown gases as the parameter. 
$\mathrm{T}_{\mathrm{sO}}, \mathrm{v} / \mathrm{T}_{\mathrm{aO}}=3.3, \mathrm{P}_{\mathrm{sO}}, \mathrm{v} / \mathrm{PaO}_{\mathrm{aO}}=80$

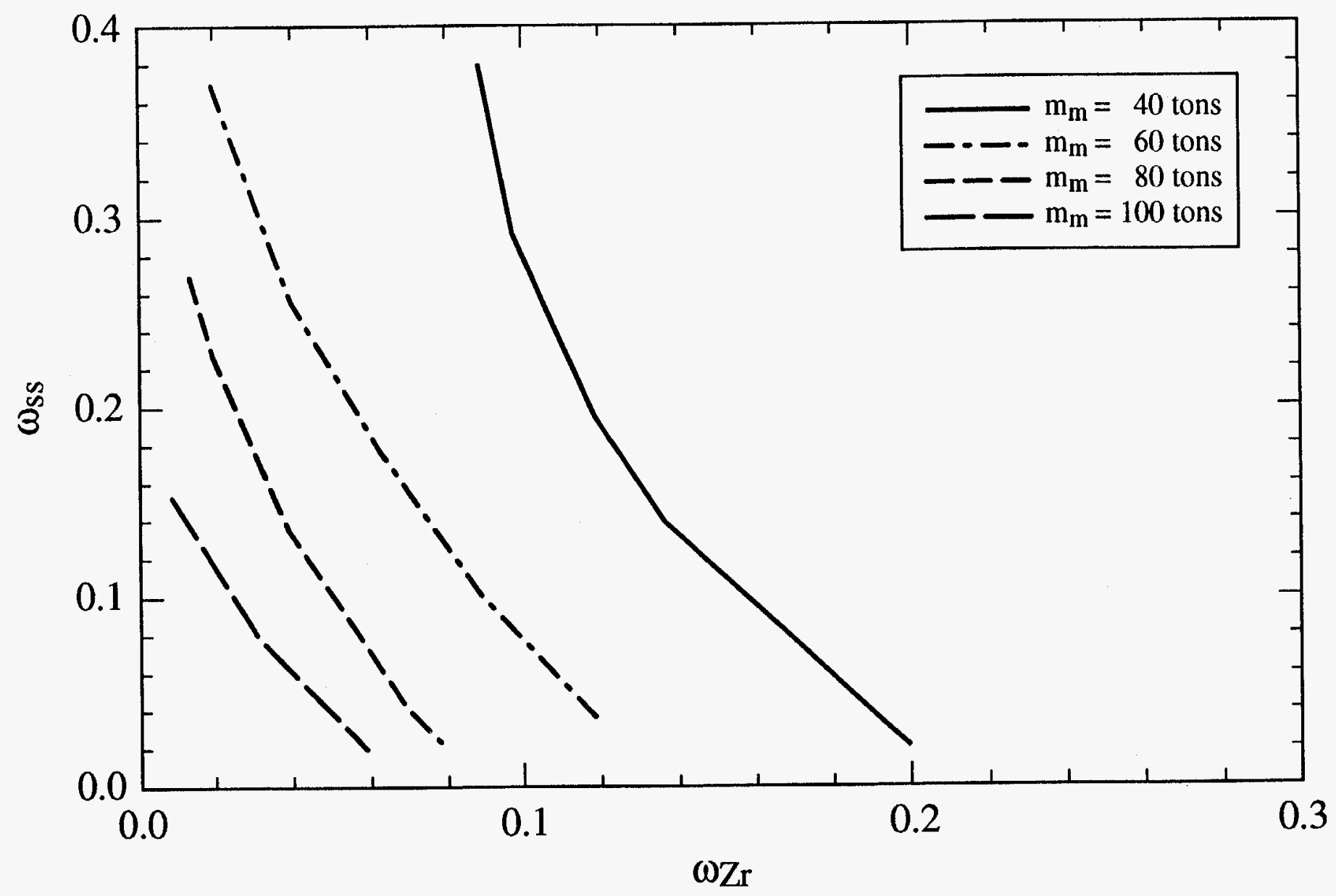

Figure D.5a. Illustration of autoignition boundaries in the $\omega_{\mathrm{ss}}-\omega_{\mathrm{Zr}}$ plane, at a pressure ratio of 80 , with the melt quantity as the parameter. Other input values: $\tau_{\mathrm{m}} / \tau_{\mathrm{s}}=0.5, \chi_{\mathrm{vO}, \mathrm{H} 2}=0$, and $\chi_{\mathrm{aO}, \mathrm{H} 2}$ obtained by oxidizing the remainder of the core zirconium (with a maximum amount of $50 \%$ of total zirconium in core), after the value $\left(m_{m} \omega_{z r}\right)$ used in any particular case considered. 


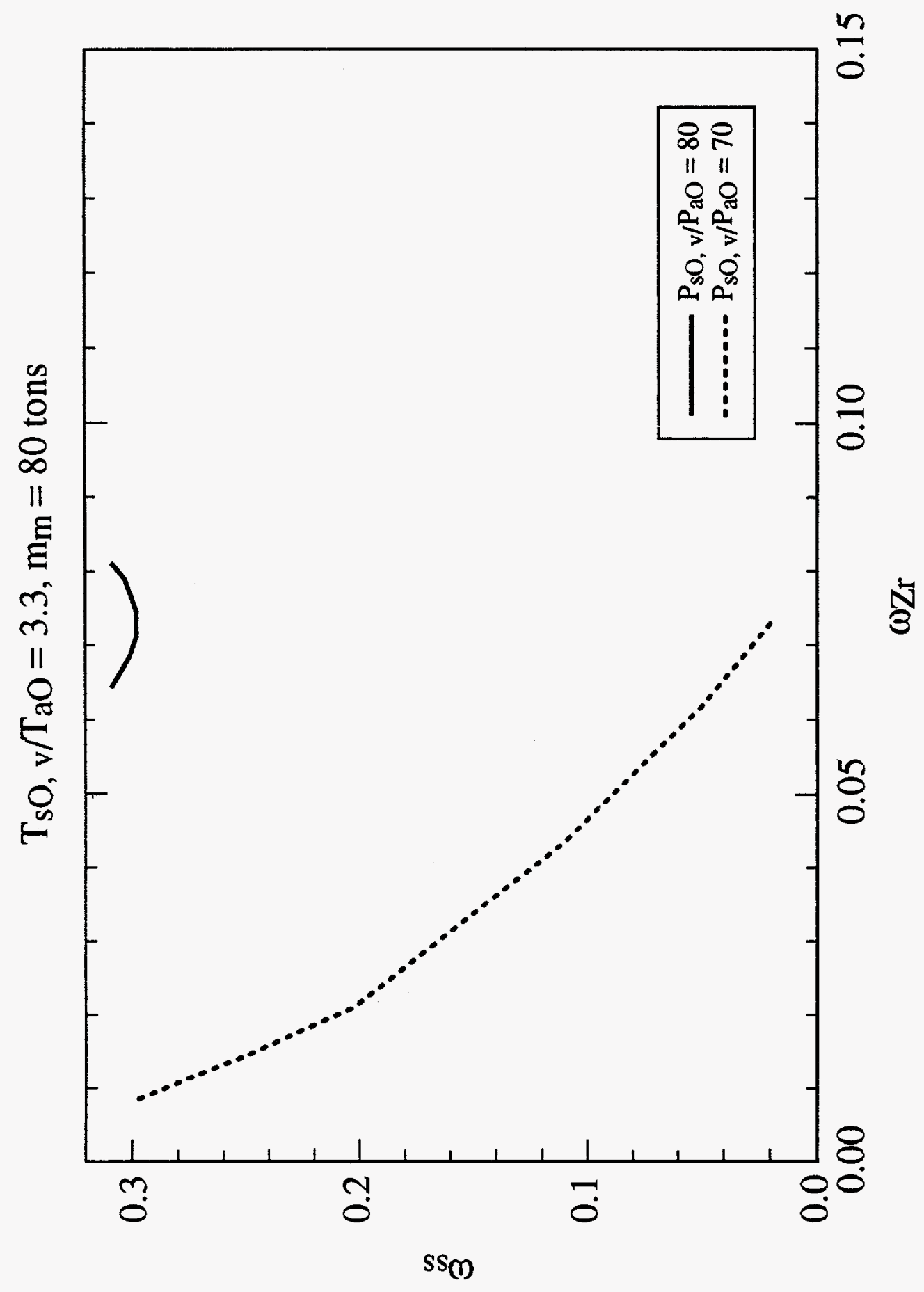

욜

8

홍

8

4

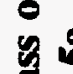

g

을

를

\%

๘

总要

$3 \stackrel{9}{3}$

.

$\Xi$

急

홍

톨.

8

틍 흥

를

을

岁

홍

홀

를

ติ

อ

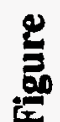




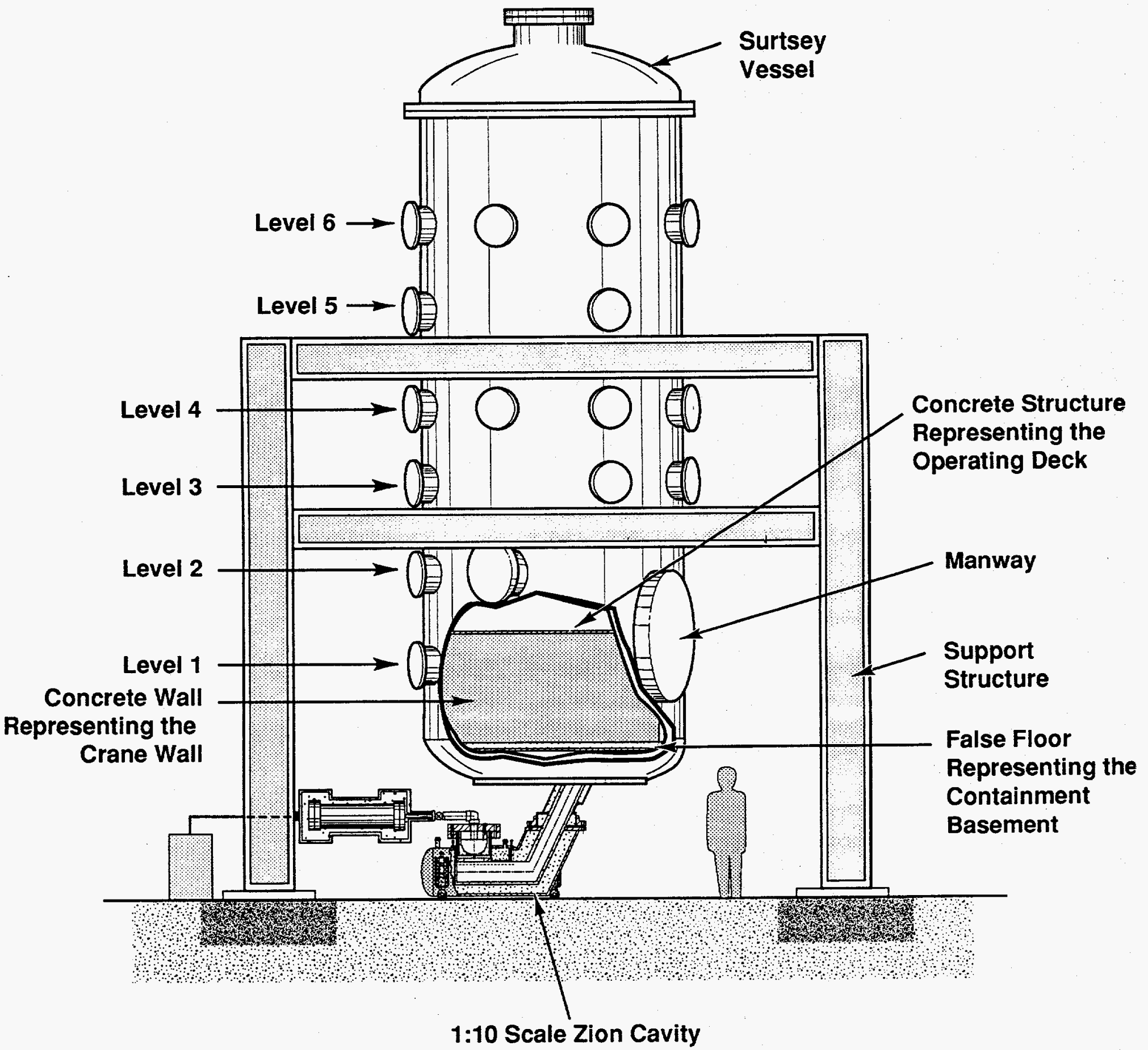

Figure D.6. Surtsey vessel, high-pressure melt ejection system, and subcompartment structures used in the SNL/IET experiments. The figure also shows instrumentation by channel number. 


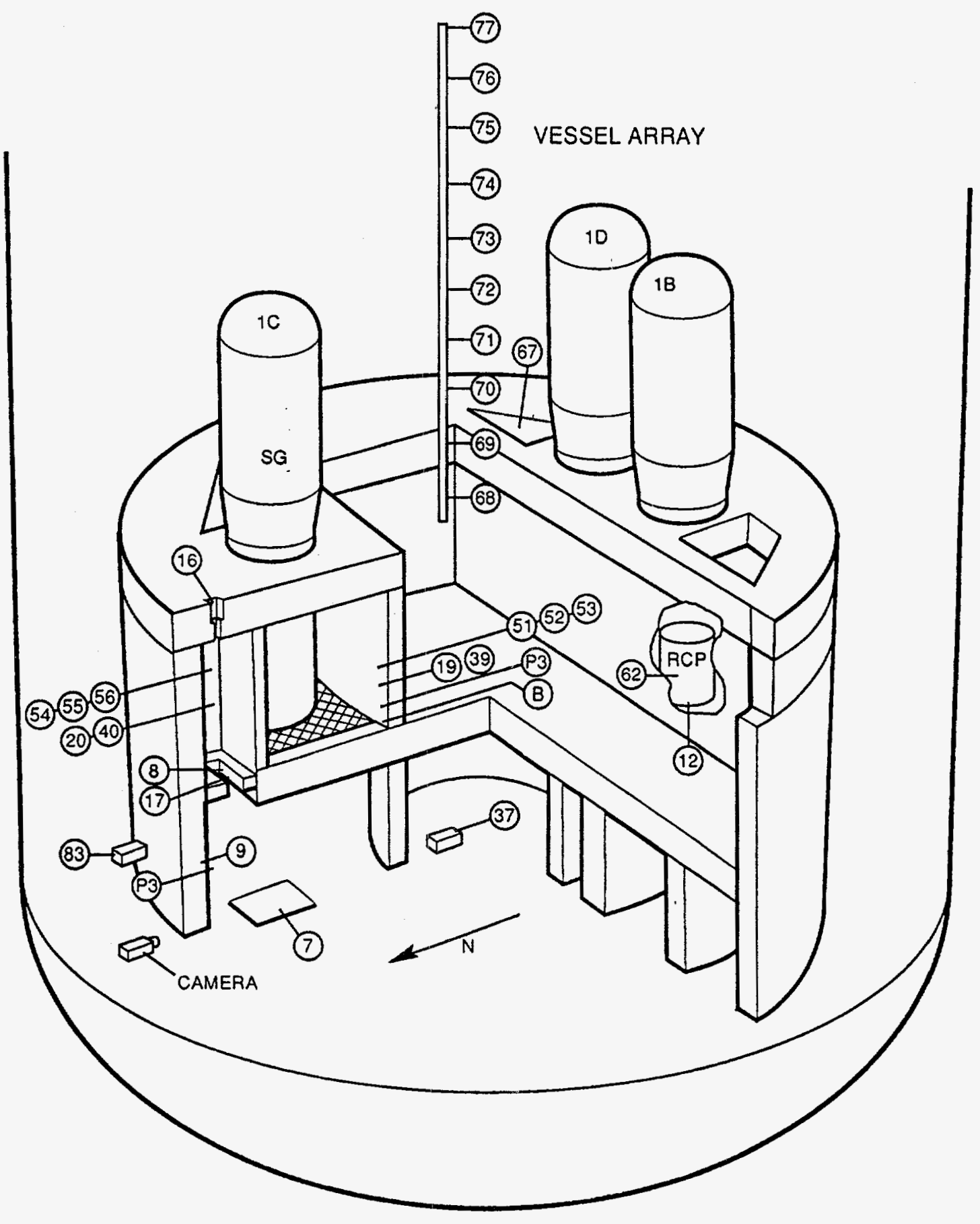

Figure D.7. Isometric view of the subcompartment structures inside the Surtsey vessel. The figure also shows instrumentation location by channel number. 


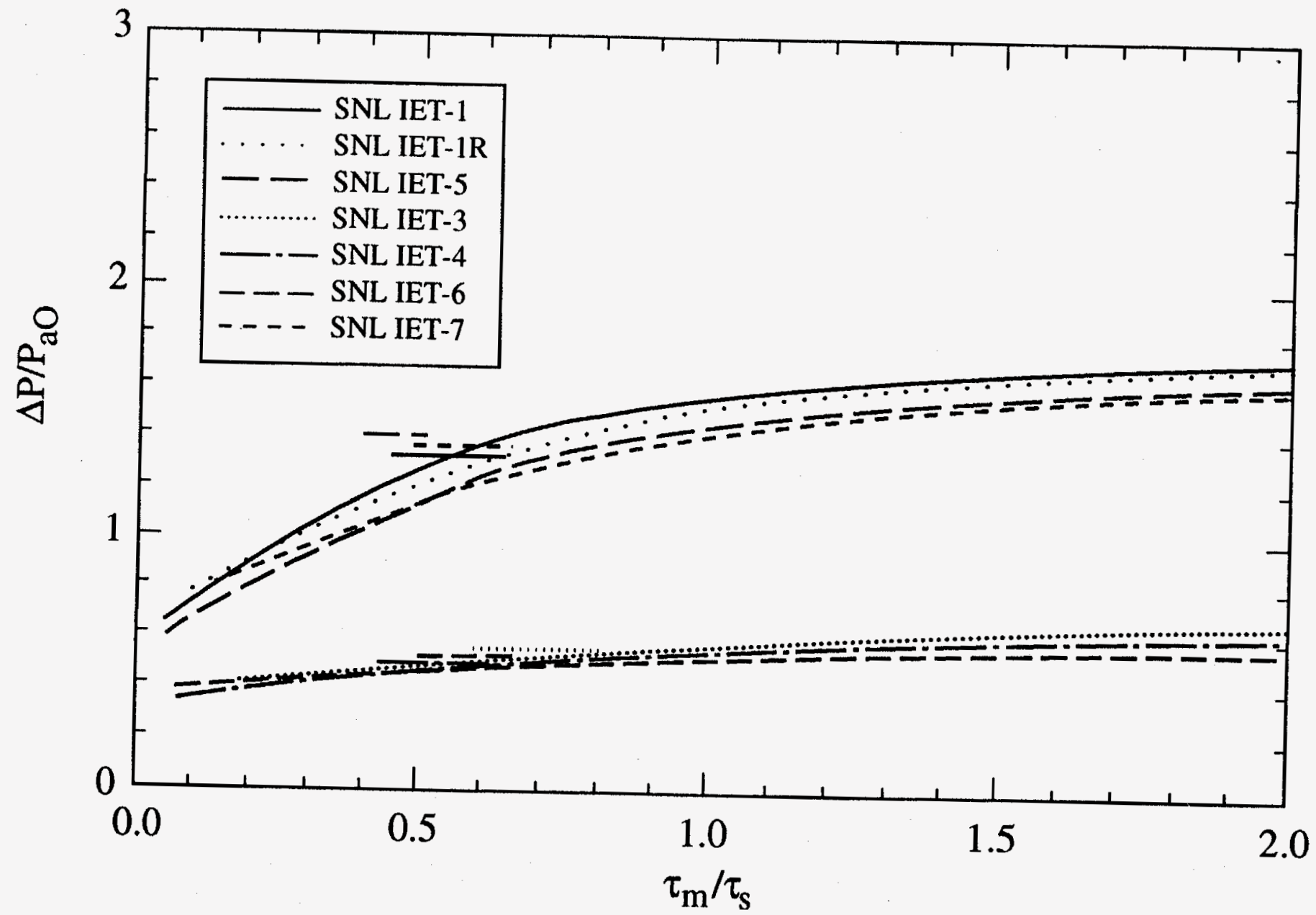

Figure D.8a. Comparison of containment pressurization predicted (lower limit of "L"-predictions) with the CLCH model and measurements in the SNL/IET series of tests. 


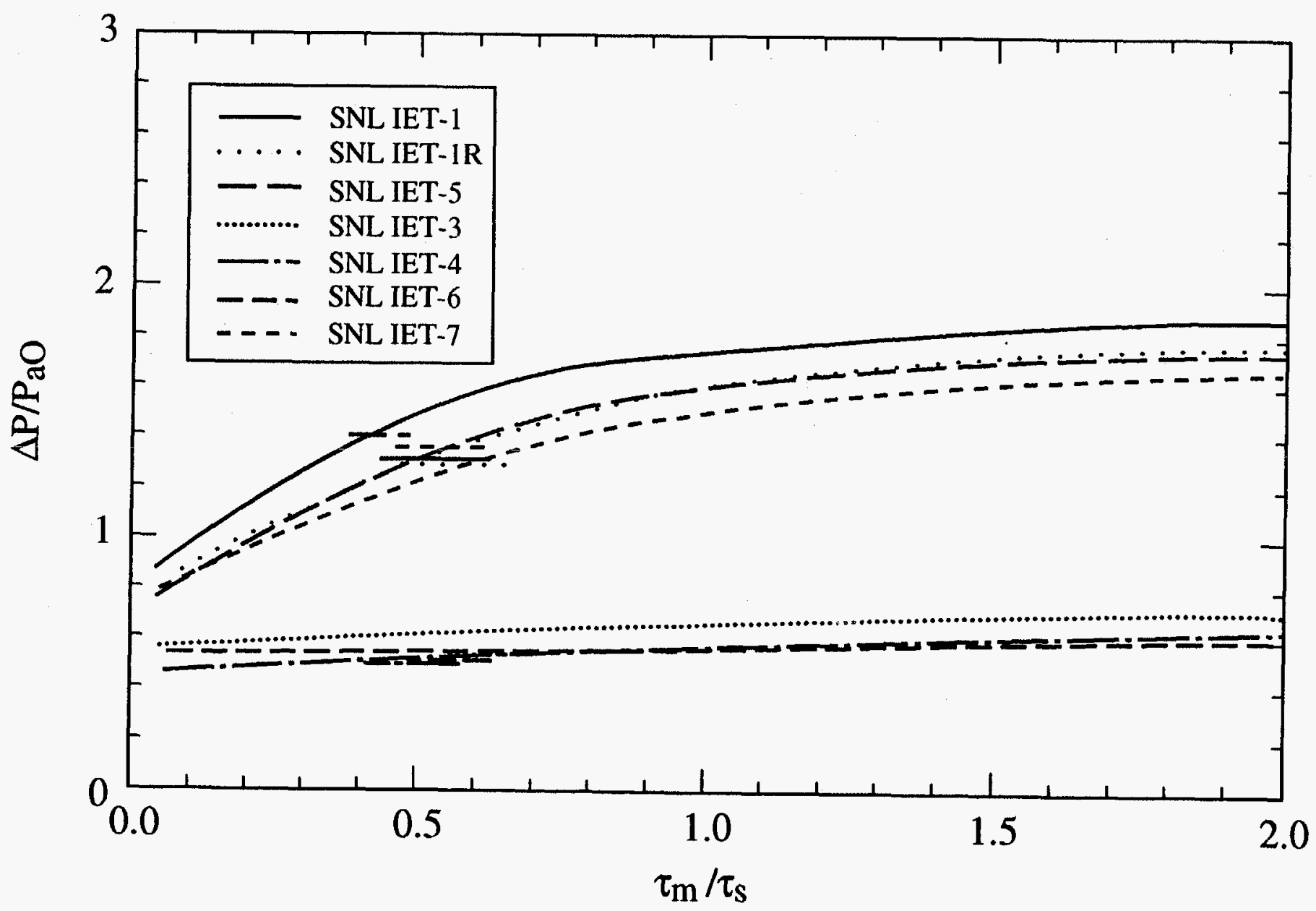

Figure D.8b. Comparison of containment pressurization predicted (upper limit of "U"-predictions) with the CLCH model and measurements in the SNL/IET series of tests. 


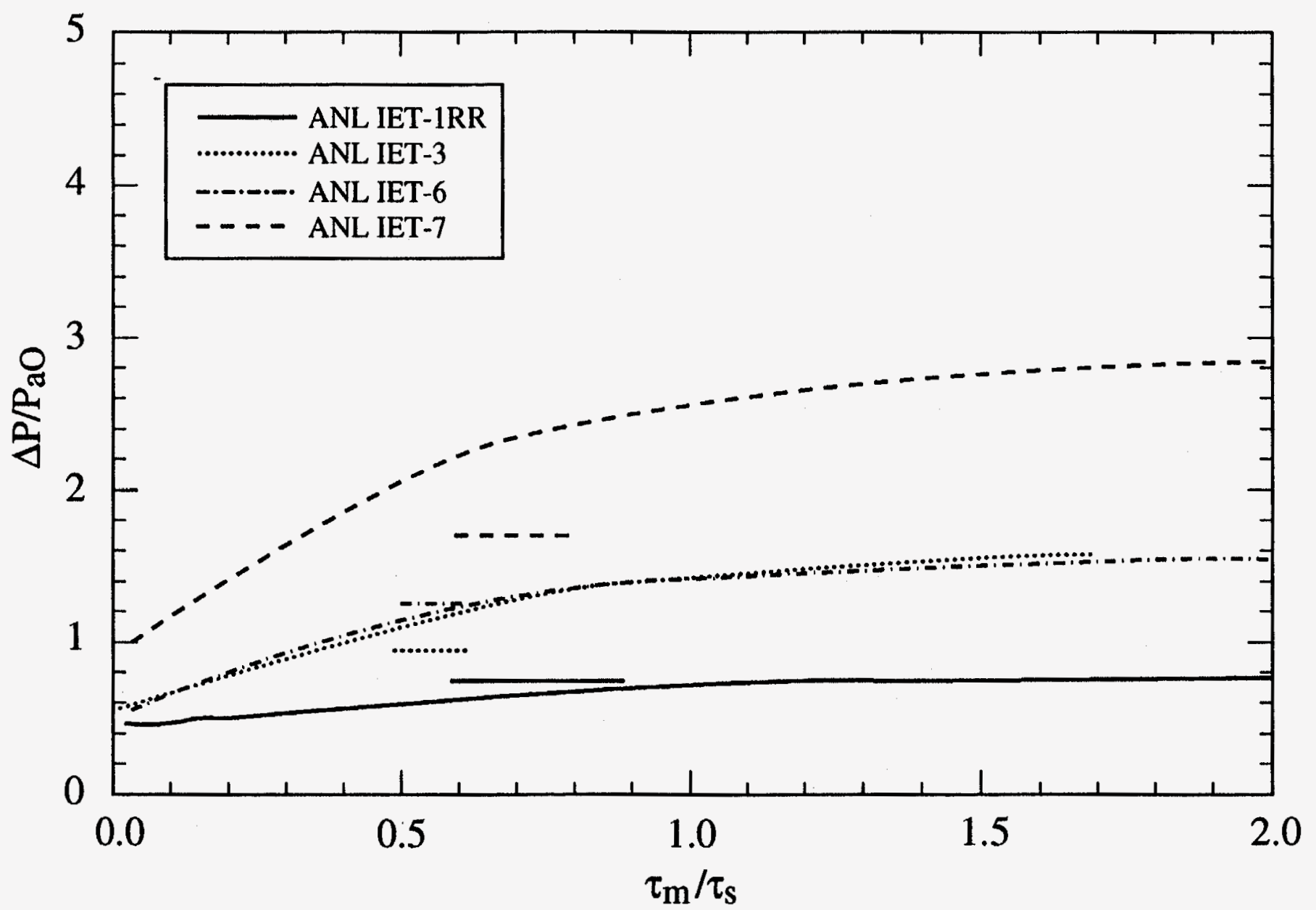

Figure D.9. Comparison of containment pressurization predicted (upper limit of "U"-predictions) with CLCH model and measurements in the ANL/IET series of tests. 


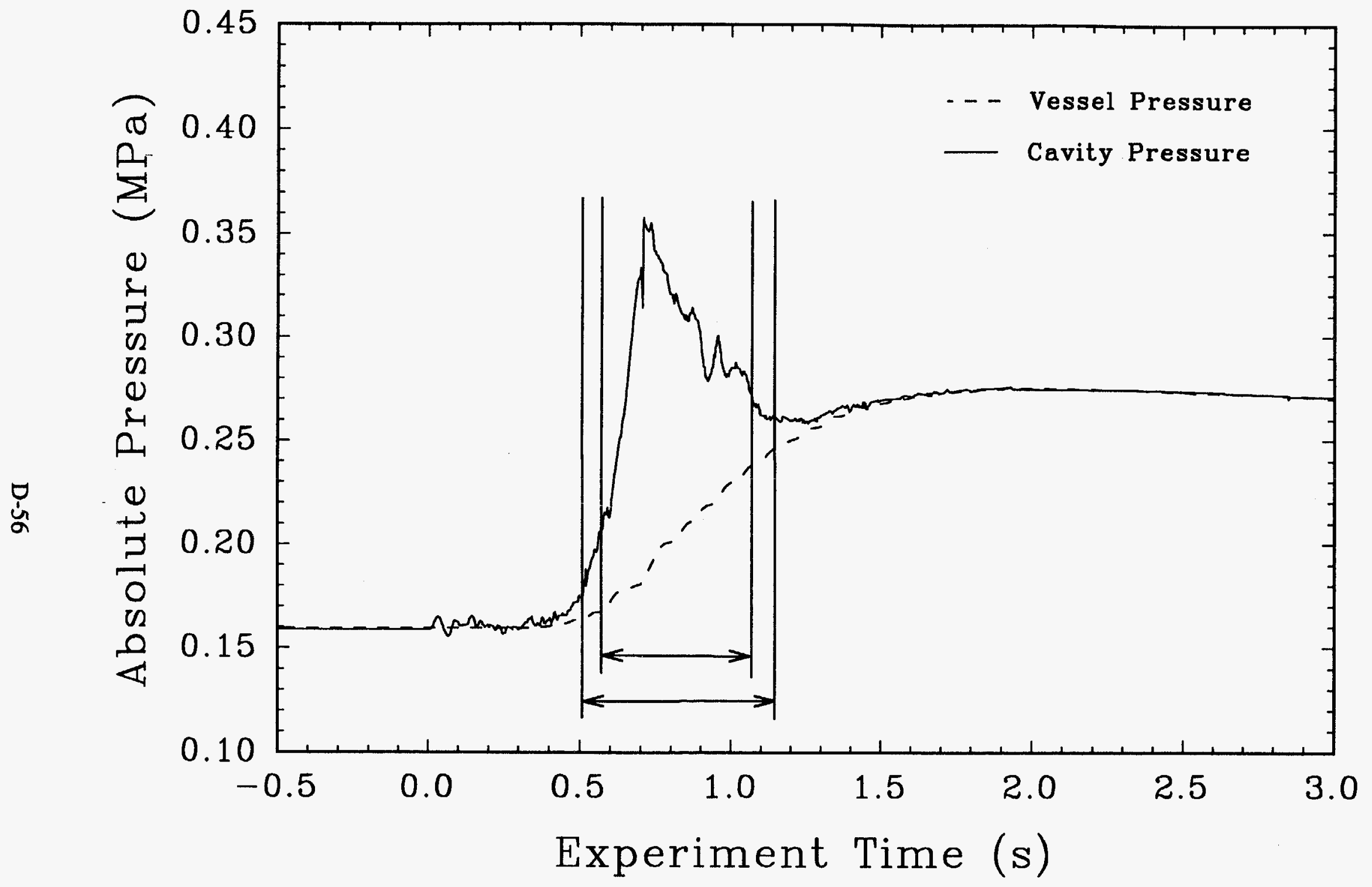

Figure D.10. Illustration of determination of the experimental value of $\tau_{\mathrm{m}}$ from the pressure transients in the cavity and upper compartment. Test LFP-2B in Surtsey. 


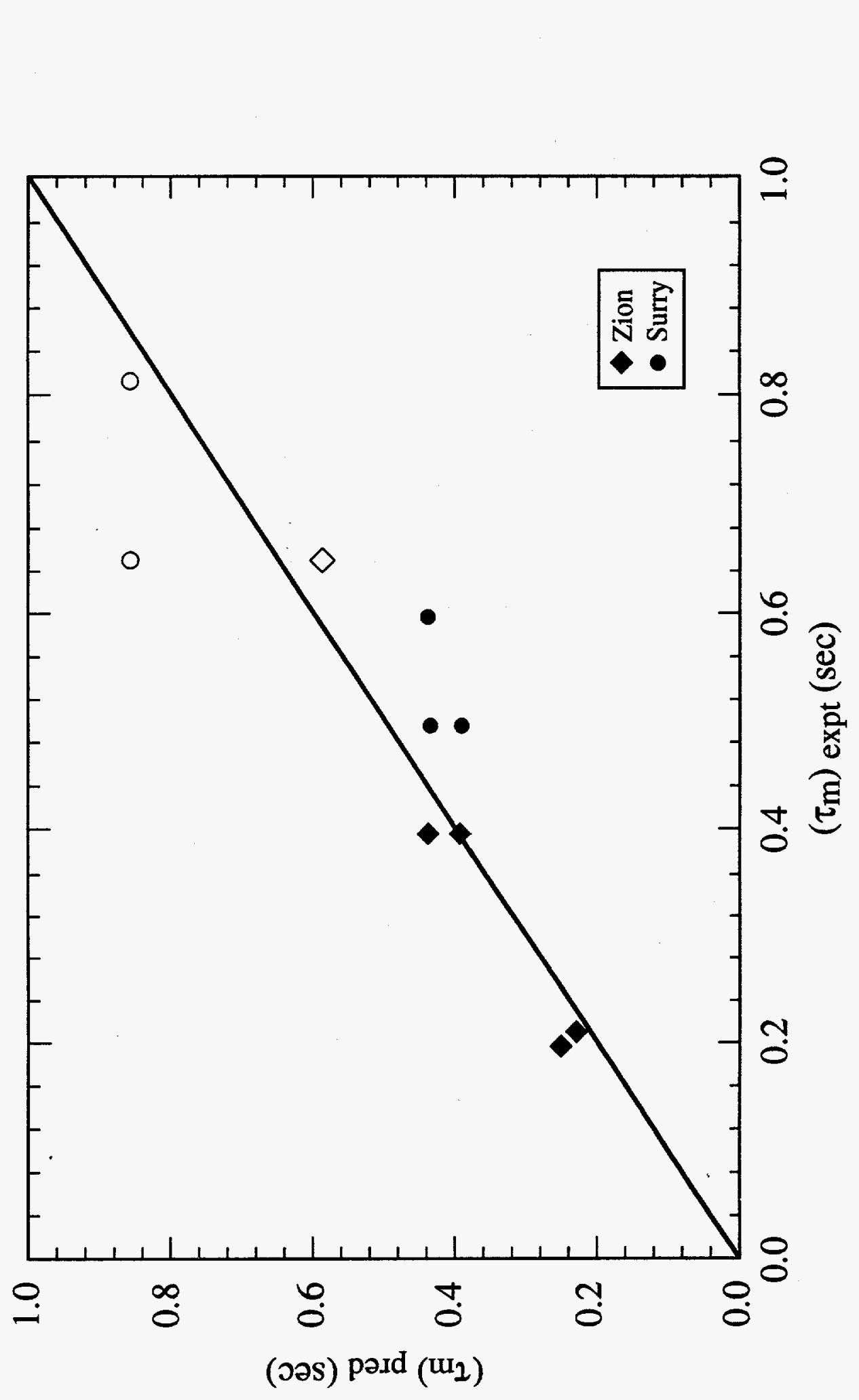

$\stackrel{8}{8}$

है

응

号

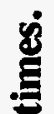

言

曾

잉

를

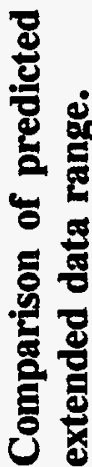

$\dot{0}$

疍 


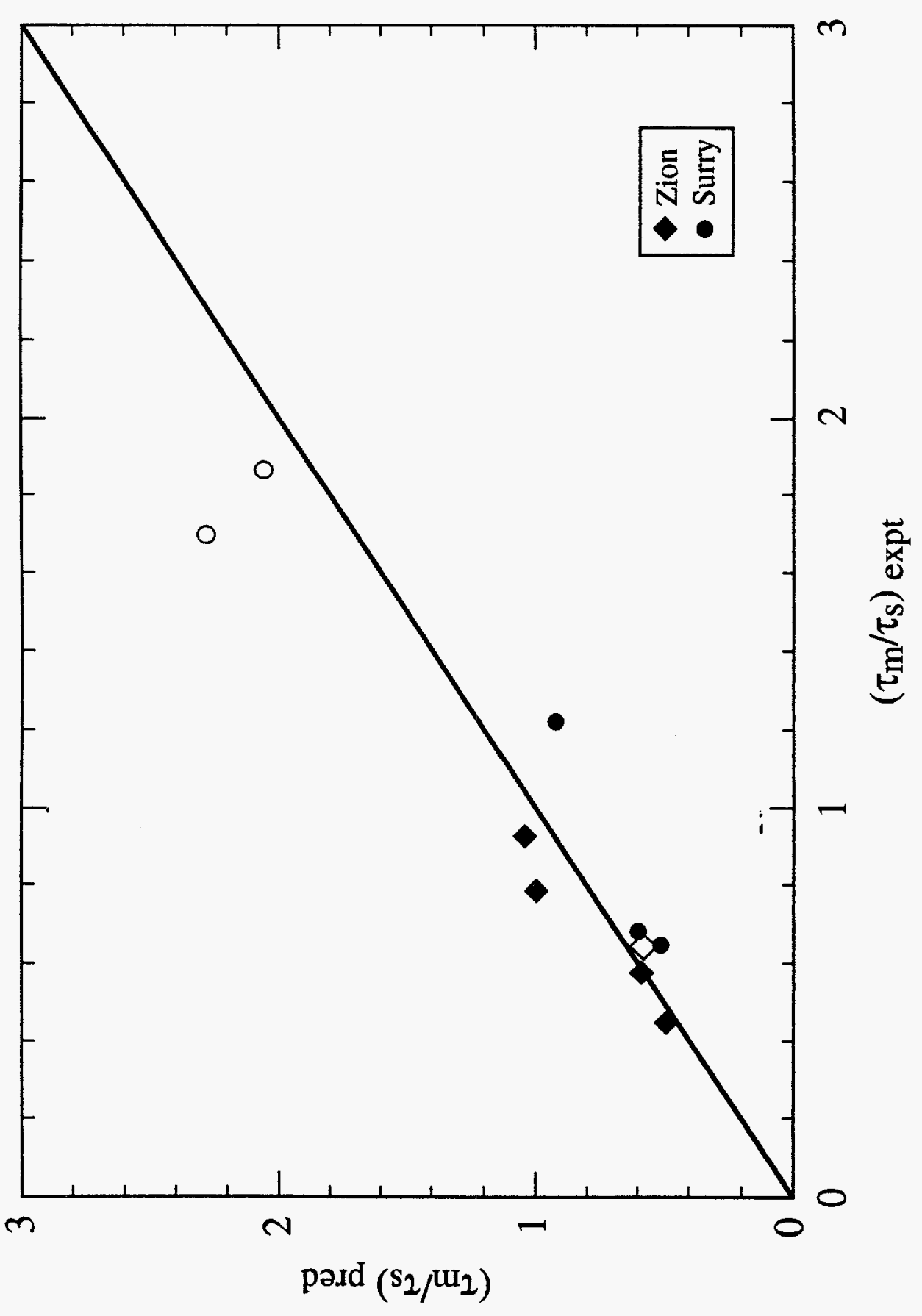

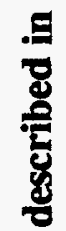

:

曹

E

$\frac{5}{3}$

竞

$\frac{\widetilde{a}}{3}$

要

농

홍

马ํ.

헝

옹

는

递

농

욜

율

농

통 를

造

퐁

ํㅜㄹ 


\section{APPENDIX E \\ A TWO-CELL EQUILIBRIUM MODEL FOR PREDICTING DCH}

Martin M. Pilch

Sandia National Laboratories

\section{E.1 INTRODUCTION}

Direct containment heating (DCH) can occur in a nuclear power plant (NPP) if, as the result of a core melt accident, molten core material accumulates on the lower head of the reactor pressure vessel (RPV) causing it to fail by a thermally induced rupture, by expulsion of an incore instrument guide tube, or by the thermally induced rupture of an incore guide tube or other penetration outside the RPV boundary (Rempe et al., 1992). DCH is only of interest if the RPV failure occurs while the reactor coolant system (RCS) is still at elevated pressure. Failure of the lower head of the RPV by one of these mechanisms initiates forcible ejection of molten core material into the reactor cavity located beneath the RPV. These processes have been termed high pressure melt ejection (HPME).

The subsequent blowdown of the RCS adds both mass and energy to the containment atmosphere. Some portions of the molten core material that are ejected into the reactor cavity can be entrained, fragmented, and dispersed into the containment atmosphere; the remainder is typically ignored in DCH analyses. Fragmented debris dispersed from the reactor cavity can rapidly liberate its thermal energy to the containment atmosphere. The metallic components of the dispersed material can oxidize with steam, liberating both energy and hydrogen. These processes will heat the containment atmosphere, possibly to the point at which steam can no longer inert the combustion of hydrogen. Collectively, these processes are termed $\mathrm{DCH}$, which might lead to early failure of the reactor containment building (RCB) by overpressurization.

DCH found its genesis in the Zion Probabilistic Safety Study (ZPSS, 1981) where it was argued that failure of the RPV would occur in a large number of accident sequences while the RCS was still at elevated pressure and that the resulting HPME and blowdown of the RCS would 
forcibly sweep melt from the cavity into the containment where the melt would settle into a coolable geometry on the containment floor. Thus, HPME and debris dispersal was thought to lead to a benign or even beneficial termination of the accident. These predictions lead to EPRI sponsored programs at ANL (Spencer et al., 1982; 1983) and NRC sponsored programs at SNL (Tarbell et al., 1984) to study debris dispersal from the cavity. The SNL program also placed heavy emphasis on characterizing the aerosol source term associated with the HPME and debris dispersal processes. Towards this end, SNL conducted the SPIT-18, 19 experiments (Tarbell et al., 1986) in a closed chamber to facilitate aerosol measurements. Unexpected heating of the atmosphere by dispersed debris damaged the facility in both tests. These tests raised concerns that HPME/DCH processes, overlooked until that time, might be a significant contributor to short-term containment pressurization in an NPP.

Coincident with these initial activities, the NRC sponsored the Containment Loads Working Group (CLWG, 1985) to examine possible overpressurization threats to the containment. Bounding calculations, assuming thermodynamic equilibrium between dispersed debris and the entire containment atmosphere, indicated that the Zion containment would be threatened with only 20 percent of the core participating in DCH (Bergeron and Williams, 1985; Pilch and Tarbell, 1986). These early estimates of containment threatening pressures were counterbalanced by a recognition that actual containments possessed a number of inherent mitigative features by virtue of their design. At the time, however, there was no convincing way to quantify the magnitude of this potential mitigation. As a consequence, the technical community became polarized. Since that time, experimental and analytical programs have addressed the issues of debris dispersal, water in the cavity and on the containment floor, and DCH loads in compartmentalized reactor geometries. These programs are briefly summarized below.

Debris dispersal from the reactor cavity has been the focus of many programs since the Zion Probabilistic Safety Study (ZPSS, 1981). Spencer et al. $(1982 ; 1983)$ showed that the threshold for dispersal from the Zion reactor cavity is reasonably predicted by the Kutateladze criterion proposed in the Zion Probabalistic Safety Study. IDCOR (1985) categorized existing cavity geometries into 14 classes and provided a subjective assessment of the dispersive or 
nondispersive qualities of each class. The IDCOR notion that cavity geometry influences debris dispersal has been confirmed only partially by more recent experiments. Separate effects experiments using low-temperature simulant fluids in the Zion, Surry, and Watts Bar geometries (Tutu et al., 1988a; b; Tutu, 1990; Tutu and Ginsberg, 1990), in the Sizewell B geometry (Macbeth and Trenberth, 1987; Rose, 1987; Macbeth et al., 1988), and in Korean designs (Kim et al., 1992; Chun et al., 1991) all show that cavity geometry is important only at low RCS pressures where dispersal is incomplete. However, correlations proposed by these authors and independent correlations (Levy, 1991) based on some of the same data all suggest that debris dispersal is nearly complete at reactor scale for RCS pressures in excess of about $4 \mathrm{MPa}$, regardless of the cavity geometry. Typical dispersal fractions of 75 percent have been observed in recent large-scale integral-effects DCH experiments (Allen et al., 1992c-h) and their smallerscale counterparts at ANL (Binder et al., 1992a-f). Henry (1989) analyzed the dispersal process and concluded that only a portion of the dispersed material is finely fragmented with the remaining material pushed from the cavity as a film. Henry's predictions have been confirmed by recent separate effects tests conducted at Purdue (Ishii et al., 1993) using water as a simulant for molten core material.

The experiments of Macbeth et al. (1988) suggest that the fraction of melt swept from the cavity is independent of physical scale. Correlations by Tutu and Ginsberg (1990) for the Zion and Surry cavities (based on 1/42 scale experiments conducted at BNL and unpublished $1 / 10$ scale experiments conducted at SNL) suggest that the extent of dispersal is nearly independent of physical scale. The correlations of Levy (1991, based on the same data) suggest that dispersal increases with physical scale. Other experiments (Kim et al., 1992; Chun et al., 1991) also show that the extent of dispersal is nearly independent of physical scale. More recently, the large-scale (1:10) integral effects DCH experiments (high temperature melts) conducted at SNL (Allen et al., 1992c-h, Allen et al., 1993b) and their smaller-scale counterparts (1:40) at ANL (Binder et al., 1992a-f) show that the extent of melt dispersal is independent of physical scale.

Reactor cavities normally exist so incore instrument guide tubes can have access to the lower head of the RPV. Most dispersal experiments have been conducted without these 
structures in the cavity. Rose (1987) found that modeling the guide tubes and their supports dramatically reduced dispersal of low temperature simulant fluids from a model of the Sizewell B cavity. The support structures are much more massive in the Sizewell reactor than typical U.S. reactors. Allen et al. (1990), however, found that the guide tubes and their supports were forcibly ejected from a model of the Zion cavity during the dispersal process. The distinguishing feature here is that a high temperature melt cut (by ablation) the supports free from the anchors in the floor of the cavity.

In summary, it appears that no cavity design can be considered retentive at the high RCS pressures of interest. Significant mitigation of DCH cannot be found in cavity design or the structures typically found in reactor cavities.

DCH experiments have been conducted at Sandia National Laboratories (SNL), Argonne National Laboratory (ANL), and Fauske and Associates (FAI). Of interest here are experiments employing high-temperature chemically reactive melts, driven under pressure into a simulated reactor cavity, with the whole system confined in a vessel so that containment pressure can be measured. A brief survey of these experiments is presented Table E.1. Experiments have been conducted at five different physical scales, two different cavity designs, with and without subcompartment structures, reactive and nonreactive blowdown gases, and reactive and nonreactive atmospheres.

The earliest DCH tests were the ANL/CWTI tests (1:30 scale) which showed significant mitigation of loads resulting from a combination of plant-specific subcompartment structures and cavity water. Some researchers felt that the observed containment pressurizations were substantially lower than would be expected at full scale because the time scale for heat and mass transfer is compressed in small-scale experiments.

The early Sandia experiments (SNL/DCH, SNL/TDS, SNL/WC) were conducted at much larger scale $(1: 10)$ and without any attempt to simulate the compartmentalized nature of real containments. In this way, separate effects information on heat and mass transfer rates, debris velocity, and other separate effects information could be obtained for development of the 
CONTAIN code. The effect of containment compartmentalization was crudely simulated in the SNL/LFP test series by placing a simple concrete slab at an adjustable height above the cavity exit. Henry (1991) also conducted DCH experiments (FAI/DCH) that included simulations of Zion subcompartment structures. These experiments produced DCH loads significantly less than would be predicted by simple bounding models. However, questions persisted on the effects of physical scale.

These early experiments were reviewed as part of an NRC-sponsored effort known as the Severe Accident Scaling Methodology (SASM) program (Zuber et al., 1991). As a result, experiment programs were redirected towards performing counterpart experiments at two different physical scales (SNL/IET and ANL/IET). These experiments, which benefited from a more focused scaling analysis (Zuber et al., 1991; Pilch et al., 1992), included detailed simulations of the Zion subcompartment structures and initial conditions closely tied to postulated accident scenarios. This testing program in Zion geometry is now complete. No strong effect of physical scale on containment loads or hydrogen production was found. Ongoing efforts, which are nearing completion, include large-scale (1:5.75 and 1:10) tests being conducted at SNL in Surry geometry and small-scale $(1: 40)$ tests being conducted at ANL using fully prototypic melts.

In addition to the experiment programs just discussed, a number of analytic efforts were initiated to improve upon the initial bounding (equilibrium) calculation performed for the CLWG. Pilch and Tarbell (1986) considered the heat transfer and oxidation kinetics of individual drops in the context of limited interaction distances (or time) within the containment. Similar modeling was performed independently by Corradini et al. (1986) using the DIRHEAT code. The-industry sponsored codes, HARDCORE/PARSEC, were developed by Sienicki and Spencer (1986; 1987). HARDCORE predicts cavity dispersal phenomena and PARSEC is a particle-tracking kinetic model for containment pressurization. HARDCORE/PARSEC were employed to analyze early ANL experiments, but they are not well suited for reactor analyses because PARSEC cannot model containment compartmentalization. 
The NRC's best estimate containment analysis code, CONTAIN (Murata et al. 1990), was modified to incorporate an airborne debris field so that kinetic calculations could be performed with nodalization appropriate to compartmentalized containments. CONTAIN is a control volume code. Early parametric calculations by Williams et al. (1987) clearly showed that compartmentalized geometries significantly mitigate DCH by limiting debris interactions to only a small portion of the available heat sink. These early parametric calculations also showed that vaporization of cavity or subcompartment water might actually enhance DCH loads by increasing energy transport to the dome. Other parameter studies using CONTAIN (Williams and Louie, 1988) identified coherence of debris dispersal with RCS blowdown as an important factor. Additional sensitivities investigated by Williams in these two pioneering citations include the effects of heat/mass transfer assumptions, hydrogen burn assumptions, the effects of hole size, and the effect of debris dispersal through the annulus.

The KIVA code is a particle tracking code that has been adapted for DCH analyses (Marx, 1989; Sweet et al., 1991). The code was intended to be an experiment analysis tool and to provide more detailed calculations against which CONTAIN could be benchmarked.

The British adopted the basic CONTAIN modeling of DCH, but wrote a special driver package, CORD (Morris, 1988), to provide detailed modeling of RPV and cavity phenomena. The Italians adapted FUMO (Fruttuoso, 1992), their containment analysis code, to perform control volume analyses of DCH with models similar to those in CONTAIN. MELCOR has also implemented parametric DCH models (Summers, 1992) where the key kinetic processes are controlled by user-specified parameters. Darwish (1991) also has developed a control volume code for performing DCH analyses. This code models RPV, cavity, and containment phenomena.

All analyses since the time of the CLWG have one element in common: they attempt to model the key kinetic processes that control DCH. Unfortunately, the parameters controlling these key rate processes are not well understood for the complex geometries of actual reactor plants, a situation that is further complicated by the unique and hostile environment that characterizes the DCH event. The latter point makes it very difficult to extract needed separate 
effects information from integral DCH tests where high temperature melts are employed. Separate effects tests (Ishii et al., 1993) using simulant fluids are being performed to supply some of the needed information. Integral assessment against the now extensive DCH database has never been performed for any of the models discussed so far.

The MAAP3B (Henry and Plys, 1990) models for DCH differ from this modeling approach (kinetics) by invoking equilibrium between "fine aerosol" and the atmosphere. However, the quantity of fine aerosol is quite small, so a little bit of debris is envisioned as interacting efficiently with a large quantity of gas. Conceptually, this is different from the model developed in Appendices D and E, which assumes that a large quantity of melt interacts efficiently with a small (gaseous) heat sink.

This paper discusses two adiabatic equilibrium models that are conservatively biased with the intent of bounding or enveloping each of the processes that contribute to containment pressurization. With this philosophy, assessment and validation of the separate effects (kinetic) models and the parameters (i.e., particle size) that control them are not required. The first, a single-cell equilibrium (SCE) model, places a true upper bound on DCH loads. This upper bound when compared with the entire $\mathrm{DCH}$ database often far exceeds experiment observations by a margin too large to be useful in reactor analyses. The single-cell model will be used as a conceptual seed for a two-cell model.

In this paper, a two-cell equilibrium (TCE) model is developed that captures the dominant mitigating features of containment compartmentalization and the noncoherence of the entrainment and blowdown processes. Although developed with a conservative bias, the two-cell model does an excellent job of correlating the relevant DCH database; and as a result, the TCE takes on the nature of being best estimate.

The germinal elements of the two-cell model were presented by Pilch (1991) and Pilch et al. (1992). The latter suggested that heat and mass transfer rates should be taken into account; however, the two-cell model developed here specifies a more realistic sink for debris interactions and additional kinetic limitations are largely eliminated. Concurrent with these 
efforts, Theofanous and Yan (1992) independently developed the convection limited containment heating model (CLCH), the current version of which is presented in Appendix D. The more recent refinements of both models have benefited by the collaborations necessary to complete the current work. The fundamental difference between the models is that the TCE model is best thought of as a batch process while the CLCH model is best thought of as a flow process.

\section{E.2 SINGLE-CELL ADIABATIC EQUILIBRIUM MODEL}

The single-cell equilibrium (SCE) model assumes that the entire containment volume can be treated as a single control volume in which there are no energy sinks. The dispersed debris is assumed to mix completely with the entire containment atmosphere and to remain airborne long enough to enable all thermal and chemical interactions to come to equilibrium. Three moderating factors are reflected in the single-cell model: metal/steam reactions may be steam limited, hydrogen combustion may be oxygen limited, and debris/gas thermal equilibrium renders energy below the equilibrium temperature unavailable for heating the atmosphere. On a containment-wide basis, these moderating factors are nonexistent or second-order effects in typical reactor applications, but they may be considerably more important in selected DCH experiments.

The energy equation for the containment atmosphere is given by

$$
\frac{d U}{d t}=\dot{Q}_{g, b}+\dot{Q}_{g, d g}+\dot{Q}_{g, H 2}
$$

where the terms on the right-hand side (RHS) represent the energy source rates due to RCS blowdown, debris/gas heat transfer, and hydrogen combustion. The energy equation for dispersed debris is given by

$$
\frac{d U_{d}}{d t}=u_{d}\left(T_{d}^{0}\right) \frac{d N_{d}}{d t}+\dot{Q}_{d, r}-\dot{Q}_{g, d g}
$$

where the first two terms on the RHS represent the energy source rates due to dispersal of debris (which carries thermal energy) into the atmosphere and the subsequent oxidation of the dispersed debris. The third term on the RHS represents the energy loss rate from the debris due to 
debris/gas heat transfer, which is conservative with the analogous source term in the gas energy equation.

Combining the energy equations for the atmosphere and the dispersed debris yields

$$
\frac{d U}{d t}=Q_{g, b}+Q_{d, r}+Q_{g, H 2}-\frac{d U_{d}}{d t}+u_{d}\left(T_{d}^{0}\right) \frac{d N_{d}}{d t}
$$

The equilibrium state is obtained by integrating this equation from $t=0$ to $t=\infty$,

$$
U\left(T_{e}\right)-U\left(T^{0}\right)=\Delta E_{b}+\Delta E_{r}+\Delta E_{H 2}+\left[U\left(T_{d}^{0}\right)-U_{d}\left(T_{e}\right)\right]
$$

where $\Delta \mathrm{E}_{\mathrm{b}}, \Delta \mathrm{E}_{\mathrm{r}}$, and $\Delta \mathrm{E}_{\mathrm{H} 2}$ are the maximum contribution that RCS blowdown, debris oxidation, and hydrogen combustion can make to changes in the atmosphere internal energy. The last grouping in this equation,

$$
U_{d}\left(T_{d}^{0}\right)-U_{d}\left(T_{e}\right)
$$

represents the thermal energy released by the debris while approaching equilibrium with the gas. This term cannot be quantified because the equilibrium temperature $\left(T_{e}\right)$ is not yet known. The following discussion addresses this difficulty.

The debris internal energy can be indexed to a reference temperature by adding and subtracting a reference energy to Equation E-5:

$$
U_{d}\left(T_{d}^{0}\right)-U_{d}\left(T_{e}\right)=U_{d}\left(T_{d}^{0}\right)-U_{d}\left(T_{r}\right)-\left[U_{d}\left(T_{e}\right)-U_{d}\left(T_{r}\right)\right]
$$

which can be simplified partially to

$$
U_{d}\left(T_{d}^{0}\right)-U_{d}\left(T_{e}\right)=\Delta E_{t}-\left[U_{d}\left(T_{e}\right)-U_{d}\left(T_{r}\right)\right]
$$

where $\Delta \mathrm{E}_{\mathrm{t}}$ is the maximum internal energy content of all dispersed debris relative to the reference temperature. 
The following decomposition based on the caloric equation of state coupled with a useful rearrangement yields

$$
U_{d}\left(T_{e}\right)=N_{d} C_{d} T_{e}=\left(N^{0}+N_{b}\right) C_{v} T_{e} \frac{N_{d} C_{d}}{\left(N^{0}+N_{b}\right) C_{v}}=U\left(T_{e}\right) \psi
$$

where

$$
\psi=\frac{N_{d} C_{d}}{\left(N^{0}+N_{b}\right) C_{v}}
$$

is a ratio of heat capacitances. The implication is that blowdown gas augments the containment atmosphere as the heat sink for debris energy. Here it is assumed that the molar heat capacities of the gases (atmosphere and blowdown gas) are constant and the same. The molar specific heat of the debris is also assumed constant and includes the heat of fusion by smearing it over the temperature range $T_{r}$ to $T_{d}{ }^{0}$. A similar manipulation yields

$$
U_{d}\left(T_{r}\right)=U\left(T_{r}\right) \psi
$$

Taking advantage of these manipulations, the maximum change in the total internal energy of the containment atmosphere can be written as

$$
\Delta U=U_{d}\left(T^{0}\right)-U\left(T^{0}\right)=\frac{\Delta E_{b}+\Delta E_{t}+\Delta E_{r}+\Delta E_{H 2}}{1+\psi},
$$

where an energy term

$$
\Delta E=-\left[U_{d}\left(T^{0}\right)-U_{d}\left(T_{r}\right)\right]=-N_{d} C_{d}\left(T^{0}-T_{r}\right)
$$

has been dropped from the numerator as negligible compared to the other energy terms. The term represents about a 3 percent correction to the thermal energy term to account for the fact that debris cooldown is bounded on the low side by the initial containment temperature and not the reference temperature. The maximum pressure rise in the containment resulting from DCH 
can be obtained by combining the caloric equation of state for the atmosphere internal energy with the ideal gas law and an identity for the ratio of gas specific heats. Doing so yields

$$
\frac{\Delta P}{P^{0}}=\frac{\Delta U}{U^{0}}=\frac{\sum \Delta E_{i}}{U^{0}(1+\psi)} .
$$

This is the working equation for the single-cell equilibrium model. The term, $1+\psi$, appears because thermal energy below the debris/gas equilibrium temperature is unavailable for heating the atmosphere. This is a second-order effect on a containment-wide basis.

The earliest considerations of DCH (CLWG, 1985) identified containment water (in the cavity or on the containment basement floor) as a potential mitigator of DCH. Simple energy arguments support containment water as a mitigator because energy absorbed in vaporizing water will not contribute to increased atmospheric temperature. Although vaporized water adds moles of steam to the containment atmosphere leading to increased pressure, the resulting pressure rise would be considerably less than if all the energy went into heating the atmosphere. Consequently, containment water is a potential mitigating factor.

This simplistic energy argument does not reflect the kinetics of debris/water interactions. Experiments (Spencer et al., 1987; Allen et al., 1992a) have shown that cavity water can enhance debris dispersal from the cavity; however, the bounding model already assumes nearly complete dispersal from the cavity for RCS pressures greater than $4 \mathrm{MPa}$. CONTAIN calculations (Williams et al., 1987) have indicated that efficient water interactions in the cavity can increase the peak pressure by as much as 20 percent compared to a dry scenario for a wide range of water masses ( $\leq 100 \mathrm{MT}$ ). Only modest increases in peak pressure and hydrogen production (Henry et al., 1991; Allen et al., 1992a; Spencer et al, 1987) have been observed in experiments. A modest decrease in pressure was observed with most of the observed pressure being attributed to vaporization of water. Analyses of the WC-1 and WC-2 experiment results (Allen et al., 1992a) suggest that only a small fraction of the available water participates in the interactions. This conclusion is supported by other experiment observations (Tarbell et al., 1991) where violent debris/water interactions in the cavity expel the bulk of the water from the 
cavity as a slug. The SNL/IET-8B (Allen et al., 1993b) was conducted with a cavity half full of water. For these reasons, cavity water is not expected to jeopardize the bounding nature of the models developed here.

The various terms and material properties necessary to fully quantify a result are discussed next.

\section{E.2.1 Molar Inventory of the Containment Atmosphere and the RCS}

The molar inventory of the containment atmosphere can be expressed (by the ideal gas law) in terms of known conditions in the containment prior to vessel breach,

$$
N^{o}=\frac{P^{0} V}{R_{u} T^{0}}
$$

Blowdown of the RCS to ambient conditions adds mass to the containment atmosphere. The amount of blowdown gas can be computed from the difference in the initial and final states in the RCS, which for an isentropic blowdown of an ideal gas can be written as

$$
\mathrm{N}_{\mathrm{b}}=\frac{\mathrm{P}_{\mathrm{RCS}}^{0} \mathrm{~V}_{\mathrm{RCS}}}{\mathrm{R}_{\mathrm{u}} \mathrm{T}_{\mathrm{RCS}}^{0}}\left[1-\left(\frac{P^{0}}{P_{R C S}^{0}}\right)^{\frac{1}{\gamma}}\right] \approx \frac{P_{R C S}^{0} V_{R C S}}{Z^{0} R_{\mathrm{u}} T_{R C S}^{0}}\left[1-\left(\frac{P^{0}}{P_{R C S}^{0}}\right)^{\frac{1}{\gamma}}\right]
$$

The term preceding the brackets represents the molar inventory of the RCS prior to vessel breach, while the term in the square brackets represents the fraction of the initial inventory that is actually convected into the containment. The fraction of RCS gas delivered to the containment is usually near unity and a second-order correction; however, high-pressure steam near saturation is not well represented as an ideal gas. The approximate expression shown in Equation E-15 accommodates this departure from the ideal by introducing a compressibility factor (which is on the order of 0.75 for saturated steam at elevated RCS pressures) into the evaluation of the initial RCS inventory. The compressibility factor is computed exactly for each experiment or reactor application. 


\section{E.2.2 Amount of Debris Participating in DCH}

The number of debris moles participating in $\mathrm{DCH}$ can be related to the initial molar inventory of molten core material on the lower head of the RPV at the time of vessel breach,

$$
N_{d}=f_{\text {disp }} f_{\text {eject }} N_{d}^{o},
$$

where $f_{\text {cject }}$ is the fraction of melt initially on the lower head of the RPV that is ejected into the reactor cavity, and $f_{\text {disp }}$ is the fraction of melt ejected into the reactor cavity that is subsequently dispersed into the containment.

Analyses of gas blowthrough and two-phase melt ejection during HPME (Pilch and Griffith, 1992) suggest that virtually all molten material in the bottom of the RPV at the time of vessel breach is ejected into the reactor cavity (i.e., $f_{\text {eject }}=1.0$ ). Recent integral effects DCH experiments (Allen et al., 1992c-h, 1993b; Binder et al., 1992a-f) exhibited $\sim 7$ percent retention of melt as a frozen crust in the melt generator. Retention by freezing, which is controlled by the surface/volume ratio of the melt, is expected to be less effective at full scale. Experiment analyses will be performed using measured values of $f_{\text {cject }}$. No reactor cavity can be considered retentive at the high RCS pressures of interest. Predictions of DCH experiments will be based on measured values of the dispersed fraction.

The conventional approach to DCH analyses assumes that only dispersed debris (because it is highly fragmented) can contribute significantly to containment pressurization on DCH time scales. More recently, it has been speculated that even debris that is not dispersed from the reactor cavity can interact significantly with blowdown gas. The current models converge with Williams' interpretation when melt ejection and dispersal are nearly complete.

\section{E.2.3 Energy Source Resulting from RCS Blowdown}

The energy gained by the containment atmosphere from blowdown of the RCS is balanced by the energy loss from the RCS by the same process, 


$$
\frac{d U_{g, b}}{d t}=-\frac{d U_{R C S}}{d t}=\frac{V_{R C S}}{\gamma-1} \frac{d P_{R C S}}{d t}
$$

The blowdown energy can be bounded by assuming that the RCS pressure reduces to the initial containment pressure,

$$
\Delta E_{b}=-\Delta U_{R C S}=\frac{V_{R C S} P_{R C S}^{0}}{\gamma-1}\left[1-\frac{P^{0}}{P_{R C S}^{0}}\right] .
$$

The term preceding the brackets represents the total internal energy of the RCS, while the bracketed term represents the fraction of this total that is convected into the containment.

\section{E.2.4 Energy Source from Debris Thermal Energy}

Molten debris dispersed from the reactor cavity carries both latent and sensible heat that can be transferred to the containment atmosphere. The thermal energy contribution represents the total internal energy of the dispersed debris referenced to the initial temperature of the atmosphere,

$$
\Delta E_{r}=U_{d}\left(T_{d}^{0}\right)-U_{d}\left(T_{r}\right)=N_{d}\left[u_{d}\left(T_{d}^{0}\right)-u_{d}\left(T_{r}\right)\right]=N_{d} \Delta u_{d}=N_{d} C_{d}\left(T_{d}^{0}-T_{r}\right)
$$

where the later equalities explicitly show the dependence on the amount of participating debris. The specific molar internal energy is indexed to the reference temperature $(298 \mathrm{~K})$, and it is both temperature and composition dependent.

\section{E.2.5 Energy Source from Debris Oxidation}

The metallic components of dispersed debris can also react with available steam to release energy to the debris and form hydrogen. The metallic components of molten core material consists of steel (chromium and iron) and possibly zirconium metal. Although zirconium and chromium are present in relatively small quantities, their combustion usually dominates the magnitude of the oxidation energy, which can be comparable to the thermal energy contribution (for some published melt compositions (Zuber et al., 1991). Oxidation of metallic components 
is expected to occur in a hierarchical fashion: zirconium, chromium, and iron (in that order). Consequently, the preferential oxidation of a small quantity of material can supply virtually all the oxidation energy. However, the oxidation of iron, although almost neutral energetically, cannot be ignored in the production of hydrogen. Almost assuredly there is sufficient blowdown steam in any reactor application to react those metals that dominate the reaction energy, which is assumed to be fully realized without regard to potential kinetic limitations. Together these assumptions favor both simplicity and a bounding result.

DCH experiments sometimes employ a chromium-laced $\mathrm{Fe} / \mathrm{Al}_{2} \mathrm{O}_{3}$ thermite as a simulant for the molten core materials expected in a reactor accident. This melt also contains trace quantities of aluminum, which behave like zirconium in the reactor melt. The assumptions and conclusions discussed above are equally applicable to this simulant material.

The maximum energy release resulting from debris oxidation can be written as

$$
\Delta E_{r}=N_{d} \Delta h_{r} \delta_{r, s t m}
$$

where the molar heat of reaction is dependent on the composition of the melt. Note that the contribution of debris oxidation to DCH loads is also dependent on the amount of material participating in $\mathrm{DCH}$.

A steam limit to the oxidation energy is introduced largely to accommodate those experiments that have been conducted with nonreactive blowdown gases (e.g., nitrogen or carbon dioxide). The factor,

$$
\delta_{r, s t m}=\frac{\sum N_{d, i} \Delta h_{r, i} \min \left[\frac{N_{s t m, i}}{\nu_{d, i} N_{d, i}} ; 1\right]}{\sum N_{d, i} \Delta h_{r, i}},
$$

represents the fraction of the oxidation energy that is released by consuming the available steam. The summation is evaluated in a hierarchial manner starting with the most reactive metal. The limiting factor in the minimization function represents the ratio of available steam to the steam 
required to oxidize the metal at a current level of the hierarchy. The stoichiometric coefficient, $v_{\mathrm{d}, \mathrm{i}}$, represents the moles of steam consumed per mole of metal. The steam available at the start of each level in the hierarchy is obtained from the recursion formula,

$$
N_{s m, i}=\max \left[0 ; N_{s m, i-1}-v_{d, l} N_{d, i}\right],
$$

which takes as its seed the initial number of steam moles in the RCS, i.e., $\mathbf{N}_{\mathrm{stm}, 1}=\mathbf{N}_{\mathrm{RCs}}^{0}$. Excluding applications with inert blowdown gases, $\delta_{\mathrm{r}, \mathrm{sm}}$ is almost always near unity.

There are four sources of oxidant with which the metals can react: oxygen in the atmosphere, steam in the atmosphere, blowdown steam, and water in the cavity or on the basement floor. On a containment-wide basis, there generally is sufficient oxidant to oxidize all the metal in the debris. The debris will preferentially oxidize with oxygen when available, and this is the more energetic reaction. If debris does react with steam, however, then hydrogen is produced that may subsequently combust with the available oxygen; in which case the net energy release of the cycle would be the same as if the debris burned directly with oxygen.

Although the net energy release is the same, there are subtle differences that should be recognized. In the former case (debris/oxygen reactions), all the chemical energy is released first in the debris droplet, thus increasing its temperature and the likelihood of continued oxidation.

In the second case (debris/steam reactions), only a portion of the chemical energy is deposited in the debris droplet, thus resulting in a lower value for the maximum possible debris temperature. The remaining chemical energy appears when the hydrogen produced by the debris/steam reaction burns elsewhere in the containment atmosphere. This energy from hydrogen combustion is released directly to the containment atmosphere. This is the basis for the modeling here because it is assumed that the greater portion of debris oxidation occurs with steam in the reactor cavity and the plume of material as it exits the cavity. There is very little oxygen available in these regions. 
There is considerable evidence that cavity water is relatively inefficient at oxidizing debris. Violent debris/water interactions separate the bulk of the water from the bulk of the debris. Hydrogen production has been observed in several experiments, however, from metal/water reactions on the basement floor. This hydrogen is produced in an oxygen lean region (subcompartment) and is produced on a time scale that cannot contribute to peak pressures even if it did burn. Hydrogen resulting from metal/water reactions on the basement floor is noteworthy only in that it can confuse the interpretation of some hydrogen production/combustion measurements in experiments.

\section{E.2.6 Energy Source Resulting from Hydrogen Combustion}

Hydrogen combustion is normally inerted by steam in most severe accident scenarios. DCH is unique in that it can heat the containment atmosphere, possibly to the point where steam can no longer inert the combustion of hydrogen. Simplicity and a bounding result are obtained by assuming that all available hydrogen is burned completely (subject only to a possible oxygen limitation) during the $\mathrm{DCH}$ event. The maximum energy release from hydrogen combustion can then be written as

$$
\Delta E_{H 2}=\left(N_{H 2, R C B}+N_{H 2, R C S}+\nu_{d} N_{d} \delta_{H 2, s t m}\right) \Delta h_{H 2} \delta_{H 2, O 2},
$$

where $\Delta h_{\mathrm{H} 2}$ is the molar combustion energy. Three sources of hydrogen must be considered: preexisting hydrogen in the containment atmosphere that was released from the RCS prior to vessel breach, hydrogen injected into the atmosphere at the time of vessel breach as part of the blowdown gases, and hydrogen produced from debris/steam reactions as part of the DCH event. Hydrogen production resulting from debris oxidation is subject to a possible steam limitation,

$$
\delta_{H 2, s e m}=\frac{\sum \nu_{d, i} N_{d, i} \min \left[\frac{N_{s e n, i}}{\nu_{d, i} N_{d, i}} ; 1\right]}{\sum \nu_{d, i} N_{d, i}},
$$

which is evaluated in a hierarchial manner similar to the analogous term in the oxidation energy term. The stoichiometric coefficient ( $\nu_{\mathrm{d}, \mathrm{i}}$ moles of hydrogen produced / mole of metal oxidized) is identical to the previously introduced stoichiometric coefficient because one mole of steam 
always produces one mole of hydrogen. In reactor applications, there usually is sufficient steam (on a global basis) to burn all the available hydrogen. Some experiments, however, have intentionally inerted the containment atmosphere, so it is useful to recognize a possible oxygen limitation to hydrogen combustion,

$$
\delta_{H 2, O 2}=\min \left[\frac{2 N_{O 2}^{o}}{N_{H 2, R C B}+N_{H 2, R C S}+\nu_{d} N_{d} \delta_{H 2, s o m}} ; 1\right] .
$$

\section{E.2.7 Material Properties}

Table E.2 lists the specific molar properties of melt species that are present in molten core material and iron/alumina thermite, which is often used as a surrogate for core material in DCH experiments. The heat capacity is treated as a constant, which is chosen so that reported values of the specific internal energy are matched at $2500 \mathrm{~K}$. The heat capacities, therefore, include the heat of fusion by implicitly smearing it over the entire temperature range. The specific molar internal energy is temperature dependent with the representative values evaluated at $2500 \mathrm{~K}$. The remaining terms are also treated as constants.

Table E.3 lists the specific molar heat capacities of gas species that typically make up a containment atmosphere or that have been employed in DCH experiments. The specific heats are treated as constants, which are evaluated at elevated temperatures to better predict the atmospheric heat sink during a DCH transient.

Effective mixture properties for the molten debris or the containment atmosphere can be computed as a mole fraction average of the species properties when the composition is specified. Representative mixture values are listed in Tables E. 2 and E.3. These mixture values are based on the representative melt and atmosphere compositions listed in Tables E.4 and E.5. In any given experiment or reactor application, mixture properties specific to the actual melt and atmosphere compositions are employed. 


\section{E.2.8 Comparison of the One-Cell Model with Experiment Data}

Figure E. 1 provides an assessment of the single-cell equilibrium model against the entire DCH database. The data are listed in Table E.6. Figure E.1 shows no correlation of the singlecell model with the experiment data. However, pressure increments all exceed measured values, thus supporting the bounding nature of the single-cell equilibrium model. Unfortunately, predicted values can exceed measured values by nearly an order of magnitude in some cases. Two quantitative measures of goodness are listed on the figure, the relative bias and the relative RMS error,

$$
\sigma_{\text {bias }}=\frac{\sum\left(\frac{\phi_{\text {pred, }, i}-\phi_{\text {meas }, i}}{\phi_{\text {pred, } i}}\right)}{N-1},
$$

$$
\sigma_{m s}^{2}=\frac{\sum\left(\frac{\phi_{\text {pred,i }}-\phi_{\text {meas }, i}}{\phi_{\text {pred }, i}}\right)^{2}}{N-1}
$$

Margins this large are of limited utility in most reactor analyses; consequently, a model is required that reflects the dominating mitigating features of $\mathrm{DCH}$ in real reactor containments.

\section{E.3.0 TWO-CELL ADIABATIC EQUILIBRIUM MODEL}

The TCE model extends the previous results in order to capture much of the mitigating effects associated with containment compartmentalization, which prevents the efficient mixing of airborne debris with the entire atmosphere by confining the bulk of the debris to the subcompartment of the containment. The essential requirements are that there are no line-of- 
flight paths for dispersed debris to reach the upper dome under its own inertia and that the subcompartment-be sufficiently large that gas velocities diffuse to the point where flowing gas is no longer capable of levitating debris $(\sim 1 \mathrm{~mm})$ through various vent spaces to the dome. The latter requirement is perhaps overly conservative because debris does not easily respond to changes in flow direction without deentraining into sheltered regions of low gas velocity; and most containment subcompartments (Zion included) require multiple changes in flow direction before vent spaces can be reached.

The primary heat sink for debris in this confined subcompartment geometry is that portion of the blowdown gas that is coherent with the dispersal processes, which may be augmented by portions of the subcompartment atmosphere. Thermal equilibrium between debris and this limited heat sink retains more energy in the debris as unavailable for additional heating of the atmosphere.

The moderating factors recognized in the single-cell model are retained here, and they are supplemented by additional features that could further limit the magnitude of containment pressures:

1. metal/steam reactions may be steam limited,

2. hydrogen combustion may be oxygen limited,

3. debris/gas thermal equilibrium renders energy below the equilibrium temperature unavailable for heating the atmosphere,

4. chemical equilibrium could limit the amount of hydrogen produced from iron/steam reactions,

5. hydrogen combustion as a diffusion flame may be inerted, and

6. the ignition threshold for volumetric combustion of preexisting hydrogen may not be reached.

The TCE model continues to treat the containment as adiabatic on the time scale of peak DCH pressures. Simple scoping calculations indicate that structure heat transfer in the dome region is way too slow to affect peak pressure. Measured pressure and temperature (gas) 
histories in the dome region of experiments indicates that cooldown takes $\sim 20-40$ times longer than heatup during the DCH event. The cavity surface area is too small for any significant heat transfer; and in any case, the surfaces are coated with a thin layer of hot melt that reduces the potential for heat transfer from the gas. Lastly, control volume type calculations for the subcompartments suggest that structure heat transfer might have a noticeable, but not dominant effect on containment pressure in some experiments where no hydrogen combustion occurs. Such assessments are particularly difficult to do correctly because experiment observations suggest that the gas is not well mixed in the subcompartment and that there is some tendency for the gas to "tunnel" through the subcompartment to the available vents. Structure heat transfer only affects the thermal energy contribution of debris to peak pressure. Hydrogen combustion, a significant energy source in $\mathrm{DCH}$, occurs in the dome and is not affected by subcompartment heat transfer. Furthermore, structure heat transfer is a surface-to-volume effect, so its impact is expected to be reduced at reactor scale. For these reasons, we do not believe that heat transfer to structures affects peak containment pressure in any significant way, so we simply chose to bound these processes in our models.

The containment is typically divided into two main volumes: upper dome and subcompartment (Figure 3.2). For a pressurized water reactor (PWR), the subcompartment typically comprises the reactor cavity and the region generally located beneath the operating floor, bounded by the crane wall and the refueling canal wall. The upper dome comprises the remainder of the containment. Debris can be dispersed from a PWR cavity through two possible flow paths. The first flow path typically exists so that incore instrument guide tubes can have access to the lower head of the RPV. Debris dispersal through this path will enter the containment subcompartment.

A second path for debris dispersal is through an annular gap surrounding the RPV. Debris dispersed through this path enters the upper dome of the containment. The annular gap is partially filled with the hot/cold leg nozzles, reflective insulation, and sometimes with neutron shields. The analysis presented here allows for the possibility that both flow paths can exist. 
The premise of the TCE model is that DCH occurs independently in the subcompartment and the upper dome, $\Delta U=\Delta U_{1}+\Delta U_{2}$. It will be shown that the jndividual contributions can be written as the product of an efficiency and the maximum internal energy change based on the single cell model,

$$
\Delta U=\left(\eta_{1}+\eta_{2}\right)(\Delta \dot{U})_{1 c}
$$

so that the containment pressurization can be conveniently written as

$$
\frac{\Delta P}{P^{0}}=\left(\eta_{1}+\eta_{2}\right)\left(\frac{\Delta P}{P^{0}}\right)_{1 C}
$$

The efficiency of DCH processes in the subcompartment and the upper dome are developed next.

\section{E.3.1 DCH Processes in the Subcompartment}

Blowdown gas and debris are assumed to enter the subcompartment in the ratio of the flow area (into the subcompartment) to the total flow area from the cavity, $\mathrm{f}_{\mathrm{al}}$. This assumption is treated more fully in Appendix I. The gas (heat sink) with which debris can exchange energy has two physical limits. The first limit conceptually corresponds to a limit where debris is injected into the subcompartment like a shotgun blast with little or no blowdown gas. In this limit, the maximum heat sink is the gas initially residing in the subcompartment. The second limit corresponds to the case where debris dispersal is accompanied by large quantities of blowdown gas. In this limit, the heat sink is that portion of the blowdown gas that is coherent with the dispersal process. For intermediate cases, the heat sink (and DCH loads) can be bounded by taking the maximum of the two limits. Physically, this means some or all of the subcompartment atmosphere will be displaced to the dome before DCH interactions take place. In either limit, hydrogen combustion is insignificant in the subcompartment because metal/steam reactions typically produce far more hydrogen than the local inventory of oxygen can burn and because most of this subcompartment oxygen may be pushed to the dome by injection of hot blowdown gas into the subcompartment.

We have a reasonable expectation that thermal and chemical equilibrium is achieved in the cavity, so that flight path limitations are not controlling. To make this assessment, we 
follow SASM (Zuber et al. 1991) and compare the interaction time between dispersed debris and coherent blowdown with the heat transfer and oxidation time constants. The interaction time (entrainment interval) is inferred directly from the SNL/IET experiments to be $\tau_{e} \sim 0.3 \mathrm{~s}$. The heat transfer time constant, $\tau_{\mathrm{HT}} \sim \Delta \mathrm{E}_{\mathrm{hEQ}} / \mathrm{R}_{\mathrm{HT}}$, can be evaluated in a manner similar to Pilch et al. (1992). Experimentally determined particle sizes $\left(D_{d} \sim 0.5 \mathrm{~mm}\right)$ and dispersal fractions $\left(f_{\text {disp }}\right.$ - 0.7) are used in evaluating the heat transfer time constant. The heat transfer time constant is $\tau_{\mathrm{HT}} \sim 0.015$ so that $\tau_{\mathrm{HT}} / \tau_{\mathrm{e}} \sim 0.05$. Thus, we reasonably expect thermal equilibrium in the SNL/IET experiments. A similar process for oxidation yields $\tau_{o x} / \tau_{e} \sim 0.01$, so we can also reasonably assume chemical equilibrium in the cavity. These experiment based estimates are quite crude and any departure from equilibrium at other scales or in other geometries becomes a difficult scaling problem. Therefore, we are motivated to assume thermal and chemical equilibrium in all our assessments, and successful comparisons with the DCH database further support this bounding modeling approach. Ishii's correlations (1993) predict similar particle sizes at reactor scale.

The energy gained by gas in the subcompartment can be written as

$$
\Delta U_{1}=\frac{f_{a l}\left(\Delta E_{b}+\Delta E_{t}+\Delta E_{r}\right)-f_{a l} N_{d} C_{d}\left(T_{1}^{0}-T_{r}\right)}{1+\psi_{1}},
$$

where

$$
\psi_{1}=\frac{f_{a l} N_{d} C_{d}}{\max \left[f_{a 1} f_{c o h} N_{R C S}^{0} ; f_{v 1} N^{0}\right] C_{v}}
$$

is the local heat capacitance ratio in the subcompartment. On a global basis, the heat capacitance ratio $(\psi)$ is generally a second-order effect; but in compartmentalized containment geometry, debris/gas heat transfer can be reduced drastically in the subcompartment because of large values of $\psi_{1}$.

The heat sink for the debris gas interactions can have an initial temperature ranging from the initial containment temperature to the initial temperature in the RCS, depending on whether the subcompartment atmosphere or the blowdown gas dominates as the heat sink. In general, 
neither dominates and mixing of the two gases forces an intermediate temperature approximated by

$$
T_{1}=\frac{f_{a} f_{c o h} N_{R C S}^{0} T_{R C S}^{0}+f_{v 1} N^{0} T^{0}}{f_{a} f_{c o h} N_{R C S}^{0}+f_{v l} N^{0}}
$$

This represents a mixture temperature before DCH interactions are considered. On a global basis, the heat sink correction to the thermal energy term, $N_{d} C_{d}\left(T^{0}-T_{r}\right)$, is quite insignificant, and it exists only because tabulated internal energies are referenced to a temperature different from the initial containment temperature. The correction can be important, however, in reactor applications where the hot blowdown gas can dominate the heat sink in the subcompartment.

Changes in the subcompartment internal energy can be normalized by the internal energy change predicted by the single-cell equilibrium model,

$$
\Delta U_{1}=\frac{f_{a l}\left(\Delta E_{b}+\Delta E_{t}+\Delta E_{r}\right)-f_{a l} N_{d} C\left(T_{1}^{0}-T_{r}\right)}{\left(1+\psi_{1}\right)(\Delta U)_{1 C}}(\Delta U)_{1 C} .
$$

Doing so allows one to define a pressure efficiency,

$$
\eta_{1}=\frac{f_{a l}\left(\Delta E_{b}+\Delta E_{t}+\Delta E_{r}\right)-f_{a l} N_{d} C_{d}\left(T_{1}^{0}-T_{r}\right)}{\left(1+\psi_{1}\right)(\Delta U)_{1 C}},
$$

characterizing the contribution of subcompartment processes to peak DCH loads. The three energy terms $\left(\Delta \mathrm{E}_{\mathrm{b}}, \Delta \mathrm{E}_{\mathrm{l}}\right.$, and $\left.\Delta \mathrm{E}_{\mathrm{r}}\right)$ are identical to their counterparts in the single-cell model. It is useful to add and subtract a hydrogen combustion energy identical to the term in the singlecell model. The correction to the thermal energy term can also be normalized by $T_{d}{ }^{\circ}-T_{r}$. Lastly, the internal energy change from the single-cell model is given by Equation E-11. Taken together, the subcompartment efficiency can be written as 


$$
\eta_{1}=\frac{1+\psi}{1+\psi_{1}} \frac{\left[f_{a 1}\left(\sum \Delta E_{i}\right)_{1 C}-f_{a l}\left(\Delta E_{H 2}\right)_{1 C}-f_{a l} N_{d} C_{d}\left(T_{d}^{o}-T_{r}\right) \frac{T_{1}-T_{r}}{T_{d}^{o}-T_{r}}\right]}{\left(\sum \Delta E_{i}\right)_{1 C}}
$$

which after a final simplification becomes

$$
\eta_{1}=f_{a l} \frac{1+\psi}{1+\psi_{1}}\left[1-\left[\frac{\Delta E_{H 2}}{\sum \Delta E_{i}}\right]_{1 C}-\left[\frac{\Delta E_{t}}{\sum \Delta E_{i}}\right]_{1 C} \frac{T_{1}-T_{r}}{T_{d}^{o}-T_{r}}\right] .
$$

The DCH efficiency for the subcompartment is written in terms of known quantities from the single-cell model. Equation E-36 reflects three factors for the subcompartment that result in reduced energy deposition in the gas: a limited heat sink reflected in a large value of $\psi_{1}$, no hydrogen combustion, and a heat sink that is hotter than the reference temperature.

\section{E.3.2 DCH Processes in the Dome}

The dome region of a reactor containment building typically involves more than ninety percent of the containment volume, but very little debris is expected to reach this region. Development of an energy equation for the dome parallels that for the subcompartment (only here, the variables are specific to the dome) with the notable exception that some or all of the hydrogen can burn in the dome, regardless of where it is produced.

The energy gained by gas in the dome can be written as

$$
\Delta U_{2}=\frac{f_{a 2}\left(\Delta E_{b}+\Delta E_{t}+\Delta E_{r}\right)+N_{H 2, b u m} \Delta e_{H 2}-f_{a 2} N_{d} C_{d}\left(T_{2}-T_{r}\right)}{1+\psi_{2}},
$$

where the local capacitance ratio is given by

$$
\psi_{2}=\frac{f_{a 2} N_{d} C_{d}}{\max \left[f_{a 2} f_{c o h}^{o} N_{R C S}^{o} ; f_{v 2} N^{o}\right] C_{v}},
$$

and where the heat sink temperature is given in a manner analogous to Eq. E.32, 


$$
T_{2}=\frac{f_{a z} f_{c o h} N_{R C S}^{o} T_{R C S}^{o}+f_{v 2} N^{o} T^{o}}{f_{a 3} f_{c o h} N_{R C S}^{o}+f_{v 2} N^{o}}
$$

A DCH efficiency for the dome can be developed in a manner similar to that for the subcompartment,

$$
\eta_{2}=\frac{f_{a 2}\left(\Delta E_{b}+\Delta E_{l}+\Delta E_{r}\right)+N_{H 2, b w n} \Delta e_{H 2}-f_{a 2} N_{d} C_{d}\left(T_{2}-T_{r}\right)}{\left(1+\psi_{2}\right)(\Delta U)_{1 c}}
$$

A more useful result is obtained by adding and subtracting a hydrogen combustion energy equivalent so that in the one-cell model, by normalizing the amount of hydrogen burned by the total hydrogen burned in the one-cell model, and by normalizing the reference energy correction to the thermal energy term by $T_{d}{ }^{0}-T_{r}$. With these suggestions, the efficiency of DCH processes in the dome can be written as

$$
\eta_{2}=\frac{1+\psi}{1+\psi_{2}}\left[f_{a 2}-\left(f_{a 2}-f_{\text {bum }}\right)\left[\frac{\Delta E_{H 2}}{\sum \Delta E_{i}}\right]_{1 C}-\left[\frac{\Delta E_{t}}{\sum \Delta E_{i}}\right]_{1 C} \frac{T_{2}-T_{r}}{T_{d}^{o}-T_{r}}\right],
$$

where

$$
f_{\text {bum }}=\frac{N_{\text {H2,bum }}}{\left(N_{H 2, \text { bum }}\right)_{I C}}
$$

is the fraction of hydrogen that could burn in the dome and actually does. This term will be quantified in Section E.3.4.

\section{E.3.3 Hydrogen Combustion in the Dome}

Hydrogen combustion occurs predominantly, if not entirely, in the dome of the reactor containment, which typically comprises at least 90 percent of the total volume. This is because the subcompartment contains only a small fraction of the containment's oxygen; and much of what is there initially will be pushed to the dome by the debris/gas plume exiting the cavity. Unfortunately, hydrogen combustion in the dome is most efficient because oxygen limitations 
are not likely to come into play and because the combustion energy goes almost entirely into heating the atmosphere (i.e., $\psi_{2}$ is small in the dome).

Three sources of hydrogen must be considered: preexisting hydrogen in the containment atmosphere that was released from the RCS prior to vessel breach, hydrogen injected into the atmosphere at the time of vessel breach as part of the blowdown gases, and hydrogen produced from debris/steam reactions as part of the DCH event. Chemical equilibrium could limit the amount of hydrogen from iron/steam reactions. Hydrogen in the subcompartment will be heated as part of the DCH event. The subsequent expansion will expel this hydrogen into the dome through various vent paths. These hot hydrogen jets are assumed to burn as diffusion flames, entraining preexisting hydrogen along with the oxygen necessary to sustain combustion. In some cases, DCH processes may heat the containment atmosphere sufficiently to induce autoignition and volumetric combustion of any remaining preexisting hydrogen. These concepts are quantified in the following discussions.

Hydrogen can be produced from metal reactions with the coherent part of the blowdown gas. Consider first the reactive metals $(\mathrm{Zr}, \mathrm{Al}$, and $\mathrm{Cr})$. The amount of hydrogen produced, subject only to a possible steam limitation, is given by

$$
N_{H 2}(R M)=\sum_{i=1}^{R M} \nu_{i} N_{d, i} \min \left[\frac{\left.f_{c o h} N_{S T M, i} ; 1\right]}{\nu_{i} N_{d, i}}\right]
$$

where the summation is evaluated in the hierarchical fashion discussed previously. Lastly, iron can oxidize and produce hydrogen,

$$
N_{H 2}(F e)=X_{F e O} \nu_{F e} N_{d, F e}^{o},
$$

if excess steam is still available. The factor, $X_{\mathrm{FeO}}^{\prime}$, represents the amount of iron that is oxidized, which could be limited by chemical equilibrium even if steam is present. 
Iron oxidizes according to the reaction,

$$
\mathrm{Fe}+\mathrm{H}_{2} \mathrm{O} \rightarrow \mathrm{FeO}+\mathrm{H}_{2}
$$

at high temperatures. At chemical equilibrium, the mole fraction of $\mathrm{FeO}$ is given by

$$
X_{F e O}=\frac{\frac{y_{H 2 O}}{y_{H 2}} K_{e q}}{1+\frac{y_{H 2 O}}{y_{H 2}} K_{e q}}
$$

where $\mathrm{K}_{\mathrm{eq}}$ is the equilibrium constant (a function of temperature only), which has a value of about $\mathrm{K}_{\mathrm{eq}} \sim 2.1$ on the temperature range $2000 \mathrm{~K}$ to $3000 \mathrm{~K}$. By definition,

$$
X_{F e O}=\left(\frac{N_{F e O}}{N_{F e O}+N_{F e}}\right)_{e q}=\frac{\left(N_{F e O}\right)_{e q}}{N_{F e}^{o}}=\frac{\left(N_{F e}\right)_{e q}}{N_{F e}^{o}},
$$

which shows that $\mathrm{X}_{\mathrm{FeO}}$ also represents the fraction of iron that is oxidized.

The steam/hydrogen ratio controls the amount of hydrogen that is oxidized. By definition;

$$
\frac{y_{H 2 O}}{y_{H 2}}=\left[\frac{N_{H 2 O}}{N_{H 2}}\right]_{e q}=\frac{N_{H 2 O}^{\prime}-X_{F e O} N_{d, F e}^{o}}{N_{H 2}^{\prime}+X_{F e O} N_{d, F e}^{o}}
$$

where $\mathbf{N}_{\mathrm{H} 2 \mathrm{O}}^{\prime}$ and $\mathbf{N}_{\mathrm{H} 2}^{\prime}$ are the moles of steam and hydrogen in contact with the iron when oxidation with the reactive metals is complete. These quantities can be related back to known RCS conditions by

$$
\begin{gathered}
N_{H 2 O}^{\prime}=f_{c o h} N_{H 2 O, R C S}^{o}-N_{H 2}(R M) \\
N_{H 2}^{\prime}=f_{c o h} N_{H 2, R C S}^{o}+N_{H 2}(R M) .
\end{gathered}
$$

Equations E-50 - E-52 can be combined with Equation E-48 to form a quadratic for $\mathrm{X}_{\mathrm{FeO}}$, the solution of which is given by 


$$
X_{F e O}=\frac{B}{2}\left[1-\left(1-\frac{4 C}{B^{2}}\right)^{1 / 2}\right]
$$

where

$$
\begin{gathered}
B=\frac{K_{e q}}{K_{e q}-1}\left[1+\frac{N_{H 2 o}^{\prime}}{N_{d, F e}^{o}}+\frac{1}{K_{e q}} \frac{N_{H 2}^{\prime}}{N_{d, F e}^{o}}\right] \\
C=\frac{K_{e q}}{K_{e q}-1} \frac{N_{H 2 o}^{\prime}}{N_{d, F e}^{o}} .
\end{gathered}
$$

This completes the information required to compute the total amount of hydrogen produced from metal steam reactions.

Most of the preexisting hydrogen in the subcompartment will be pushed to the dome when the debris/gas plume enters the subcompartment dome, so that hydrogen in the subcompartment is comprised of blowdown hydrogen and hydrogen produced from metal/steam reactions,

$$
N_{H 2}(j e t)=f_{a 1} N_{H 2, R C S}^{o}+N_{H 2}(R M)+N_{H 2}(F e)
$$

This hydrogen will be heated by the DCH event, and the resulting expansion will expel most of this hydrogen to the dome.

Hot hydrogen/steam jets entering the upper dome are expected to burn as standing diffusion flames. This has been observed in SNL/ANL counterpart DCH experiments. Other experiments in the test series, however, have shown that if the atmosphere is inerted sufficiently, the combustion of the hot jet can be snuffed out entirely. Demonstration that hydrogen jets will not burn under some reactor conditions could lead to large margins of safety; consequently, there is a need to define the threshold conditions for a hot hydrogen jet where oxygen must be entrained from the environment in order to sustain combustion. 
Williams (1992a) has supplied such a threshold condition. Consider a hot hydrogen/steam jet with temperature $T_{j}$ entering the oxygen-bearing dome region. Hydrogen can burn only if some oxygen-bearing atmosphere is entrained into the jet. The entrained atmosphere comes in cold, and it must be heated by combustion to at least the jet temperature,

$$
\delta N_{e} C_{p}\left(T_{j}-T^{0}\right) \leq 2 X_{o 2} \delta N_{e} \Delta e_{H_{2}},
$$

otherwise the jet temperature cannot be sustained. This cooling of the jet causes a crisis because the chemical reactions are so strongly temperature dependent. Williams (1992) suggested that there is a jet temperature of about $1000 \mathrm{~K}$ below which combustion could not be sustained. This is closely related to the autoignition temperature for hydrogen jets, which Stamps and Berman (1991) report to be about $1000 \mathrm{~K}$. This defines a critical oxygen concentration for the atmosphere,

$$
\left(X_{o 2}\right)_{c r i t}=\frac{1}{2} \frac{C_{p}\left[T_{j}-T^{o}\right]}{\Delta e_{H 2}},
$$

below which jet combustion is incomplete as it cools to the threshold temperature. The critical oxygen concentration ( $\sim 5$ percent) takes its minimum value when the jet temperature just equals the threshold temperature. This prediction is consistent with observations from the NTS tests, where Shepard (1987) noted that hydrogen diffusion flames extinguished when the background oxygen concentration dropped below $\sim 5-8$ percent.

This criterion explains only partially the existing experiment database for jet combustion, and it would not limit jet combustion in most DCH scenarios. More restrictive criteria might be expected when one focuses on the competition between chemical kinetics and the kinetics of the entrainment/dilution processes. These kinetic considerations suggest that the threshold for jet combustion is scale dependent and much more restrictive at a small scale. Review of a related phenomenon, blowoff of diffusion flames, also suggests a similar scale dependence. Here, small-scale jets may not burn while combustion of sufficiently large jets is absolutely stable. Thus, failure to sustain a diffusion flame in some small-scale experiments might be an 
artifact of scale alone and not other DCH conditions. Confirmation of these ideas might come from $1 / 6^{\text {th }}$ scale DCH tests to be conducted at Sandia National Laboratories.

The hot hydrogen/steam jet can burn only because oxygen is entrained into the jet; assuming of course, that the threshold criterion for jet combustion is met. Entrainment also carries some of the preexisting hydrogen into the hot jet, and this entrained hydrogen can also burn. The total amount of jet hydrogen and preexisting hydrogen that can burn in the diffusion flame can be written as

$$
N_{H 2}(\text { flame })=N_{H 2}(j e t)+f_{p r e} N_{H 2}^{o}
$$

where

$$
N_{H 2}(j e t)=N_{H 2, R C S}^{o}+N_{H 2}(R M)+N_{H 2}(F e)
$$

is the total of all hydrogen that is produced in the cavity and subcompartment that has the potential to reach the dome by vents or through the annular gap around the RPV.

The fraction of preexisting hydrogen that is entrained and burned in the jet can be bounded by assuming that enough atmosphere is entrained to burn the jet hydrogen that enters the dome plus any entrained hydrogen,

$$
N_{H 2}(j e t)+X_{H 2} N_{e}=2 X_{o 2} N_{e}
$$

The entrained fraction is then obtained by normalizing the moles of atmosphere entrained by the initial number of moles in the atmosphere,

$$
f_{p r e}=\frac{N_{e}}{N^{o}}=\frac{N_{H 2}(j e t)}{N^{o}} \frac{1}{2 X_{o 2}-X_{H 2}}
$$

Not all the preexisting hydrogen in the containment atmosphere will be entrained into the jet and burn. In general, a quantity $\left(1-\mathrm{f}_{\mathrm{pre}}\right) \mathrm{N}_{\mathrm{H} 2}^{\circ}$ remains. This remaining hydrogen can burn in the dome, subject only to possible oxygen limitations, if the peak containment temperature first reaches a temperature of about $1100 \mathrm{~K}$; at which point, autoignition and volumetric 
combustion of the remaining hydrogen occurs. Quantification of the autoignition temperature is discussed in Appendix F.

The total amount of hydrogen burned can be normalized by the total hydrogen burned in the one-cell model,

$$
f_{\text {bum }}=\frac{\left.N_{H 2} \text { (burned }\right)}{\left(N_{H 2}\right)_{1 C}} .
$$

From the preceding discussions, three cases must be considered:

$$
f_{\text {bum }}=0
$$

when the threshold criterion for jet combustion is not reached,

$$
f_{\text {bum }}=\frac{N_{H 2}(\text { flame }) \min \left[\frac{2 N_{O 2}^{o}}{N_{H 2}(\text { flame })} ; 1\right]}{\left(N_{H 2}\right)_{1 C}}
$$

when a diffusion flame burns, and

$$
f_{\text {bum }}=1.0
$$

when DCH processes in conjunction with a diffusion flame autoignite preexisting hydrogen.

\section{E.3.4 Comparison of the Two-Cell with Experiment Data}

Comparison of the TCE model with experiment data requires that the mass distribution throughout the containment be specified. Measured values of the melt ejection fraction, melt dispersal fraction, and melt transport fractions are used in the model predictions. Measured values of the coherence time (Table E.8) are also used in the comparisons. Pressure predictions of the two-cell model are compared to experiment data in two steps: data with nonreactive atmospheres (i.e. no chance of hydrogen combustion) and data where hydrogen combustion occurred (or could have occurred). The latter will be preceded by an assessment of hydrogen 
production predictions with experiment measurements. Model predictions and experiment measurements are listed in Table E.6.

Figure E. 2 compares predicted pressure efficiencies with measured efficiencies for those experiments where hydrogen combustion is inerted by excluding oxygen from the atmosphere. The measured efficiency is obtained by normalizing the measured pressure rise by the maximum possible pressure rise as predicted by the single-cell equilibrium model. The two-cell model does an excellent job of correlating the data. This has important implications. The SNL/LFP and ANL/CWTI tests employed only the crudest representation of containment compartmentalization, while the SNL/ANL IET tests and the FAI/DCH tests employed accurate and complex representations of the Zion subcompartment geometry. The SNL/IET (Surry) tests employed accurate and complex representations of the Surry subcompartment geometry. Yet all the tests show reasonable correlation with the TCE model.

Hydrogen produced by metal reactions with the coherent part of the blowdown steam is the most important of several possible sources of hydrogen because this is the hydrogen that is heated and dispersed to the dome as a hot jet, which is likely to burn as a diffusion flame on the time scale of peak containment pressure. Figure E.3 compares predicted hydrogen with measured hydrogen for those tests that had no water in the cavity or containment and also had nonreactive atmospheres. Also excluded are experiments with particularly poor dispersal from cavity. Model predictions are in good agreement with data, so this important source of hydrogen production is well validated to within uncertainties in estimating the coherence ratio for the tests.

Figure E. 4 compares model predictions of hydrogen production with experiment data for those tests that had reactive atmospheres, or water in the cavity, or water on the containment floor. Model predictions, based on metal reactions with coherent steam, consistently underpredict the data by a factor of $\sim 2$.

First, it should be noted that the model predicts the amount of hydrogen that is produced (and likely to burn) on DCH time scales. This is not what the measurements represent. In 
particular, measurements of hydrogen produced and burned can be distorted and misleading for several reasons: -

1. Post DCH iron/oxygen reactions severely distort the measurements of hydrogen combustion and production.

2. Long term metal/water reactions cannot be separated from short term hydrogen production during the DCH event.

3. Short term measurements are distorted by stratification and separation of gas species in the dome and subcompartment, and long term measurements are distorted by items 1 and 2 above.

For these reasons, measurements of hydrogen production and combustion in tests with containment water and/or reactive atmospheres are of limited utility for model validation. It's worth noting that items 1 and 2 represent no limitation whatsoever for dry tests with nonreactive atmospheres. and limitation 3 can be minimized by mixing fans or waiting until the atmosphere mixes naturally.

Hydrogen jets enter the upper dome through various vents in the operating deck where, in general, it is expected to burn as a diffusion flame, subject to possible inerting (Eq. E.56) as suggested by Williams (1992). Table E.7 compares the Williams' criterion with observed jet behavior. Detection of jet combustion is based on visual observations and measured containment pressurization. Inferring jet combustion from changes in the oxygen inventory is ambiguous for the reasons discussed previously. Table E.7 shows that hydrogen combustion is predicted in all cases except for SNL/IET-5 where both prediction and observation indicate that the jet should not and did not burn.

The only violation of experiment observation is ANL/IET-8 where combustion would have been expected based on the Williams' criterion. More restrictive criteria, based on a competition between the kinetics of chemical and hydrodynamic processes, are likely to be scale dependent with the threshold for sustained combustion being broader at larger scale. The ANL/IET-8 experiment is noteworthy in that it was conducted in an air/steam/hydrogen 
atmosphere that was contaminated by hydrocarbon gases. Other tests (SNL/IET-9 and ANL/UIB) have-been conducted near the threshold without inerting the jet combustion. It is sufficient to note that the Williams' criterion is conservative, predicting combustion where it was not observed.

Hydrogen production and combustion thresholds have been validated by parts. It remains to validate integral predictions of those tests conducted with reactive atmospheres. Predictions are compared to experiment data in Figure E.5. The scatter is only slightly worse than the cases with nonreactive atmospheres. This integral agreement supports the notion that only hydrogen produced from coherent steam will burn.

Lastly, Figure E. 6 compares TCE predictions of the TCE model with all experiment data. For compartmentalized geometry, the comparisons are presented in terms of efficiency and in terms of pressure rise. Comparison of the pressure rise results with those from the single cell model (Figure E.1) illustrates the tremendous improvement that the two-cell model has over the single-cell model. Agreement of the TCE model with experiment data clearly demonstrates that dominant mitigating mechanisms are adequately reflected in the model. The agreement is remarkable given that tests have been performed at $1 / 5.75,1 / 10,1 / 20,1 / 30$, and $1 / 40$ physical scale; therefore, DCH loads are insensitive to physical scale. We also note the variety of subcompartment geometries employed in the tests, ranging from simple slabs to complex representations of Zion and Surry geometries. We therefore conclude that containment loads are also insensitive to details of subcompartment geometry.

\section{E.4 Coherence of Blowdown Gas with Debris Dispersal}

The TCE model assumes that debris/gas interactions are largely limited to that portion of the blowdown gas that is coherent with the dispersal process. The ratio of the characteristic dispersal time to the characteristic time constant for blowdown is termed the coherence ratio. Smaller values of the coherence ratio means that the primary heat sink for debris/gas thermal interactions is smaller and that metal/steam reactions are more likely to be steam limited. Evaluations of DCH pressures in experiments were based on measured values of the coherence 
ratio. These measured values form a database suitable for the validation of proposed models for the coherence ratio.

The CLCH model and the TCE model employ slightly different definitions of the coherence ratio:

$$
\begin{gathered}
{\left[R_{\tau}\right]_{C L C H}=\frac{\tau_{m}}{\tau_{s}}=\frac{\tau_{m} V_{R C S}}{C_{d} A_{h} \sqrt{\gamma R T_{R C S}^{0}}}} \\
{\left[R_{\tau}\right]_{T C E}=\frac{\tau_{e}}{\tau_{b}}=\tau_{c} \frac{M_{g, R C S}^{o}}{\dot{M}_{g, R C S}^{0}}=\left[\frac{2}{\gamma+1}\right]^{\frac{\gamma+1}{2(\gamma-1)}\left[R_{\tau}\right]_{C L C H}=0.58\left[R_{\tau}\right]_{C L C H}} .}
\end{gathered}
$$

Notice that the two definitions differ only by a constant factor, which has a value of 0.58 for most cases of interest. For the reactor applications of interest, the definition of the coherence ratio employed in the TCE model is approximately equal to the fraction of RCS gas that is coherent with the dispersal process (i.e., $f_{\text {coh }} \approx \tau_{e} / \tau_{b}$, for $\tau_{e} / \tau_{b} \leq 0.5$ ). Because of this direct analogy, $\left[\mathrm{R}_{\tau}\right]_{\mathrm{TCE}}$ will be employed in the following discussions, and the subscript denoting the TCE definition will be dropped. The fraction of the blowdown gas that is coherent with debris dispersal is given by,

$$
f_{c o h}=1-\frac{M_{g}^{o}}{M_{g, e}}=1-\left(\frac{P_{e}}{P^{o}}\right)^{\frac{1}{\gamma}}=1-\left(1+\frac{\gamma-1}{-2} R_{\tau}\right)^{\frac{-2}{\gamma-1}}
$$

For $\mathrm{R}_{\tau} \leq 0.5, \mathrm{f}_{\text {coh }} \sim \mathrm{R}_{\tau}$, so that $\mathrm{R}_{\tau}$ is directly proportional to the amount of blowdown gas that can react with the debris.

The database for the coherence ratio largely overlaps the range of individual parameters that are of interest to reactor applications. However, the database does not include all possible combinations of parameters for each of the potential applications; consequently, a correlation for the coherence ratio is required in order to fill gaps in the database. It is significant that any such process is more closely analogous to interpolation rather than order of magnitude extrapolation. 
The notion that noncoherence (between debris dispersal and RCS blowdown) can limit DCH interctions-is not unique to the TCE model. Ginsberg and Tutu (1987) were the first to suggest this limitation. Williams and Louie (1988) also demonstrated the limitation through parametric CONTAIN calculations. The CLCH model (Appendix D) also considers noncoherence as a basic modeling process. These analytic reflections all have a solid basis in experiment observations.

Unpublished real-time flash $\mathrm{x}$-rays taken at SNL show that dispersal is complete well before blowdown. In addition, many experiments have been conducted (e.g., Allen et al. 1991b; Allen et al. 1992a,b) with pyrometers focused on the cavity exit. Pyrometer signals also confirm the notion of noncoherence, and they suggest that cavity pressurization records can also be used to define the coherent interval.

\section{E.4.1 Model for the Coherence Ratio}

The model developed here is not intended tc be a detailed accounting of all possible transient processes occuring in the cavity; rather, it is intended to capture the key parameter dependencies with the intent of correlating experiment data. The model for the coherence ratio is the based on the following four-step process:

1. Derive the momentum equation for debris within the cavity.

2. Normalize the momentum equation such that the dependent variables and their derivatives are of order unity.

3. Estimate the characteristic entrainment rate and the characteristic entrainment time.

4. Estimate the coherence ratio.

As a precursor to this process, the dispersal rate can be written as 


$$
\dot{M}_{d}=\epsilon \rho_{d} A_{c} v_{d}
$$

where the liquid fraction is quite small $(\epsilon \leq 0.10)$. In addition, the gas flow rate through the cavity,

$$
\dot{M}_{z}=\rho_{g, c} A_{c} v_{g, c},
$$

is equal to the gas flow rate through the breach in the RPV.

The momentum equation for debris within the cavity can be written as

$$
\frac{V_{c}}{A_{c}} \frac{d \dot{M}_{d}}{d t}=F-\frac{\dot{M}_{d}^{2}}{\epsilon \rho_{d} A_{c}}
$$

where the first term on the RHS represents the sum total of all forces on the debris and where the second term on the RHS represents the outflow of debris momentum from the cavity. The force term will be developed based on the following restrictions:

1. The flow pattern is predominantly dispersed droplets with a size insensitive to the gas flow parameters.

2. Dispersal is complete or nearly complete.

3. The velocity of dispersed debris is small compared to gas velocities.

The threshold for debris dispersal is controlled by the Kutateladze number,

$$
K u^{2}=\frac{\rho_{g, c} v_{g, c}^{2}}{\sqrt{g \sigma \rho_{d}}},
$$

which represents sufficient conditions to levitate debris particles against gravity. The second restriction above ensures that gravity forces can be ignored; that the flow pattern is more likely dispersed droplets, and that the particle size is more likely in a regime where it is insensitive to gas flow parameters. Experiments have shown that the debris velocity is less than ten percent of predicted gas velocities; consequently, the drag terms can be based solely on the gas velocity. 
With these assumptions the drag force on a single drop can be written as

$$
F_{p}=C_{d, p} \frac{1}{2} \rho_{g, c} v_{g, c}^{2} \frac{\pi D_{p}^{2}}{4}
$$

so that the total drag on all droplets can be written as

$$
F=F_{p} N_{p}=C_{d, p} \frac{1}{2} \rho_{g, c} v_{g, c}^{2} \frac{\pi D_{p}^{2}}{4} \frac{V_{d}}{\frac{\pi D_{p}^{3}}{6}}
$$

which after rearrangement becomes

$$
F=\frac{3}{4} C_{d, \rho} \frac{\dot{M}_{g}^{2}}{\rho_{g, c} A_{c}^{2}} \in \frac{V_{c}}{D_{p}}
$$

Pilch et al. (1981) have shown that the mass mean particle size is insensitive to flow parameters,

$$
D_{p}-8 \times 10^{-3} D^{0}
$$

for sufficiently large Weber numbers, i.e.,

$$
W e=\frac{\rho_{g, c} v_{g, c}^{2} D^{o}}{\sigma} \geq 10^{3}
$$

More recently, measurements by Ishii (1993) taken during dispersal of water from Zion cavities confirms the insensitivity to flow parameters when the flow is sufficiently vigorous.

Assuming that the initial particle size scales with the thickness of films within the cavity,

$$
D_{o} \sim \epsilon^{o} V_{c}^{1 / 3}
$$

then it can be shown that $\mathrm{We} \geq 10^{3}$ for typical conditions $\left(\mathrm{P}_{\mathrm{RCS}}^{\mathrm{O}}=8 \mathrm{MPa}, \mathrm{D}_{\mathrm{h}}=0.4 \mathrm{~m}\right.$ fullscale equivalent) in $1 / 40$ th scale experiments and that the Weber number increases with increasing physical scale. With these considerations, the total drag on all debris particles becomes 


$$
F=\frac{94 C_{d, \rho}}{\epsilon^{o}} \frac{\dot{M}_{g}^{2}}{\rho_{g, c} A_{c}} \frac{V_{c}^{2 / 3}}{A_{c}} \epsilon .
$$

The momentum equation can now be normalized such that the dependent variables and their derivations are of order unity,

$$
\frac{V_{c}}{A_{c}} \frac{\dot{M}_{d, m}}{t_{r}} \frac{d \dot{M}_{d}^{*}}{d t^{*}}=F^{*} F_{m}-\frac{\dot{M}_{d, m}^{2}}{\epsilon^{o} \rho_{d} A_{c}} \frac{\left(\dot{M}_{d}^{*}\right)^{2}}{\epsilon^{*}}
$$

where

$$
\begin{aligned}
\dot{M}_{d}^{*} & =\frac{\dot{M}_{d}}{\dot{M}_{d, m}} \\
\dot{M}_{g}^{*} & =\frac{\dot{M}_{g}}{\dot{M}_{g}^{o}} \\
t^{*} & =\frac{t}{t_{r}} \\
F^{*}=\frac{F}{F_{m}} & =\frac{F}{94 C_{d, p} \frac{\left(\dot{M}_{g}^{o}\right)^{2}}{\rho_{g, c} A_{c}} \frac{V_{c}^{2 / 3}}{A_{c}}} \\
\epsilon^{*} & =\frac{\epsilon}{\epsilon^{o}} .
\end{aligned}
$$

The characteristic (maximum dispersal rate can be estimated by setting the time derivative to zero and recognizing that the starred terms are all of order unity; consequently,

$$
F_{m}=\frac{\dot{M}_{d, m}^{2}}{\epsilon^{o} \rho_{d} A_{c}}
$$

which yields

$$
\dot{M}_{d, m}=\left[94 C_{d, p} \frac{V_{c}^{2 / 3}}{A_{c}} \frac{\rho_{d}}{\rho_{g, c}} \epsilon^{o}\right]^{\frac{1}{2}} \dot{M}_{g}^{o}
$$

for the characteristic entrainment rate. 
The characteristic entrainment time is defined as

$$
\tau_{e}=\frac{f_{d} M_{d}^{o}}{\dot{M}_{d, m}}
$$

And the characteristic time for blowdown of the RCS is given by

$$
\tau_{b}=\frac{M_{g}^{o}}{\dot{M}_{g}^{o}}
$$

The coherence ratio can be estimated from

$$
R_{\tau}=\frac{\tau_{e}}{\tau_{b}}=f_{d}\left(\frac{0.011}{C_{d, p}} \frac{A_{c}}{V_{c}^{2 / 3}} \frac{\rho_{g, c}}{\rho_{d}} \epsilon\right)^{1 / 2} \frac{\rho_{d} V_{c}}{M_{g}^{0}}
$$

In experiments employing high temperature melts, the gas temperature in the cavity is expected to approach the initial debris temperature, and the observed cavity pressure (peak) often exceeds the containment pressure by at least a factor of two. The latter observation implies that gas flow from the cavity is choked, and consideration of two-phase flow effects can only reinforce the conclusion. The gas density in the cavity is then approximated by

$$
\rho_{g, c} \approx \frac{M_{g}^{o}}{V_{R C S}}\left[\frac{T_{R C S}^{o}}{T_{d}^{o}}\right]^{1 / 2} \frac{A_{h}}{A_{c}} \frac{C_{d, h}}{C_{d, c}}
$$

The key feature here is that the gas density in the cavity is controlled by upstream conditions and independent of containment conditions. With this expression and the definition of $\epsilon^{\circ}=M_{d}^{o} /\left(\rho_{d} V_{c}\right)$, the final form of the coherence ratio can be written

$$
R_{\tau}=\frac{\tau_{e}}{\tau_{b}}=C_{1} f_{d}\left(\frac{T_{R C S}^{o}}{T_{d}^{o}}\right)^{1 / 4}\left(C_{d, k} \frac{M_{d}^{o}}{M_{g}^{o}} \frac{A_{h} V_{c}^{1 / 3}}{V_{R C S}}\right)^{1 / 2}
$$


where " $\mathrm{C}_{1}$ " is a constant that has been determined by a least squares curve fit to experiment data.

The coherence ratio is predicted to be independent of physical scale and only weakly dependent on cavity geometry. The coherence ratio is proportional to the hole diameter. It is instructive, but not preferable because steam is not an ideal gas, to express the initial gas mass in terms of pressure and temperature. Doing so shows that the coherence ratio is proportional to the three-fourths power of the initial RCS temperature and inversely proportional to the square root of the RCS pressure.

\section{E.4.2 Validation of Coherence Ratio Model}

The coherence ratio determines how much blowdown gas has been vented from the RCS on the same time scale as debris dispersal. Figures E.7 and E.8 show a typical cavity pressurization record and a typical accumulator blowdown curve from an experiment (SNL/IET-9). The entrainment interval is determined primarily from the cavity pressurization record. Pyrometers placed at the cavity exit show that the cavity pressure joins the containment pressure at the end of debris dispersal. Despite independent measures, cavity pressure and pyrometers, the interpretation of the entrainment interval is still inherently subjective. The end of the entrainment interval is marked by $\tau_{c}^{\prime}$ and corresponds to a final pressure $\mathrm{P}_{c}$ in the RCS. The decline in RCS pressure over the entrainment interval is a direct measure of the amount of gas vented into the cavity, and for an isentropic expansion within the RCS,

$$
f_{c o h}=\frac{\Delta M_{g}}{M_{g}^{o}}=1-\frac{M_{g}^{o}}{M_{g, e}}=1-\left(\frac{P_{e}}{P^{o}}\right)^{1 / \gamma} .
$$

This expression applies even though depressurization passes through three distinct phases. For computational convenience, it is useful to idealize the blowdown process as a single-phase gas discharge from a fixed size orifice (after any possible ablation). For isentropic expansion in the RCS and isentropic nozzle flow, the ideal blowdown history can be approximated by 


$$
\frac{P}{P^{o}}=\left[1+\frac{\gamma-1}{2} \frac{t}{\tau_{b}}\right]^{\frac{-2 \gamma}{\gamma-1}},
$$

where the characteristic blowdown time is given by

$$
\tau_{b}=\frac{M_{g}^{o}}{\dot{M}_{s}^{o}} \text {. }
$$

Physically, the pressure will be reduced to 29 percent of its initial value (for $\gamma=1.33$ ) after one time constant, and 61 percent of the initial gas mass will have been vented from the RCS.

The effective coherence ratio, assuming the idealized blowdown and consistent with the measured depressurization over the entrainment interval, is obtained from Equation E-89,

$$
R_{\tau}=\frac{\tau_{e}}{\tau_{b}}=\frac{2}{\gamma-1}\left[\left(\frac{p^{0}}{P_{e}}\right]^{\frac{\gamma-1}{2 \gamma}}-1\right] .
$$

The real utility of this formulation is that the idealized flow will predict the same quantity of vented gas (using this value of the coherence ratio) as the actual flow will vent by the end of the measured entrainment interval. Measured values of the coherence ratio are presented in the last column of Table E.8. The supporting experiment information is listed in the prior two columns.

Columns 2-10 of Table E.8 provide all the information necessary to evaluate the RHS of Equation E-87. The discharge coefficient for reactor applications is conservatively taken as 0.6 (sharp-edged orifice) even though some of the experiments exhibit values less than this because of two phase flow effects and plumbing losses. Table E.9 examines the applicability of the existing database to Zion applications. It is clear that the database largely overlaps typical reactor applications. In particular, the recent SNL/ANL counterpart tests (Zion) and ANL/U tests, and the 1:5.75 scale SNL/IET (Surry) tests are closely matched to the reactor applications. The database includes tests with $\sim 1 \mathrm{~m}$ diameter holes (full scale equivalent) and scaled melt masses $\sim 125 \%$ of the entire Zion core. 
Measured values of the coherence ratio are compared with the RHS of Equation E-87 in Figures E.9 and E.10. The data shown in these plots are restricted to cases where the dispersal is complete or nearly complete (i.e., $f_{\text {disp }} \geq 0.5$ ) and excludes a few points with peculiar blowdown histories or where the dispersal fraction was too low because these cases clearly violate the choke flow modeling assumption for the cavity. Six points (out of 44 possible) fall into this category and they can be clearly identified in Table E.8 as having dispersals less than 50 percent. Three additional tests (ANL/IET-1R, ANL/CWTI-5, and FAI/DCH-4) are excluded because of peculiar blowdown histories. ANL/IET-1R was excluded because it had an unknown quantity of water in the melt generator. ANL/CWTI-5 was excluded because of a discontinuous blowdown history caused by valve actions. FAI/DCH-4 was also excluded because it had a discontinuous blowdown history for unknown reasons.

Cavity design is the sole systematic deviation of the data from the correlation. Variations with cavity design, which are not fully accounted for by the model, are not surprising given that such variations are well documented in experiments that define the low pressure dispersal curve. This implies that different values of $C_{1}$ are required in Equation E-87 for each cavity design. Figure E.11 shows all Zion and Surry data together demonstrating that little is lost by combining the data sets. Such small variations with cavity design are of no real concern when thinking in terms of extrapolation to other similar cavity designs because uncertainties in the database tend to envelope any differences and because the coherence ratio is still small in the parameter range of reactor applications (even when small differences in cavity design are taken into account).

Experiments have been conducted at 1:40, 1:30, 1:20, 1:10, and 1:5.75 scale. The data confirm model predictions that there is no effect of physical scale. Experiments have been conducted at driving pressures ranging from 4 to $13 \mathrm{MPa}$, with hole sizes ranging from $0.4 \mathrm{~m}$ to $1.0 \mathrm{~m}$ (full scale equivalent), and melt densities ranging from $4000-8000 \mathrm{~kg} / \mathrm{m}^{3}$. These dependencies are adequately accounted for by the model. The success of the model is quite remarkable given the rather extreme variations of the database. 


\section{E.5 Scaling Perspectives}

The two-cell equilibrium model is already in nondimensional format so that the controlling scaling groups are easily identified in the form most amenable to a physical interpretation. Some of the scaling implications of the models are better illustrated when it is recognized that variations in material properties between various applications are second order effects. With this approximation, the scaling dependencies can be written as

$$
\frac{\Delta P}{P^{0}}=F\left[\frac{P^{0}}{P_{R C S}^{0}} ; \frac{V}{V_{R C S}} ; \frac{N^{0}}{N_{R C S}^{0}} ; \frac{N_{d}^{0}}{N^{0}} ; \frac{T_{d}^{0}}{T_{R C S}^{0}} ; X_{H 2, R C S} ; X_{H 2, R C B} ; X_{\mathrm{Zr}} ; X_{s s} ; \frac{\tau_{e}}{\tau_{b}}\right] \text {. }
$$

Debris transport phenomena and the coherence ratio have been shown to be independent of physical scale. This compact representation shows that DCH loads are largely independent of physical scale.

This conclusion must be tempered with the acknowledgment that threshold phenomena for hydrogen combustion are at least weak functions of physical scale. The current threshold criterion for jet combustion is conservative and independent of physical scale (although less conservative criteria might be). The threshold criterion for autoignition is a weak function of physical scale, with lower thresholds expected at reactor scale.

\section{E.6 Conclusions}

A simple two-cell equilibrium model has been developed to predict containment pressurization from DCH. The TCE model captures the major mitigating effects of containment compartmentalization and noncoherence of the dispersal and blowdown processes. The existing DCH database has been used to extensively validate both separate effects and integral effects models. DCH loads are shown to be insensitive to physical scale and details of the subcompartment geometry. The TCE model is developed with a conservative bias for some of the key processes; however, comparison with experiment data shows that the model is also close to best estimate. A simple model is developed to predict the coherence ratio for reactor applications. The coherence ratio is independent of physical scale and only weakly dependent 
on cavity design. The database for validation of the coherence ratio is quite prototypic, so application of the correlation is a matter of interpolation rather than order of magnitude extrapolation. ,

\section{E.7 REFERENCES}

Allen, M.D., Nichols, R.T., Pilch, M. (1990). A Demonstration Experiment of Steam-Driven, High-Pressure Melt Ejection: The HIPS-10S Test, NUREG/CR-5373, SAND89-1135, Sandia National Laboratories, Albuquerque, NM.

Allen, M.D., M. Pilch, R.T. Nichols, J.E. Brockmann, D.W. Sweet, W.W. Tarbell (1991a). Experimental Results of Direct Containment Heating by High-Pressure Melt Ejection into the Surtsey Vessel: The DCH-3 and DCH-4 Tests, SAND90-2138, Sandia National Laboratories, Albuquerque, NM.

Allen, M.D., M. Pilch, R.T. Nichols and R.O. Griffith (Oct. 1991b). Experiments to Investigate the Effect of Flight Path on Direct Containment Heating $(D C H)$ in the Surtsey Test Facility: The Limited Flight Path (LFP) Tests, NUREG/CR-5728, SAND91-1105, Sandia National Laboratories, Albuquerque, NM.

Allen, M.D., M. Pilch, R.O. Griffith and R.T. Nichols (Mar, 1992a). Experiments to Investigate the Effect of Water in the Cavity on Direct Containment Heating (DCH) in the Surtsey Test Facility - The WC-1 and WC-2 Tests, SAND91-1173, Sandia National Laboratories, Albuquerque, NM.

Allen, M.D., M. Pilch, R.O. Griffith and R.T. Nichols (Mar. 1992b). Experimental Results of Tests to Investigate the Effects of Hole Diameter Resulting from Bottom Head Failure on Direct Containment Heating (DCH) in the Surtsey Test Facility - The WC-1 and WC-3 Tests, SAND91-2153, Sandia National Laboratories, Albuquerque, NM.

Allen, M.D., M. Pilch, R.O. Griffith, R.T. Nichols and T.K. Blanchat (July 1992c). Experiments to Investigate the Effects of 1:10 Scale Zion Structures on Direct Containment Heating (DCH) in the Surtsey Test Facility: The IET-1 and IET-1R Tests, SAND92-0255, Sandia National Laboratories, Albuquerque, NM.

Allen, M.D., M. Pilch, R.O. Griffith, D.C. Williams and R.T. Nichols (June 1992d). The Third Integral Effects Test (IET-3) in the Surtsey Test Facility, SAND92-0166, Sandia National Laboratories, Albuquerque, NM. 
Allen, M.D., T.K. Blanchat, M. Pilch and R.T. Nichols (Sept. 1992e). The Effects of Condensate Levels of Water on Direct Containment Heating (DCH) in Zion-Like Geometry: The Fourth Integral Effects Test (IET-4) Conducted in the Surtsey Test Facility, SAND92-1241, Sandia National Laboratories, Albuquerque, NM.

Allen, M.D., T.K. Blanchat, M. Pilch and R.T. Nichols (Nov. 1992f). Experimental Results of an Integral Effects Test in a Zion-Like Geometry to Investigate the Effects of a Classically Inert Atmosphere on Direct Containment Heating: The IET-5 Experiment, SAND92-1623, Sandia National Laboratories, Albuquerque, NM.

Allen, M.D.,T.K. Blanchat, M. Pilch and R.T. Nichols (Nov. 1992g). An Integral Effects Test in a Zion-Like Geometry to Investigate the effects of Pre-Existing Hydrogen on Direct Containment Heating in the Surtsey Test Facility - The IET-6 Experiment, SAND92-1802, Sandia National Laboratories, Albuquerque, NM.

Allen, M.D.,T.K. Blanchat, M. Pilch and R.T. Nichols (Nov. 1992h). An Integral Effects Test to Investigate the Effects of Condensate Levels of Water and Pre-Existing Hydrogen on Direct Containment Heating in the Surtsey Test Facility - The IET-7 Experiment, SAND92-2021, Sandia National Laboratories, Albuquerque, NM.

Allen, M.D. et al. (1994a). Test Results on Direct Containment Heating by High-Pressure Melt Ejection into the Surtsey Vessel: The TDS Test Series, SAND91-1208, Sandia National Laboratories, Albuquerque, NM.

Allen, M.D. et al. (Feb. 1993b). Experiments to Investigate the Effects of Fuel/Coolant Interactions on Direct Containment Heating: The IET-8A and IET-8B Experiments, SAND92-2849, Sandia National Laboratories, Albuquerque, NM.

Allen, M.D. et al. (1994b). Experiments to Investigate Direct Containment Heating Phenomena With Scaled Models of the Zion Nuclear Power Plant in the Surtsey Test Facility, NUREG/CR-6044, SAND93-1049, Sandia National Laboratories, Albuquerque, NM.

Bergeron, K.D. and D.C. Williams (1985). "CONTAIN Calculations of Containment Loading of Dry PWRs," Nuc. Engr. Des., 90, 153-159.

Binder, J.L., L.M. McUmber and B.W. Spencer (May 1992a). Quick Look Data Report on the Integral Effects Test $1 R$ in the Corexit Facility at Argonne National Laboratory, draft for review, Argonne National Laboratory, Argonne, IL.

Binder, J.L., L.M. McUmber and B.W. Spencer (May 1992b). Quick Look Data Report on the Integral Effects Test 1RR in the Corexit Facility at Argonne National Laboratory, draft for review, Argonne National Laboratory, Argonne, IL.

Binder, J.L., L.M. McUmber and B.W. Spencer (July 1992c). Quick Look Data Report on the Integral Effects Test-3 in the Corexit Facility at Argonne National Laboratory, draft for review, Argonne National Laboratory, Argonne, IL. 
Binder, J.L.,L.M. McUmber and B.W. Spencer (Aug. 1992d). Quick Look Data Report on the Integral Effects Test-6 in the Corexit Facility at Argonne National Laboratory, draft for review, Argonne National Laboratory, Argonne, IL.

Binder, J.L., L.M. McUmber and B.W. Spencer (Sept. 1992e). Quick Look Data Report on the Integral Effects Test-7 in the Corexit Facility at Argonne National Laboratory, draft for review, Argonne National Laboratory, Argonne, IL.

Binder, J.L., L.M. McUmber and B.W. Spencer (Oct. 1992f). Quick Look Data Report on the Integral Effects Test-8 in the Corexit Facility at Argonne National Laboratory, draft for review, Argonne National Laboratory, Argonne, IL.

Binder, J.L.,L.M. McUmber, and B.W. Spencer (April 1993a). Direct Containment Heating Experiments in Zion Nuclear Power Plant Geometry Using Prototypic Core Materials: The ULA and UIB Tests, ANL/RE/LWR 93-3, Argonne National Laboratory, Argonne, IL.

Binder, J.L., L.M. McUmber, and B.W. Spencer (May 1993b). Direct Containment Heating Experiments in Zion Nuclear Power Plant Geometry Using Prototypic Core Materials: The UZ Test, ANL/RE/LWR 93-3, Argonne National Laboratory, Argonne, IL.

Blanchat, T.K. et al. (Apr. 1994). Experiments to Investigate Direct Containment Heating Phenomena With Scaled Models of the Surry Nuclear Power Plant, NUREG/CR-6152, SAND93-2519, Sandia National Laboratories, Albuquerque, NM.

Carter, J.C.et al. (1990). Prevention of Early Containment Failure Due to High Pressure Melt Ejection and Direct Containment Heating for Advanced Light Water Reactors, DOE/ID-10271, MICS-90032.

Chun, M.H., D.S. So and C.S. Lee (1991). "A Parametric Study of the High Pressure Melt Ejection from Two Different Scale Reactor Cavity Models," Int. Con. Heat Mass Trans., vol. $18,619-628$.

CLWG (1985). Estimates of Early Containment Loads from Core Melt Accidents, NUREG1079, U.S. Nuclear Regulatory Commission, Washington, D.C.

Corradini, M.L., I. Huhtiniemi, M.H. Kim, G.A. Moses, and L.C. Pong (Sept. 1986). Application of a Direct Heating Model to Sandia Surtsey Tests, UWRSR-50, University of Wisconsin, Madison, WI.

Darwish, S. (1991). Containment Response to Direct Containment Heating in Pressurized Water Reactors, Ph.D. Dissertation, University of Michigan.

Fruttuoso, G., A. Manfredini, F. Oriold, G. Sandrelli and M. Valisi (1992). "A Model for the Analysis of Containment Behavior During High-Pressure Melt Ejection Scenarios," ANS/ENS Int. Conf., Chicago, IL., Nov. 15-20. 
Ginsberg, T. and N.K. Tutu (1987). Safety Research Programs Sponsored by Office of Nuclear Regulatory.Commission, Quarterly Progress Report, NUREG/CR-2331, Vol. 7, No. 2.

Henry, R.E. (1989). "Evaluation of Fission Product Release Rates During Debris Dispersal," PSA 1989, Proc. of the ANS/ENS International Topical Meeting: Probability Reliability and Safety Assessment, 375-383.

Henry, R.E. and M.G. Plys (1990). MAAP-3.OB---Modular Accident Analysis Program for LWR Power Plants: User Guidance, Electric Power Research Institute Report EPRI NP7071-CCML, Volumes 1, 2, and 3.

Henry, R.E. et al. (1991). "Direct Containment Heating Experiments in a Zion-like Geometry," in 26th National Heating Transfer Conference, Vol. 87.

IDCOR (1985). Technical Support for Issue Resolution, IDCOR Technical Report 85.2.

Ishii, M., S.T. Revankar, G. Zhang, Q. Wu, and P. O'Brien (March 1993). Separate Effects Experiments on Phenomena of Direct Containment Heating - Air-Water Simulation Experiments in Zion Geometry, PU NE-93/1, Purdue University, West Lafayette, IN.

Kim, M., C. Chung, H. Kim and S. Kim (1992). "Experimental Study on Direct Containment Heating Phenomena," ANS Winter Meeting, Chicago, IL.

Levy, S. (1991). "Debris Dispersal From Reactor Cavity During Low Temperature Simulant Tests of Direct Containment Heating. Part I: Tests with Constant Gas Flow Rates; Part II: Tests with Blowdown Gas Conditions," Proceedings National Heat Transfer Conference, Minneapolis, MN.

Macbeth, R.V. and Trenberth (1987). Experimental Modeling of Core Debris Dispersion from the Vault Under a PWR Pressure Vessel - Part 1. Preliminary Experimental Results, AEEWR1888.

Macbeth, R.V. et al. (1988). Experimental Modeling of Core Debris Dispersion from the Vault Under a PWR Pressure Vessel - Part 3. Results of Varying the Size Scaling Factor of the Model Used, AEEW-R2426, Winfrith, UK.

Marx, K.D. (1989). "A Computer Model for the Transport and Chemical Reaction of Debris in Direct Containment Heating Experiments," Nuc. Sci. Eng., 102, 391-407.

Morris, B.W. (1988). CORDE - A Model for Core Debris Ejection and Dispersal from a PWR Pressure Vessel (Pre-Release Version 1), PWR/SAWG/PC(88) 424, Winfrith, UK.

Murata, K.K.,D.E. Carroll, K.E. Washington, F. Gelbard, G.D. Valdez, D.C. Williams and K.D. Bergeron (1990). User's Manual for CONTAIN 1.1: A Computer Code for Severe Nuclear Reactor Accident Containment Analysis, NUREG/CR-5026, SAND87-2309, Sandia National Laboratories, Albuquerque, NM. 
Pilch, M. and W.W. Tarbell (1986). Preliminary Calculations on Direct Heating of $a$ Containment Atmosphere by Airborne Core Debris,NUREG/CR-4455, SAND85-2439, Sandia National Laboratories, Albuquerque, NM.

Pilch, M., W.W. Tarbell and J.E. Brockmann (Sept. 1988). The Influence of Selected Containment Structures on Debris Dispersal and Transport Following High Pressure Melt Ejection from the Reactor Vessel, NUREG/CR-4914, SAND87-0940, Sandia National Laboratories, Albuquerque, NM.

Pilch, M. (1991). "Adiabatic Equilibrium Models for Direct Containment Heating," Water Reactor Safety Information Meeting, Bethesda, MD (also submitted to NED).

Pilch, M.M., M.D. Allen and R.O. Griffith (Aug. 1992). Kinetic Limitations to Adiabatic Equilibrium Models for Direct Containment Heating (DCH), SAND92-0009C, 28th ASME/AICHE/ANS National Heat Transfer Conference, San Diego, CA.

Pilch, M. and R.O. Griffith (June 1992). Gas Blowthrough and Flow Quality Correlations for Use in the Analysis of Pressure Melt Ejection (HPME) Events, SAND91-2322, Sandia National Laboratories, Albuquerque, NM.

Pilch, M.M.,M.D. Allen and R.O. Griffith (August 1992). "Kinetic Limitations to Adiabatic Equilibrium Models for Direct Containment Heating," SAND92-000C, in 28th ASME/AICHE/ANS National Heat Transfer Conference San Diego, CA, Aug. 9-12.

Pilch, M., C.A. Erdman, and A.B. Reynolds (1981). Acceleration Induced Breakup of Liquid Drops, NUREG/CR-2247, U.S. Nuclear Regulatory Commission, Washington, DC.

Rempe, J.L., S.A. Chavez, G.L. Thinnes, C.M. Allison, G.E. Korth, R.J. Witt, J.J. Slenicki, S. Kong Wang, C.H. Heath and S.D. Snow (Mar. 1992). Light Water Reactor Lower Head Failure Analysis, NUREG/CR-5642, EGG-2618, Idaho National Engineering Laboratory, ID.

Rose, P.W. (1987). Experimental Modeling of Core Debris Dispersion from the Vault Under a PWR Pressure Vessel - Part 2. Results of Including the Instrument Tubes Support Structure in the Experiment, AEEW-R2143.

Shepard, J.E. (August 1987). Analysis of Diffusion Flame Tests, NUREG/CR-4534, SAND86-0419, Sandia National Laboratories, Albuquerque, NM.

Sienicki, J.J. and B.W. Spencer (1986). "A Multifluid, Multiphase Flow and Heat Transfer Model for the Prediction of Sweepout from a Reactor Cavity," Proceedings of 4th Miami International Symposium on Multi-phase Transport and Particulate Phenomena, Miami Beach, FL, December 15-17, 1986. 
Sienicki, J.J. and B.W. Spencer (1987). "The PARSEC Computer Code for Analysis of Direct Containment Heating by Dispersed Debris, Heat Transfer--Pittsburg 1987, ed. R.W. Lyczkowski, AIChE Symposium Series No. 257, Vol. 83, p. 355, American Institute of Chemical Engineers, New York.

Spencer, B.W. et al. (1982). Sweepout Thresholds in Reactor Cavity Interactions, ANL/LWR/SAF 82-1, Argonne National Laboratory, Argonne, IL.

Spencer, B.W. et al. (1983). "Phenomenological Investigations of Cavity Interactions Following Postulated Vessel Melt-Through," NUREG/CP-0027, vol. 2, Proc. Int. Mtg. on Thermal Nuclear Reactor Safety, Chicago, IL, Aug. 28-Sept. 2.

Spencer, B.W., J.J. Sienicki and L.M. McUmber (Mar. 1987). Hydrodynamics and Heat Transfer Aspects of Corium-Water Interactions, EPRI NP-5127, Argonne National Laboratory, IL.

Stamps, D.W. and M. Berman (1991). "High-Temperature Hydrogen Combustion in Reactor Safety Applications," NSE, 109, 39-48.

Summers, R.M. (1992). "Letter Report Summarizing the Implementation of the DCH Model into MELCOR," Letter Report to NRC, April 15.

Sweet, D.W., K.E. Washington and M. Pilch (1991). Further Development of the KIVA-DCH Code for the Analysis of the Transport and Chemical Reaction of Molten Debris in Direct Containment Heating Experiments, SAND90-2535, Sandia National Laboratories, NM.

Tarbell, W.W. et al. (1984). High-Pressure Melt Streaming (HIPS) Program Plan, NUREG/CR-3025, SAND82-2477, Sandia National Laboratories, Albuquerque, NM.

Tarbell, W.W. et al. (1986). Pressurized Melt Ejection into Scaled Reactor Cavities, NUREG/CR-4512, SAND86-0153, Sandia National Laboratories, Albuquerque, NM.

Tarbell, W.W. et al. (1987). Results from the DCH-1 Experiment, NUREG/CR-4871, SAND86-2483, Sandia National Laboratories, Albuquerque, NM.

Tarbell, W.W. et al. (1988). DCH-2: Results from the Second Experiment Performed in the Surtsey Direct Heating Test Facility, NUREG/CR-4917, SAND87-0976, Sandia National Laboratories, Albuquerque, NM.

Tarbell, W.W. et al. (Mar. 1991). Pressurized Melt Ejection into Water Pools, NUREG/CR-3916, SAND84-1531, Sandia National Laboratories, Albuquerque, NM.

Tutu, N.K. et al. (1988a). Debris Dispersal from Reactor Cavities During High Pressure Melt Ejection Accident Scenarios, NUREG/CR-5146, BNL-NUREG-52147, Brookhaven National Laboratory, Upton, NY. 
Tutu, N.K.et al. (1988b). "Low Pressure Cutoff for Melt Dispersal from Reactor Cavities," Fourth Proc. of Nuclear Thermal Hydraulics, 29-37.

Tutu, N.K. and T. Ginsberg (Oct. 1990). A Letter Report on the Results of Melt Dispersal Experiments with Surry and Zion Cavity Models, Brookhaven National Laboratory, NY.

Tutu, N.K. (Apr. 1990). Melt Dispersal Characteristics of the Watts Bar Cavity, Technical Report A-3024, Brookhaven National Laboratory, NY.

Williams, D.C., K.D. Bergeron, D.E. Carroll, R.D. Gasser, J.L. Tills and K.E. Washington (May 1987). Containment Loads Due to Direct Containment Heating and Associated Hydrogen Behavior: Analysis and Calculations with the CONTAIN Code, NUREG/CR-4896, SAND87-0633, Sandia National Laboratories, Albuquerque, NM.

Williams, D.C. and D.L. Louie, (1988). "CONTAIN Analyses of Direct Containment Heating Events in the Surry Plant," Proc. of the Thermal Hydraulics Division, ANL/ENS Winter Meeting, Washington, D.C., Oct. 31-Nov. 4.

Williams, D.C. (Sept. 1992). An Interpretation of the Results of Some Recent Direct Containment Heating (DCH) Experiments in the Surtsey Facility, SAND92-0442C, presented at the NURETH-5 Conference, Salt Lake City, UT.

ZPSS (1981). Zion Probabilistic Safety Study, Commonwealth Edison Co., Chicago, IL.

Zuber, et al. (1992). An Integrated Structure and Scaling Methodology for Severe Accident Technical Issue Resolution, draft for comment, NUREG/CR-5809, EGG-2659.

\section{E. 8 NOMENCLATURE}

\begin{tabular}{|c|c|c|}
\hline$A_{c}$ & $=$ & cavity flow area \\
\hline $\mathbf{A}_{\mathrm{b}}$ & $=$ & flow area of RCS breach \\
\hline$C_{d}$ & $=$ & discharge coefficient \\
\hline$C_{d}$ & $=$ & molar heat capacity of debris \\
\hline $\mathrm{C}_{\mathrm{d}, \mathrm{c}}$ & $=$ & gas discharge coefficient for flow from cavity \\
\hline $\mathrm{C}_{\mathrm{d}, \mathrm{h}}$ & $=$ & gas discharge coefficient for hole in RPV \\
\hline $\mathrm{C}_{\mathrm{d}, \mathrm{p}}$ & $=$ & drag coefficient for a single particle \\
\hline $\mathrm{C}_{\mathrm{v}}$ & $=$ & molar heat capacity of the containment atmosphere \\
\hline$D_{p}$ & $=$ & particle diameter \\
\hline $\mathrm{D}_{0}$ & $=$ & characteristic initial particle size \\
\hline $\mathrm{F}$ & $=$ & forces causing debris dispersal \\
\hline$f_{a 1}$ & $=$ & $\begin{array}{l}\text { fraction of the total flow area from the reactor cavity t } \\
\text { communicates with the subcompartment }\end{array}$ \\
\hline $\mathrm{f}_{\mathrm{a} 2}$ & $=$ & $\begin{array}{l}\text { fraction of the total flow area from the reactor cavity that } \\
\text { communicates with the dome }\end{array}$ \\
\hline
\end{tabular}




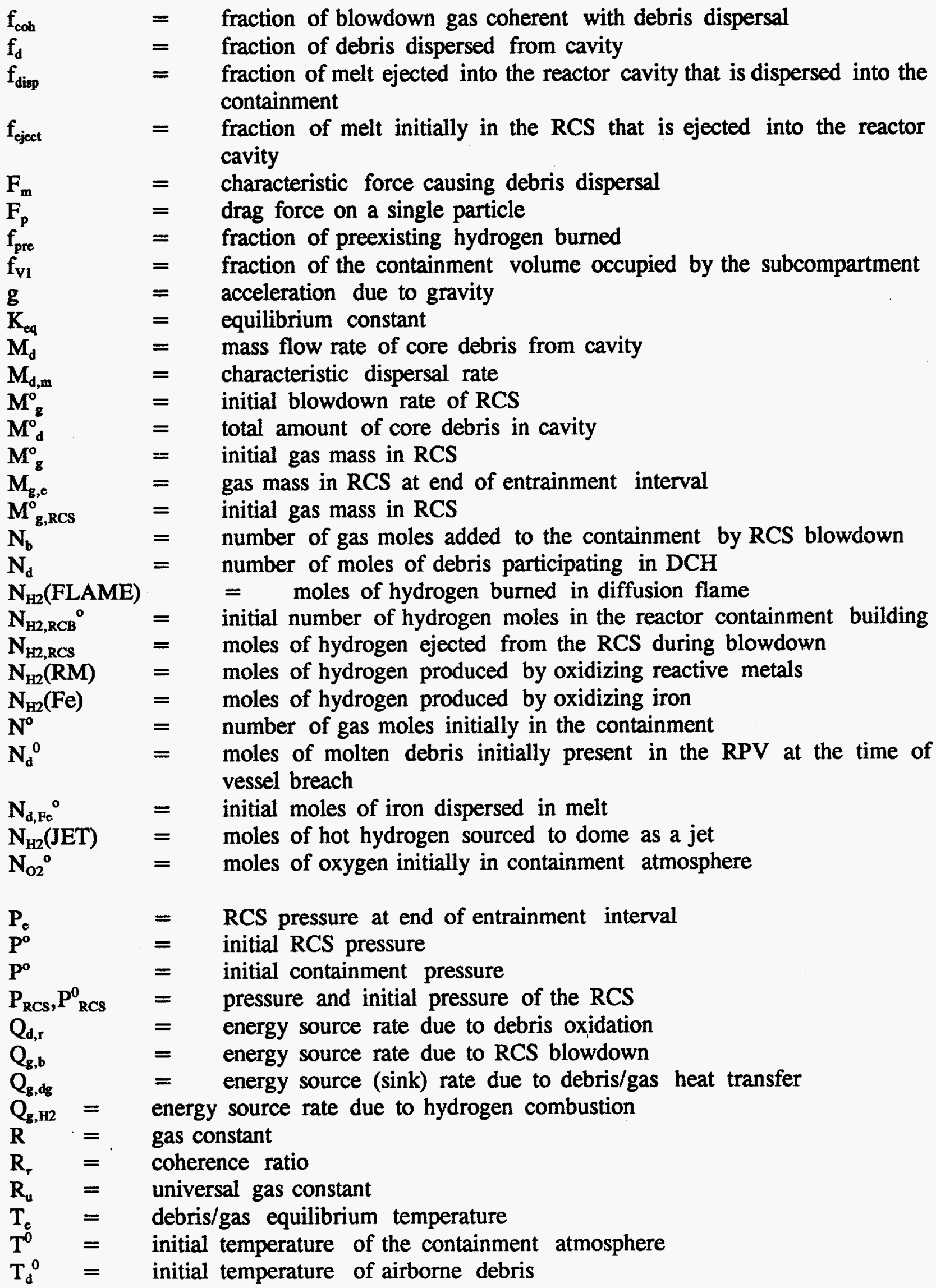




\begin{tabular}{|c|c|c|}
\hline $\mathrm{T}_{\mathbf{j}}$ & $=$ & source temperature of hot hydrogen jet \\
\hline & $=$ & reference temperature, $298 \mathrm{~K}$ \\
\hline $\mathrm{T}_{\mathrm{RCS}}^{0}$ & $=$ & initial gas temperature of the RCS \\
\hline & $=$ & temperature of core debris \\
\hline & $=$ & reference time \\
\hline $\mathbf{T}_{\text {RCS }}^{\circ}$ & $=$ & initial RCS temperature \\
\hline$u_{d}$ & $=$ & molar internal energy of airborne debris \\
\hline$u_{d, \mathrm{i}}$ & $=$ & molar internal energy of the $i^{\text {th }}$ species in the airborne debris \\
\hline II & $=$ & internal energy of the entire containment atmosphere \\
\hline$U_{d}$ & $=$ & internal energy of all dispersed debris \\
\hline $\mathbf{U}^{\circ}$ & $=$ & initial internal energy of the entire containment atmosphere \\
\hline $\mathrm{U}_{\mathrm{RCS}}$ & $=$ & internal energy of RCS gas \\
\hline $\mathbf{V}_{\mathrm{c}}$ & $=$ & volume of cavity \\
\hline $\mathbf{V}_{\mathrm{d}}$ & $=$ & volume of core debris in cavity \\
\hline $\mathbf{v}_{\mathbf{d}}$ & $=$ & velocity of debris exiting cavity \\
\hline $\mathbf{v}_{\mathbf{g}, \mathbf{c}}$ & $=$ & velocity of blowdown gases \\
\hline $\mathrm{V}_{\mathrm{RCS}}$ & $=$ & volume of RCS \\
\hline & $=$ & containment volume \\
\hline $\mathbf{V}_{\text {RCS }}^{0}$ & $=$ & RCS volume \\
\hline We & $=$ & Weber number \\
\hline $\begin{array}{l}\mathrm{X}_{\mathrm{FeO}} \\
\left(\mathrm{X}_{\mathrm{O} 2}\right)_{\text {crit }} \\
\mathrm{Z}^{0}\end{array}$ & $=$ & $\begin{array}{l}\text { fraction of iron in dispersed melt that is oxidized } \\
=\quad \text { critical oxygen concentration to support jet combustion } \\
\text { compressibility factor for high-pressure steam near saturation }\end{array}$ \\
\hline
\end{tabular}

GREEKS

$\gamma=$ isentropic exponent

$\epsilon, \epsilon^{0}=$ liquid fraction and initial liquid fraction in the cavity

$\rho_{\mathrm{d}}=$ density of molten core debris

$\rho_{\mathrm{g}, \mathrm{c}}=$ density of blowdown gases in cavity

$\sigma \quad=\quad$ surface tension of melt

$\tau_{\mathrm{b}}=$ blowdown time constant in TCE model

$\tau_{\mathrm{e}}=$ entrainment interval in TCE model

$\tau_{\mathrm{m}}=$ entrainment interval in CLCH model

$\tau_{\mathrm{s}}=$ blowdown time constant in CLCH model

$\gamma=\mathrm{C}_{\rho} / \mathrm{C}_{\mathrm{v}}$ is the isentropic exponent of blowdown gas

$\Delta \mathrm{E}_{\mathrm{b}}=$ maximum energy contribution due to blowdown 1

$\Delta \mathrm{E}_{\mathrm{H} 2}=$ maximum energy contribution due to hydrogen combustion

$\Delta \mathrm{E}_{\mathrm{r}}=$ maximum energy contribution due to debris oxidation

$\Delta \mathrm{E}_{\mathrm{q}}=$ maximum energy contribution due to debris oxidation

$\Delta \mathrm{e}_{\mathrm{H} 2}=$ molar heat of reaction for hydrogen combustion

$\Delta \mathrm{h}_{\mathrm{r}}, \Delta \mathrm{h}_{\mathrm{r}, \mathrm{i}}=$ debris and species oxidation energies in steam referenced to $298 \mathrm{~K}$

$\delta_{\mathrm{r}, \mathrm{STM}}=$ steam limitation to debris oxidation energy

$\delta_{\mathrm{H} 2, \mathrm{STM}}=\quad$ steam limitation to hydrogen production

$\delta_{\mathrm{H} 2,02}=$ oxygen limitation to hydrogen combustion

$\Delta \mathbf{P}=$ pressure rise in the containment resulting from the $\mathrm{DCH}$ event

$\Delta \mathrm{u}_{\mathrm{d}}=$ specific molar internal energy of debris referenced to initial temperature of containment atmosphere 
$\Delta \mathrm{U}=$ total internal energy gained by the containment atmosphere

$\nu_{\mathrm{d}}, \nu_{\mathrm{d}, \mathrm{i}}=$ stoichiometric coefficient (moles of hydrogen produced/moles of debris) for debris oxidation or species

$\eta_{1}, \eta_{2}=$ pressure efficiency for subcompartment and upper dome respectively

$\sigma_{\text {bins }}=$ relative bias between predictions and measurements

$\sigma_{\mathrm{ms}}=$ relative RMS between predictions and measurements

$\tau_{\mathrm{e}}=$ characteristic entrainment time

$\tau_{\mathrm{b}}=$ characteristic blowdown time

$\psi=$ heat capacitance ratio

$\psi_{1}, \psi_{2}=$ heat capacitance ratio for the subcompartment and upper dome respectively

$\eta=\eta_{1}+\eta_{2}=$ total DCH efficiency 
Table E.1

Survey of DCH relevant experiments

\begin{tabular}{||c|c|c|c|c|}
\hline Experiment Series & $\begin{array}{c}\text { Number } \\
\text { of Tests }\end{array}$ & $\begin{array}{c}\text { Nominal } \\
\text { Scale }\end{array}$ & $\begin{array}{c}\text { Cavity } \\
\text { Type }\end{array}$ & Water \\
\hline $\begin{array}{c}\text { SNL/DCH } \\
\text { (Tarbell et al., 1987; 1988) } \\
\text { (Allen et al., 1991a) }\end{array}$ & 4 & $1: 10$ & Zion & None \\
\hline $\begin{array}{c}\text { SNL/TDS } \\
\text { (Allen et al., 1994a) }\end{array}$ & 7 & $1: 10$ & Surry & None \\
\hline $\begin{array}{c}\text { SNL/LFP } \\
\text { (Allen et al., 1991b) }\end{array}$ & 6 & $1: 10$ & Surry & None \\
\hline $\begin{array}{c}\text { SNL/WC } \\
\text { (Allen et al., 1992a,b) }\end{array}$ & 3 & $1: 10$ & Zion & $\begin{array}{c}\text { None } \\
\text { Cavity }\end{array}$ \\
\hline $\begin{array}{c}\text { SNL/IET-Zion } \\
\text { (Allen et al., 1992c-h, } \\
\text { 1993b, 1994) }\end{array}$ & 9 & $1: 10$ & Zion & $\begin{array}{c}\text { Cavity } \\
\text { Cavity/Basement }\end{array}$ \\
\hline $\begin{array}{c}\text { SNL/IET-Surry } \\
\text { (Blanchat et al., 1994) }\end{array}$ & 3 & $1: 5.75$ & Surry & $\begin{array}{c}\text { None } \\
\text { Cavity/Basement }\end{array}$ \\
\hline $\begin{array}{c}\text { ANL/CWTI } \\
\text { (Spencer et al., 1987) }\end{array}$ & 2 & $1: 30$ & Zion-like & Cavity/Basement \\
\hline $\begin{array}{c}\text { ANL/IET } \\
\text { (Binder et al., 1992a-f) }\end{array}$ & 6 & $1: 40$ & Zion & $\begin{array}{c}\text { None } \\
\text { Cavity }\end{array}$ \\
\hline $\begin{array}{c}\text { ANL/U } \\
\text { (Binder et al., 1993a, b) }\end{array}$ & 3 & $1: 40$ & Zion & None \\
\hline $\begin{array}{c}\text { FAI/DCH } \\
\text { (Henry et al., 1985) }\end{array}$ & 4 & $1: 20$ & Zion & $\begin{array}{c}\text { Basement } \\
\text { Cavity/Basement }\end{array}$ \\
\hline
\end{tabular}


Table E.1 (continued)

Survey of DCH relevant experiments

\begin{tabular}{||c|c|c|c|c|c||}
\hline $\begin{array}{c}\text { Experiment } \\
\text { Series }\end{array}$ & $\begin{array}{c}\text { Driving } \\
\text { Gas }\end{array}$ & $\begin{array}{c}\text { Driving } \\
\text { Pressure } \\
(\mathrm{MPa})\end{array}$ & $\begin{array}{c}\text { Melt Mass } \\
(\mathrm{Kg})\end{array}$ & $\mathrm{Melt}$ Composition & $\begin{array}{c}\text { Hole } \\
\text { Size }\end{array}$ \\
\hline SNL/DCH & $\mathrm{N}_{2}$ & $2.6-6.7$ & 20,80 & $\mathrm{Fe} / \mathrm{Al}_{2} \mathrm{O}_{3}$ & 0.06 \\
\hline SNL/TDS & $\mathrm{H}_{2} \mathrm{O}$ & $3.7-4.0$ & 80 & $\mathrm{Fe} / \mathrm{Al}_{2} \mathrm{O}_{3} / \mathrm{Cr}$ & 0.065 \\
\hline SNL/LFP & $\mathrm{H}_{2} \mathrm{O}$ & $2.5-3.6$ & 50,80 & $\mathrm{Fe} / \mathrm{Al}_{2} \mathrm{O}_{3} / \mathrm{Cr}$ & $0.04-0.09$ \\
\hline SNL/WC & $\mathrm{H}_{2} \mathrm{O}$ & $3.8-4.6$ & 50 & $\mathrm{Fe} / \mathrm{Al}_{2} \mathrm{O}_{3} / \mathrm{Cr}$ & $0.04-0.10$ \\
\hline $\begin{array}{c}\text { SNL/IET } \\
\text { Zion }\end{array}$ & $\mathrm{H}_{2} \mathrm{O}$ & $5.9-7.1$ & 43 & $\mathrm{Fe} / \mathrm{Al}_{2} \mathrm{O}_{3} / \mathrm{Cr}$ & 0.04 \\
\hline $\begin{array}{c}\text { SNL/IET } \\
\text { Surry }\end{array}$ & $\mathrm{H}_{2} \mathrm{O}$ & 12 & 158 & $\mathrm{Fe} / \mathrm{Al}_{2} \mathrm{O}_{3} / \mathrm{Cr}$ & $0.07^{2}-0.098$ \\
\hline ANL/CWTI & $\mathrm{N}_{2}$ & $4.7-5.0$ & 4.1 & $\mathrm{UO}_{2} / \mathrm{ZrO}_{2} / \mathrm{SS}$ & 0.13 \\
\hline ANL/IET & $\mathrm{H}_{2} \mathrm{O}$ & $5.7-6.7$ & $0.72,0.82$ & $\mathrm{Fe} / \mathrm{Al}_{2} \mathrm{O}_{3} / \mathrm{Cr}$ & 0.011 \\
\hline ANL/U & $\mathrm{H}_{2} \mathrm{O}$ & $3.0-6.0$ & 1.13 & $\mathrm{UO}_{2} / \mathrm{Zr}_{2} / \mathrm{ZrO}_{2} / \mathrm{SS}$ & 0.011 \\
\hline $\begin{array}{c}\text { FAI/DCH } \\
\mathrm{N}_{2},\end{array}$ & $2.4-3.2$ & 20 & $\mathrm{Fe} / \mathrm{Al}_{2} \mathrm{O}_{3}$ & 0.025 \\
\hline
\end{tabular}


Table E.1 (concluded)

Survey of DCH relevant experiments

\begin{tabular}{|c|c|c|c|c|}
\hline $\begin{array}{l}\text { Experiment } \\
\text { Series }\end{array}$ & $\begin{array}{c}\text { Containment } \\
\text { Pressure } \\
\text { (MPa) }\end{array}$ & $\begin{array}{l}\text { Annular } \\
\text { Gap } \\
\text { Around } \\
\text { RPV }\end{array}$ & $\begin{array}{l}\text { Atmosphere } \\
\text { Composition }\end{array}$ & $\begin{array}{l}\text { Containment } \\
\text { Structures }\end{array}$ \\
\hline SNL/DCH & 0.08 & no & Air, Ar & Open Containment \\
\hline SNL/TDS & $0.09-0.23$ & no & Air, Ar & Open Containment \\
\hline SNL/LFP & 0.16 & no & $\mathrm{Ar}$ & $\begin{array}{c}\text { Compartmentalized } \\
\text { by Slab }\end{array}$ \\
\hline SNL/WC & 0.16 & no & $\mathrm{Ar}$ & Essentially Open \\
\hline $\begin{array}{l}\text { SNL/IET } \\
\text { Zion }\end{array}$ & 0.2 & no & $\begin{array}{c}\mathrm{N}_{2}, \mathrm{~N}_{2} / \mathrm{Air} \\
\mathrm{N}_{2} / \mathrm{Air} / \mathrm{H}_{2} \\
\mathrm{CO}_{2} / \mathrm{Air} / \mathrm{H}_{2}\end{array}$ & $\begin{array}{c}\text { Zion } \\
\text { Subcompartment } \\
\text { Structures }\end{array}$ \\
\hline $\begin{array}{l}\text { SNL/IET } \\
\text { Surry }\end{array}$ & $0.13-0.19$ & $\begin{array}{c}\text { no } \\
\text { partial } \\
\text { insulation }\end{array}$ & $\mathrm{Air} / \mathrm{H}_{2} \mathrm{O} / \mathrm{H}_{2}$ & $\begin{array}{c}\text { Surry } \\
\text { Subcompartment } \\
\text { Structures }\end{array}$ \\
\hline ANL/CWTI & 0.1 & no & $\mathrm{Ar}$ & $\begin{array}{c}\text { Compartmentalized } \\
\text { by Baffle }\end{array}$ \\
\hline ANL/IET & 0.2 & no & $\begin{array}{c}\mathrm{N}_{2}, \mathrm{~N}_{2} / \mathrm{Air} \\
\mathrm{N}_{2} / \mathrm{Air} / \mathrm{H}_{2}, \\
\mathrm{H}_{2} \mathrm{O} / \mathrm{Air} / \mathrm{H}_{2}\end{array}$ & $\begin{array}{c}\text { Zion } \\
\text { Subcompartment } \\
\text { Structures }\end{array}$ \\
\hline ANL/U & 0.2 & no & $\mathrm{N}_{2} / \mathrm{Air} / \mathrm{H}_{2}$ & $\begin{array}{c}\text { Zion } \\
\text { Subcompartment } \\
\text { Structures } \\
\end{array}$ \\
\hline FAI/DCH & 0.1 & no & $\mathbf{N}_{2}$ & $\begin{array}{c}\text { Zion (Like) } \\
\text { Subcompartment } \\
\text { Structures }\end{array}$ \\
\hline
\end{tabular}


Table E.2.

Specific molar properties of debris

\begin{tabular}{|c|c|c|c|c|}
\hline Species & $\underset{\mathrm{J} / \mathrm{mole} / \mathrm{K}}{\mathrm{C}_{\mathrm{d}}}$ & $\begin{array}{l}\Delta \mathrm{u}_{\mathrm{d}}(2500) \\
\mathrm{MJ} / \mathrm{mole}\end{array}$ & $\underset{\mathrm{MJ} / \mathrm{mole}}{\Delta \mathrm{h}_{\mathrm{r}}}$ & $\begin{array}{c}\nu_{d}^{*} \\
\text { mole- } \\
H 2 / \text { mole }\end{array}$ \\
\hline $\mathrm{Zr}$ & 42.315 & 0.0932 & 0.598 & 2 \\
\hline $\mathrm{Al}$ & 35.667 & 0.0785 & 0.397 & 1.5 \\
\hline $\mathrm{Cr}$ & 44.668 & 0.0984 & 0.207 & 1.5 \\
\hline $\mathrm{Fe}$ & 47.712 & 0.1051 & 0.002 & 1 \\
\hline $\mathrm{Ni}$ & 44.250 & 0.0974 & 0 & 0 \\
\hline $\mathrm{UO}_{2}$ & 126.55 & 0.2787 & 0 & 0 \\
\hline $\mathrm{ZrO}_{2}$ & 116.87 & 0.2573 & 0 & 0 \\
\hline $\mathrm{Al}_{2} \mathrm{O}_{3}$ & 163.20 & 0.3594 & 0 & 0 \\
\hline Corium & 75.01 & 0.165 & 0.111 & 0.765 \\
\hline Thermite & 74.7 & 0.164 & 0.042 & 0.843 \\
\hline
\end{tabular}

Table E.3

Specific molar heat capacity of containment atmosphere

\begin{tabular}{|c|c|}
\hline Species & $\begin{array}{c}\mathrm{C}_{\mathrm{v}} \\
\mathrm{J} / \mathrm{mole} / \mathrm{K}\end{array}$ \\
\hline $\mathrm{O}_{2}$ & 25.9 \\
\hline $\mathrm{N}_{2}$ & 24.1 \\
\hline $\mathrm{H}_{2} \mathrm{O}$ & 32.4 \\
\hline $\mathrm{H}_{2}$ & 21.2 \\
\hline $\mathrm{CO}_{2}$ & 33.1 \\
\hline $\mathrm{Ar}$ & 12.5 \\
\hline Atmosphere & 28.52 \\
\hline
\end{tabular}


Table E.4

Representative composition of corium and thermite

\begin{tabular}{|c||c|c||c|c||}
\hline \multirow{2}{*}{ Species } & \multicolumn{2}{c||}{ Corium } & \multicolumn{2}{c|}{ Thermite } \\
\cline { 2 - 5 } & $\begin{array}{c}\text { Mass } \\
\text { Fraction }\end{array}$ & $\begin{array}{c}\text { Mole } \\
\text { Fraction }\end{array}$ & $\begin{array}{c}\text { Mass } \\
\text { Fraction }\end{array}$ & $\begin{array}{c}\text { Mole } \\
\text { Fraction }\end{array}$ \\
\hline $\mathrm{Zr}$ & 0.1250 & 0.1528 & 0 & 0 \\
\hline $\mathrm{Al}$ & 0 & 0 & 0.0130 & 0.0316 \\
\hline $\mathrm{Cr}$ & 0.0430 & 0.0920 & 0.1080 & 0.1363 \\
\hline $\mathrm{Fe}$ & 0.1620 & 0.3218 & 0.5050 & 0.5916 \\
\hline $\mathrm{Ni}$ & 0.0200 & 0.0377 & 0 & 0 \\
\hline $\mathrm{UO}_{2}$ & 0.3900 & 0.1607 & 0 & 0 \\
\hline $\mathrm{ZrO}_{2}$ & 0.2600 & 0.2351 & 0 & 0 \\
\hline $\mathrm{Al}_{2} \mathrm{O}_{3}$ & 0 & 0 & 0.3740 & 0.2405 \\
\hline
\end{tabular}

Table E.5

Representative composition of a containment atmosphere

\begin{tabular}{|c|c|}
\hline Species & Mole Fraction \\
\hline $\mathrm{O}_{2}$ & 0.1055 \\
\hline $\mathrm{N}_{2}$ & 0.3968 \\
\hline $\mathrm{H}_{2} \mathrm{O}$ & 0.4877 \\
\hline $\mathrm{H}_{2}$ & 0.0202 \\
\hline $\mathrm{CO}_{2}$ & 0 \\
\hline $\mathrm{Ar}$ & 0 \\
\hline
\end{tabular}




\begin{tabular}{|c|c|c|c|c|c|c|c|}
\hline Test & $\begin{array}{c}\Delta \mathrm{P}(\mathrm{MPa}) \\
\text { Meas. }\end{array}$ & $\underset{1 \text {-cell }}{\Delta \mathrm{P}(\mathrm{MPa})}$ & $\begin{array}{c}\Delta \mathrm{P}(\mathrm{MPa}) \\
\text { 2-cell }\end{array}$ & $\begin{array}{c}\eta \\
\text { Meas. }\end{array}$ & $\stackrel{\eta}{2-\text { cell }}$ & $\begin{array}{c}\mathrm{N}_{\mathrm{k2}}(\mathrm{g}-\text {-mole }) \\
\text { Meas. }\end{array}$ & $\begin{array}{c}\mathrm{N}_{\mathrm{H2}} \text { (g-mole) } \\
\text { Predicted }\end{array}$ \\
\hline SNL/DCH-1 & 0.063 & 0.162 & - & 0.389 & - & - & - \\
\hline SNL/DCH-2 & 0.280 & 0.602 & - & 0.465 & - & - & - \\
\hline SNL/DCH-3 & 0.181 & 0.635 & - & 0.285 & - & - & - \\
\hline SNL-DCH-4 & 0.200 & 0.454 & - & 0.441 & - & - & - \\
\hline SNL/TDS-1 & 0.290 & 0.615 & - & 0.472 & - & - & 194 \\
\hline SNL/TDS-2 & 0.290 & 0.593 & - & 0.489 & - & 178 & 175 \\
\hline SNL/TDS-3 & 0.260 & 0.479 & - & 0.543 & - & 223 & 195 \\
\hline SNL/TDS-4 & 0.329 & 0.625 & - & 0.526 & - & 150 & 178 \\
\hline SNL/TDS-5 & 0.220 & 0.444 & - & 0.496 & - & 157 & 143 \\
\hline SNL/TDS-6 & 0.331 & 0.681 & - & 0.486 & - & 167 & 173 \\
\hline SNL/TDS-7 & 0.312 & 0.659 & - & 0.473 & - & 154 & 174 \\
\hline SNL/LFP-1A & 0.117 & 0.685 & 0.087 & 0.171 & 0.127 & 235 & 190 \\
\hline SNL/LFP-1B & 0.066 & 0.200 & 0.068 & 0.330 & 0.340 & 128 & 77 \\
\hline SNL/LFP-2A & 0.102 & 0.387 & 0.133 & 0.264 & 0.343 & 151 & 117 \\
\hline SNL/LFP-2B & 0.118 & 0.462 & 0.140 & 0.255 & 0.302 & 154 & 146 \\
\hline SNL/LFP-2C & 0.131 & 0.463 & 0.139 & 0.283 & 0.301 & 184 & 176 \\
\hline SNL/LFP-8A & 0.172 & 0.330 & - & 0.521 & - & 139 & 101 \\
\hline SNL/WC-1 & 0.272 & 0.550 & - & 0.495 & - & 145 & 132 \\
\hline SNL/WC-2 & 0.275 & 0.548 & - & 0.502 & - & 181 & 103 \\
\hline SNL/WC-3 & 0.267 & 0.527 & - & 0.507 & - & 184 & 178 \\
\hline SNL/IET-1 & 0.098 & 0.353 & 0.129 & 0.278 & 0.365 & 233 & 150 \\
\hline SNL/IET-1R & 0.110 & 0.309 & 0.116 & 0.356 & 0.376 & 248 & 130 \\
\hline
\end{tabular}




\begin{tabular}{|c|c|c|c|c|c|c|c|}
\hline Test & $\begin{array}{c}\Delta \mathrm{P}(\mathrm{MPa}) \\
\text { Meas. }\end{array}$ & $\underset{1-\text { cell }}{\Delta \mathrm{P}(\mathrm{MPa})}$ & $\begin{array}{c}\Delta \mathrm{P}(\mathrm{MPa}) \\
\text { 2-cell }\end{array}$ & $\begin{array}{c}\eta \\
\text { Meas. }\end{array}$ & $\begin{array}{c}\eta \\
2-\text { cell }\end{array}$ & $\begin{array}{c}\mathrm{N}_{\mathrm{H} 2}(\mathrm{~g} \text {-mole }) \\
\text { Meas. }\end{array}$ & $\begin{array}{c}\mathrm{N}_{\mathrm{H} 2} \text { (g-mole) } \\
\text { Predicted }\end{array}$ \\
\hline SNL/IET-3 & - $\quad 0.246$ & 0.516 & 0.186 & 0.477 & 0.361 & 227 & 115 \\
\hline SNL/IET-4 & 0.262 & 0.575 & 0.209 & 0.456 & 0.363 & 303 & 137 \\
\hline SNL/IET-5 & 0.103 & 0.568 & 0.088 & 0.181 & 0.156 & 319 & 124 \\
\hline SNL/IET-6 & 0.279 & 0.826 & 0.271 & 0.338 & 0.328 & 319 & 133 \\
\hline SNL/IET-7 & 0.271 & 0.792 & 0.252 & 0.342 & 0.318 & 274 & 147 \\
\hline SNL/IET-8B & 0.244 & 0.911 & 0.295 & 0.268 & 0.324 & 299 & 145 \\
\hline SNL/IET-9 & 0.283 & 0.611 & 0.375 & 0.463 & 0.615 & 560 & 916 \\
\hline SNL/IET-10 & 0.326 & 0.712 & 0.422 & 0.458 & 0.592 & 1227 & 1064 \\
\hline SNL/IET-11 & 0.426 & 0.904 & 0.486 & 0.471 & 0.538 & 1643 & 1097 \\
\hline SNL/IET-12 & & & & & & & \\
\hline ANL/CWTI-5 & 0.380 & 0.861 & 0.314 & 0.441 & 0.365 & - & - \\
\hline ANL/CWTI-6 & 0.120 & 0.485 & 0.104 & 0.247 & 0.215 & - & - \\
\hline ANL/IET-1R & 0.170 & 0.378 & 0.139 & 0.450 & 0.368 & 4.00 & 3.37 \\
\hline ANL/IET-1RR & 0.150 & 0.348 & 0.131 & 0.431 & 0.377 & 4.00 & 3.65 \\
\hline ANL/IET-3 & 0.190 & 0.661 & 0.210 & 0.287 & 0.318 & 4.65 & 2.08 \\
\hline ANL/IET-6 & 0.250 & 0.706 & 0.259 & 0.354 & 0.367 & 4.89 & 2.55 \\
\hline ANL/IET-7 & 0.166 & 0.586 & 0.194 & 0.283 & 0.331 & 5.19 & 2.61 \\
\hline ANL/IET-8 & 0.133 & 0.656 & 0.235 & 0.203 & 0.359 & 5.22 & 3.07 \\
\hline ANL/U1A & 0.045 & 0.135 & 0.073 & 0.333 & 0.543 & 5.0 & 1.23 \\
\hline ANL/U1B & 0.111 & 0.502 & 0.144 & 0.221 & 0.287 & 6.0 & 2.93 \\
\hline
\end{tabular}




\begin{tabular}{|c|c|c|c|c|c|c|c|}
\hline- & - & \$9I.0 & $\angle S I^{\circ} 0$ & $6 \angle 0^{\circ} 0$ & $6 \angle t^{\circ} 0$ & $S \angle 0^{\circ} 0$ & $\mathrm{t}-\mathrm{H} \supset \mathrm{a} / \mathrm{IVI}$ \\
\hline- & - & SLI'0 & $2 I^{\circ} 0$ & $180^{\circ} 0$ & E9t०0 & $2 S 0^{\circ} 0$ & $\varepsilon-H \supset व / I \forall J$ \\
\hline- & - & SLI"0 & SII 0 & $180^{\circ} 0$ & $t S t^{\circ} 0$ & $250^{\circ} 0$ & Z-HDव/IVJ \\
\hline - & - & SLI'O & LEI 0 & $180^{\circ} 0$ & $t S t=0$ & $290^{\circ} 0$ & I-HDव/I $\forall \mathbf{J}$ \\
\hline 26.1 & 10 & $9 t t^{\circ} 0$ & $\hbar Z \varepsilon^{\circ} 0$ & $902^{\circ} 0$ & $\varepsilon 9 b^{\circ} 0$ & OSI 0 & Zח/TNV \\
\hline 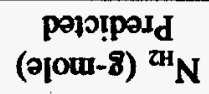 & 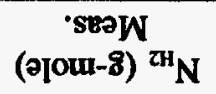 & $\begin{array}{c}\text { Ile0-Z } \\
u\end{array}$ & ${ }^{\cdot s E \partial W}$ & $\begin{array}{c}I \mid \partial \partial-Z \\
\left(\varepsilon_{d W} d \nabla\right) d \nabla\end{array}$ & $\begin{array}{c}\| \beta \partial-I \\
\left(E_{d W}\right) d \nabla\end{array}$ & $\begin{array}{c}\text { 'seə⿳亠口冋 } \\
\left(\mathbf{g}_{\mathrm{dW}}\right) \mathrm{d} \nabla\end{array}$ & $j^{1 s e}$ \\
\hline
\end{tabular}


Table E.7

Inerting criteria for jet combustion

\begin{tabular}{||l|c|c|c|c||}
\hline \multicolumn{1}{|c|}{ Test } & $\left(\mathrm{X}_{\mathbf{0}}\right)_{\text {MRAS }}$ & $\begin{array}{c}\text { Jet Combustion } \\
\text { Observed }\end{array}$ & $\left(\mathrm{X}_{\mathbf{0} 2}\right)_{\mathrm{CrRT}}$ & $\begin{array}{c}\text { Jet Combustion } \\
\text { Predicted }\end{array}$ \\
\hline SNL/IET-3 & 0.090 & yes & 0.047 & yes \\
\hline SNL/IET-4 & 0.095 & yes & 0.047 & yes \\
\hline SNL/IET-5 & 0.044 & no & 0.060 & no \\
\hline SNL/IET-6 & 0.098 & yes & 0.046 & yes \\
\hline SNL/IET-7 & 0.096 & yes & 0.046 & yes \\
\hline SNL/IET-8B & 0.102 & yes & 0.046 & yes \\
\hline SNL/IET-9 & 0.063 & yes & 0.050 & yes \\
\hline SNL/IET-10 & 0.105 & yes & 0.045 & yes \\
\hline SNL/IET-11 & 0.138 & yes & 0.041 & yes \\
\hline ANL/IET-3 & 0.108 & yes & 0.045 & yes \\
\hline ANL/IET-6 & 0.099 & yes & 0.045 & yes \\
\hline ANL/IET-7 & 0.108 & yes & 0.046 & yes \\
\hline ANL/UIB & 0.057 & yes & 0.046 & yes \\
\hline ANL/IET-8 & 0.077 & no & 0.040 & yes \\
\hline
\end{tabular}




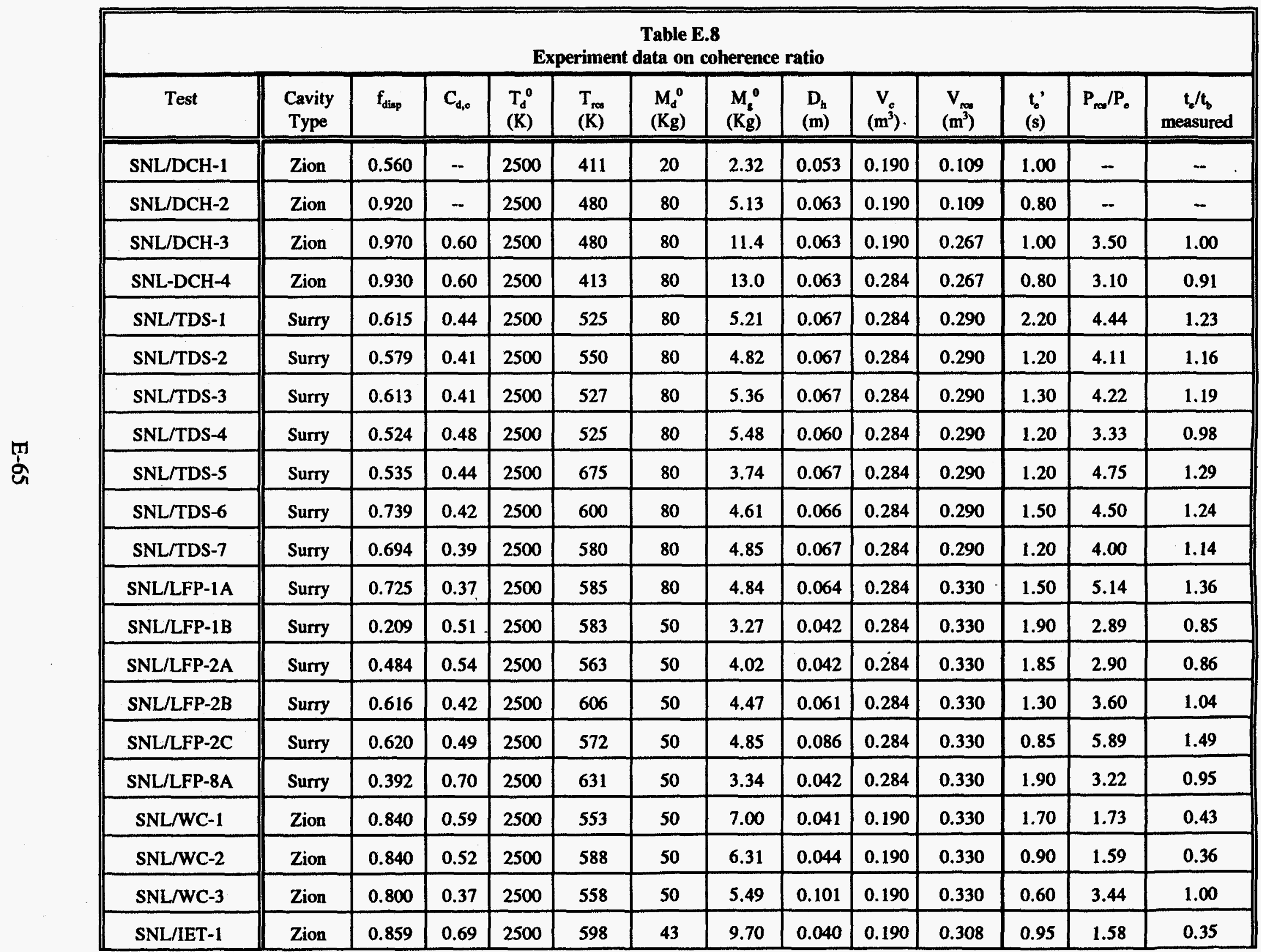




\begin{tabular}{|c|c|c|c|c|c|c|c|c|c|c|c|c|c|c|c|c|c|c|c|c|c|}
\hline \multirow{14}{*}{ 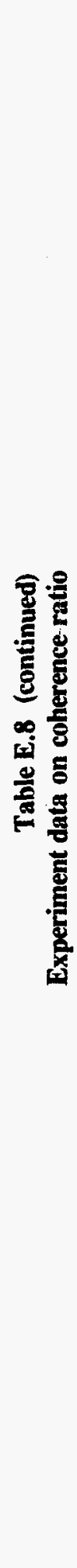 } & 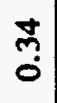 & के & 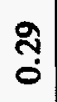 & 饣̊? & $\bar{m}$ & ஜ̊ & ח̊n. & $\stackrel{\infty}{+}$ & $\begin{array}{l}8 \\
0 \\
\dot{0}\end{array}$ & $\begin{array}{l}\tilde{0} \\
0 \\
0\end{array}$ & $\stackrel{\text { ț }}{-}$ & ¿্ & $\stackrel{\infty}{-}$ & $\begin{array}{l}8 \\
0 \\
0\end{array}$ & 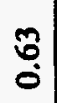 & స్ & ֻn? & 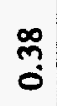 & $\stackrel{\sim}{\stackrel{\sim}{0}}$ & $\bar{n}$ & \% \\
\hline & $\stackrel{n}{\sim}$ & $\stackrel{g}{g}$ & $\stackrel{8}{-}$ & $\stackrel{g}{\sigma}$ & ஜํ. & $\stackrel{\infty}{\infty}$ & $\stackrel{\infty}{n}$ & $\stackrel{\Xi}{-}$ & $\begin{array}{l}\nwarrow \\
\text { i }\end{array}$ & $\stackrel{\widetilde{N}}{i}$ & $\begin{array}{l}\infty \\
0 \\
0\end{array}$ & $\stackrel{R}{=}$ & $\frac{\nabla}{\infty}$ & $\frac{ \pm}{\Delta}$ & $\underset{\sim}{\sim}$ & $\stackrel{f}{\sim}$ & $\stackrel{\infty}{\sim}$ & $\stackrel{B}{6}$ & $\Xi$ & $\underset{0}{8}$ & $\Xi$ \\
\hline & $\stackrel{2}{2}$ & $\begin{array}{l}8 \\
0 \\
0\end{array}$ & $\begin{array}{l}\infty \\
\infty \\
0\end{array}$ & $\underset{-8}{8}$ & $\begin{array}{l}8 \\
0 \\
0\end{array}$ & ঙ્ণ & ঙ્ & 8 & $\stackrel{0}{=}$ & ్ㅗ & $\stackrel{n}{=}$ & $\begin{array}{l}8 \\
0 \\
0\end{array}$ & $\begin{array}{l}\text { ஜి } \\
0\end{array}$ & $\begin{array}{l}8 \\
\stackrel{8}{0} \\
0\end{array}$ & ্ْণি & 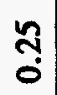 & ָ̊ & ָุ & 유. & $\begin{array}{l}8 \\
0 \\
0\end{array}$ & ñ \\
\hline & $\begin{array}{c}\infty \\
\stackrel{\infty}{\circ} \\
0\end{array}$ & $\begin{array}{c}\infty \\
\text { ஸे } \\
\dot{0}\end{array}$ & 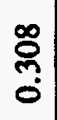 & $\begin{array}{l}\infty \\
\stackrel{\infty}{0} \\
0\end{array}$ & 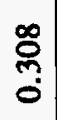 & 号 & 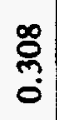 & $\stackrel{\text { Iִ }}{-}$ & 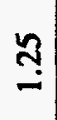 & $\stackrel{\beth}{=}$ & 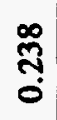 & $\begin{array}{l}8 \\
8 \\
0\end{array}$ & $\begin{array}{l}\overline{8} \\
\dot{8} \\
0\end{array}$ & $\begin{array}{l}\overline{8} \\
\overline{8} \\
0\end{array}$ & $\begin{array}{l}\overline{8} \\
\dot{8} \\
0\end{array}$ & $\begin{array}{l}\overrightarrow{8} \\
\dot{8} \\
0\end{array}$ & $\begin{array}{l}\overline{8} \\
8 \\
0\end{array}$ & $\begin{array}{l}\overrightarrow{8} \\
\dot{8}\end{array}$ & $\begin{array}{l}\overline{8} \\
8\end{array}$ & $\begin{array}{l}\overline{8} \\
\dot{8} \\
0\end{array}$ & $\begin{array}{l}\overline{8} \\
\dot{8} \\
0\end{array}$ \\
\hline & $\frac{8}{\circ}$ & $\frac{8}{0}$ & $\frac{8}{0}$ & $\frac{8}{0}$ & $\frac{8}{0}$ & $\frac{8}{0}$ & $\frac{8}{0}$ & $\bar{n}$ & $\bar{n}$ & $\bar{n}$ & $\begin{array}{c}\hat{\infty} \\
\stackrel{1}{0}\end{array}$ & $\begin{array}{c}\delta \\
\\
0\end{array}$ & $\begin{array}{l}\hat{8} \\
0\end{array}$ & $\begin{array}{c}\tilde{8} \\
\dot{0}\end{array}$ & 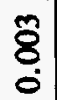 & $\begin{array}{c}\tilde{\delta} \\
0 \\
0\end{array}$ & $\stackrel{\tilde{\delta}}{0}$ & $\stackrel{m}{8}$ & $\underset{8}{8}$ & $\begin{array}{l}\tilde{8} \\
0\end{array}$ & $\overbrace{0}$ \\
\hline & $\begin{array}{l}\stackrel{+}{0} \\
\dot{0}\end{array}$ & $\begin{array}{l}\text { ठे } \\
\stackrel{0}{0}\end{array}$ & $\underset{̛}{\tilde{O}}$ & $\underset{\delta}{\tilde{\delta}}$ & 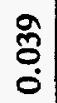 & જ̊ & $\underset{\delta}{\stackrel{\delta}{\delta}}$ & $\begin{array}{l}\text { to } \\
\dot{0}\end{array}$ & $\stackrel{\infty}{8}$ & 号 & \begin{tabular}{l}
$\mathscr{0}$ \\
\hdashline \\
0
\end{tabular} & $\stackrel{m}{0}$ & $\stackrel{m}{\sigma}$ & ठ̊ & $\stackrel{m}{0}$ & $\frac{\pi}{0}$ & $\stackrel{T}{\square}$ & $\underset{0}{T}$ & ㄱ: & $\overline{\overline{0}}$ & $\overline{0}$ \\
\hline & $\frac{\mathbb{N}}{\infty}$ & $\tilde{m}_{\infty}^{\infty}$ & $\stackrel{\infty}{\circ}$ & $\underset{\infty}{\underset{\infty}{*}}$ & $\frac{\infty}{a}$ & $\frac{8}{\circ}$ & $\frac{\infty}{a}$ & そั & $\begin{array}{c}m \\
\infty \\
\infty\end{array}$ & $\frac{0}{6}$ & $\stackrel{m}{0}$ & 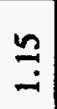 & స్స్ & $\frac{ \pm}{0}$ & $\frac{E}{0}$ & $\frac{\tilde{n}}{0}$ & $\frac{ \pm}{0}$ & $\frac{8}{0}$ & $\frac{\infty}{0}$ & $\stackrel{n}{\delta}$ & $\frac{8}{0}$ \\
\hline & $\mathscr{q}$ & $\dddot{q}$ & $\stackrel{m}{q}$ & $\stackrel{m}{\forall}$ & $\stackrel{m}{\forall}$ & $\mathscr{m}$ & $\mathscr{q}$ & $\stackrel{\infty}{n}$ & $\stackrel{\infty}{n}$ & $\stackrel{\infty}{n}$ & 요 & $\begin{array}{l}= \\
\dot{\nabla}\end{array}$ & $\frac{m}{\dot{\sigma}}$ & $\begin{array}{l}\tilde{\infty} \\
0 \\
0\end{array}$ & $\begin{array}{l}0 \\
0 \\
0\end{array}$ & $\begin{array}{l}\infty \\
0 \\
0\end{array}$ & $\underset{0}{\stackrel{1}{0}}$ & $\underset{0}{\overparen{5}}$ & $\frac{m}{i}$ & $\stackrel{m}{=}$ & $\stackrel{m}{\Xi}$ \\
\hline & $\stackrel{\mathscr{D}}{\curvearrowleft}$ & $\stackrel{\mathscr{\infty}}{\mathscr{\sigma}}$ & $\tilde{n}$ & $\underset{\not}{\mathbb{\infty}}$ & $\bar{n}$ & ฉి & $\bar{n}$ & $\stackrel{\infty}{\infty}$ & $\stackrel{\infty}{0}$ & 8. & $\stackrel{N}{\sim}$ & §̊ & 忍 & $\frac{n}{6}$ & 8 & 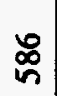 & 8 & ஜำ & $\frac{R}{n}$ & $\underset{n}{\mathbb{N}}$ & 8 \\
\hline & $\begin{array}{l}8 \\
\text { క }\end{array}$ & 8 & $\begin{array}{l}8 \\
\text { స్ }\end{array}$ & 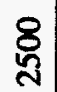 & 8 & 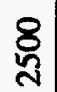 & 8 & 8 & 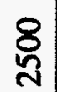 & 8 & ஜ̊ & $\frac{8}{m}$ & $\frac{8}{m}$ & $\begin{array}{l}8 \\
\end{array}$ & $\begin{array}{l}8 \\
\text { చ్ }\end{array}$ & 8 & 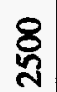 & 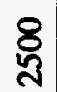 & $\begin{array}{l}8 \\
\text { ㄱ }\end{array}$ & $\frac{8}{3}$ & $\frac{8}{N}$ \\
\hline & $\stackrel{a}{\sigma}$ & $\underset{8}{*}$ & $\tilde{n}$ & 융 & $\begin{array}{l}\forall \\
\dot{0}\end{array}$ & $\frac{a}{0}$ & $\begin{array}{c}n \\
m \\
0\end{array}$ & $\begin{array}{l}\infty \\
0 \\
0\end{array}$ & $\begin{array}{l}g \\
0\end{array}$ & $\ddot{\sigma}$ & $\begin{array}{l}8 \\
0\end{array}$ & $\begin{array}{l}\tilde{0} \\
0\end{array}$ & 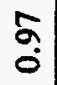 & $\dot{\vec{n}}$ & $\vec{n}$ & $\stackrel{\infty}{\stackrel{m}{0}}$ & $\stackrel{\infty}{\stackrel{\infty}{\circ}}$ & $\stackrel{\infty}{\stackrel{\infty}{0}}$ & $\underset{0}{\sigma}$ & \& & ণ্ \\
\hline & $\frac{\tilde{n}}{\dot{0}}$ & $\begin{array}{l}\text { त్ర్ర } \\
\text { : }\end{array}$ & $\begin{array}{l}0 \\
\infty \\
0 \\
0\end{array}$ & $\begin{array}{l}\text { त్రె } \\
0 \\
0\end{array}$ & $\begin{array}{l}\text { 怘 } \\
\stackrel{0}{0}\end{array}$ & 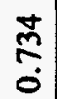 & $\begin{array}{l}0 \\
\infty \\
\infty \\
0\end{array}$ & $\begin{array}{l}\mathscr{0} \\
\infty \\
0 \\
0\end{array}$ & $\frac{\widetilde{\sigma}}{\dot{0}}$ & $\frac{2}{\circ}$ & $\stackrel{?}{\stackrel{f}{+}}$ & 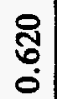 & 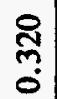 & $\frac{\tilde{n}}{0}$ & 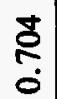 & $\underset{⿱ 亠 䒑}{\stackrel{5}{0}}$ & $\begin{array}{l}\hat{\delta} \\
0 \\
0\end{array}$ & $\underset{\infty}{\stackrel{\infty}{\infty}}$ & $\frac{8}{8}$ & $\frac{8}{0}$ & $\frac{\varkappa}{\circ}$ \\
\hline & 总 & 옥 & 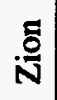 & i̊ & $\stackrel{\overline{0}}{\frac{0}{N}}$ & 离 & is & 趈 & ह & ह & $E$ & 通 & 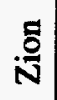 & 总 & స్ํำ & ī & iี & is & iี & 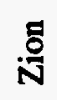 & : \\
\hline & 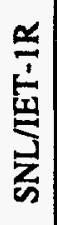 & 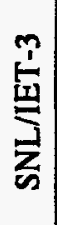 & 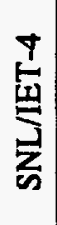 & 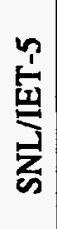 & 量 & 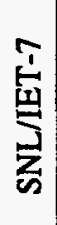 & 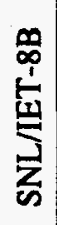 & 点 & $\frac{\text { 亶 }}{\sum_{n}^{\frac{1}{2}}}$ & 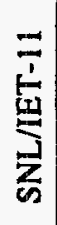 & $\frac{N}{\sum_{n}^{\frac{1}{2}}}$ & $\frac{n}{z}$ & 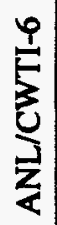 & 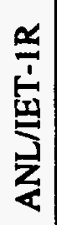 & 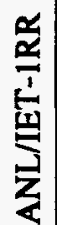 & 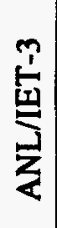 & 量 & 点 & 占 & $\underset{⿱ 乛 龰}{\stackrel{3}{2}}$ & $\sum_{\frac{2}{3}}^{\frac{9}{2}}$ \\
\hline
\end{tabular}




\begin{tabular}{|c|c|c|c|c|c|c|c|c|c|c|c|c|c|}
\hline \multicolumn{14}{|c|}{$\begin{array}{r}\text { Table E.8 (concluded) } \\
\text { Experiment data on coherence ratio }\end{array}$} \\
\hline ANL/U2 & Zion & 0.295 & 0.57 & 2700 & 595 & 1.13 & 0.105 & 0.011 & 0.003 & 0.0061 & 0.60 & 4.25 & 1.29 \\
\hline FAI/DCH-1 & Zion & 0.900 & 0.77 & 2300 & 300 & 20 & 1.44 & 0.025 & 0.024 & 0.040 & 1.00 & 4.57 & 1.26 \\
\hline FAI/DCH-2 & Zion & 0.900 & 0.77 & 2300 & 300 & 20 & 1.44 & 0.025 & 0.024 & 0.040 & 1.00 & 3.75 & 1.08 \\
\hline FAI/DCH-3 & Zion & 0.900 & 0.77 & 2300 & 300 & 20 & 1.35 & 0.025 & 0.024 & 0.040 & 1.00 & 4.57 & 1.26 \\
\hline FAI/DCH-4 & Zion & 0.900 & -- & 2300 & 500 & 20 & 1.22 & 0.025 & 0.024 & 0.104 & 1.00 & 3.36 & 0.98 \\
\hline
\end{tabular}




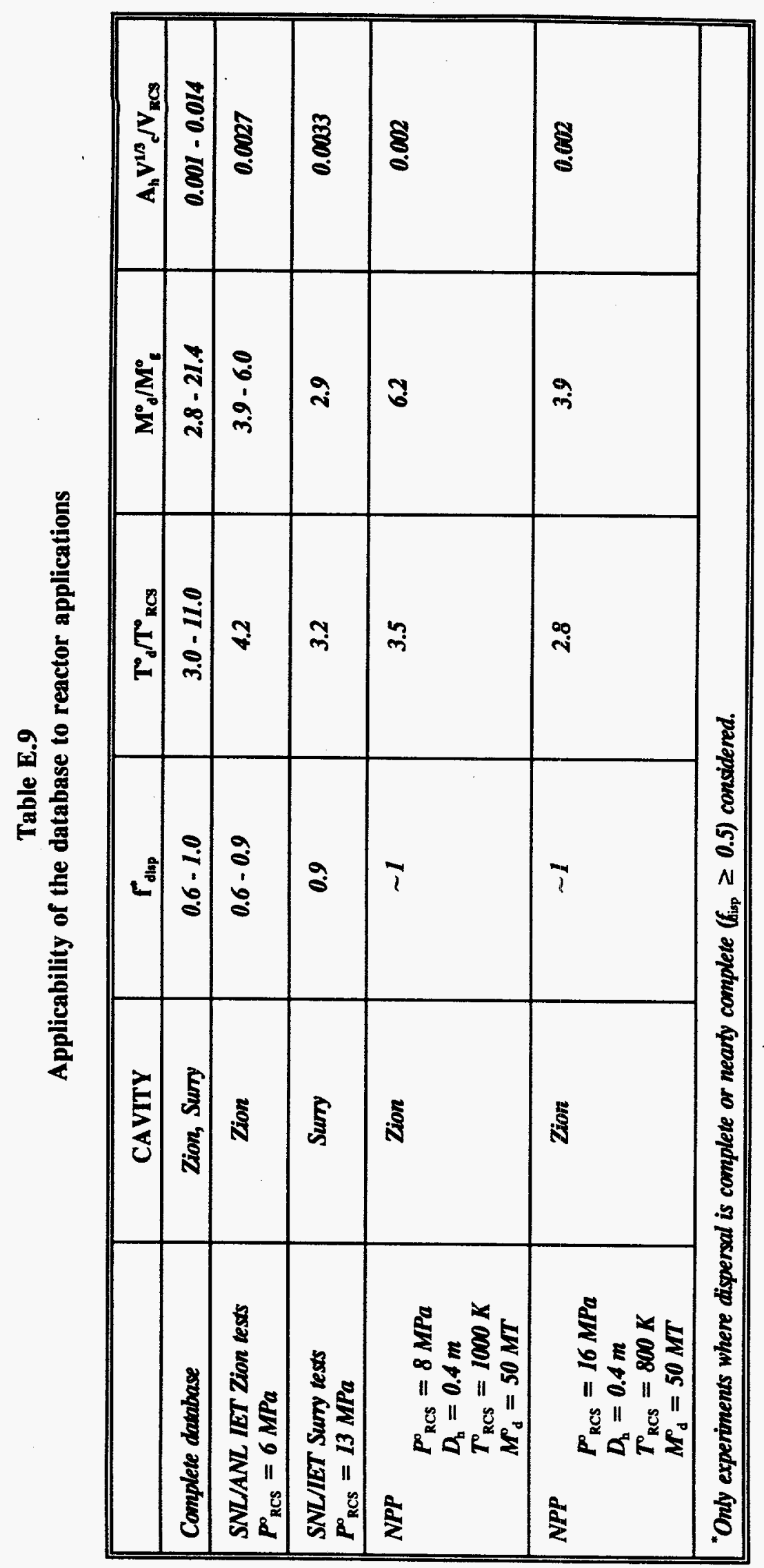

E-68 


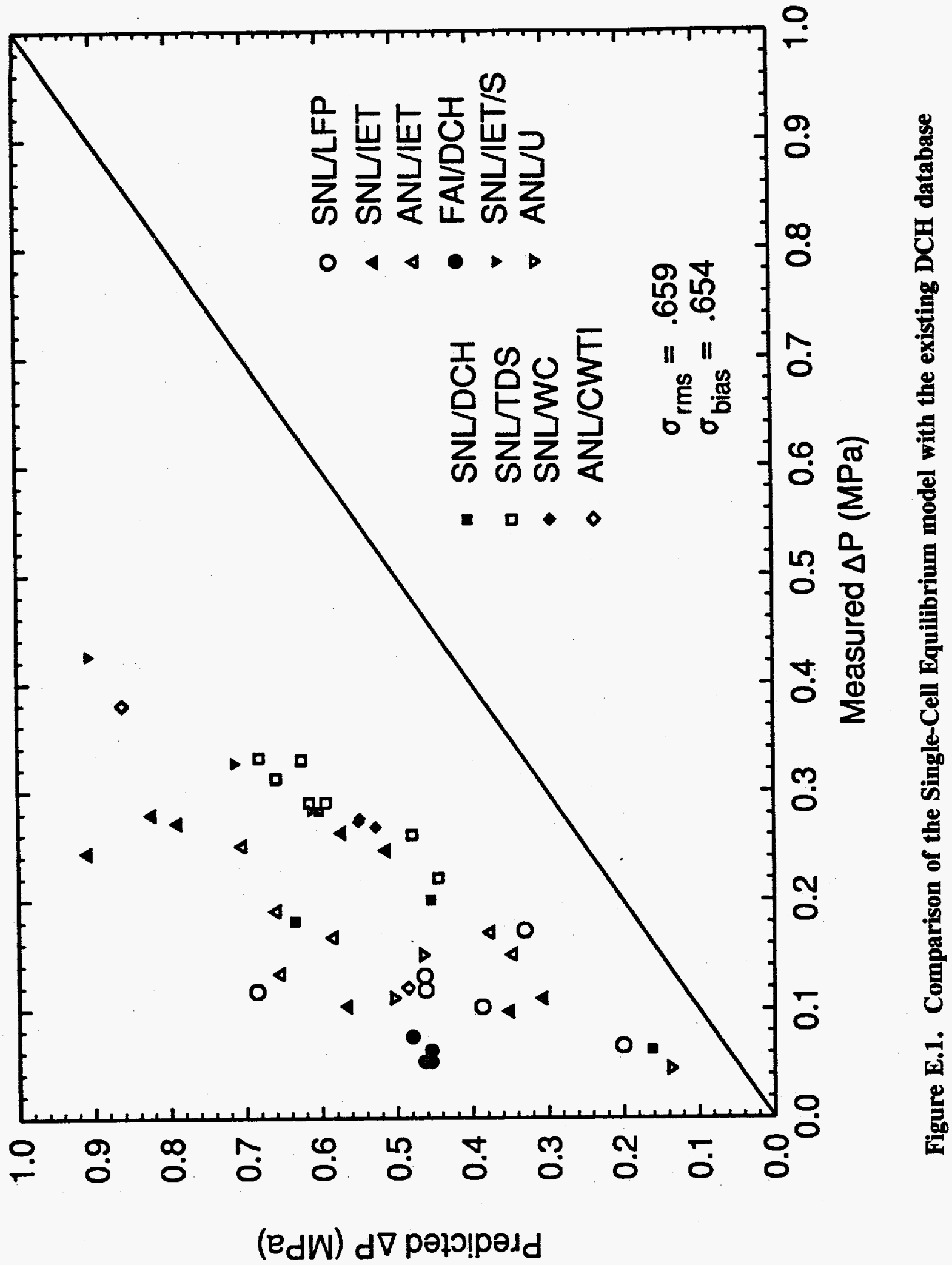




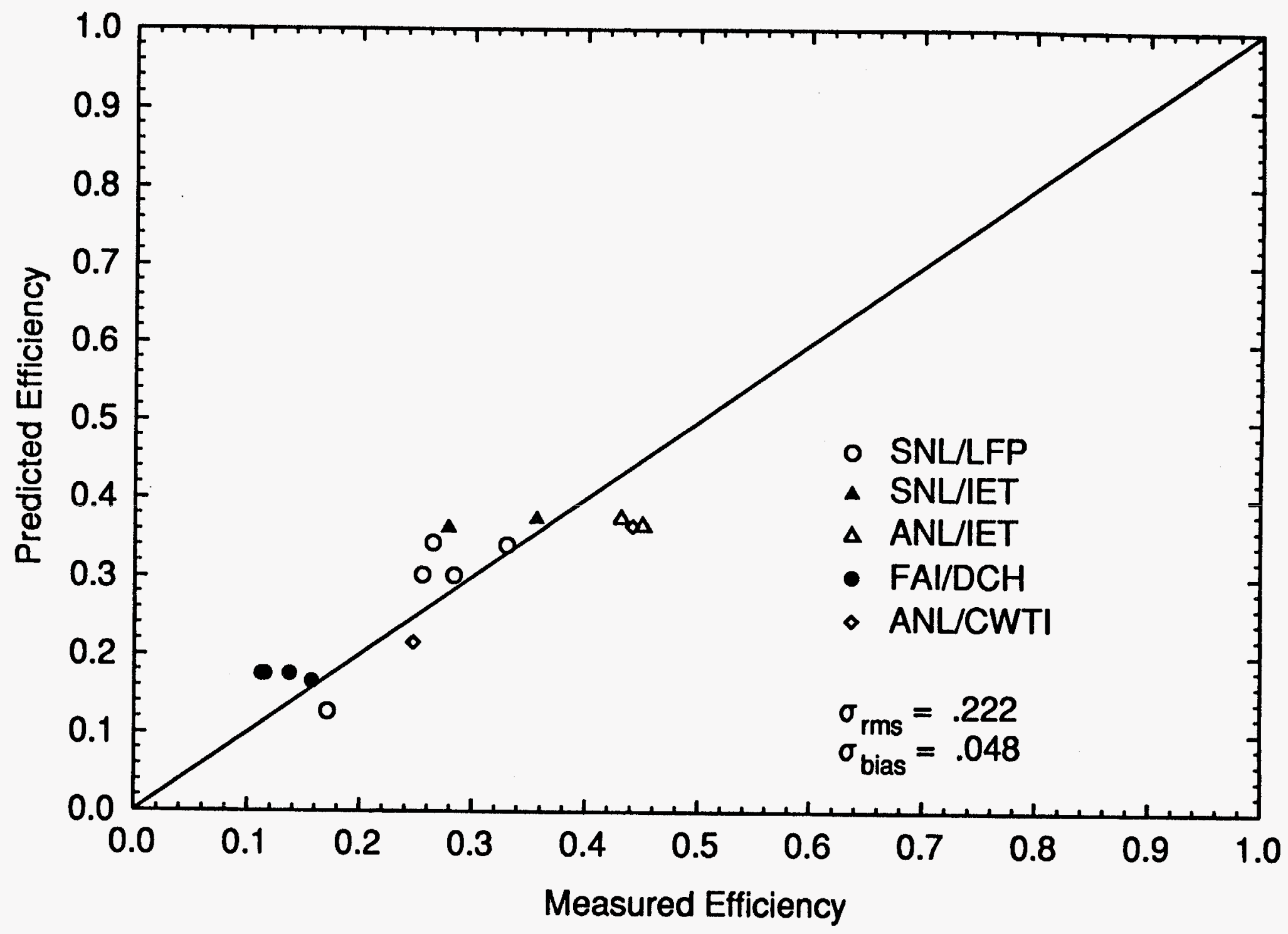

Figure E.2. Validation of the Two-Cell Equilibrium Model with experiments where the atmosphere was inert 


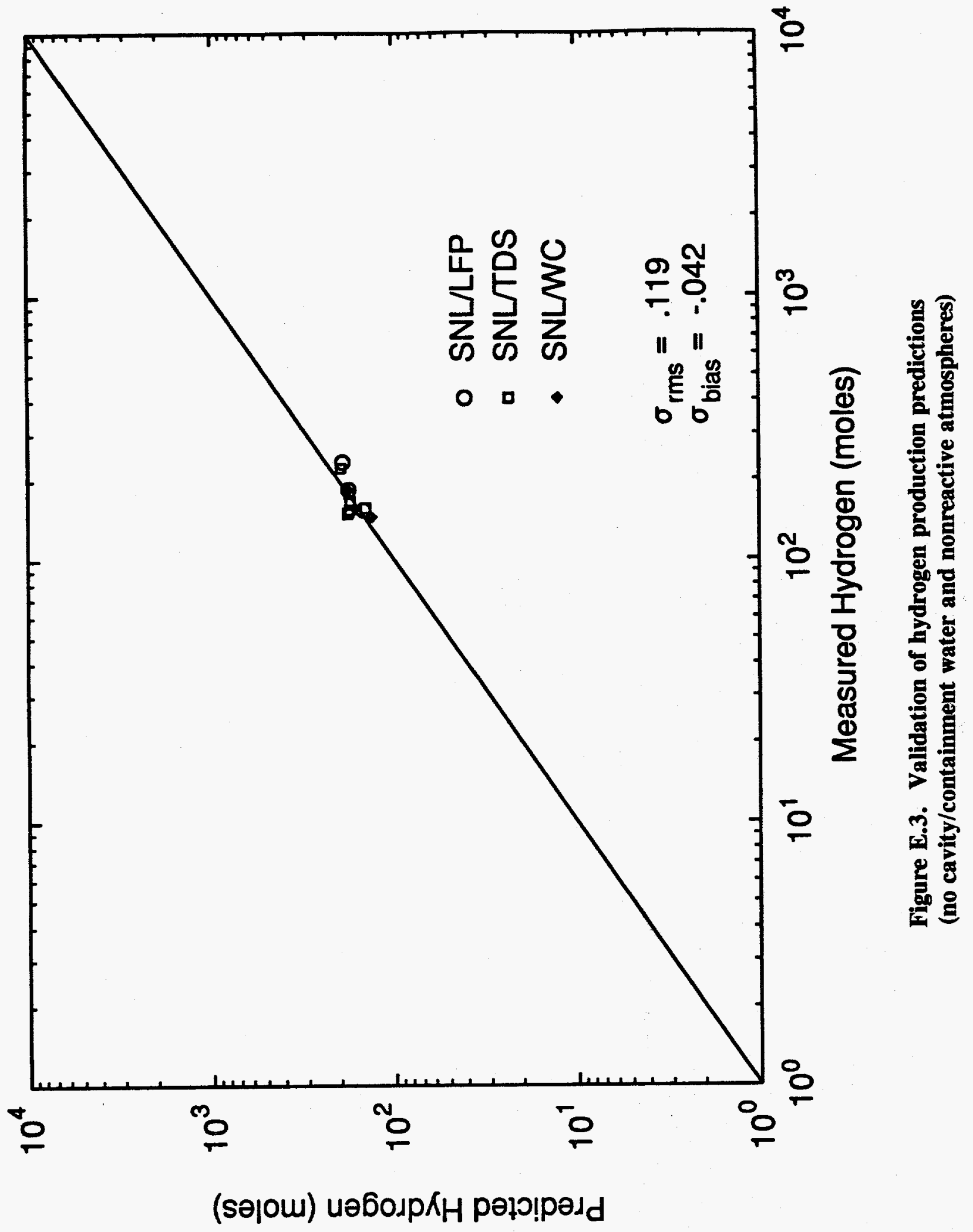




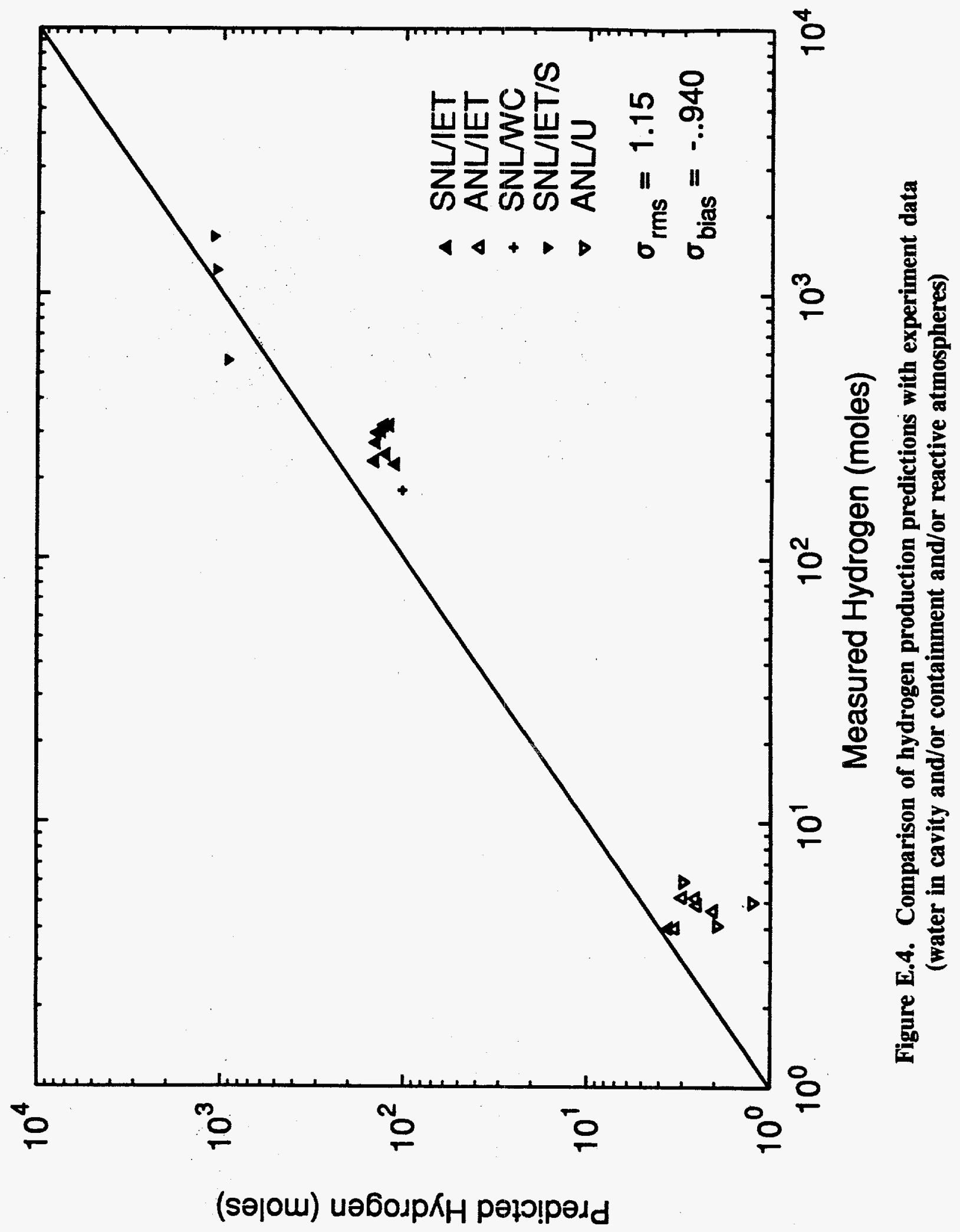




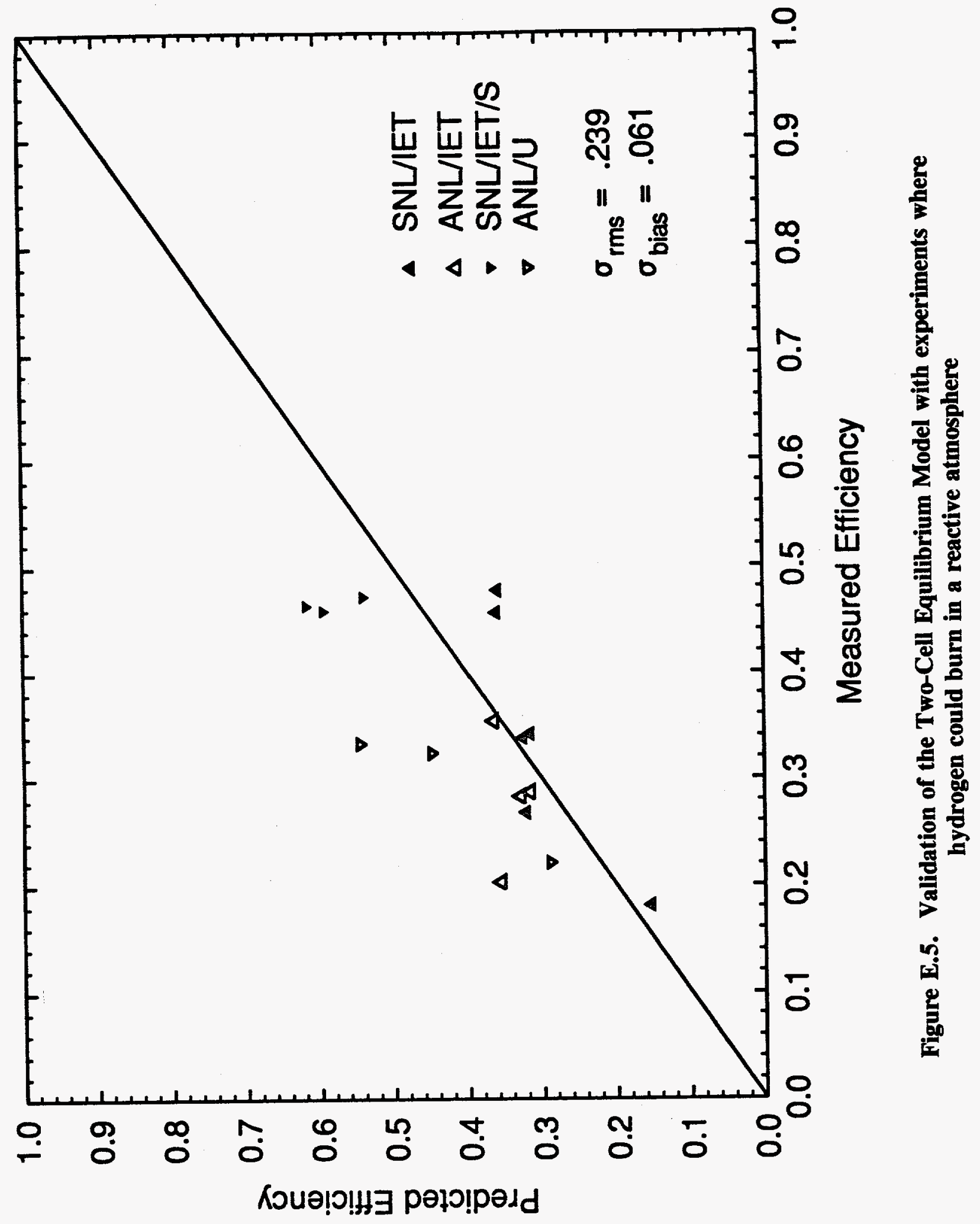



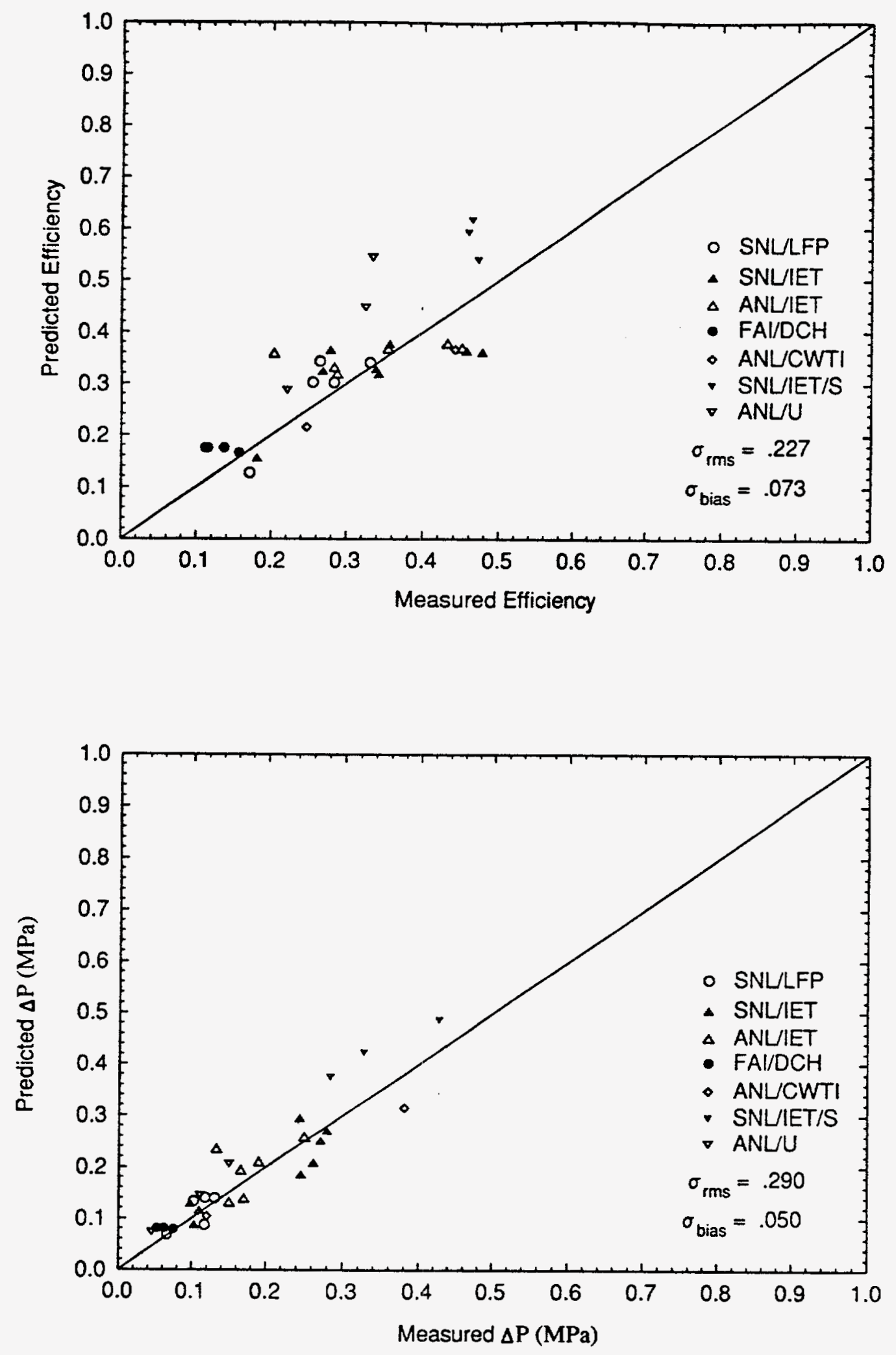

Figure E.6. Validation of the Two-Cell Equilibrium Model against all experiments with compartmentalized geometry 


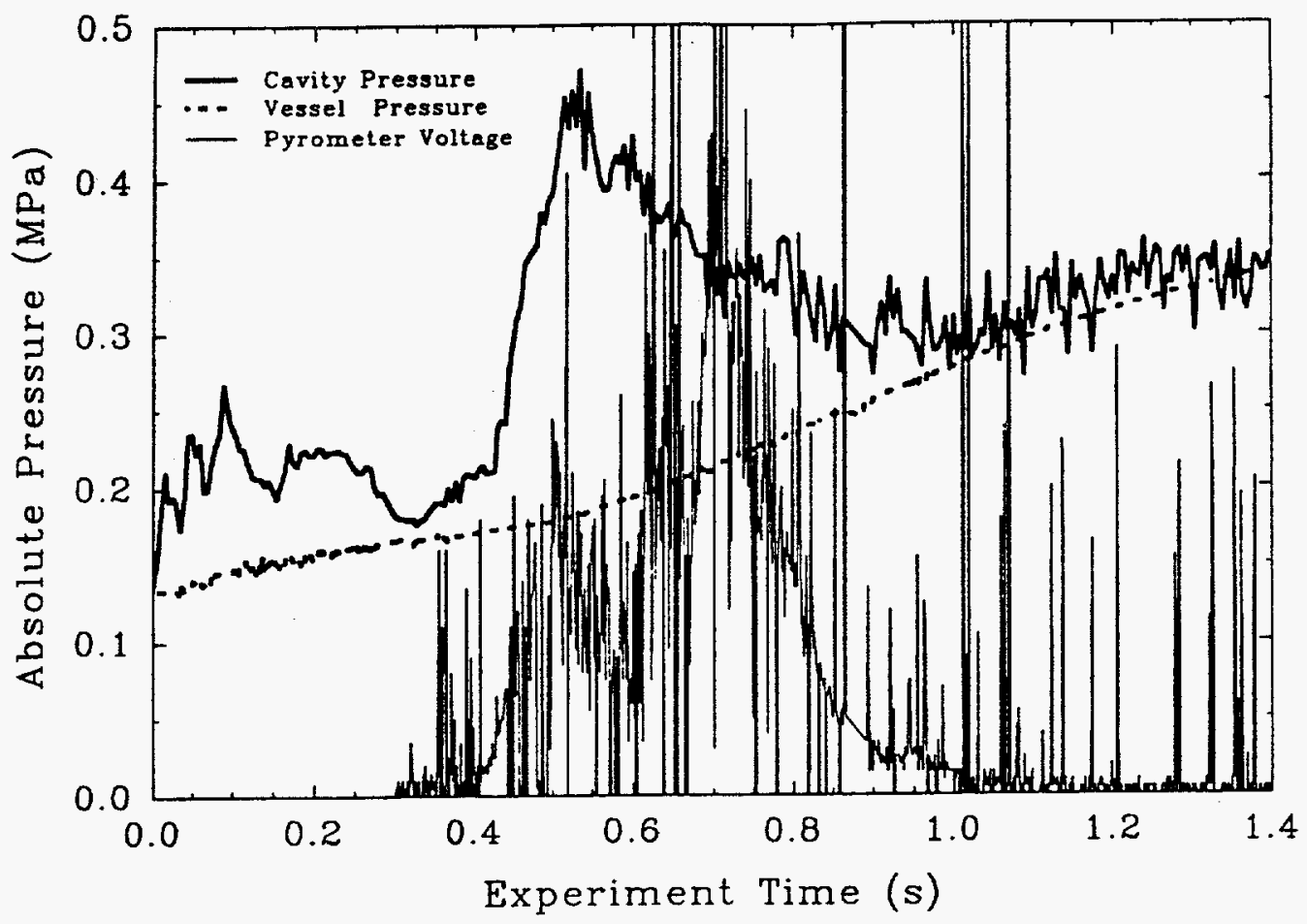

Figure E.7. Typical cavity pressurization record

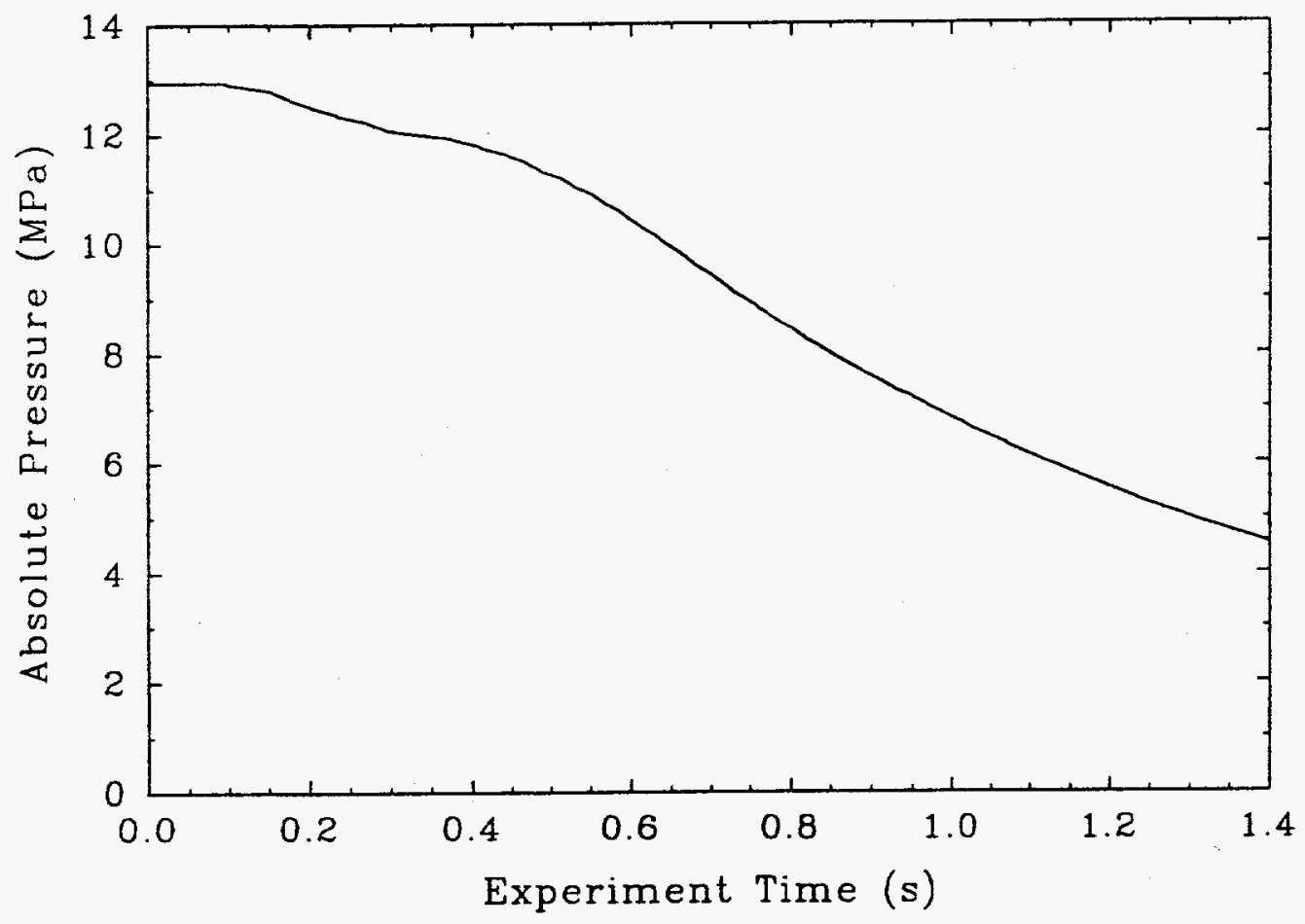

Figure E.8. Typical accumulated (RCS) blowdown record 


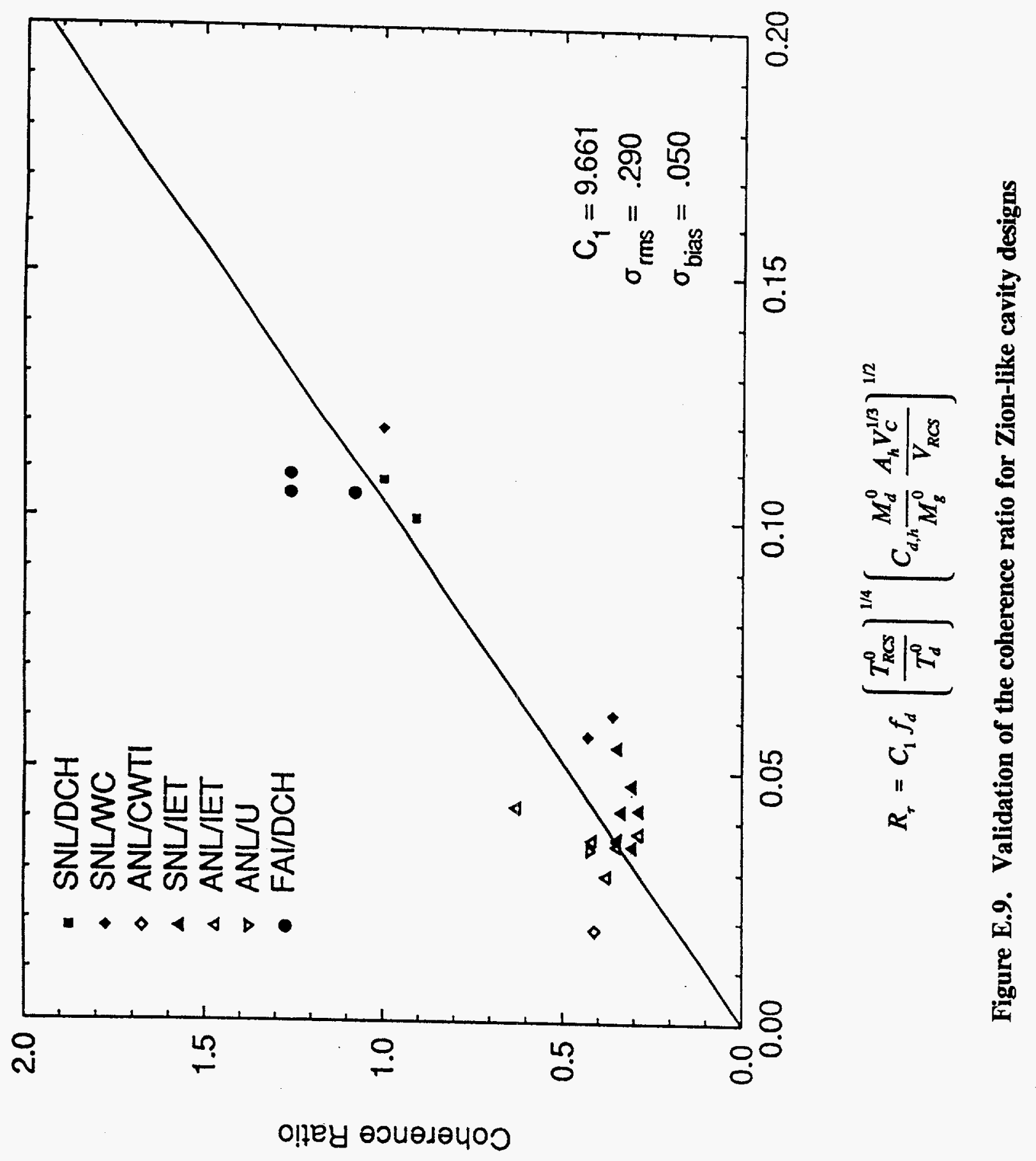




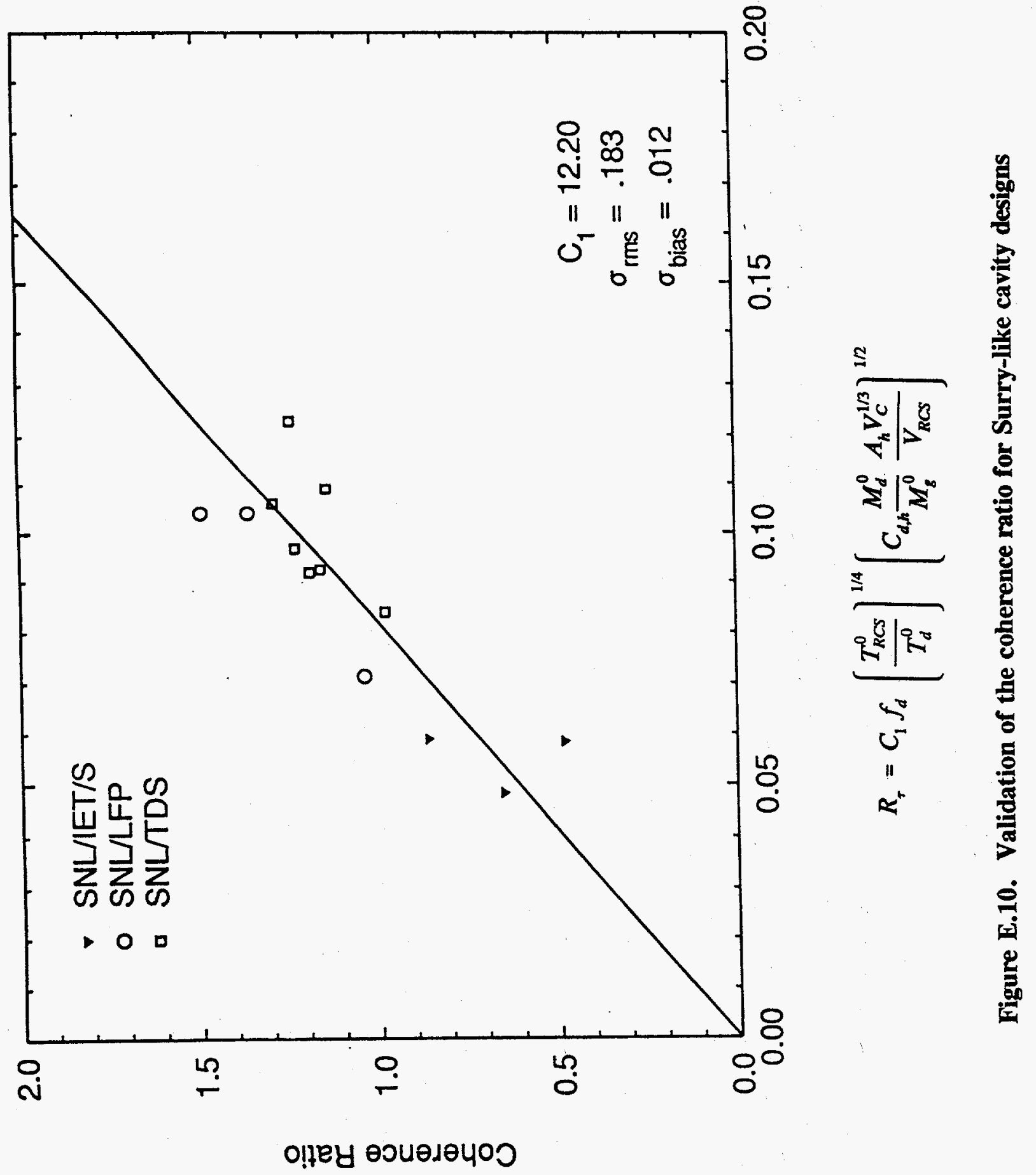




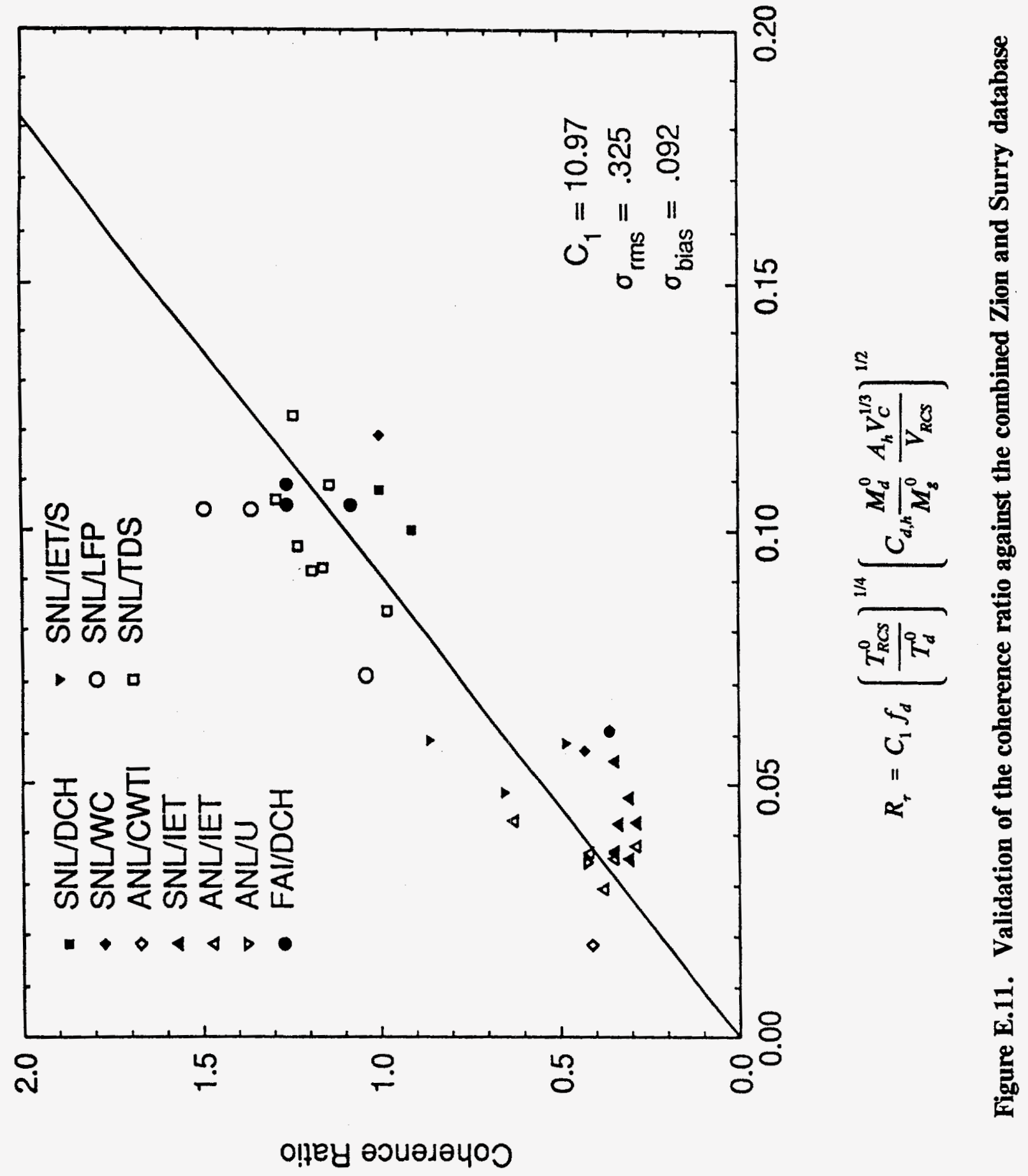




\title{
APPENDIX F \\ AUTOIGNITION TEMPERATURE IN DCH EVENTS
}

\author{
Martin M. Pilch \\ Sandia National Laboratories
}

\section{F.1 INTRODUCTION}

This appendix recommends an autoignition temperature suitable for $\mathrm{DCH}$ analyses. We first examine reported autoignition temperatures from small scale experiments. Such measurements are not wholly suitable because the database does not fully overlap expected conditions in a DCH event and because questions of scale effects cloud any possible extrapolation to reactor applications. We overcome these shortcomings by developing a model that balances reaction kinetics with heat losses to containment structures. Lastly, we examine recent large scale DCH experiments employing prototypic air steam atmospheres with preexisting hydrogen. We finally conclude that mixing limitations likely preclude autoignition in DCH events.

The potential to "autoignite" preexisting hydrogen in the containment has long been a fundamental uncertainty in DCH analyses. Autoignition is a volumetric oxidation process that does not require a spark or pilot flame for combustion to occur. Typically, autoignition is thought of as a runaway process where heat generation greatly outpaces heat losses. Autoignition is primarily controlled by reaction kinetics (which are strongly temperature dependent) at the molecular scale; and as such, autoignition may be though of as a fundamental property of combustion. In the context of $\mathrm{DCH}$, we seek to define a critical atmosphere temperature where all preexisting hydrogen in the containment is assumed to burn rapidly, and contribute to the peak containment pressure, which occurs on a time scale of $\sim 15 \mathrm{~s}$. This definition broadens the notion of autoignition somewhat by leaving open the possibility that processes other than reaction kinetics can control volumetric combustion in containment atmospheres. 


\section{F.2 REACTION KINETICS}

Stamps and Berman (1991) have reviewed the experiment literature on autoignition of hydrogen. The results are summarized in Figure F.1. It is noteworthy that the database is derived exclusively from very small-scale experiments, where the gas mixture is heated uniformly without significant heat losses to the containment vessel. For stoichiometric mixtures, autoignition occurs at about $800 \mathrm{~K}$, which increases somewhat with the addition of steam. There is almost no data for lean mixtures ( $<7$ percent) that are of interest to DCH. Figure F.1 suggests, however, that the autoignition temperature increases as the mixture becomes more lean. Conti and Hertzberg (1988) report autoignition at $873 \mathrm{~K}$ for 6 percent hydrogen in air. They caution, however, that the effect of physical scale is unknown. Stamps and Berman (1991) cite three experiments suggesting that the autoignition temperature decreases with increasing scale. Since heat losses are minimal in these experiments, it suggests that radical destruction, a surface to volume effect like heat transfer, is responsible for the scale effect. Lastly, no data can be found on autoignition in atmospheres containing a micro mist of water drops; a condition expected in reactor containments where saturated conditions are common.

Stamps and Berman (1991) note that reported autoignition temperatures can vary with the experiment technique. The data in Figure F.1 were obtained using uniform temperature techniques where the mixture is heated uniformly throughout its volume and where the autoignition threshold is demarcated by those mixtures that produce a slight pressure rise. These are relatively benign events $(\Delta \mathrm{P} \sim 0.01-0.03 \mathrm{MPa})$, and similar pressurizations during a DCH event would be inconsequential.

In contrast, Sheldon (1984) reports an autoignition temperature of $\sim 1200 \mathrm{~K}$ using a hot surface technique. Similarly, Tamm et al., (1987) reports that hydrogen/air/steam mixtures (5-55 percent $\mathrm{H}_{2}, 10-55$ percent steam) can be ignited with a glow-plug heated to -975-1150 K. It can be argued whether such techniques are a true measure of autoignition. If they are a measure of autoignition, then these more energetic thresholds are $-200-300$ $\mathrm{K}$ higher than the more benign thresholds defined by the uniform temperature techniques. 
Lastly, Zabetakis (1956) and Shepard (1985) showed that pure hydrogen jets would autoignite at $\sim 900-1000 \mathrm{~K}$ in air. Zabetakis further showed that the autoignition temperature increased with the addition of steam.

The deficiency in relevant experiment data has been partially addressed here with calculations performed using the SENKIN code (Lutz et al., 1991). The combustion of hydrogen involves a large number of intermediate reactions, and the SENKIN code calculates the kinetics of each of these reactions.

Table F.1 summarizes results for a case with 38 percent steam and 4.8 percent preexisting hydrogen. The first two columns list the atmosphere temperature and pressure prior to the $\mathrm{DCH}$ event. The third column lists some plausible atmosphere temperatures after the DCH event (without combustion of any preexisting hydrogen) while column four shows the containment pressure consistent with the assumed temperatures given in column three. Columns three and four, along with the assumed composition of the atmosphere, represent the total input for the kinetic calculations.

Output from the calculations are listed in columns five and six. Column five lists the induction time, which represents the time where 5 percent of the energy has been released. Most of this' time is spent building up a pool of radicals that are involved in the energy releasing reactions (Dougherty and Rabitz, 1980). Column six lists the reaction time, which is defined as the time necessary to release 95 percent of the energy. Note that the induction time is about 75 percent of the reaction time. The induction and reaction times from Table F.1 are plotted on Figure F.2.

The high hydrogen concentration and low steam concentration in Table F.1 tend to favor more rapid reactions. Less favorable conditions are examined in Table F.2 where the atmosphere is 70 percent steam with 2 percent preexisting hydrogen. For these less favorable conditions, the induction time is shorter and the reaction time is longer. Furthermore, the time over which energy is released is longer than Table F.1 results. 
Temperature is the key sensitivity while composition is a second-order effect. The induction and reaction times from Table F.2 are plotted in Figure F.3.

The SENKIN results show that the induction and reaction times are very strong functions of temperature, while variations in composition have only a second order effect. The SENKIN results suggest that reaction times at $\sim 800 \mathrm{~K}$ are comparable to DCH time scales in a full-size reactor, but that somewhat higher atmosphere temperatures would be required at smaller scale because of the compressed time scales. This tradeoff between the energy release time scales and the time scale for heat loss to structures will be quantified next.

SENKIN calculations of the induction period are performed as if the atmosphere is at constant temperature. Real containment (and experiment) atmospheres are decidedly not adiabatic, where the atmosphere temperature is expected to decay according to

$$
\frac{T-T^{o}}{T_{m}-T^{o}}=e^{-t / \tau_{m}}
$$

In this formulation, a more conservative result (i.e., lower autoignition temperature) is obtained by ignoring the mixing time relative to the heat transfer time. Temperature decay, however, is not the only loss mechanism. Additionally, the idestruction of radicals at containment walls and surfaces will contribute to losses. Difficult to analyze, a conservative bound is obtained by ignoring radical destruction. Mixing and radical destruction are expected to be second order effects, as will be shown later.

The SENKIN results are not directly applicable to situations where the atmosphere temperature decays according to Equation F.1. This shortcoming is circumvented by invoking the lifetime rule,

$$
\int_{0}^{\tau_{\text {mone }}} \frac{d t}{\tau_{i n d}(T)}=1
$$

to define an effective induction time, $\tau_{\text {ind,e }}$, for the temperature varying atmosphere. Closure with Equations F.1 and F.2 is obtained by supplying a curve fit, 


$$
\begin{gathered}
\tau_{\text {ind }}(T)=a \mathrm{e}^{\mathrm{b}+\mathrm{c} / \mathrm{Tm}} \\
\mathrm{a}=3.841 \times 10^{-12} \mathrm{~s} \\
\mathrm{~b}=-0.025 \\
\mathrm{c}=2.314 \times 10^{4} \mathrm{~K}
\end{gathered}
$$

to the induction time near $800 \mathrm{~K}$ in Figure F.2.

The three coupled equations can be normalized, resulting in the following functional dependence:

$$
\frac{\tau_{i n d, e}}{\tau_{i n d}\left(T_{m}\right)}=f\left[\frac{\tau_{i n d}\left(T_{m}\right)}{\tau_{H T}} ; \frac{T_{m}}{T^{o}}\right] \approx f\left[\frac{\tau_{i n d}\left(T_{m}\right)}{\tau_{H T}} ; \frac{800}{380}\right]
$$

The coupled equations are easily solved numerically. Sensitivity studies show that the effective induction time (normalized) is insensitive to the temperature ratio $\left(T_{m} / T^{\circ}\right)$ for typical accident conditions, so a minimum value with the potential to autoignite is used. This choice minimizes the predicted autoignition temperature.

The result of this analysis is depicted in Figure F.4. As expected, the effective induction time equals the constant temperature induction time when the heat transfer time is sufficiently long; i.e., $\tau_{\text {ind, }}\left(\mathrm{T}_{\mathrm{m}}\right) / \tau_{\mathrm{HT}} \rightarrow 0$. As the heat transfer time decreases, (i.e., $\tau_{\text {ind }}\left(T_{m}\right) / \tau_{\text {HT }}$ increasing), a sharp threshold is reached where $\tau_{\text {ind,e }} / \tau_{\text {ind }}\left(T_{m}\right)$ goes to infinity. Beyond the threshold, autoignition is impossible. The condition for autoignition can be expressed as

$$
\frac{\tau_{\text {ind }}\left(T_{m}\right)}{\tau_{H T}} \preceq 0.067
$$

which yields 


$$
T_{m}=\frac{c}{\ln \left[0.067\left(\frac{\tau_{H T}}{a}\right)\right]-b}
$$

for the autoignition temperature when Equation F.3 is substituted into Equation F.5.

Some representative results are shown in Table F.3. The observed heat transfer time for a typical SNL/IET experiment is about $40 \mathrm{~s}$. All other things being the same, the heat transfer time scales as the facility size, from whence the representative ANL and NPP values are derived. Table F.3 shows that the autoignition temperature is $-780 \mathrm{~K}$ at reactor scale and increases somewhat as the facility scale decreases. Order of magnitude variations in the heat transfer time constant result in only 8 percent $(\sim 60 \mathrm{~K})$ variations in the autoignition temperature. As the dome temperature never exceeds $\sim 650 \mathrm{~K}$ in the SNL/ANL counterpart experiments, no autoignition should be expected, nor was it observed.

The characteristic heat transfer time scale in Equation F.6 is, in general, not known a priori, but it is known to be a function of both scale and peak temperature (without autoignition in the containment). Heat transfer to the containment structures is dominated by radiation, so that the time constant for heat transfer can be expressed as

$$
\begin{gathered}
\tau_{H T}=\frac{1}{\gamma-1} \frac{\Delta P_{m}}{\sigma T_{m}^{4}} \frac{V}{A_{s}} \\
\tau_{H T}=\frac{\Delta E}{\dot{E}}=\frac{\left(N_{R C B}^{o}+N_{R C S}^{o}\right) C_{v} T_{m}-N_{R C B}^{o} C_{v} T^{\circ}}{\sigma T_{m}^{4} A_{s}} .
\end{gathered}
$$

Equation F.7 explicitly shows that the characteristic heat transfer time scales as the facility size $\left(\tau_{\mathrm{HT}} \sim \mathrm{V} / \mathrm{A}_{\mathrm{s}}\right)$. The neglect of convective losses does not significantly alter the prediction of autoignition because the convective contribution is small and because order of magnitude variations in the heat transfer time produce only 8 percent variations in the autoignition temperature. 
The temperature dependence of the characteristic heat transfer time is shown explicitly in Equation F.8. Combining Equation F.8 and Equation F.6 yields a nonlinear equation for the autoignition temperature. With a seed of $800 \mathrm{~K}$, the nonlinear equation is strongly convergent in one or two fixed point iterations. Autoignition temperatures calculated by this procedure are quite close to those listed in Table F.1. For Zion-specific conditions, the autoignition temperature is $\sim 790 \mathrm{~K}$, which is most analogous to the more benign threshold discussed previously. The threshold for more energetic events, that might be of interest to $\mathrm{DCH}$, might be in $\sim 1000-1100 \mathrm{~K}$ range.

The scale dependence of the autoignition temperature at stoichometric conditions can be tested against experiment data. The measured autoignition temperatures at three different scales are listed in Table F.4. Heat transfer losses in these experiments are negligible, because the vessel itself is preheated to test conditions, which is then used to heat the gas. Consequently, radical destruction, a surface to volume effect like heat transfer, is the dominant effect. In accord with model predictions, the autoignition temperature increases with decreasing physical scale. The autoignition temperature normalized to the first set of conditions can be written as

$$
\begin{aligned}
T_{m} & =\frac{c}{\ln \left(d V^{1 / 3}\right)-b} \\
d & =1.074 \times 10^{14} .
\end{aligned}
$$

The predicted autoignition temperatures for the other two scales agree well with the measured values. Thus, the predicted scale dependence is both qualitatively and quantitatively validated by data.

If radical destruction at reactor scale and geometry could be characterized by the same constant (d) obtained from small scale experiments, then radical destruction is a second order effect compared to temperature decay in the atmosphere. This result is obtained by noting that the equivalent value of $d$ for heat transfer (obtained from Equations F.6 and F.7) is about 30 times smaller than the value for radical destruction. 


\section{F.3 AUTOIGNITION IN STRATIFIED ATMOSPHERES}

Autoignition of preexisting hydrogen under $\mathrm{DCH}$ conditions can be examined more closely with the aid of recent prototypic experiments. Table F.5 compares five experiments grouped according to the average dome temperature observed in the experiment: Two experiments where the average dome temperature is below the predicted autoignition threshold, two experiments where the average dome temperature exceeds the lower autoignition threshold, and one experiment where the average dome temperature greatly exceeds the lower autoignition threshold. Table F.5 compares the predicted pressure rise (assuming complete combustion of all preexisting hydrogen) with the measured pressure rise. The large difference between measured and predicted values suggests that significant burning of preexisting hydrogen did not occur in the experiments, at least not on the time scale of peak pressurization, i.e., $\sim 2 s$.

Gas samples taken during these tests qualitatively suggest that little preexisting hydrogen burned in SNL/IET-6, 7; but in SNL/IET-11, the gas samples qualitatively suggest that nearly all of the preexisting hydrogen might have burned. The qualitative nature of gas samples arises because of uncertainties over mixing, long term hydrogen production/combustion, and long term metal/oxygen reactions.

In SNL/IET-11, the gas samples qualitatively suggest that significant burning of preexisting hydrogen might have occurred, but any such burning is not reflected in the peak pressure. We now seek explanations for this apparent anomaly. Although preexisting hydrogen does not burn as an autoignition event in these experiments, some of the preexisting hydrogen must be entrained (along with oxygen) into hot hydrogen jets venting from the subcompartment. Entrainment of oxygen into these hot hydrogen/steam jets is essential if combustion as a diffusion flame is to be sustained, and there is indisputable evidence from the experiments that these jets are burning. This entrainment process is modeled in both the CLCH and TCE models. We consider that the computation of the autoignition temperature is in some serious error. We note that kinetic modeling of hydrogen combustion at the molecular level is quite mature and codes like SENKIN, and 
SENKIN itself, have been put to the test of time, so no problem is expected here. Quantitative treatment of losses, by heat transfer or radical destruction, requires scrutiny. Heat transfer time constants used in the prediction are in good agreement with the observed temperature decay in the dome. Section F.2 suggests that radical destruction is a second order effect, although this conclusion has its basis on small scale experiments that do not approximate $\mathrm{DCH}$ conditions. In either case, heat transfer or radical destruction, the magnitude of the loss mechanism would have to be a thousand times larger in order to explain the absence of autoignition in SNL/IET-9, 10, and 11.

The model developed in Section F.2 and the prior discussion both assume that atmosphere gas are well mixed. A second bounding state considers that the atmosphere be quite stratified on the time scale of peak pressurization. In particular, we expect hot hydrogen/steam jets to burn as they vent to the dome. These hot gases will continue to rise and stratify at the dome displacing the preexisting atmosphere downwards. Thus, hot gas near the dome is expected to be steam rich with the dominant noncondensible being any residual hydrogen from the jet. The preexisting atmosphere is displaced downwards and remains relatively cool, being heated only by stray debris particles and radiation from the hotter gases. The displaced atmosphere is too cool to autoignite. The compelling experiment evidence for this stratification, is of course, the observed temperature gradients, as illustrated in Figure F.5, in the dome, where temperatures range from $\sim 1500 \mathrm{~K}$ at the dome to $\sim 600 \mathrm{~K}$ on the operating deck.

This additional combustion of preexisting hydrogen likely occurred as a mixing limited process that did not contribute to peak containment pressure. This can be seen by comparing the mixing limited energy release rate with the heat transfer rate to structures,

$$
\frac{\dot{Q}_{H 2}}{\dot{Q}_{H T}}=\frac{X_{H 2} \Delta e_{H 2}}{C_{V} \Delta T} \frac{\tau_{H T}}{\tau_{M X}}-\frac{A_{s, C}}{A_{h}} .
$$

where, 


$$
\tau_{M D} \sim \frac{M_{R C B}^{o}}{\dot{M}_{b}}
$$

The heat transfer time constant is $\sim 40 \mathrm{~s}$ and the mixing time constant $\sim 70 \mathrm{~s}$. In addition, it may be sufficient to cool all regions of the dome to $\sim 800-900 \mathrm{~K}$ to prevent any combustion during mixing. This occurs in $-20 \mathrm{~s}$. Time sequenced gas sampling at various locations in the SNL/IET-11 experiment suggest that the dome is relatively well mixed by $\sim 120 \mathrm{~s}$. Under these conditions, the heat transfer rate exceeds the energy release rate by about an order of magnitude. Thus, this mixing limited combustion, if it occurs, cannot contribute to peak containment pressurization. We note that measured pressures in SNL/IET-11 are substantially less than would be expected based on nearly complete combustion of preexisting hydrogen. Furthermore, equation F.10 indicates that this conclusion is preserved by geometric scaling, thus allowing the experiment observation to be extrapolated to full scale reactor applications. Although we expect these conclusions to be generally applicable, we note that different reactors have different venting arrangements to the dome that might significantly alter the mixing processes. In this regard, we note tht SNL/IET-9, 10, 11 where conducted in Surry geometry.

\section{F.4 Summary}

The autoignition temperature for well mixed atmospheres is insensitive to atmosphere composition and convective losses. Radical destruction at surfaces is a second order effect. A benign autoignition threshold is about $\sim 790 \mathrm{~K}$ at reactor scale and increases with decreasing facility size. Small scale experiments suggest that a more energetic threshold might be in the range of $-1000-1100 \mathrm{~K}$.

Rapid volumetric combustion of preexisting hydrogen on DCH time scales did not occur in large scale experiments conducted under fully prototypic conditions. Any combustion of preexisting hydrogen is largely explained by entrainment into burning hydrogen jets. Stratification of the containment atmosphere is proposed as the mitigating mechanism on DCH time scales. In particular, hot gases venting from the subcompartment 
rise to the dome displacing the cooler preexisting atmosphere downwards with minimal heating. Some mixing limited combustion may occur in more severe DCH events, but this additional combustion of preexisting hydrogen is too slow to contribute to peak containment pressures. With this as the controlling physics, it becomes difficult to envision how autoignition could ever occur; however, we conservatively place the autoignition temperature for NPP analyses at $1100 \mathrm{~K}$. This is the highest of the average dome temperatures measured in the experiments for which autoignition did not occur.

Additional confirmation of this conclusion could be provided by future DCH tests if reliable gas samples are taken in the upper dome. In particular, we seek to show that the condensable fraction is high and that the noncondensible fraction is depleted in oxygen and possibly enriched in hydrogen. Additionally, the test should be conducted at a higher hydrogen concentration to better distinguish between autoignition and entrainment processes.

\section{F.5 REFERENCES}

Conti, R.S. and M. Hertzberg (Sept./Oct. 1988). "Thermal Autoignition Temperatures for Hydrogen-Air and Methane-Air Mixtures, " J. Fire Sci., Vol. 6, pp 348.

Dougherty, E.P. and H. Rabitz (1980). "Computational Kinetics and Sensitivity Analysis of Hydrogen-Oxygen Combustion," J. Chem. Phys., 72(12), 6571-6586.

Lutz, A.E., et al. (1991). SENKIN: A FORTRAN Program for predicting Homogeneous Gas Phase Chemical Kinetics with Sensitivity Analysis, SAND87-8248, Sandia National Laboratories, Albuquerque, NM.

Sheldon, M. (June 1984). Fire Eng. J., 43, 27.

Shepherd, J.E. (Feb. 1985). "Hydrogen-Steam Jet-Flame Facility and Experiments," NUREG/CR-3638, SAND84-0060, Sandia National Laboratories.

Stamps, D.W. and Marshall Berman (1991). "High-Temperature Hydrogen Combustion in Reactor Safety Applications," Nuc. Sci. and Engr., 109, 39-48.

Tamm, H., M. Ungurian and R.M Kumar (July 1987). "Effectiveness of Thermal Ignition Devices in Rich Hydrogen-Air-Steam Mixtures," EPRI NP-5254, Electric Power Research Institute. 
Zabetakis, M.G. (Sep. 1956). "Research on the Combustion and Explosion Hazards of Hydrogen-Water Vapor-Air Mixture," AECU-3327, U.S. Atomic Energy Commission.

\section{F.6 NOMENCLATURE}
$\mathrm{A}_{\mathrm{h}} \quad=\quad$ area of hole in RPV lower head
$\mathrm{A}_{\mathbf{s}}=$ surface area of containment dome
$\mathrm{C}_{\mathrm{v}} \quad=\quad$ molar specific heat of the atmosphere
$\mathbf{M}_{\mathrm{RCB}}^{\circ}=\quad$ mass of containment atmosphere
$\mathbf{N}_{\text {RCB }}^{\circ}=$ moles of gas initially in containment atmosphere
$\mathbf{N}_{\text {RCS }}^{\mathbf{v}} \quad$ moles of gas initially in the reactor coolant system
$\mathrm{T}^{\circ}=$ temperature of the containment heat sinks
$\mathrm{T}_{\mathrm{m}}=$ maximum atmosphere temperature from $\mathrm{DCH}$ without invoking autoignition of preexisting $\mathrm{H}_{2}$
$\mathrm{V}=$ containment volume
$\mathrm{X}_{\mathrm{H} 2}=$ hydrogen concentration
$\Delta \mathrm{e}_{\mathrm{H} 2}=$ molar combustion energy for hydrogen
$\Delta \mathrm{P}_{\mathrm{m}}=$ maximum pressure rise in the containment without autoignition
$\sigma=5.67 \times 10^{-8} \mathrm{~J} / \mathrm{m}^{2 / \mathrm{K}}$, Boltzman constant
$\tau_{\text {ind }}=$ induction time
$\tau_{\text {ind,e }}=$ effective induction time in a temperature decaying atmosphere
$\tau_{\mathrm{HT}}=$ time constant for heat transfer from the atmosphere
$\tau_{\mathrm{MX}}=$ mixing time constant 
Table F.1. Kinetics of hydrogen combustion

$\mathrm{X}_{\mathrm{H} 2}=0.048 ; \mathrm{X}_{\mathrm{H} 20}=0.38 ; \phi=0.20$

\begin{tabular}{||c|c|c|c|c|c||}
\hline \multicolumn{2}{|c|}{ Prior to DCH } & \multicolumn{2}{c|}{ After DCH } & \multirow{2}{*}{$\begin{array}{c}\text { Induction } \\
\text { Time(s) }\end{array}$} & $\begin{array}{c}\text { Reaction } \\
\text { Time(s) }\end{array}$ \\
\cline { 1 - 4 } $\mathrm{T}_{1}(\mathrm{~K})$ & $\mathrm{P}_{1}(\mathrm{ATM})$ & $\mathrm{T}_{2}(\mathrm{~K})$ & $\mathrm{P}_{2}(\mathrm{ATM})$ & 1008 & 1301 \\
373 & 1.974 & 700 & 3.704 & 16.6 & 22.2 \\
373 & 1.974 & 800 & 4.234 & 0.61 & 0.81 \\
373 & 1.974 & 900 & 4.763 & $4.77 \times 10^{-3}$ & $5.81 \times 10^{-3}$ \\
373 & 1.974 & 1100 & 5.821 & & \\
\hline
\end{tabular}

Table F.2. Kinetics of hydrogen combustion $X_{\mathrm{H} 2}=0.02 ; X_{\mathrm{H} 20}=0.70 ; \phi=0.17$

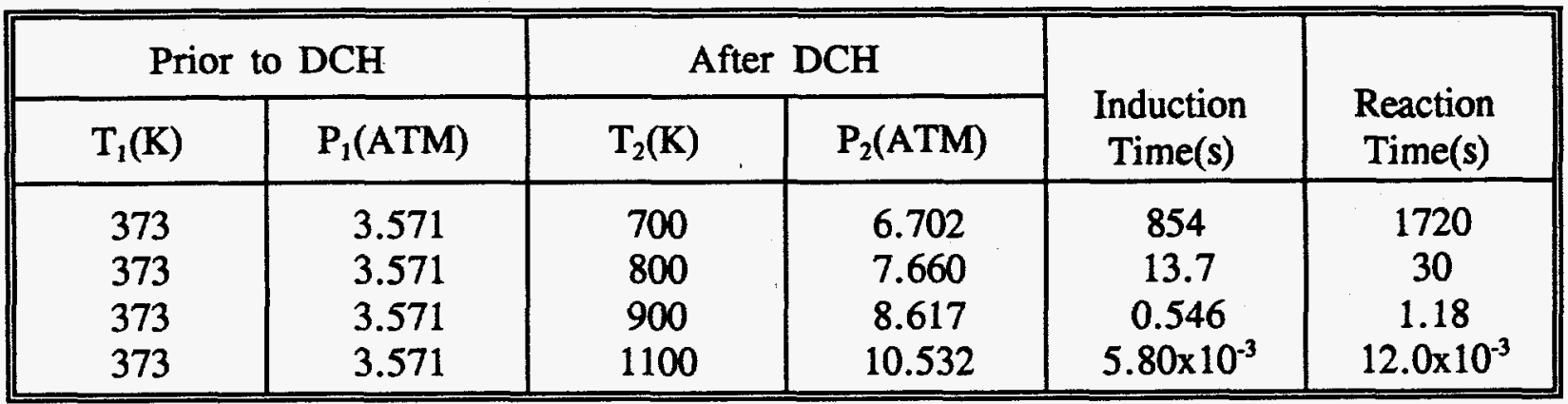

Table F.3. Scale effect on autoignition temperature

\begin{tabular}{|c|c|c|}
\hline & $\tau_{\mathrm{HT}}$ & $\mathrm{T}_{\mathbf{m}}$ \\
\hline ANL/IET $1: 40$ & 10 & 893 \\
\hline SNL/IET $1: 10$ & 40 & 848 \\
\hline NPP 1:1 & 400 & 782 \\
\hline
\end{tabular}

Table F.4. Validation of scale dependence*

\begin{tabular}{|c|c|c|c|}
\hline Volume $\left(\mathrm{m}^{3}\right)$ & Measured $\left(\mathrm{T}_{\mathrm{m}}\right)$ & Predicted $\left(\mathrm{T}_{\mathrm{m}}\right)$ & Percent Difference \\
\hline $1.2 \times 10^{-3}$ & 769 & -- & -- \\
\hline $0.43 \times 10^{-3}$ & 789 & 778 & -1.4 \\
\hline $0.072 \times 10^{-3}$ & 805 & 793 & -1.5 \\
\hline "Data in this table is from Conti and Hertzberg (1988). \\
\hline
\end{tabular}


Table F.5. Combustion of preexisting hydrogen in DCH tests

\begin{tabular}{|c|c|c|c|c|c|}
\hline & SNL/IET-6 & SNL/IET-7 & SNL/IET-9 & SNL/IET-10 & SNL/IET-11 \\
\hline Average dome temp $(\mathrm{K})$ & -700 & $\sim 700$ & $\sim 900$ & -900 & $\sim 1100$ \\
\hline $\begin{array}{c}\text { Autoignition temp (K) } \\
\text { Benign } \\
\text { Energetic } \\
\end{array}$ & $\begin{array}{r}\sim 850 \\
\sim 1100 \\
\end{array}$ & $\begin{array}{r}\sim 850 \\
\sim 1100 \\
\end{array}$ & $\begin{array}{r}\sim 800 \\
-1100 \\
\end{array}$ & $\begin{array}{r}\sim 800 \\
\sim 1100 \\
\end{array}$ & $\begin{array}{r}\sim 800 \\
-1100\end{array}$ \\
\hline Hydrogen concentration & 0.026 & 0.040 & 0.023 & 0.026 & 0.031 \\
\hline Meas. $\Delta \mathrm{P}(\mathrm{MPa})$ & 0.28 & 0.27 & 0.28 & 0.33 & 0.43 \\
\hline $\begin{array}{c}\text { Pred. } \begin{array}{l}\Delta \mathrm{P}(\mathrm{MPa}) \\
\text { all preexisting } \\
\text { hydrogen }\end{array} \\
\end{array}$ & 0.42 & 0.48 & 0.39 & 0.48 & 0.60 \\
\hline
\end{tabular}




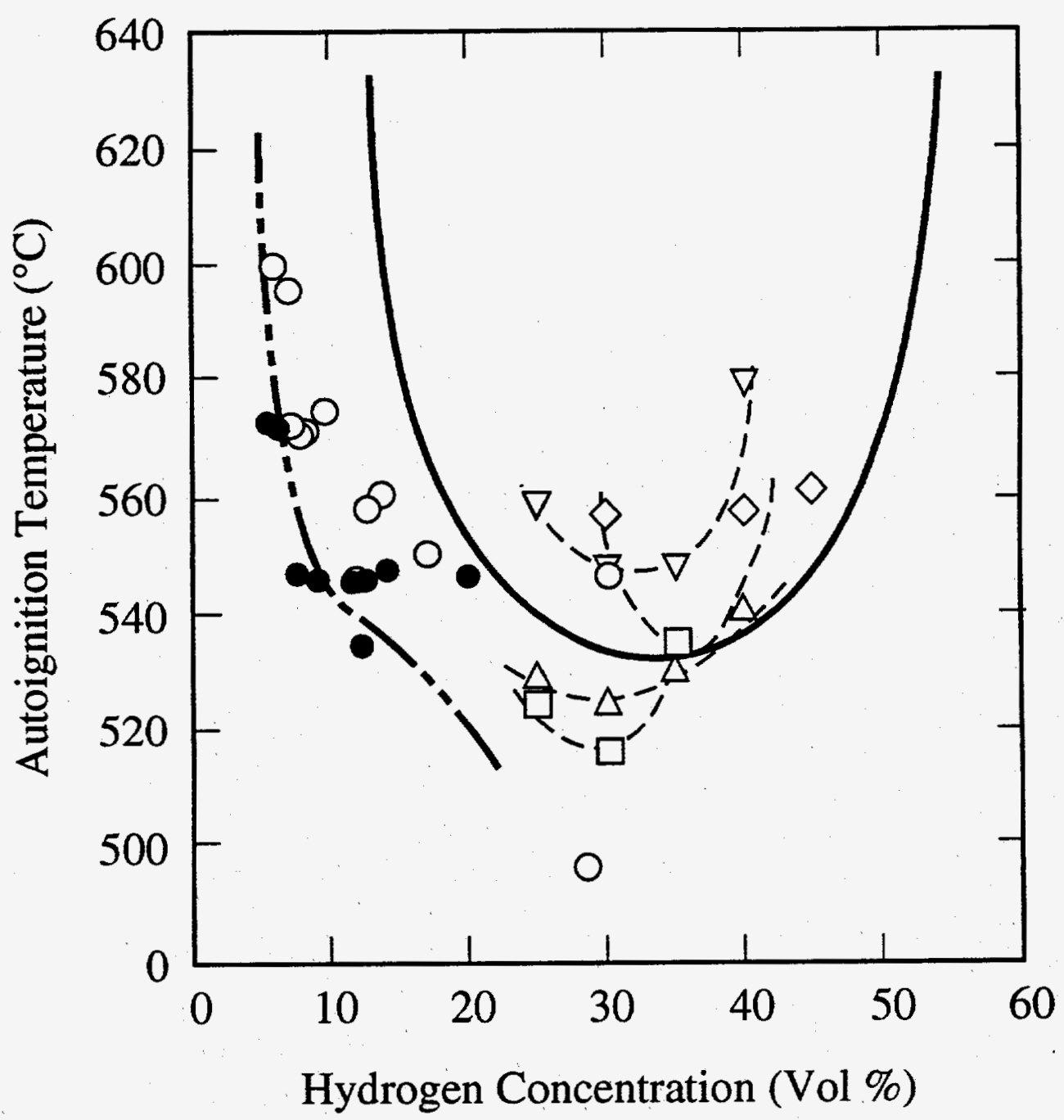

Figure F.1. Reported autoignition temperatures in small scale experiments. 


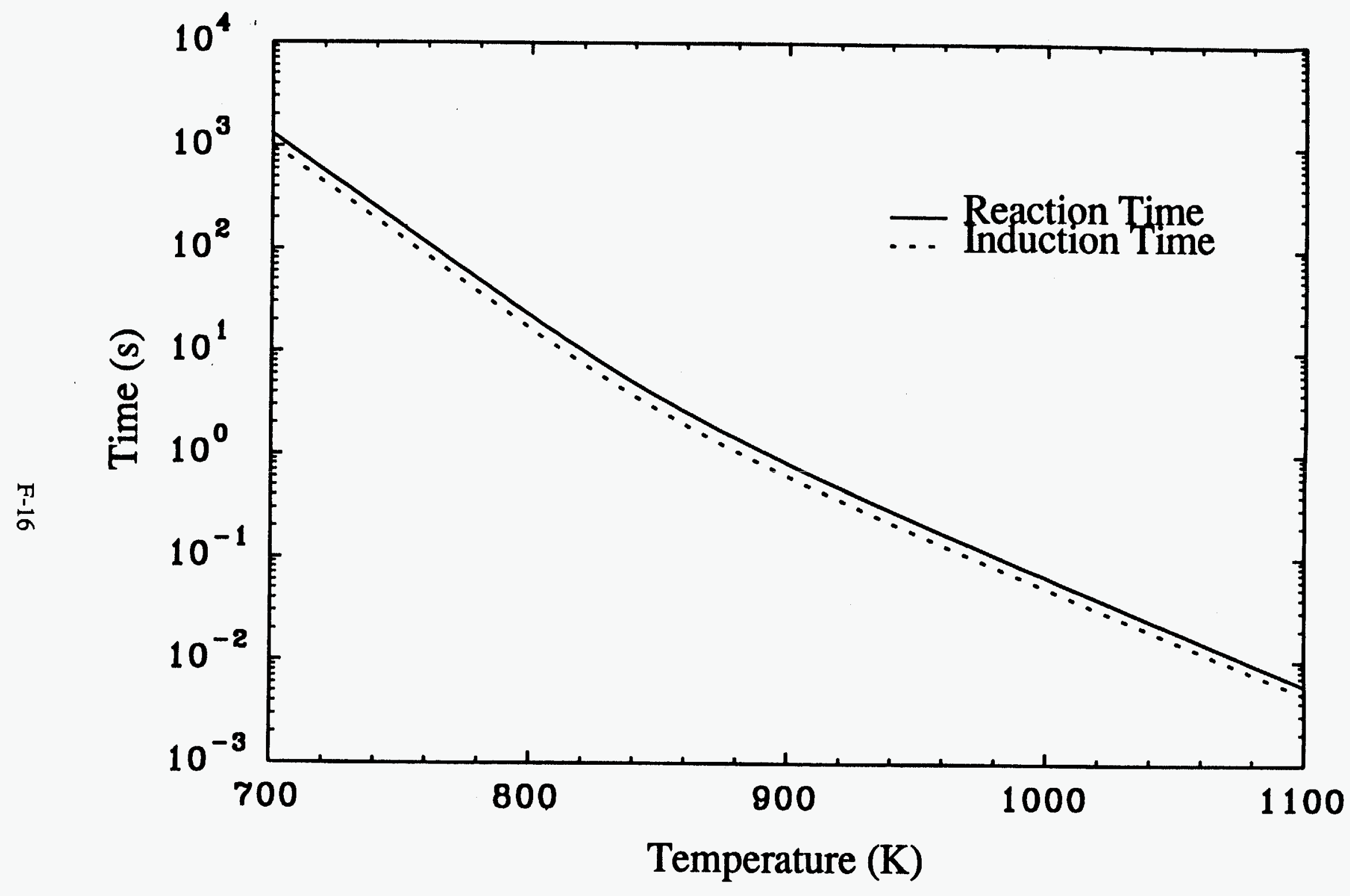

Figure F.2. Case I; SENKIN calculations for volumetric hydrogen combustion

$$
\left(X_{\mathrm{H} 2}=0.048 ; X_{\mathrm{H} 2 \mathrm{O}}=0.38 ; \Phi=0.20\right) \text {. }
$$




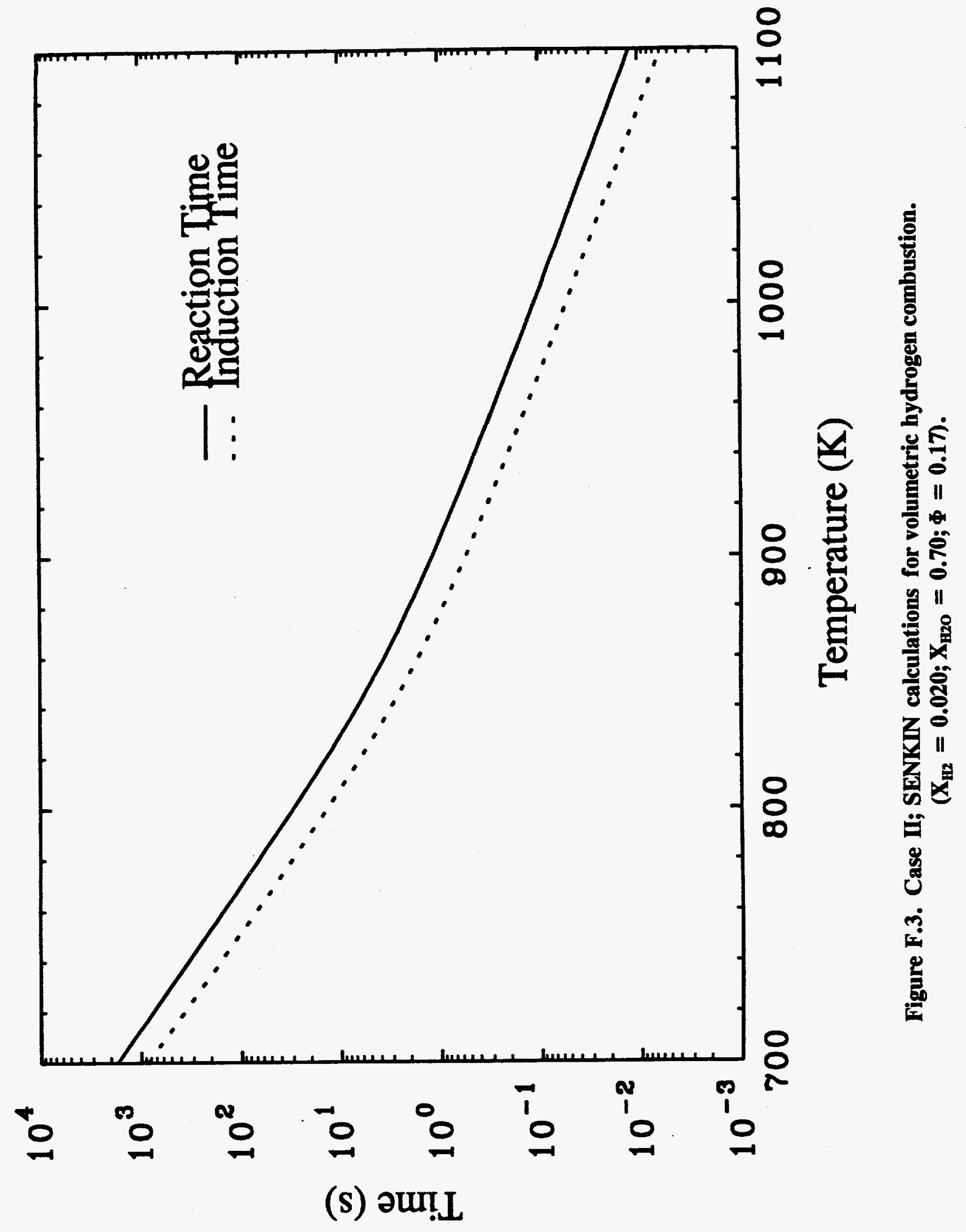




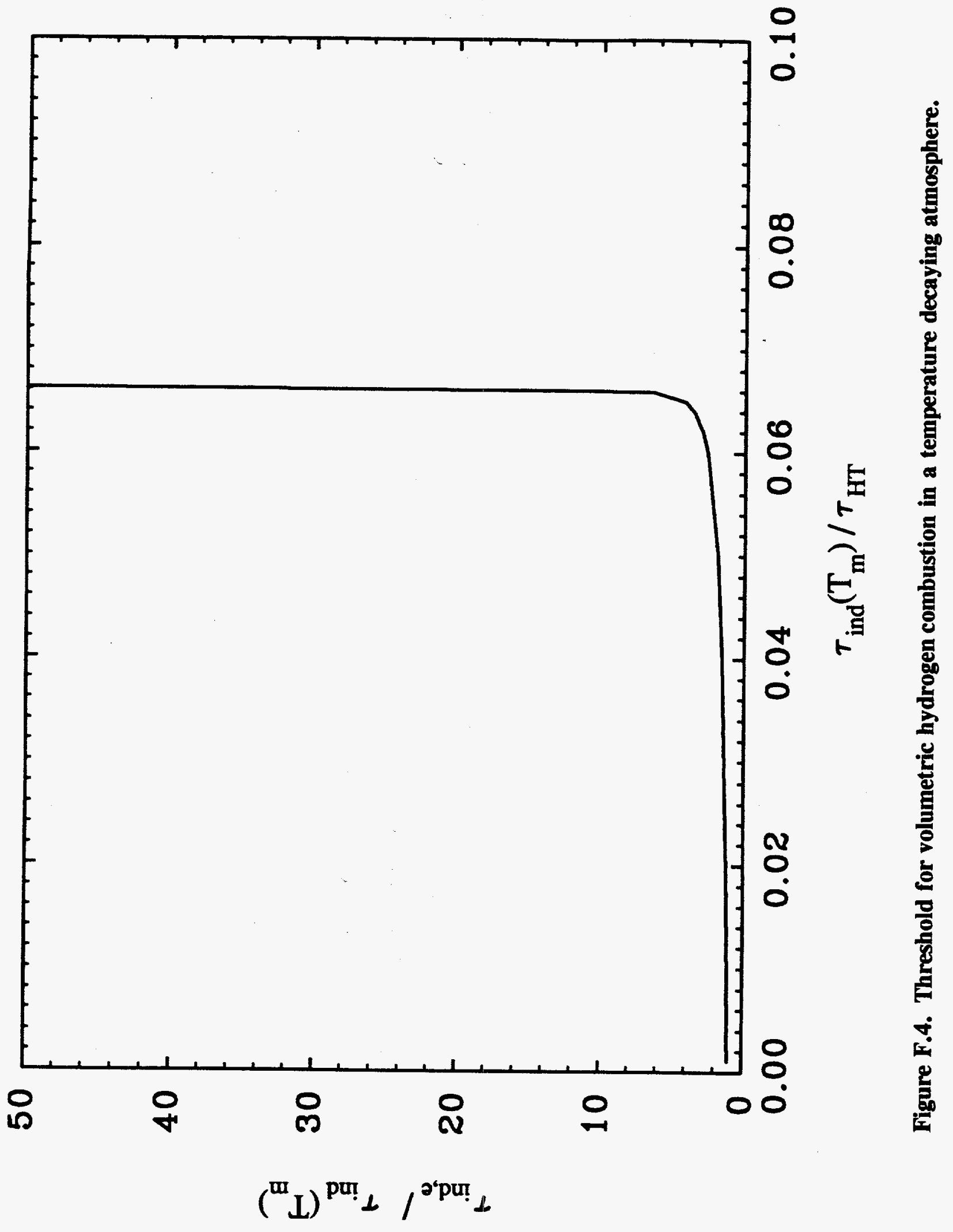

F-18 


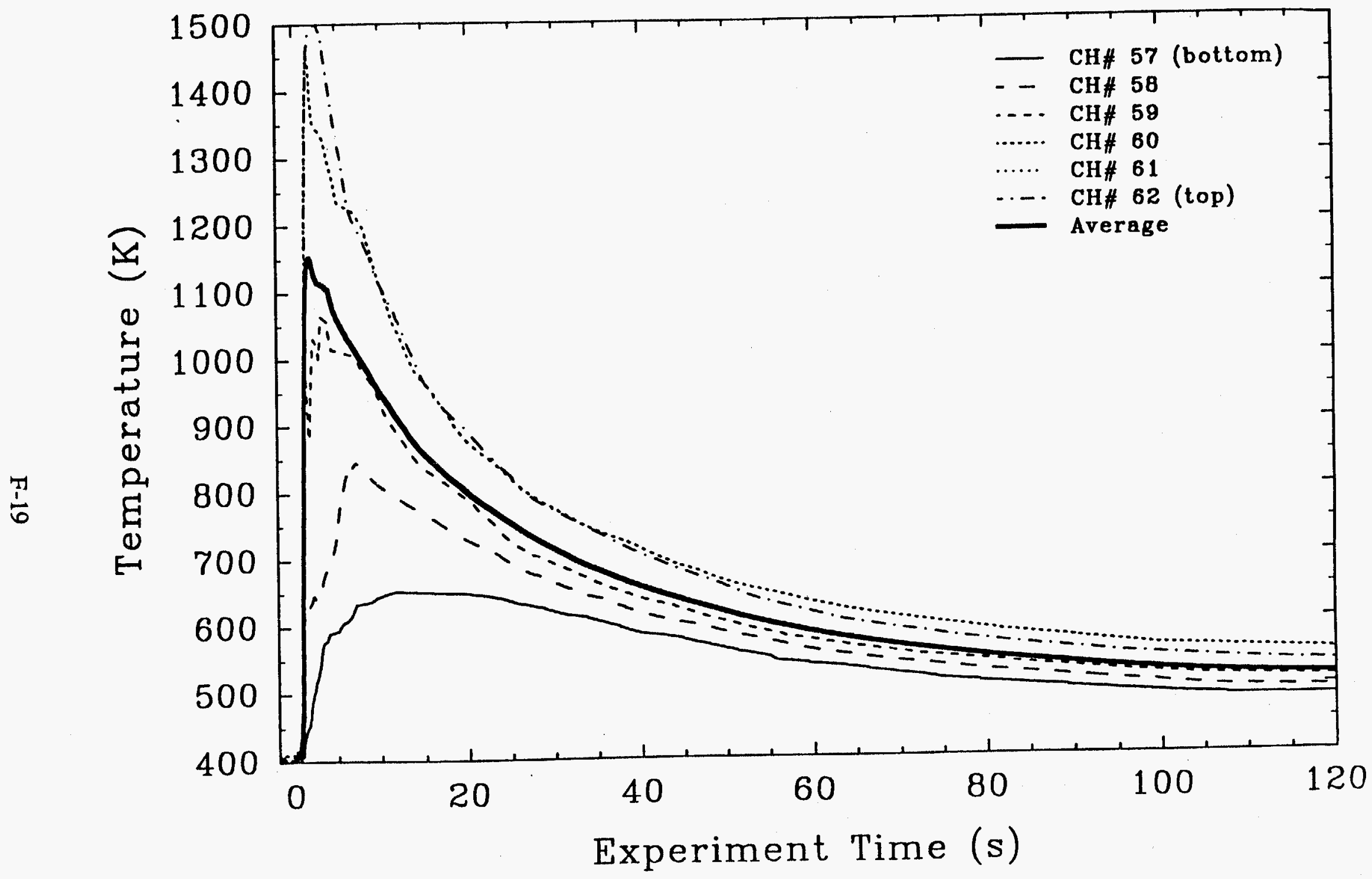

Figure F.5. Temperature history of the upper dome during the IET-10 experiment. 


\title{
APPENDIX G THE SANDIA INTEGRAL EFFECTS TEST SERIES
}

\author{
Thomas K. Blanchat \\ Michael D. Allen \\ Martin Pilch \\ Sandia National Laboratories \\ Robert T. Nichols \\ KTech Corp.
}

\section{G.1 INTRODUCTION}

In a light water reactor core-melt accident, an instrument guide tube penetration in the bottom head of the reactor pressure vessel (RPV) may fail while the primary system is pressurized. The aperture formed in the RPV by tube ejection can lead to the rapid expulsion of molten core debris into the reactor cavity. The blowdown of the reactor coolant system (RCS) may then break up core debris into particles which can be entrained in the high-velocity steam blowdown gas and ejected from the cavity into the reactor containment building (RCB). This chain of events is called a high-pressure melt ejection (HPME). As the fragmented, molten debris is dispersed into the RCB, three mechanisms may cause a rapid increase in pressure and temperature: (1) efficient debris-to-gas heat transfer, (2) exothermic metal/oxygen reactions, and (3) hydrogen combustion. These processes leading to increased loads on the containment building are referred to as direct containment heating $(\mathrm{DCH})$. Understanding factors that enhance or mitigate $\mathrm{DCH}$ is necessary because the load imposed on the RCB may potentially threaten its integrity.

The Surtsey Test Facility at Sandia National Laboratories (SNL) is used to perform scaled experiments that simulate hypothetical HPME accidents in a nuclear power plant (NPP). These experiments are designed to investigate the phenomena associated with DCH. High-temperature, chemically reactive melt is ejected by high-pressure steam into a 1:10 linear scale model of a reactor cavity. Debris is entrained by the steam blowdown into the Surtsey vessel, where specific phenomena, such as the effect of subcompartment structures, 
water in the cavity and on the containment basement floor, and hydrogen generation and combustion, can be studied.

A series of Integral Effects Tests (IET) was funded by the NRC to investigate the effect these phenomena have on the peak pressure increase in a HPME. Condensate levels of water were present on the scaled reactor cavity floor in the majority of the tests. Water was also on the containment basement floor inside the crane wall for some tests. Prior to the HPME, the Surtsey vessel atmosphere was either inert or reactive. In certain tests, the vessel contained preexisting hydrogen. The preexisting hydrogen represented levels produced by partial clad oxidation during the core degradation process in a pump seal loss-of-coolant accident.

\section{G.2 EXPERIMENT DESCRIPTION}

Figure G.1 is a composite view of the Surtsey vessel, the HPME delivery system, and the subcompartment structures used in the IET experiments. This figure shows the instrument penetration ports at six levels in the Surtsey vessel. The circled numbers in Figures G.1 through G.3 correspond to the channel numbers in the data acquisition system.

The Surtsey IET tests (Allen et al., 1992c,d,e,f,g,h) were conducted with 1:10 linear scale models of the primary structures in the Zion Nuclear Generating Station, including the RPV, cavity, in-core instrument tunnel, and subcompartment structures. The RPV was

modeled with a melt generator that consisted of a steel pressure barrier, a cast $\mathrm{MgO}$ crucible, and a thin steel inner liner. The melt generator/crucible had a hemispherical bottom head containing a graphite limitor plate with a $3.5-\mathrm{cm}$ exit hole to simulate the ablated hole in the RPV bottom head that would be formed by ejection of an instrument guide tube and hole ablation in a severe NPP accident.

The cavity used in the IET tests was designed to withstand internal pressures of 6.9 MPa with a safety factor of 4 (Figure G.2). The inclined portion of the instrument 
tunnel entered the bottom head of Surtsey at a 26 degree angle from vertical, as it does in Zion. A false concrete floor was constructed in the Surtsey vessel similar to the floor of the Zion basement so that the inclined portion of the instrument tunnel was about 2.7 times the correct scaled length of the Zion instrument tunnel.

The subcompartment structures included 1:10 linear scale models of the crane wall, four steam generators, four reactor coolant pumps (RCP), the opening in the floor of the seal table room for the instrument guide tubes, the seal table room, the biological shield wall, the refueling canal, the radial beams and the gratings àt the RCP deck, and the operating deck (Figure G.3). The steam generators, RCPs, and gratings were made of steel, and the other structures were constructed of reinforced concrete. All of the structures were painted with an epoxy-base paint commonly used in U.S. nuclear reactors.

The steam accumulator tank was typically pressurized to $\approx 6.3 \mathrm{MPa}$ with superheated steam. After the pressurization sequence, the iron oxide/aluminum/chromium thermite mixture was ignited remotely with a braided wire fuse placed on top of the compacted thermite. After the thermite was ignited, the pressure in the crucible rapidly increased. This pressure increase verified that the thermite reaction had started and signaled the operator to fail the burst diaphragm separating the steam accumulator tank and the molten thermite in the melt generator. This brought superheated steam into contact with the molten thermite. Upon contacting and failing a fusible brass plug at the bottom of the crucible, the molten thermite in the crucible was expelled by high-pressure steam into the cavity.

Zero time for HPME was set by the data acquisition system as the time at which the melt failed the brass plug and entered the cavity. This event was signaled by a photodiode located at the melt plug exit. When the hot melt burst through the brass plug, the intense light emitted from the melt caused the photodiode to emit a signal that was used to mark the initiation of the HPME. 


\section{G.2.1 Initial Conditions}

The majority of the IET tests were conducted with the following initial conditions: (1) the melt simulant was $43 \mathrm{~kg}$ of iron oxide/aluminum/chromium powder; (2) the driving gas was $\approx 500 \mathrm{~g} \cdot$ moles of superheated steam $(\approx 580 \mathrm{~K})$ at an initial absolute pressure of 6.3 MPa; and (3) the initial absolute pressure in the Surtsey vessel was $\approx 0.2 \mathrm{MPa}$. The Surtsey vessel gas concentrations were varied. The cavity contained either a scaled condensate level of water or was one-half full, and the containment basement floor was either dry or contained a scaled condensate level of water. Table G.1 lists the exact initial conditions for all of the IET experiments.

Some of the IET experiments were intended to simulate scenarios in which the Zion containment atmosphere contained preexisting hydrogen. The flammability limits of hydrogen/oxygen/diluent mixtures are required to predict the consequences of certain lossof-coolant accidents in which hydrogen combustion can be a factor. Knowing the flammability limits will allow assessment of the severity of any possible damage due to hydrogen combustion in an accident situation. Figure G.4 shows a hydrogen/oxygen/nitrogen flammability chart (Kumar, 1985). Hydrogen concentrations inside the envelope are combustible. Typically, the Surtsey vessel ambient atmosphere, even with preexisting hydrogen, was on the edge of the envelope, hence global combustion of hydrogen probably would not occur.

Hydrogen produced in the cavity may possibly burn as a jet as it vents from the subcompartments to the upper dome. Initially, the composition of the hydrogen/oxygen/nitrogen jet is the same as the composition of the containment atmosphere. During the reactor coolant system (RCS) blowdown, hydrogen produced during the HPME can enrich the hydrogen fraction in the jet, but the relative portions of oxygen and nitrogen remain the same. Figure G.4 shows a line drawn from a 100 percent hydrogen concentration to the ambient atmosphere condition of the vessel during the IET-7 test. The line represents the locus of all possible jet combinations that start at the vessel ambient 
conditions. This line indicates there is a potential 'for combustion as the hot jet mixes with the atmosphere.

Flammability criteria are shown in Figure G. 4 for $295 \mathrm{~K}$ and $473 \mathrm{~K}$. The DCH event will heat the containment atmosphere. The hydrogen jet can also be heated significantly by DCH processes in the subcompartment structures. The IET experiments investigated the potential for the HPME event to burn preexisting hydrogen on a time scale that will contribute to the peak pressure.

\section{G.2.2 Measurements and Instrumentation}

The most significant variables measured in the IET experiments were: (1) the increase in pressure and temperature in the Surtsey vessel, (2) the cavity pressure, (3) the number of $\mathbf{g} \cdot$ moles of hydrogen generated by the reaction of metallic debris with steam driving gas and water in the cavity, (4) the debris particle size, and (5) the mass of debris recovered from the Surtsey vessel. The instrumentation and techniques used to make these measurements are described in the sections below.

\section{G.2.2.1 Pressure Measurements}

Six pressure transducers with a range of 0-0.69 MPa, two at each level 1,3 , and 5 (channels 21 through 26 in Figure G.1), were used to measure the pressure in the upper dome of the Surtsey vessel. These transducers were mounted in tapped holes in instrument penetration ports in the sides of the Surtsey vessel. The tapped holes were filled with steel turnings to protect the sensing ends from direct impact with molten debris. Pressure transducers with a range of $0-6.9 \mathrm{MPa}$ were used to measure the gas pressure in the accumulator tank, in the space between the rupture disks of the burst diaphragm (channel 33 in Figure G.2), and in the crucible above the thermite (channels 34 and 35 in Figure G.2). A pressure transducer with a range of 0-1.4 MPa was used to measure the gas pressure in the scaled reactor cavity (channel 36 in Figure G.2). Pressure transducers with 
a range of $0-0.69 \mathrm{MPa}$ were used to measure the gas pressure in the subcompartment structures and in the seal table room (channels 39 and 40 in Figure G.3). These transducers were metal diaphragm strain gauge-type pressure transducers (Model 141-1, Precise Sensor, Inc., Monrovia, CA). In addition, two pressure transducers were embedded in the concrete walls of the round section of the cavity under the melt generator (labeled P1 and P2 in Figure G.2), and were piezoelectric-type gauges with a range of 0-6.9 $\mathrm{MPa}$. The specified accuracy from the manufacturer for the pressure transducers is less than \pm 0.50 percent at full-scale output. These instruments are routinely recalibrated at SNL against instruments traceable to the National Institute of Standards and Technology, and accuracies are always within the manufacturer's specifications. The frequency response is $22 \mathrm{kHz}$ (16 $\mu$ s rise time) for the 0-0.69 $\mathrm{MPa}$ range pressure transducers and $36 \mathrm{kHz}$ (10 $\mu \mathrm{s}$ rise time) for the 0-6.9 MPa range pressure transducers. The data acquisition system recorded data from the pressure transducers at a rate of 1400 data points per second per channel from thermite ignition to about $60 \mathrm{~s}$ following the HPME transient.

\section{G.2.2.2 Temperature Measurements}

During the HPME transient, the gas temperatures in the Surtsey vessel were measured with five aspirated thermocouple assemblies. An aspirated thermocouple assembly consisted of three bare type- $K$ thermocouples $(0.127-\mathrm{mm}$ wire) mounted in an anodized aluminum tube. Each tube was opened with a solenoid-operated valve that was actuated remotely by a signal from the photodiode under the melt plug immediately after the HPME transient. One of these assemblies was installed through instrumentation ports at each level 1,3, and 5 (channels 41 through 49 in Figure G.1). A thermocouple assembly was also installed through the refueling canal wall just above the radial concrete beam on the same side as the instrument tunnel exit. This thermocouple assembly was used to measure gas temperature inside the subcompartment structures (channels 51,52, and 53 in Figure G.3). Another thermocouple assembly was installed through the crane wall into the seal table room (channels 54,55, and 56 in Figure G.3). Calculations by SNL have shown that the worst-case temperature underprediction by the thermocouple assemblies would be 
13 percent at the beginning of the HPME event when the gas temperatures are low to 6 percent at equilibrium when the gas temperatures have peaked (Blanchat, 1992).

One type-K thermocouple array (channels 68 through 77 in Figure G.3) was installed in the Surtsey vessel in the IET-7, IET-8A, and IET-8B tests to measure bulk gas temperature above the operating deck. The array consisted of ten approximately equally spaced thermocouples. The array was suspended above the refueling canal at vessel centerline. In the IET-4, IET-5, and IET-6 tests, two arrays with five equally spaced thermocouples were installed. One was suspended near the northeast vent above RCP 1C and the other was located near the west end of the refueling canal. All type-K thermocouples were made of $0.254-\mathrm{mm}$ wire with a $1.6-\mathrm{mm}$ sheath. The temperature range was $273 \mathrm{~K}$ to $1523 \mathrm{~K}$. The maximum limit of error using the manufacturer's calibration is $\pm 9.4 \mathrm{~K}$ at $1523 \mathrm{~K}$ with a 0.3 -s time constant. The thermocouples had the sheath removed at the tip, exposing the junction to ensure a fast time response. The thermocouples were located $\approx 1.8 \mathrm{~m}$ from the Surtsey vessel wall.

Four type-K thermocouples were installed inside the triangular vent space above the 1A, 1B, 1C, and 1D RCPs (channel 67 in Figure G.3). These thermocouples measured the temperature of the gas as it exited the subcompartment structures. Four type-K thermocouples were installed approximately $10 \mathrm{~cm}$ below the 1A, 1B (channel 12 in Figure G.3), 1C, and 1D RCPs. These thermocouples measured the temperature of the gas as it flowed through the subcompartment structures.

The temperature of the driving gas in the steam accumulator tank was measured using two type- $\mathrm{K}$ thermocouples that extended through the accumulator shell and were secured in place using pressure-tight fittings. Measurements from these thermocouples were important because the measured temperature and pressure in the accumulator tank were used to calculate the number of $g \cdot$ moles of steam driving gas.

Two pyrometers (channels 37 and 83 in Figure , G.3) were used to measure the temperature of the debris as it exited the instrument tunnel exit. An optical pyrometer (type 
$11 \times 20$, Ircon Inc., Niles, IL) was located inside the biological shield wall and was focused just above the instrument tunnel exit through a fused silica window sealed inside the biological shield wall. Another optical pyrometer (type 11x30, Ircon Inc., Niles, IL) was located outside the crane wall and was focused through a fused silica window sealed inside the crane wall. The focal point was the window surface, which was directly in the flight path of the debris ejected from the cavity. A debris emissivity of 0.9 was assumed when converting the results in $\mathrm{mV}$ from the optical pyrometers to temperature in $\mathrm{K}$. A debris emissivity near the blackbody value was assumed because the debris appeared black when inspected posttest. The calculated debris temperature is not very sensitive to the assumed debris emissivity. For example, at approximately $2000 \mathrm{~K}$ a 13 percent change in the assumed emissivity resulted in only a 1.9 percent change in the calculated debris temperature.

The optical pyrometers had a response time of $1.5 \mathrm{~ms}$ to 95 percent of their full range. A low-range controller was installed on the $11 \times 20$ pyrometer, and a high-range controller was installed on the $11 \times 30$ pyrometer for the IET tests. The low-range controller could measure temperatures between $1323 \mathrm{~K}$ and $1773 \mathrm{~K}$, and the high-range controller could measure temperatures between $1873 \mathrm{~K}$ and $2773 \mathrm{~K}$ with a specified accuracy of 1 percent of the full-scale temperature. In a transient event such as a HPME experiments, the accuracy of the pyrometer measurements was expected to be no better than $\pm 25 \mathrm{~K}$. The pyrometers were factory calibrated and the type $11 \times 30$ pyrometer is routinely recalibrated (with the fused silica window) by the Sandia Radiant Heat Facility. The type $11 \times 20$ optical pyrometer is sealed inside the biological shield wall, and thus it cannot be recalibrated.

Data points from the thermocouples and the pyrometers were recorded by the data acquisition system at a rate of 10 per second prior to thermite ignition. Then, just prior to thermite ignition, the data acquisition system was switched to the fast data acquisition mode, in which data points were recorded at a rate of 1400 per second. 


\section{G.2.2.3 Gas Composition}

Pre-evacuated $500-\mathrm{cm}^{3}$ gas grab sample bottles were used to collect samples from the vessel (labeled L2, L4, L6, and B in Figures G.1 and G.3) and cavity (labeled C in Figure G.2) at several locations and times. Three background samples at levels 2, 4, and 6 were obtained by opening solenoid valves remotely for $10 \mathrm{~s}$ just prior to ignition of the thermite. Three gas grab sample bottles located at levels 2,4 , and 6 were opened remotely for $10 \mathrm{~s}$ at 2 minutes after the HPME. Three gas grab sample bottles at levels 2, 4, and 6 were opened manually for $10 \mathrm{~s}$ at $\approx 30$ minutes after the HPME. In IET-8A, the 2 minute sample occurred at $30 \mathrm{~s}$ and the 30-minute samples were taken at 900 minutes. Also, in IET-8B, three additional gas grab sample bottles located at levels 2, 4, and 6 were opened remotely for $10 \mathrm{~s}$ at $15 \mathrm{~s}$ after the HPME. One background sample inside the subcompartment structures was obtained by opening a solenoid valve remotely for $10 \mathrm{~s}$ just prior to ignition of the thermite. Three gas grab samples were taken from inside the subcompartment structures: two were opened $2 \mathrm{~s}$ after the HPME and remained open for $5 \mathrm{~s}$, and one was opened 2 minutes after the HPME for $10 \mathrm{~s}$. In addition, one background gas grab sample was obtained from the cavity, and two gas grab samples were taken from the cavity following the HPME: one was opened as the HPME was initiated and remained open for $2 \mathrm{~s}$, and the other was opened at $0.5 \mathrm{~s}$ following the HPME and remained open for $2 \mathrm{~s}$ (labeled $\mathrm{C}$ in Figure G.2). The gas samples were analyzed using gas mass spectroscopy by Battelle Pacific Northwest Laboratories in Richland, WA.

\section{G.2.2.4 Posttest Debris Recovery}

The total debris mass dispersed into the Surtsey vessel and the debris mass in specific locations were determined by a very careful posttest debris recovery procedure. The following measurements were made: (1) the mass of the molten debris in the cavity and inclined portion of the instrument tunnel; (2) the mass on the horizontal surfaces outside the subcompartment structures; (3) the mass on the vertical surfaces outside the subcompartment structures; (4) the mass recovered from the floor inside the structures; (5) 
the mass recovered from the horizontal surfaces other than the floor inside the structures; (6) the mass recovered from the vertical surfaces inside the structures; (7) the mass recovered from the doorways inside the structures; (8) the mass recovered from the seal table room; (9) the mass recovered from the rooms adjacent to the seal table room; and (10) the mass recovered from the melt generator/crucible.

\section{G.2.2.5 Cameras}

Typically, two high-speed 16-mm cameras were used. Two cameras were mounted outside the Surtsey vessel: one on the top port, and one on the level 3 port. In IET-5, IET-6, and IET-7, a high-speed camera was mounted inside the vessel. The camera inside the Surtsey vessel was located outside the crane wall and viewed a grid in front of the chute exit. The grid (2.54-cm squares) was constructed of $1.65-\mathrm{mm}$-diameter buss wire (tinned copper). The purpose of this camera was to determine if the subcompartment structures filled immediately with aerosols, thus obstructing the optical pyrometers. This camera was also used to obtain information concerning the debris flow regime and velocity. In addition to the high-speed cameras, two camcorders were used. One camcorder was mounted on the top port of the Surtsey vessel and focused downward to film the HPME event, and the other camcorder was set up outside to view the overall vessel and high-pressure melt ejection system.

\section{G.3 EXPERIMENTAL RESULTS}

\section{G.3.1 Blowdown History}

In the IET experiments, the free volume in the crucible and in the $10-\mathrm{cm}$-diameter pipe above the crucible (volume $=0.018 \mathrm{~m}^{3}$ ) was purged with nitrogen. The accumulator tank (volume $=0.29 \mathrm{~m}^{3}$ ) was pressurized with superheated steam to $\approx 6.3 \mathrm{MPa}$. The thermite was ignited at about $-10 \mathrm{~s}$. Crucible pressure started to rise, and at $\approx 0.4 \mathrm{MPa}$, the 
burst diaphragm separating the steam accumulator tank and the molten thermite was failed remotely by the operator. This brought steam into contact with the molten thermite a few seconds before the HPME. The number of $g$-moles of steam driving gas was calculated at HPME initiation ( $t=0 \mathrm{~s}$ ) using accumulator steam pressure, temperature, and volume. At $t=0 \mathrm{~s}$, the steam pressure was normally about $6.3 \mathrm{MPa}$, the steam temperature near 580 $\mathbf{K}$, and the volume of the accumulator tank plus the piping and void in the crucible was $0.308 \mathrm{~m}^{3}$. Therefore, the steam driving gas was calculated for each of the IET experiments and was usually about $500 \mathrm{~g} \cdot$ moles (Table G.2).

The steam blowdown from the accumulator tank was complete at $\approx 4 \mathrm{~s}$ for all of the IET tests, with the exception on the IET-8A test. The steam driving system was not used in the IET-8A experiment. The nitrogen purge gas above the crucible rose in pressure when the thermite ignited. This gave a total of about $4 \mathrm{~g}$-moles of driving gas when the melt plug failed. In IET-8A the molten thermite flowed under gravity through the hole in the melt generator into the reactor cavity model, which was half filled with water.

\section{G.3.2 Surtsey Vessel Pressure}

Figure G.5 compares the Surtsey vessel pressure measured in the IET experiments. The initial absolute pressure was $\approx 0.20 \mathrm{MPa}$, as listed in the table of initial conditions (Table G.1). The pressures measured at levels 1,3 , and 5 in the Surtsey vessel with three different pressure transducers were virtually identical. Table G.2 lists the peak pressure increase in the IET experiments. The peak pressures were reached at $\approx 3 \mathrm{~s}$ after the beginning of the HPME transient.

The effect of hydrogen combustion and driving pressure are readily seen in Figure G.5. In IET-1 and 1R, the vessel was inerted with nitrogen, and the hydrogen

produced by the steam reaction with the metallic debris during the accumulator blowdown could not burn. The measured peak pressure increases in IET-1 and IET-1R were $98 \mathrm{kPa}$ and $110 \mathrm{kPa}$, respectively. In IET-5, the vessel was "classicallyinerted" with carbon dioxide 
(a steam surrogate), and preexisting hydrogen was present. Very little hydrogen combustion occurred; the peak pressure increase measured in IET-5 was $100 \mathrm{kPa}$, which is similar to the fully inerted cases, IET-1 and IET-1R. With essentially no driving gas (IET-8A), a peak pressure increase of $100 \mathrm{kPa}$ was measured. When the hydrogen was allowed to burn (IET-3, IET-4, IET-6, IET-7, and IET-8B), pressure increases of 240-280 kPa were measured, indicating a significant contribution to containment pressurization. Higher peak pressures might be expected in the tests with preexisting hydrogen in the vessel.

This result indicates that the preexisting hydrogen combustion did not burn on the same time scale as the HPME, and thus did not contribute significantly to the peak pressure increase in the Surtsey vessel.

\section{G.3.3 Cavity Pressure}

The timing of debris ejection from the cavity into the subcompartment structures is important when analyzing a HPME/DCH event and is best understood by comparing the cavity pressure with the Surtsey vessel pressure. Figure G.6 is a plot comparing the cavity pressures measured in the IET-1, IET-3, IET-8A, and IET-8B experiments. IET-1 and IET-3 represent the majority of the tests; IET-8A and IET-8B used a cavity half filled with water. In these experiments, a small initial pressure spike was caused by efficient gas heating and gas expansion due to molten brass, steel, and thermite entering the cavity. The second peak in the IET-1 experiment was apparently due to a steam explosion. The second peak in the IET-3 experiment was due to rapid vaporization of water, and lagged the explosion peak because the vaporization process was slower than a steam explosion. The third peak in all the tests was the result of debris entrainment from the cavity by the steam blowdown. The debris entrainment interval lasted $\approx 0.4 \mathrm{~s}$, whereas steam blowdown lasted $\approx 4 \mathrm{~s}$ in all of the IET tests. Steam explosions in the cavity did not result in an increase in the vessel pressure. Steam explosions were seen in IET-8A and IET-8B. A delayed steam explosion occurred in IET-8A near the end of the molten pour into the cavity half filled with water. The $4 \mathrm{MPa}$ pressure spike was the largest recorded in all the IET tests. A series of 
steam explosions was seen in IET-8B. The explosions began immediately after the HPME initiation and continued throughout the blowdown of melt from the crucible, yielding the highest integrated pressure recorded in the IET test series.

\section{G.3.4 Video Results and Interpretation}

The high-speed video cameras viewed the HPME through Plexiglas ports (Figure G.1) installed in the top head of the vessel and at level 3. A bright orange plume was seen in the upper dome of the Surtsey vessel in all the tests that had a reactive atmosphere ( 9 to 10 mole percent $\mathrm{O}_{2}$ ), indicating that a hydrogen burn did occur. Individual luminous molten debris particles were ejected from the subcompartment structures and were observed moving toward the upper dome of the Surtsey vessel. The following gives a synopsis of typical observations from the high-speed cameras. At about $0.2 \mathrm{~s}$, a brief, faint orange gas jet came into view and was probably a hydrogen burn from the seal table room plug opening or the RCP $1 \mathrm{C}$ vent. At about $0.4 \mathrm{~s}$, a broader and brighter orange gas jet appeared. Molten particles could be seen rising in the gas jet. At about 1 second, molten particles began to fall. The gas burn started to dissipate at about $1.5 \mathrm{~s}$, and by $2.5 \mathrm{~s}$ the view was obscured by high aerosol concentrations.

The top port camcorder showed aerosols exiting the seal table room plug opening and the crane wall doorway $(t=0.03 \mathrm{~s})$. The second frame showed that the RCP vents in the operating deck floor were filled with aerosols. The third frame showed that the vessel was filled with aerosols to a level slightly above the steam generators $(t=0.10 \mathrm{~s})$. Bright, white plumes were seen at the plug opening, RCP $1 \mathrm{~A}$ and $1 \mathrm{C}$ vents, and at the crane wall doorway by $0.16 \mathrm{~s}$.

\section{G.3.5 Debris Recovery}

Debris in the Surtsey vessel was recovered from four basic locations: (1) from inside the subcompartment structures, i.e.inside the crane wall below the operating deck, (2) from 
the Surtsey vessel outside the structures, (3) from the cavity and instrument tunnel chute, and (4) from the crucible. Table G.2 gives the amount of debris dispersed into Surtsey in the IET experiments. The total molten mass available for dispersal into the vessel is usually about 20 percent greater that the initial thermite charge due to the melting of the inner wall of the crucible, vaporization of the fusible brass plug, ablation of concrete in the cavity and structures, and oxidation of metallic debris. Table G.2 also gives the results of the posttest sieve analysis (sieve mass median diameter) using debris recovered from the Surtsey vessel outside the subcompartment structures. The particle size analysis discounted all debris with size $>9.4 \mathrm{~mm}$.

\section{G.3.6 Debris Temperature Measurements}

The type-C thermocouple installed on the cavity wall was mounted behind a small ridge of concrete and was thus protected from direct exposure to airborne debris. Therefore, this thermocouple was measuring gas temperature in the cavity. The debris gas temperature reached $\approx 1600-1700 \mathrm{~K}$. The type- $\mathrm{C}$ thermocouple installed at the seal table room floor opening and at the debris flight path contact point on the crane wall typically gave a debris peak temperature of $\approx 2200-2300 \mathrm{~K}$.

Two optical pyrometers were used in the IET experiments to measure the temperature of the debris. A peak debris temperature of about $1600 \mathrm{~K}$ was measured for the type $11 \times 20$ pyrometer installed inside the biological shield and focused on the chute exit. A peak debris temperature of about $2200-2300 \mathrm{~K}$ was measured by the type $11 \times 30$ pyrometer. Debris temperature measurements of $2300 \mathrm{~K}$ were determined during the LFP and WC tests (Allen et al., 1991; Allen et al., 1992a,b). The lower temperatures determined by the optical pyrometer focused above the chute exit in the IET tests may have been caused by trapped aerosols in the subcompartment structures that obscured the optical path between the sensing head and the focal point above the chute exit. The flow area for aerosols out of the subcompartment is 15 percent of the flow area around the structure used 
in the LFP tests (Allen et al., 1991), and the flow path is much more tortuous. The video films confirm that the structures were completely filled with high aerosol concentrations.

\section{G.3.7 Gas Temperature Measurements}

Figure G.7 shows the measured temperatures in the triangular vent spaces above the 1A RCP plotted against time for the IET tests. The peak temperature in the 1A vent space normally reached about $1000 \mathrm{~K}$ regardless of hydrogen combustion. In IET-1, the thermocouple was bent away from the vent opening by the steam explosion and thus the reading was low. Molten debris impacted the thermocouple in IET-3 and gave a high temperature measurement. These temperatures are well below combustion temperatures, indicating the gas jet was burning above the vent opening. Large amounts of water in the cavity in IET-8A and IET-8B limited the gas temperature in the vent space to near saturation values.

Gas temperatures from the vessel dome thermocouple arrays are shown in Figure G.8. These thermocouples measured temperatures from the operating deck to above level 6. Typically, the bottom thermocouple measured a higher temperature than the top thermocouple. The average vessel bulk temperature peaks at about $600-700 \mathrm{~K}$ at about $3 \mathrm{~s}$ for the tests that had reactive atmospheres. These temperature are well below autoignition temperature of the mixture ( $\approx 900 \mathrm{~K}$ ). Large amounts of cavity water (IET-8B), low driving pressure resulting in minimal debris dispersal (IET-8A), and an inerted atmosphere resulting in limited hydrogen combustion (IET-5) reduced the vessel bulk temperature to $400-460 \mathrm{~K}$.

The distance from the RCP thermocouples to the center of the vessel thermocouple arrays was $4.75 \mathrm{~m}$ and the vessel temperatures lagged subcompartment temperatures by about $0.6 \mathrm{~s}$. Therefore, a vessel bulk gas velocity of $\approx 8 \mathrm{~m} / \mathrm{s}$ was calculated. 


\section{G.3.8 Gas Composition Measurements}

Normally, about sixteen gas grab samples were taken from the Surtsey vessel in the IET experiments. Background samples from Surtsey were taken just prior to ignition. The background gas concentrations are listed in Table G.1. The measured oxygen and hydrogen concentrations in mole percent and amounts in $\mathrm{g} \cdot$ moles are plotted versus experiment time in Figures G.9-G.12. The amounts of hydrogen in $\mathrm{g} \cdot$ moles are listed in Table G.2 for each IET test. The values given include the amount preexisting in the vessel, the amount produced by steam/metal reactions in the HPME, the amount burned at 30 minutes, and the amount measured posttest.

Figure G.9 shows oxygen depletion measurements. Background sample measurements are shown for the majority of the tests, along with 2 and 30 minute results. There were no 2-minute samples in IET-1R and IET-3. In IET-8A, the samples were taken at $30 \mathrm{~s}$ and 900 minutes. In IET-8B, additional samples were taken at $15 \mathrm{~s}$. As expected, oxygen levels remained constant in IET-1 and IET-1R. In IET-5, the $\mathrm{CO}_{2}$ inerted test, oxygen depletion was about 0.4 mole percent. The gravity pour (IET-8A) resulted in oxygen depletion of about 1.0 mole percent. Oxygen depletions of about 2-2.5 mole percent were measured between $t=0$ and $t=2$ minutes in the tests with reactive atmospheres.

Figure G.10 gives the hydrogen measurement results. IET-1, IET-1R, and IET-5 measurements show that the majority of the hydrogen (about 3-3.5 mole percent) was being produced in the first few minutes, with a slight long-term buildup. In tests with a reactive atmosphere (IET-3 and IET-4), the hydrogen produced by the HPME burned and the concentrations were less than 1 mole percent. Figure G.10 indicates that in tests with preexisting hydrogen (IET-6 and IET-7), more hydrogen was burned than was produced in the first two minutes. IET-8B shows that driving melt into a cavity half filled with water can increase hydrogen levels very quickly. Hydrogen measurements in the cavity for all IET tests indicate very high levels (50-84 mole percent) by $2 \mathrm{~s}$ into the HPME transient. This indicates that the entraining gas in the cavity was a mixture of steam and hydrogen that is 
important because many analytical entrainment models require the composition of the entraining gas.

Figure G.11 compares the time rate of hydrogen combustion in the IET tests. Hydrogen combustion was based on assuming all oxygen depletion was due to reaction with hydrogen, and is calculated using the stoichiometric chemical reaction for the formation of water. Little combustion was seen in IET-1 and IET-1R. The baseline test, IET-3, with the reactive atmosphere and no basement water, shows about $190 \mathrm{~g}$ 'moles burned. The addition of water on the basement (IET-4) indicates that slightly more hydrogen burned (235 $\mathrm{g} \cdot$ moles). The largest amounts of hydrogen (about $330 \mathrm{~g} \cdot$ moles) burned in the tests with preexisting hydrogen in a reactive atmosphere (IET-6 and IET-7). With $\mathrm{CO}_{2}$ as a surrogate for steam, only $50 \mathrm{~g} \cdot$ moles burned, even though $202 \mathrm{~g} \cdot$ moles preexisted. The $15 \mathrm{~s}$ samples taken in IET-8B show that the majority of hydrogen burned very quickly.

Figure G.12 compares the time rate of hydrogen production in the IET tests. Hydrogen production amounts are calculated by subtracting the pretest hydrogen amount from the sum of the posttest hydrogen amount and the amount of hydrogen burned, calculated from oxygen depletion measurements. About $220-320 \mathrm{~g} \cdot$ moles of hydrogen were produced in all high-pressure steam driven tests. About $100 \mathrm{~g} \cdot$ moles were produced in IET-8A, the gravity pour test.

\section{G.4 SUMMARY}

The IET experiments were conducted to investigate the effects of subcompartment structures, condensate levels of water, and hydrogen production and combustion on the containment load. Linear scale models of the Zion NPP were constructed in the Surtsey vessel. High-pressure steam at $\approx 6.3 \mathrm{MPa}$ was used to eject an initial charge of $43 \mathrm{~kg}$ of molten thermite into Surtsey. Pressure and temperature measurements indicated that much of the generated hydrogen burned as gas was pushed out of the subcompartment structures. This was confirmed by analyses of vessel background and posttest gas samples. 
Experimental results suggest that the hot jets of hydrogen produced by debris oxidation in the cavity and subcompartment burned as a diffusion flame in the dome. The hydrogen combustion contributed significantly to containment pressurization. It was determined that the combustion of hydrogen jets and preexisting hydrogen can be inerted. In addition, combustion of preexisting hydrogen seemed to occur on a longer time scale than combustion of hydrogen produced in the HPME by steam/metal reactions, and therefore did not contribute significantly to containment pressurization.

\section{G.5 REFERENCES}

Allen, M.D., M. Pilch, R.T. Nichols, and R.O. Griffith (Oct. 1991). Experiments to Investigate the Effect of Flight Path on Direct Containment Heating (DCH) in the Surtsey Test Facility: The Limited Flight Path (LFP) Tests, NUREG/CR-5728, SAND91-1105, Sandia National Laboratories, Albuquerque, NM.

Allen, M.D., M. Pilch, R.O. Griffith, and R.T. Nichols (Mar. 1992a). Experiments to Investigate the Effect of Water in the Cavity on Direct Containment Heating (DCH) in the Surtsey Test Facility - The WC-1 and WC-2 Tests, SAND91-1173, Sandia National Laboratories, Albuquerque, NM.

Allen, M.D., M. Pilch, R.O. Griffith, and R.T. Nichols (Mar. 1992b). Experimental Results of Tests to Investigate the Effects of Hole Diameter Resulting from Bottom Head Failure on Direct Containment Heating (DCH) in the Surtsey Test Facility - The WC-1 and WC-3 Tests, SAND91-2153, Sandia National Laboratories, Albuquerque, NM.

Allen, M.D., M. Pilch, R.O. Griffith, D.C. Williams, and R.T. Nichols (Mar. 1992c). The Third Integral Effects Test (IET-3) in the Surtsey Test Facility, SAND92-0166, Sandia National Laboratories, Albuquerque, NM.

Allen, M.D., T.K. Blanchat, M. Pilch, and R.T. Nichols (Sept. 1992d). The Effects of Condensate Levels of Water on Direct Containment Heating (DCH) in Zion-Like Geometry: The Fourth Integral Effects Test (IET-4) Conducted in the Surtsey Test Facility, SAND92-1241, Sandia National Laboratories, Albuquerque, NM.

Allen, M.D., M. Pilch, R.O. Griffith, R.T. Nichols, and T.K. Blanchat (July 1992e). Experiments to Investigate the Effects of 1:10 Scale Zion Structures on Direct Containment Heating (DCH) in the Surtsey Test Facility: The IET-I and IET-1R Tests, SAND92-0255, Sandia National Laboratories, Albuquerque, NM. 
Allen, M.D., T.K. Blanchat, M. Pilch, and R.T. Nichols (Nov. 1992f). Experimental Results of an Integral Effects Test in a Zion-Like Geometry to Investigate the Effects of a Classically Inert Atmosphere on Direct Containment Heating: The IET-5 Experiment, SAND92-1623, Sandia National Laboratories, Albuquerque, NM.

Allen, M.D., T.K. Blanchat, M. Pilch, and R.T. Nichols (Dec. 1992g). An Integral Effects Test in a Zion-Like Geometry to Investigate the Effects of Pre-existing Hydrogen Direct Containment Heating in the Surtsey Test Facility: The IET-6 Experiment, SAND92-1802, Sandia National Laboratories, Albuquerque, NM.

Allen, M.D., T.K. Blanchat, M. Pilch, and R.T. Nichols (Dec. 1992h). An Integral Effects Test to Investigate the Effects of Condensate Levels of Water and Pre-existing Hydrogen on Direct Containment Heating in the Surtsey Test Facility: The IET-7 Experiment, SAND92-2021, Sandia National Laboratories, Albuquerque, NM.

Blanchat, T.K. (May 1992). "Aspirated Thermocouple Calculations," Letter Report to the U.S. Nuclear Regulatory Commission, Sandia National Laboratories, Albuquerque, NM.

Kumar, R.K. (Jul./Aug. 1985). "Flammability Limits of Hydrogen-Oxygen-Diluent Mixtures," Journal of Fire Sciences, Vol. 3. 
Table G.1

Initial conditions for the IET experiments

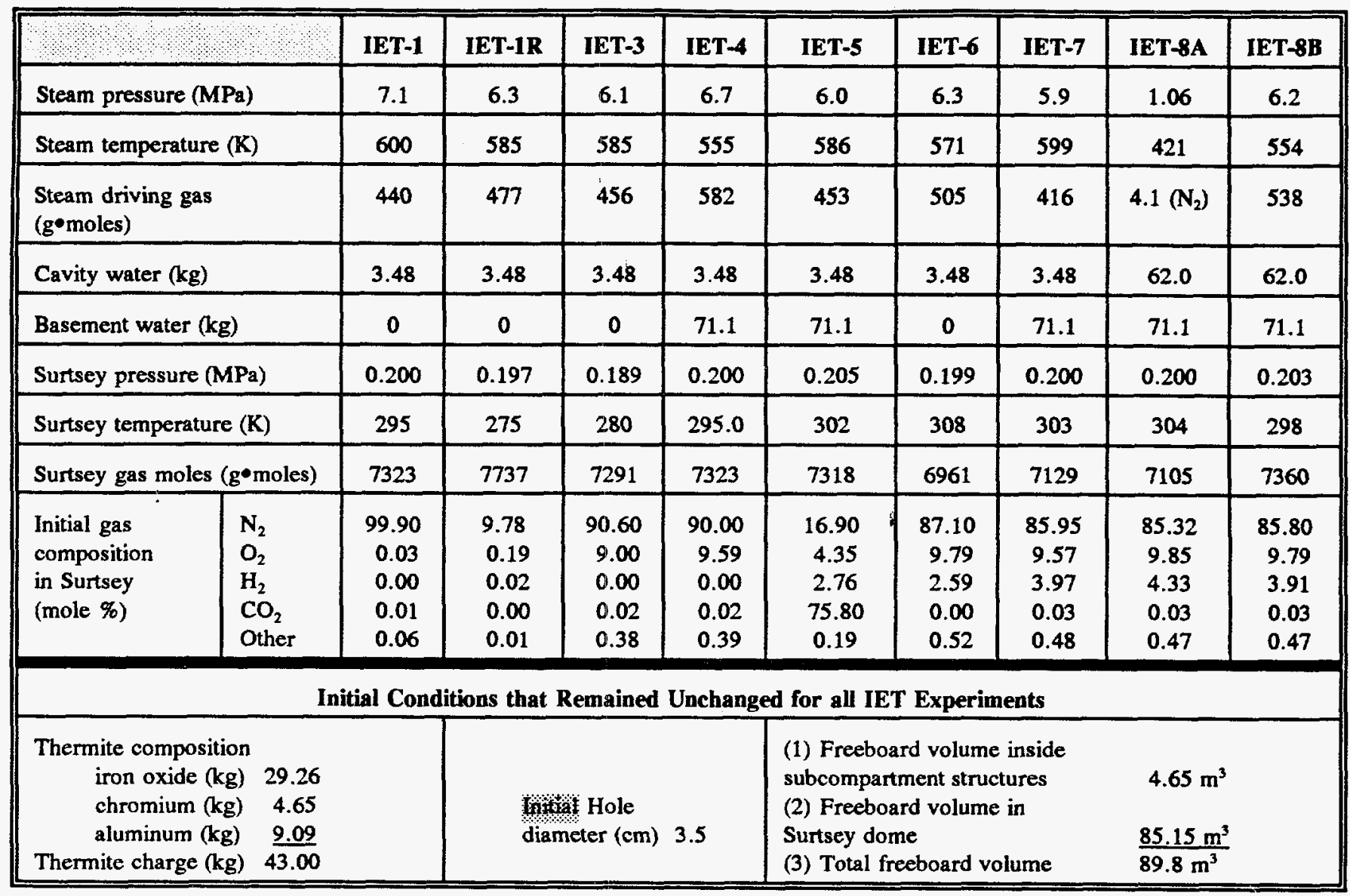


Table G.2

Summary of the results of the IET experiments

\begin{tabular}{|c|c|c|c|c|c|c|c|c|c|}
\hline & IET-1 & IET-1R & IET-3 & IET-4 & IET-5 & IET-6 & IET-7 & IET-8A & IET-8B \\
\hline $\begin{array}{l}\text { Moles of } \mathrm{H}_{2} \mathrm{O} \\
\text { driving gas ( } \mathrm{g} \bullet \text { moles) }\end{array}$ & 440 & 477 & 456 & 582 & 453 & 505 & 416 & $4.1\left(\mathrm{~N}_{2}\right)$ & 538 \\
\hline Cavity water (kg•moles) & 63 & 63 & 63 & 63 & 63 & 63 & 63 & 1116 & 1116 \\
\hline Basement water (kg॰moles) & 0 & 0 & 0 & 1280 & 1280 & 0 & 1280 & 1280 & 1280 \\
\hline Ablated hole diameter $(\mathrm{cm})$ & 4.04 & 4.02 & 4.53 & 4.22 & 4.31 & 3.91 & 4.08 & 3.50 & 4.10 \\
\hline $\begin{array}{l}\text { Total debris dispersed } \\
\text { into Surtsey }(\mathrm{kg})\end{array}$ & 43.0 & 36.2 & 34.3 & 40.7 & 33.1 & 42.5 & 36.7 & 8.6 & 42.9 \\
\hline \multicolumn{10}{|l|}{ Oxygen (g・moles) } \\
\hline - Pretest & 2 & 15 & 656 & 702 & 318 & 681 & 683 & 700 & 700 \\
\hline \multicolumn{10}{|l|}{ Hydrogen (g`moles) } \\
\hline - Pretest & 0 & 1 & $\mathbf{0}$ & 0 & 202 & 180 & 283 & 308 & 288 \\
\hline - Produced $(30 \mathrm{~m})^{\prime}$ & 233 & 248 & 227 & 303 & 319 & 319 & 274 & 176 & 299 \\
\hline . - Burned $(30 \mathrm{~m})^{9}$ & 3 & 11 & 190 & 240 & 53 & 345 & 323 & 154 & 281 \\
\hline - Posttest $(30 \mathrm{~m})^{f}$ & 230 & 238 & 37 & 63 & 468 & 154 & 234 & 330 & 306 \\
\hline$\triangle \mathrm{P}$ due to the HPME ( $\mathrm{kPa})$ & 98 & 110 & 246 & 262 & 103 & 279 & 271 & 87 & 244 \\
\hline
\end{tabular}

The IET-8A posttest results and the hydrogen produced and burned analyses were obtained from data acquired at 900 $\mathrm{min}$. 


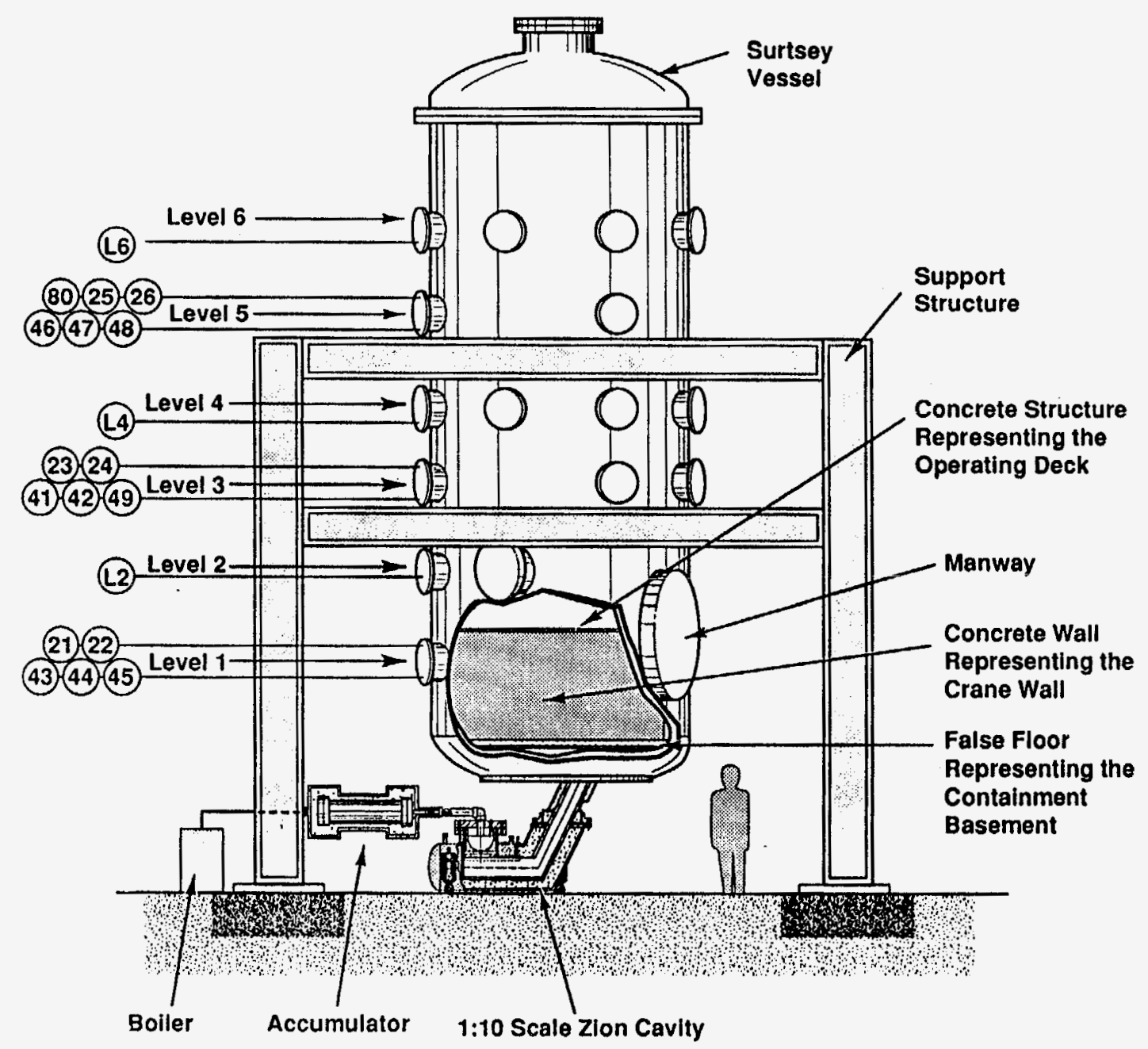

Note: All pressure transducers have Individual penetratlons.

Figure G.1. Surtsey vessel, high-pressure melt ejection system, and subcompartment structures used in the IET experiments. The figure also shows instrumentation location by channel number. 


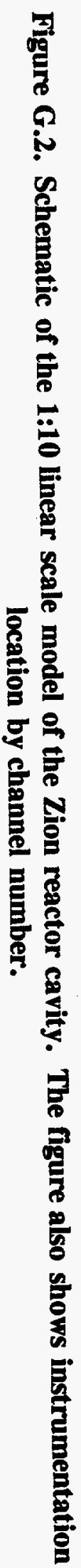

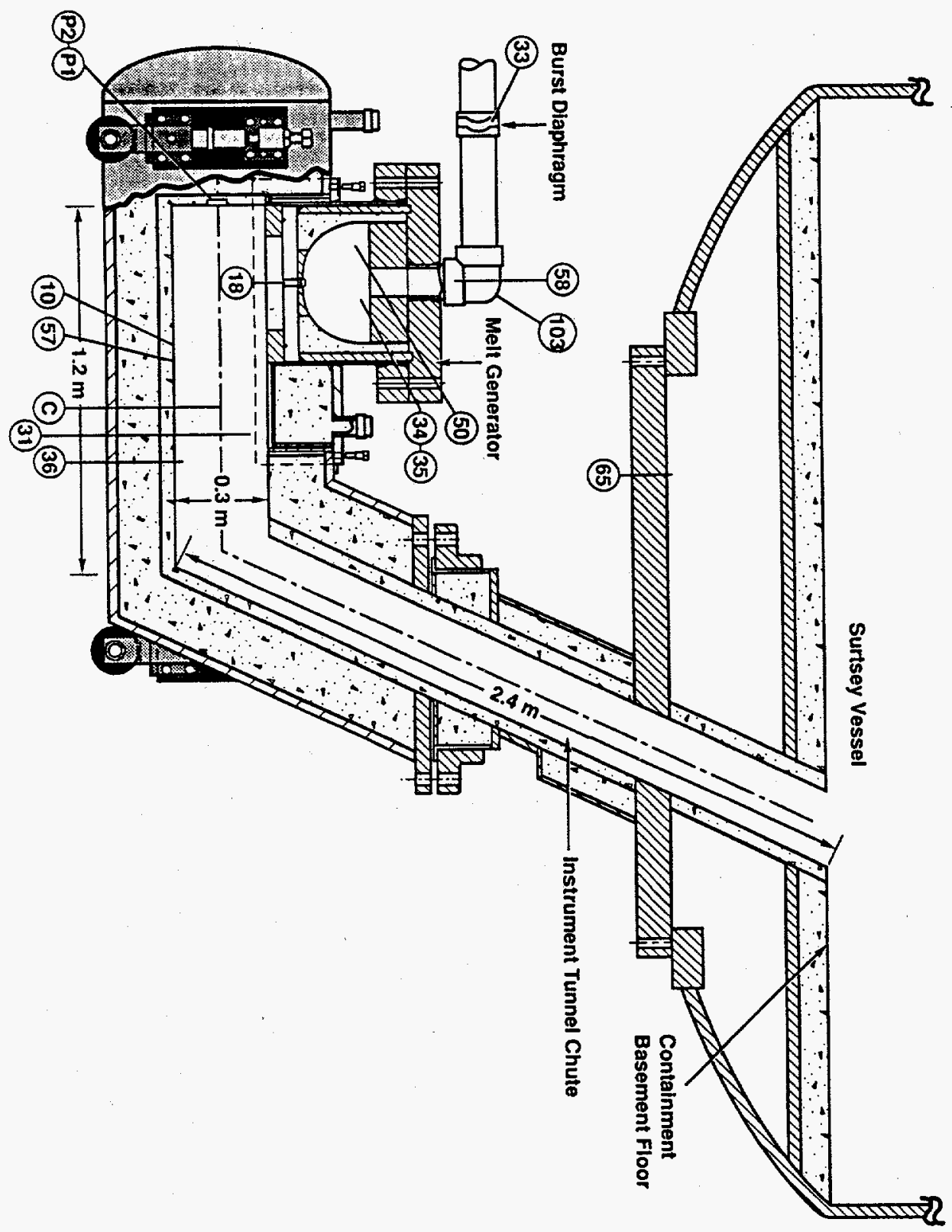




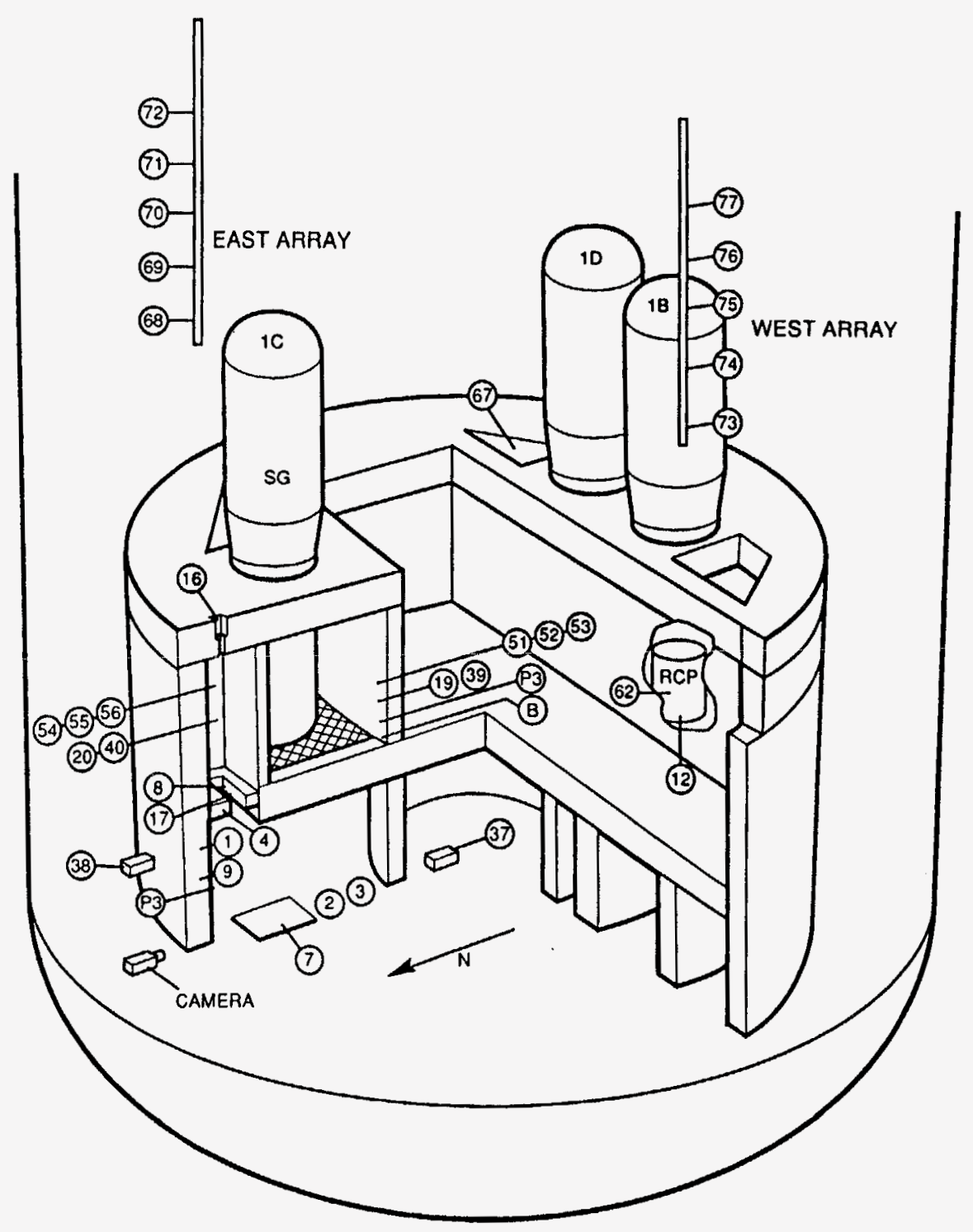

Figure G.3. Isometric view of subcompartment structures inside the Surtsey vessel. The figure also shows instrumentation location by channel number. 


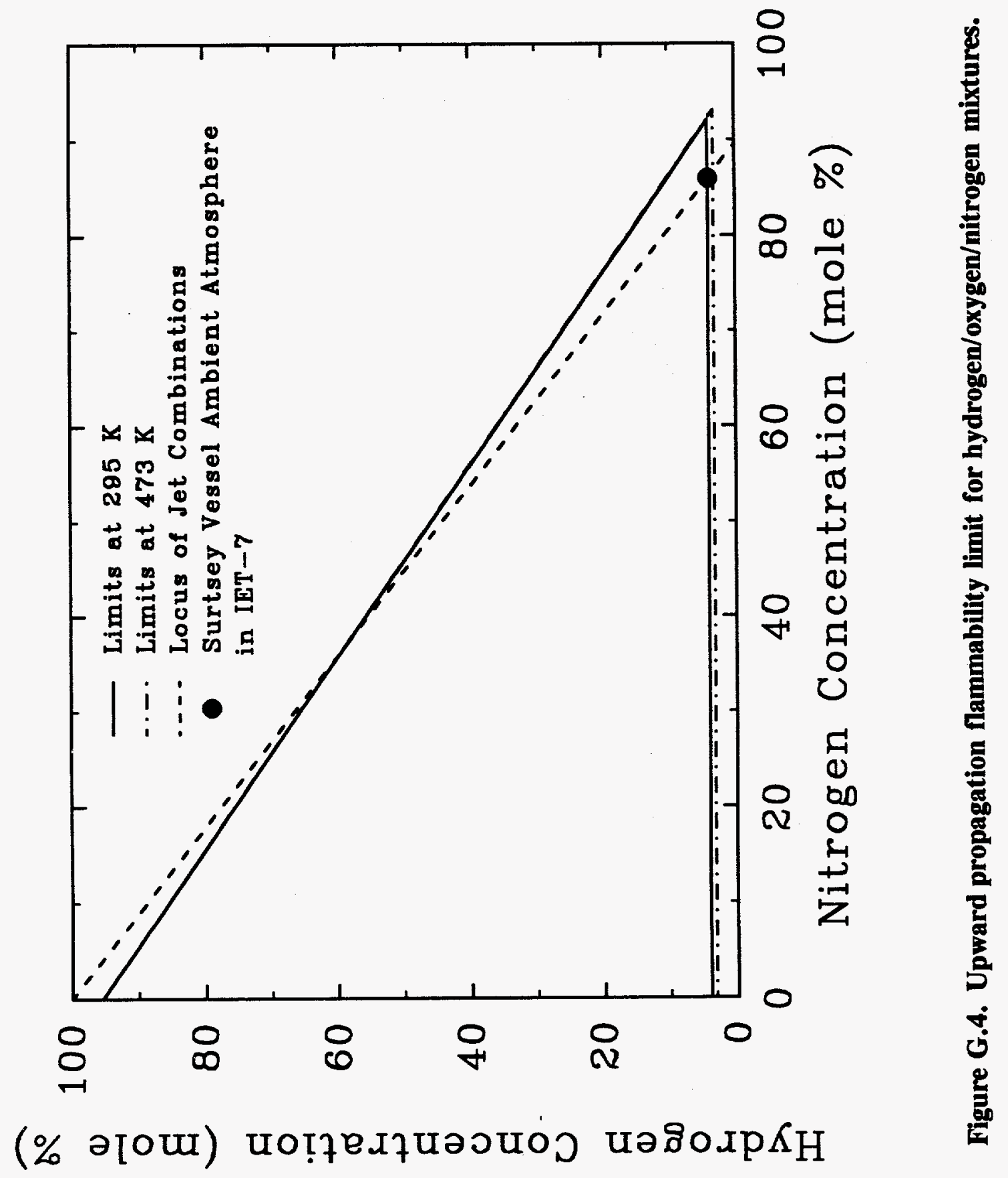




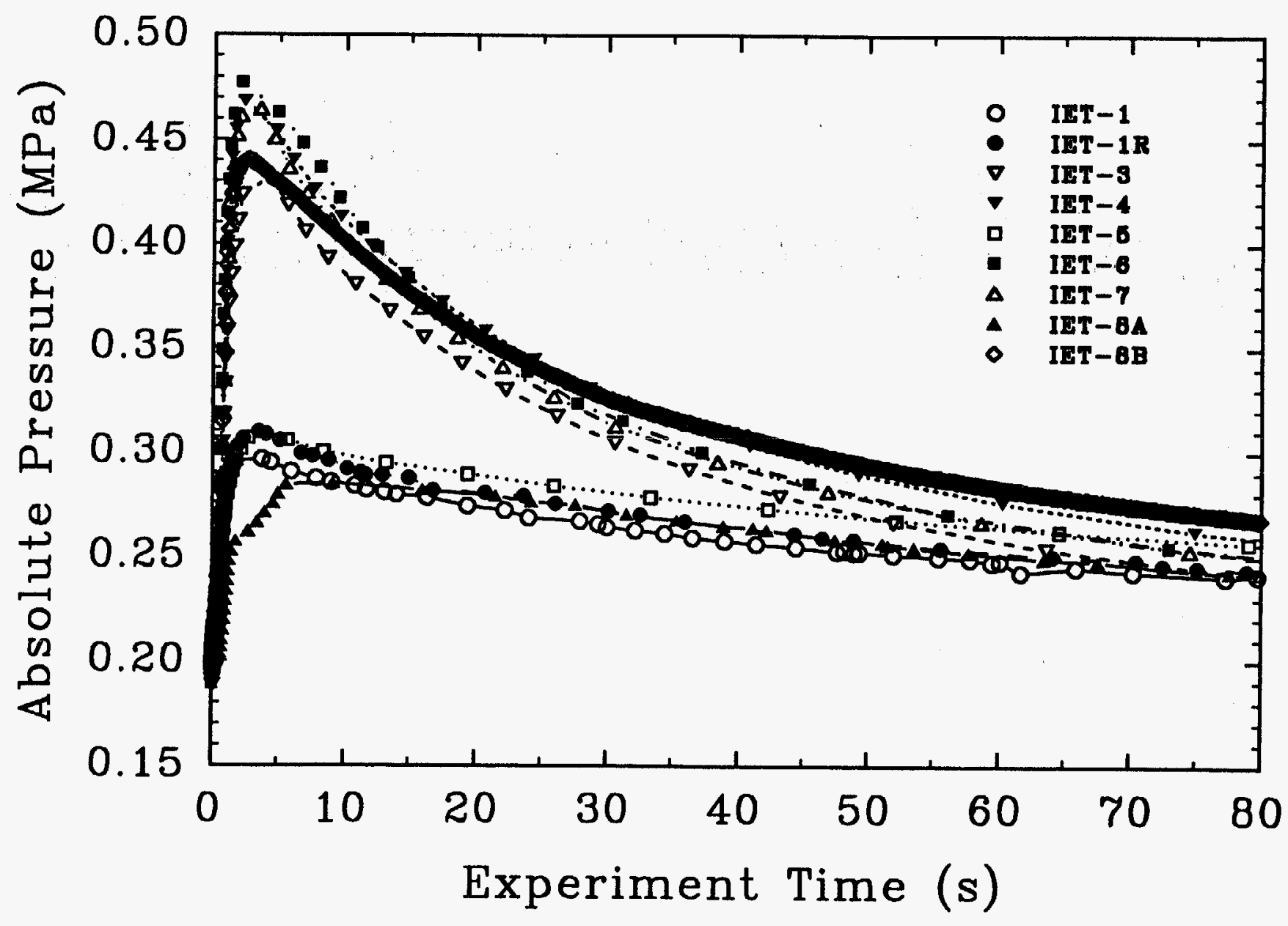

Figure G.5. Surtsey vessel pressure comparisons versus time for the IET experiments. 


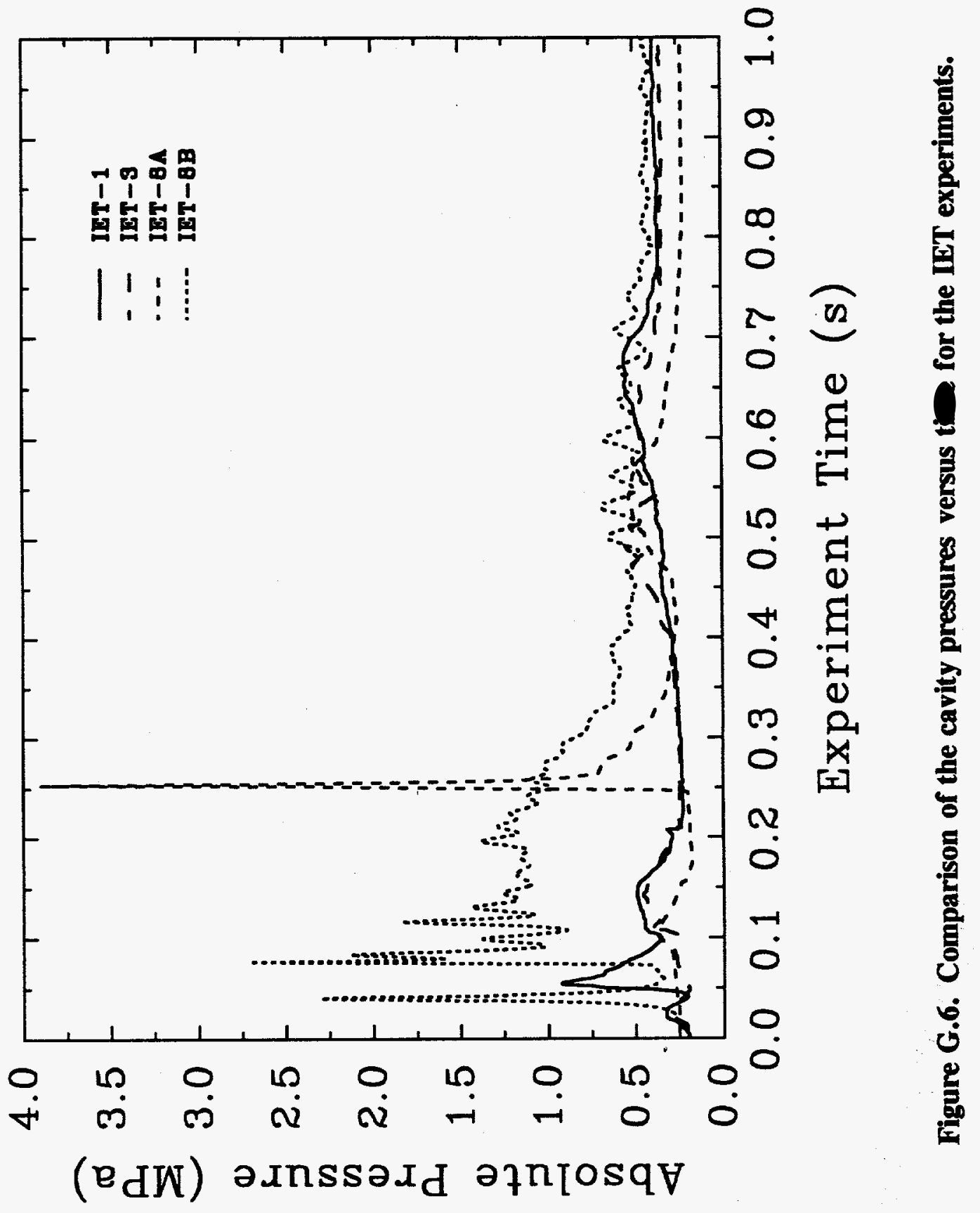




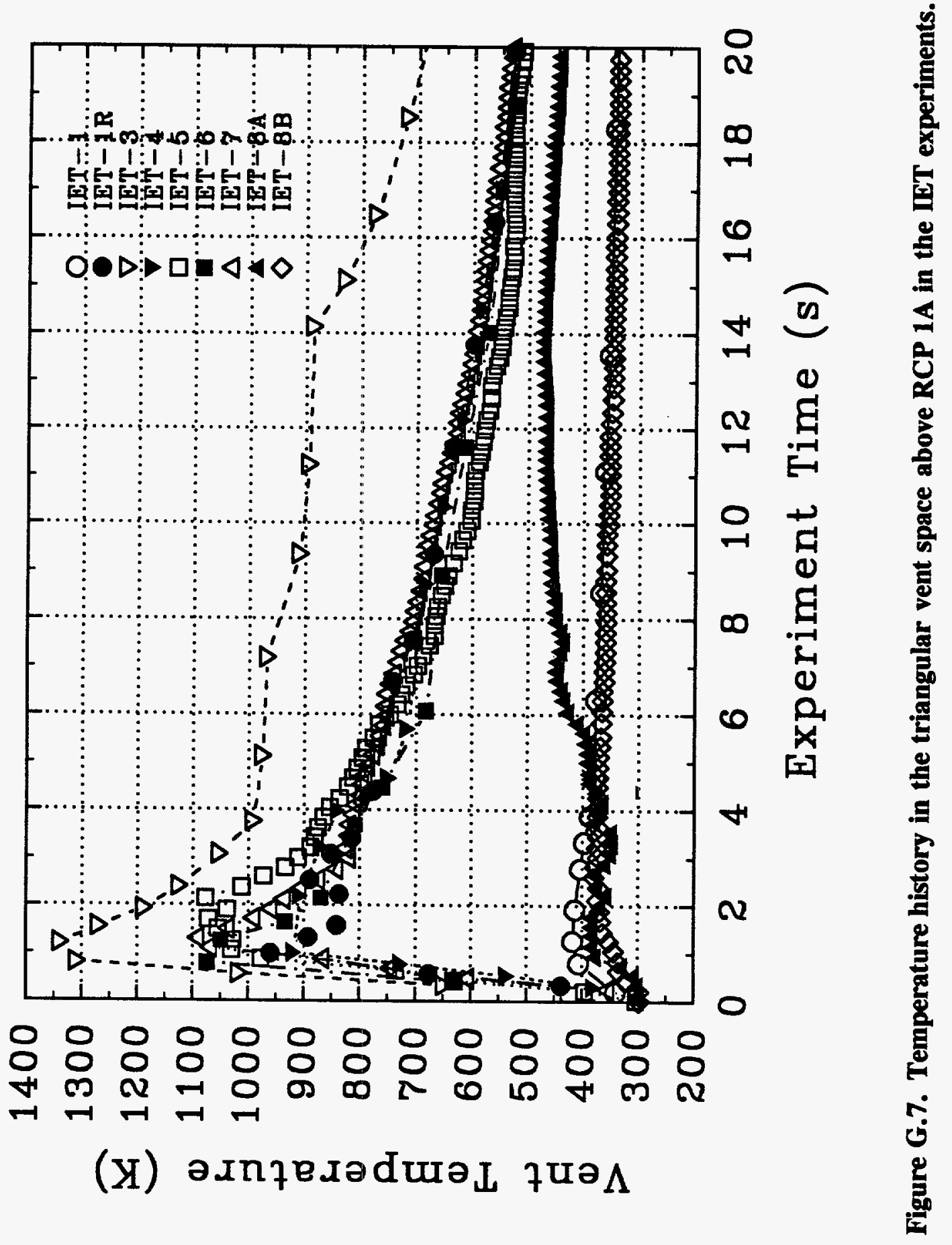




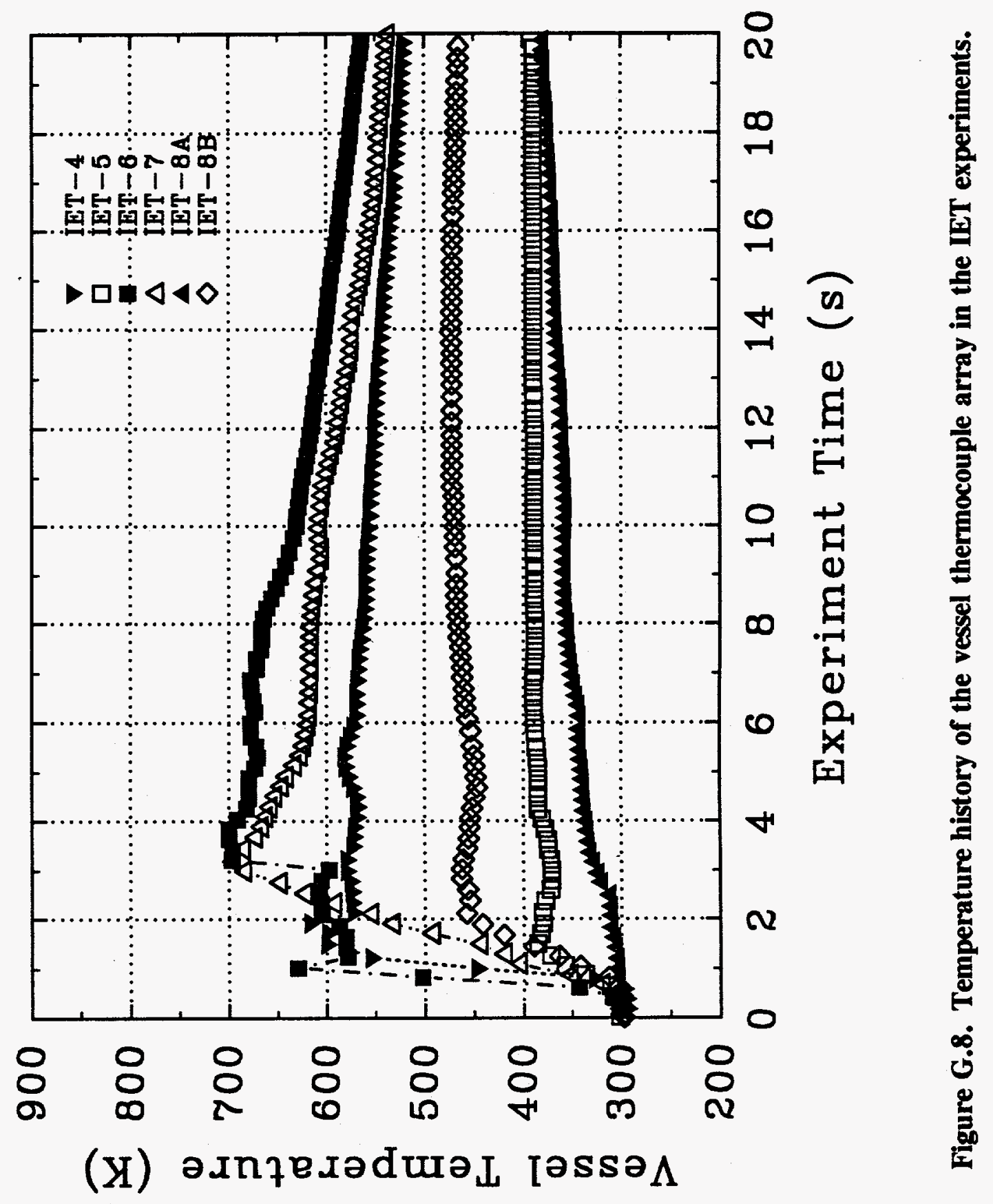




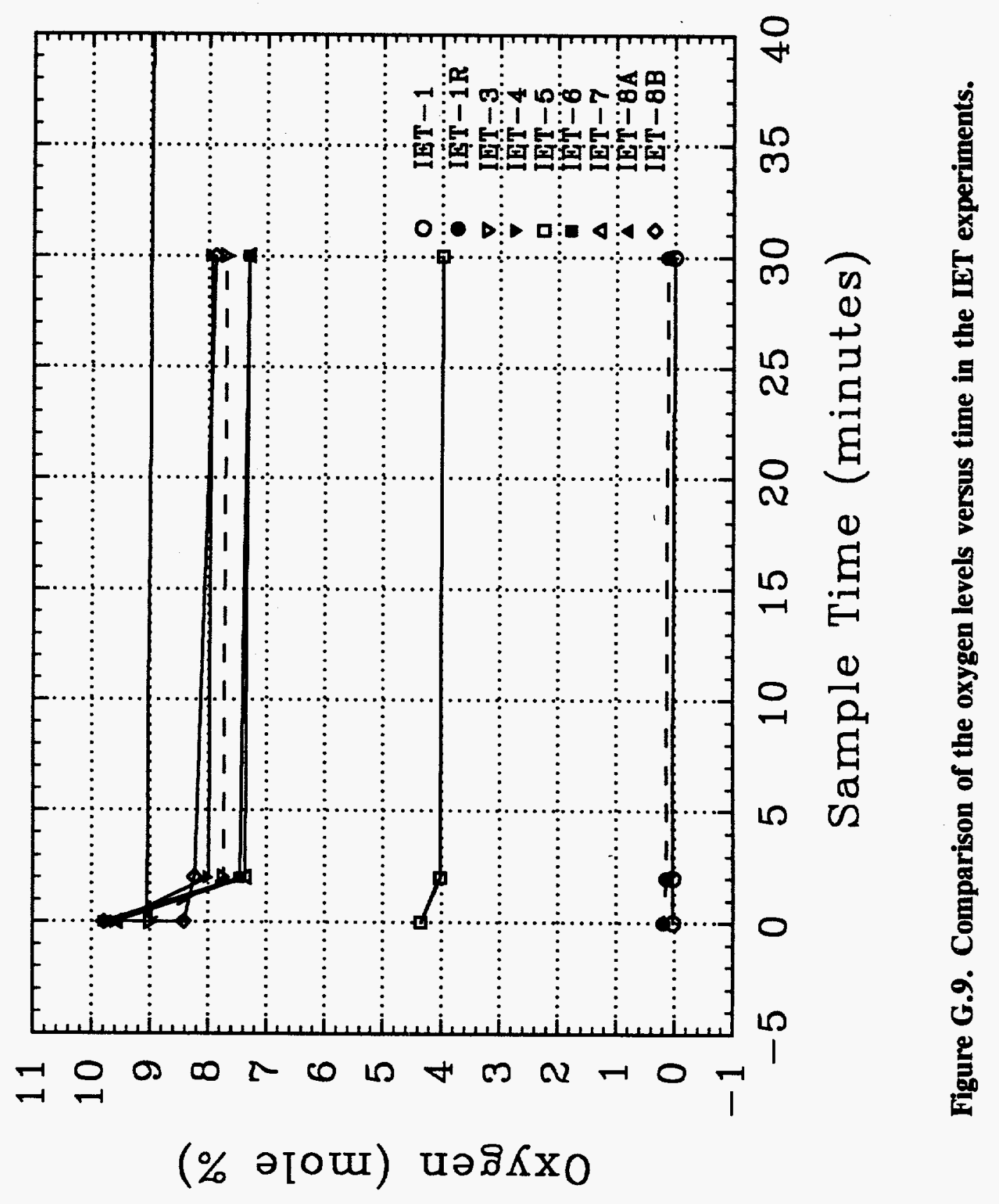




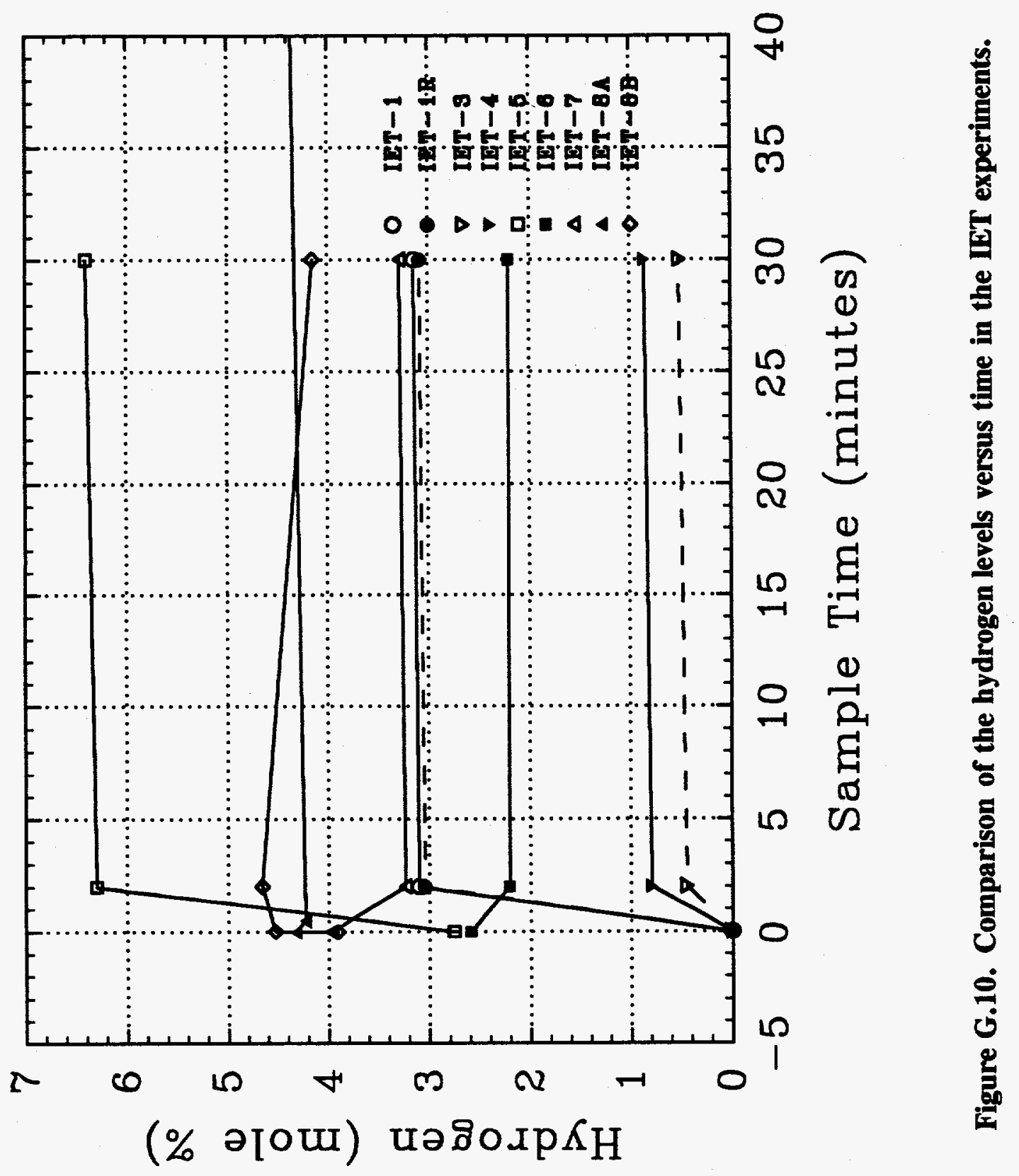




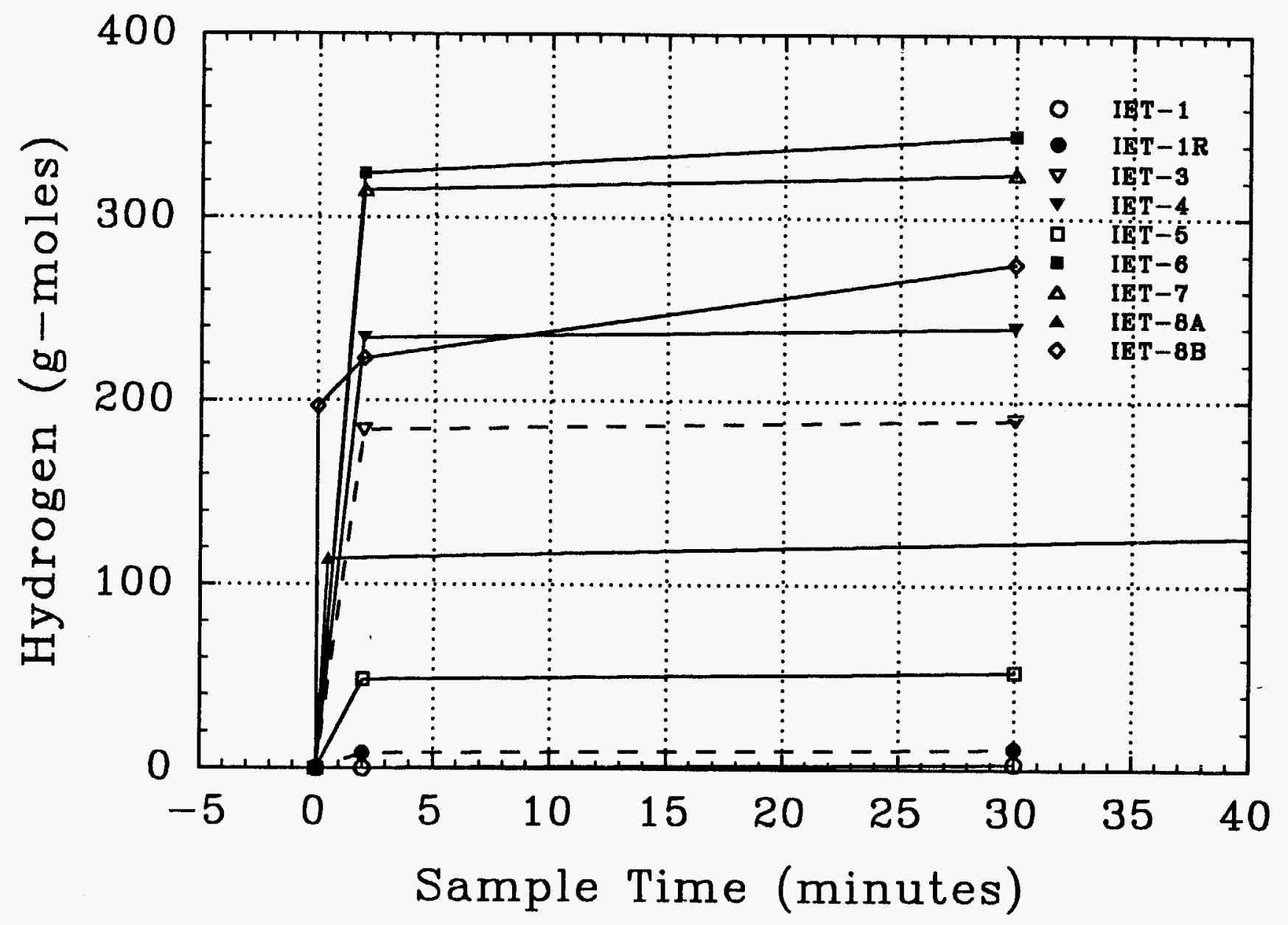

Figure G.11. Comparison of the hydrogen combustion versus time in the IET experiments. 


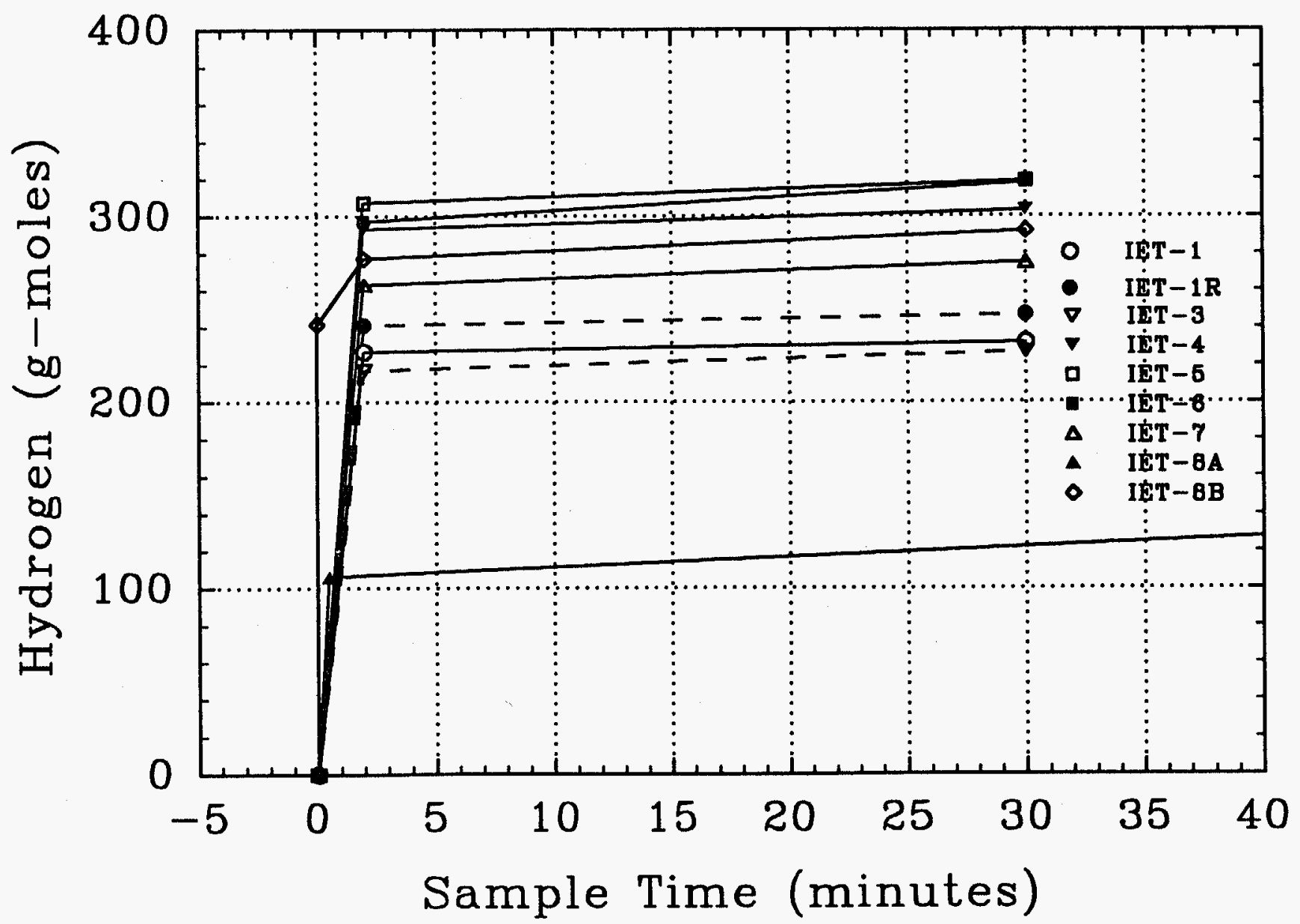

Figure G.12. Comparison of the hydrogen production versus time in the IET experiments. 


\title{
APPENDIX H \\ RESULTS OF DIRECT CONTAINMENT HEATING INTEGRAL EXPERIMENTS AT 1/40 SCALE AT ARGONNE NATIONAL LABORATORY
}

\author{
J. L. Binder, L. M. McUmber and B. W. Spencer \\ Argonne National Laboratory
}

\section{H.1 INTRODUCTION}

The NRC has been sponsoring a research program to resolve the DCH issue. An important part of this effort is an integral effects testing program. In general, the objective of this program is to assess the effects of scale on DCH phenomena. This is being accomplished by performing integral and counterpart experiments in two different facilities. Experiments at 1/40 linear scale are being conducted at Argonne National Laboratory and at 1/10 linear scale at Sandia National Laboratories. The more specific objective of the counterpart testing is to simulate the fundamental interrelated processes and effects of a HPME. The experiments incorporate melt ejection from the vessel, high pressure blowdown of primary system, entrainment and sweepout of debris from the cavity, transport and trapping in the lower containment subcompartments, oxidation of metallic constituents, combustion of hydrogen, and heat transfer to and vaporization of water in the containment. The experiments employed the geometry of the Zion Nuclear Power Plant (NPP). These tests provide important data in order to validate system level codes. In addition the experiments will be used to evaluate scaling methodologies proposed by the SASM group and SNL.

This Appendix reports on the ANL experiments. The specific objective of the experiments reported here is to conduct integral DCH tests applying the SNL scaling methodology using a $1 / 40$ scale mockup of the SNL $1 / 10$ scale facility. Useful tests, counterpart to the SNL tests, have been insured by employing linear geometric scaling to the greatest extent feasible. The facility includes models of the vessel lower head, cavity, subcompartments and containment dome. In addition, operating conditions were matched to the greatest extent possible to minimize sources of difference in the results, other than the scale distortions. 
Measurements in the tests are made of the primary system pressure history, the cavity and containment pressure responses, gas temperatures, debris disposition, hydrogen production and oxygen depletion.

The integral tests at ANL have addressed several questions. The first and most important relates to the effect of scale on DCH phenomena as has been pointed out. Comparison of test results between ANL and SNL have indicated little effect of scale on debris/gas heat transfer and steam/metal reactions that produce hydrogen. The scale effects on hydrogen combustion are somewhat more unclear. However, the results indicate a small increase in hydrogen combustion, with an increase in scale from $1 / 40$ to $1 / 10$. The ANL tests have also addressed the question of whether steam in the containment atmosphere will inert hydrogen combustion. Two tests were run comparing $50 \%$ inerting of air by nitrogen and steam in the containment. The results indicated that steam was effective in inerting the hydrogen combustion while the nitrogen was not. The ANL tests have also addressed questions regarding the debris sweepout process from the cavity. Gas temperature measurements indicate that the blowdown gases and the melt nearly thermally equilibrate during the cavity sweepout and that this process alone significantly contributes to the measured pressure response of the containment. The ANL tests have also addressed the question of over what time scale is hydrogen produced during HPME. Gas sample analyses have indicated that significant hydrogen is produced in the cavity during the sweepout over the time scale of the primary system blowdown. This hydrogen results from steam oxidation reaction with the "reactive" metal in the melt. However, data indicate that hydrogen is produced on a time scale well after the blowdown. This hydrogen may be produced from slow reactions with "non-reactive" iron. The effectiveness of the subcompartment structures in trapping debris was also addressed in these experiments. The results here indicate that only $5-10 \%$ of the debris ejected from the vessel is transported to the upper dome.

\section{H.2 DESCRIPTION OF THE EXPERIMENTS}

Specification of the experiments began first with the selection of the NPP and the accident sequence. The selected NPP is the ZION generating station. The accident is 
precipitated by a station blackout followed by a pump seal LOCA. The core melts and relocates to the vessel lower head. The HPME is begun by a failure of an instrument tube penetration.

Table H.1 provides a summary of the specified reference initial and boundary conditions for the NPP, SNL and ANL scales. For convenient comparison of the ANL and SNL dimensions, columns are given with the equivalent full scale value. The hole diameter in the experiments were scaled to the final calculated hole diameter in the NPP because ablation of the hole during the melt ejection could not be scaled properly. The composition of the containment atmosphere was the main parameter varied in the tests.

The driving pressure specification in the test was dictated by a pump seal LOCA as 6.2 MPa. The only significant area of geometric distortion in the experiments was the scaled volume of primary system. Due to facility limitations, the SNL volume is approximately $\mathbf{1 8 . 2}$ percent underscaled with respect to the ANL RCS volume.

The core melt simulant used was iron/alumina thermite with the addition of chromium. The chromium does not participate in the thermite reaction, however, it adds a "reactive" metal to the simulant. The chromium will oxidize with steam similar to zirconium and is, therefore, a good substitute. The same thermite and chromium powders were used in both the ANL and SNL tests. Due to non-uniformities in the iron oxide powder used in the thermite, the reaction was non-stoichiometric and resulted in 1.4 mass percent of the simulant containing aluminum. Further details on this can be obtained in Allen et al. (1991). The excess aluminum adds additional "reactive" metal. The temperature of the simulant at ejection has been measured in the SNL facility by two-color pyrometers as $2550 \mathrm{~K}$. This is 230 degrees of superheat with respect to the melting point of the alumina. The specific enthalpy of the simulant at $2550 \mathrm{~K}$ is $2.8 \mathrm{MJ} / \mathrm{kg}$ compared to $1.15 \mathrm{MJ} / \mathrm{kg}$ for the prototype melt at $2600 \mathrm{~K}$. The specific metal-steam oxidation energy is $1.20 \mathrm{MJ} / \mathrm{kg}$ for the simulant and $1.22 \mathrm{MJ} / \mathrm{kg}$ for the prototype melt. The mass of hydrogen produced per mass of melt oxidized by steam is 0.0318 and 0.0156 for the simulant and prototype, respectively. These oxidation data include the iron. The density of the simulant melt is $4000 \mathrm{~kg} / \mathrm{m}^{3}$, approximately one-half of the prototype melt. 
The scaling rationale for selecting the initial simulant melt mass was based on preserving the ratio of total melt energy input, including oxidation and hydrogen combustion energy, to containment volume between the prototype and experiment. In effect, this matches the maximum expected pressure increase from a single cell adiabatic calculation. Details on this calculation is given in the results. Applying this approach resulted in the specification of $0.71 \mathrm{~kg}$ of melt ejected in the ANL experiments.

The ANL experiments were conducted in the Corium EX-Vessel Interaction (COREXIT) facility. A schematic of the experiment apparatus is shown in Figure H.1. Major components of the facility include an explosion resistant containment cell, a $1.51 \mathrm{~m}^{3}$ expansion vessel (EV) and a high pressure steam boiler. The expansion vessel stands approximately 3.4 meters high and is $\mathbf{0 . 7 6}$ meters in diameter. The vessel is trace heated and insulated. It can accommodate a steam atmosphere.

The steam delivery system consists of an accumulator volume, representing the primary system volume, and a pneumatically actuated ball valve designed for high pressure steam. The accumulator, valve and all piping in the steam delivery system are heated and insulated.

The Zion cavity model was designed and built from drawings supplied by the SNL DCH team. A schematic of the cavity is shown in Figure H.2. Bolted on top of the pipe body is a saddle piece, referred to as the top cap, which contains the melt generator and injector (MGI). The cavity keyway is elongated by a transition chute which connects the cavity to the bottom of the expansion vessel. The elongation is required in order to allow room for the melt generator to fit underneath the expansion vessel. Thus, the keyway, is elongated by 1.7 times its correctly scaled length. The melt generator is shown in Figure H.3. The melt generator also includes a baffle plate in order to diffuse the steam jet entering from the accumulator.

The model of the Zion subcompartment structures is shown schematically in Figure H.4. The model is a scaled down version of the model used in the SNL test. Prominent features which are modeled include the seal table room, refueling canal, biological shield wall, reactor coolant pumps, steam generators, floor grating and operating deck floor. The walls and 
floors are constructed from concrete and mortar. The structure has been painted with epoxy paint. The model was built up from the lower flange of the expansion vessel. The perimeter of the model is defined by a circular concrete wall which simulates the crane wall in the plant. The walls and floors are held together by $1 / 4^{\prime \prime}$ threaded rods. Seals are made at various joints with high temperature RTV silicon rubber.

Table H.2 details the type and location of instrumentation that was recorded during the test. All pressure measurements were taken with strain gauge type transducers. Temperature measurements were made with type $\mathrm{K}$ thermocouples at various locations. The thermocouples in the subcompartment model were bare junction. This allows for the fastest response to the high velocity hot gases entering the subcompartment model. The thermocouples located in the expansion vessel were also bare. Cavity gas temperatures were measured by an aspirated thermocouple assembly. The assembly consists of a bare junction thermocouple, a tungsten rhenium, shielded by $1 / 4$ " stainless steel tube. The tube has a slot cut in the end to draw gas through and over the bead. The flow area through the slot equals the cross sectional flow area of the tube. The beads are set back away from the slots. The tube is inserted into the cavity through a hole in the wall near the cavity exit. The end of the tube is connected to a solenoid valve which vents the assembly to a gas bottle. The solenoid valve is opened from 0 to 0.5 seconds after the start of the HPME. The start of the high pressure melt ejection is signalled by a twisted pair of varnished copper wires located just below the brass melt plug. When melt is ejected it contacts the wires, vaporizing the varnish and making an electrical connection between the two wires. This signal actuates the automatic gas sampling system. Gas composition measurements were made by use of gas grab sample bottles. All sample bottles were evacuated prior to the tests. The disposition of the thermite melt was measured after the test. The recovery was typically made by vacuuming the debris from each specific location of interest. The debris is maintained in sealed plastic bags. Particle sizing, when possible, was carried out with a sonic sifter.

Test operations are begun by preheating the apparatus to the correct initial temperatures. If called for by the test, water is added to the cavity. The EV is then pressurized to the initial condition. The steam generator is brought to the test specified pressure. The accumulator is 
pressurized with steam from the boiler to the test specification. The test is ready to begin the automatic sequence.

The test is begun by starting the data acquisition and then depressing a start button which starts a timer. This applies power to the ignitor assembly which starts the thermite reaction. The reaction proceeds downward until it hits a burn wire located above the melt plug. This actuates the opening of the steam valve. The valve opening time is typically 100 milliseconds. At some time after the steam introduction, the thermite reaction reaches the brass plug in the melt generator, and fails the plug. This starts the high pressure melt ejection and is signalled by the burn wire under the plug. The burn wire signal starts a timer which actuates the automatic gas sample bottles. At specified times after the melt ejection gas samples are also taken manually.

\section{H.3 EXPERIMENT RESULTS}

Table H.3 summarizes the initial conditions for the six Integral Effects Tests (IET) completed. A brief description of each test and the rationale for selecting the conditions of each of the test is summarized as followed. IET-1R and 1RR were counterpart to the SNL IET-1 and $1 \mathrm{R}$ tests. These tests contained initially nitrogen inerted containment atmospheres to allow a separate measurement of the hydrogen produced by metal oxidation of the blowdown steam. IET-1R was repeated in IET-1RR for two reasons. First, the application of the steam to melt generator was mistimed with the failure of the brass plug and the melt was partially ejected under low pressure conditions. Second, the blowdown time of the accumulator (primary system) was elongated due to vaporization of significant amounts of condensate in the system.

The IET-3 test was counterpart to SNL IET-3. The initial conditions for IET-3 were nominally the same as IET-1RR with the exception of the containment atmosphere. The initial atmosphere composition was 50 mole percent air and 50 mole percent nitrogen. Hydrogen produced by metal/steam reactions can combust with the oxygen in the atmosphere. 
IET-6 was counterpart to SNL IET-6. This test further changed the atmosphere composition by adding preexisting hydrogen. The amount of hydrogen added was consistent with the levels produced by approximately $50 \%$ in-vessel zirconium oxidation during the core degradation process.

IET-7 was not run counterpart to any specific SNL test. The initial conditions in this test were nominally the same as IET-3 with the exception of the initial containment pressure which was reduced by one half. This test was designed to test the effect of the ratio of the initial driving pressure to the initial containment pressure. This has been identified as an important scaling group in the CLCH model of Theofanous (Appendix D).

The IÉT-8 test was not run counterpart to any specific SNL test. This test nominally repeated the same initial conditions of IET- 6 with the exception that the nitrogen is replaced with steam. This test represents a more realistic state of the containment during a pump seal LOCA.

Table H.4 summarizes the results of all the tests. The driving pressure in these tests varies from 5.7 to $6.7 \mathrm{MPa}$. Figure $\mathrm{H} .5$ shows a typical pressure history in the vessel obtained in the experiments. Figure H.6 shows the mass flow rate of steam exiting the vessel. This results indicates that HPME in the experiments is characterized initially by the ejection of melt and steam simultaneously. This is followed by a period of single phase steam ejection starting at approximately 0.22 seconds. Similar results were obtained in all of the experiments.

Figure H.7 plots the containment pressure response obtained in all of the experiments. It is noted that the largest increase was obtained in the test containing preexisting hydrogen, IET-6. The second and third largest increases were obtained in IET-3 and 7, where the containment atmospheres were partially inerted with nitrogen. The lowest increases were obtained in the fully inerted IET-1RR and the partially steam inerted IET-8.

Figure H.8 indicates the typical pressure response of the cavity in the tests. Also plotted is the containment pressure and the output of a photodiode positioned at the cavity exit. The photodiode outputs a signal when the luminescent melt is present at the cavity exit. This 
indicates that the pressure difference between the cavity and containment is associated with the sweepout of the melt from the cavity. Figure H.9 plots the temperature of the gases exiting the cavity in IET-3 as measured by an aspirated thermocouple assembly located near the cavity exit. This measurement indicates the high heat transfer rates that occurs between the melt and blowdown gases during the cavity sweepout period. The cavity sweepout is also characterized by the significant conversion of the blowdown steam to hydrogen. This is indicated by the results of gas grab samples taken in the cavity during the sweepout period. The results of cavity gas grab sample analysis for the tests indicate 30 to 60 mole percent hydrogen. These samples were taken from 0 to 0.5 seconds after the start of the HPME.

In addition to the gas samples taken in the cavity, many gas samples were taken in the upper dome. All of these samples were taken nominally at the same elevation at different radial locations near the vessel walls. In tests IET-1 through 3 samples were taken at one and 7.5 minutes after the HPME. Three samples were taken at each time. The samples were found to be very consistent and the results were averaged to obtain the vessel atmosphere composition post-test. In IET- 6 through 8 gas samples were also taken at 30 seconds after the HPME. These samples indicated lower hydrogen and greater oxygen concentrations than those samples taken at later times. Table H.5 summarizes the results of gas sample measurements. These data have significant impact on the interpretation of hydrogen production and combustion in the experiments. This will be expanded on in detail in the following section.

Table H.6 summarizes the debris disposition for the ANL IET tests. The distribution of the debris was consistent in all the tests. It is noted that there was nearly complete ejection of the melt (over 90 percent) from the melt generator in all tests. The sweepout fraction from the cavity varied from 69 to 79 percent in all of the tests. The data indicate that of the debris swept out of the cavity, nearly 90 percent of it is trapped within the subcompartment. Of the debris retained in the subcompartment 20 to 30 percent of it is trapped in the seal table room. All of the debris retained in the cavity is present as an evenly dispersed crust on the walls and the floor. 
The size of the debris particles is an important piece of information. However, it is difficult to characterize the size after the test. The debris retained in the subcompartment is typically present as re-agglomerated particles. Therefore, it is difficult to characterize their size. Only the debris that is transported to the upper dome appears to solidify at the size that is produced by the HPME. Table H.7 summarizes that results of a sonic sifting analysis of the debris found outside the subcompartment.

A meaningful way to compare tests at different scales or with different initial conditions is on the basis of the measured pressurization efficiency, $\eta$.

$$
\eta=\frac{\Delta P_{\text {exp }}}{\Delta P_{\text {max }}}
$$

Where $\Delta \mathrm{P}_{\mathrm{EXP}}$ is the peak pressure increase measured in the upper dome, and $\Delta \mathrm{P}_{\mathrm{MAX}}$ is the maximum expected pressure increase based on a single cell adiabatic equilibrium calculation. Pilch (Appendix E) has developed in detail a single cell equilibrium model for calculating the bounding pressure increases due to a HPME. This was the basis for the scaling rationale used to select the initial melt mass. The maximum pressure increase results from the contributions of the four energy sources to the containment.

It gives a bounding estimate because it makes the following assumptions. All of the debris that is ejected from the vessel into the cavity is assumed to participate and fully equilibrate with the containment atmosphere. It assumes all of the metal in the melt oxidizes in steam to the extent that steam is available. All of the hydrogen produced in these reactions is burned to the extent that oxygen is available. Finally, it does not account for potential mitigating effects of water in the cavity or in the containment. The efficiency calculation was carried out for the ANL integral tests and the results are shown in Table H.8.

The sweepout of the melt by the high velocity blowdown gases leads to a high degree of mixing in the cavity. This efficient mixing process leads to nearly complete oxidation of the "reactive" metals in the melt and nearly complete thermal equilibration of the melt and blowdown steam. This is supported by measurements of the gas temperature exiting the cavity, 
Figure H.9, and the large hydrogen concentrations found in the cavity gas samples. When the melt is ejected from the cavity into the lower subcompartments the majority, 90 to $95 \%$, is trapped by structures, where it can no longer efficiently transfer energy to the containment atmosphere. Thus, the cavity interaction becomes the dominant process by which the melt energy is transferred to the containment.

In IET-6, 7 and 8, gas sample measurements were made also at 30 seconds after the start of the HPME. These measurements indicated that the concentration of hydrogen and oxygen was changing well after the HPME. Figures H.11 and H.12 show the number of grammoles of hydrogen and oxygen in the containment atmosphere as a function of time elapsed from the start of the HPME for IET-6 and 8. The physical significance of the plots is still open to interpretation, however, the following explanations seem plausible.

In the case of IET-6, there was visual evidence of a hydrogen burn that occurred on the time scale of the blowdown. This evidence was obtained by video cameras in the upper dome looking down on the subcompartment structures. The burn occurred as hydrogen produced in cavity exited, passed through the subcompartment and up into the upper dome. The duration of the burn was on the order of 0.2 seconds and commenced just after the start of the HPME. Thus, the visual evidence indicated a burn of hydrogen as a plume exiting the cavity that scaled with the blowdown time. However, the data in Figure $\mathrm{H} .11$ show the continued depletion of oxygen and increase of hydrogen well after the blowdown. Extrapolating the oxygen data back to time zero yields a depletion of approximately $1.8 \mathrm{gram}$-moles of oxygen on the time scale of the blowdown or sweepout. This would correspond to the combustion of 3.6 gram-moles of hydrogen on the time scale of the sweepout. This is consistent with 4.0 gram-moles of hydrogen produced in the inerted IET-1RR test. The data in Figure H.11 shows a continued slight increase in $\mathrm{H}_{2}$ and decrease in $\mathrm{O}_{2}$ well after the HPME. This can be attributed to the long time oxidation of iron in the melt. There is no indication that any of the pre-existing $\mathrm{H}_{2}$ burned in IET-6.

The results obtained in IET-6 is contrasted with results obtained in IET-8. The conditions for these two tests were comparable with the exception of steam in the containment 
atmosphere in IET-8 as opposed to nitrogen in IET-6. In IET-8 there was no visual evidence that indicated a hydrogen burn in IET-8, as was obtained in IET-6. The data in Figure H.12 indicate very little depletion of $\mathrm{O}_{2}$ on the sweepout time scale. However, there is a large increase in the hydrogen moles due to oxidation of metal in the melt by steam. This predominately occurred in the cavity, during sweepout, as in all other tests. The data show the total depletion of one gram-mole of oxygen over a long time scale. This can be attributed to the further oxidation of iron in the melt.

\section{H.4 CONCLUSIONS}

A series of six integral experiments have been completed that investigate DCH phenomena in Zion Nuclear Reactor geometry at 1/40 scale. Three experiments, IET-1RR, 3 and 6, were counterpart to $1 / 10$ scale integral experiments at SNL. These tests directly addressed issue of scale effects on $\mathrm{DCH}$ phenomena. In addition, tests were conducted that investigated the effect containment atmosphere initial condition by decreasing the initial pressure in IET-7 and partially inerting with steam in IET-8. The following major results were obtained in these tests:

1) The lower subcompartment structures were effective in trapping 90 to $95 \%$ of the debris that exited the cavity.

2) Tentative data in the ANL tests indicate significant amounts of hydrogen being produced and oxygen being depleted well after the HPME. In addition, the fraction of the pre-existing hydrogen that burns remains unanswered. More experiments are required in order to resolve the hydrogen burn question.

3) A decrease in the initial containment pressure from 0.2 to $0.1 \mathrm{MPa}$ did not produce a significant change in the containment loading. The efficiency was approximately the same while the pressure increase was less due to the lower atmospheric heat capacity in the lower pressure test. 
4) The effect of a more prototypic atmosphere composition was investigated in the IET-8 test. In this test the initial containment atmosphere contained $50 \%$ steam and 50 percent air. The steam was effective in inerting the combustion of the hydrogen compared to the IET-3, 6 and 7 tests, which contained initially 50\% air and 50\% nitrogen.

\section{H.5 References}

Allen, M.D., M. Pilch, R.T. Nichols, and R.O. Griffith (1991). Experiments to Investigate the Effect of Flight Path on Direct Containment Heating (DCH) in the Surtsey Test Facility, NUREG/CR-5728, 1991. 
Table H.1. Summary of specified reference initial and boundary conditions

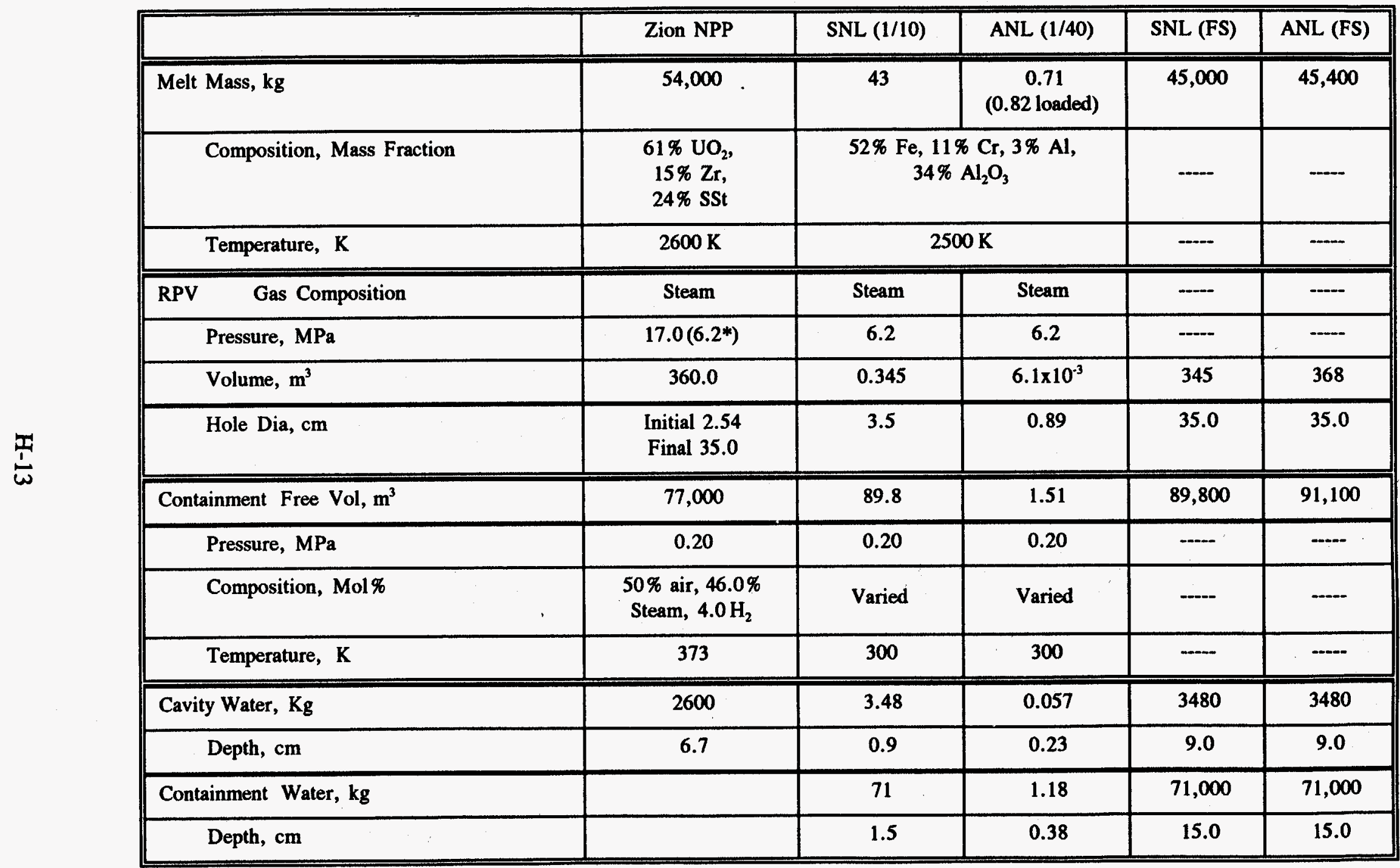

*pump seal LOCA initiated by Station Blackout. 
Table H.2. Instrumentation

\begin{tabular}{|c|c|c|c|}
\hline $\begin{array}{c}\text { Channel } \\
\text { No. }\end{array}$ & Type $^{(1)}$ & Range & Location/Purpose \\
\hline 1 & Current/Continuity & $0-50 \mathrm{mV}$ & Ignition signal and start of HPME \\
\hline 2 & Thermocouple & $0-485^{\circ} \mathrm{C}$ & Accumulator Gas Temperature \\
\hline 3 & $\bar{n}$ & 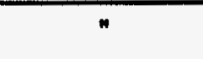 & $"$ \\
\hline 4 & Pressure Transducer & $0-1500$ psig & Accumulator Pressure \\
\hline 5 & $" \quad "$ & $n$ & $"$ \\
\hline 6 & Continuity & $0-1.5 \mathrm{~V}$ & Signal to Open Steam Valve \\
\hline 7 & Pressure Transducer & $0-1500$ psig & MGI Pressure \\
\hline 8 & $" n$ & $n$ & $n$ \\
\hline 9 & $" n$ & $0-100 \mathrm{psig}$ & Cavity Pressure \\
\hline 10 & Thermocouple & $0-485^{\circ} \mathrm{C}$ & Cavity Floor Temperature \\
\hline 11 & 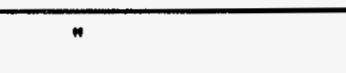 & $"$ & " " \\
\hline 12 & Photocell & $0-1 \mathrm{~V}$ & Cavity Window/Measure Melt Ejection \\
\hline 13 & Thermocouple & $0-1233^{\circ} \mathrm{C}$ & Seal Table Room Gas Temperature \\
\hline 14 & Microswitch & $0-6 \mathrm{~V}$ & Valve Open Signal \\
\hline 15 & Pressure Transducers & $0-125$ psia & EV Pressure \\
\hline 16 & 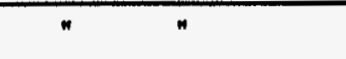 & $\overline{7}$ & $" \quad "$ \\
\hline 17 & Thermocouple & $0-1233^{\circ} \mathrm{C}$ & Subcompartment Gas Temperature \\
\hline 18 & $"$ & $"$ & $" \quad "$ \\
\hline 19 & $n$ & $"$ & " $" \quad "$ \\
\hline 20 & " & " & " $" \quad "$ \\
\hline 21 & Pressure Transducer & $0-100$ psig & EV Pressure \\
\hline
\end{tabular}


Table H.2. Instrumentation (continued)

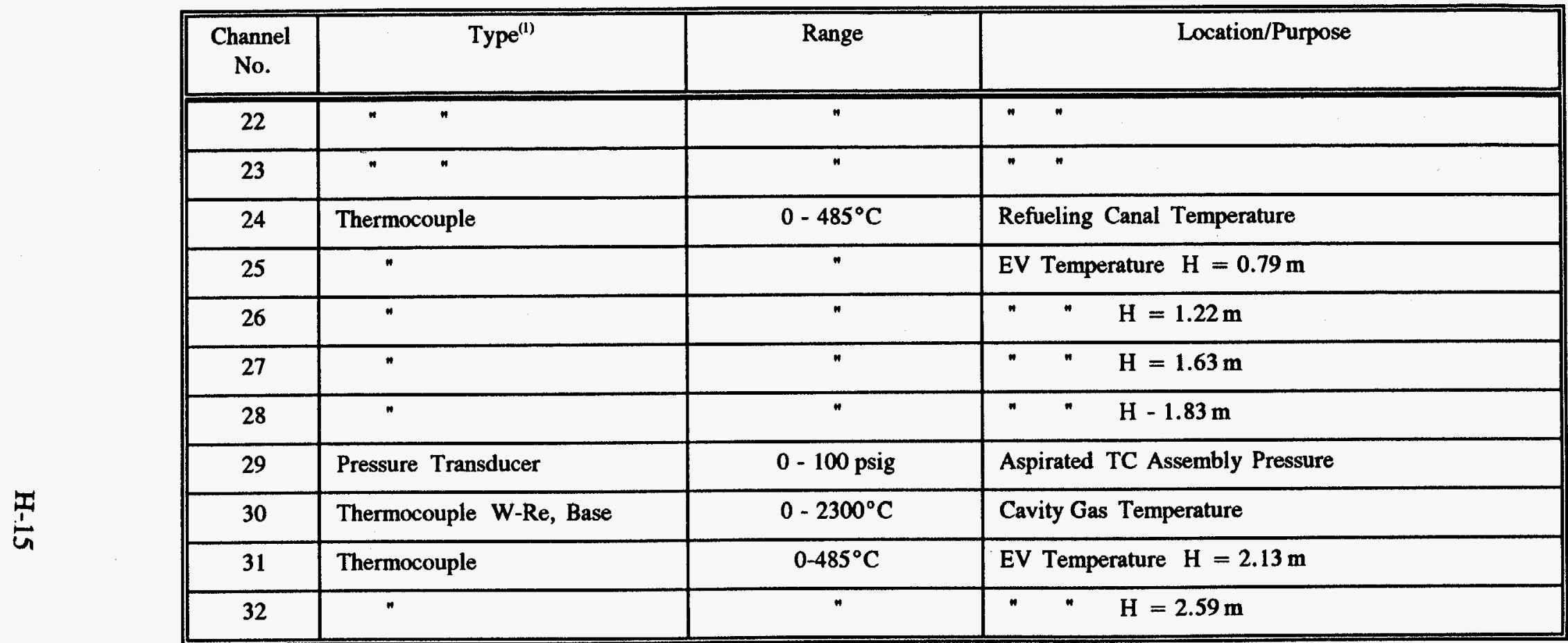

(1) All thermocouples are bare bead type $\mathrm{K}$ unless otherwise noted.

$\mathrm{H}=$ Height above operating deck. 
Table H.3. Initial conditions for $\mathrm{ANL}$ Fe/ $\mathrm{Al}_{2} \mathrm{O}_{3}-\mathrm{Cr}$ tests

\begin{tabular}{||l|c|c|c|c|c|c||}
\hline & IET-1R & IET-1RR & IET-3 & IET-6 & IET-7 & IET-8 \\
\hline \hline $\mathrm{D}_{\mathrm{H}}, \mathrm{cm}$ & 0.89 & 1.3 & 1.1 & 1.1 & 1.1 & 1.1 \\
\hline $\mathrm{P}_{\mathrm{o}}, \mathrm{MPa}$ & 6.2 & 6.7 & 5.7 & 6.6 & 6.1 & 6.5 \\
\hline $\mathrm{g}$-moles Steam & 8.55 & 9.84 & 8.43 & 9.65 & 8.88 & 9.36 \\
\hline $\mathrm{P}_{\infty}, \mathrm{MPa}$ & 0.2 & 0.2 & 0.2 & 0.2 & 0.1 & 0.2 \\
\hline $\mathrm{T}_{\infty}, \mathrm{K}$ & 308 & 318 & 318 & 315 & 318 & 477 \\
\hline $\mathrm{EV}$ Atm, Mole \% & & & & & & \\
\hline \hline $\mathrm{N}_{2}$ & 99.9 & 99.9 & 88.8 & 87.5 & 89.9 & 37.4 \\
\hline $\mathrm{O}_{2}$ & 0.0026 & 0.12 & 10.8 & 9.9 & 10.1 & 7.7 \\
\hline $\mathrm{H}_{2} \mathrm{O}$ & $\sim 0$ & $\sim 0$ & $\sim 0$ & $\sim 0$ & $\sim 0$ & 50.0 \\
\hline $\mathrm{H}_{2}$ & $\sim 0$ & $\sim 0$ & $\sim 0$ & 2.0 & $\sim 0$ & 3.9 \\
\hline
\end{tabular}


Table H.4. Summary of results from ANL 1/40 scale tests

\begin{tabular}{|l|c|c|c|c|c|c||}
\hline & IET-1R & IET-1RR & IET-3 & IET-6 & IET-7 & IET-8 \\
\hline \hline $\mathrm{P}_{\mathrm{o}}, \mathrm{MPa}$ & 6.2 & 6.7 & 5.7 & 6.6 & 6.1 & 6.5 \\
\hline$\Delta \mathrm{T}_{\mathrm{pe}, \mathrm{g}^{(1)}}$ & -0.6 & 0.22 & 0.28 & 0.29 & 0.81 & 0.42 \\
\hline Ejected Melt Mass, kg & 0.81 & 0.79 & 0.75 & 0.69 & 0.71 & 0.70 \\
\hline Blowdown Duration, s (P/P。 $=0.1)$ & 3.20 & 0.61 & 1.00 & 0.76 & 0.82 & 0.82 \\
\hline Blowdown Steam, g-moles & 8.55 & 9.84 & 8.43 & 9.65 & 8.88 & 9.36 \\
\hline Initial EV Pressure, MPa & 0.2 & 0.2 & 0.2 & 0.2 & 0.1 & 0.2 \\
\hline
\end{tabular}

Initial EV Atmosphere Composition, mole\%

\begin{tabular}{||l|c|c|c|c|c|c||}
\hline \hline $\mathrm{H}_{2}$ & $\sim 0$ & $\sim 0$ & $\sim 0$ & 2.0 & $\sim 0$ & 3.9 \\
\hline $\mathrm{O}_{2}$ & 0.0026 & 0.12 & 10.8 & 9.9 & 10.1 & 7.7 \\
\hline $\mathrm{N}_{2}$ & 99.9 & 99.9 & 88.8 & 87.5 & 89.9 & 37.4 \\
\hline$\Delta \mathrm{P}_{\max , \text { cavily }}, \mathrm{kPa}$ & 920 & 550 & 200 & 480 & 430 & 290 \\
\hline$\Delta \mathrm{P}_{\max , \text { dome }}, \mathrm{kPa}$ & 170 & 150 & 190 & 250 & 166 & 133 \\
\hline
\end{tabular}

(1)Elapsed time from pressurization of melt gerierator to onset of melt ejection.

${ }^{(2)}$ An unknown amount of debris was lost from this region during the recovery procedures. 
Table H.5. Summary of gas sample measurements for ANL IET-1, 1R, 1RR, 3 and 6

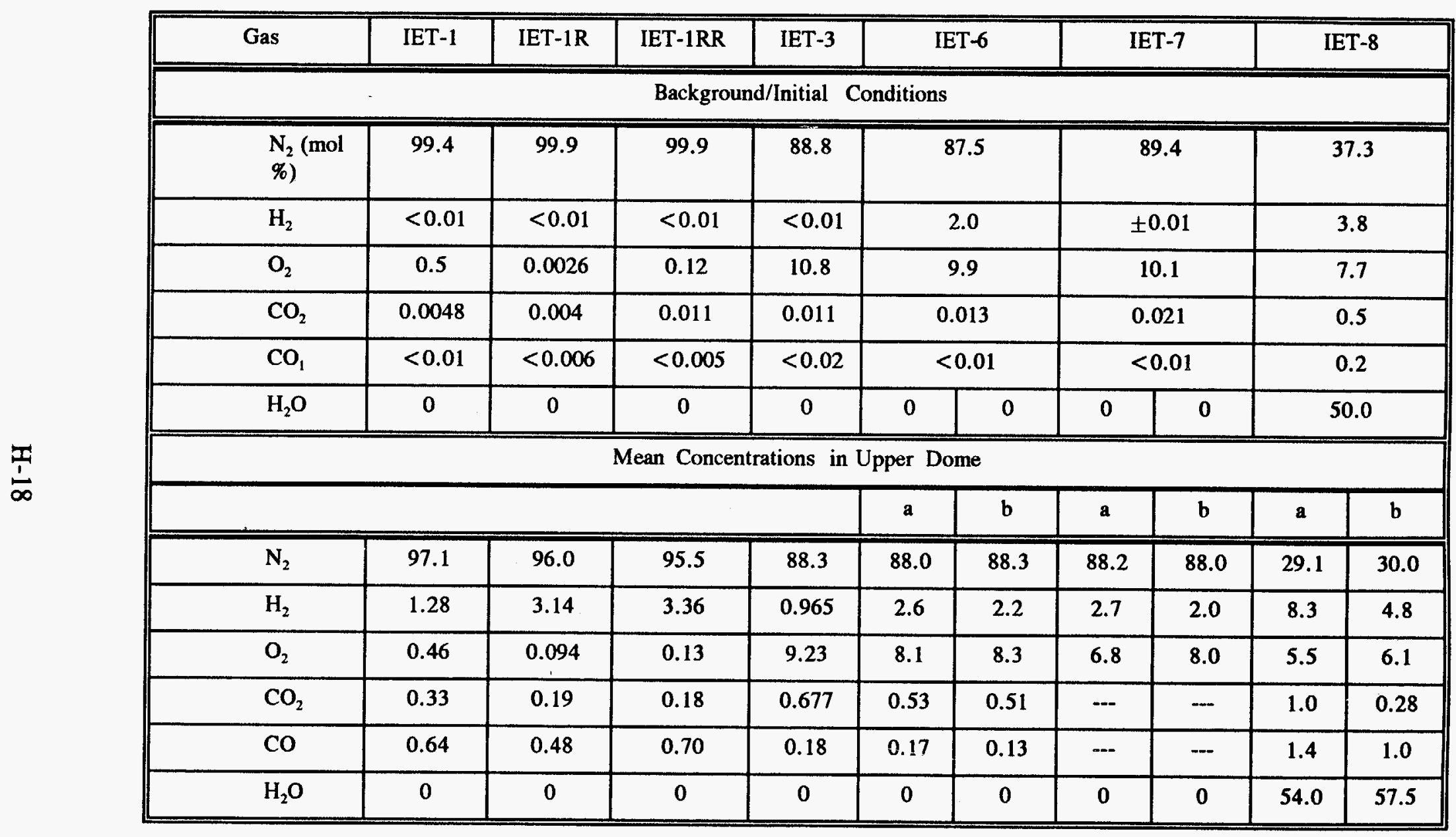

a) Mean of samples taken at 1 and 7.5 minutes.

b) Means of samples taken at 30 seconds. 
Table H.6. Summary of debris disposition

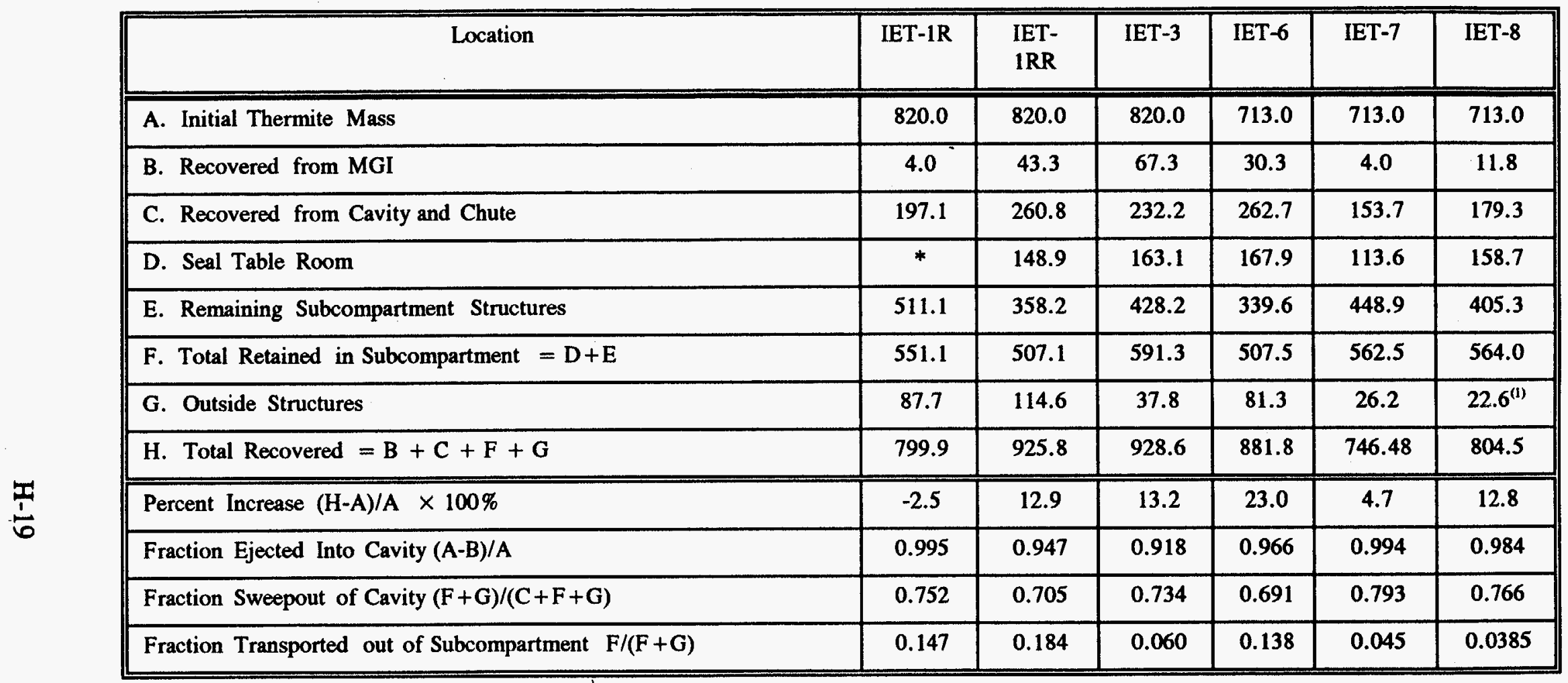

1 An unknown amount of debris was lost during the vacuuming procedure. 
Table H.7. Particle size

\begin{tabular}{|c|c|c|c||}
\hline Test & $\begin{array}{c}\text { Driving Pressure, } \\
\text { MPa }\end{array}$ & $\begin{array}{c}\text { Hole } \\
\text { Size, } \\
\mathrm{mm}\end{array}$ & $\begin{array}{c}\text { D, } \\
\mathrm{mm}\end{array}$ \\
\hline 1R & 6.2 & 11 & 700 \\
\hline IRR & 6.7 & 13 & 458 \\
\hline 3 & 5.7 & 11 & 1009 \\
\hline 6 & 6.6 & 11 & 1044 \\
\hline 7 & 6.1 & 11 & 400 \\
\hline
\end{tabular}

Table H.8. DCH pressurization results

\begin{tabular}{||l|c|c|c|c|c|}
\hline & IET-1RR & IET-3 & IET-6 & IET-7 & IET-8 \\
\hline \hline a) $\begin{array}{l}\text { Experiment peak pressurization in cavity } \\
\text { region, KPa }\end{array}$ & 550 & 200 & 480 & 430 & 290 \\
\hline b) $\begin{array}{l}\text { Experiment peak pressurization in done region, } \\
\mathrm{KPa}\end{array}$ & 150 & 190 & 250 & 166 & 133 \\
\hline c) $\begin{array}{l}\text { Theoretical maximum pressurization } \\
\text { (adiabatic) }\end{array}$ & 479 & 904 & 1106 & 813 & 1108 \\
\hline d) $\mathrm{DCH}$ Efficiency $=\frac{(\mathrm{b})}{\mathrm{C}} \times 100$ & 31 & 21 & 23 & 20 & 13 \\
\hline
\end{tabular}




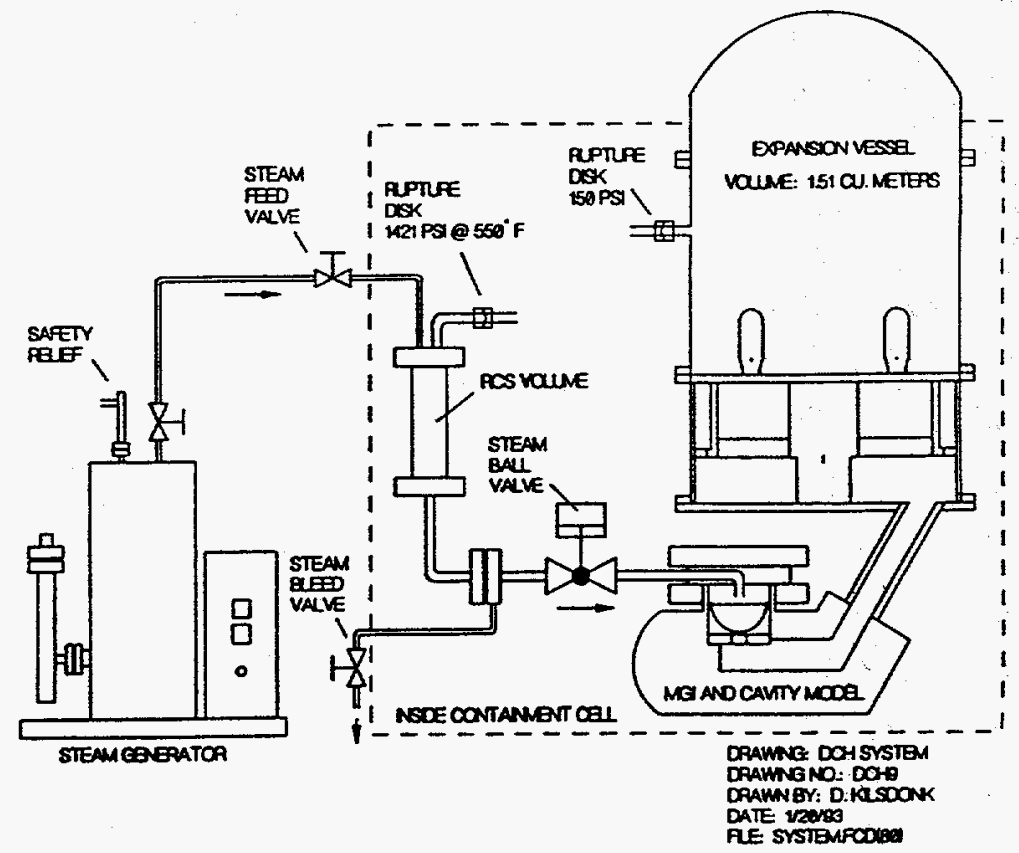

Figure H.1. COREXIT facility.

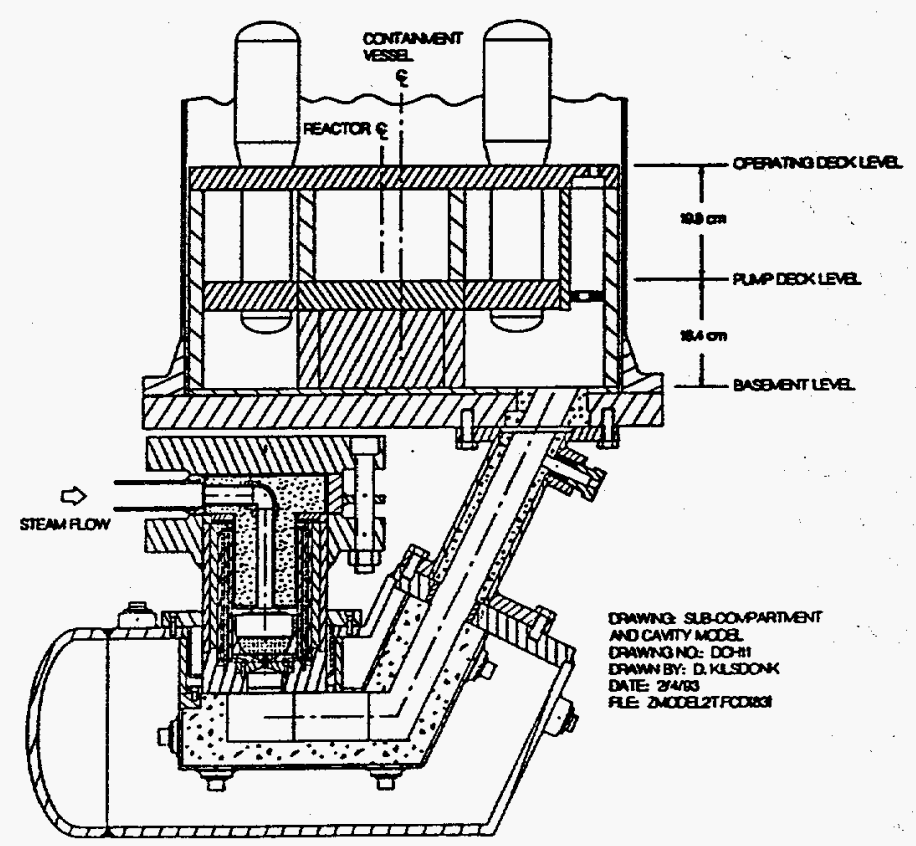

Figure H.2. Zion cavity model. 


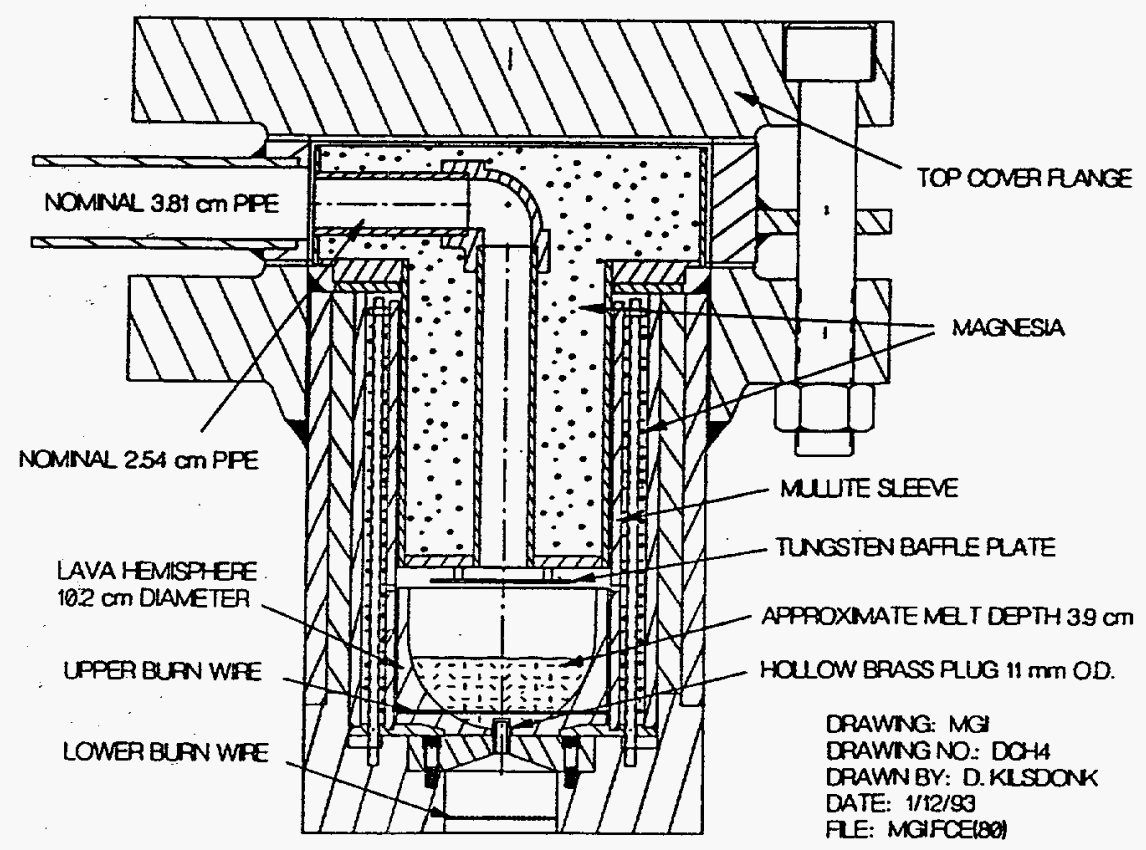

Figure H.3. Schematic of melt generator and injector (MGI).

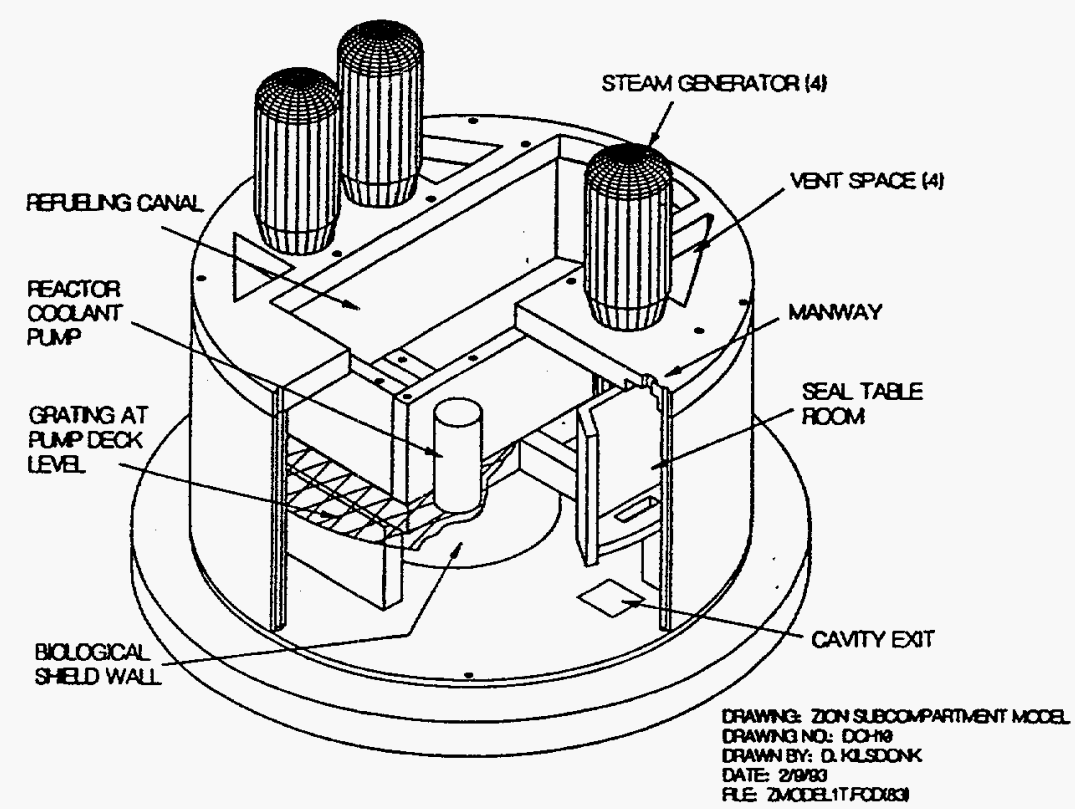

Figure H.4. Schematic of the subcompartment model. 


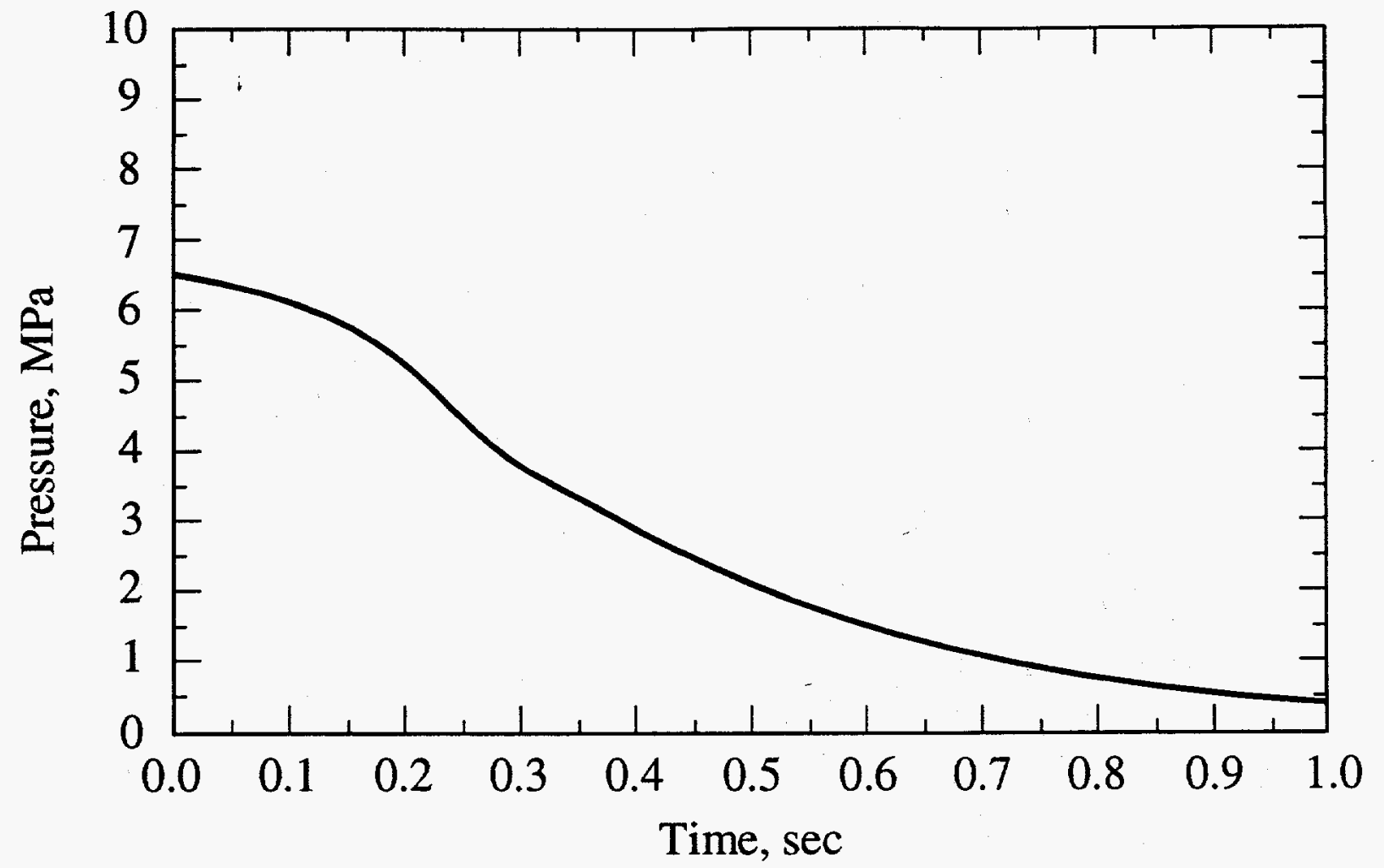

Figure H.5. IET-8 blowdown history.

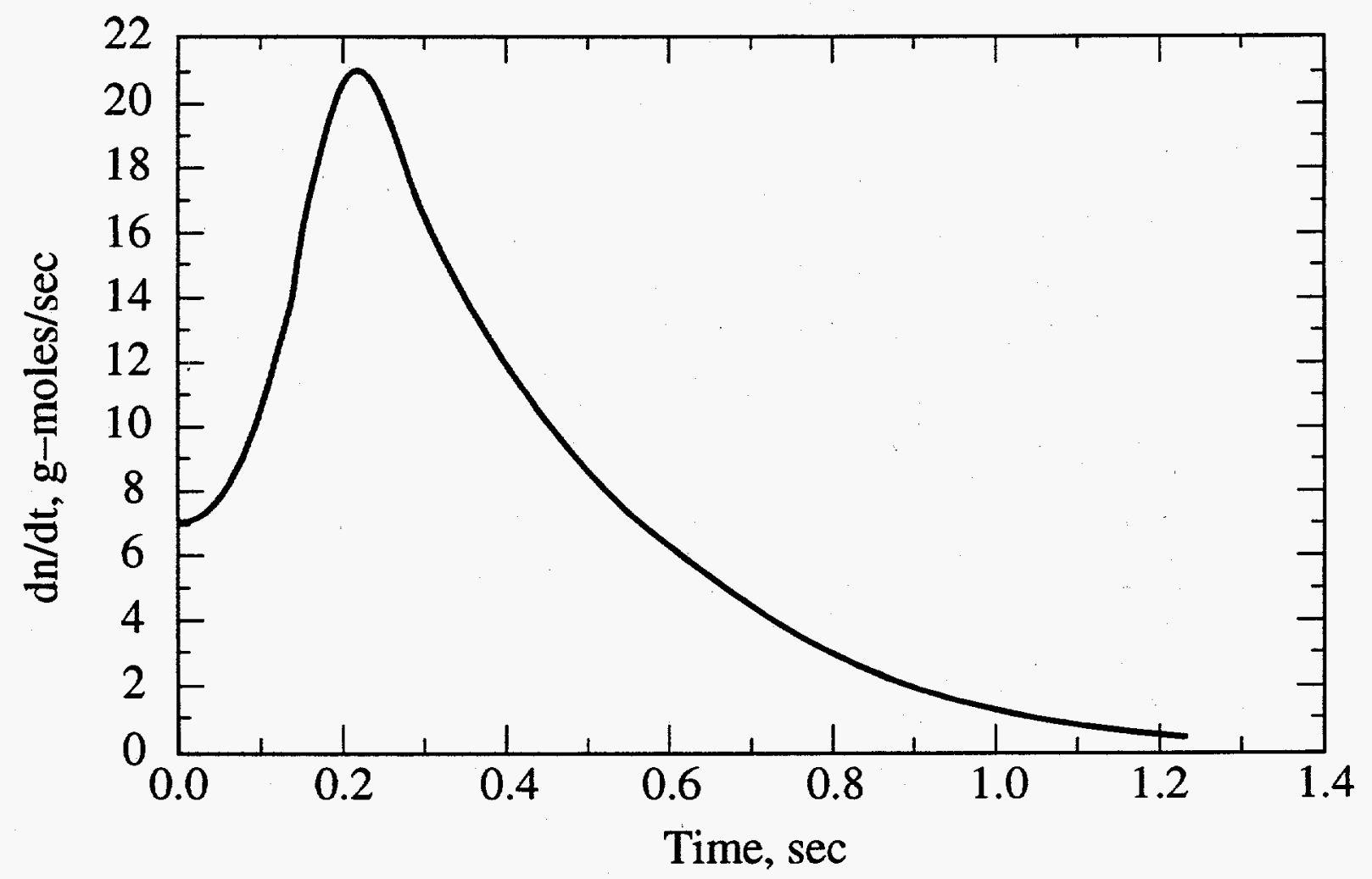

Figure H.6. IET-8 RCS blowdown rate. 


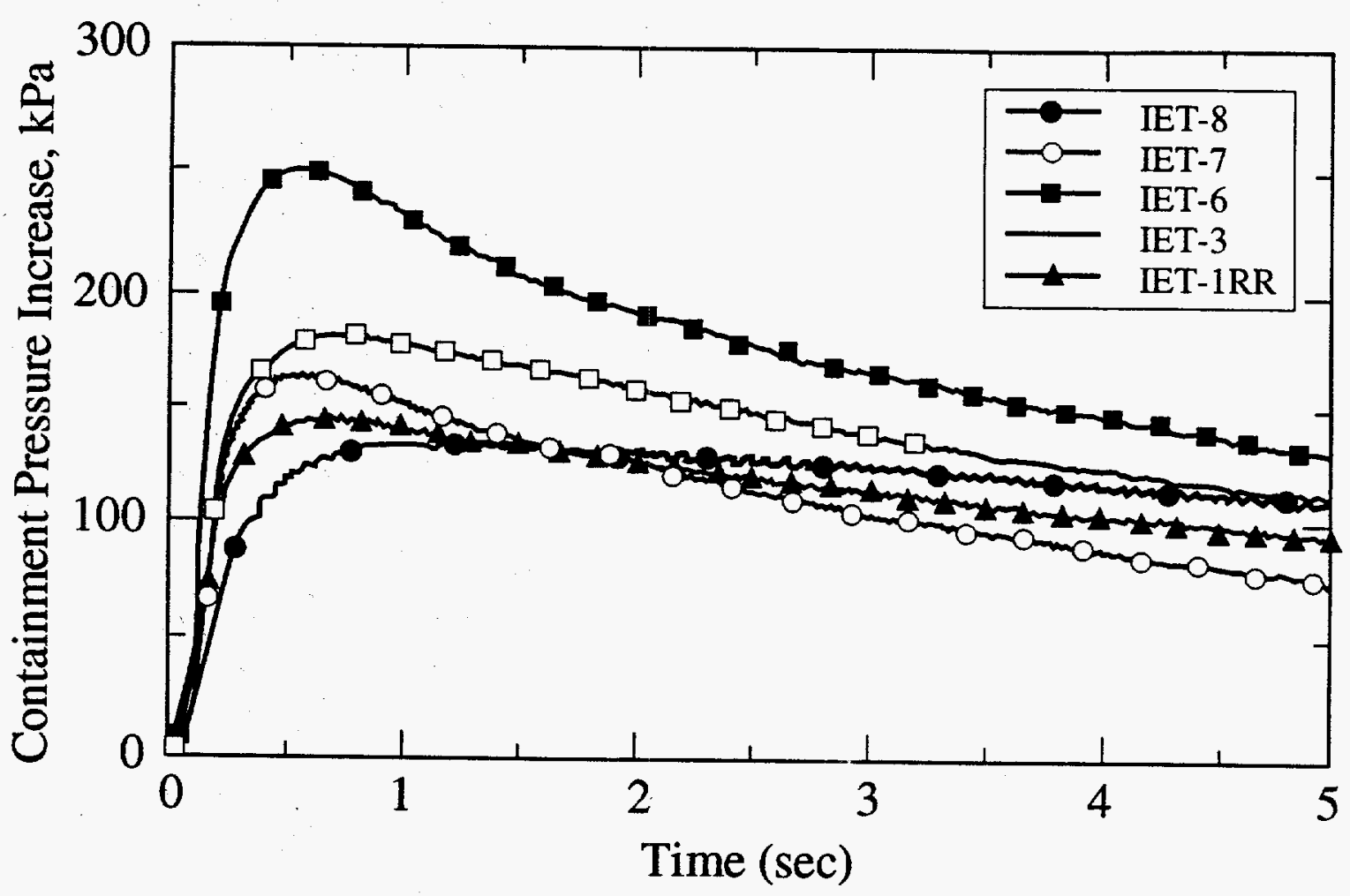

Figure H.7. ANL IET results.

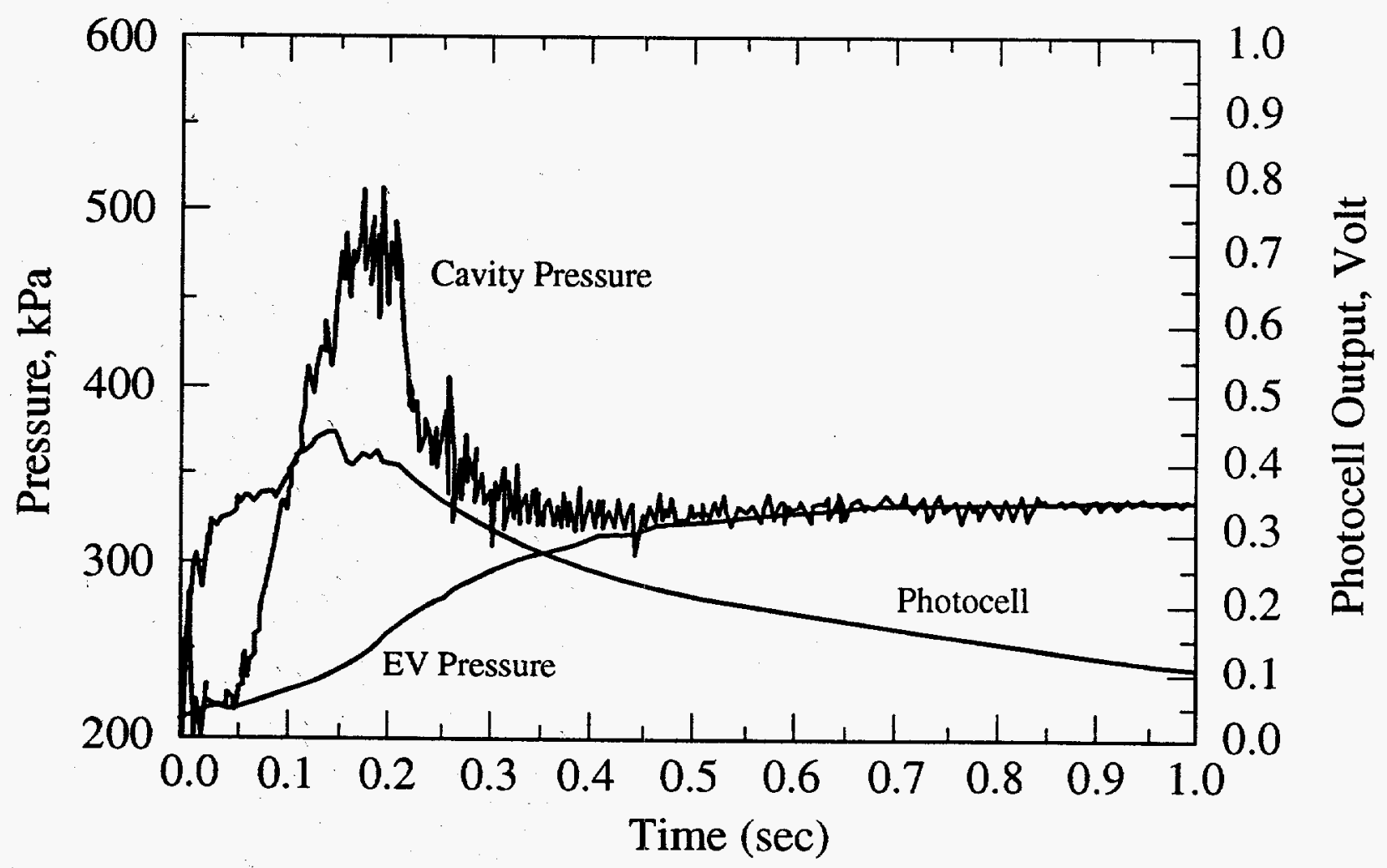

Figure H.8. IET-8 cavity pressure and photocell output. 


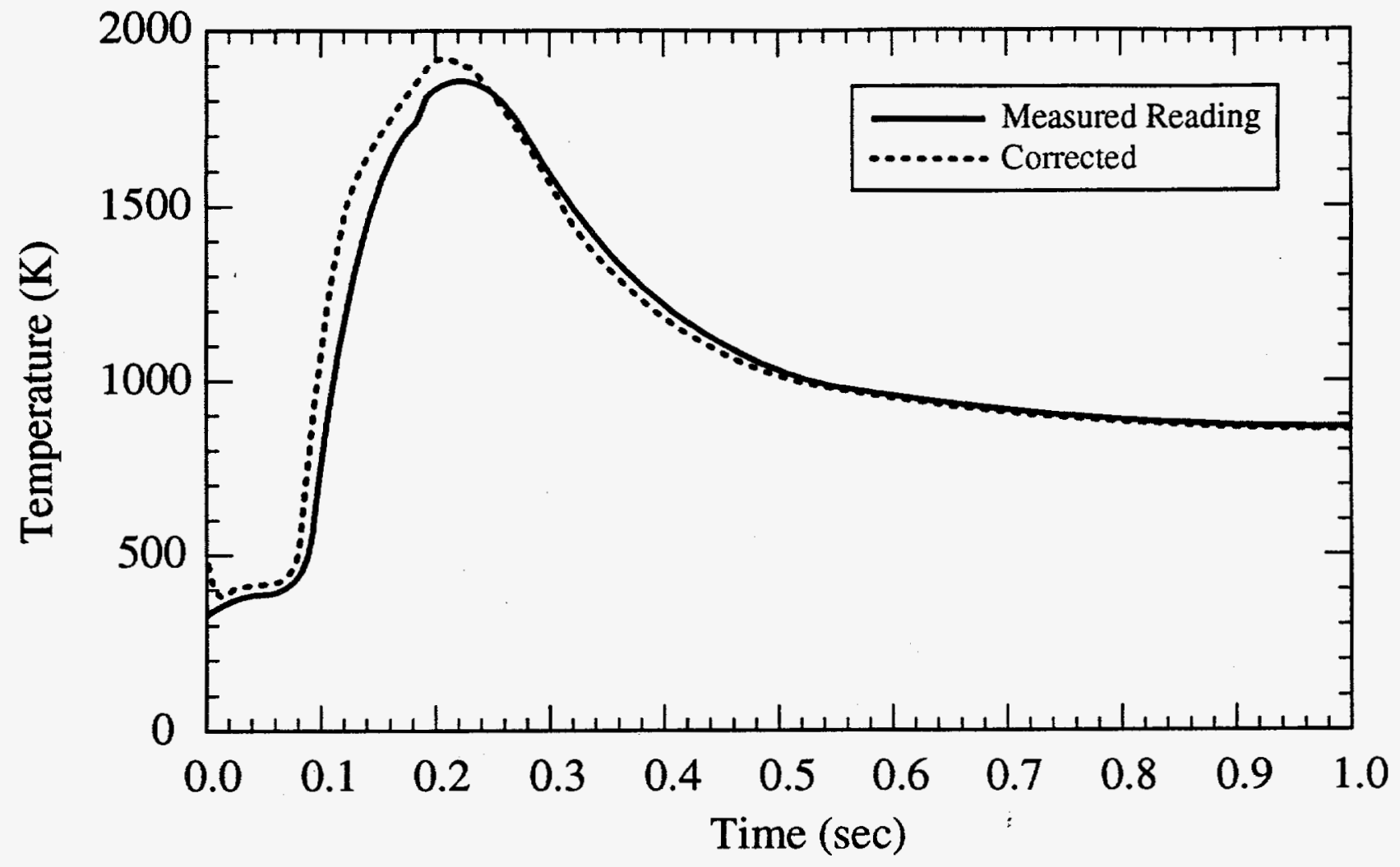

Figure H.9. Cavity gas temperature ohtained in the IET-3 test.

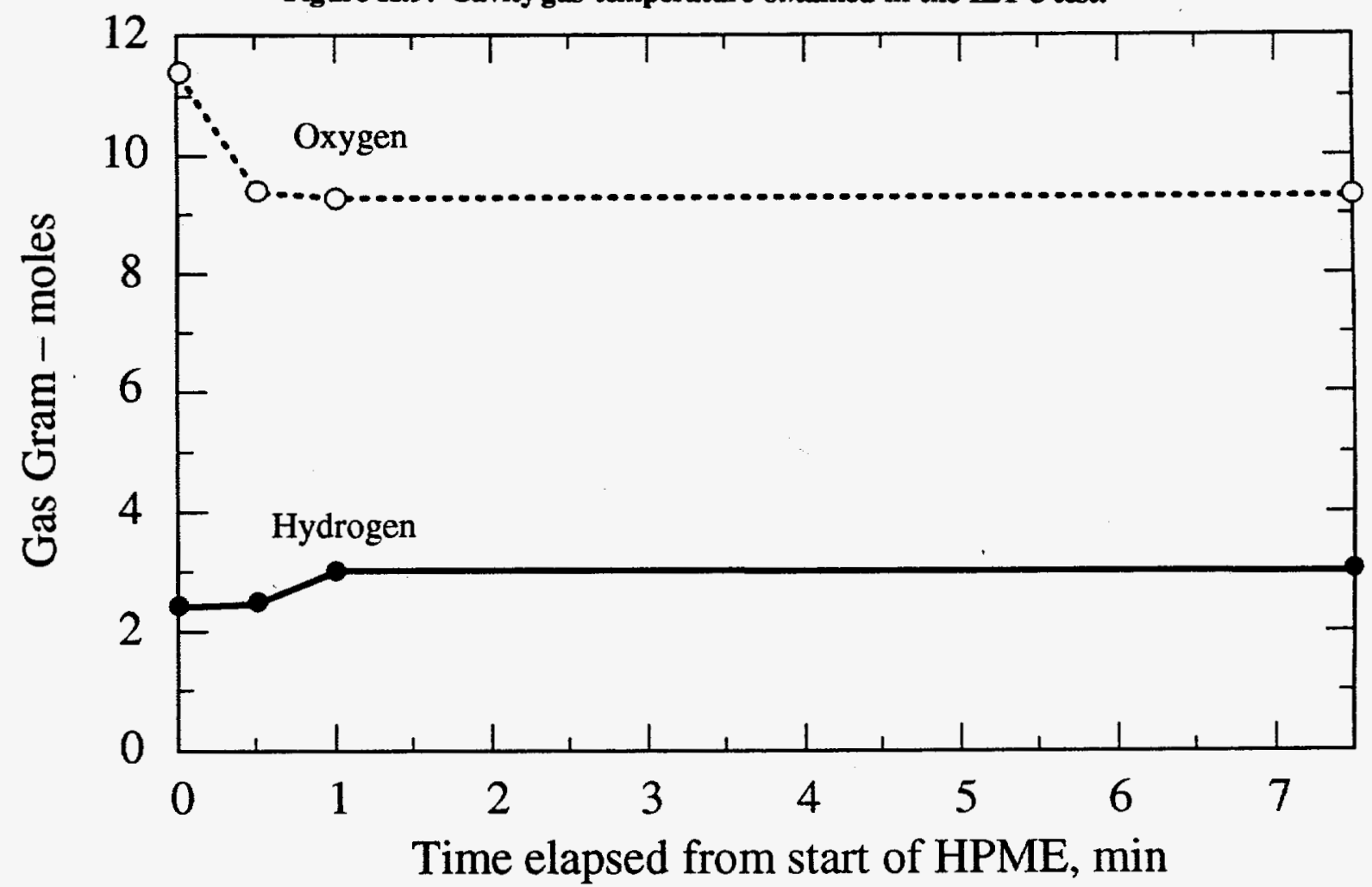

Figure H.10. Number of oxygen and hydrogen moles in IET-6. 


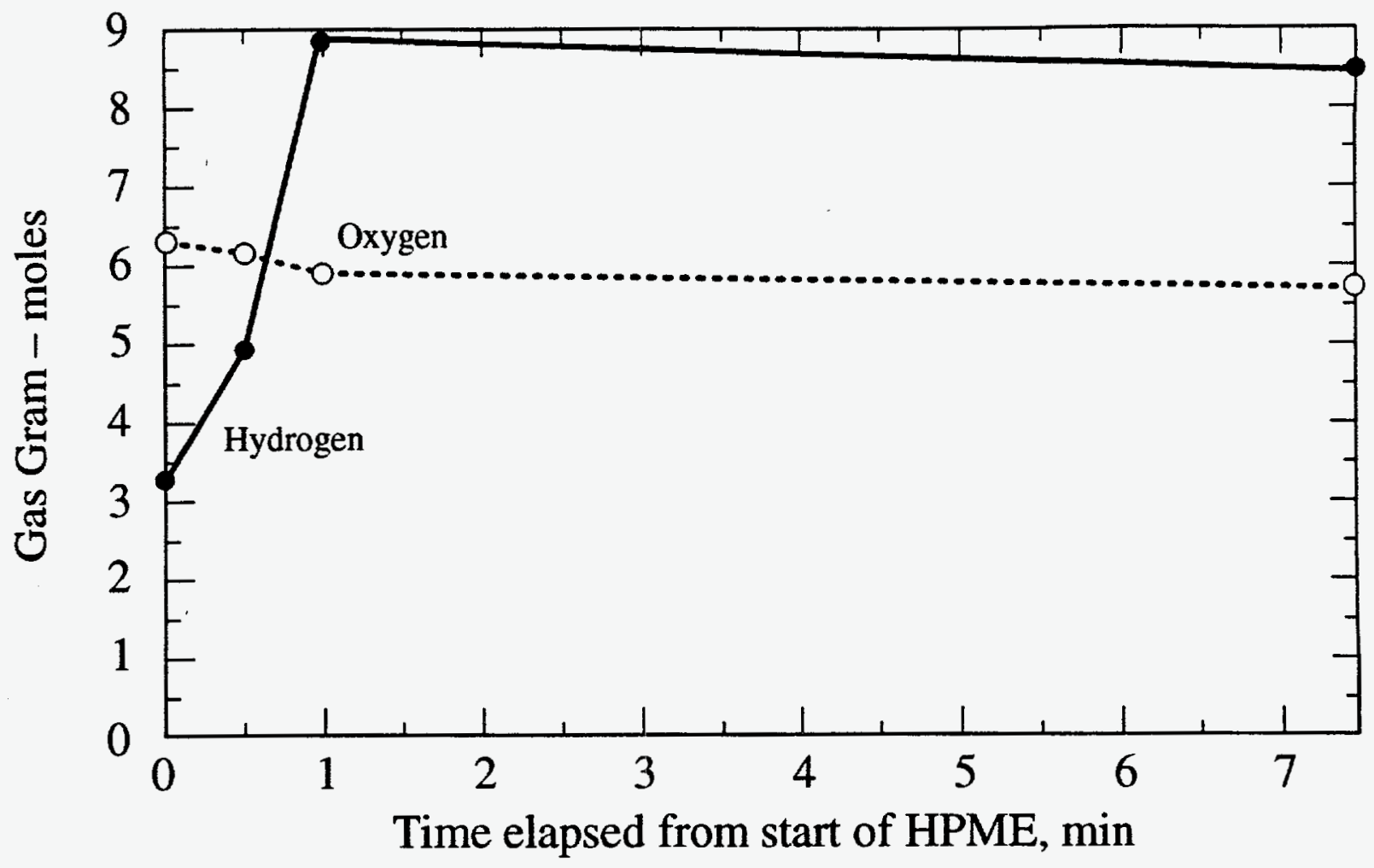

Figure H.11. Number of oxygen and hydrogen moles in IET-8. 


\section{APPENDIX I \\ THE ROLE OF THE ANNULAR GAP \\ AROUND THE RPV}

Martin M. Pilch

Sandia National Laboratories

\section{I.1 INTRODUCTION}

The annular gap around the reactor pressure vessel (RPV) is a potentially important pathway for debris dispersal. Debris dispersed from the cavity through this pathway enters the upper dome of the containment where direct containment heating $(\mathrm{DCH})$ processes are most efficient. The HIPS-8C experiment (Pilch et al., 1988) demonstrated that significant debris can be dispersed through the annular gap (Zion-like geometry) when insulation and nozzles are not present.

The insulation in the Zion plant is mostly void with a layer of stainless steel (SS) foil sandwiched between two sheets of SS sheet metal. The insulation fills about half the gap between the RPV and the cavity walls. The open flow area outside the insulation is required for natural circulation cooling of the enclosure. The insulation is constructed in a number of boxlike panels, one attached to another by sheet metal screws or pop rivets. The entire assembly is hung from the hot-leg and cold-leg nozzles.

The fate of the insulation under DCH conditions has been a matter of speculation. Some researchers argue that the insulation will crumple up and restrict the flow path. Others argue that the insulation will be blown from the gap or compressed against the RPV, thus presenting the maximum flow area for debris dispersal. These speculations were recently put to the test in a 1:5.75 scale experiment in Surry geometry where the annular gap and RPV insulation were modeled. In this experiment, melt carried into the gap cut and melted the insulation allowing it to be swept clear of the gap by blowdown and debris. Thus, the insulation

offered no resistance to debris and gas transport through the gap. As a cautionary note, some reactors other than Zion have neutron shields placed in the gap, and some researchers feel that 
this additional hardware could impede debris dispersal. The potential for this mitigation must be evaluated on a plant specific basis. We now seek to characterize the amount of debris dispersed from the cavity directly to the dome through the annular gap.

\section{I.2 FRACTION DISPERSED THROUGH ANNULAR GAP}

Debris can be dispersed through the main tunnel leading to the containment subcompartment and through the annular gap leading directly to the dome. We note that the fraction dispersed in each direction is controlled by the fractional flow resistance in each direction. To first order then, the fraction of debris dispersed through the annular gap is given by

$$
f_{g, A}=\frac{A_{g}}{A_{T}+A_{g}}
$$

where $A_{E}$ and $A_{T}$ are the minimum flow areas in the annular gap and the instrument tunnel respectively.

This expression can be derived both from the perspective of choked flow from the cavity and incompressible flow from the cavity. For choked flow, the gas flow rate through the gap and the tunnel are given by

$$
\dot{m}_{g}=c_{g} A_{g} P_{c}\left[\frac{f_{\gamma}}{R T_{c}}\right)^{1 / 2} \text { and } \dot{m}_{T}=C_{T} A_{T} P_{c}\left(\frac{f_{\gamma}}{R T_{c}}\right)^{1 / 2}
$$

so that

$$
f_{g, A}=\frac{\dot{m}_{g}}{\dot{m}_{T}+\dot{m}_{g}}=\frac{C_{g} A_{g}}{C_{T} A_{T}+C_{g} A_{g}} \approx \frac{A_{g}}{A_{T}+A_{g}} .
$$

The discharge coefficients are bounded by 0.6 for a sharp edged orifice and 1.0 for a perfect nozzle. Since neither extreme is expected in either flow path, the two discharge coefficients will have similar values and the simplified approximation is justified. 
For incompressible flow, the gas flow rates are given by

$$
\dot{m}_{g}=A_{\delta}\left(\frac{2 \rho_{c} \Delta P}{K_{g}}\right]^{1 / 2} \text { and } \dot{m}_{T}=A_{T}\left(\frac{2 \rho_{c} \Delta P}{K_{T}}\right)^{1 / 2}
$$

so that

$$
f_{g, A}=\frac{\dot{m}_{g}}{\dot{m}_{T}+\dot{m}_{g}}=\frac{\frac{A_{g}}{\sqrt{K_{g}}}}{\frac{A_{T}}{\sqrt{K_{T}}}+\frac{A_{g}}{\sqrt{K_{g}}}} \approx \frac{A_{g}}{A_{T}+A_{g}} .
$$

Since contraction and expansion losses at the restrictions play such an important role in the two flow paths, the loss coefficients are indeed similar, and the simplified model is again justified.

Table I.1 uses those DCH experiments that have been conducted with an annular gap to validate Equation I.1. The first column lists the dispersal fraction computed from Equation I.1. The second column lists the measured fraction of dispersed mass that entered the dome through the annular gap. Such comparisons validate the notion that dispersal through the gap is determined by the fractional flow resistance associated with the gap.

Dispersal through the annular gap at Zion can now be characterized. The minimum tunnel flow area is $-5.6 \mathrm{~m}^{2}$. The annular gap at Zion is $0.17 \mathrm{~m}$ wide; and the outside diameter of the RPV is $\sim 4.8 \mathrm{~m}$. The minimum flow area through the gap occurs at the level of the hot and cold leg nozzles, which occlude $80 \%$ of the gap's circumference about the vessel. Thus, the minimum flow area in the gap is $-0.51 \mathrm{~m}^{2}$, and the fraction of dispersed debris transported through the gap is $\sim 0.09$.

Dispersal through the annular gap generally occurs under choked flow conditions; consequently, a simple uncertainty analysis yields 


$$
\sigma_{f}=\frac{\delta f_{g, A}}{f_{g, A}}=\left[\left(1-f_{g, A}\right)^{2}+\left(1-f_{g, A}\right)^{-2}\right]^{1 / 2} \frac{\delta C}{C}
$$

For the representative values $\mathrm{f}_{\mathrm{g}, \mathrm{a}} \sim 0.15, \mathrm{C}=\mathrm{C}_{\mathrm{g}}=\mathrm{C}_{\mathrm{T}} \sim \mathrm{D} .8, \delta \mathrm{C} \sim 0.1$, then the expected uncertainty in $\mathrm{f}_{\mathrm{g}, \mathrm{a}}$ is about $19 \%$. Although there are only 3 data points in Table I.1, the relative standard deviation that is computer from the data is also abut $19 \%$, so the uncertainty assessment is consistent with the data. For the Zion assessment $\left(f_{\mathrm{g}, \mathrm{A}} \sim 0.09\right)$, the expected uncertainty is about $18 \%$.

\section{I.3 REFERENCES}

Blanchat, T.K. et al. (April 1994). Experiments to Investigate Direct Containment Heating Phenomena With Scaled Models of the Surry Nuclear Power Plant, NUREG/CR-6152, SAND93-2519, Sandia National Laboratories, Albuquerque, NM.

Pilch, M. et al. (Sept. 1988). The Influence of Selected Containment Structures on Debris Dispersal and Transport Following High Pressure Melt Ejection From the Reactor Vessel, NUREG/CR-4914, SAND87-0940, Sandia National Laboratories, Albuquerque, NM.

\section{I.4 NOMENCLATURE}

$\begin{array}{lll}\mathrm{A}_{\mathrm{g}}, \mathrm{A}_{\mathrm{T}} & = & \text { minimum flow area in the gap and tunnel } \\ \dot{\mathrm{m}}_{\mathrm{g}}, \dot{\mathrm{m}}_{\mathrm{T}} & = & \text { gas flow rate in the gap and tunnel } \\ \mathrm{C}_{,}, \mathrm{C}_{\mathrm{g}}, \mathrm{C}_{\mathrm{T}} & = & \text { discharge coefficient, generally or for the gap and tunnel } \\ \mathrm{f}_{\mathrm{g}, \mathrm{A}} & = & \text { fraction of debris dispesed through gap } \\ \mathrm{P}_{\mathrm{c}} & = & \text { cavity pressure } \\ \mathrm{T}_{\mathrm{c}} & = & \text { gas temperature in cavity } \\ \mathrm{R} & = & \text { gas constant } \\ \mathrm{f}_{\gamma} & = & \text { function of the isentropic exponent } \\ \mathrm{K}_{\mathrm{g}}, \mathrm{K}_{\mathrm{T}} & = & \text { loss coefficient for the gap and tunnel } \\ \Delta \mathrm{P} & = & \text { pressure difference between the cavity and the containment } \\ \rho_{\mathrm{c}} & = & \text { gas density in the cavity }\end{array}$


Table I.1. Validation of debris dispersal through the annular gap

\begin{tabular}{||l|c|c|}
\hline \multicolumn{1}{|c|}{ Experiment } & $\mathbf{f}_{\mathbf{q}, \mathbf{A}}$ & $\mathbf{f}_{\mathbf{z}, \mathbf{m}}$ \\
\hline \hline SNL/HIPS-8C & 0.27 & $\sim 0.24$ \\
\hline $\begin{array}{l}\text { SNL/IET-11 } \\
\text { (Blanchat et al., 1994) }\end{array}$ & 0.15 & $\sim 0.17$ \\
\hline $\begin{array}{l}\text { SNL/IET-9 } \\
\text { (Blanchat et al., 1994) }\end{array}$ & 0.06 & $\sim 0.08$ \\
\hline
\end{tabular}




\section{APPENDIX J \\ CONTINUED ENLARGEMENT OF THE INITIAL FAILURE SITE \\ IN THE REACTOR PRESSURE VESSEL}

Martin M. Pilch

Sandia National Laboratories

\section{J.1 INTRODUCTION}

Molten core material is considerably hotter than the melting point of the RPV steel; consequently, corium discharge could be accompanied by rapid ablation of the hole that was initially formed in the RPV. In rupture scenarios, the formation of a hole creates a localized stress concentration that might cause the initial failure to propagate to a much larger size. These processes not only accelerate corium discharge, but the resulting hole size has a direct influence on RCS blowdown, debris fragmentation, dispersal of debris from the cavity, and subsequent containment phenomena. In this report, the final hole size plays a central role in quantification of the coherence ratio.

Sections J.2-J.4 develop a model for the final hole size after ablation. Applicability of the model to both experiment and reactor analyses is addressed. The ablation model is validated against existing experiment data in Section J.5. Extrapolation outside the database is required for NPP applications. Sensitivity studies over the extremes of the controlling parameters form the basis for treatment of hole ablation within the probabilistic framework. Section J. 6 shows that RCS depressurization effectively eliminates any possibility for continued enlargement of a rupture once it is formed.

The germinal elements of the current ablation model were first presented by Pilch and Tarbell (1985). Their work was motivated by an earlier model developed as part of the Zion Probabilistic Safety Study (ZPSS, 1981). Moody (Referenced in Zuber et al., (1991)) presented an ablation model and then proceeded to examine the scaling implication of potential experiments. Although similar in their basic concept, these models are distinguished by their treatment of the melt/substrate heat transfer coefficient and by their treatment of the melt/substrate interface temperature. 


\section{J.2 HOLE ABLATION - PRELIMINARY CONCEPTS}

Ablation of the orifice will occur when the interface temperature between the wall material and the flowing core debris reaches the melting point of the RPV steel. For many conditions of interest, there is a short delay before wall ablation is initiated. The analysis that follows quantifies the conditions under which this delay occurs and the magnitude of the delay. The equation describing hole ablation will be developed following this initial discussion.

Temperature profiles are assumed to be one-dimensional in a direction normal to the flow of core material through the hole. The instantaneous contact temperature between the walls of the orifice and the melt is given by

$$
T_{c}=\frac{T_{w} k_{w} \sqrt{\alpha_{d}}+T_{d} k_{d} \sqrt{\alpha_{w}}}{k_{w} \sqrt{\alpha_{d}}+k_{d} \sqrt{\alpha_{w}}}
$$

For typical conditions, the contact temperature, $T_{c}$, is about $1550 \mathrm{~K}$, which is below the melting point of the RPV wall (steel) and the freezing point of the oxide components in the core melt. Conditions at instantaneous contact favor crust formation (i.e. frozen core material) without melting of the RPV substrate. This is case 1 shown in Figure J.1.

The convective heat flux from the flowing core debris to the crust will cause the RPV substrate to heat up and begin melting (Epstein, 1976) in a time given approximately by

$$
t_{1}=\frac{\pi}{4 \alpha_{w}}\left[\frac{k_{w}\left(T_{m p, w}-T_{w}\right)}{h_{d, w}\left(T_{d}-T_{m p, d}\right)}\right] .
$$

The Zion PRA (ZPSS, 1981) proposed that a thin crust ( $\sim 66 \mu \mathrm{m}$ in the NPP case) of frozen core material could float on a layer of molten wall material. This is depicted as case 2 in Figure J.1. During HPME, however, the velocity of discharging material is more likely to entrain nearly all crust and molten wall material. In this case, the flowing core material is in direct contact with the ablating surface. 
Assuming no ablation of the hole, the time required to discharge all the melt is approximated by

$$
t_{2}=\frac{M_{d}^{o}}{C_{d \rho_{d} A_{h}^{o}}\left[\frac{2}{\rho_{d}}\left(P_{R C S}^{o}-P_{c}^{g}\right)\right]^{1 / 2}}
$$

Comparing the two times $\left(t_{1}\right.$ and $t_{2}$ ) for typical NPP conditions indicates that wall melting is initiated long before all the corium is fully discharged from the RPV. The delay time can be ignored under these circumstances and ablation can be assumed to start with the initiation of flow through the hole.

There are two possible situations where the above approximation is not valid: rupture of the lower head and small scale experiments. If the initial hole in the lower head is sufficiently large (as might occur by a rupture type failure), then the melt ejection time could be comparable to the time required to initiate ablation. This case can be ignored, however, because if ablation is erroneously assumed to start with the onset of flow, there will be an insignificant amount of ablation during the very short period of corium discharge. Predicting a little more ablation where it might not occur is a conservative bias in this report in that larger hole sizes lead to larger containment loads.

Small-scale experiments may also lead to a potential violation of the approximation if the initial hole size is larger than dictated by geometric scaling from the NPP value. The combination of small mass and a disproportionately large hole lead to conditions that look more like the rupture scenario. This is a potential concern only for experiments that are used to validate the ablation model. The ratio $\left(t_{1} / t_{2}\right)$ has been checked for these experiments and the assumption of instantaneous ablation is valid for the database used to validate the model. 


\section{J.3 HOLE ABLATION}

Once wall melting is initiated, the ablation rate quickly reaches a steady state. This steady state ablation rate can be obtained by balancing the convection transfer of energy to the substrate with the energy required to heat and melt the wall:

$$
\frac{d D}{d t}=\frac{2 h_{d, w} \Delta T_{r}}{\rho_{w}\left[C_{p, w}\left(T_{m p, w}-T_{w}\right)+h_{f, w}\right]}=\dot{D}_{h, r e f} .
$$

The heat transfer coefficient, $h_{d, w}$, and the reference temperature difference, $\Delta T_{r}$, are important constitutive relations that will be discussed in Section J.4. They are assumed constant in this analysis; therefore,the ablation rate is also a constant. Integrating yields

$$
D_{h, f}-D_{h}^{o}=\frac{2 h_{d, w} \Delta T_{r}}{\rho_{w}\left[C_{p, w}\left(T_{m p, w}-T_{w}\right)+h_{f, w}\right]} t_{d}=\dot{D}_{h, \text { ref }} t_{d},
$$

which after normalization becomes

$$
\frac{\Delta D}{D^{o}}=\frac{\dot{D}_{h, r e f}}{D^{o}} t_{d}=\frac{t_{d}}{\tau_{D}} .
$$

The discharge time $\left(\mathrm{t}_{\mathrm{d}}\right)$ is controlled by the amount of melt on the lower head and the time-dependent hole size. Integrating the continuity equation for melt mass,

$$
\frac{d M_{d}}{d t}=-\rho_{d} \frac{\pi}{4}\left(D_{h}^{o}+\dot{D}_{h, \text { ref }} t\right)^{2} v_{d}=\dot{M}_{d, r}^{o}\left[1+\frac{t}{\tau_{D}}\right]^{2},
$$

yields a cubic equation for the discharge time,

$$
\frac{t_{d}}{\tau_{D}}\left[1+\frac{t_{d}}{\tau_{D}}+\frac{1}{3}\left[\frac{t_{d}}{\tau_{D}}\right]^{2}\right]=\frac{\tau_{m}}{\tau_{D}}
$$


In this formulation,

$$
\tau_{D}=\frac{D_{h}^{0}}{\dot{D}_{h, \text { ref }}}=\frac{D_{h}^{o}}{\left(\frac{2 h_{d, w} \Delta T_{r}}{\rho_{w}\left[C_{p, w}\left(T_{m p, w}-T_{w}\right)+h_{f, w}\right]}\right]}
$$

is the characteristic time required to double the hole size by ablation, and

$$
\tau_{m}=\frac{M_{d}^{o}}{\dot{M}_{d, r}^{0}}=\frac{M_{d}^{o}}{\rho_{d} C_{d} \frac{\pi\left(D_{h}^{o}\right)^{2}}{4}\left[\frac{2}{\rho_{d}}\left(P_{R C S}^{o}-P_{c}^{o}\right)\right]^{1 / 2}}
$$

is the characteristic time required to discharge all the melt assuming the hole does not ablate.

There are two physical limits of interest. In the case of a large rupture, the discharge time is expected to be small compared to the characteristic ablation time $\left(t_{d} / \tau_{D}<<1\right)$, in which case

$$
\frac{t_{d}}{\tau_{D}} \approx \frac{\tau_{m}}{\tau_{D}}
$$

The second physical limit is associated with a penetration failure (i.e., a small initial hole size). Here the discharge time without ablation is long and ablation largely controls the discharge time $\left(\tau_{\mathrm{m}} / \tau_{\mathrm{D}}>>1\right)$. In this extreme, $\mathrm{t}_{\mathrm{d}} / \tau_{\mathrm{D}}>>1$, and the appropriate root of the cubic equation becomes

$$
\frac{t_{d}}{\tau_{D}} \approx\left(3 \frac{\tau_{m}}{\tau_{D}}\right)^{1 / 3}
$$

A useful interpolation function that recovers these two extremes is given by 


$$
\frac{t_{d}}{\tau_{D}}=\frac{\frac{\tau_{m}}{\tau_{D}}}{1+0.6934\left(\frac{\tau_{m}}{\tau_{D}}\right)^{2 / 3}} .
$$

For rupture failures $\left(\tau_{\mathrm{m}} / \tau_{\mathrm{d}}<1\right)$, this approximation underpredicts the discharge time (hence hole ablation) by no more than 4.8 percent, with the largest error occurring at $\tau_{\mathrm{m}} / \tau_{\mathrm{D}}=0.01$. This nonconservative error is of no concern since uncertainties in the final hole size are totally dominated by uncertainties in predicting the initial rupture size. For penetration failures $\left(\tau_{\mathrm{m}} / \tau_{\mathrm{D}}>1\right)$, the interpolation function conservatively overpredicts the discharge time (hence hole ablation) by no more than 11 percent, with the largest error occurring at $\tau_{\mathrm{m}} / \tau_{\mathrm{D}} \sim 10^{3}$. The interpolation function will overpredict the final hole size by about 6 percent for penetration failures in reactor applications for hole ablation. A conservative bias of this magnitude is judged acceptable.

\section{J.4 CONSTITUTIVE RELATIONS}

Quantitative evaluation of ablation requires that three constitutive relations be specified: the single-phase liquid discharge coefficient $\left(\mathrm{C}_{\mathrm{d}}\right)$, the characteristic temperature gradient driving ablation $\left(\Delta \mathrm{T}_{\mathrm{r}}\right)$, and the melt/wall heat transfer coefficient $\left(\mathrm{h}_{\mathrm{d}, \mathrm{w}}\right)$. The quantification procedure for each is specified next.

The minimum possible discharge coefficient occurs when the flow through a hole in the RPV resembles flow through a sharp-edged orifice; in which case $C_{d}=0.6$. This choice has done well at predicting melt discharge in DCH experiments. Furthermore, the minimum discharge coefficient maximizes the final hole size after ablation (although the result is not very sensitive to the choice).

The Zion Probabilistic Safety Study (ZPSS, 1981) assumed that a $66 \mu \mathrm{m}$ crust insulates the RPV steel from melt flowing through the lower head. The melting point of the crust $\left(\mathrm{T}_{\mathrm{mp}, \mathrm{c}}\right)$ then controls convective heat transfer to the wall, 


$$
\Delta T_{r}=T_{d}-T_{m p, c} .
$$

The current study conservatively assumes that any crust and all molten wall material is stripped from the surface so that

$$
\Delta T_{r}=T_{d}-T_{m p, w} .
$$

This choice maximizes ablation, but it is also supported in an integral sense by the successful validation of the model against experiment data.

Special care is required in evaluating the heat transfer coefficient because rapid ablation has a feedback effect that reduces the heat transfer coefficient and because the flow cannot fully develop in the orifice. The feedback effect (Bird, Stewart, and Lightfoot, 1960; Suo-Antilla, 1979) is accounted for by

$$
\begin{gathered}
h_{d, w}=h_{d, w}^{\prime} \frac{\beta}{e^{\beta}-1} \\
\beta=\frac{\rho_{w} C_{p, w} \dot{D}_{h, r}^{\prime}}{2 h_{d, w}^{\prime}}
\end{gathered}
$$

Corrections of this sort due to rapid mass transfer have been experimentally validated (Mickley et al., 1954) for values of $\beta$ up to about 3 where the heat transfer coefficient was reduced to about 20 percent of its uncorrected value.

For much of the ablation process, the hole diameter is comparable to or greater than the thickness of the lower head; consequently, entrance region effects must be taken into account. Entrance regions effects are accounted for by taking the maximum of the turbulent heat transfer coefficient (local at the exit of the orifice) from a flat plate correlation and a correlation for fully developed flow. The flat plate correlation is given by

$$
h_{d, w}^{\prime}=0.0292 \frac{K_{d}}{L} \operatorname{Re}_{l}^{0.8} \operatorname{Pr}^{0.33}
$$


where

$$
\begin{gathered}
\operatorname{Re}_{L}=\frac{\rho_{d} \nu_{d} L}{\mu_{d}} \\
\operatorname{Pr}=\frac{C_{p, d} \mu_{d}}{k_{d}} .
\end{gathered}
$$

The correlation for fully developed flow is given by

$$
h_{d, w}^{\prime}=0.023 \frac{K_{d}}{D_{h}} \operatorname{Re}_{D}^{0.8} \operatorname{Pr}^{0.33}
$$

where

$$
R e_{D}=\frac{\rho_{d} v_{D} D_{h}}{\mu_{d}}
$$

For typical conditions, the flow in the orifice is not fully developed and the flat plate correlation is used. The assumption of turbulent flow maximizes the heat transfer coefficient, although most reactor applications favor the development of turbulent boundary layers.

\section{J.5 VALIDATION OF THE ABLATION MODEL}

Table J-1 summarizes the appropriate initial conditions for experiments that can be used to validate the ablation model. In all cases, the melt was $\mathrm{Fe} / \mathrm{Al}_{2} \mathrm{O}_{3}$ thermite; and in the case of the LFP tests (Allen et al., 1991) the thermite was laced with about 10 percent chromium. The melt was pressure driven through a steel plate with an initial hole size of $0.0254 \mathrm{~m}$ or $0.048 \mathrm{~m}$. The steel plate was either $0.0254 \mathrm{~m}$ or $0.0508 \mathrm{~m}$ thick. The melt mass ranged from $10-80 \mathrm{~kg}$. The HIPS, DCH, TDS, and LFP tests (Pilch et al., 1988; Tarbell et al., 1986; Tarbell et al., 1987; Allen et al., 1994; Allen et al., 1991) were all HPME/DCH tests where the hole was allowed to ablate freely. The MICE tests (Marshall et al., 1988) were conducted specifically to look at ablation as a function of the initial temperature of the steel plate. 
Table J. 2 summarizes the model predictions. The melting point of steel is about 1700 $\mathrm{K}$; so in most (but not all) cases, temporary crust formation on nonablating steel is expected. However, the ratio $t_{1} / t_{2}$ is always much less than unity indicating ablation will be initiated long before melt ejection is complete. The parameter $\beta$ has values as large as 1.2 indicating that the ablation rate is only about half of what would be expected if the correction associated with high mass transfer rates is overlooked. The ratio $\tau_{\mathrm{m}} / \tau_{\mathrm{D}}$ cannot be measured, so only predicted values are listed. Lastly, the predicted ablation is listed alongside the measured ablation.

Experiment results are compared with model predictions in Figure J.2. The relative RMS error and the relative bias indicate that the model is well validated over the range of experiment data. Rupture failures at reactor scale occur at $\tau_{\mathrm{m}} / \tau_{\mathrm{D}} \sim 0.04$, which is almost an order of magnitude outside the database. Extrapolation to lower values of $\tau_{\mathrm{m}} / \tau_{\mathrm{D}}$ is of no concern because hole ablation does little to increase the hole size when a large rupture occurs. Penetration failures at reactor scale could occur at $\tau_{\mathrm{m}} / \tau_{\mathrm{D}}$ values two orders of magnitude outside the range of the database. The adequacy of the model for penetration failures at reactor scale remains untested.

\section{J.6 SENSITIVITY STUDIES ON HOLE ABLATION}

The final hole size following ablation can be expressed functionally as

$$
D_{h_{f}}=f\left(M_{d}, \text { composition, } P_{R C S}^{o}, P_{c}^{o}, T_{d}^{o}, T_{w}, L, D_{h}^{g}\right)
$$

It is useful to examine the sensitivity of hole size to each of the governing parameters. Table J.3 lists a representative base case about which variations will be examined. The base case values mostly are patterned after SASM (Zuber et al., 1992) recommendations. As such, the base case values should be viewed mostly as best estimates for the exercise. The predicted hole size following ablation is $0.416 \mathrm{~m}$ for the base case. This is the basis on which hole sizes were selected for the SNL/ANL counterpart tests. 
Tables J.4 - J.9 specifically address the sensitivity of the final hole size to each of the first seven parameters in Equation J-23. Each sensitivity study varies only the parameter of interest with all others remaining at their base values. Mass variations are taken over the extreme range of possible values defined in Scenarios I through IV. Melt composition is varied from fully oxidic to fully metallic. RCS pressure is varied over the range of interest, and variations in containment pressure can be ignored since it is negligible compared to the RCS pressure. The melt temperature is varied over the range of possible eutectics. The lower head temperature is varied from saturation to about $1000 \mathrm{~K}$ where rupture would be expected. Lower head thickness is varied over a range typical of PWRs. Variations over these extremes changes the hole size by no more than 20 percent from the base case.

Table J.10 shows the sensitivity of the final hole size to variations in the initial hole size. The first entry is characteristic of a penetration failure, and the final hole size is $0.416 \mathrm{~m}$. The second entry corresponds to a "small" rupture. The final hole size differs little from that of a penetration failure; consequently small ruptures $\left(D_{h}^{\circ} \leq 0.5 \mathrm{~m}\right)$ can be treated like a penetration failure. The third entry assumes that a rupture produces a hole initially comparable to the final hole size associated with a penetration failure. The last entry corresponds to an extreme rupture. In the case of these large rupture failures, the contribution of ablation to the final hole size is small compared to uncertainty in the initial rupture size.

Theofanous has raised the issue of whether ablation following multiple (simultaneous) penetration failures could cause the growing holes to interact and combine in such a way as to cause a yet larger portion of the head to fail. Table J.11 addresses the issue of multiple penetration failures. As an extreme, $90 \mathrm{mt}$ of melt is considered. The melt mass (available to flow through each hole) decreases with each additional failure; consequently, the final hole size of any given penetration also decreases with each additional failure. A minimum of three simultaneous failures in a triangular pattern is required if the holes are to interact in such a way to cause a larger portion of the head to fail. For three simultaneous failures, the maximum size of one failure is only $0.353 \mathrm{~m}$ while the spacing between penetrations is about $0.50 \mathrm{~m}$; consequently, multiple penetration failures cannot interact. 
Table J.11 does show that the final equivalent diameter of all multiple failures increases with the number of failures, although the sensitivity is not excessive. The last column in Table J.11 lists the time required to eject the extreme of $90 \mathrm{mt}$ of melt through all available holes. For only one penetration failure, the discharge time is only $5.1 \mathrm{~s}$. The coherence of multiple failures only occurs if each failure occurs within an interval small compared to $5.1 \mathrm{~s}$. We believe that this is extremely unlikely; consequently, the possibility of multiple failures can be disregarded.

\section{J.7 HOLE EXPANSION FOLLOWING RUPTURE}

The relocation of melt into the lower plenum and the nonuniform accumulation of debris will create "hot spots" on the lower head. Witt (1994) has shown that such localized heating may eventually cause the RPV to bulge locally (like a blister) and rupture. Formation of this initial hole in the RPV is accompanied by doubling of the stress (relative to the free field) in the vicinity of the hole. A hole once formed will have a tendency to grow because of this stress concentration; but to do so, the hole must propagate into cooler

steel outside the hot spot that still has some residual strength. Furthermore, the initial rupture will initiate blowdown of the RCS, which will begin to relieve the stress on the lower head. The following analysis shows that it is unlikely for the hole to expand after the initial rupture.

Creep rupture of the lower head can be predicted by using the correlational approach of Larson and Miller (1952). For RPV steel, the time to creep rupture is a function of both stress and temperature, which can be expressed as

$$
\frac{t_{r}(\sigma, T)}{A_{t r}}=\left(\frac{\sigma_{r}}{\sigma}\right)^{\frac{T_{r}}{T}}
$$

where the reference quantities are given by

$$
\begin{aligned}
& \mathrm{A}_{t r}=3.60 \times 10^{-17} \mathrm{~s} \\
& \sigma_{\mathrm{r}}=5.69 \times 10^{12} \mathrm{~Pa} \\
& \mathrm{~T}_{\mathrm{r}}=4000 \mathrm{~K}
\end{aligned}
$$


This correlation is valid for stresses less than $275 \mathrm{MPa}$. For comparison, the stress in the lower head at full system pressure is only $13.3 \mathrm{MPa}$.

Consider a hot spot with temperature, $T$, surrounded by a "cool" region with temperature $T-\Delta T$. The hot spot will rupture in time $t_{T}\left(\sigma^{\circ}, T\right)$ and the cool region will rupture in time $\mathrm{t}_{\mathrm{r}}\left(\sigma^{\circ}, \mathrm{T}-\Delta \mathrm{T}\right)$. Forming their ratio and noting that $\Delta \mathrm{T} / \mathrm{T}<<1$, yields

$$
F=\left(\frac{\sigma^{o}}{\sigma_{r}}\right)^{\frac{T_{r} \Delta T}{T^{2}}}
$$

for the lifefraction (in the cool region) that has been expended when the hot spot first fails. For full system pressure $\left(\sigma^{\circ}=13.3 \mathrm{MPa}\right)$, a hot spot temperature of $1000 \mathrm{~K}$, and a trivial cooling increment $(\Delta \mathrm{T}=5 \mathrm{~K})$, the lifefraction expended in the cool region is only 81 percent. This means that significant life remains in the cool region when the hot spot first fails.

This remaining life is then challenged by a sudden concentration of stress near the hole while finding possible reprieve in the fact that the RCS starts to blowdown. We seek conditions under which the cooler regions will not fail during the blowdown period. Invoking a life fraction rule to account for the transient stress distribution,

$$
\int_{0}^{\infty} \frac{d t}{t_{r}(\sigma, T-\Delta T)}=\int_{0}^{t_{r}(\sigma, T)} \frac{d t}{t_{r}(\sigma, T-\Delta T)}+\int_{t_{r}(\sigma, T)}^{\infty} \frac{d t}{t_{r}[\sigma(t), T-\Delta T]} \leq 1,
$$

ensures that the initial rupture cannot expand into the cool region. The first integral on the RHS is the lifefraction expended in the cool region when the hot spot fails. The stress is constant at $\sigma^{\circ}$ over this period. The second integral on the RHS represents the lifefraction expended during the transient blowdown period. Assuming isothermal flow for convenience, the transient stress near the hole can be written as

$$
\sigma(t)=2 \sigma^{0} e^{-t / \tau_{*}}
$$


where $\tau_{b}$ is time constant for RCS blowdown. The factor of 2 accounts for the stress concentration created by formation of the initial hole.

Combining Equation $\mathrm{J}-24, \mathrm{~J}-26$, and $\mathrm{J}-27$ and noting that $\Delta \mathrm{T} / \mathrm{T}<<1$, yields a transcendental equation,

$$
\left(\frac{\sigma^{\infty}}{\sigma_{r}}\right)^{\frac{T, \Delta T}{T^{2}}}+\frac{\tau_{b}}{t_{r}\left(\sigma^{\infty}, T\right)}\left[\frac{\sigma^{o}}{\sigma_{r}}\right)^{\frac{T, \Delta T}{T^{2}}}[2]^{\frac{T_{r}}{T}\left(1+\frac{\Delta T}{T}\right)} \frac{T}{T_{r}}\left(1-\frac{\Delta T}{T}\right) \leq 1,
$$

for the minimum temperature increment that will prevent the hole from propagating into the cooler regions. Consider some representative numbers: $\mathrm{D}_{\mathrm{h}}^{\circ}=0.4 \mathrm{~m}, \mathrm{P}_{\mathrm{RCs}}^{\circ}=16 \mathrm{MPa}$, $\mathrm{T}=1000 \mathrm{~K}, \tau_{\mathrm{b}}=5 \mathrm{~s}, \mathrm{t}_{\mathrm{r}}=120 \mathrm{~s}$. For these conditions, the cool region need only be $4 \mathrm{~K}$ (or more) cooler than the hot spot to prevent continued spreading of the hole. Thus, almost trivial temperature gradients can prevent spreading of a rupture. There is a need for experiment data to confirm these model predictions.

Actually, the sample conditions cited above are rather extreme. Lower RCS pressures will decrease the $\Delta \mathrm{T}$ requirement by reducing stress. The characteristic blowdown time has a stronger impact on $\Delta \mathrm{T}$; larger blowdown times give larger $\Delta \mathrm{T}$ requirements. However, the cited value is already a maximum because hole sizes smaller than $0.4 \mathrm{~m}$ are not likely. If a smaller rupture occurred, it would ablate back to $0.4 \mathrm{~m}$.

\section{J.8 SUMMARY}

Hole ablation plays an important role in defining the final hole size after failure of the lower head of the RPV. In the case of a large rupture, hole ablation does little to increase the hole size. Uncertainty in the initial rupture size dominates estimates of the final hole size, and ablation can be ignored. Hole ablation totally controls the final hole size for penetration failures. The final hole size is not very sensitive to extreme variations in the controlling parameters. Multiple penetration failures cannot interact to produce a 
much larger hole; and lastly, the simultaneous failure of multiple penetrations can be discounted. A blister or local rupture resulting from a hot spot is the most likely rupture mechanism of the lower head. However, trivial temperature gradients outside the hot spot are predicted to prevent the rupture from propagating beyond the initial rupture site. There is a need for experiment data to confirm these model predictions.

\section{J.9 REFERENCES}

Allen, M.D., et al. (1991). Experiments to Investigate the Effect of Flight Path on Direct Containment Heating (DCH) in the Surtsey Test Facility, NUREG/CR-5728, SAND91-1105, Sandia National Laboratories, Albuquerque, NM.

Allen, M.D., et al. (1994). Test Results on Direct Containment Heating by High-Pressure Melt Ejection into the Surtsey Vessel: The TDS Test Series, SAND91-1208, Sandia National Laboratories, Albuquerque, NM.

Bird, R.B., Stewart, W.E., and Lightfoot, E.N. (1960). Transport Phenomena, John Wiley \& Sons, Inc.

Larson, F.R. and J. Miller (July 1952). "A Time-Temperature Relationship for Rupture and Creep Stress," Trans. ASME, 765-775.

Marshall, B.W., et al. (Nov. 1988). Reactor Safety Research Semiannual Report, NUREG/CR-5039, Vol. 2, U.S. Nuclear Regulatory Agency, Washington, D.C.

Mickley, H.S., R.C. Ross, A.L. Squyers, and W.E. Stewart (July 1954). Heat, Mass, and Momentum Transfer for Flow over a Flat Plate with Blowing or Suction, NACA-TN/3208.

Pilch, M. and W.W. Tarbell (1985). High Pressure Ejection of Melt from a Reactor Pressure Vessel, NUREG/CR-4383, SAND85-0012, Sandia National Laboratories, Albuquerque, NM.

Suo-Antilla, A.J. (Jan. 1979). Simplified Multicomponent Phase Transition Model, LA-7557- MS, Los Alamos Scientific Laboratory, Los Alamos, NM.

Tarbell et al. (1987). Results from the DCH-1 Experiment, NUREG/CR-4871, SAND86-2483, Sandia National Laboratories, Albuquerque, NM.

Witt, R.J. (1994). "Local Creep Rupture Failure Modes on a Corium-Loaded Lower Head," accepted for publication, Nuc. Eng. Des.

ZPSS (1981). Zion Probabilistic Safety Study, Commonwealth Edison Co., Chicago, IL. 
Zuber, et al. (1991). An Integrated Structure and Scaling Methodology for Severe Accident Technical Issue Resolution, draft for comment, NUREG/CR-5809, EGG-2659.

\section{J.10 NOMENCLATURE}

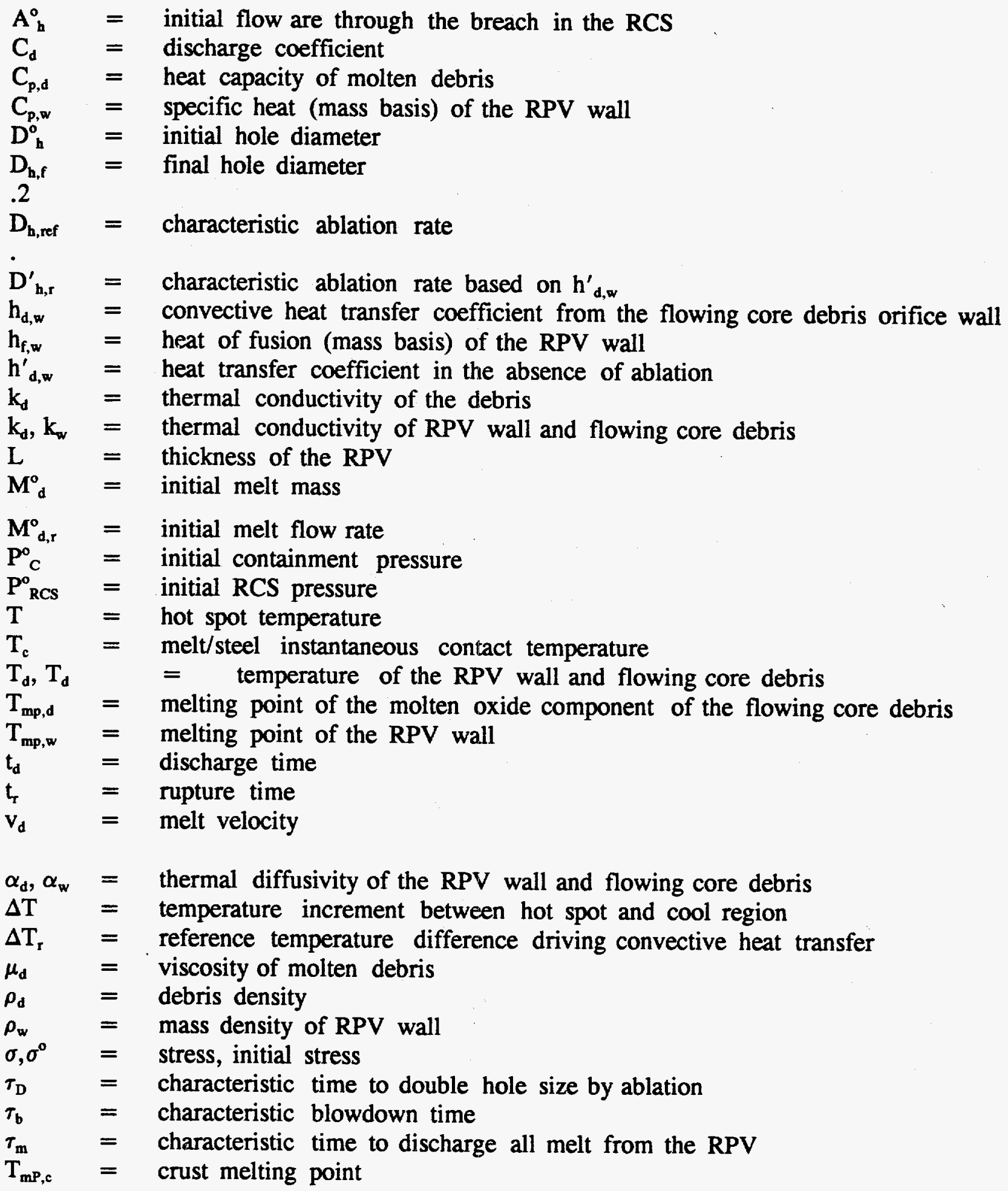


Table J.1

Initial conditions for validation of hole ablation model

\begin{tabular}{|c|c|c|c|c|c|c|c|}
\hline Test & $\begin{array}{r}P_{\text {Ros }}^{\circ} \\
(\mathrm{MPa}) \\
\end{array}$ & $\begin{array}{r}\mathbf{P}_{\mathbf{C}}^{\circ} \\
(\mathrm{MPa}) \\
\end{array}$ & $\begin{array}{l}\mathbf{M}_{\mathrm{d}}^{\circ} \\
(\mathrm{kg}) \\
\end{array}$ & $\begin{array}{l}\mathbf{T}^{\circ}{ }_{d} \\
(\mathbf{K})\end{array}$ & $\begin{array}{l}D_{k}^{\circ} \\
(m)\end{array}$ & $\begin{array}{c}\mathbf{L} \\
(\mathrm{m})\end{array}$ & $\begin{array}{l}T_{w} \\
(\mathbf{K}) \\
\end{array}$ \\
\hline $\begin{array}{l}\text { MICE-6 } \\
\text { Marshall et al. } 1988 \\
\end{array}$ & 2.26 & 0.082 & 60 & 2700 & 0.0254 & 0.0254 & 553 \\
\hline MICE-7 & 2.80 & 0.082 & 60 & 2700 & 0.0254 & 0.0254 & 708 \\
\hline MICE-8 & 3.10 & 0.082 & 60 & 2700 & 0.0254 & 0.0254 & 1268 \\
\hline MICE-10 & 1.38 & 0.082 & 60 & 2700 & 0.0254 & 0.0254 & 833 \\
\hline MICE-11 & 2.45 & 0.082 & 60 & 2700 & 0.0254 & 0.0254 & 1043 \\
\hline MICE-12 & 2.45 & 0.082 & 60 & 2700 & 0.0254 & 0.0254 & 309 \\
\hline MICE-13 & 2.03 & 0.082 & 60 & 2700 & 0.0254 & 0.0254 & 973 \\
\hline MICE-14 & 2.41 & 0.082 & 50 & 2700 & 0.0254 & 0.0254 & 511 \\
\hline MICE-16 & 3.25 & 0.082 & 60 & 2700 & 0.0254 & 0.0254 & 1058 \\
\hline MICE-17 & 2.23 & 0.082 & 50 & 2700 & 0.0254 & 0.0254 & 1053 \\
\hline $\begin{array}{l}\text { SNL/HIPS-2C } \\
\text { Tarbell et al. } 1986 \\
\end{array}$ & 11.7 & 0.082 & 80 & 2700 & 0.0254 & 0.0508 & 300 \\
\hline $\begin{array}{l}\text { SNL/HIPS-3J } \\
\text { Pilch et al. } 1988\end{array}$ & 4.85 & 0.082 & 80 & 2700 & 0.0254 & 0.0508 & 300 \\
\hline $\begin{array}{l}\text { SNL/DCH-1 } \\
\text { Tarbell et al. } 1987\end{array}$ & 2.35 & 0.082 & 10 & 2700 & 0.048 & 0.0508 & 300 \\
\hline $\begin{array}{l}\text { SNL/TDS-4 } \\
\text { Allen et al. } 1994\end{array}$ & 3.85 & 0.230 & 80 & 2700 & 0.048 & 0.0508 & 300 \\
\hline $\begin{array}{l}\text { SNL/LFP-1A } \\
\text { Allen et al. } 1991 \\
\end{array}$ & 3.6 & 0.160 & 80 & 2500 & 0.048 & 0.0508 & 300 \\
\hline $\begin{array}{l}\text { SNL/LFP-2B } \\
\text { Allen et al. } 1991\end{array}$ & 3.5 & 0.160 & 50 & 2500 & 0.048 & 0.0508 & 300 \\
\hline
\end{tabular}


Table J.2

Validation of the hole ablation model

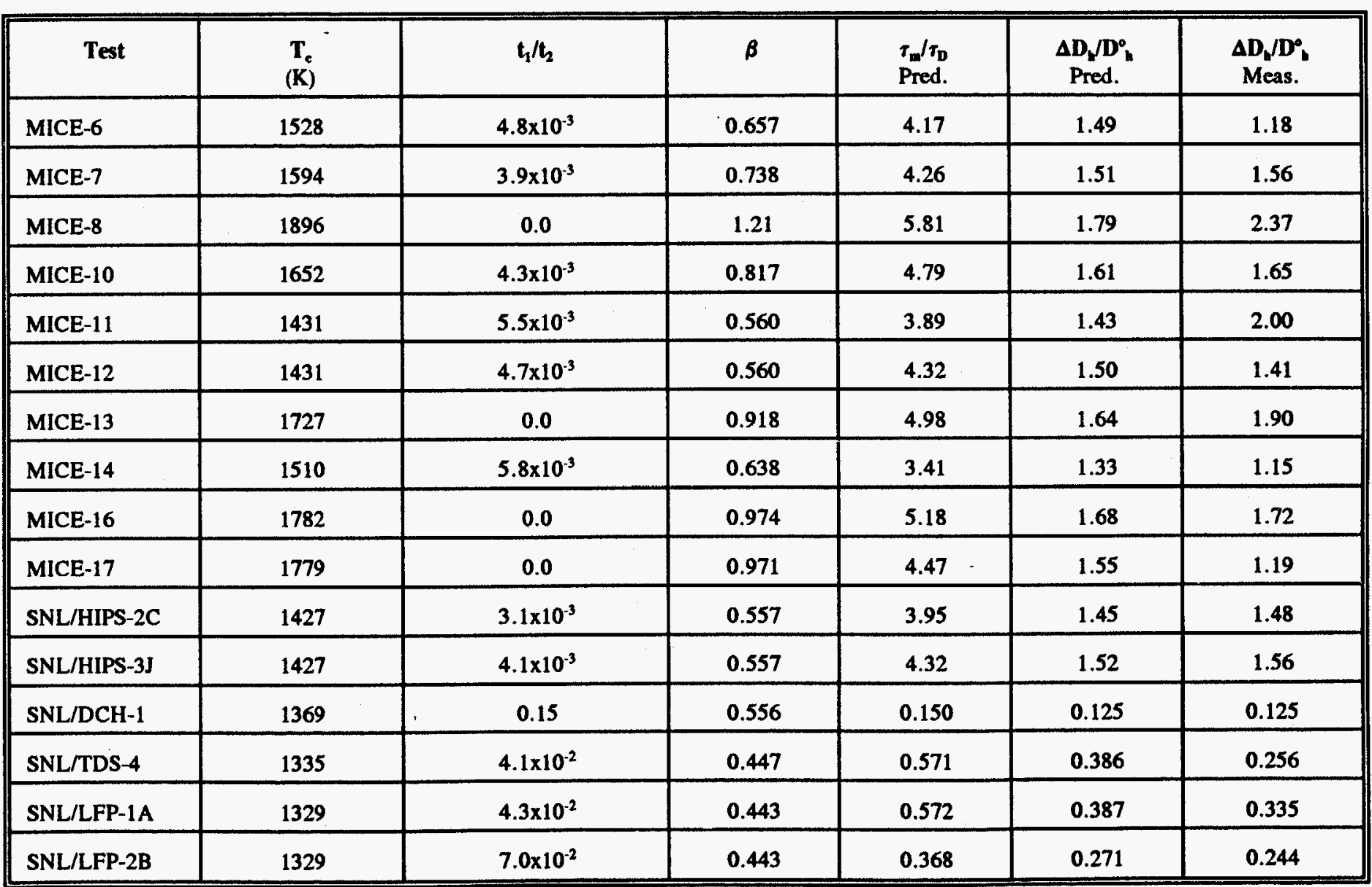


Table J.3

Base case for sensitivity studies

\begin{tabular}{|c|c|}
\hline Parameter & Value \\
\hline $\mathbf{M}^{\circ}{ }_{\mathrm{d}}(\mathrm{mt})$ & 50 \\
\hline $\mathrm{f}_{\mathrm{UO} 2}$ & 0.527 \\
\hline $\mathrm{f}_{\mathrm{ZrO} 2}$ & 0.098 \\
\hline $\mathrm{f}_{\mathrm{Zr}}$ & 0.139 \\
\hline $\mathrm{f}_{\mathrm{Pc}}$ & 0.142 \\
\hline $\mathrm{f} \in \mathrm{r}$ & 0.035 \\
\hline $\mathrm{f}_{\mathrm{Ni}}$ & 0.059 \\
\hline $\mathrm{P}_{\mathrm{RCS}}{ }_{\mathrm{MPa}}(\mathrm{MPa}$ & 16 \\
\hline $\mathrm{P}_{\mathrm{C}}{ }(\mathrm{MPa})$ & 0.2 \\
\hline $\mathrm{T}_{\mathrm{d}}{ }_{\mathrm{d}}(\mathrm{K})$ & 2800 \\
\hline $\mathrm{T}_{\mathrm{w}}(\mathrm{K})$ & 800 \\
\hline $\mathrm{D}_{\mathrm{h}}^{\circ}(\mathrm{m})$ & 0.0254 \\
\hline $\mathrm{L}(\mathrm{m})$ & 0.14 \\
\hline $\mathrm{D}_{\mathrm{h}, \mathrm{f}}(\mathrm{m})$ & 0.416 \\
\hline
\end{tabular}

Table J.4

Sensitivity to initial melt mass

\begin{tabular}{|c|c|}
\hline $\mathbf{M}_{\mathrm{d}}^{\mathrm{o}}(\mathrm{mt})$ & $\mathrm{D}_{\mathrm{h}, \mathrm{f}}(\mathrm{m})$ \\
\hline 30 & 0.353 \\
\hline 50 & 0.416 \\
\hline 90 & 0.502 \\
\hline
\end{tabular}


Table J.5

Sensitivity to variations in melt composition

\begin{tabular}{|c|c|}
\hline Composition & $\mathrm{D}_{\mathrm{h}, \mathrm{f}}(\mathrm{m})$ \\
\hline Oxide & 0.299 \\
\hline Oxide/Metallic & 0.416 \\
\hline Metallic & 0.506 \\
\hline
\end{tabular}

Table J.6

Sensitivity variations in RCS pressure

\begin{tabular}{|c|c|}
\hline $\mathrm{P}_{\mathrm{RCS}}^{\mathrm{o}}(\mathrm{MPa})$ & $\mathrm{D}_{\mathrm{h}, \mathrm{f}}(\mathrm{m})$ \\
\hline 16 & 0.416 \\
\hline 8 & 0.400 \\
\hline
\end{tabular}

Table J.7

Sensitivity to melt temperature

\begin{tabular}{|c|c|}
\hline $\mathrm{T}^{\circ}{ }_{\mathrm{d}}(\mathrm{K})$ & $\mathrm{D}_{\mathrm{h}, \mathrm{f}}(\mathrm{m})$ \\
\hline 2500 & 0.392 \\
\hline 2800 & 0.416 \\
\hline
\end{tabular}

Table J.8

Sensitivity to lower head temperature

\begin{tabular}{|c|c|}
\hline$T_{\mathrm{w}}(\mathrm{K})$ & $\mathrm{D}_{\mathrm{h}, \mathrm{f}}(\mathrm{m})$ \\
\hline 600 & 0.409 \\
\hline 800 & 0.416 \\
\hline 1000 & 0.430 \\
\hline
\end{tabular}


Table J.9

Sensitivity to lower head thickness

\begin{tabular}{|c|c|}
\hline$L(m)$ & $D_{\mathrm{h}, \mathrm{f}}(\mathrm{m})$ \\
\hline 0.12 & 0.420 \\
\hline 0.14 & 0.416 \\
\hline
\end{tabular}

Table J.10

Sensitivity to initial hole size

\begin{tabular}{|c|c|c|}
\hline Failure Mode & $\mathrm{D}_{\mathrm{h}}^{\mathrm{o}}(\mathrm{m})$ & $\mathrm{D}_{\mathrm{h}, \mathrm{f}}(\mathrm{m})$ \\
\hline Penetration & 0.0254 & 0.416 \\
\hline Small Rupture & 0.20 & 0.424 \\
\hline Rupture & 0.416 & 0.511 \\
\hline Large Rupture & 1.0 & 1.026 \\
\hline
\end{tabular}

Table J.11

Sensitivity to the number of simultaneous penetration failures

\begin{tabular}{|c|c|c|c|c|}
\hline $\begin{array}{c}\text { Number of } \\
\text { Failures }\end{array}$ & $\begin{array}{c}\mathbf{M}_{\mathrm{d}}^{\circ} / \text { Failure } \\
(\mathrm{MT})\end{array}$ & $\begin{array}{c}\mathrm{D}_{\mathrm{h}, \mathrm{f}}(\mathrm{m}) \\
\text { each fail. }\end{array}$ & $\begin{array}{c}\mathrm{D}_{\mathrm{h}, \mathrm{f}}(\mathrm{m}) \\
\text { equiv. }\end{array}$ & $\mathrm{t}_{\mathrm{d}}(\mathrm{s})$ \\
\hline 1 & 90 & 0.502 & 0.502 & 5.1 \\
\hline 2 & 45 & 0.402 & 0.569 & 4.1 \\
\hline 3 & 30 & 0.353 & 0.611 & 3.5 \\
\hline 4 & 22.5 & 0.322 & 0.644 & 3.2 \\
\hline
\end{tabular}




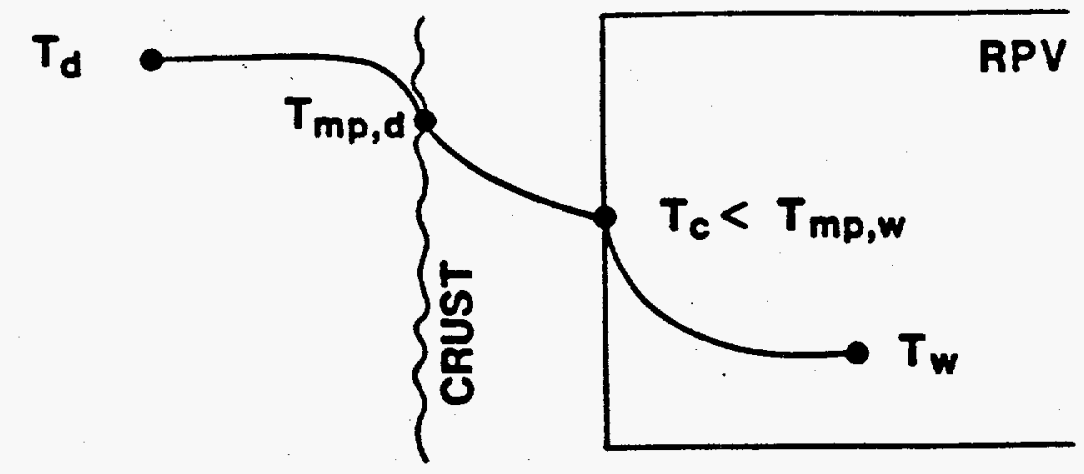

CASE 1: BEFORE ABLATION

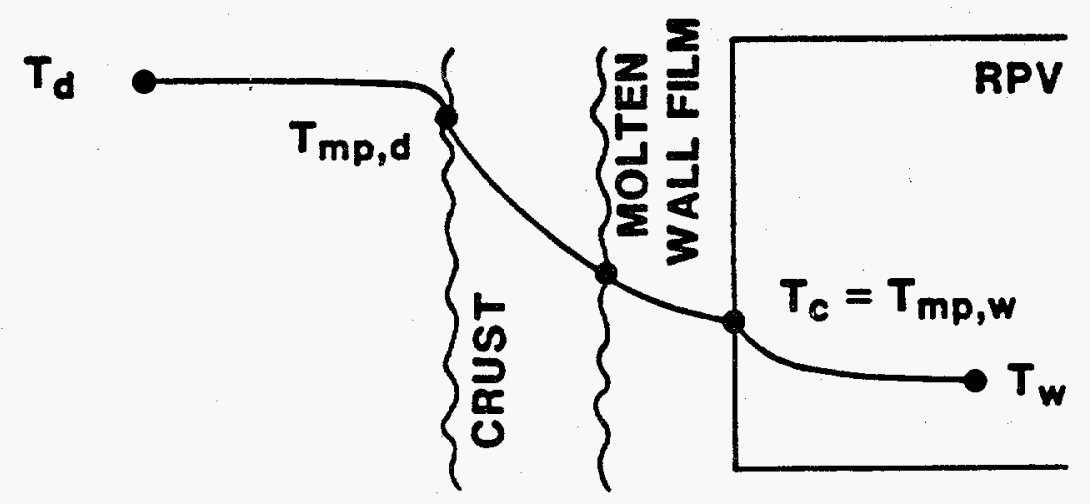

CASE 2: ABLATION WITH INTERVENING CRUST

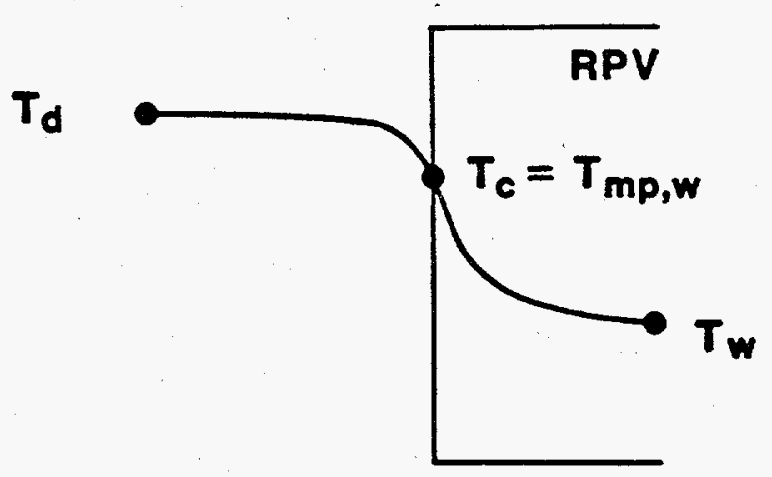

CASE 3: ABLATION WITH NO CRUST

Figure J.1. Thermal conditions in the orifice walls before and after the initiation of ablation 


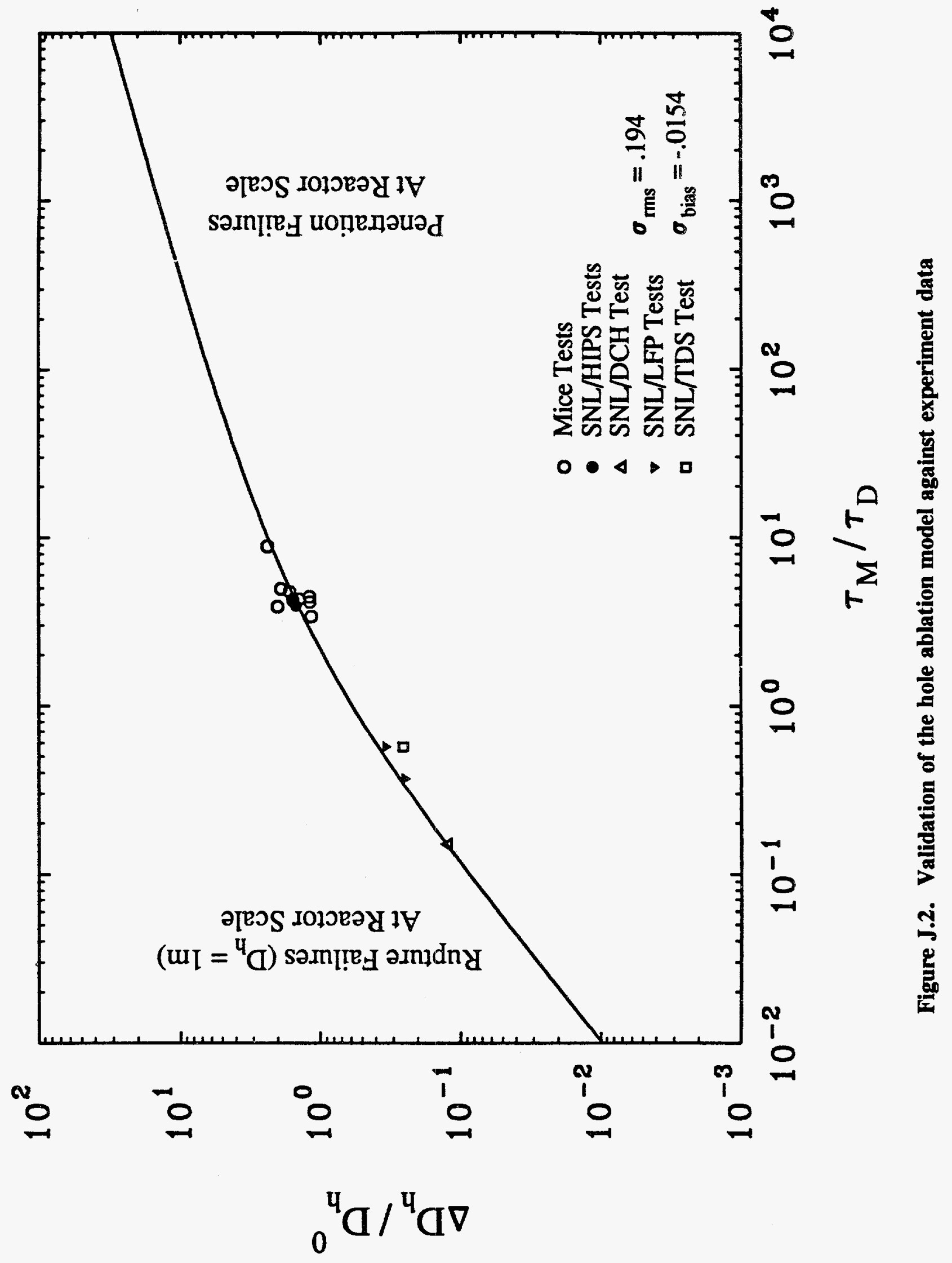




\title{
APPENDIX K \\ COMPARISON OF MELT MASS AND COMPOSITION \\ QUANTIFICATIONS WITH PRIOR WORK
}

\author{
Martin M. Pilch \\ Sandia National Laboratories
}

\section{K.1 INTRODUCTION}

Initial conditions have been set forth in Section 3 with the intent to envelope in a comprehensive fashion the full range of conditions that might reasonably lead to significant DCH loads. Having done so, there is a natural curiosity to compare these quantifications with prior work. Tables K.1 - K.3 fill this need for Scenarios I, II, and IV. Suitable comparisons with Scenario III could not be found.

At the outset, we should state that no potential comparisons are fully consistent with the plant and scenarios discussed in this report, so some compromise is necessary to make suitable comparisons. More importantly, however, is the general recognition that current system level codes have not yet achieved an adequate predictive capability for late phase core melt progression. Prior summary efforts (i.e.,NUREG-1150 and SASM) are therefore the most useful for comparison since these activities employed panels of knowledgeable experts who were able to synthesize the experimental and analytical information available at the time. Since the time of these summary efforts, new information has become available and this new data is reflected in our current quantifications. In general, the current melt quantities and compositions produce less severe DCH loads.

NUREG-1150 was the first summary assessment of core melt progression parameters, which only addressed the core fraction that is molten and the fraction of cladding oxidized. NUREG-1150 assessments were largely based on MARCH, early MAAP, and preliminary MELPROG calculations. NUREG-1150 made no distinction in melt conditions between penetration failure and rupture failure; consequently, NUREG-1150 results are compared with Scenarios I and II. 
SASM (Zuber et al., 1991) is the most recent of the summary assessments, and it was focused specifically on the $\mathrm{DCH}$ issue. Consequently, we place the greatest credibility on their recommendations. We note that the SASM results are all based on the assumption that downward failure of the crucible occurs and all the molten material drains into the lower plenum. Assessment of steel mass in the SASM effort was largely based on a MELPROG (Kelly et al., 1987) calculation of a station blackout accident where significant upper plenum melting was predicted. It should be noted that melting of upper plenum steel is strongly correlated with surge line or hot leg failure, which in fact is predicted in the MELPROG calculation and more recent SCDAP/RELAP5 calculations. The SASM calculation also shows significant $\mathrm{Zr}$ metal in the melt, which is a partial artifact of MELPROG calculations that were used in guiding the assessment. In the calculations, complete downward failure of the crucible was assumed, which has the effect of bringing the entire core blockage ( $\mathrm{Zr}$ metal and core steel) into the lower plenum. Current knowledge does not support this picture of relocation. SASM made explicit recommendations for situations similar to Scenarios I and II considered here. The SASM recommendations were specifically for Surry, so the Zion entries have been scaled from the Surry recommendations.

Since the time of SASM, a few SCDAP/RELAP5 calculations for the Zion plant (Knudson, 1993) have become available. These later calculations were intentionally biased to accelerate core melt progression and bottom head failure. SCDAP/RELAP5 calculations were provided to us for a full system pressure case and several cases with RCP leaks. The latter were excluded from the comparison because they either had extensive depressurization of the RCS $(\mathrm{P}<4 \mathrm{MPa})$ by the time of melt relocation and bottom head failure or there was no molten material on the lower head at the time of predicted rupture. It is noteworthy, however, that surge line failure was predicted in the full pressure case, although the calculation was carried on to vessel breach without depressurization. Since bottom head failure occurred so rapidly after crucible failure and melt relocation in the SCDAP/RELAP calculation, the code results are best compared with Scenario I.

Heames and Smith (1987) used MELPROG-PWR/MOD1 to analyze a pump seal LOCA in the Surry plant. This calculation progressed in a manner similar to our gradual 
relocation scenario and eventually led to rupture of the lower head similar to Scenario IV. Hot leg failure was predicted in this calculation during clad relocation to the lower head, although the calculation was continued to bottom head failure with only the RCP leaks. The RCS was fully depressurized (RCP leaks alone) at the time of bottom head failure. The large quantity of molten steel in this calculation arises because steel relocation and freezing was not modeled in the debris bed and because bottom head failure was delayed because of the low system pressure. In this MELPROG calculation, the conditions leading to the gradual relocation were precipitated by clearing of the loop seals, which was assumed to occur in all loops simultaneously. Modern assessments suggest that only one loop might clear and the effect on homogenizing the core temperature would not be as strong.

Returning now to Table K.1 - K.3, we see three numbers for some entries. These represent the extremes and best estimate of the distribution. The SASM recommendations have been scaled to Zion. In addition, some SASM entries are shown in parenthesis. Here, we try to correct the SASM entries for improvements in understanding so that they are more directly comparable to our current recommendations. Comparisons with prior work generally support our current quantifications, although the current melt quantities and compositions produce less severe DCH loads. Any potential deviations are fully explained by improved understanding of core melt progression.

\section{K.2 REFERENCES}

Heames, T.J. and R.C. Smith (1987). "Integrated MELPROG/TRAC Analyses of a PWR Station Blackout", Nuclear Engineering and Design, 125, 175-188.

Knudson, D.L. (April 19, 1993). Transmittal of SCDAP/RELAP5/MOD3 Results for the Zion Power Station, Letter Report to NRC, EG\&G Idaho, Inc., Idaho Falls, ID.

Kelly, J.E., R.J. Henninger, and J.F. Dearing (Jan. 1987). MELPROG/TRAC-PWT/MOD1 Analysis of a TMLB' Accident Sequence, NUREG/CR-4742, SAND86-2175, Sandia National Laboratories, Albuquerque, NM.

Zuber, N. et al. (1991). An Integrated Structure and Scaling Methodology for Severe Accident Technical Issue Resolution, Draft Report for Comment, NUREG/CR-5809, EGG-2659, EG\&G Idaho, Inc., Idaho Falls, ID. 
Table K.1

Comparison of prior work with Scenario I

\begin{tabular}{|c|c|c|c|c|}
\hline & Scenario I & NUREG-1150 & SASM" & SCDAP/RELAP5 \\
\hline Total Melt Mass (mt) & $0 / 22.2 / 52.9$ & . & $60.7(44.3)^{b, c}$ & 11.2 \\
\hline Core Fraction & $0 / 0.18 / 42$ & $0 / 0.28 / 0.60$ & $.49(.35)^{b, c}$ & 0.09 \\
\hline $\mathrm{UO}_{2}$ Mass (mt) & $0 / 20 / 45$ & & 32.0 & 8.62 \\
\hline $\mathrm{ZrO}_{2}$ Mass (mt) & $0 / 2.2 / 7.9$ & & 5.92 & 1.90 \\
\hline Zr Mass (mt) & 0 & & $8.45(0)^{c}$ & 0 \\
\hline Steel Mass (mt) & 0 & & $11.94(4.0)^{\mathrm{b}}$ & 0.65 \\
\hline CRM Mass (mt) & 0 & & 2.34 & 0 \\
\hline Temperature $(\mathrm{K})$ & 2800 & & 2500 & 3170 \\
\hline Fraction $\mathrm{Zr}$ Oxidized & $0.15 / 0.40 / 0.65$ & $0.08 / 0.315 / 0.763$ & 0.40 & 0.382 \\
\hline \multicolumn{5}{|c|}{$\begin{array}{l}\text { " Reported values scaled to Zion. } \\
\text { b Steel mass excluding contribution from upper plenum. } \\
\text { c Assuming Zr metal retained in core blockages. }\end{array}$} \\
\hline
\end{tabular}


Table K.2

Comparison of prior work with Scenario II

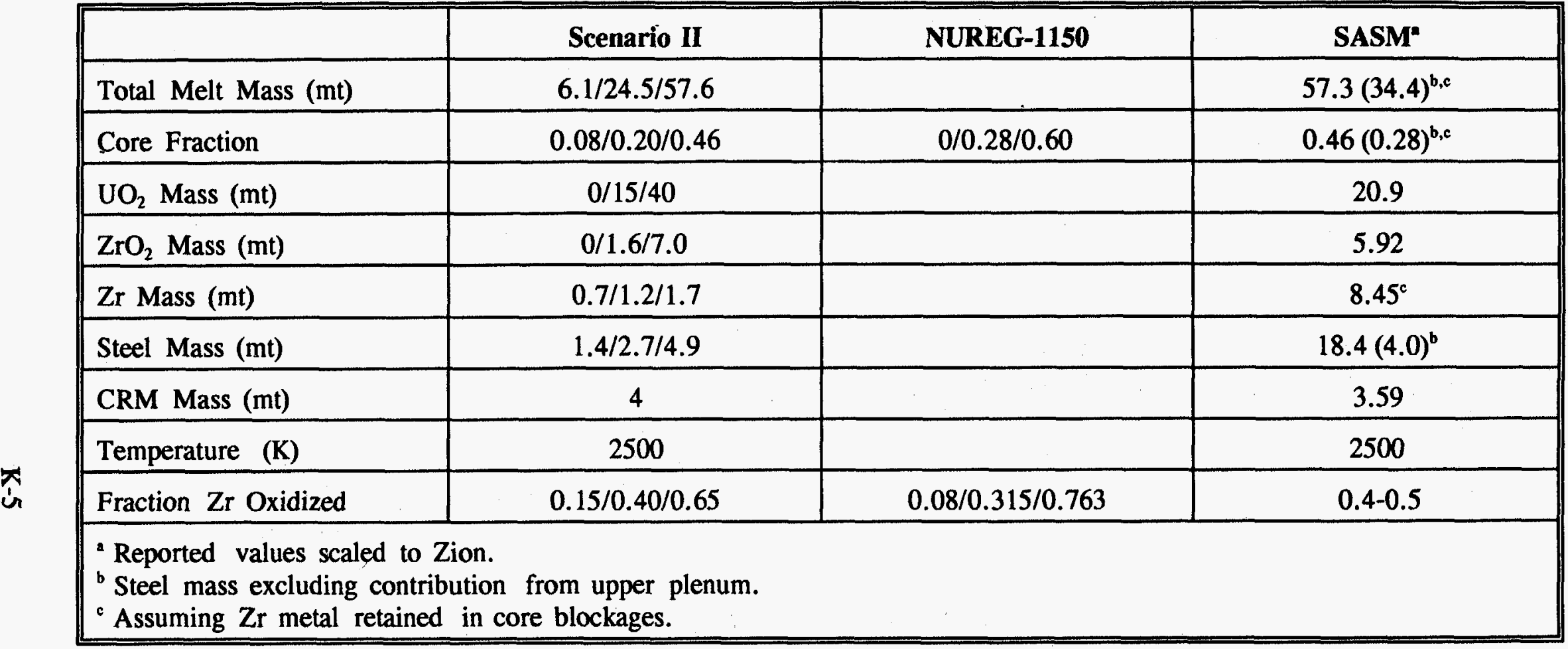


Table K.3

Comparison of prior work with Scenario IV

\begin{tabular}{|c|c|c|}
\hline & Scenario IV & MELPROG-PWR/MOD1 \\
\hline Total Melt Mass (mt) & $4 / 19 / 54.1$ & 44.02 \\
\hline Core Fraction & $0.3 / 0.15 / 0.43$ & 0.35 \\
\hline $\mathrm{UO}_{2}$ Mass $(\mathrm{mt})$ & $0 / 0 / 20$ & 4.38 \\
\hline $\mathrm{ZrO}_{2}$ Mass (mt) & $0 / 0 / 4.3$ & 0.64 \\
\hline $\mathrm{Zr}$ Mass $(\mathrm{mt})$ & $0 / 0 / 0.80$ & 0.19 \\
\hline Steel Mass $(\mathrm{mt})$ & $0 / 15 / 25$ & 35.5 \\
\hline CRM Mass (mt) & 4 & 3.31 \\
\hline Temperature $(\mathrm{K})$ & 2350 & 2100 \\
\hline Fraction $\mathrm{Zr}$ Oxidized & $0.30 / 0.60 / 0.80$ & $\sim 0.8$ \\
\hline
\end{tabular}




\section{DISTRIBUTION}

U. S. Nuclear Regulatory Commission (6) Office of Nuclear Regulatory Research

Attn: C. Tinkler, T-10-K-8

R. Lee, $\mathrm{T}-10-\mathrm{K}-8$

A. Rubin, T-10-K-8

F. Eltawila, T-10-K-8

W. Hodges, T-10-E-37

T. King, T-10-E-37

Washington, DC 20555-0001

U. S. Nuclear Regulatory Commission (2) NRC/RES

Attn: E. Beckjord, MS: T-10-F-12

T. Speis, MS: T-10-F-12

Washington, DC 20555-0001

U.S. Nuclear Regulatory Commission (2) Office of ACRS

Attn: M.D. Houston, T-2-E-26

T. Kress, T-2-E-26

Washington, DC 20555-0001

U. S. Department of Energy

Office of Nuclear Safety Coordination

Attn: R. W. Barber

Washington, DC 20545

U. S. Department of Energy (2)

Albuquerque Operations Office

Attn: C. E. Garcia, Director

For: C. B. Quinn

R. L. Holton

P. O. Box 5400

Albuquerque, NM 87185

Professor Theo G. Theofanous

Department of Chemical \& Nuclear

Engineering

Director, Center of Risk Studies \& Safety

University of California

Santa Barbara, CA 93106

Electric Power Research Institute

Attn: A. Michaels

3412 Hillview Avenue

Palo Alto, CA 94303
UCLA

Nuclear Energy Laboratory

Attn: I. Catton

405 Hilgaard Avenue

Los Angeles, CA 90024

Brookhaven National Laboratory (3)

Attn: R. A. Bari

T. Pratt

N. Tutu

$130 \mathrm{BNL}$

Upton, NY 11973

Argonne National Laboratory (4)

Attn: J. Binder

C. Johnson

L. Baker, Jr.

B. Spencer

9700 S. Cass Avenue

Argonne, IL 60439

Fauske and Associates, Inc.

Attn: R. Henry

16W070 West 83rd Street

Burr Ridge, IL 60952

General Electric Company

Nuclear Energy

Attn: F. J. Moody

175 Curtner Avenue

San Jose, CA 95125

Battelle Columbus Laboratory (2)

Attn: R. Denning

J. Gieseke

505 King Avenue

Columbus, OH 43201

Department of Energy

Scientific and Tech. Info. Center

P. O. Box 62

Oak Ridge, TN 37831 
Distribution

Purdue University

School of Nuclear Engineering

Attn: M. Ishii

West Lafayette, IN 47907

University of Wisconsin

Nuclear Engineering Department

Attn: M. L. Corradini

1500 Johnson Drive

Madison, WI 53706

Richard R. Hobbins

2955 North Fish Creek Rd.

P.O. Box 971

Wilson, WY 83014

Battelle Pacific Northwest Laboratory

Attn: M. Freshley

P. O. Box 999

Richland, WA 99352

FOREIGN DISTRIBUTION:

AECL CANDU

Sheridan Park Research Community

2251 Speakman Avenue

Attn: V.J. Nath

Mississauga, Ontario L5K 1B2

CANADA

AECL Research (5)

Chalk River Research Laboratories

Attn: B.H. McDonald

L.N. Carlucci

D.S. Cox

L.W. Dickson

R.S. Dickson

Chalk River, Ontario KOJ 1 JO

CANADA

AECL Research (2)

Whiteshell Laboratories

Attn: S.R. Mulpuru

L.A. Simpson

Pinawa, Manitoba ROE 1LO

CANADA
AERE Harwell (4)

Didcot

Attn: R.G.J. Ball

N.E. Beatham

M.A. Mignanelli

A.L. Nichols

Oxfordshire OX11 ORA

UNITED KINGDOM

Atomic Energy Council (2)

Attn: Yi-Bin Chen

S.J. Shieh

67, Lane 144

Keedling Road, Section 4

Taipei, Taiwan 106

REPUBLIC OF CHINA

Belgonucleaire SA (2)

Rue du Champ de Mars 25

Attn: H. Bairiot

J. Basselier

B-1050 Brussels

BELGIUM

Cadarache Center for Nuclear Studies (5)

Attn: B. Andre

P. Dumaz

M. Schwartz

A. Meyer-Heine

F. Serre

F-13108 Saint Paul-Lez-Durance Cedex

FRANCE

Com. Nacional de Seguridad Nucl. Salvag

Colonia Narvarte Delegation B. Juarez

Attn: M.M. Vaillard

Dr. Abrragan \#779

C.P. 03020

MEXICO

Consejo de Seguridad Nuckan

SOR Angela de la Cruz No. 3

Attn: J. Bagues

28056 Madrid

SPAIN 
Consejo de Seguridad Nuclear (2)

Justo Dorado 11

Attn: J.E. deCarlos

J.A. Martinez

28040 Madrid

SPAIN

Committee on the Use of Atomic Energy

for Peaceful Purposes

69 Shipchenski

Prokhod Blvd.

Attn: Y. Yanev

1574, Sofia

BULGARIA

Director Research, Science Education CEC (2)

Rue De La Loi 2000

Attn: W. Balz

B. Tolley

1049 Brussels

BELGIUM

E.T.S. Ingenieros Industriales

Attn: A. Alonso

Jost Gutierrez Abascal, 2

28006 Madrid

SPAIN

Finnish Centre for Radiation and

Nuclear Safety

Department of Nuclear Safety

P.O. Box 268

Attn: J.V. Sandberg

SF-00101 Helsinki

FINLAND

ENEL-CRTN

Via Monfalcone 15

Attn: E. Borioli

20132 Milan

ITALY

E.T.S. Ingenieros Industriales

Jost Gutierrez Abascal, 2

Attn: A. Alonso

28006 Madrid

SPAIN
Gesellschaft Fuer Reaktorsicherheit

Attn: M. Finnhaber

M. Sonnenkalb

K. Trambauer

Forschungsgelande

D-8046 Garching

GERMANY

Gesellschaft fur Reaktorsicherheit (GRS)

Postfach 101650

Glockengrasse 2

5000 Koeln 1

GERMANY

Hungarian Atomic Energy Commission

H-1374 Budapest, P.O. Box 565

Attn: S. Elo

Budapest

HUNGARY

Institut de Protection et de Surete Nucleaire (6)

CEN/FAR-B.P. No. 6

F-92265

Fontenay-aux-Roses

Attn: J. Bardelay

J. Duco

M. Gomolinski

M. LeComte

M. LiVolant

R. Pochard

Cedex

FRANCE

Institute of Nuclear Energy Research

P.O. Box 3

Attn: Sen-I Chang

Lung-Tan

TAIWAN 325

Institute for Electric Power Research (2)

Division of Nuclear \& Power Engineering

Attn: Z. Techy

L. Voross

POB 233

H-1368 Budapest

HUNGARY 
Distribution

Japan Atomic Energy Research Institute (4)

Tokai-mura

Naku-gun

Attn: K. Soda

J. Sugimoto

Y. Maruyama

N. Yamano

Ibaraki-ken, 319-11

JAPAN

JRC Ispra Establishment (5)

Thermodynamics and Radiation Physics

Attn: J. Capitao

Y. Drossinos

P. Fasoli-Stella

A.V. Jones

I. Shepherd

J-201020 Ispra (Varese)

ITALY

Jozef Stefan Institute

Jamova 39

Attn: B. Mavko

61111 Ljubljana

SLOVENIA

Kernforschungszentrum Karlsruhe (3)

P.O. Box 3640

Attn: S. Hagen

P. Hoffman

B. Kuczera

75 Karlsruhe

GERMANY

Korea Atomic Energy Research Institute 150 Dukjin-dong, Yoosung-gu

Attn: Hee-Dong Kim

Taejeon 305-353

KOREA

Korea Institute of Nuclear Safety

Safety Review and Assessment Division

P.O. Box 16, Daeduk-Danji

Attn: J.J. Lee

Taejon, 305-353

KOREA
Netherlands Energy Research Foundation (6)

P.O. Box 1

Attn: A.A. Booij

E. Cordfunke

M.E. Huntelaar

R. Konings

S. Spoelstra

P. Stoop

1755 ZG Petten (NH)

THE NETHERLANDS

Nuclear Power Engineering Center

Fujitakanko Building

17-1, 3-Chrome, Toranomon, Minato-Ku

Attn: Kenji Takumi

Tokyo, 105

JAPAN

Nuclear Electric (3)

Berkeley Nuclear Laboratory, Berkeley

Attn: C. Chapman

J. Eccles

J. Gwyther

Gloucestershire GL 13 9PB

UNITED KINGDOM

Nucleare e della Protezione Sanitaria (3)

(DISP)

Ente Nazionnle Energie Alternative (ENEA)

Viale Regina Margherita, 125

Cassella Postale M. 2358

Attn: G. Petrangeli

M. Pezzilli

G. Saponaro

1-00144 Roma A.D.

ITALY

Nuclear Regulatory Authority

Bajkalska 27

Attn: J. Misak

82007 Bratislave

SLOVAK REPUBLIC 
Nuclear Research Institute (2)

Attn: J. Kujal

F. Pazdera

25068 Rez

CZECH REPUBLIC

Nuclear Safety Insitute (4)

Russian Research Center KI

I Kurchatov Square

Attn: V. Asmolov

E.G. Basanski

V. Demin

S.B. Dorofeev

123182 Moscow

RUSSIA

N.V. Kema

P.O. Box 9035

Attn: P. Kloeg

6800 ET Arnhem

THE NETHERLANDS

Ontario Hydro (2)

700 University Avenue

Attn: O. Akalin

F.C. Iglesias

Toronto, Ontario M5G 1X6

CANADA

Paul Scherrer Institute

Attn: P. Hosemann

CH-5232 Villigen, PSI

SWITZERLAND

Polytechnical University of Madrid

Nuclear Engineering Department

Jose Gutierrez Abascal, 2

Attn: A. Alonzo-Santos

28006 Madrid

SPAIN
Power Reactor Nuclear Fuel Development

Corporation (PNC)

9-13, 1-Chome

Akasaka

Attn: A. Watanabe

Minato-Ku, Tokyo

JAPAN

Reactor Centrum Nederland

Attn: K.J. Brinkman

1755 ZG Petten

THE NETHERLANDS

Research Centre Rossendorf, Inc.

Forschungszentrum Rossendorf

Postfach 19

Attn: Dr. H. Funke

DO-8051 Dresden

GERMANY

Royal Institute of Technology (2)

Department of Nuclear Reactor Engineering

Attn: K.M. Becker

B.R. Sehgal

S-10044 Stockholm

SWEDEN

Russian Academy of Sciences (3)

Nuclear Safety Institute

52, B. Tulskaya

Attn: L. Bolshov

V. Chudanov

V.F. Strizhov

113191 Moscow

RUSSIA

State Office for Nuclear Safety

Slezska 9

Attn: J. Stuller

12000 Prague 2

CZECH REPUBLIC 
Distribution

Statens Karnkraftinspektion (2)

P.O. Box 27106

Attn: W. Frid

L. Hammar

S-10252 Stockholm

SWEDEN

Studsvik Nuclear

S-611 82, Nykoping

Attn: K.O. Johansson

SWEDEN

Swiss Federal Nuclear Safety Inspectorate (2)

Attn: S. Chakraborty

U. Schmocker

Ch-5232 Villigen - HSK

SWITZERLAND

Technical Research Centre of Finland

Vuorimiehentie 5

Attn: L. Mattila

SF-02150 Espoo

FINLAND

Technische Universitat Munchen

Attn: H. Karwat

8046 Garching, Forschungagelande

Munich

GERMANY

Toshiba Corporation

8 Shinsugita-Cho, Isogo-Ku

Attn: M. Naito

Yokohama 235

JAPAN

UKAEA Culham Laboratory

Attn: B. D. Turland E5.157

Abingdon

Oxfordshire OX14 3DB

UNITED KINGDOM

UKAEA, Risley Nuclear Laboratories (4)

Risley, Warrington

Attn: A.T.D. Butland

I.H. Dunbar

G.F. Holford

C.D. Wheatley

Cheshire WA3-4NE

UNITED KINGDOM

UKAEA, Winfrith Technology Centre (7)

Attn: B.R. Bowsher

T.J. Haste

S.R. Kinnersly

J.N. Lillington

A. Mason

D. Sweet

D.A. Williams

Dorchester Dorset DT2 8DH

UNITED KINGDOM

Ruhr-University of Bochum

Dept. of Nuclear \& New Energy System

Attn: U. Brockmeier

GERMANY

University of Stuttgart (2)

IKE

Pfaffenwaldring 31

Attn: U. Bieder

N. Kourti

D-7000 Stuttgart 80

GERMANY

VATESI (2)

Gediminis Prospect 36

Attn: A. Kaliatka

P. Vaisnys

Vilnius

LITHUANIA 
SANDIA DISTRIBUTION: (30)

MS0100 Document Processing for DOE/OSTI, 7613-2 (10)

MS0619 Technical Publications, 7151

MS0736 N.R. Ortiz, 6400

MS0739 D.C. Williams, 6429

MS0742 J.E. Kelly, 6414

MS0744 W.A. von Riesemann, 6403

MS0744 D.A. Powers, 6404

MS0745 S.L. Thompson, 6418

MS0745 R.C. Smith, 6418

MS0745 T.J. Tautges, 6418

MS0899 Technical Library, 7141 (5)

MS1137 M.D. Allen, 6422

MS1137 T.K. Blanchat, 6422

MS1137 M.M. Pilch, 6422

MS1139 K.O. Reil, 6423

MS1139 R.C. Schmidt, 6423

MS9018 Central Technical Files, 8523-2 


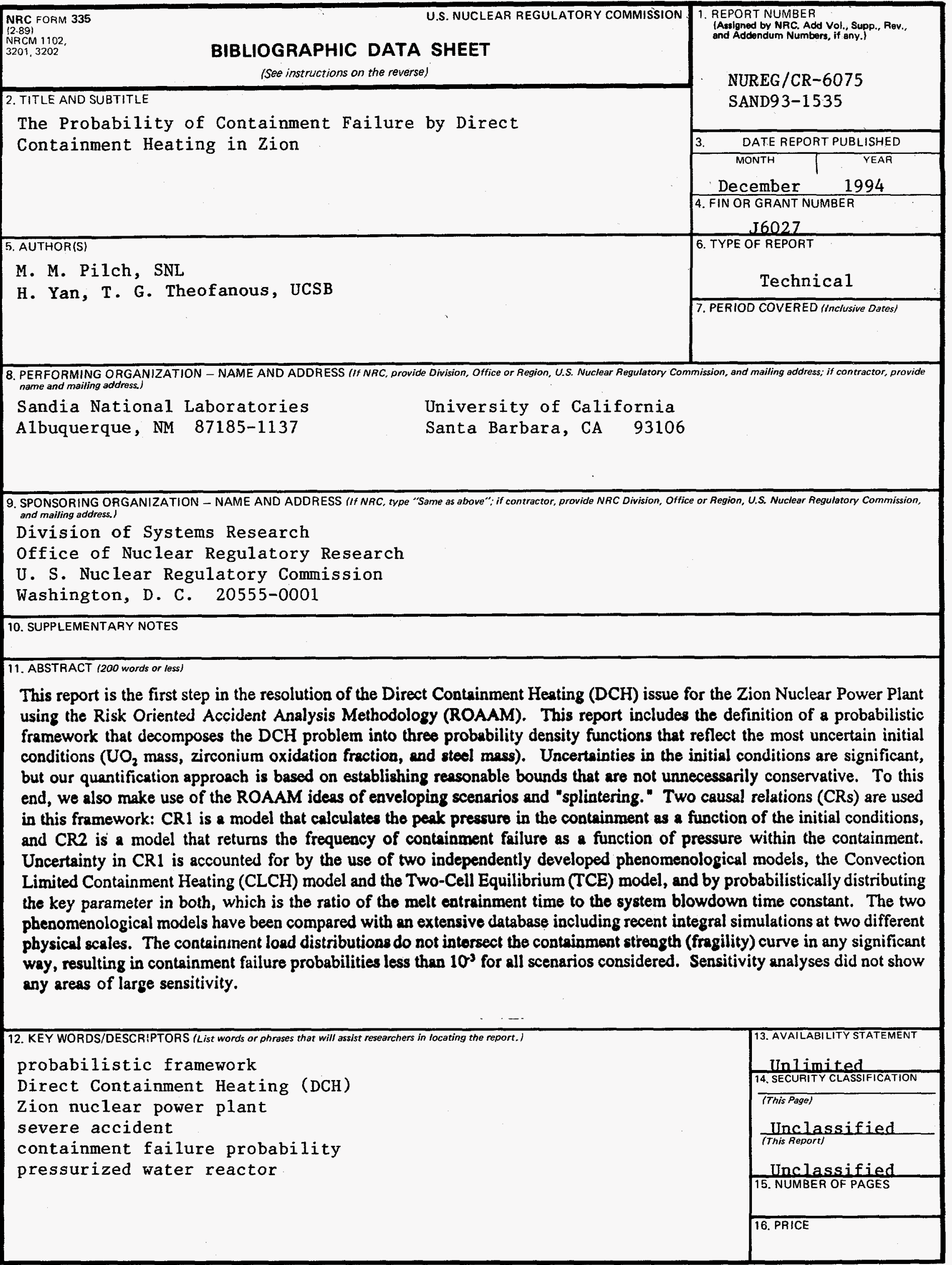

